COLUMBIA LIBRARIES OFFSITE

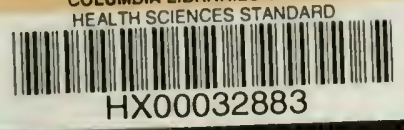

RECAP 


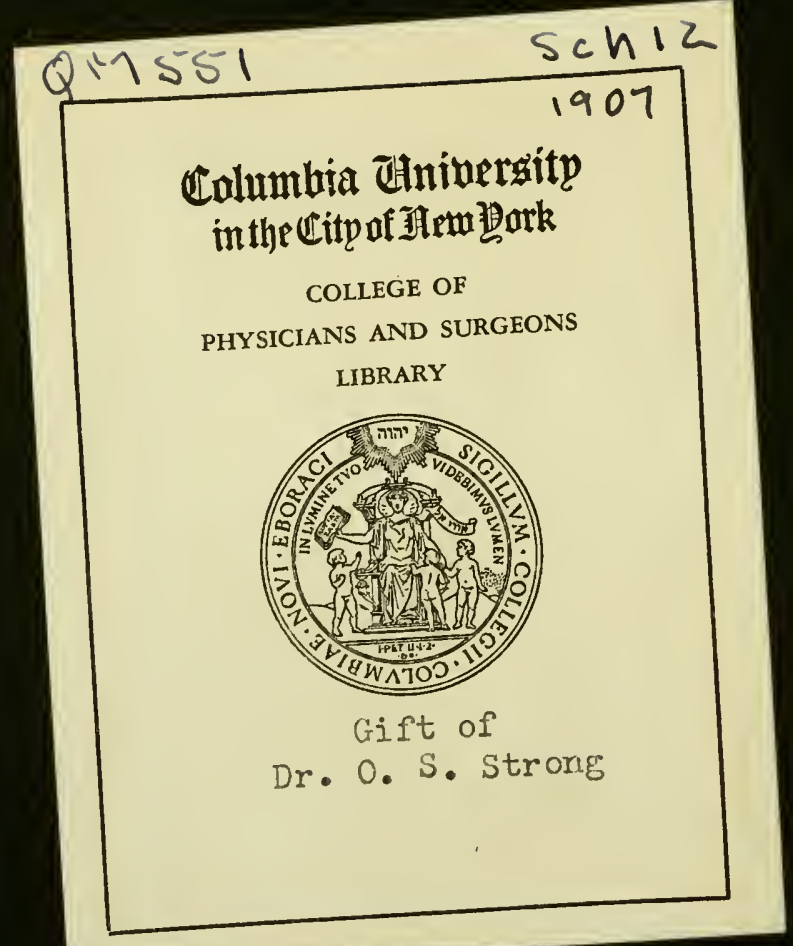


Oststron

$$
\begin{aligned}
& 437 \text { w. } 5985 . \\
& \text { 4.4. City. }
\end{aligned}
$$


Digitized by the Internet Archive in 2010 with funding from Columbia University Libraries 
H ISTOLOGY 
By' the same Author.

DIRECTIONS FOR CLASS WORK IN PRACTICAL PHYSIOLOGY:

Elementary Physiology of Muscle and Nerve and of the Vascular and Nervous Systems.

With 48 Diagrams to show arrangement of Apparatus. Sro. 3s. net.

LONDON : LONGMANS. GREEN \& CO.

A COURSE OF PRACTICAL HISTOLOGY Containing plain directions for individual work in Histology.

Svo. 7 s. 6 d.

LONDON : SMITH, ELDER \& CO. 


\section{Osseling \\ 437 W.ST St. \\ THE ESSENT' I A I S S}

()F

II I S T O L O G Y

DESCRIPTIVE AND PR.ACTICAL

FOR THE L'SE OF STUDE.ITS

BI

E. A. SCHÄFER, LL.1)., Sc.D., F.R...

PROFESSOR OF PHYSIOLOGY IX THE UXIVERSITY OF EDINBTRGH

FORMERLY JODRELL PROFESSOR OF PHYSIOLOGY IX UNIVFRAITY COLLEGE, LOXDOY

SEVEXTH EDITION

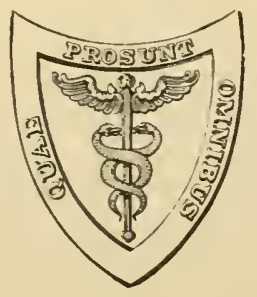

LEA BROTHERS \& CO. PHILADEPHIA AND NEW YORK 1907 
$\because$

$$
\begin{aligned}
& \text { QM551 } \\
& \text { Sk12 } \\
& 1907
\end{aligned}
$$




\section{PREFACE TO THE SEVENT'H EDITION.}

Thus Book is written with the object of supplying the student with directions for the mieroseopical examination of the tissues. At the same time it is intended to serve as an Elementary Text-book of Histology; comprising the essential facts of the seience, lut omitting less important details.

For conveniently accompanying the work of a class of medical students, the book is divided into fifty lessons. Each of these may be supposed to oceupy from one to three hours, according to the relative extent to which the preparations are made beforehand by the teacher, or during the lesson by the students. A few of the preparations cannot well be made by a elass, but it has been thought advisable not to injure the completeness of the work by omitting mention of them.

Only those methods are reeommended upon which experience has proved that full dependence ean be placed, but the directions given are for the most part capable of easy verbal modifieation in aceordance with the ideas or experience of different teachers.

The present edition has been eonsiderably enlarged, partly by additions to the text-especially that deseriptive of the strueture 
of the central nervous system, a proper knowledge of which is essential to students of medieine-partly by the provision of new illustrations derived from many sourees. The author desires to express his recognition of the readiness with which other authors have placed illustrations at his disposal. This recognition is especially due to Professor Sobotta and to Professor Ramón Cajal, the latter of whom was good enough to lend many of his original drawings for reproduction in this work.

A new feature is the printing of many of the illustrations in colour, which it is believed will give a better idea of the appearance of the stained preparations.

To Dr. P. T. Herring, who has read and corrected the final proofs; and to Professor Sherrington, who has looked through the chapters on the eentral nervous system, the author begs to offer his grateful acknowledgments. 


\section{CONTEN'TS.}

INTRODUCTORY.

PAGE

Exumeration of the Tissues-Gexeral Structure of A mimal Cella,

\section{LESSON 1.}

Use of the Microscope-Examination of Comyon Objects, . . 24

LESSONS II. AND III.

Humax Blood-Corpuscles-Development of Blood-Corpuscles-

BoNe-MARROW, . . . . . . . . . . . 28

\section{LESSON IV.}

Action of Reagexts upox the Humay Blood-Corpuscles, • . 41

\section{LESSON V.}

Blood-Corpuscles of Amphibla, . . . . . . . . 45

\section{LESSON VI.}

Ameboid Phenomena of the Colourless Blood-Corpuscles, . 48

LESSON VII.

Epithelium, . . . . . . . . . . . . 52 


\section{LESSON VIII.}

Columsar axd Ciliated Epithelium,

\section{LESSON IX.}

Connective Tissues: Areolar axd Adipose Tissue-Retifory TISSE , . . . . . . . . .

\section{LESSON $\mathrm{X}$.}

Coxyective Tissues (continued) : Elastic Tissue-Fibrous TissueDevelopment of Coxyective Tissue,

\section{LESSON XI.}

Consective Tissues (continued): Articular Cartilage-Synovial

Membranes, . . . . . . . . . 86

\section{LESSON XII.}

Consective Tissues (continued): Costal Cartilage-FibroCartilage, . . . . . . . . . . . 9

\section{LESSON XIII.}

Connective Tissues (continued): Structure axd Developanet of Bosk

\section{LESSON XIV.}

Striated Muscle,

\section{LESSON XV.}

Connectioy of Muscle with Tendox-Blood-Vessels of MuscleCardiac Muscle-Development of Muscle-Plain Muscle,

\section{LESSON XVI.}

Nerve-Fibres, 
LESSONS XVII. AXD XVIII.

Nerve-Cells-Neuroglia-Developuext of Nerve-Fibres ANi

Nerve-Cells-Degeneration and Regeneration, . . .

PAGE

LESSON XIX.

Modes of Termination of Nerve-Fibres, 166

LESSON XX.

The Larger Blood-Vessels, 184

\section{LESSON XXI.}

Syaller Blood-Vessels-Lyyph-Vessels-Serocs Membrayes. Microscopic Study of the Circulation-Developmext of Blood-Axd LyMpH-Vessels,

\section{LESSON XXII.}

LyMPH-GLaNdS-ToNsil-ThyMUS, 203

\section{LESSON XXIII.}

Spleex-Suprarexal Capsules-Thyroid Body-Pitultary Body, 213

\section{LESSONS XXIV. AND XXV.}

Skix, Nalls, Hairs, etc.-Mammary Glayds, . 226

LESSON XXVI.

Heart, .

LESSON XXVII.

Trachea AND Lusgs, 


\section{LESSON XXVIII.}

Structure and Development of the Teeth, . . . . . 263

LESSON XXIX.

Tongue axd Mucous Membrane of the Mouth--Taste-Buds-

Pharynx and Cesophagus, . . . . . .

\section{LESSON XXX.}

Salivary Glaxds,

LESSON XXXI.

Stomach,

LESSONS XXXII. AND XXXIJI.

Silall ANd Large Intestine, . . . . . . . . : $\quad$ : 295

LESSONS IXXIV. AND XXXV.

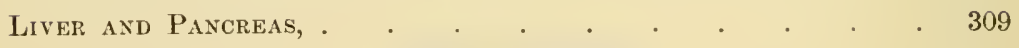

LESSON XXXVI.

KIDNEY,

\section{LESSON XXXVII.}

Ureter, Bladder, and Male Generative Organs,

\section{LESSON XXXVIJI.}

Generative Organs of the Female,

LESSON XXXIX. AND XL.

SPINAL Cord, 
CONTENTS.

LESSON XII. 374

LESSONS XLII. AND XLIII.

Poxs Varoli, Mesexcephalos, axd Thalamexcephalon, . . 390

LESSONS XLIV. AND XLV.

Cerebellum axd Cerebrum, . . . . . . . . . . 4 41 T

LESSONS XLVI., XLVII. AND XLVIII.

ErE, . . . . . . . . . . . . . . 443

\section{LESSON XLIX.}

Olfactory Mecous Membraye-Exterxal axd Middle Ear, . 46i

LESSON L.

INTERAL EAR, . . . . . . . . . . . 472

APPENDIX.

Methods, . . . . . . . . . . . . . . 484

INDEX, . . . . . . . . . . 501 



\title{
THE ESSEN'TIALS OF HISTOLOGY
}

\author{
INTRODUCTORY.
}

\author{
EYCHERATIOY OF THE TISSUES ATD THE GENERAL \\ STRCCTCRE OF ANIMAL CELLS.
}

Animal Histology ${ }^{1}$ is the science which treats of the minute structure of the tissues and organs of the animal body; it is studied with the aid of the microscope, and is therefore also termed Micioscopic Anatomy.

Every part or organ of the body, when separated into minute fragments, or when cxamined in thin sections, is found to consist of certain textures or tissues, which differ in their arrangement in different organs, but each of which exhibits characteristic structural features.

The following is a list of the principal tissues which compose the body :-

1. Epithelial.

2. Connective: Areolar, Fibrous, Elastic, Adipose, Lymphoid, Cartilage, Bone.

3. Muscular: Toluntary, Involuntary or plain, Cardiac.

4. Nervous.

Some organs are formed of several of the above tissues, others contain only one or two.

It is convenient to include such fluids as the blood and lymph amongst the tissues, because they are studied in the same mauner and contain cellular elements similar to those met with in some of the other tissues.

All the tissues are, prior to differentiation, nasses of cells (embryonic cells). In some tissues other tissue-elements become developed which take the form of filres. Thus the epithelial tissues are composed throughout life entirely of cells, only slightly modified in

${ }^{1}$ From iorós, a web or texture. 
structure, and the nervous and muscular tissues are formed of cells which are greatly modified to form the characteristic fibres of those tissues. On the other hand, in the connective tissues an amorphous material becomes formed between the cells which is termed intercellular substance or ground substance, and in this substance fibres make their appearance, sometimes, as in the fibrous connective tissue, in so large an amount as to occupy the whole of the intercellular substance, and greatly to preponderate orer the cells. This ground substance, by virtue of its containing a certain amount of inorganic chlorides, has the property of becoming stained brown or black by nitrate of silver and subsequent exposure to light, in which case the cells, which remain unstained, look like white spaces (cell-spaces) in the ground substance. When an epithelial tissue is similarly treated, the narrow interstices between the cells are also stained, from which it may be concluded that a similar substance exists in small amount between the cells of this tissue. It has here been termed cement-substance, but it is better to apply to it the general term intercellular substance.

The cells of a tissue are not always separate from one another, but are in many cases connected by bridges of the cell-substance, which pass across the intercellular spaces. This is especially the case with the cells of the higher plants, but it has also been found to occur in animal tissues, as in some varieties of epithelium and in cardiac and plain muscular tissue. Occasionally the connexion of the cells of a tissue is even closer, and lines of separation between them are almost or entirely absent. The term syncytium is given to any such united mass of cells.

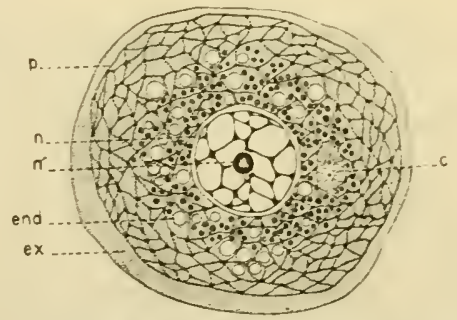

Fig. 1.-DIAGRAM OF a CELL, HighLY Magsified.

p, protoplasm, consisting of hyaloplasm and a network of spongioplasm; ex, exoplasm; end, endoplasm, with distinct granules and vacuoles; $r$, double centrosome; $n$, nucleus; ; $n$, nuclcolus.

Cells.-A cell is a minute portion of living substance (cytoplasm), which is sometimes inclosed by a cell-membrane and always contains a specially differentiated part which is known as the nucleus.

The cytoplasm of a cell (fig. 1,p) is composed of protoplasm, which consists chemically of proteid or nucleoproteid substances, with which 
lecithin, a combination of fatty acid with glycerophosphoric acid, and cholesterin, a monatomic alcohol, having many of the physical characters of fats, appear always to be associated. The protoplasm

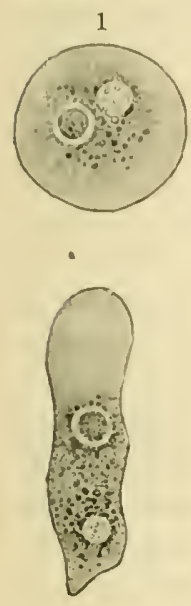

5
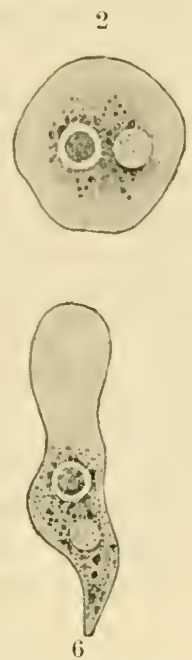

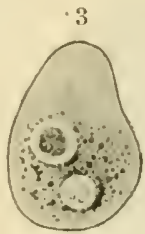

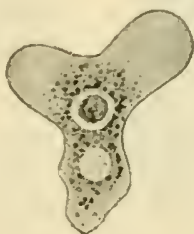

7
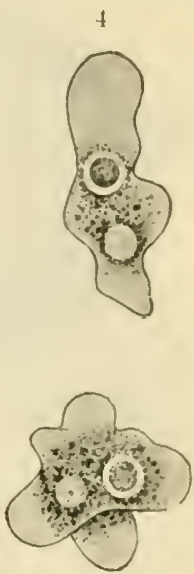

S

Fig. 2.- Successive chaxges Exhibiten by ax amaba. (Terworn.)

tends during life to exhibit movements which are apparently spontaneous, and when the cell is uninclosed by a membrane a change in the shape, or even in the position of the cell, may be thereby produced. This is characteristically shown in the movements of the unicellular organism known as the amceba (fig. 2); hence the name

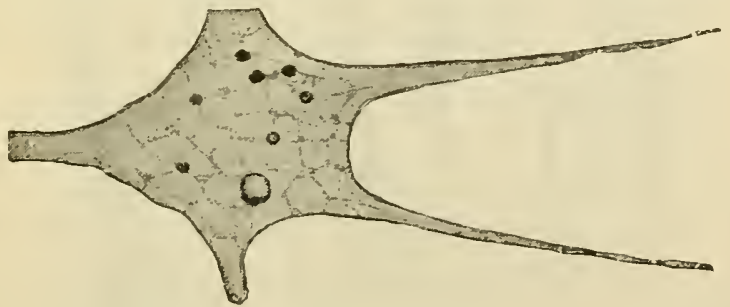

Fig. 3.-Protoplasmic structure in a pseudopodidm of a Foramixifer (MILIOLA). (Verworn, after Biitschli.)

amceboid morement, by which it is generally designated. ${ }^{1}$ The protoplasm often, but not always, contains a fine spongework, which takes under high powers of the microscope the appearance of a network (figs. 1, 3), the remainder of the protoplasm being a clear

1 The amoboid phenomena of cells will be studied later (in the colourless corpuscles of blood). 
substance which occupies the interstices of the sponge, and may also cover the surface or project beyond the rest of the cell. A

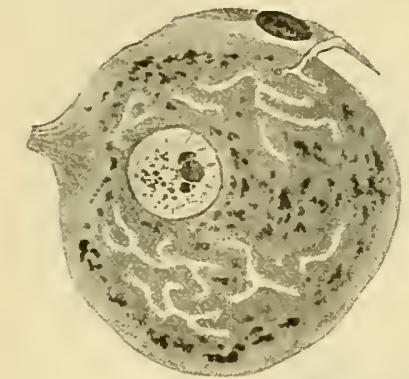

Fig. 4.-TrophospongiUM (CANALISATION) WITHIN A GANGLION CELL. (E. Holmgren.)

granular appearance is often produced by the knots in the network when imperfectly observed looking like separate granules. The material which forms the reticulum is termed spongioplasm; the clearer material which occupies its meshes is hyaloplasm. The protoplasm of some cells show's a considerable degree of differentiation into fibrils which may be unbranched or may form a network within the cell. Some cells exhibit a fine canalisation of their protoplasm (fig. 4), and according to Holmgren the canaliculi are in many cases occupied by branching processes of other (nutrient) cells, which form what he terms a "trophospongium."

Protoplasm often, if not always, includes actual granules of a

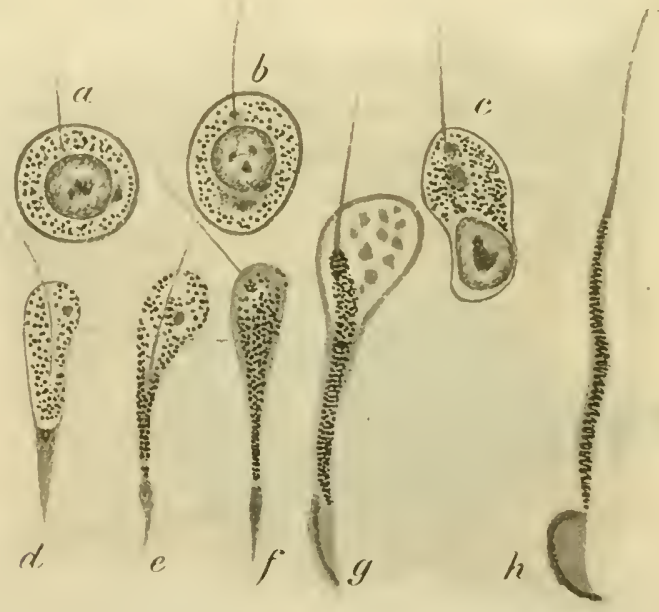

Fig. 5. - Cells Froy the testicle of the yOUse IN PROCEss OF traxsforIIATION INTO SPERMATOZOA. (Benda.)

The "mitochoudria" are darkly stained and are seen in the successive stages $(a$ to $g)$ to be arranging themselves so as to constitute the spiral filament of the spermatozoon (h).

proteid nature. Some of these granules may be essential constituents of the protoplasm (Altmann); others are materials which 
have been formed by the protoplasm, and which are in a sense accidental inclusions. That the former are of importance appears to be evident from the fact that many of the chemical changes of cells occur in them. Moreover they are closely associated with the most active part of the protoplasm, the part, namely, in the neighbourhood of the nucleus, and appear to become formed in this part, and from it to extend through the cell. When fibrils are formed in the protoplasm, they are beliered to be produced from the granules in question, to which the name mitochondria has been given (Benda), (fig. 5). The mitochondria are sometimes collected into a spherical mass near the mucleus which stains more deeply than the rest of the cytoplasm (fig. 6). To this body the term paranucleus has been applied. The gramules referred to may be regarded as actual constituents of the cytoplasm, and formed directly from its protoplasm. As indicating this close connexion with protoplasm they may conveniently be termed deuto-

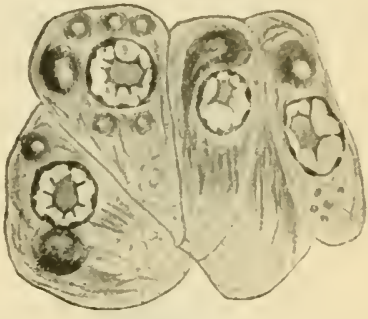

Fig. 6.-PANCREAS CELLS OF Frog, SHOWING PARANECLECS AND CHONDROMITOME FIBRILS FORMED FROMI MITOCHOXDRIA. (Gurwitsch, after Matthews.)

plasm. This name has also been used to include materials which are merely included in the cytoplasm and not factors in its constitution, such as pigment granules, fat globules, and racuoles containing watery fluid, with or without glycogen or other substances in solution. Materials which are thus included in the protoplasm of a cell are either stored up for the nutrition of the cell itself, or are converted into substances which are eventually extruded from the cell in order to serve some purpose useful to the whole organism, or to be got rid of from the body. The term paraplusm may be employed to denote any such materials within a cell. Paraplasm is often present in sufficient quantity to reduce the cytoplasm to a relatively small amount, the bulk of the cell being occupied by other material, as when starch becomes collected within vegetable cells or fat within the cells of adipose tissue. It is frequently the case that the paraplasm and deutoplasm are confined mainly to the middle of the cell in the neighbourhood of the nucleus, an external zone of the protoplasm being left clear. The two portions of protoplasm which are thus somewhat imperfectly differentiated off from one another are termed respectively the endoplasm and the exoplasm (fig. 1). They are exhibited in the amceba (fig. 2), and also in the white blood-corpuscle (fig. 8). 
According to the view adrocated by Bitschli the apparent reticulun or spongioplasm of a cell is the optical effect of a soft honercomb or froth-like structure: in other words, the meshes of the reticulum do not communicate with one another as in a sponge, but are closed cavities as in a honercomb. Biitschli finds indications of the same alveolar structure in all cells, including nerve-fibres and muscle-fibres, and has devised experiments with drops of froth made up of a mixture of oil and alkaline carbonate or sugar solution, which, when examined in water under the microscope, initate very closely not only the structural appearance (fig. 7 ) but even the so-called spontaneons

$A$

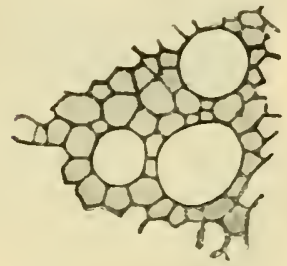

$B$

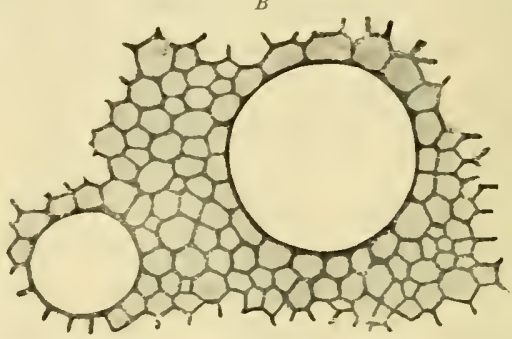

Fig. i.-COMPARINON OF PROTOPLASM WTTH OIL AYD WATER EMULSION.

A. Protoplasm of Thalassicola.

$B$. Froth-like appearance of a mixture of oil and cane sugar. (Verworn, after Butschli.)

or amoboid movements of actual protoplasm. It may be stated, however, that although it is a matter of difficulty to determine whether a microscopic reticulum is a sponge-work or a honeycomb, it is probable that neither structure is essential to living substance, for the outermost layer of the cell protoplasm, which is usually the most active in exhibiting movements, of ten shows no indication of such structure. And further, it has been shown by Hards that a colloid solution such as that which exists in protoplasm may, under some circumstances, appear homogeneous and under others may separate out into two parts, one more solid the other more fluid, and after such separation may exhibit either a granular, a reticular, or a honeycomb structure, according to circumstances. "Nor is a "froth" necessary for the imitation of amceboid movements, for similar movements, due to changes in surface tension, are brought about in a simple oil drop or in a drop of oil-clad albumen when brought in contact with solution of soap or of any alkali (Berthold, Quincke). A drop of any colloid solution containing electrolytes is also subject to such changes of surface tension when exposed to varying electrical influences, so that these amoboid movements, which are certainly "vital," are capable of being explained by well-kuown plyysical laws

There are grounds for believing that a very fine pellicle covers the exterior of the protoplasm of all free cells, and that this pellicle is composed of a material which, although not soluble in water, is permeable to watery tluids, and may also allow the passage of solids without rupture. Such a material might be furnished by the lecithin and cholesterin (Overton), which are, as we have seen, constant constituents of cell-protoplasm. It must, however, be stated that it has not been proved that these substances are collected at the surface of protoplasm.

Properties of living matter.-Living cells exhibit (1) irritability or the property of responding to stimuli ; (2) metabolic or chemical changes which result in assimilation or the taking in of nutrient matter and converting it into living substance (anabolism), and disassimilation, the property of break- 
ing lowu or getting rid of such substance (katabolism); (3) reproduction resulting in the multiplication of cells. Of these properties (2) and (3) are certainly soverned of inthenced by the cell-nuclens, and (3) appears to be usmally initiated by the centrosome (see below). The irritability of the cell lepends, however, mainly upon the cytoplasm itself. It is in consequence of this property that protoplasm reacts, sometimes by contraction sometimes hy relaxation, to mechanical, chemical, thermal, and electrical stimuli, and in the case of some cells (e.g. the pigment-cells and cones of the retina) to the stimulus of light. The imcboid movements of cells are a manifestation of irritibility, being produced and influenced by various external conditions and stimuli. Sonetimes the result of a stimulus is to cause a cell or organism to move towards the source of excitation (attraction); in other cases the movement is in the reverse direction (repulsion). The terms positive and negative chemotaxis, phototaxis, thermotaxis, and the like, are user to indicate the nature of the effects produced by various forms of stimulation.

Attraction-sphere and centrosome.-In some cells, as already indicated, there are fine but distinct striæ or fibrils (cytomitome) running in definite directions. These are very commonly met with in fixed

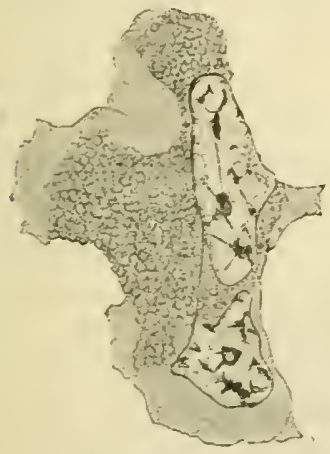

Fig. 8.-Ax AMGEBOID CELL (WHITE CORPC'SCLE OF NEWT) TERY HIGHLY IAGXIFIED.

Showing a double nucleus with recticulum of chromoplasm, and the protoplasm com. posed of two portions, a clearer exoplasm, and a granular-looking endoplasm.

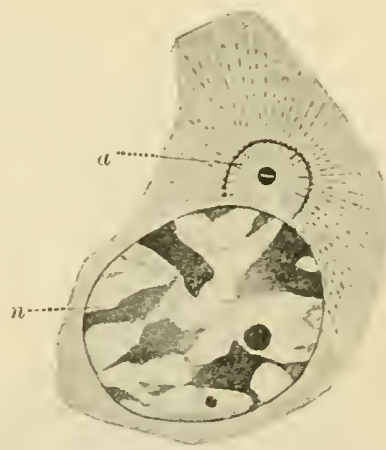

Fig. 9.-A CELL (WHITE BLOON-CORPUSCLE) SHOWLY ITS ATTRACTION-SPHERE.

(Wilson, after M. Heidenhain.)

In this, as in most cases, the attraction-sphere, $a$, lies near the nucleus, $n$.

cells, such as various kinds of epithelium-cells, nerve-cells, and musclecells. But besides these special differentiations, which appear to be related to special functions, there are other fibril-like structures in the cell-protoplasm, associated with what is known as the centrosome (figs. 1,9). This is a minute particle (centriole), usually situated near the nucleus, and staining darkly with iron-hæmatoxylin, surrounded by a clear area (attraction-sphere), and from it radiate into the surrounding protoplasm a number of fine fibrils with dot-like enlargements at intervals. The attraction-sphere, with its central particle, was first noticed in the ovum and was at first supposed to be peculiar 
to the egg-cell, but it has now been recognised in very many kinds of cells, and, in animal cells, is of nearly universal occurrence. The structures in question are frequently double (fig. 1), the twin spheres being connected by a spindle-shaped system of delicate fibrils (achromatic spindle): this duplication invariably precedes the division of a cell into two.

In some cells the centrioles are multiple; this is frequently the case with lencocytes and always with the giant-cells of bone marrow. The material which inmediately surrounds the centrosone, and of which the radiating fibres and the fibres of the spindle are composed, is considered by sone to he distinct in nature from the general protoplasm: it has been termed the archoplasm. It appears clear that in some cells the centrosome and archoplasm may have an existence independent of one auother; thus no centrosome has been found in the cells of the higher plants, although the archoplasmic fibres are very well marked in them during cell-division.

A cell-membrane is rarely distinct in animal cells. When present, it is usually formed by transformation of the external layer of the protoplasm, but its chemical nature has not been sufficiently investigated. In plant cells a cellulose membrane is of common occurrence.

The nucleus of the cell (fig. $1, n$ ) is a small vesicle, spherical, ovoid, elongated, annular, or irregularly lobulated (figs. 8, 9, 10), embedded in the protoplasm. Cells have sometimes two or more nuclei. The nucleus is bounded by a membrane which incloses a clear substance (nuclear hyuloplasm, karyoplasm), and the whole of this substance is generally pervaded by an irregular network of fibres, some coarser, others finer (nuclear reticulum, karyomitome). The membrane is the outermost layer of the nuclear reticulum, and may itself have meshes like a basket-work, thus allowing direct communication between the hyaloplasm of the cell and that of the nucleus. The knots of the nuclear reticulum are sometimes very distinct and give an appearance of conspicuous granules within the nucleus (pseudonucleoli). The nucleus usually contains a single distinct highly refracting spherical particle known as the nucleolus. This is sometimes multiple, and occasionally has a vacuole-like globule in its interior. The material of the nucleolus differs in its chemical and staining reactions from the nuclear reticulum, but prior to cell-division it becomes indistinguishable from the substance of the nuclear fibres. Whether it blends with them or becomes absorbed and removed is at present uncertain. The nuclear membrane, intranuclear fibres, and nucleoli all stain deeply with hæmatoxylin and with basic dyes generally; this property distinguishes them from the nuclear matrix, and they are accordingly spoken of as chromatic (containing chromatin, which in the nucleus appears to be chemically identical with nuclein), the hyaloplasm being achromatic. Sometimes instead of being united into a network the intranuclear 
fibres take the form of convoluted filaments (chromosomes), having a skein-like arrangement (fig. 11). This is always found when a nucleus is about to divide, but it may also occur in the resting

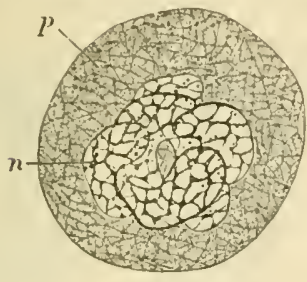

Fig. 10.-CELL FroM BONE-MARROW: (Carnoy.)

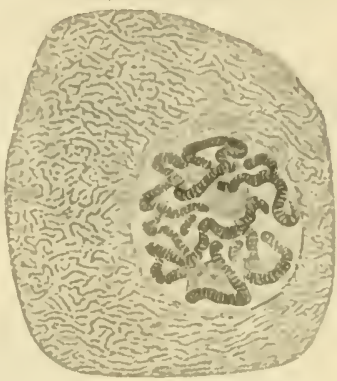

Fig. 11.-GLANT-Cell OF ChirosoIr's. (Flemming.)

1", protoplasm with fine rcticulum; $n$,

nucleus, long and folded, with intra.

nuclear network.

condition. These filaments may sometimes be seen with high magnification to be made up of fine juxtaposed particles (chromomeres) arranged either in single or double rows (fig. 12), which impart a cross-striated appearance to the filament. The chromomeres are united to form the chromosomes by a non-staining material to which

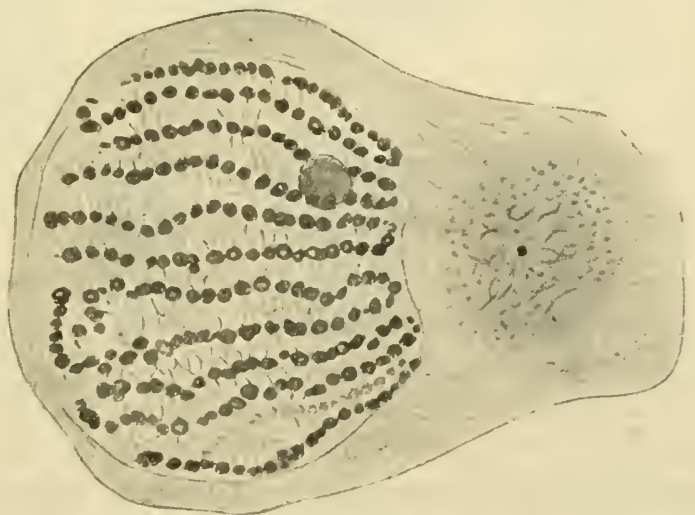

FIG, 12.- SPERMATOCYTE OF PROTEUS, SHOWING CHROMOSONES OF NCCLEU FORMED OF PARTICLES OF CHROMATIN UNITED BY ACROMATIC FILAMENTS. (Gurwitsch, after Hermann.)

The nucleolus is distinct from the chromosomes. In the crtoplasm an archoplasmic mass containing mitochondria is seen on the right.

the term linin has been applied. The nuclear fibres are sometimes clumped together into a solid mass which comprehends the nucleolus when present, and has the appearance of an enlarged nucleolus. The 
fibres within the nucleus have been observed to undergo spontaneous changes of form and arrangement, but these become much more evident during its division. The division of the protoplasm is always preceded by that of the nucleus, and the nuclear fibres undergo during division a series of remarkable transformations which are known collectively by the term karyolinesis (Schleicher) or mitosis (Flemming). These changes may easily be studied in the division of epithelium cells, but exactly similar phenomena have been shown to occur in cells belonging to other tissues.

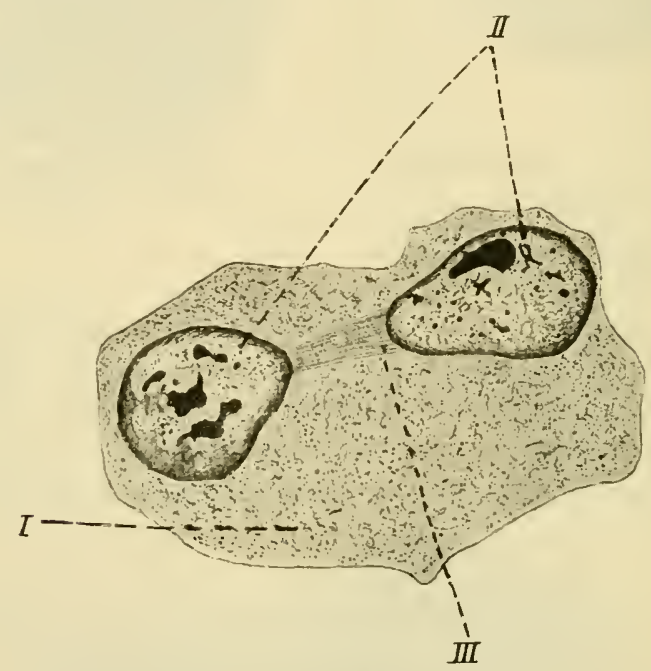

Fig. 13,-CELL OF BLADDER EPITHELIUM, SHOWING AMITOTIC DIVISION OF NUCLECS. (Nemileff.)

I. cytoplasm; II. daughter nuclei ; III. strand of fibrils uniting daughter nuclei.

The simple division of a nucleus by a process of fission without karyokinetic changes is termed amitotic division: it occur's in comparatively rare instances, and is not usually followed by the division of the cell, so that it is apt to result in the formation of bi-nucleated and multi-nucleated cells, as in the superficial layer of the epithelium of the urinary bladder and in some of the giant cells of bone-marrow.

The nucleus of the cell is not only concerned with its division and multiplication in the manner shown below, but takes an active part in the chemical (metabolic) processes which occur in the protoplasm. Hence cells deprived artificially of their nuclei do not assimilate nourishment, and lose any power of secretion they may have possessed, although the protoplasm may continue for a time to live and exhibit amceboid movements. 
Division of cells. - The division of a cell is preceded by the division of its attraction-sphere, and this again appears to determine the division of the nucleus. The latter, in dividing, passes through a series of remarkable changes, which may thus be brietly summarised

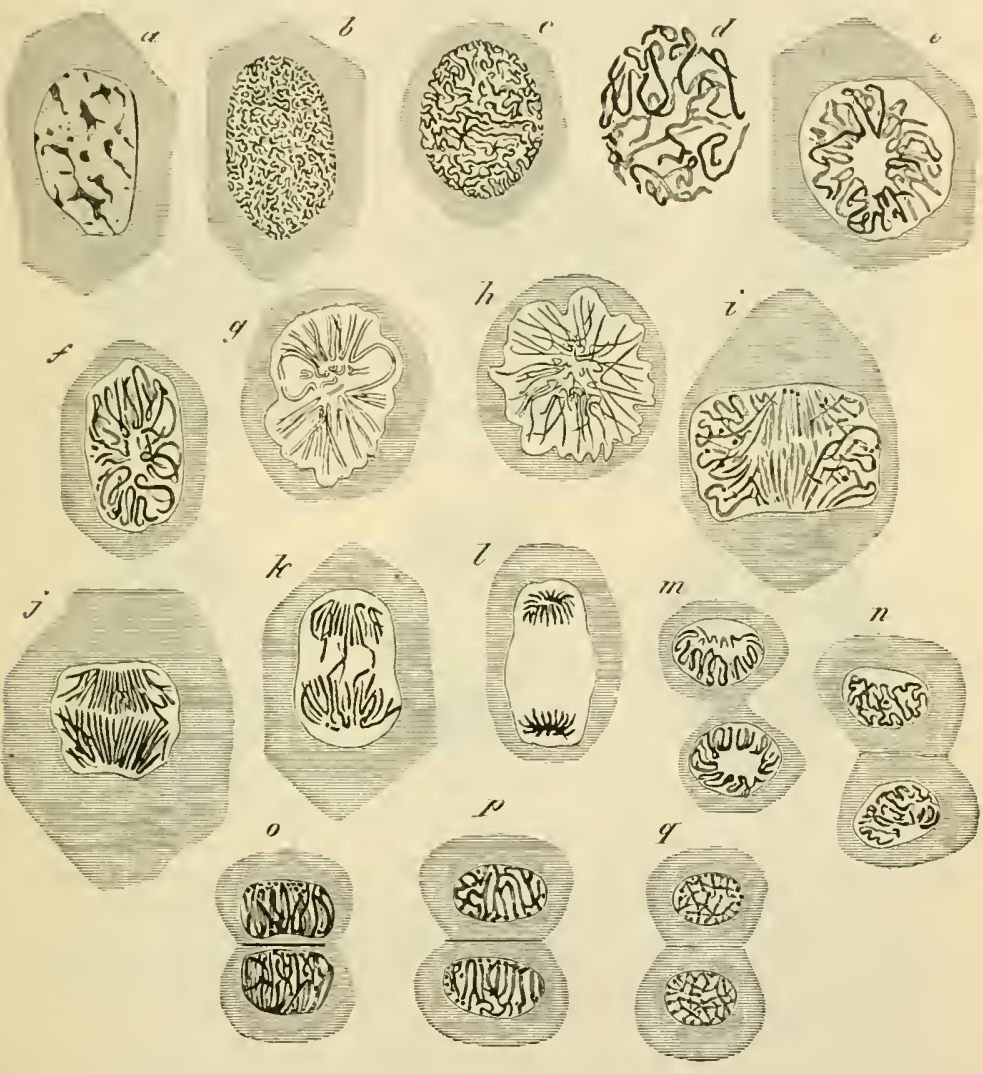

FIG. 14.-EPITHELIUSI-CELLS OF SALAMAXDRA LARVA IN DIFFERENT PHASES OF DIVISION BY KARYOKINESIS OR MITOSIS. (Flemming.)

as they occur in typical animal cells such as the epithelium cells of Salamandra :-

1. The network of chromoplasm-filaments of the resting nucleus becomes transformed into a sort of skein, formed apparently of one long convoluted filament, but in reality consisting of a number of filaments (spirem); the nuclear membrane and the nucleoli disappear or are merged into the skein (fig. 14, $a$ to $d$ ).

2. The filament breaks into a number of separate portions, often 
V-shaped, the chromosomes. The number of chromosomes varies with the species of animal or plant; in some animals the dividing nuclei may contain at this stage only four chromosomes; in man there are said to be twenty-four in the ordinary or somatic cells; a like number occurs in many animals and plants; others have more or fewer. As soon as the chromosomes become distinct they are often arranged radially around the equator of the nucleus like a star (aster, fig. 1t,e, $f, g$ ).
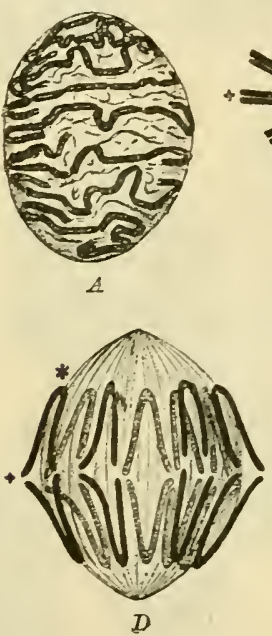
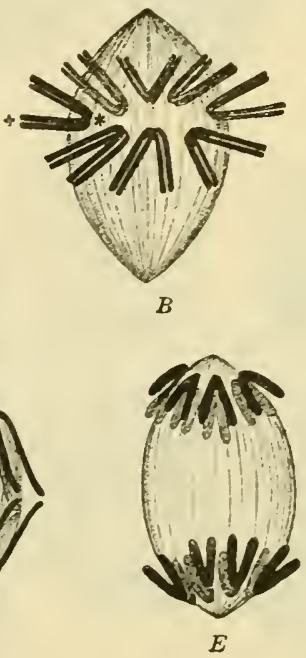
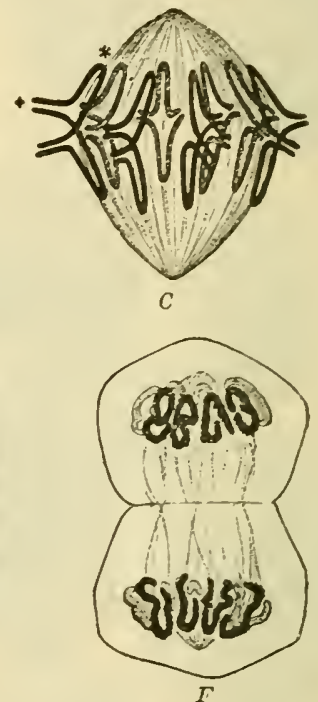

FIG. 15.-THE PRINCIPAL PHASES OF THE NCCLEAR CHROMATIN FILAMENTS IN THE PROCESS OF ORDINARY MITOSIS OF THE SOJATIC CELL. (Flemming.)

$A$, skein or spirem; $B$, aster with splitting of ehromosomes; $C$, separation of the split chromosomes (metakinesis); $D$, continuation of this process; $E$, diaster; $F$, dispirem. The cell protoplasm is represented in outline in $F$ : it has itself undergone division at this stage. In this figure the (somatic) cells represented are supposed to have eight chromosomes.

3. Each of the chromosomes splits longitudinally into two, so that they are now twice as numerous as before (stage of clearage, fig. 14, $h, i)$. This longitudinal cleavage may occur at an earlier stage.

4. The fibres separate into two groups, the ends being for a time interlocked (fig. 14, $j, k$ ).

5. The two groups pass to the opposite poles of the now elongated nucleus and form a star-shaped figure at either pole (dicster, fig. 14, l). Each of the stars represents a daughter nucleus.

$6,7,8$. Each star of the diaster goes through the same changes as the original nucleus, but in the reverse order-viz. a skein, at first more open and rosette-like (fig. 14, $m$ ), then a closer skein (fig. 14, n), 


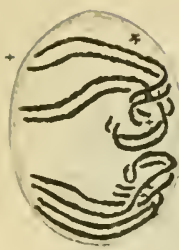

A

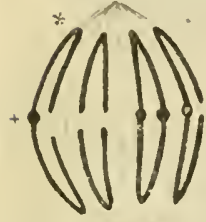

D

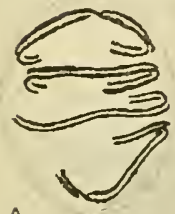

A
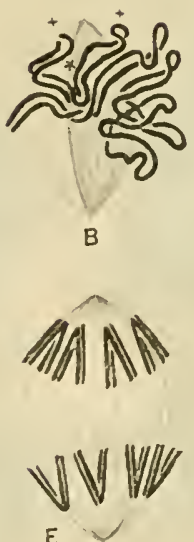

E

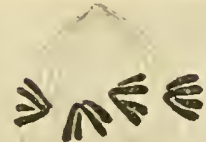

B
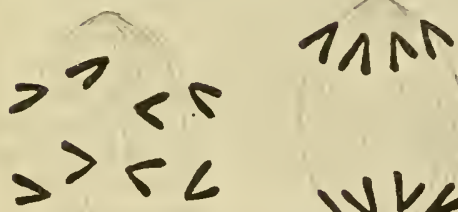

D

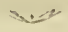

B

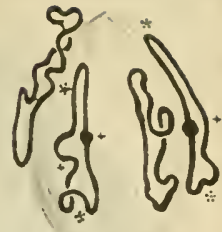

C

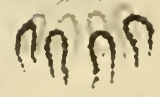

SU06:

F

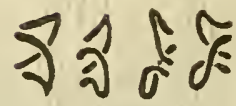

C
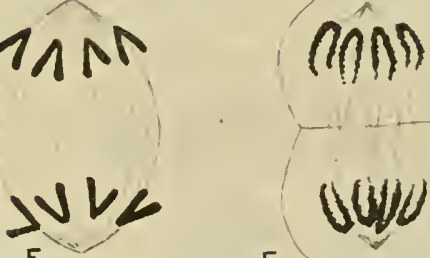

Fig. 16.-HETERo-TYPICAL AND HOMO-TTPICAL MITOSIS OF THE GEXER.TTITE CELL. (Flemming.)

The asterisk marks the iniddle, the cross the end of a chromosome.

The changes are to be compared with those shown in fig. 15. In the hetero-typical form the chromosomes are already arranged in pairs before division commences; this condition (geninal condition, A) having becn produced in the synaptic prophase. $A$ longitudinal split is seen in the diaster stage and the daughter nuclei have the somatic number of chromosomes ( $s$ in this instance). In the homo-typical for to there is no longitudinal split of the V-shaped chromosones and the separation

form the daughter nuclei results in a reduction to one-half the somatic 
then a network (fig. 14, o, p, q); passing finally into the typical reticular condition of a resting nucleus.
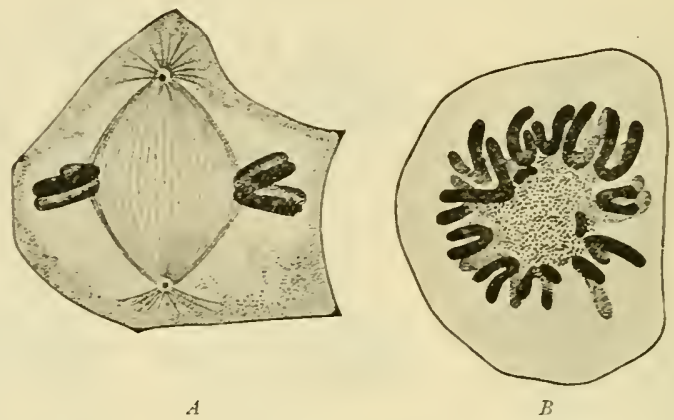

FIG. 17.-SPERMOCYTES OF SALAMANDRA SHOWISG V-SHAPED CHROMOSOMES AT THE EQLATOR OF THE SPINDLF. (Wilson, after Drüner.)

$A$, seen in profile; four chromosomes only are represented.

$B$, seen end-on. All twenty-four chromosomes are represented; the fibrils of the spindle are seen in optical section.

The splitting and separation of the chromosomes is often spoken of as the metaphuse (metuhinesis); the stages leading up to this beiug temed the anaplase and those by which the process is terminated the kataplase or telophase.

The node of division of the nuclear chromatin above described is frequently spoken of as somatic or ordinary mitosis (fig. 15) to distinguish it from two modes of division which are only seen normally at certain stages of multiplication of the generative cells, and which are known as heterotypical and homotypical mitosis (fig. 16). In the latter the chromosomes do not undergo the usual longitudinal splitting, but one half of the total number passes into each danghter nucleus, so that the number of chromosomes in each of these is ouly one half the usual somatic number. This is termed the reduction-dirision. ${ }^{1}$ Heterotypical mitosis (which immediately precedes the homotypical) is characterised by a peculiar arrangement of the chromosomes, the split halves of which, before sejarating to pass to the danghter nuclei, tend to adhere together in the form of loops or rings, or in the case of short straight chromosomes into small quadrangular masses (tetrads), all of which are observable in various instances of heterotypical nitosis. (see fig. 19).

It is further noteworthy that the generative cells which later undergo the reduction-division above described exhibit either immediately (sperm-cells) or a long while (germ-cells) before the maiotic dirisions a remarkatle series of changes in their nuclear chromatin; the chromosomes becoming first distinct in place of forming a network, then entangled together at one side of the nucleus (synaptic condition), and finally beconing again distinct, but now arranged in pairs (gemini) which later take varions forms, such as double rods, loops, or rings as in heterotypical mitosis, but without forthwith proceeding to nuclear division.

The protoplasm of the cell divides soon after the formation of the diaster (fig. 14, $m$ ). During division fine lines are seen in the proto-

$$
1 \text { "Maiotic division" or "maiosis" of Farmer, Moore and Walker. }
$$


plasm, radiating from the centrosomes at the poles of the nucleus, whilst other lines form a spindle-shaped system of achromatic fibres
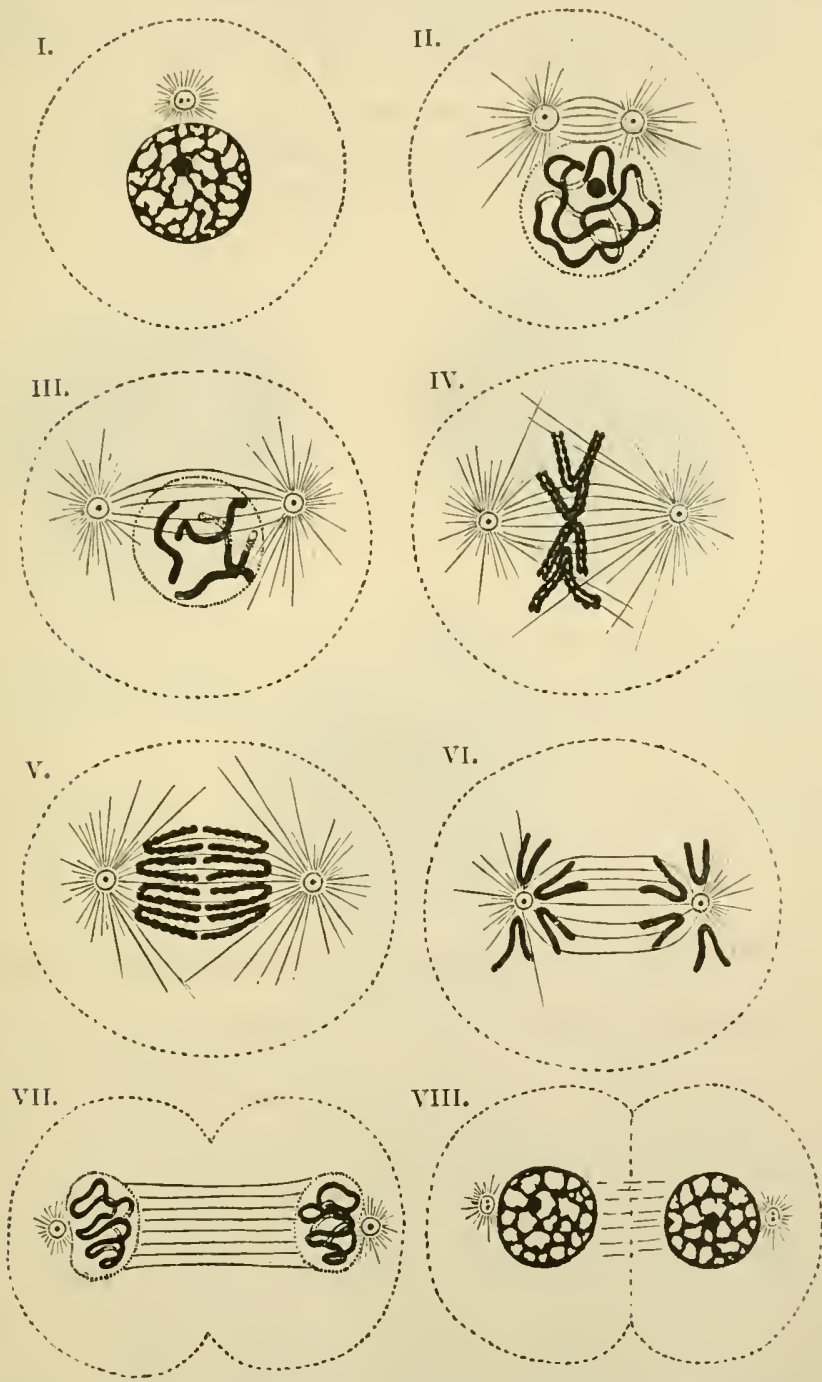

Fig, 18,-DiagraM SHOWING THE CHANges Which OCCUR IN THE CENTROSOMES AND NCCLEUS OF A CELL IN THE PROCESS OF MITOTIC DIVISION.

The nucleus is supposed to have four chromosomes.

within the nucleus, diverging from the poles towards the equator (fig. 18). These are usually less easily seen than the chromatic fibres 
or chromosomes already described, but are not less important, for they are derived from the attraction-spheres. These, with their centrosomes, as we have seen, always initiate the division of the cell; indeed they are often found divided in the apparently resting nucleus, the two particles being united by a small system of fibres forming a minute spindle at one side of the nucleus (fig. 1). When mitosis is about to take place this spindle enlarges, and as the changes in the chromatin of the nucleus which have been above
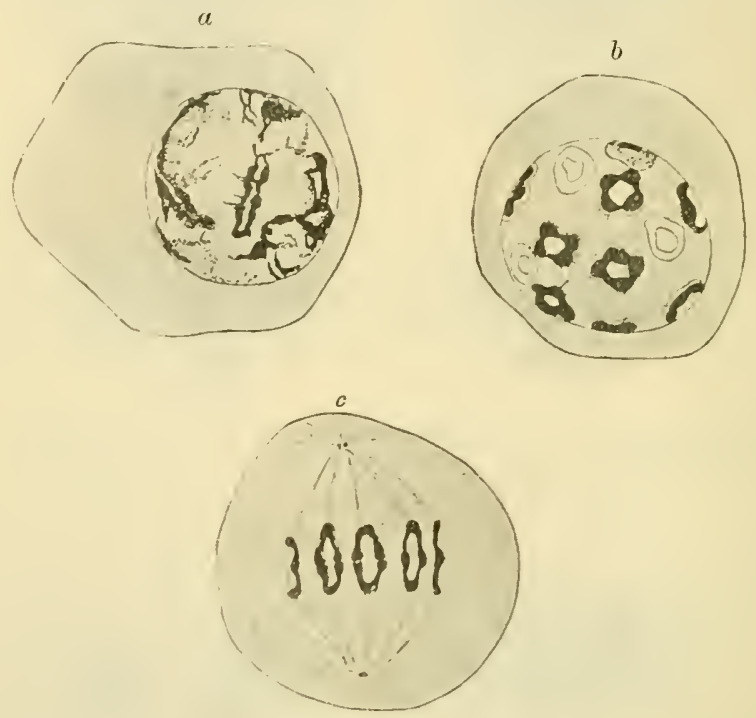

Fig. 19. - ThREE STAGES OF HeTERotYPE MITOSIS IN SPERMATOCYTE OF TRITON. (Moore.)

a, geminal condition of chromosomes; $b$, gemini arranged in quadrate loops or tetrads ; $c$, separation of tetrads into the duplex chromosomes of the daughter nuelei.

described occur-which changes involve the disappearance of the nuclear membrane-the spindle gradually passes into the middle of the mitotic nucleus, with the two poles of the spindle at the poles of the nucleus, and with the fibres of the spindle therefore completely traversing the nucleus (fig. 18). The spindle-fibres appear to form directing lines, along which the chromosomes pass, after the clearage, towards the nuclear poles to form the daughter nuclei.

In some cells, especially in plants, the line of division of the protoplasm of the cell becomes marked out by thickenings upon the fibres of the spindle which occur just in the plane of subsequent division, and have been termed collectively the cell-plate (fig. 20). But in most animal cells no cell-plate is formed, the protoplasm simply becoming constricted into two parts midway between the two 
daughter nuclei. Each daughter cell so formed retains one of the two attraction-partieles of the spindle as its centrosome, and when the daughter cells are in their turn again about to divide this centro some divides first and forms a new spindle, and the whole process goes on as before.

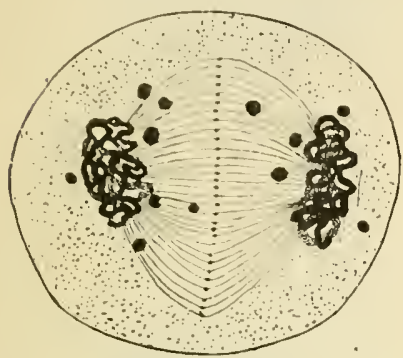

Fig. 20.-CELL-PLATE IN DIVJjING SPORE-CELL OF LILY.

(Gurwitsch, after Zimmermann.)

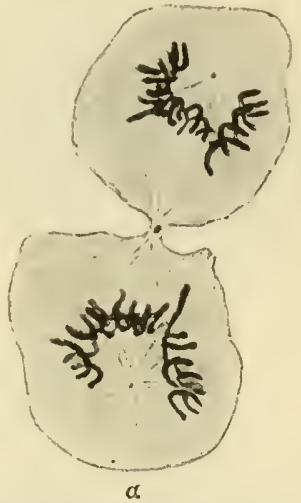

Fig. 21.-Divining cell constricted TO FORM TWO DAUGHTER CELLS EACH WITH CENTrosouE. (Geberg.)

The particle at the junction of the daughter cells represents a rudimentary cell-plate.

Rarely the division of a nucleus is into three or more parts instead of two. In such cases the centrosome becomes correspondingly multiplied and the achromatic system of fibres takes a nore complex form than the simple spindle.

Division of the Ovum.-Usually the two daughter cells are of equal size; but there is a notable exception in the case of the ovum, which, prior to fertilisation, divides twice (by hetero- and homotypical mitosis respectively) into two very unequal parts, the larger of which retains the designation of ovum, while the two small parts which become detached from it are known as the polar bodies (fig. 22). Further, in the formation of the second polar body a reduction-livision occurs, and the nucleus of the ovum, after the polar bodies are extruded, contains only one half the number of chromosomes that it had previously (e.g. twelve in place of the normal twenty-four in man, and two instead of four in Asearis megalocephalia (var. bivalens), fig. $22, C)$. Should fertilisation supervene the chromosomes which are lacking are supplied by the male element (sperm-cell), the nuclens of which has also undergone, in the final cell-division by which it was produced, the process of reduction in the number of chromosomes to one half the normal number. The two redneed nuclei-which are formed respectively from the remainder of the meleus of the oocyte 
(ovum) after extrusion of the polar bodies, and from the head of the spermatozoon, which contains the nucleus of the sperm-cell-are known (within the ovum) as the sperm and germ nuclei or the male and

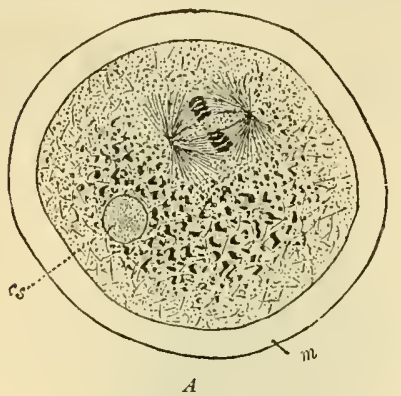

$A$

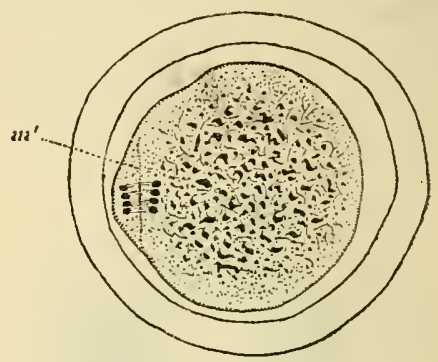

B

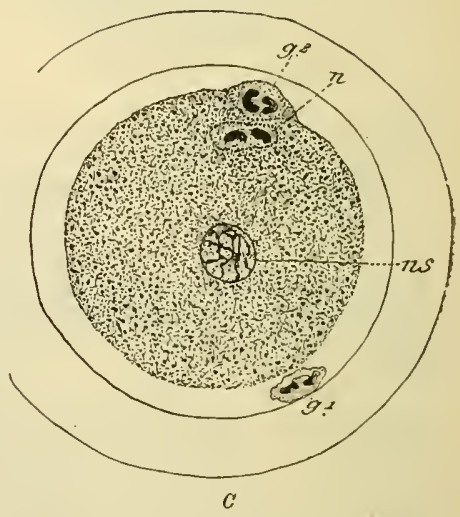

Fig. 22.-Foriation of the POLAR GLOB. CLES AND REDUCTION OF THE NUMBER OF CHROMOSOMES IN THE OVUM OF ASCARIS MIEGALOCEPHALA.

$A, B$, ovum showing division of nucleus to form first polarglobule (Van Gehuchten). m, gelatin. ous envelope of ovum ; $m^{\prime}$, membrane dividing the polar globule from the ovum; es (in $A$ ) head of spermatozoon.

$C$, formation of second polar globule (Carnoy) $g^{1}$, first; $g^{2}$, second polar globule : $n$, nucleus of ovum, now containing only two chromosomes; $n s$, nucleus formcd from head of spermatozoon.

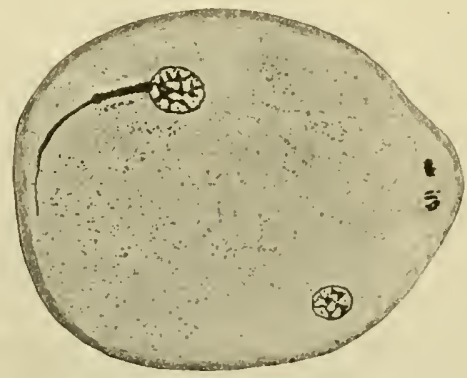

Fig. 23.-OVUM OF BAT WITH POLAR BODIES AND GERM. AND SPERM-NUCLEI. (Van der Stricht.)

The development of the sperm-nucleus from the head of the spcrmatozonn is very evident in this case, because the rest of the spermatozoon happens not to have been thrown off. 
female pronuclei. When these blend, the ovum again contains a nucleus with the number of chromosomes normal to the species (fig. 2t, $E$ ).
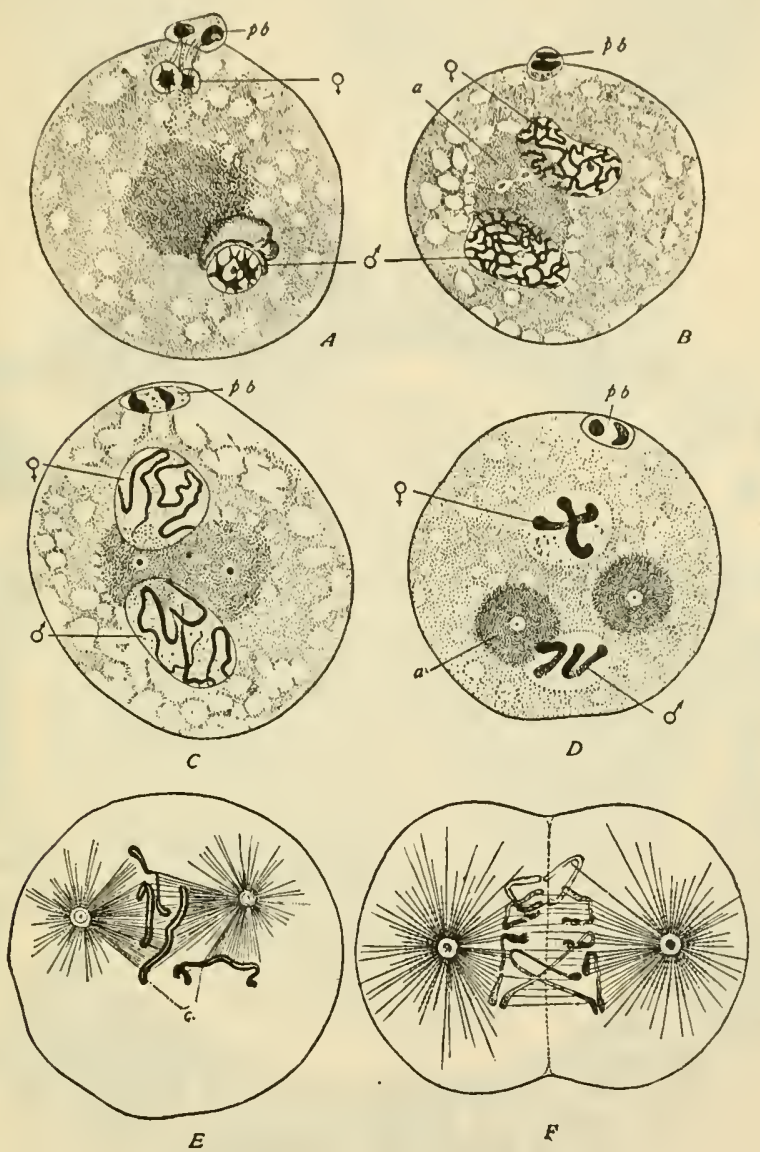

Fig. 24.-Fertilisation and First division of ovUm of ascaris MegaloCEPHALA (slightly modified from Boveri and Wilson).

$A$, second polar globule just formed; the head of the spermatozoon is beconing changed into a reticular nueleus ( $\hat{\delta})$, which, however, shows distinctly two chromosomes; just above it, its archoplasm is shown: the egg-nucleus (ㅇ) also shows two chromo. somes.

$B$, both pro-nuclei are now reticular and enlarged; a double ccntrosome $(a)$ is visible in the archoplasm which lies between them.

$C$, the chromatin in each nucleus is now converted into two filamentous chromosomes; the centrosomes are separating from one another.

$D$, the chromosomes are more distinct and shortened; the nuclear membranes have disappuared; the attraction-spheres are distinet.

$E$, mingling and splitting of the four chromosomes $(c)$; the achromatic spindle is fully formed.

$F$, separation (towards the poles of the spindle) of the halves of the split chromosomes, and commencing division of the cytoplasm. Each of the daughter cells now has four chromosomes; two of these have been derived from the ovum nucleus, two from the spermatozoon nucleus. 
When it divides after fertilisation each daughter cell is found to contain the normal or somatic number of chromosomes, derived from the splitting of both male and female elements, half the number from the one and half from the other.

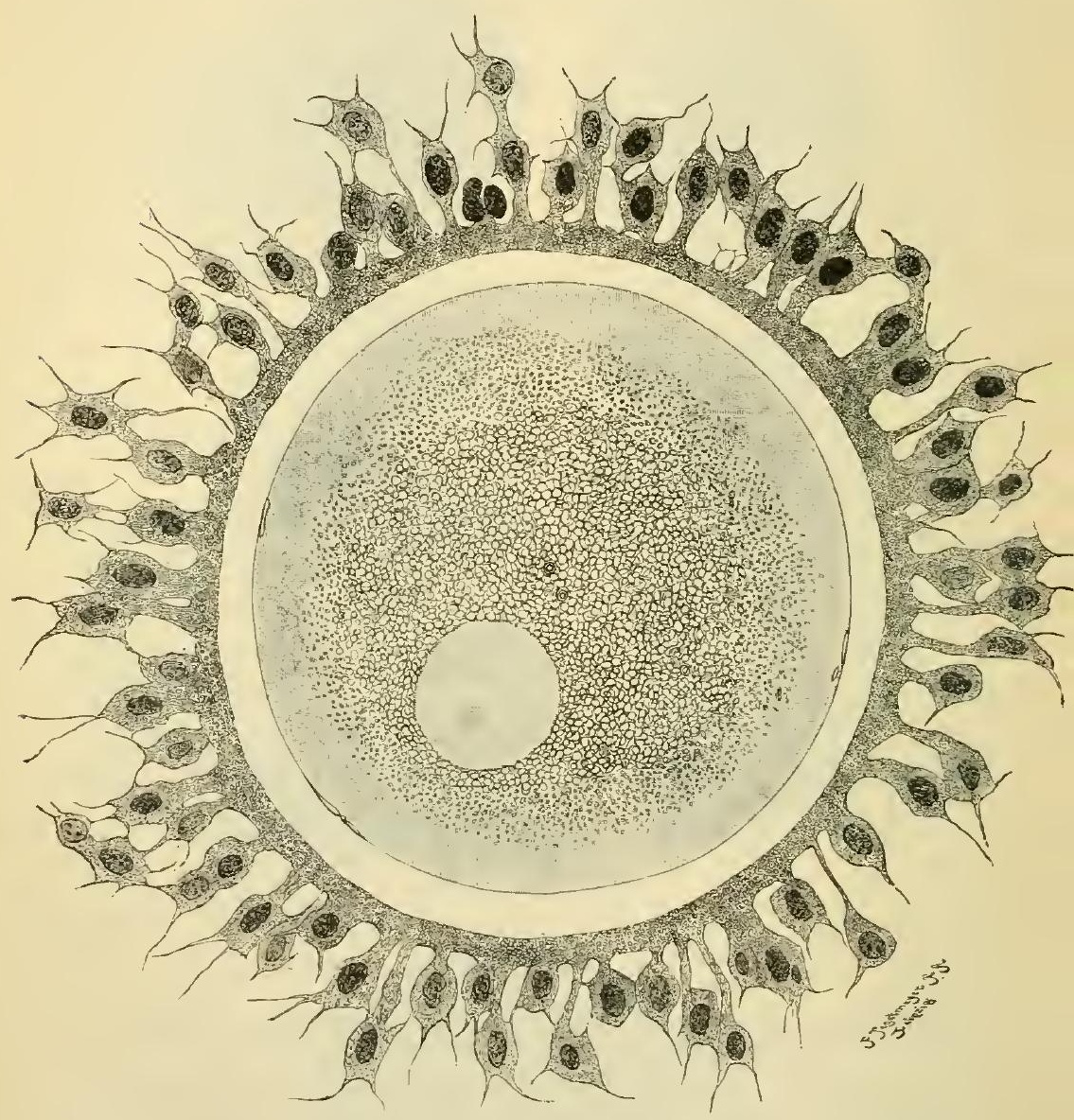

Fig. 25.-HUMAN OVUM (OOCITE) FROM GRAAFiAN FOLLICle: EXAMINED FRESH IN LIQUOR FOLLICULI WITH VERY HIGH MAGNIFYING POWER. (Waldeyer.)

The cells which are attached to the ontside, and which appear to be joined into a syn. cytium around the ovum, are follicular cells belonging to the discus proligerus. Within them is the clear membrane of the ovum (zona pellucida). The cytoplasm of the ovum shows a distinction between clear ectoplasm and granular endoplasm: the large granules are yolk particles. The nucleus (gcrminal vesicle) is clear. The nucleolus (germinal spot) is distinct.

Formation of the tissues. - It appears to be established beyond doubt that new cells can only be formed from pre-existing cells. 

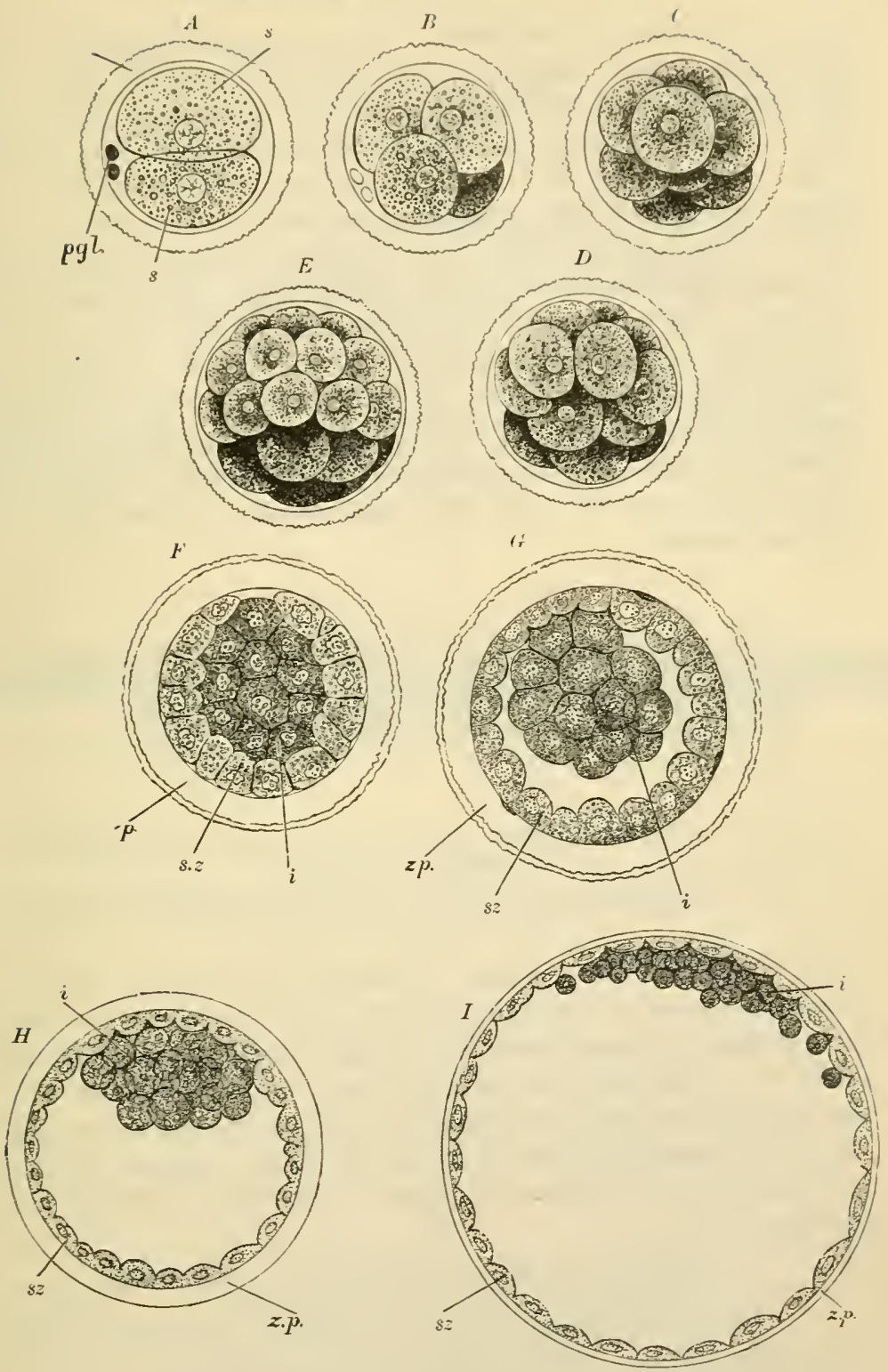

Fiston OF OVU3 INTO

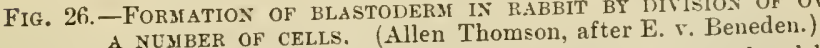

A NUMBER OF CELLS. (Allen Thomson, after E. . Benolar globules; $s, s$,

$A$ to $E$, division of ovum and formation of mulerry mass of appearance. This early cells of primary division which already show a diffcrence of appear an sections of the differentiation is not, however, accepted by most authorities. Fictida); $s z$, subzonal ovum in subsequent stages. $z p$, inembrane of orum (zona pellucida), laser, by means of which the ovum becomes attached to the utic lavers. The membrane; $i$, inner cell-mass, which gives rise to the blastodermic layers. The accumulation of fluid between ectoderm and entoderm the subzonal laser of clear ovum out to form the so-called blastodermic vesicle. Ther cell-mass. 
In the early embryo the whole body is an agglomeration of cells. These have all been formed from the orum or egg-cell (fig. 25), which, after fertilisation, divides first into two cells, these again into two, and so on until a large number of cells (embryonic cells) are produced. These form at first an outer clear stratum lying at the surface (fig. $26 \quad s \%$ ) and a darker grannlar mass attached to this layer at one part, but elsewhere separated from it by clear fluid. Eventually the cells of the inner mass arrange themselves in the form of a membrane (blastoderm) which is composed of three layers. These layers are known respectively as the ectoderm, mesoderm, and entoderm. The ectoderm gives rise to most of the epithelial tissues and to the tissues of the nervous system; the entoderm to the epitbelium of the alimentary canal (except the mouth), and the glands in connection with it; and the mesoderm to the connective and muscular tissues.

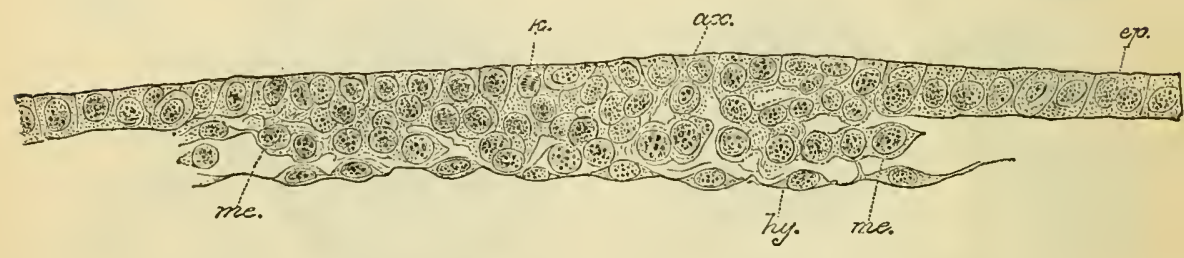

Fig. 27.-SECTION OF BLASTODERM SHOWING THE COMMENCING FORMATION OF THE MESODERM. (Kölliker.)

ep, ectoderm ; $h y$, entoderm ; me, mesoderm ; $a x$, axial part of eetoderm with cells undergoing division $(k)$. The mesoderm is growing from this part.

The tissues are formed either by changes which occur in the intercellular substance, or by changes in the cells themselves; frequently by both these processes combined amongst the cells which are least altered from their embryonic condition are the white corpuscles of the blood, and these may be regarded therefore as typical animal cells.

The histogenetical relation between the three layers of the blastoderm and the several tissues and organs of the body is exhibited in the following table:-

The epithelium of the skin or epidermis, and its arpendages, viz., the hairs, nails, sebaceous and sweat glands, and mammary glands.

The epithelium of the mouth, and the epithelium of the anus and anal canal. The salivary and other glauds whieh open into the mouth. The enamel of the teeth. The gustatory organs.

The epithelium of the lower part of the vrethra and vagina.

The epithelium of the nasal passages, and of the eavities and glands which open into them.

The epithelium covering the front of the eye. The crystalline lens. The retina.

The epithelium lining the membranous labyrinth of the ear. The epithelium lining the exterual auditury meatus.

The epithelium lining the central eanal of the spinal cord, the aqueduet of Sylvius, and the fourth, third, and lateral ventrieles of the brain.

The tissues of the nervous systern.

The pituitary body. The pineal gland. The medulla of the suprarenal cajsules. 
Tho enmective tissues.

The bluod-and lynuh-eorpuseles.

The spleen and other vaseular and lympluatic glands.

Mesodern.

The epithelinl lining of the heart, blood-vessels, lymphaties, and serous men branes (endothelium)

'The epithelium of the uriniferous tubules.

The epithelium of the internal generative organs, and the generatire products in both sexes.

The museular tissues, voluntary, involuntary, and eardiac.

Tho epithelium of the alimentary eanal (from the pharynx to the lower end of the reetum) and of all the glands which open into it (ineluding the liver and panereas).

The epitheliım of the Eustachian tube and eavity of the tympanum.

The epithelium of the larynx, trachea, and bronchi, and of all tlieir rarnifieations. The epithelium of the pulmonary alreoli.

The thyroid body. The thymus gland.

The epithelium of the urinary blidder and ureters, and of part of the urethra.

1 All the comnective tissues, the endothelium (mesothelium) of the vaseular system, and the vascular and $15 \mathrm{mphatic}$ glands are formed frow a special jart of the mesoderm termed parablast or mesenclume, which eonsists of a syneytium of branelsed eells with a homogeneous intercellular matrix. Plain museular tissue is for the inost part also formed from mesenchyme, but in certain situations, as in the sweat glands and museular tissue of the iris, it is said to be ecto. dermal in oricin. 


\section{LESSON I.}

\section{USE OF THE MICROSCOIE. EXAMINATION OF CERTAIN COMMON OBJECTS.}

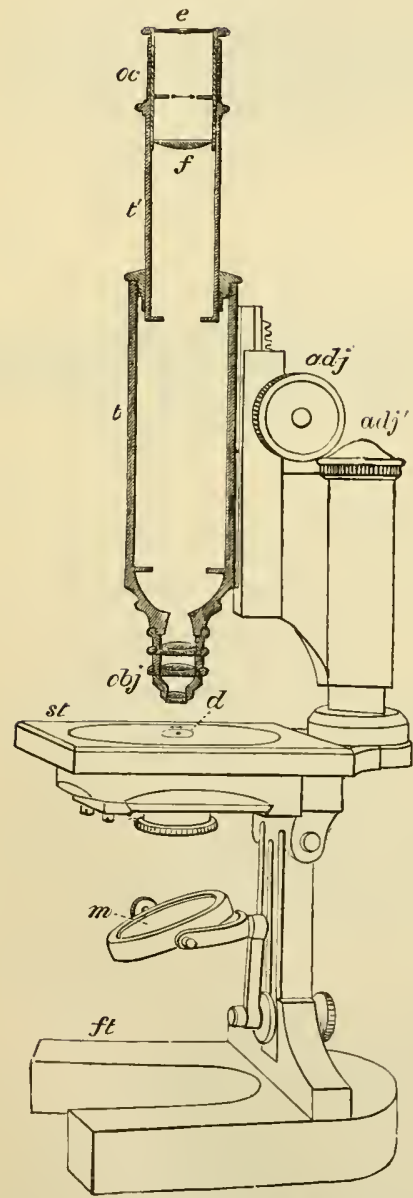

Fig. 28.-Diagram OF MICRoscope.
THE requisites for practical histology are a good compound microscope; slips of glass technically known as 'slides, upon which the preparations are made; pieces of thin glass used as covers for the preparations; a few instrunients, such as a microtome, a scalpel, scissors, forceps, and needles mounted in wooden bandles; and a set of fluid re-agents for mounting and staining microscopic preparations. ${ }^{1}$ A sketch-book and pencil are also necessary, and must be constantly employed.

The microscope (fig. 28) consists of a tube $\left(t t^{\prime}\right) 160$ millimeters $(6 \cdot 4$ inches) long having two systems of lenses, one at the upper end termed the 'eye-piece' or 'ocular' $(o c)$, the other at the lower end termed the 'objective' $(o l j)$. For ordinary work there should be at least two objectives-a low power working at about 8 millineters ( $\frac{1}{3}$ inch) from the object, and a high power, having a focal distance of about 3 millimeters ( $\frac{1}{6}$ inch); it is useful also to have a lower power (commanding a larger field of view) for finding objects readily, and two or more ocular's of different power. The focus is obtained by cautiously bringing the tube and lenses down towards the object by the coarse adjustment, which is usually a rack-and-pinion movement $(a d j)$, and focussing exactly by the tine arljustment, which is always a finely cut screw $\left(a d j^{\prime}\right)$.

The stage (st) upon which the prepartions are placed for examination, the mirror $(m)$ which serves to reflect light up through the central aperture in the stage and along the tube of the instrument, and the diaphragm $(d)$ below the stage

${ }^{3}$ The direations for making the principal fluids used in histological work will be found in the Appendix. 
which is nsed to regulate the amount of light thus thrown 11 , are all parts the employment of which is realily molerstood. A substage condenser (not shown in the diagram), which serves to concentrate the light thrown up by the mirror to the centre of the object, is valuable when high powers and staincl preparations are employed.

The combinations of objectives and oculars alove referred to will generally give a magnifying power of from 50 to 400 diameter's, and this is sufticient for most purposes of histology. But to bring out ninute points of detail in the strneture of cells and of certain tissues examination with much higher magnifying powers may be necessary. Objectives of high power are usually marle as immersion-lenses; i.e. they are constructed to form a proper image of the oljject when the lowermost lens of the system is inmersed in a layer of liquid which lies on the cover-grlass of the object and has a refractive index not far removed from that of the glass itself. For this purpose either water or an essential oil (oil of cedarwooll) is used. The advantages obtained by the employment of these lenses, especially those for oil-immersion, are:-increased working fistance from the object, increased angle of apertme with sharper definition of the object, and increased amormt of light traversing the nicroscope.

The best lenses for' lisstological work are made of the so-called 'apochromatic' glass ; specially constructed 'compensating' eye-pieces are used with these.

A scale for measuring objects should be constructed for each microscope. To do this, put a stage-micrometer (which is a glass slide ruled in the centre with lines $\frac{1}{10}$ and $\frac{1}{100}$ millimeter apart) under the microscope in such a manner that the lines run from left to right (the microscope must not be inclined). Focus them exactly. Put a piece of white card on the table at the right of the microscope. Look through the instrmment with the left eye, keeping the right eye open. The lines of the micrometer will appear projected upon the paper. Mark their apparent distance with pencil upon the card, and afterwards make a scale of hines in ink, of the same interval apart. A magnified representation is thus obtained of the micrometer scale. Mark npon it the number of the eye-piece and of the objective, and the length of the microscope-tube. This scale-card will serve for the measurement of any object without the further use of the micrometer. To measure an object, place the scale-card upon the table to the right of the microscope and view the object with the left eye, keeping the right eye open. The object appears projected upon the scale, and its size in $\frac{\lambda}{10}$ or $\frac{1}{100}$ of a millimeter can be real off. It is essential that the same objective and eye-piece should be employed as were nsed in making the scale, and that the microscope tube should be of the same length. The lines on English stage-micrumeters are often ruled $\frac{1}{100}$ and $\frac{1}{1000}$ inch apart. ${ }^{1}$

Before beginning the study of histology the student should endeavour to familiarise himself with the use of the microscope, and at the same time learn to recognise some of the chief objects which are liable to occur accidentally in microscopic specimens. On this account it has been considered desinable to introduce directions for the examination and recognition of starch-granules, monlds and torule, air-bubbles, linen, cotton, and woollen fibres, and the usual constituents of the dust of a room, into the first practical lesson (fig. 29).

1. Examination of starch-granules. Gently scrape the cut surface of a potato with the point of a kuife; shake the starch-granules so obtained into a drop of water upon a clean slide and apply a cover-glass.

With the low power the starch granules look like dark specks differing

${ }^{1}$ For the method of measuring with an ocular micrometer, and for determining the magnifying power of a microscope, the reader is referred to the author's Course of Practical Histology. 


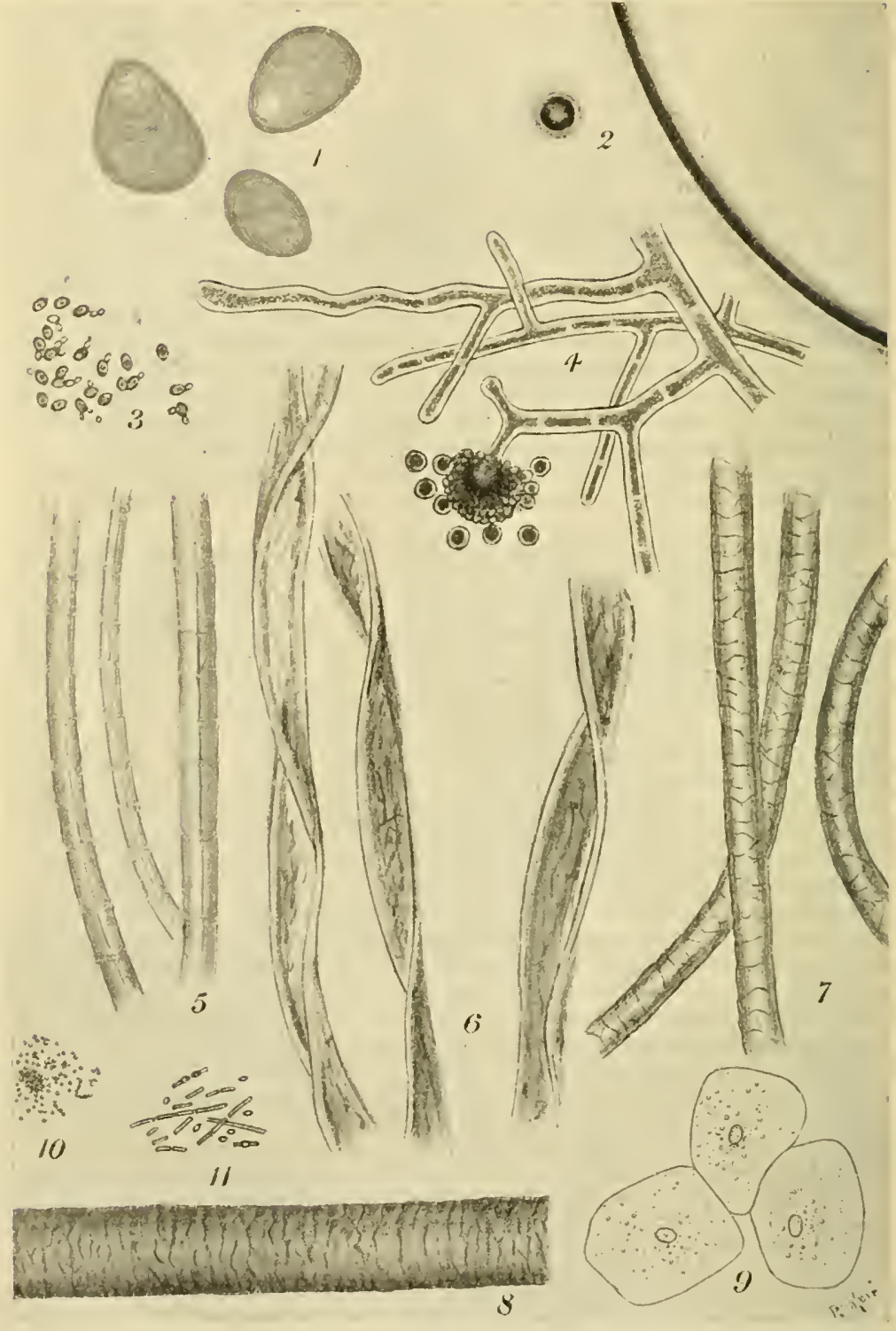

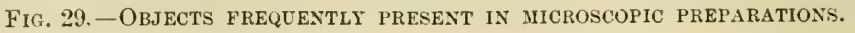

1. Starch granules; 2, a small air bubble and part of a large one ; 3 , seast torulie; 4, a mould (Aspergillus glaucus); 5 , linen fibres; 6 , cotton fibres; 7 , wool ; 8 , hair, hurna1s ; 9, epithelium scales; 10, micrococci; 11, bacilli and spores (B. subtilis). Magnified about 250 diameters. 
considerably in size; under the high power they are clear, flat, ovoid particles (tig. 29, 1), with a sharp ontline when exactly focussed. Notice the change in appearance of the outline as the microscope is focusserl up, and down. On close examination fine concentric lines are to be seen in the granules arranged around a minute spot which is generally placerl eccentrically near the smaller end of the gramule. Sketch two or three starch granules.

Notice the appearance of air-bubbles in the water. If comparatively large they are clear in the middle, with a broad dark border due to refraction of the light; if small they may look entirely dark.

2. Examine some reast which has been grown in solution of sugar. Observe the yeast-particles or torule, some of them budding. Euch torula contains al clear vacuole, and has a well-defined outline, due to a membrane. Sketch two or three torulit.

3. Examine some monld in water. Notice the loug branching filaments (hyphe), and also the torula-like particles (spores) from which hyphre may in some instances be seen sprouting. Sketch part of a hypha.

4. Examine fibres of linen and of cotton in water, using a high power. Compare the well-defined, rounded, relatively straight or but slightly twisted linen, with the longer, broader but thimner, and more twisted cotton fibres. Sketch one of each kind.

5. Mount one or two hairs from the head in water and look at them first with the low, then with the high power. Examine also fibres from any woollen material and compare them with the hairs. They have the same structure, although the wool is finer and is curled; its structure may be obscured by the dye. Draw one or two of each.

6. Examine a drop of hay infusion, which has been standing a day or two, for bacteria and other putrefictive organisms. The active movements which these exhibit are due to minute cilia or flagella, which can only be made .visible by special staining methods and a very high magnifying power. Any minute inactive particles, organic or inorganic, which occur in this or other fluids may be seen to exhibit a peculiar tremulous dancing movement which is known as the 'Brownian' movement.

7. Examine some dust of the room in water with a high power. In addition to groups of black particles of carbon (soot) there will probably be seen fibres of linen, cotton, or wool, and shed epithelium-cells derived from the epidernis. 


\section{LESSONS II. AND III.}

\section{STUDY OF THE HUMAN BLOOD-CORPUSCLES.}

1. HAving cleaned a slide and cover-glass, prick the finger above the nail and mount a small drop of blood quickly, so that it has time neither to dry nor to coagulate. Examine it at once with the high power.

Note $(\alpha)$ the coloured corpuscles mostly in rouleaux and clumps, but some lying apart seen flat or in profile; $(b)$ the colourless corpuscles, easily made out if the cover-glass is touched by a needle, on account of their tendency to stick to the glass, whilst the coloured corpuscles are driven past by the currents set up; $(c)$ in the clear spaces, fibrin-filaments and elementary particles or blood-platelets.

Sketch a roll of colonred corpuscles and one or two colourless corpuscles. Count the number of colourless corpuscles in a field of the microscope.

2. To be made as in $\$ 1$, but the drop of blood is to be mixed upon the slide with an equal amount of isotonic saline solution, so that the red corpuscles tend to be less masserl together, and their peculiar shape is better displayed.

Sketch a red corpuscle seen on the flat and another in profile or (optical section). Also a crenated corpuscle.

Measure ten red corpuscles, and from the results ascertain the average diameter of a corpuscle. Measure also the largest and the smallest you can find.

3. Make a preparation of blood as in $\$ 1$ and put it aside to coagulate Keep the edges from drying by placing it in a moist chamber or by occasionally breathing upon it. After a few ninutes place a drop of 1 p.c. methyl violet at one edge of the cover and allow this to pass in and mix with the blood: it may be drawu through the preparation by applying a small piece of blotting paper to the opposite edge. The dye stains the nuclei of the white corpuscles, the blood-platelets, the network of fibrin-filaments, and the membranes of the red blood-corpuscles.

The three preparations just described cannot be kept, but the two following will serve as permanent preparations of blood :-

4. To fix and stain the coloured corpuscles:-Place upon a slide a drop of 1 p.c. osmic acid mixed with an equal amount of saturated aqueous solution of eosin. Prick the finger, and mix the blood directly with the coloured fluid, stirring them together with a needle. Cover the mixture and put aside for an hour, protected from evaporation; then place a drop of glycerine and water at the edge of the cover-glass. When this has passed under fix the cover-glass with gold size.

5. To study the granules of the colourless corpuseles and their different reactions to staining reagents, a film of blood is inclosed between two coverglasses, which are at ouce separated and the film on each quickly dried in the air. A slide may be used instead of a cover-glass; the drop of blood is placed close to the ground edge of one slide and this is drawn evenly over the middle of another. The films are fixed by immersion for one hour or more in a mixture of alcohol and ether, equal parts of each. They are then stained by (1) a saturated solution of eosin in 75 p.c. alcohol (three minutes), after which they are rinsed with water, and are then treated with (2) a 1 p.c. 


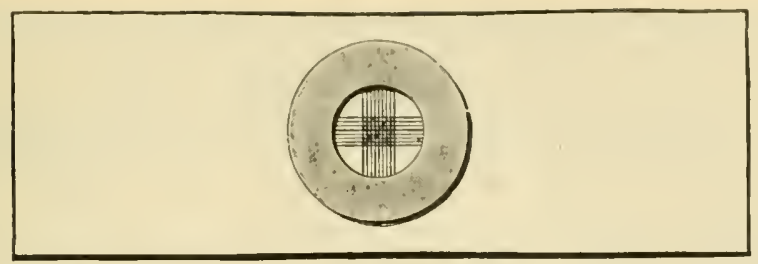

FIG. 30- - HEMACYTOMKIER SLIHE, RULED IN SQUARES FOK THE RNUMERATION OF BLOON-CORPUSCLES.
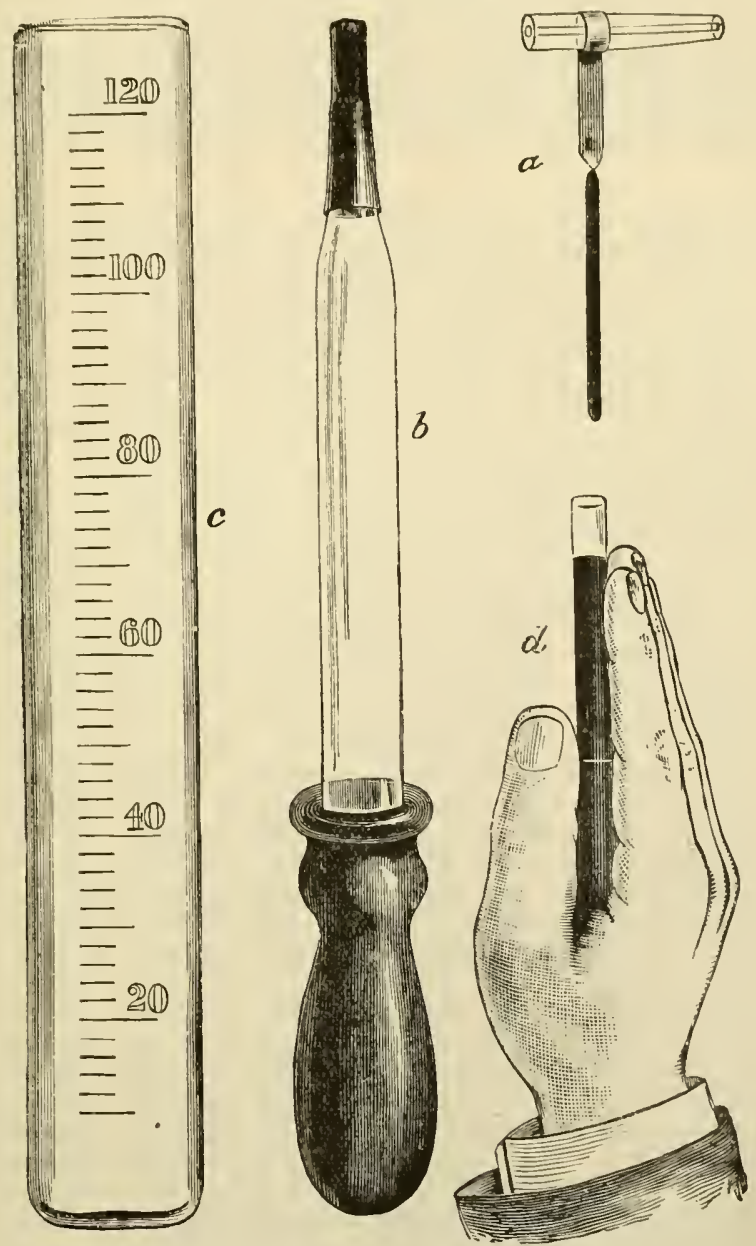

Fig. 31.-Oliver's apparatus for estimatiNg the NUMBer of Corpuscles IN BLOOD BY MEANS OF THE OPACITY METHOD.

a, pipette for measuring blood; $\iota$, dropper for addiug mixing solution ; $c$, graduated tube ; $d$, mode of observing.

$a, b, c$, natural size. 
solution of methylene blue (one minute). The film is again rinsed with water, rapidly dried, and monnted in xylol balsam or dammar. ${ }^{1}$

6. Monnt in xylol balsam or dammar sections of marrow from a long bone of a rabbit fixed with mercuric chloride or formol and stained with eosin and methylene blue. Observe the fat-cells, the supporting reticular tissue, the proper marrow-cells in this tissue, the myeloplaxes and the erythroblasts.

7. Tease in salt solution or serum some of the red marrow from the rib of a recently killed animal. Observe and sketch the proper marrow cells and look for myeloplaxes and nucleated coloured blood-corpuscles (erythroblasts).

8. Make a film preparation of red marrow by smearing a little upon a cover-glass or slide, allowing it to dry quickly, and placing it in a mixture of equal parts of ether and alcohol. After an hour or more in this, the preparation nay be stainerl with eosin and methylene blue in exactly the same way as a film preparation of blood (see $\$ 5$ ), and mounted in xylol balsam or dammar.

9. Enumeration of the blood-corpuseles. This is done by some form of blood-comter such as the hrmacytometer of Gowers, or the similar apparatus of Thoma. This instrument consists of a glass slide (fig. 30), the centre of which is ruled into $\frac{1}{10}$ millimeter squares and surrounded by a glass ring $\frac{x}{10} \mathrm{~mm}$. thick (in Gowers' instrument, the ruling is into $\frac{1}{5} \mathrm{~mm}$. squares with a ring $\frac{1}{5} \mathrm{~mm}$. thick). There must also be proviled a pipette (fig. $31, a$ ) for measuring the blood, constructed to hold about 5 cubic millimeters of fluid ; a dropper (fig. $31, b$ ) to deliver the diluting solution; a small cylindrical mixing glass, not shown in the figure, with a mark indicating 100 times the capacity of the blood pipette; a small glass stirrer, and a guarded needle. The diluting. solution may either be that of Hayem, viz. distilled water $200 \mathrm{cc}$, sulphate of soda 5 grms., common salt 1 grm., corrosive sublimate 0.5 grm., or that of Marcano, viz. $97 \mathrm{cc}$. of a solution of sulphate of soda in distilled water of sp. gr. 1020, to which is added chloride of sodium 1 grm., and formol 3 ec. A little of the diluting solution is put in the mixing vessel, the finger is pricked, and the pipette filled exactly with blood (by capillarity). The blood is then washed ont of it with diluting solution, by aid of the dropper, into the mixiug vessel, which is now filled up to the 100 mark with diluting solution, and the blood and this are thoronghly mixed. A drop of the mixture is next placed in the centre of the cell, the cover-glass is gently laid on (so as to touch the drop, which thus forms a layer $10 \mathrm{~mm}$. thick between the slide and cover-glass), and pressed down by two brass springs. In a few mimutes the corpuscles have sunk to the bottom of the layer of fluid and rest on the squares. The number in ten squares is then comnted, and this, multiplied by 100 , gives the number in a cubic millimeter of the mixture, or if again multiplied by 100 (the amount of dilution) the number in a cubic millimeter of blood.

For the enumeration of the white corpuscles the blood is diluted only 10 times instead of 100 times. It is also convenient to use one half per cent. solution of acetic acid just colonred with methyl violet as a diluent (Thoma). This destroys the coloured corpuscles and stains the nuclei of the white.

A rapid method of estimating the number of colonled corpuscles is that devised by $\mathrm{G}$. Oliver. The blood is taken up as before in a capillary pipette (fig. 31, a), and is washed ont of this with Hayen's fluid by the dropper, $b$, into a flattened gradnated glass nixer, $c$, the dilnent being adrled until the flame of a small wax candle in a dark room will just show sharply through the mixture, when the vessel is held close to the eye and about ten feet from the candle and so that the light traverses the greater thickness of fluid. The

'Other stains, such as Ehrlich's tri-acid and the Ehrlich-Biondi, may also be employed for films. 
grahuatious are so armuged that for normal blood $(5,000,000$ corpuscles per eub. nmm.), the mixture will now stand exactly at the 100 nark: if the blow contain nore or fewer corpuseles than normal, it will require a greater or less dilution to attain the requisite transhocency, and the nark at which the mixture then stands will indicate the percentage of corpuscles as compared with the normal.

Another rapid method of estimating the relative number of blood-corpuscles is to determine the corpuseular volume in a known amomnt of blood. This is done by the use of the hiematoerit, in which the blood, suitably diluted, is centrifugalised and the volmme of corpuscles read off on a scale.

The coloured blood-corpuscles.-The colonred eorpuscles are composed of a delicate colourless highly elastie (? protoplasmic) envelope, and colourel fuid contents, consisting mainly of a solution of hæmoglobin.

Fig. 32.-HUMAN RED BLOOD-CORPUSCLES : Photograph magnified 650 diameters.

The existence of such an envelope is shown by the osmotic effect of water upon the corpuscle, which passing in through the envelope, distends, and eventually bursts the corpuscle and sets free the contents. The description which is current in many text-books that the red corpuseles consist of a porous solid stromu, permeated with dissolved hæmoglobin, is incompatible with this and similar reactions. Moreover, the envelope can be distinctly seen with the microscope, especially in the amphibian corpuscle, and can be stained by reagents. The envelope contains lecithin and cholesterin in considerable amount, and these substances impart a certain greasiness to the surface of the corpuscle. It is in all probability due to such greasiness that 
the corpuscles run together into rouleaux when the blood comes to rest (see p. 43).

Under the microscope blood is seen to consist of a clear fluid (plasma), in which are suspended the blood-corpuscles (fig. 32). The latter are of two kinds: the red or coloured (erythrocytes), which are by far the most numerons, and the white, pale, or colourless (leucocytes). In addition to these more obvious corpuscles, blood contains a variable number of minute particles which were termed by Zimmermann the elementury particles of the blood, but which are now more usually known as the blood-platelets on account of their flattened form.

Erythrocytes. - When seen singly the coloured corpuscles are not distinctly red, but appear of a reddish-yellow tinge. In the blood of man and of all other mammals, except the Camelidæ, they are biconcave circular disks. Their central part usually has a lightly shaded aspect under a moderately high power, but this is due to their biconcave shape, not to the presence of a nucleus. They have, as just stated, a strong tendency to become aggregated into rouleaux and clumps when the blood is at rest, but if it is disturbed they readily become separated.

If the density of the plasma is increased in any way, as by evaporation, many of the red corpuscles become shrunken and crenated by the passage of water out of the corpuscle. On the other hand, a diminution in the density of the plasma tends to cause the red corpuscles to become cup-shaped, but it is erroneous to describe this as the normal form of the corpuscle.

The average diameter of the human red corpuscle is 0.0075 millimeter ${ }^{1}$ (about $\frac{1}{3200}$ inch), but a few will always be found somewhat larger $(0.0085)$ and a few somewhat smaller $(0.0065 \mathrm{~mm} .)^{2}$

There are from four to five millions of coloured corpuscles in a cubic millimeter of blood.

Leucocytes.-The colourless corpuscles of human blood are protoplasmic cells, averaging $0.01 \mathrm{~mm} .\left(\frac{1}{2500}\right.$ inch) in diameter when spheroidal, but they vary much in size. They are far fewer than the coloured corpuscles, usually numbering not more than eight to ten thousand in a cubic millimeter (about 1 to 600 red corpuscles). Moreover, they are specifically lighter, and tend to come to the surface of the preparation. If examined immediately the blood is drawn, they are spherical in shapc, but soon become flattened and

${ }^{1}$ Also expressed as $7 \cdot 5 \mu$ or micromillimeters; a micromillimeter being $\frac{1}{100 \overline{0}}$ millimeter.

2 The following list gives the diameter in parts of a millimeter of the red bloodcorpuscles of some of the common domestic animals:-Dog, 0.0073 ; rabbit, 0.0069 ; cat, $0 \cdot 0065$; goat, $0 \cdot 0041$. 
then irregular in form (fig. 33), and their outline continually alters, owing to the amoba-like changes to which they are subject. In some kinds (phugocytes) the protoplasm tends to take in foreign partieles with which the cells come in contact; in others there seems to be little or no such tendency. Some of the colourless corpuseles are very pale and filled with fine granules, others contain coarser and more distinet gramules in their protoplasm ; others again have a hyaline protoplasm without any apparent gramules. In some corpuscles (lymplocytes) the protoplasm forms only a relatively thin coating to the meleus. The corpuscles are classified according to the eharacter and appearanee of the nucleus and the nature and staining qualities of the gramules in

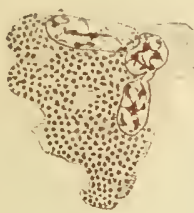

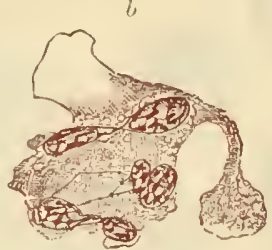

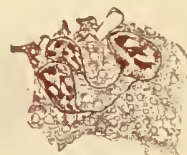

Fig. 33.-THRE AMEBOLD WHITE CORPUSCles OF THE NEWT, KILLED BY INSTANTANEOUS APPLICATION OF STEAM.

$a$, ensinophil cell ; $b, c$, polymorphous cclls. The nuclei appear multiplc, but are seen to be connected with fine filaments of nuclear substanee traversing the protoplasm.

the protoplasm. Thus some granules are readily stained by basic dyes such as methylene blue, and such granules are accordingly termed basophil. Distinct coarse basophil granules are, however, rare in normal blood, although cells with these granules are normally present in the marrow and in some connective tissues, and make their appearance in the blood in leucocythrmia. On the other hand, some granules more readily take up colour from acid dyes, such as eosin, and these have been termed oxyphit or cosinophil. Other cells possess granules (cmphophil) which are stained by both aeid and basic dyes; and others chiefly by nentral dyes (neutrophil). In some cells more than one kind of granule is met with. The protoplasm may also contain clear spaces or vacuoles. Each lencocyte has at least one nucleus, which is difficult to see in a fresh preparation, but is easily seen after the action of most reagents and after staining. There is also a centrosome with attraction-sphere, but special methods of staining are necessary to exhibit these. (See fig. 9, p. 7.)

The following are the chief varieties of leucocytes:-1. Polymorphs. Cells with lobed or multipartite nuclei and a relatively large amount of protoplasm, which is highly amoboid (fig. 33, $b$ and $c$ ). These are often termed multi-(poly-)nuclear, but the nucleus is rarely if ever multiple, 
its scveral parts being nearly always joined by threads of nuclear substance. The cells in question vary in size, but when spherical are usually not quite $0.01 \mathrm{~mm}$. in diameter. Their protoplasm stains with eosin, this being due to the presence of fine oxyphil granules (Kanthack and Harly). They are highly amoboid and phagocytic, and constitute from sixty to seventy per cent. of all the leucocytes of the blood (fig. 34, a).

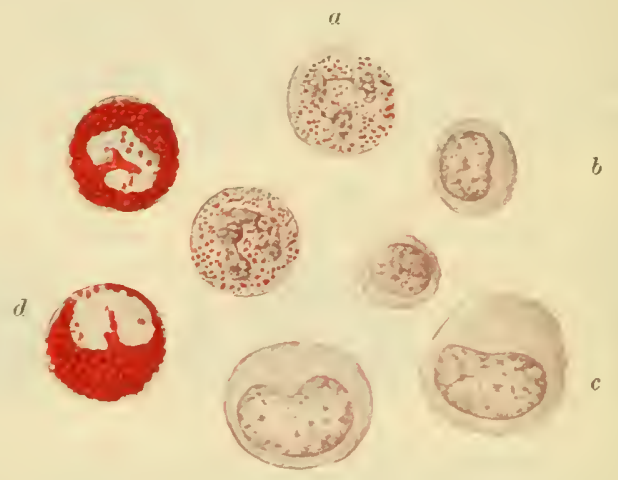

Fig. 34.-VARIOUS KINDS OF COLOURLEAS CORPUSCLE., SHOWING THE DIFFERENT CHARACTERS OF THE GRANULES. (From a film preparation of normal human bloorl.) Two of each kind are representerl.

2. Lymphocytes.-These are small cells, with a very limited amount of clear protoplasm around the nucleus, which is simple, not lobed or divided (fig. 34, 6 ). The amwboid phenomena are less marked in them than in the other varieties of leucocytes. The protoplasm stains with methylene blue. They are about 0.0065 $\mathrm{mm}$. in diameter, but some are larger and appear to be transitional between this and the next variety. They constitute from fiftcen to thirty per cent. of the total number of leucocytes in the blood. They are relatively more numerous in infancy.

3. Mucrocytes.--Large uninucleated cells similar to the last, but larger, and containing much more protoplasm (fig. 34, c). Some, however, are smaller and are regarded as transitional forms from the last variety. The nucleus may be spherical, oval, or kidney-shaped. The protoplasm is hyaline; it stains slightly with methylene blue, perhaps owing to very fine basophil granules. These cells are highly amceboid and phagocytic. Including the transitional forms, they constitute about five per cent. of all the leucocytes in blood.

4. Eosinophils.-These are characterised by their coarse granulcs, which stain deeply with acid dyes, such as eosin. Their average 
diameter in the spherical condition is $0.01 \mathrm{~mm}$. The nuclens may be simple or lobed (fig. 34, 1 ; fig. 33, $\iota$ ). They are amoboid, but less actively so than the finely granular cells. They are more variable in number than the other varieties, constituting sometimes not more than one per cent., and at other times as much as ten per cent. of the total lencocytes of blood.

5. Busophils.-These are rarely if ever found in normal blood (adult), but oceur in chikdren and in certain pathological conditions affecting the bone marrow.

Blood-platelets. - In the clear fluid in which the blood-corpuscles are suspended, a network of fine straight intererossing filaments (fibrin)

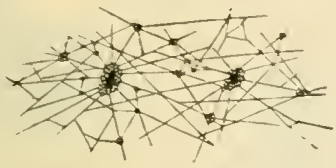

FIg. 35.-NeTwORK OF FIBRIs, SHOW: AFTER WASHING AWAY THE CORPLSCLES FROM A PREPARATION OF BLOOD THAT HAS BEEN ALLOWED TO CLOT ; MANY OF THE FILAMENTS RADIATE FROM SMALL CLCIIPS OF BLOOD-PLATELETS.

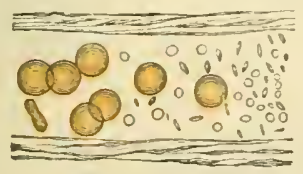

FIG. 36. - BLOOI-CORPCSCLES AND ELEMEXTARY PARTICLES OR BLOOD-PLATELETS, WITHIX A SMALL VEIx. (From Osler.)

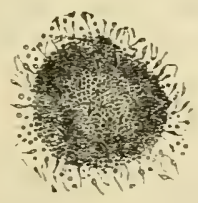

Fig. 37.-A MiAs OF BLOON-PL.ATELETs, FROM HCMAX BLOOD. (Osler.)

A few at the edge are detached from the rest. The preparation had been kept in salt solu. tion on the warm stage for some time, thus causing a partial breaking up of the mass of platelcts. These will be obscrred to have filaments attached to them.

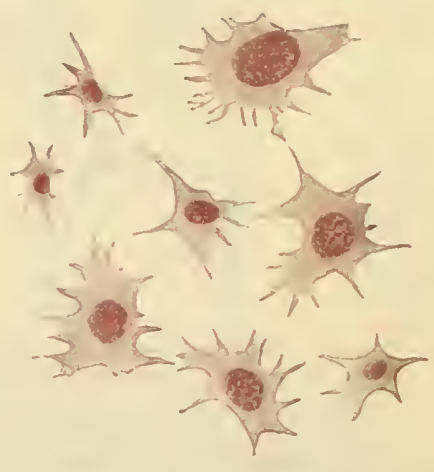

Fig. 38.-Blood-Piatelets, Highli MAGNIFIED, SHOWING THE AMEBOID FORMS WHICH THEY ASSUME WHEN EXAMINED UXDER SUITABLE CONDITIONS. AND ALSO EXHIBITING THE CRROMATIC PARTICLE WHICH EACH PLATELET CONTAINS, AND WHICH HAS BEEN REGARDED AS A NCCLECS. (After Kopsch.)

soon makes its appearance (fig. 35). These often seem to radiate from minute round colourless discoid particles less than one-third the diameter of a red corpuscle, either separate or collected into groups or masses, of variable, sometimes of considerable, size. These are the elementary particles, blood-platelets, or thrombocytes. In the blood-ressels they are 
discrete but immediately clump together in drawn blood (fig. 37). If, however, the blood is examined on agar jelly containing certain salts in definite proportions, the platelets can be kept separate, and may then be submitted to very high powers of the microscope. The result of such examination seems to show that the blood-platelets are not mere inert particles, as has generally been supposed, but that they are protoplasmic and amoboid, and that each one contains a nucleus (fig. 38), that they are in fact minute cells (Deetjen). Blood platelets vary greatly in number: they are estimated by Brodie and Riussell to amount to from 5 millions to 45 millions in the cubic centimeter of blood.

Fatty particles, derived from the chyle, may also occur in the plasma.

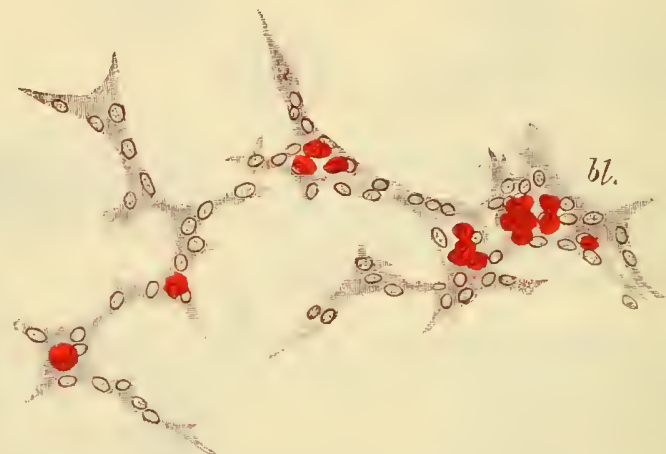

Fig. 39.-DEVELopMENT OF BLOOD-VESSELS AND BLOOD-CORPUSClES IN THE VASCULAR AREA OF THE GUINEA-PIG.

$u l$, blood-corpuseles becoming frec in the intcrior of a nucleated protoplasmic mass.

Development of red blood-corpuscles. - In the embryo, the first-formed coloured blood-corpuscles are amœboid nucleated cells, the protoplasm of which contains hæmoglobin. These embryonic blood-corpuscles are developed within cells of the mesoderm (mesenchyme), which are united with one another to form a syncytium (fig. 39). The nuclei of the cells multiply, and around some of them there occurs an aggregation of coloured protoplasm. Finally the network becomes hollowed out by an accumulation of fluid in the syncytial protoplasm, and thus are produced a number of capillary blood-vessels, within which the coloured nucleated portions of protoplasm are set free as embryonic blood-corpuscles (erythroblasts, fig. 39, $b l$ ). Within the circulation these multiply by mitotic division, and thus become rapidly more numerous.

In later embryonic life, nucleated coloured corpuscles disappear from manmalian blood, and are replaced by the usual discoid corpuscles. Many of these are doubtless clerived from the nucleated embryonic 
blood-cells, the absence of the nuclens being aceounted for either by its atrophy or extrusion from the cell or by the separation of a part of the colonred cell-substance. The foetal liver has been supposed to be one of the places of formation of red blood-corpuseles. Erythrocytes are also formed at a somewhat later stage of development within certain cells of the comnective tissne (vasoformative cells), a portion of the substance of the cell becoming coloured by hamoglobin, and separated into globular particles (figr. $40, a, b, c$ ), which are gradually moulded into disk-shaped red corpuscles. In the meantime the cells

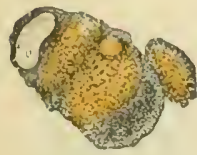

$a$

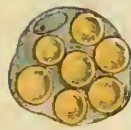

b

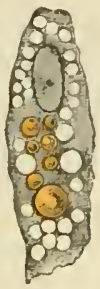

c
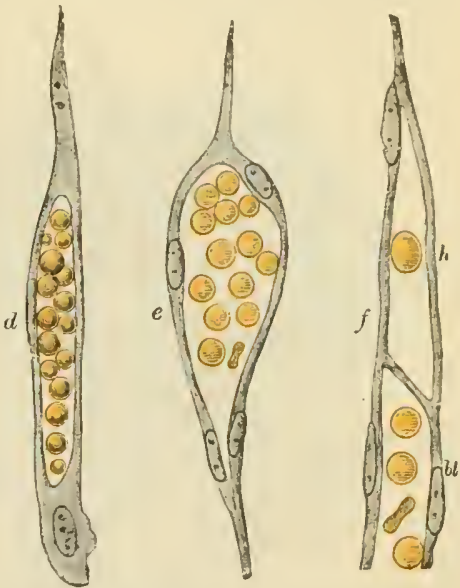

Fig 40.-BLOOD-CORPUSClES DEVELOPING WITHIN CONNECTIVE-TISSUE CELLS. $a$, a ccll containing diffused hæmoglobin; $b$, a cell flled with coloured globules; $c$, a cell containing coloured globules in the protoplasin, within wlich also are numerous vacuoles; $d$, an elongated cell with a cavity in its protoplasm occupied by fluid and blood-corpuscles mostly globular; $e$, a hollow cell, the nucleus of which has multiplied. The new nuclei are arranged around the wall of the cavity, the corpuscles in which have now hecome discoid ; $f$, shows the mode of union of a 'hrmapoietic' cell, which in this instance contains only one corpuscle, with the prolongation $(l l)$ of a previously existing vessel.

become hollowed out, and join with similar neighbouring cells to form blood-vessels (fig. $40, d, e, f$ ). The process is therefore the same as in the early embryo, except that cell-nuclei are not ineluded in the hæmoglobin-holding protoplasm. ${ }^{1}$

I It has been suggested by some writers that the vasoformative cells containing coloured corpuscles in various stages of formation are in reality portions of an already formed vascular network which is undergoing atrophy; and that the corpuscles within such cells are not in process of formation but of disappearance. But since the appearances in question are seen in parts in which vascular tissnes (such as fat) are undergoing not atrophy but formation; and since, moreover, the hæinatoidin crystals and pigment granules which are characteristic of the disintegration of erythrocytes within cells are not present, it seems more reasonable to interpret the appearances as indicative of intracellular development of blood-corpuscles by differentiation of part of the protoplasn of the vasoformative mesenchyme cell, rather than a degeneration of already formed blood-vessels and blood-corpuscles. 
Formation in bone-marrow. - Although no nucleated coloured corpuscles (erythroblasts) are as a rule to be seen in the blood in postembryonic life, they are found in the marrow of the bones, and in some animals also found in the spleen. They vary in size, most measuring about $\cdot 00 \mathrm{imm}$. (normoblasts), but some being considerably larger (megaloblasts), and others considerably smaller (microblasts). It is probable that the red disks are formed from these nucleated red corpuscles of the marrow by the nucleus disappearing and the coloured

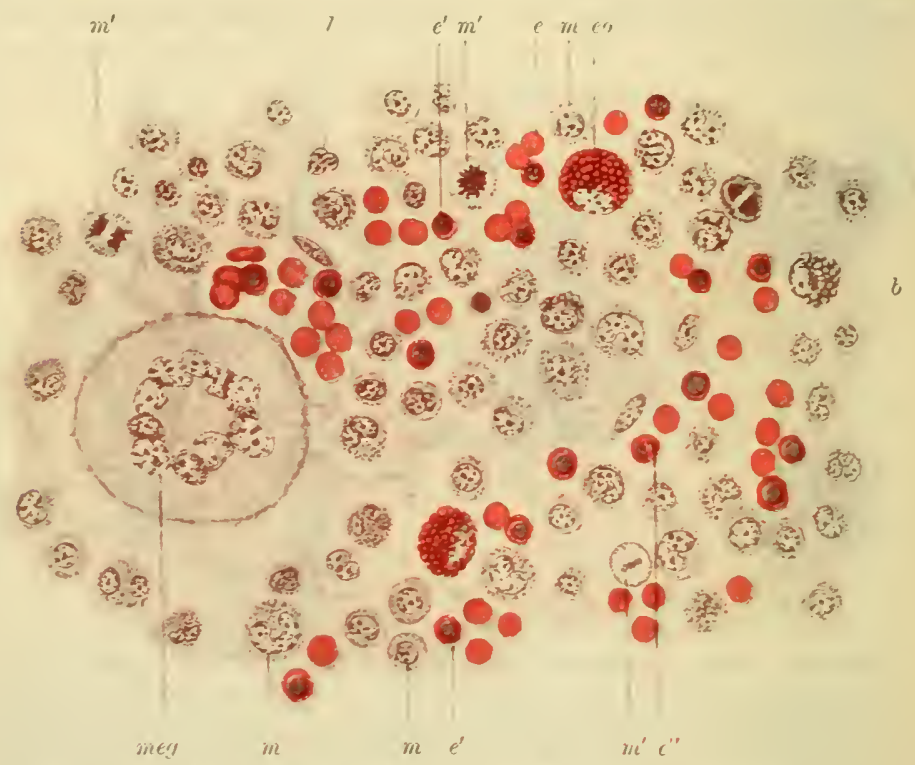

Fig 41.-Red MarRow of Yotxg RabBit. Magnified 450 diameters.

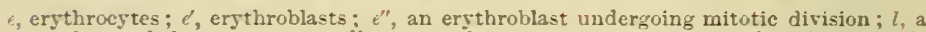
polymorph leucucyte; $m$, ordinars myelocytes; $m$, myelocytes undergoing tnitotic division; 6, an ecosinophil myelocyte ; $b, a$ basuphil nnyelocyte ; meg, a giant-cell or megakaryocyte.

protoplasm becoming moulded into a discoid shape. At what time this formation of blood-corpuscles in the bone-marrow begins has not been ascertained, but after it has commenced it continues throughout the whole of life-the red marrow, especially that of the ribs, being especially active in this respect. In mammals the formation of nucleated coloured corpuscles appears to take place within the tissue of the marrow external to the blood-vessels. It is uncertain to what extent the capillary vessels of the marrow are limited by a complete endothelium (see p. 40), but in any case the formed erythroblasts seem to readily pass into the blood stream. ${ }^{1}$

${ }^{1}$ In birds the erythroblasts are confined to the large blood-channels of the marrow, and the transformation into ery throcytes occurs within these channels. 
The marrow of bone is of a yellow colour in the shafts of the long bones of most animals, and is there largely composed of adipose tissue, but in the shafts of the long bones of some animals, and in the cancellated tissue of most, it is usually red, the colour being partly due to the large amount of blood in its vessels. This red marrow (fig. 41) is chietly composed of spherieal cells-the myelocytes or marrou-cells-which resemble rather large blood-lencocytes, and, like these, are amwboid. They also exhibit the same kind of differences as to the character of the granules which they contain, some being oxyphil and others anphophil or neutrophil. But while the blood-leneocytes rarely contain any coarse basophil granules, some

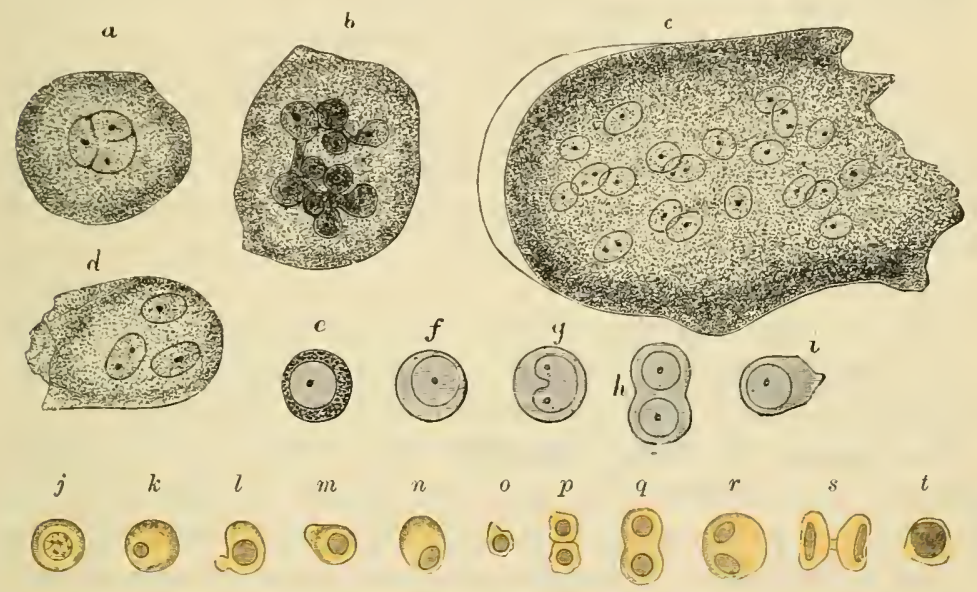

Fig, 42.-Cells OF THE RED MARROW OF THE GUINEA-PIG. (Highly magnified.) a, a large cell, the nucleus of which appears to be partly divided into three by constrictious: $b$, a cell, the enlarged nueleus of which shows an appearance of being constricted into a number of smaller nuclei; $c$, a so-called giant-cell or inyeloplaxe with many nuclei; $d$, a smaller myeloplaxe with three nuclei; $e-i$, proper cells of the marrow; $j-t$, various forms of coloured nucleated cells (erythroblasts), some in process of division; in others the nucleus appears to be undergoing atrophy.

of the marrow eells contain these in considerable numbers. There are also to be seen mingled with the marrow-leneocytes a number of corpuscles somewhat smaller in size, nucleated, and at least some of them amceboid, but of a reddish tint (fig. 41, $e^{\prime}$ ). These cells, which are termed erythroblasts, resemble the nucleated coloured blood-corpuscles of the embryo, and are believed to be cells from which the coloured blood-disks become developed. Many of them are in process of mitotic division. Others are seen with the nuelens in a more or less atrophied condition (fig. $42, k$ ) ; from this it may perhaps be inferred that the transformation into a discoid blood-corpusele is accompanied by the disappearance of the nueleus (Bizzozero). Lastly, the marrow 
contains a number of very large cells, the giant-cells or myeloplaxes of Robin (fig. 41, meg: fig. 42, $a-d$ ). These are especially numerous wherever bone is becoming absorbed, but are not confined to such situations, being indeed normal constituents of marrow. Sometimes they possess several nuclei, but most-the so-called megakaryocytescontain but one large nucleus, which has usually an annular form. They are also characterised by possessing a number of centrioles grouped together near the nucleus. Lastly, the existence of cells within the marrow containing blood-corpuscles in various stages of transformation into pigment, similar to those which occur in the spleen-pulp, has been noted (Osler).

The marrow is very vascular, the capillaries and veins being large and thin-walled; indeed, according to some authorities, the walls of the capillaries are imperfect, so that there is an open communication between them and the interstices of the tissue, and in this way it is supposed that the coloured blood-disks, which are, it is believed, produced from the coloured nucleated cells (erythroblasts) of the marrow, may get into the circulation. There is not, however, an interstitial circulation of blood in the marrow such as is found in the spleen, nor does injection material such as carmine gelatine pass into the interspaces of the tissue, but remains confined to the vessels, so that the existence of an open communication is doubtful.

Development of white corpuscles.-The uhite blood- and lymphcorpuscles occur originally as free cells, which are believed to find their way into the vessels from the circumjacent mesoderm. They do not occur within the first-formed blood-ressels of the embryo nor within the vasoformative cells. In later stages of foetal life and during the whole of post-embryonic life they become formed in the bone-marrow as well as in lymph-glands and other organs composed of lymphoid tissue, and pass from these directly into the lymphatics and into the blood.

It is probable, but has not been ascertained with certainty, that the lymphocytes are all produced in lymph-glands and other lymphoid tissues, and that the macrocytes are formed by enlargement of the lymphocytes. On the other hand, the polymorphs and the coarsely granular oxyphil cells are believed to be formed within the bone marrow, which contains cells of similar character. Cells with wellmarked basophil granules are also met with in bone marrow, and sometimes, in abnormal conditions, pass in large numbers into the blood. 
LESSON IV.

\section{ACTION OF REAGEATS UPON THE HUMAN BLOOD- CORPUSCLES.}

1. MAKE a preparation of human blood, and apply a drop of water, at one edge of the cover-glass. Examine at a place where the two thuids are becoming mixel. Notice particularly the first effect of water upon both red and white corpuscles, as well as the ultimate action.

Sketch both kinds of corpuscles under the action of water.

2. Repeat on another preparation, using very dilute alkali $(0.2$ per cent. caustic potash) instead of water. Notice the complete solution first of the white and then of the coloured corpuscles as the alkali reaches them.

3. Repeat on another preparation, using dilute acetic acid (1 per cent.). Observe that the effect of the acid upon the coloured corpuscles is similar to that of water, but that it has a different action upon the colourless corpuscles.

Sketch two or three of the latter after the action is completed.

4. Make a preparation of blood mixerl with salt solution, as in Lesson II. ㄹ, and investigate the action of tannic acid (1 part tannic acid to 100 of distilled water) in the same way.

Sketch two or three coloured corpuscles after the action is complete.

5. Examine blood-crystals of rat, guinea-pig, and squirrel. Preparations of hiemoglobin crystals cammot be kept permanently.

6. Prepare hæmin by heating a dry smear of blood on a slicle with glacial acetic acil. The crystals of hienin are permanent.

Structure of erythrocytes. - The action of reagents upon the human red blood-corpuscles shows that, although to all appearance homogeneous, they in reality consist of an external envelope of colourless material which forms a thin film inclosing the dissolved colouring matter or hemoglobin. Thus, when water reaches the corpuscles, it passes through the film and swells the corpuscle, causing it to become globular; eventually the film is burst through, and the colouring matter escapes into the serum. The addition of hyperisotonic solution of salt, on the

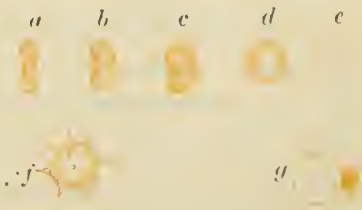

FIG. 43.

a.e, successive effeets of water upon a red corpusele ; $f$, effcet of solution of salt; $g$, effeet of
tannic acid.

other hand, by increasing the density of the fluid in which the corpuscles float, causes diffusion of water out of the corpuscle, and consequent shrinking and corrugation of the surface, the crenated form 
(fig. $43, f$ ) being thereby produced. The same change is brought about by evaporation of water, if the blood is exposed to air. The separation of hemoglobin from the corpuscle can be effected not only by water (fig. $43, a-e)$, but also by dilute acids, by the action of heat $\left(60^{\circ} \mathrm{C}\right.$.), the freezing and thawing of blood, the action of ether or chloroform, and the passage of electric shocks. Bile and dilute alkalies rapidly cause the red corpuscles to become spherical and then almost instantly effect their complete solution (hæmolysis). The mixing of blood from one species of animal with the blood or serum of animals of other species frequently also has a similar effect. In this case the hæmolytic

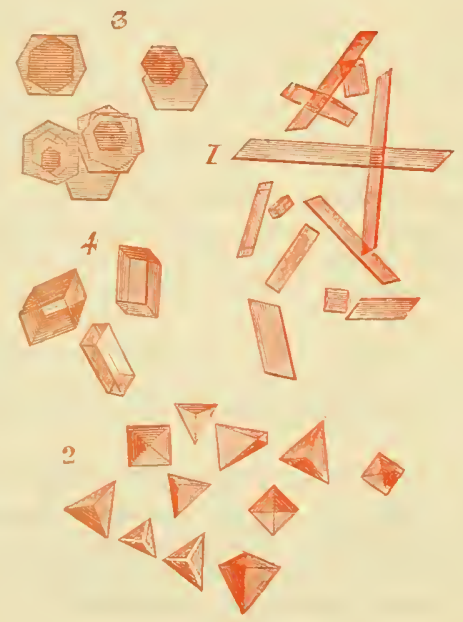

Fig. 44.-Blood cristals, MagNified.

1, from human blood; 2, from the guinea-pig; 3 , squirrel ; 4, hamster.

action is exerted by some constituent (hæmolysin) of the foreign blood, which is special for each species and against which the "host" can render itself immune if, prior to any large quantity of the foreign blood or serum being injected, successive small injections be made; an "antihremolysin" being gradually produced. This fact is not only of interest as bearing upon the general doctrine of immunity, but also serves to detect the source of a given sample of blood.

Tannic acid produces a peculiar effect upon the red corpuscles (fig. $43, g)$; the hremoglobin is discharged from the corpuscle, but is immediately altered and precipitated, remaining adherent to the envelope in the form of a round or irregular globule of a brownish tinge (hrematin?).

Some of these reactions occur by a process of osmosis as in the case of water, but in others a solution of the envelope of the corpuscle is produced 
by the reagent, and the hiemoglobin is thus allowed to escape. 'The film or envelope is probably composed of protoplasm containing, besides nucleoproteids, lecithin and cholesterin (myelin), and these ase substances which possess many of the physical properties of fats, although of a different chemianl composition. If we assume that such fatty substances form an external film to the corpuscle, the running of the red disks into rumleatux can readily be explained, since it has been shown by Norris that disks of any material, e.g. cork, suspended in a fluid, tend in the same way to adhere in rouleaux, provided their surfaces are covered with a layer which is not wetted by the Huid. We may also explain on the same hypothesis the fact that no rent is ever seen in the envelopes of the red corpuseles even when they appear to have burst after imbibition of water, for, if the film which repiresents an envelope is myelinic in nature, any rent in it would tend inmediately to close 11 again when the opposed edges come in contact.

It was also shown by Norris that droplets of fluid encompassed by myelin have a tendency to assiume a Hattened shape.

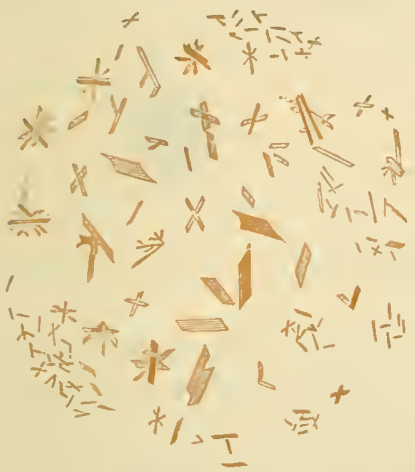

Flg. 45.-H.モMIN CRYSTALS, MAGNIFIEN. (Preyer.)

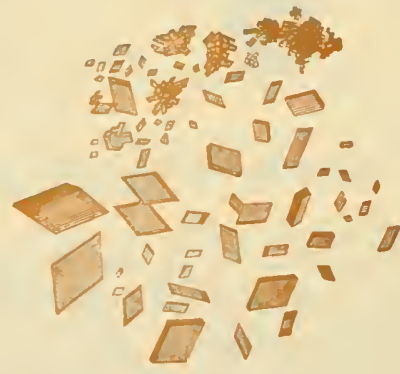

Fig. 46.-HeMatoIDIN CRYSTALS. (Frey.)

The more solid part of the red corpuscle is often termed the stroma, but this name rests upon an entirely false conception of the structure of the corpuscle. In adopting the name, it was supposed that the corpuscle is formed of a lomogeneous porous material (stroma-Rollett), in the pores of which the hremoglobin is contained, but there is no reasonable foundation for this belief, which fails to explain, except on the assumption of a still more complex hypothesis, the well-known osmotic phenomena of the corpuscle; whereas the supposition that there exists a delicate external film or envelope inclosing a coloured fluid is in accordance with all the known facts regarding the action of reagents upon these bodies. It is true that in the fresh mammalian corpuscle the envelope is too delicate to be actually observer in the optical section of the corpuscle, but in the blood-corpuscles of amphibia it can be quite distinctly seen, and with any slight increase in density of the plasma it tends to becrine wrinkled and the creases in it are plainly visible. In these corpuscles also the nucleus becomes readily displaced in drawn blood from its position in the centre of the corpuscle and may lie quite at the side; this is a clear indication of the fluid nature of the contents of the corpuscle, and by analogy we may fairly assume a similar constitution for the mammalian corpnscle. Lastly, it is possible to stain the envelope of the red corpuscles of a different colour from the remainder of the corpuscle.

Blood-crystals-Hæmoglobin. - In the blood of many animals (fig. 44), crystals of hemoglobin readily form after its separation from the red 
corpuscles. These crystais are rhombic prisms in man and most animals, e.g. the rat, but tetrahedra in the guinea-pig, and hexagonal plates in the squirrel. In these animals they at once appear on shaking up the blood with chloroform or ether, or even on the addition of water, with or withont subsequent evaporation.

Hæmin.-Tlis name has been applied to the minute lark-brown rhombic crystals of hydrochlorate of hæmatin (fig. 45), which are formed when dried blood from any somce whatever is lieated with glacial acetic acirl.

Hæmatoidin.--This occur's in the form of brownish yellow crystals (fig. 46). It is found in old blood extravasations and in other places where bloodcorpuscles are undergoing disintegration within the tissues.

Action of reagents on leucocytes.-The structure of the colourless corpuscles is also brought out by the action of some of the reagents above noticed. As the water reaches them their amoboid movements cease; they become swollen out into a globular form by imbibition
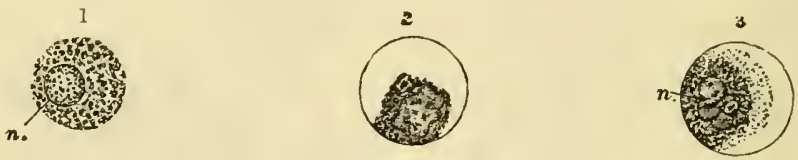

FIG. 47 .

1, first effect of the action of water upon a whitc blood-corpuscle; 2 , 3 , white corpuscles treated with dilute acetic acid ; $n$, nucleus.

of fluid (fig. 47, 1), and the granules within the protoplasm can be seen to be in active Brownian motion. Their nuclei also become clear and globular, and are more conspicuous than before. With the further action of the water, the corpuscle bursts and the granules are set free.

Acids have an entirely different action upon the white corpuscles. Their nuclei become somewhat shrunken and very distinct (fig. 47, 2 and 3), and a granular precipitate is formed in the protoplasm around the nucleus. At the same time, a part of the protoplasm generally swells out so as to form a clear bleb-like expansion (an appearance which also often accompanies the death of the corpuscle from other causes). Dilute caustic alkalies rapidly cause the complete destruction of the white corpuscles. 


\section{I.ESSON V.}

\section{TIE BLOOI)-CORPUSCLES OF AMPIIBIA.}

1. OвтAlx a drop of frog's, toad's or newt's blood, and wix it with a very small quantity of salt solution upon a slide. Examine with the high power. Notice the shape of the colonred corpuscles both when seen flat and edgeways, and the nucleus within each.

Ileasure ten corpuscles (long and short diameters), and from the results obtain the average dinensions of a corpuscle.

Notice also the colourless corpuscles, smaller than the rerl, but larger than the pale corpuscles of human blood, although otherwise generally resembling these.

Sketch two or three red corpuscles and as many white.

Be careful not to mistake the rounded liberated nuclei of crushed red corpuscles for pale corpuseles.

Enormons cells and nuclei belonging to the cutaneous glands as well as the granmar secretion of those glands may be present in this preparation if it is obtained from the newt's tail.

2. Apply a drop of water to the edge of the cover-glass of the same preparation and notice its action upon the corpuscles.

Sketch two or three corpuscles altered by the action of the water.

3. Mount another drop of blood, and apply dilute acetic acid (1 per cent.) instead of water at the edge of the cover-glass. Make sketches showing the effect of the acid upon both red and white corpuscles.

4. Examine the corpuseles of newt's blood which has been allowed to flow into boric acid solution (2 per cent.). Notice the effect produced upon the coloured corpuscles. Sketch one or two.

5. Mount drops of glycerine-jelly containing (a) frog's blood aud (b) bird's blood, previously fixed by Flemming's solutiou and stained with picrocarmine.

6. Make a film preparation of amphibian or avian blood as described on p. $28, \leq 5$.

The coloured blood-corpuscles of amphibia (fig. 48), as well as of nearly all vertebrates below mammals, are biconvex elliptical disks, considerably larger than the biconcave cirenlar disks of mammals. ${ }^{1}$ In addition to the coloured body of the corpuscle, which consists, as in mammals, of hæmoglobin inclosed within an envelope, there

'The following are the dimensions in parts of a millimeter of the coloured corpuscles of some oviparous vertebrates :-

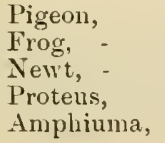

Long diamcter.

$0 \cdot 0147$

$0 \cdot 0 \cdot 2 \cdot 2 \cdot 3$

$0 \cdot(6,293$

$0 \cdot 1.5 \mathrm{Su}$

$0 \cdot 0750$
Short diameter:

0.006 .5

0.0157

0.0195

0.0350

$0 \cdot 0460$ 
is a colourless nucleus, also of an elliptical shape, but casily becoming globular, especially if liberated by any means from the corpusele. The nucleus resembles that of other.cells in structure, being bounded by a membrane and having a network of chromatin. It is not very

A

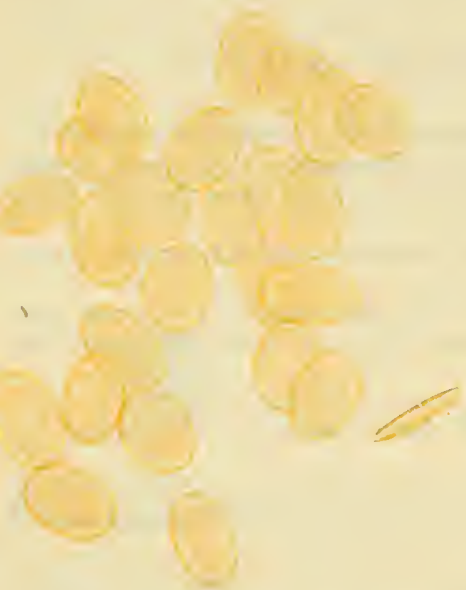

P

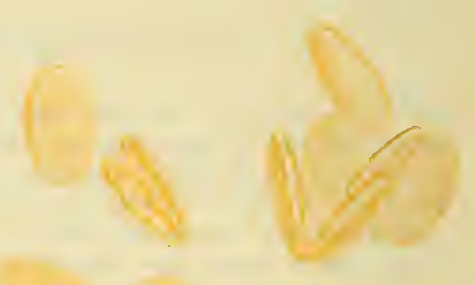

Fig. 48.-Aмphibian Ertthrocytes. (From photographs.) Magnified 450 diameters.
A, from the frog.
$B$, from the toad.

distinct in the unaltered corpuscle, but is brought clearly into view by the action of reagents, especially acids. The action of reagents upon the red corpuscle of amphibia is otherwise similar to that upon the mammalian corpuscle, water and acetic acid causing it to swell into a globular form and then to become decolorised; solution of salt causing wrinkling of the envelope, and so on. As a first effect, water and certain other fluids may cause the hæmoglobin to retire from the envelope at the points where the fluid is passing through the membrane: a stellate appearance is thereby often produced (Hünefeldt, Hensen). Boric acid causes the hæmoglobin of the newt's corpuscle to become partially or wholly collected around the nucleus, which may then be extruded from the corpuscle (Brücke).

Immediately within the envelope, at the periphery of the amphibian erythrocyte, is a band of fine fibrils which are stained by gentian violet (Meves) and can also be seen cut across in sections of the corpuscles (Bryce).

The colourless corpuscles of amphibia, although larger, are very similar to those of mammals. Like them, they are either wholly pale and finely granular or inclose a number of very 
distinct grannles of similar nature to those met with in mammals. These corpuscles vary mnch in size and in the activity of their amehoid movements: those which have a multilobular mucleus (fig. $3: 3, b, c)$ are usually the most active. Reagents have the same eflect upon them as on those of mammals. The presence of glyeogen naay be demonstrated in them by its reaction with iodine (port-wine colour).

The blood-platelets (thrombocytes) in the frog are fewer in number than in mammals. Many are of a spindle shape. They contain a mueleus-like borly and like the bloor-platelets of mammals they show amohoid changes and tend rapidly to clump together in drawn blood. 


\section{LESSON VI.}

\section{THE AMBCEBOID PHENOMEVA OF THE COLOURLESS BLOOD-CORPUSCLES.}

1. MAKE a preparation of blood from the finger in the usual way. Draw a brush just moistened with perfectly neutral oil around the edge of the coverglass to check evaporation. Place the preparation upon a 'warm stage,' and heat this to about the temperature of the body $\left(38^{\circ} \mathrm{C}\right.$.). Bring a white corpusele under observation with the high power, and watch the changes of shape which it undergoes. 'To become convinced of these alterations in form, make a series of outline sketches of the same corpuscle at intervals of a minute.

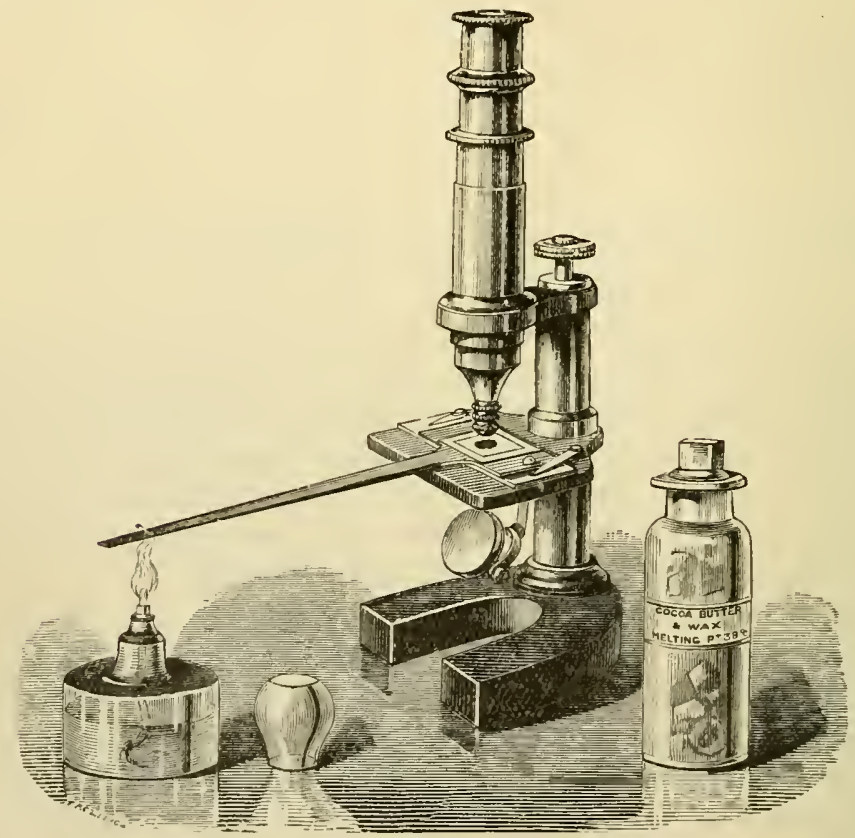

F1G. 49.- SLMPLE WARUING APPARATUS, COMPLETE, SHOWN IN OPERATION.

The simplest form of warm stage is a copper plate of about the size of an ordinary slide, perforated in the centre and with a long tongue of the same metal projecting from the middle of one edge (fig. 49). The copper plate rests upon the stage of the microscope, with a piece of cloth or other nonconducting material between. The preparation is made upon an ordinary slide or on a large cover-glass, which is placed upon the warm stage and 
pressed into contact with it by the brass clips. Heat is applied to the copper tongue by a small spirit-lanip thane, and a greater or less amount is conducted to the warm stage and the superjacent preparation according to the point to which the thame is applied. 'To ascertain that the right temperature is got and maintained, put two pieces of parathin, one melting at $35 \mathrm{C}$. $\left(95^{\circ} \mathrm{F}\right.$ ) and another at $38^{\circ} \mathrm{C} .\left(100^{\circ} \mathrm{F}.\right)$, on either side of the preparation. The temperature must be such that the first piece is melted and remains so whilst the second remains ummelted. ${ }^{1}$

2. Mount a drop of frog's or newt's blood diluted with an equal amount of salt solution, and examine it in the same manner upon the copper stage, at first cold, afterwards warm ; the temperature must, however, be kejt below $30^{\circ} \mathrm{C}$. Observe the effect of heat in acclerating the amoboid movements of the pale corpuscles. Sketch one at intervals of a minute $(a)$ in the cold, $(b)$ whilst warnied.

3. Take some yeast which has been mixel with salt solution, and mix a very little of the yeast and salt solution with a fresh drop of newt's blood, slightly oiling the edge of the cover-glass as before. Endeavour to observe the inception of the yeast-torule by the white corpuscles. Sketch one or two corpuscles containing torulie.

Milk-globules or particles of carbon or of vermilion may also be used for' this experiment, but the process of inception or 'feeding' is most readily observed with the yeast particles.

4. At the beginniug of the lesson collect a drop of newt's or frog's blood into a fine capillary tube, seal the ends of the tube, and nount it in a rlrop of oil of cedar-wood or dammar varnish (or the clot may be blown ont into a drop of salt solution on a slide and mounter in this solution). Towards the end of the lesson examine it to see white corpuscles emigrating from the shrunken clot (see fig. 50).

5. To obtain a specimen with the white corpuscles fixed in amseboid condition, make a preparation of newt's blood, mixed with salt solution, and set it aside for ten minutes. By this time the corpuscles will be freely amoboid, and will probably show well-marked psendopodia. To fix them in this condition let a jet of steam from a flask or kettle play for two or three seconds upon the cover-glass. The heat instantly kills the corpuscles, and they are fixed in the form they presented at the moment the steam was applied. They may now be stained by passing dilute hæmalum ${ }^{2}$ under the cover-glass, or by removing the latter and staining with eosin and methylene blue in the manner recommended on p. 28 , $\$ 5$. If hremalum is used, the stain is followed by dilute glycerine, after which the cover may be cemented and the preparation kept.

The amœboid phenomena which are exhibited by the protoplasm of the colourless blood-corpuscles consist of spontaneous changes of form, produced by the throwing out of processes or pseudopodia in various directions. When first thrown out the pseudopodia are quite clear; they appear to be produced by a flowing of the hyaloplasm (see p. 4). If the corpuscle is stimulated, either mechanically, as by

${ }^{1}$ For exact work, an apparatus somewhat more complex than the above is required. For description of sueh, see A Course of Practical Histology.

${ }^{2}$ Delafield's or Ehrlich's hæmatoxylin can be substituted for hæmalum wherever the latter is mentioned. The water used for the dilution of hrematoxylin solutions must always be distilled. 
tapping the cover-glass, or electrically, the pseudopodia are retracted, the corpuscle becoming spherical. A change of form caused by the protrusion of the psendopodia may, when active, be followed by changes in place or actual locomotion (migration) of the corpuscle. When a pseuclopodium, or the external surface of the corpuscle, comes in contact with any foreign particle, the protoplasm tends to flow round and enwrap the particle, which is then drawn into the corpuscle; particles thus incepted may be conveyed by the corpuscle in its movements from one place to another (fig. 51). This property plays an important part in many physiological and pathological processes; thus cells in the spleen resembling large leucocytes-the

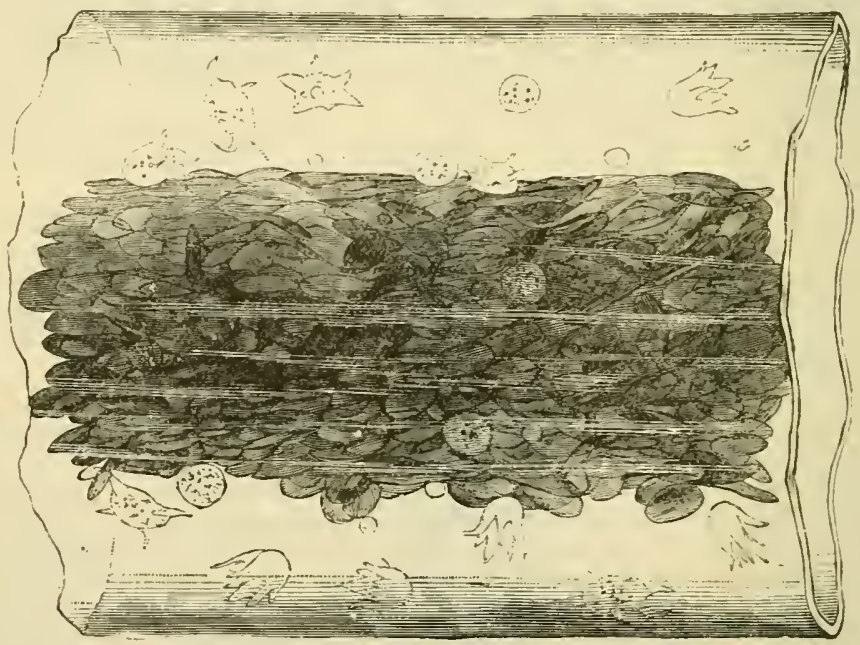

FIG. 50.-WHITE CORPCSCLES OF FROG's BLOOI MIGRATING FROM \&HRCXKEN CLOT WITHIX A CAPILLARY TUBE. (From Sanderson's Handbook for the Physiological Laboratory.)

so-called splenic cells-incept blood-corpuscles, which become broken down within them; and pathogenic bacteria become taken into the protoplasm of certain leucocytes (on this account termed phagocytes), there to be destroyed (Metchnikoff). The phagocytic properties of the leucocytes become especially developed as the result of the action upon the bacteria of certain chemical substances which are present to a greater or less extent in blood and which are termed opsonins (Wright).

It is probable that particles of organic matter which are taken up by the pale corpuscles may undergo some slow process of intracellular digestion within their protoplasm. 
The processes of the granular corpuscles are quite clear at first; the granules afterwards flow into them.

The migration of the colourless corpuscles from the blood-vesseis into the surrounding tissues (which especially oceurs in inflamed parts), or from a blood-clot into the surrounding serum (fig. 50), is due to these amwboid properties.

The conditions which are favourable to this amoboid activity of the white corpuseles are (1) the natural slightly alkaline medium, such as plasma, serum, or lymph, or faintly alkaline normal saline solution. Any increase of density of the medium produces a diminution of anceboid activity, whilst, on the other hand, a slight decrease in its density bas the opposite effect; $(2)$ a certain temperature. In

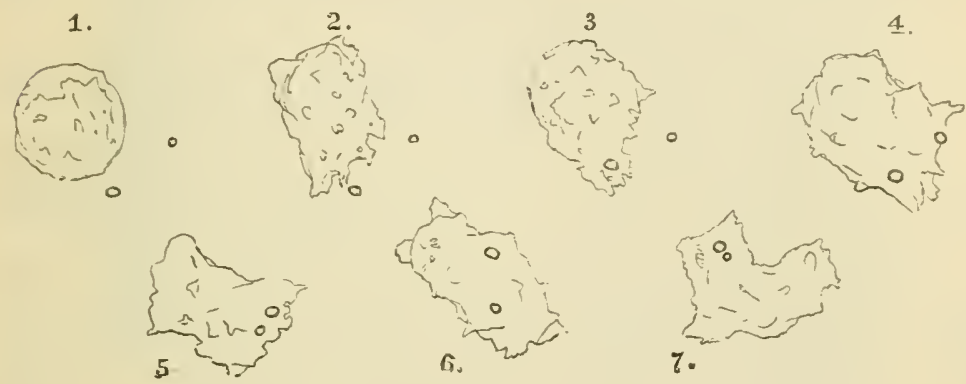

FIG. 51.-CHANges OF FORM OF A WHITE BLOOD-CORPLSCLE SKETCHED AT INTERTALS OF A FEW MINCTES, SHOWIAG THE INCEPTION OF TWO SMALL GRANCLES AND THE CHANGES OF POSITION THESE CNDERWENT WITHIN THE CORPCSCLE.

warm-blooded animals the phenomena cease below about $10^{\circ} \mathrm{C}$. When gradually warmed the white corpuscles become more and more active up to a certain point, the maximum being a few degrees above the natural temperature of the blood. Above this point they become spheroidal and at a somewhat higher temperature their protoplasm is coagulated and killed. Acids at once kill the corpuscles and stop the movements. Narcotic gases and vapours, such as carbonic acid gas or chloroform vapour, also arrest the movement, but it recommences after a time if their action is not too prolonged. 


\section{LESSON VII.}

\section{EPITHELIUM AND SECRETING GLANDS.}

1. Mocst a drop of saliva and examine first with a low, afterwards with a high power. Observe the nucleated epithelium-cells, some single, and others still adhering together by overlapping edges. Measure three or four, and also their nuclei. Sketch one or two on the flat and one edgeways. Notice the salirary corpuscles, which are nigrated white blood-corpuscles, swollen out by imbibition of water. The preparation may be stained with diluted hemalum and preserred with glycerine.

2. Put a small shred of human epidermis into a drop of strong canstic potash solution (35 p.c.) for five minutes. Then break it up in water with needles, cover and examine. Observe the now isolated swollen cells.

3. Study the arrangement of the cells in a section through some stratified epithelium, such as that of the mouth, skin, or cornea. ${ }^{1}$ Notice the changes in shape of the cells as they are traced towards the free surface. Measure the thickness of the epithelium. Count the number of layers of cells.

4. Make a preparation of the epithelium of the urinary bladder, which may be moderately distended with bichromate of potash solution (1 part to $800^{\circ}$ of salt solution), and after an hour or two cut open and placed in more of the same solution. Take a small scraping of the lining epithelium on the point of a scalpel, and break it up by tapping it in a drop of rery ditute hæmatoxylin on a slide. Pnt a small hair in the drop and corer. Add a small drop of glycerine at one edge : allow this to diffuse under. Cement next day. Observe the large flat superficial cells, and the pear-shaped cells of the second laver. Sketch one of each kind. The cells will vary greatly in appearance according to the amount of distension of the organ.

5. Study the minute structure of epithelium-cells and their nuclei, both at rest and dividing, in sections of the skin of the newt's tail, or in shreds of peritoneum or of epidermis or in sections of the salamander-tadpole. The preparation mar, for this purpose, be stained either with hematoxylin or iron-hematoxylin, or with some aniline dye such as saffranin. ${ }^{1}$

Sketch an epithelium-cell with resting nucleus, and others with nuclei in different phases of mitosis.

The simple saccular skin-glands of Amphibia may also be studied in these preparations.

An epithelium is a tissue composed entirely of cells separated by a very small amount of intercellular substance (cement-substance) and generally arranged so as to form a membrane covering either an external or internal free surface.

The structure of epithelium-cells, and the changes which they undergo in cell-division, are best seen in the epidermis of the newt

${ }^{1}$ The methods of preparing and staining sections are giren in the Appendix. 
or of the salamander-tadpole (fig. 52); in the latter especially, the cells and nuelei are much larger than in mammals.

Structure of the cells. - Wach epithelium-cell consists of protoplusm containing a mucleus. The protoplasm may either look granular, or it may have a reticulated appearance, or may exhibit fibrils. The nucleus is spherical or ovoid. Usually there is only one, but there may be two or more. The cell-substanec is often modified in its chemical nature; its external layer may become hardened to form a

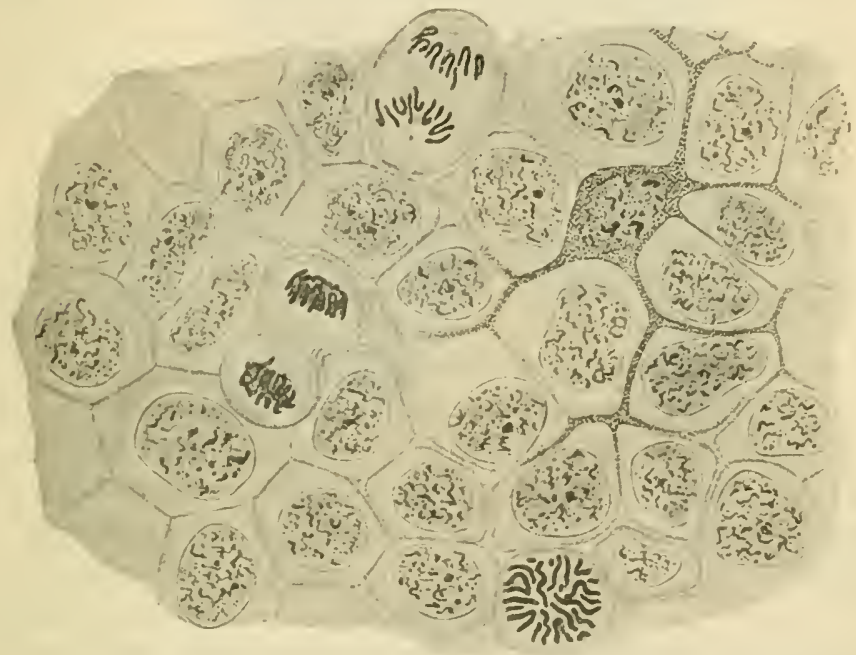

Fig. 52,-EPIDERMIS CELLS OF A LARVAL SALAMIANDER. Magnified 400 diameters. (Wilson.)

Three of the cells are undergoing division. The intercellular channels are bridged across by fine fibrcs. At one plaee a branched pigment cell is lying between the epithelium cells.

sort of membrane, or the whole cell may become horny (keratinised); or there may be a separation of materials (granules) within the cell which are ultimately used by the organism, as in some secreting glands.

Classification of epithelia.-Epithelia are somewhat illogically classified partly according to the shape and arrangement of the cells, partly according to their function. Thus we speak of scaly or parement, cubical, columnar, glandular, and ciliated epithelium. Most of these are simple epithelia, with the cells only one layer deep. If forming several superposed layers, the epithelium is said to be strutified, and then the shape of the cells differs in the different layers. Where there are only three or four layers in an epithelium, it is termed transitional. 
Stratified epithelium covers the anterior surface of the cornea, lines the mouth, pharnyx (lower part), gullet, anal canal and part of the urethra, and forms the epidermis which covers the skin. The vocal cords are also covered by stratified epithelium. In the female it also lines the vagina and covers the os uteri. The cells nearest the

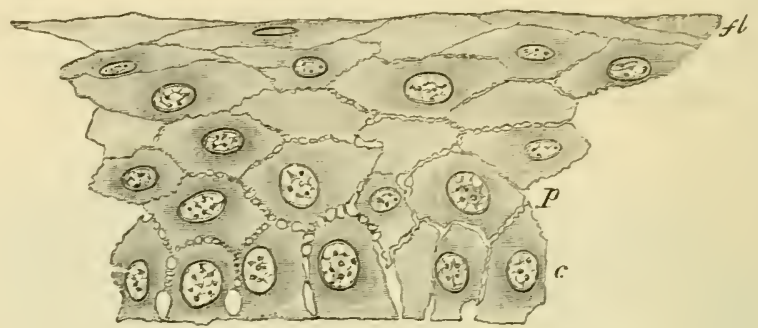

Fig, 53.- SECTION OF THE STRATIFIED EPITHELIUM COVERING THE FRONT OF THE CORSEA OF THE EYE (JIS).

$c$, lowermost columnar cells; $p$, polygonal cells ahore these; $f$, flattened cells near the surface. Between the cells are seen intercellular channels bridged over by processes which pass from cell to cell.

surface are always flattened and scale-like (fig. $53, f$; fig. 54 ), whereas the deeper cells are polyhedral, and those of the deepest layer somewhat columnar in shape (fig. 53, c). Moreover, the deep cells are soft and protoplasmic, and are separated from one another by a system of intercellular channels, which are bridged across by numerous fibres passing from cell to cell; giving the cells, when separated, the

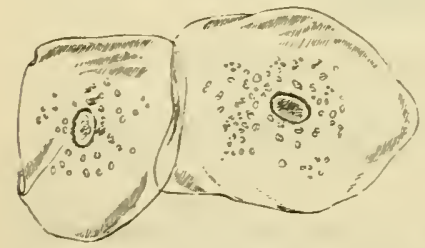

FIG. 54.-EPITHELIOJI-SCALES Froy THE INSIDE OF THE MOCTH. (Magnified 260 diameters.) appearance of being beset with short spines (prickle-cells of Max Schultze). These 'bridging fibres' are not peculiar to stratified epithelium, but occur in many if not in all kinds of epithelia.

The deeper cells multiply by mitotic division, the nuclei first dividing in the manner already described. The newly formed cells tend as they enlarge to prish those external to them nearer to the surface, from which they are eventually thrown off. As they approach the surface they become hard and horny, and in the case of the epidermis entirely lose their cellular appearance, which can, however, be in a measure restored by the action of alkalies $(\$ 2)$. The cast-off superficial cells of the stratified epithelium of the mouth, which are seen in abundance in the saliva ( $\$ 1)$, are less altered, and the remains of a nucleus is still visible in them (fig. 54). The stratified epithelium of the human skin (epidermis) shows many peculiarities: these will be considered when the skin itself is treated of. 
Transitional epithelium is a stratified epithelium consisting of only three or four layers of cells. It occurs in the urinary bladder, the ureter, and the pelvis of the kidney. The superficial cells (fig. $55, a$ ) are large and flattened; they often have two nuclei. Their free surface is eovered with il euticular stratum (Erggeling), and on their under surfice they exhibit depressions, into which fit the larger ends of pyriform cells, which form the next layer (fig. 55, b). Between the tapered ends of the pyriform cells one or two layers of smaller polyhedral cells are found. The epithelium seems to be renewed by mitotic division of these deeper cells; it is probable that the superficial cells also multiply, but in this case by amitosis.
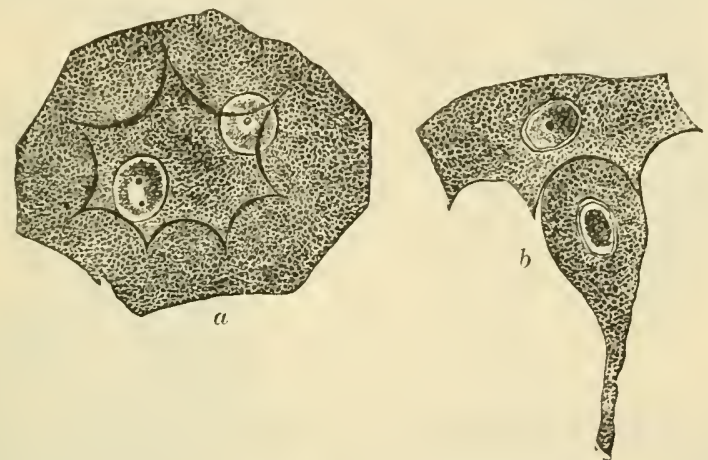

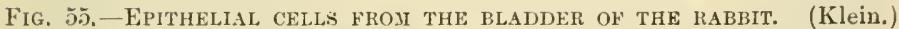
(Magnified 500 diameters.)

$a$, large flattened cell from the superficial layer, with two wuclei and with strongly marked ridges and intervening depressions on its under surface; $b$, pear-shaped cell of the second layer adapted to a depression on one of the superfieial cells.

Simple scaly or pavement epithelium is found in the saccules of the lungs, in the ducts of the mammary glands, in the kidney (in the tubes of Henle, lining the capsules of the Malpighian bodies, and covering the glomeruli), and also lining the cavities of serous membranes (fig. 56), and the interior of the heart, blood-vessels, and lymphatics. When occurring on internal surfaces, such as those of the serous membranes, blood-ressels, and lymphatics, it is often spoken of as endothelium or mesothelium. According to v. Brunn the eells of a serous epithelium may be provided with a striated border on their free surface, somewhat like that which is found on columnar cells.

Columnar epithelium and ciliated epithelium are for the most part found covering the inner surface of mucous membranes; which are membranes moistened by mucus and lining passages in communication with the exterior, such as the alimentary eanal and the respiratory and generative passages. The cells of a columnar epithelium form a single 
layer, varying in thickness according to the length of the constituent cells, and when the cells of a columnar epithelium are short, the epithelium is spoken of as cubical, such as that which lines the vesicles of the thyroid gland.

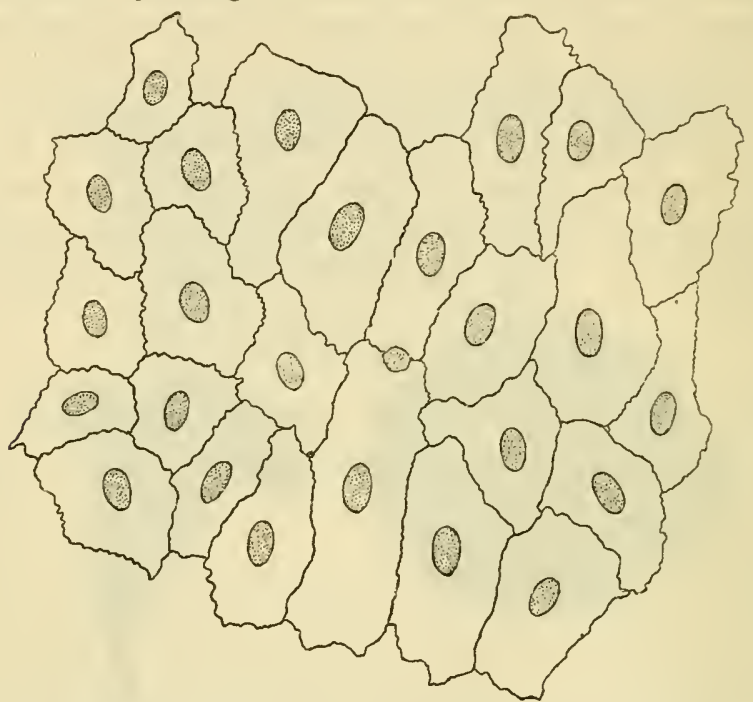

FIG. 56.--PADEMENT EPITHELIUM OR ENDOTHELIUM OF A SEROUS MEMBRANE.

Nitrate of silver preparation. Carmine staiNisg of NUClei.

Ciliated epithelium is found in man throughout the whole extent of the air-passages and their prolongations, but not in the uppermost part of the nostrils which is supplied by the olfactory nerves, nor in the lower part of the pharynx, nor in the terminal bronchioles and pulmonary alveoli. It also occurs in the Fallopian tubes and the greater part of the uterus; in the efferent tubes of the testicle; and in the ventricles of the brain, and the central canal of the spinal cord.

\section{GLANDULAR EPITHELIUII AND SECRETING GLANDS.}

Glandular epithelium is the essential tissue of all the organs which are known as secreting glands. Glands are of two chief kinds. Those which are best known and which are termed secreting glands proper are furnished with a duct which ramifies in all parts of the gland and by means of which the products of the secretory activity of the gland-cells are brought to a free surface. Such glands have been developed as involutions of the surface upon which they open, and their epithelium is continuous with that of this surface, and is in some cases, especially where the surface upon which the gland opens is covered with columnar 

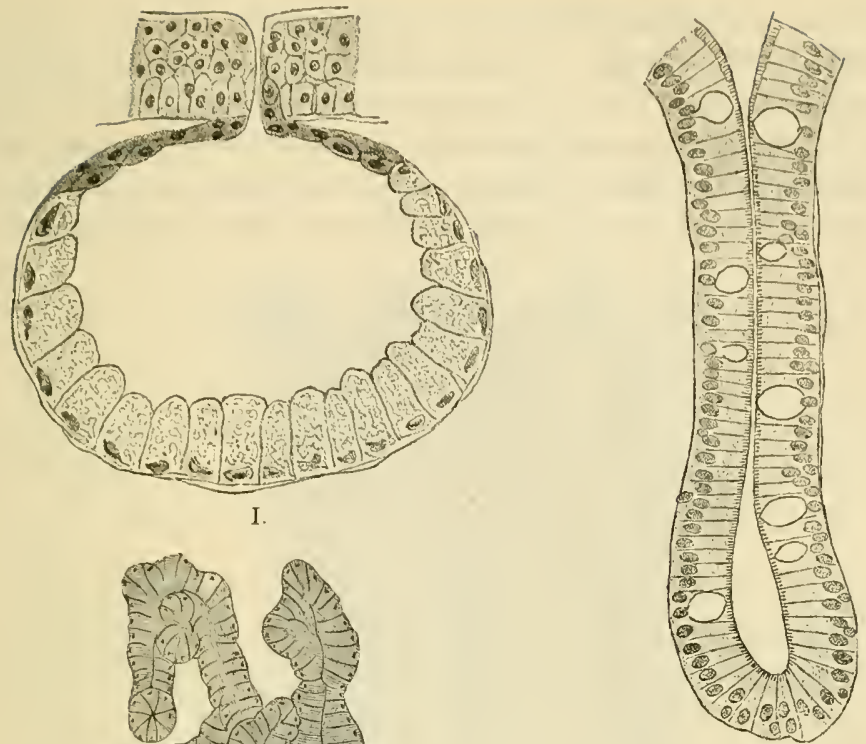

II.

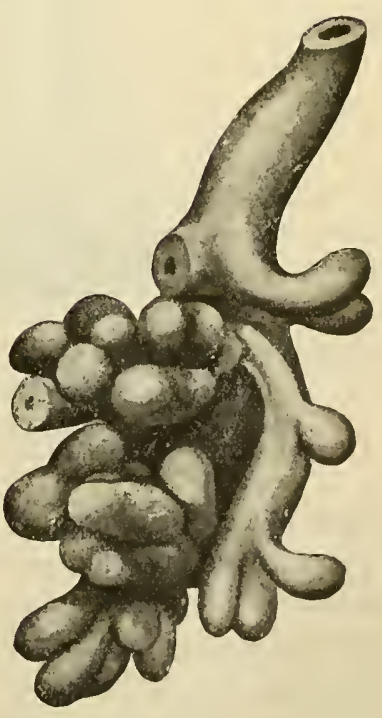

V.

IV.

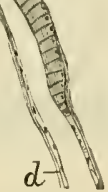

Fig. 57.-VARIOUS KINDS OF GLANDS.

I. Simple saccular gland from amphibian skin (Flemming). II. Simple tubular gland from intestine (Flemming). III. A small racemose gland with a single duct into which a number of irregularly tubular acini open (Flemming). IV. Part of a tubuloracemose gland with the acini unravelled (Flemming). V. Wax inodel of a small tubulo-racemose gland from the epiglottis (Maziarski). 
epithelium, of a similar character to the epithelium of the surface; in others different in character. In most glands the epithelium alters as we trace the duct back into the recesses or alreoli of the gland, and it is in these that the characteristic glandular cells, which are generally polyhedral in shape, are found. Every such involution or ingrowth of epithelium to form a gland is, when first formed, of a simple character,

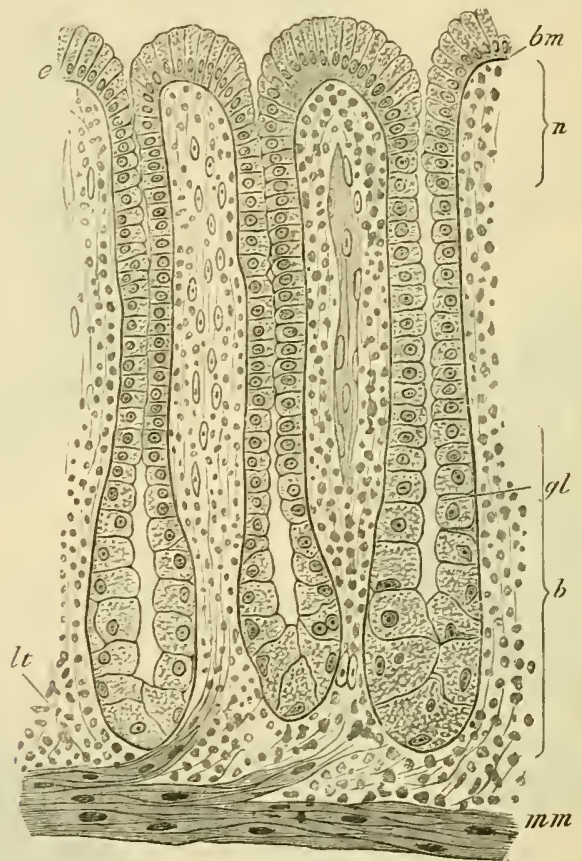

Fig. 58. - SiJiple tUbULAR GLANDS SEEN IN A SECTION OF THE MUCOUS MEMBRANE OF THE STOMACH OF THE KANGAROO.

$\epsilon$, epithelium of general surfaee; $b m$, basement membrane; $n$, neek or duet of gland; $l$, base or fundus; $g l$, glandular epithelium; $l t$, lymphoid tissue; $m m$, muscular tissue of the mucous membrane.

shaped like a test-tube or flask and filled with a solid mass of cells, but it presently becomes hollowed out and the cells are left as a lining to the connective tissue membrane which bounds the involution. The gland may remain simple and unbranched (simple saccular and simple tubular glands, fig. 57, I. and II.), or it may branch again and again until a complicated structure, in some cases small, in others of considerable size, is produced (compound tubular and compound saccular (or racemose) glands (fig. 57, III., IV., V.), instances of which are furnished by the kidneys and salivary glands respectively). The cells which furnish the secretion of the gland and which line the secreting parts of the tubules of a tubular 
gland, or the alveolar enlargements (acini) at the ends of the ducts of a racemose gland, are frequently partly or wholly filled with granules in the intervals of secretory activity, and these granules become discharged or dissolved and pass into the secretion during activity. Secreting glands are always abundantly supplied with blood-vessels and nerves. The former are distributed in the comnective tissue which holds together the acini and groups of acini (lobules) of the gland; the latter are supplied partly to the blood-vessels and partly ramify amongst the secretory epithelium cells.

The liver differs from all other secreting glands in being composed of solid masses of cells (hepatic lobules) instead of tubular acini lined by epithelium. It exhibits also other important differences in the nature of its blood-supply and the relation between the blood and the livercells.

The other kind of secreting glands, known as the internally secreting glands, are not furnished with ducts and are usually described (along with the spleen and the lymphoid structures) as ductless glands. The internally secreting glands are, like the externally secreting organs, composed of epithelial cells, sometimes grouped in solid masses (e.g. suprarenal gland), in other cases disposed around hollow vesicles (e.g. thyroid) which become filled with the material of the secretion. But as in these glands there is no duct the secretion is carried into the blood either directly by the blood-vessels of the gland or indirectly through the lymphatics.

The detailed study of the glands and of other epithelial structures may be reserved until the organs in which they occur are described, but columnar and ciliated epithelia will be dealt with in the next Lesson.

The hairs and nails and the enamel of the teeth are modified epithelial tissues. They will be deseribed along with the skin and structures connected with the mouth respectively. 


\section{LESSON VIII.}

\section{COLCMAR AND CILIATED EPITHELIUIS: ACTIOY OF CILLA.}

1. BrEsk up in dilute glycerine a shred of epithelium from a minute piece of the mucous membrane of intestine (frog) that has been treated with 1 per cent. osmic acirl for some hours, and has subsequently macerated in water for a few days. The cells easily separate on tapping the corer-glass. Measure and sketch one or two cellis.

The cover-glass may be at once fixed by gold size.

2 Prepare ciliated epithelium from a trachea that has been in chromic acid solution (1 to 2000 normal saline) for a few dars, in the same war as with transitional epithelium ( 5, p. 52). Measure in one or two of the cells $(a)$ the length of the cells, $(b)$ the length of the cilia, $(c)$ the size of the nucleus. Sketch two or three cells.

3. Mount in sea-water one or two bars of the gill of the marine mussel (fig. 59). Study the action of the large cilia. Now place the preparation upon the copper warm stage (see Lesson VI.) and observe the effect of raising the temperature.

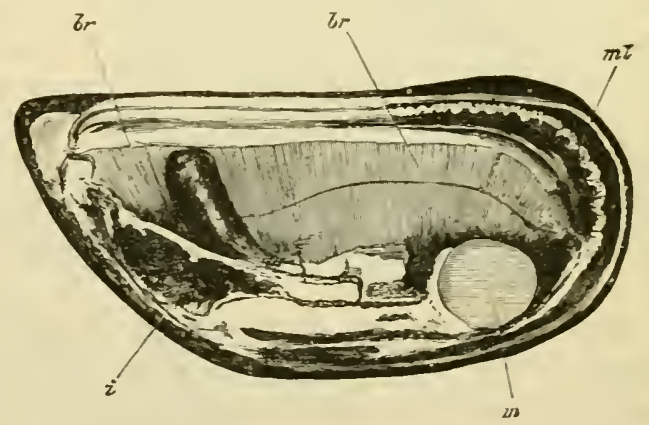

Flg. 59.-VALVE of Mrssel (MrTLCS EDCLIS) SHOWING $b r$, $r$, THE EXPAXDED GILLS OR BRANCHIE, WHICH, OWISG TO THE LITTLE BARS OF WHICH THET ARE COMLPOSED, PRESEYT A STRIATED ASPECT.

$m$ mantle; $m$, cut adductor muscle; $i$, mass of riscera; the dark projection just abore is the foot.

Keep this preparation until the end of the lesson, by which time many of the cilia will have become languid. When this is the case pass a drop of dilute potash solution ( 1 part $\hat{\mathrm{K}} \mathrm{HO}$ to 1000 of sea-water) under the coverglass and observe the effect.

4. Cement with sealing-wax a piece of small glass tubing to a slide so that one end of the tube comes nearly to the centre of the slide. Tu do this effectually the slide must be heated and some sealing-wax melted on to it and allowed to cool. The glass tube is then made hot and applied to the slide, embedding itself as it does so in the sealing-wax. Apply a ring 
of putty or modelling wax (half an inch in diameter and rising above the grlass tube) so as to include the end of the tube. Nake a deep notch in the ring opposite the tube for the exit of the gas. Place a drop of water within the ring (fig. 60).

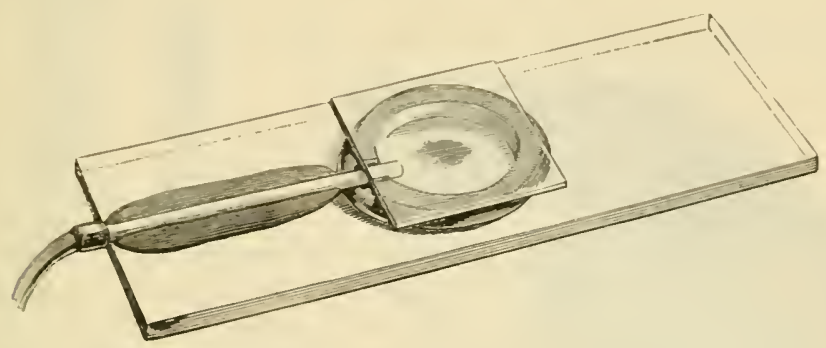

Fig. 60.-MOIST CHAMBER ADAPTED FOR PASSING A GAS OR FAPOUR TO A PREPARATION CNDER THE MICROSCOPE.

Put a bar from the gill upon a cover-glass in the least possible quantity of sea-water ; invert the cover-glass over the putty ring, and press it gently and evenly down. The preparation hangs in a moist chamber within which it can be studied through the eover-glass, and into which gases or vapours can be passed and their effects obserred.

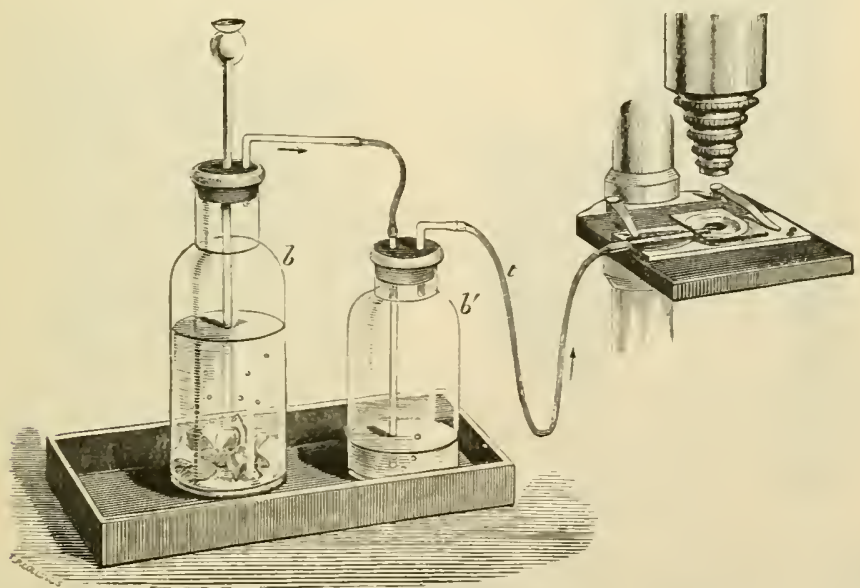

Fig, 61.-METHOD of SUBJEctivg a PREPaRation to a STREAM OF CARBoN DIOXIDE.

$b$, bottle containing marble and hydrochloric acid ; $b^{\prime}$, wash-bottle, connected by indiarubber tube, $t$, with the moist chamber, $s$.

Pass $\mathrm{CO}_{2}$ through the chamber, and after observing the effect replace it by air (see fig. 61). Repeat with ether and with chloroform vapour.

Columnar epithelium.-The cells of a columnar epithelium (fig. 62) are prismatic columns, which are set closely side by side, so that when seen from the surface a mosaic appearance is produced. They often 
taper somewhat towards their attached end, which is generally truncated, and set upon a basement membrane. Their free surface is

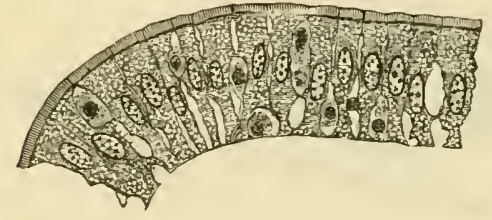

FIG. 62.

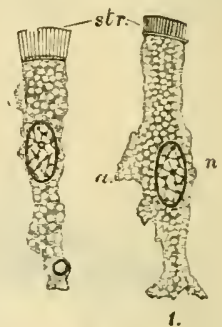

FIG. 63.

Fig. 62. - A ROW OF COLUMNAR CELLS FROM THE INTESTINE OF THE RABBit. Smaller cells are secn between the epithclium-cells; these are leucocytes.

Fig. 63.-COLUMAar EPITHELICM-CELlS OF THE RABBIT'S INTESTINE.

The cells have been isolated after maceration in very weak chromic acid. The cells are much vacuolated, and one of them has a fat.globule adhering to it near its attached end ; the striated border $(s(r)$ is well seen, and the bright disk scparating it from the cell-protoplasm: $n$, nucleus, with intranuclear network; $a$, a thinmed-out winglike projection of the cell which probably fitted between two adjacent cells.

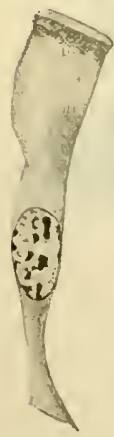

FIG. 64 .

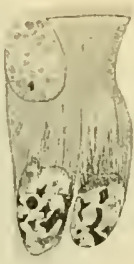

FIG. 6รั.

FIG. 64.--A COLEMNAR EPITHELIUM-CELL, SHOWING MASS OF FIBRILS (CYTOMITOME) Withis the crtoplasM. (M. Heidenhain.)

Fig. 65.-A GOBLET OR MUCUS-SECRETING CELL IN COLUMNAR EPITHELIUMI. (M. Heidenhain.)

The centrosome is in the mucigen-mass. An ordinary columnar cell is also shown.

Fig. 66.-Ciliated colcmNar epithelicm, From the trachea of a RABBit. $m^{1}, m^{2}, m^{3}$, mucus-secreting cells in various stages of mucigen formation. The preparation was treated with dilute chromic acid.

covered by a thick striated border (fig. 63 , str.) which may sometimes become detached in teased preparations. The protoplasm of the cell is highly vacuolated and reticular, and fine longitudinal strix may be 
seen in it, which appear continuous with the strix of the free border. Between the striated border and the protoplasm of the cell is a highly refracting disk which contains fine dumb-bell shaped particles set rertically, connected below with the fibrils or stria which run throngh the cell protoplasm (fig. 64, 65). It has been suggested that these particles are formed by multiplication of the centrosome, but the fact cannot be regarded as established. The nuclens is ovoid and reticular. The lateral borders of the cells are often somewhat irregular or jagged, the result of the presence of amoboid cells, which are generally found between the columnar cells, at least in the intestine. After a meal containing fat the epithelium-cells of the small intestine contain fat globules, which become stained black in osmic preparations.

Columnar epitheliun-cells are found lining the whole of the interior of the stomach and intestines: they are also present in the ducts of most glands, and sometimes also in their secreting tubes and saccules. The epithelium which covers the ovary is also of a modified columnar shape, but cells having all the structural peculiarities indicated above are found only in the alimentary canal and in its diverticula.

Goblet-cells. - Some of the cells of a columnar epithelium, and also cells of glandular, ciliated, and transitional epithelia, contain mucigen, which is laid down within the cell in the form of

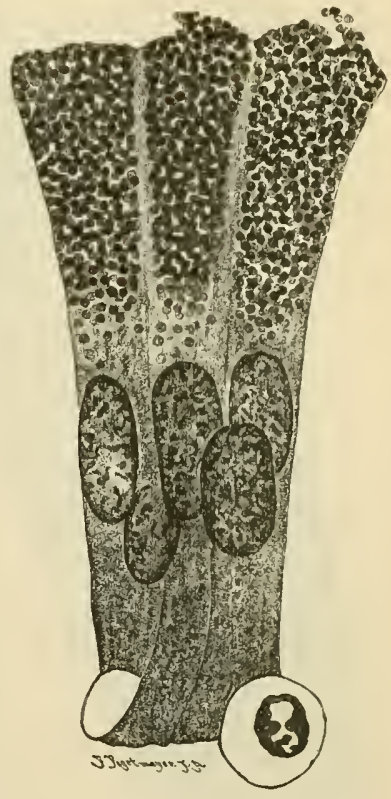

Fig. 67.-Three MUCUS-SECRETING CELLS YROM THE STOMACH, FILLED WITH MUCIGEN GRANULES, SOME OF WHICH ARE IN PROCESS OH EXTRUSION. (M. Heidenhain.) granules (fig. 65, fig. $66, \mathrm{~m}^{1}, \mathrm{~m}^{2}$; fig. 67). These granules eventually swell up to form globular masses which may run together and greatly distend the part of the cell nearest the free border. When the mucigen is extruded as mucus the cell takes the form of an open cup or chalice (fig. $66, \mathrm{~m}^{3}$ ), hence the name.

These goblet-cells, or, as they are more appropriately termed, mucussecreting cells, are probably not mere temporary modifications of the ordinary columnar and ciliated cells amongst which they are found, but permanently differentiated cells, which, after having got rid of their mucus by extrusion, again form a fresh supply in the same way as 
before. In the gastric mucous membrane all the surface epithelium is composed of mucus-secreting cells, and they extend also into the mouths of the glands. In the large intestine also most of the cells both of the surface and in the glands are goblet-cells. According to the observations of Carlier those of the gastric mucous membrane are connected together laterally by protoplasmic fibres.

Ciliated epithelium. - The

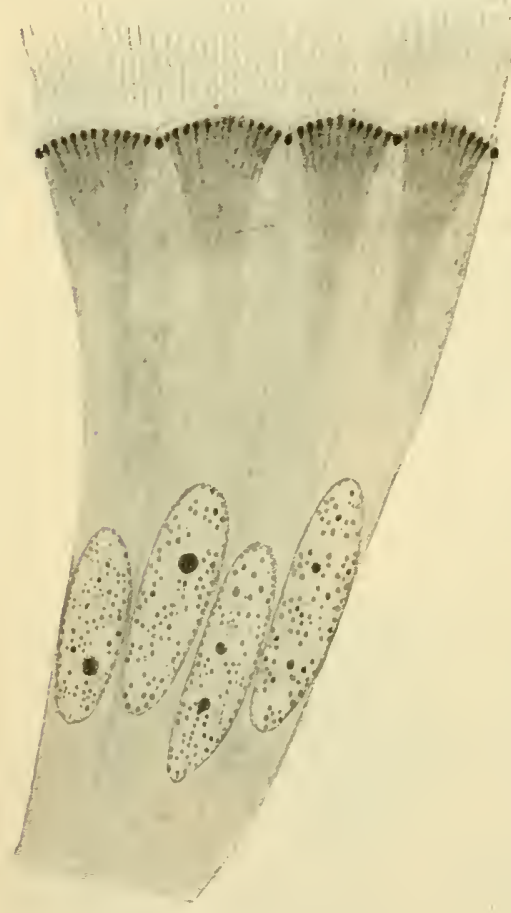

Fig. 68.-Four ciliated cells. (Lénhossek.) cells of a ciliated epithelium are usually columnar in shape (figs. $66,68)$, but in place of the striated border of the ordinary columnar cell the free surface is surmounted by a bunch of fine tapering filaments (vibratile cilia), which, during life, move spontaneously to and fro, and serve to produce a current in the fluid which covers them. The border upon which the cilia are set is bright in the living condition: after fixation it appears formed of little juxtaposed lnobs or basal purticles, to each of which a cilium is attached.

In the large ciliated cells which line the alimentary canal of some molluscs (figs. 68, 70), and with less distiuctness in the ciliated cells of vertebrates, the knob may be observed to be prolonged into the protoplasm of the cell as a fine varicose filament, termed the rootlet of the cilium. Since the axial fibril in the tail of the spermatozoon (which is commonly regarded as a cilium) is developed in connection with the centrosome, it has been supposed that the cilia of an ordinary ciliated cell may also be outgrowths from the (multiplied) centrosome. But althongh it may be the case that the basal particles are formed by the division of the centrosome of the cell, in which case the rootlets may represent the fibrils of archoplasm which radiate from the centrosome of such a cell as the white corpuscle (fig. 9), it appears not to be true that the cilia are developed from these basal particles, for the cilia sometimes appear before the basal particles. In plant spores, which have no centrosomes, the cilia are developed from amœeloid processes of the ectoplasm of the cell (Strassburger). Similar basal particles and longitudinal fibrils are found in columnar cells ( $\mathrm{pp} .62,63$ ), and these are probably homologous with the knobs and rootlets of the ciliated cell, while the bunch of cilia of the latter is represented by the striated border of the colunmar cell. 
Schuberg has described in the cilia of certain infusoria an end-piece which stains ditferently from the rest of the eilimm (fig 71).

The action of cilia.-When in motion a cilium is bent quickly over in one direction with a lashing whip-like movement, immediately recovering itself. When vigorous the action is so rapid, and the rhythm so frequent (ten or more times in a second), that it is im-

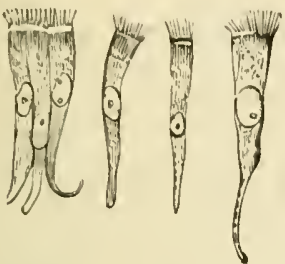

Fig. 69.-COLtuNar CILIATED EPITHELICM-CELLS FROM THE LOWER PART OF THE HUMAN NASAL PASSAGES. EXAMINED FRESH IN SERUM. (Sharpey.)

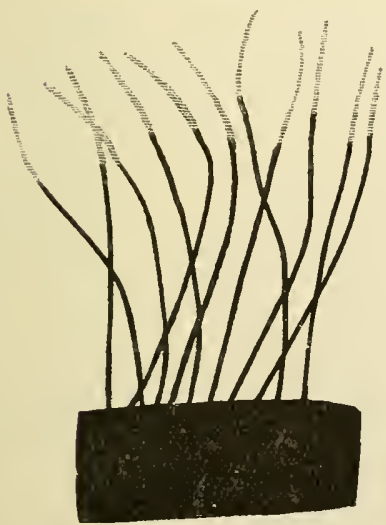

Fig. 71.-Cilia of rrontonia leucas. (A. Schuberg.)

Löffler's flagellum stain. $\times 2250$.

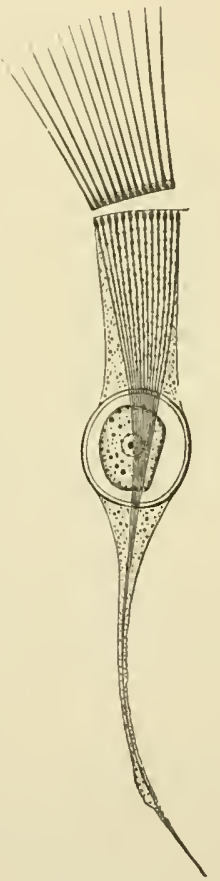

Fig. 70.-CILIATEl) CELL, FROM THE INTESTINE OF A MOLLESC. (Engelmann.)

possible to follow the motion with the eye. All the cilia upon a ciliated surface are not in action at the same instant, but the movement travels in waves over the surface. If a cell is detached from the general surface, its cilia continue to act for a while, but their movement at once ceases if they are detached from the cell. If, however, a portion of the cell protoplasm is detached with them, they will continue to move for a time.

The rhythm is slowed by cold, quickened by warmth; but heat 
beyond a certain point kills the cells. The movement will continue for some time in water deprived of oxygen. Both $\mathrm{CO}_{2}$ gas and ether and chloroform vapour arrest the action, but it recommences on restoring air, if their action is not too prolonged. Dilute alkaline solutions quicken the activity of cilia, or may even restore it shortly after it has ceased.

Theories of ciliary action.-Varions attempts have been made to explain the manner in which cilia act. One hrpothesis supposes that one side only of each cilium is contractile, the other side being elastic, or that there is a more rigid but elastic axis and a contractile covering. This supposition is negatived by the fact that in heat rigor the cilia are not bent over as they would be by the contraction which always accompanies rigor, but stand up straight. It is moreover impossible to suppose that a soft structure like a cilimm conld be bent over in a uniform gentle curve by contraction along one side; such contraction conld only produce shortening and wrinkling of the cilium, effects which are never olserved. Another hypothesis assumes that the projecting cilia are set in action by rhythmic lateral contractions in the protoplasm ; which, by moving the rootlets, canse the cilia to bend over as a whip is bent by movements of the wrist applied to its handle. But this again implies an amount of rigidity which cilia do not possess, for it must be borne in mind that they have to overcome the resistance of fluid, and of fluid which is in many cases highly viscons.

If in onr ignorance of the structure of the individual cilia we are to form an idea as to the cause of the rhythmical bending over of these minute cell processes, the simplest hypothesis appears to be to assume that they are curred flattened hollow filaments, the interior communicating with the cellprotoplasm. ${ }^{1}$ If this is the case, then rhythmical variations of pressure within the cell-protoplasm, which might, as in the case of amoboid movements, be caused by alterations in surface tension, would be transmitted to the cilia and wouli cause the curve to open ont, and again to assert itself, according to the degree of tension within the tubular filament. Such action can be initated with a fine curved and fiattened indiarubber tube attacherl to a pressure bag. Any increase of pressure within the tube canses it to straighten out; on again decreasing the pressure the tube benls over exactly in the manner of a cilium. This hypothesis has the arkantage over the others which have been offered that it explains the morements of cilia on a theory which is precisely similar to that which gives the most probable explanation of amoboid movements of protoplasm, viz., that they are due to variations in surface tension, and it thus brings these two forms of protoplasmic activity into line with one another. It will presently be shown that the changes which occur in muscle in contraction are susceptible of a similar explanation.

${ }^{1}$ All cilia and cilium-like structures (flagella) which are sufficiently large to show any structural differentiation, exhibit an external membrawous covering and a clear and usually structureless contents, but the miute size of ordinary cilia prevents one from determining whether this is also the case with them. 
LESSON IX.

THE CONNECTIVE TISSUES.

\section{AREOLAR AND ADIPOSE TISSUE. RETIFORM TISSUE.}

1. TAKE a little of the subcutaneous tissue or of the intermuscular connective tissue of a rabbit or guinea-pig and spread it out with neelles on a dry slide into a large thin film. Keep the centre moist by occasionally breathing on it, but allow the edgres to dry to the slicle. Before commencing put a drop of salt solution on a cover-glass, and now invert this over the film. Examine with a high power. Sketch one or two bundles of white fibres and also one or two elastic fibres, distinguishable from the former by their sharp ontline, isolated course, and by their branching. Sketch also one or more connectivetissue corpuscles, if any such are visible in the clear interspaces. Look also for migratory rells (leucocytes). Next carefully remove the cover-glass and replace the salt solution by dilute acetic acid (l per cent.). Watch its effect in swelling the white fibres and bringing more clearly into view the elastic fibres and corpuscles. Look for constricted bundles of white fibres.

2. Make another very thin film in the same way, but allow to dry completely. Pour over the film a 1 per cent. solution of magenta in 50 per cent. alcohol, to which 1 drop per cubic centimeter of a 1 per cent. solution of gentian violet in alcohol has just been added. After one minute drain this otf, wipe round the specimen and allow the remainder of the staining solution to dry on the film. When completely dry mount in dammar. The elastic fibres are deeply stained; the cells are also well shown.

3. Prepare another film of the subcutaneous tissue, including a little adipose tissue. Fix by pouring over it formol (10 p.c.) and leave this in contact with the film for 20 minutes. Wash with water and stain with saturated solution of Sudan III. or Scharlach R. in 75 p.c. alcohol ; wash with 75 p.c. alcohol to remove stain from everything except fat, then wash with water and stain with dilnte hæmatoxylin. Mount in glycerine and water. Examine first with a low and afterwards with a high power. The fat is well brought out by the Sudan III. or Scharlach R. stain; if the preparation is from a young animal, fat-cells will be found in process of formation. Measure and sketch two or three of the cells.

The fat may also be stained, without prior fixation, by treatment with 1 p.c. osmic acid solution.

4. Spread ont another large film of connective tissue, letting its edges dry to the slide, but keeping the centre moist by the breath. Place on its centre a large drop of nitrate of silver solution (1 per cent.). After five minutes wash this away with distilled water, and expose to direct sumlight until stained brown. Now allow the film to dry completely, and cover it in dammar varnish or Canada balsam dissolved in xylol. Sketch the outlines of two or three of the cell-spaces.

5. To display retiform tissue the following method is recommended (Spalteholz). Place a piece of the organ (e.g. lymphatic gland) for twenty. 
four hours or more in alcohol, then overnight at $38^{\circ} \mathrm{C}$. in a 1 per cent. solution of carbonate of soda to which a few drops of a solution containing trypsin have been added. Cautiously transfer the semi-digested structure to alcohol again, and leave it for a few hours. Embed in paraftin in the ustial way and stain the sections with iron hrematoxylin. The fibrils of connective and retiform tissue are the only structures which have remained undigested and they are deeply coloured by the hrematoxylin.

The connective tissues include areolar tissue, adipose tissue, elastic tissue, fibrous tissue, reticular and lymphoid tissue, cartilage and bone. All these tissues agree in certain microscopical and chemical characters. They, for the most part, have a large amount of intercellular substance in which fibres are developed, and these fibres are of two kinds-white and yellow or elastic. Moreover, there are many points of similarity between the cells which occur in these tissues; they are all developed from the same embryonic formation, and they tend to pass imperceptibly the one into the other. Besides this, the use of these several tissues is similar; they mostly serve to connect and support the other tissues, performing thus a passive mechanical function. They may therefore be grouped together, although differing considerably in external and even in nicroscopic characters. Of the connective tissues, however, there are three which are so intimately allied as to be naturally considered together, being composed of exactly the same elements, although differing in the relative development of those elements: these are the areolar, elastic, and fibrous tissues. Adipose tissue and reticular tissue may both be looked upon as special modifications of areolar tissue. Areolar tissue being the commonest and, in a sense, the most typical, its structure may be considered first.

Areolar tissue.-The areolar tissue presents to the naked eye an appearance of fine transparent threads and laminæ which intercross in every direction with one another, leaving intercommunicating meshes, or areolæ, between them. When examined with the microscope, these threads and fibres are seen to be principally made up of wavy bundles of exquisitely fine transparent fibres (uhite fibres, fig. 73, A). The bundles run in different directions, and may branch and intercommunicate with one another (fig. 75); but the individual fibres, although they pass from one bundle to another, never branch or join other fibres. The fibres are cemented together into the bundles by a clear substance containing mucin, and the same clear material forms also the basis or ground. substance of the tissue, in which the bundles themselves course, and in which also the corpuscles of the tissue lie embedded. This groundsubstance between the bundles can with difficulty be seen in the fresh tissue on account of its extreme transparency; but it can be brought to view by staining with nitrate of silver, as in $\$ 4$. The whole of the 
tissne is thereby stained of a yellowish brown eolour, with the exception of the spaces which are occupierl by the corpuseles (cell-spaces).

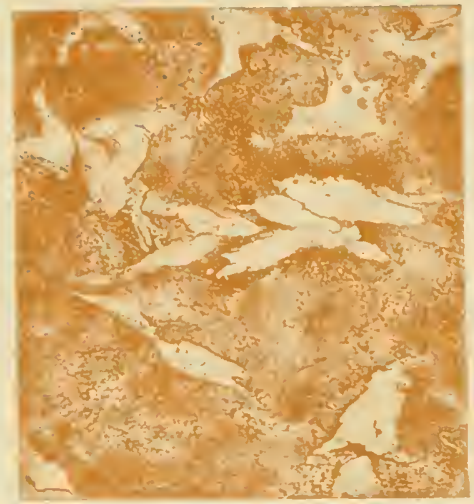

Fig. 72, Grousd substayce of connective tissue stained By silver.

The cell-spaces are unstained. From a photograph. Magnified 250 diameters.

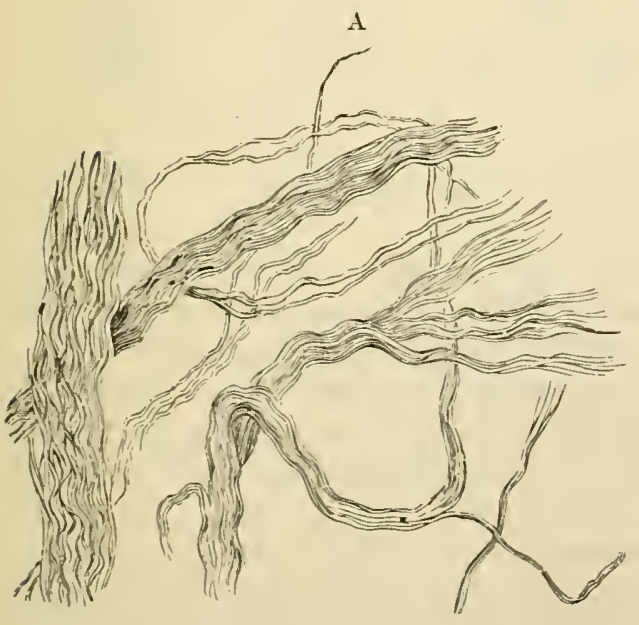

B

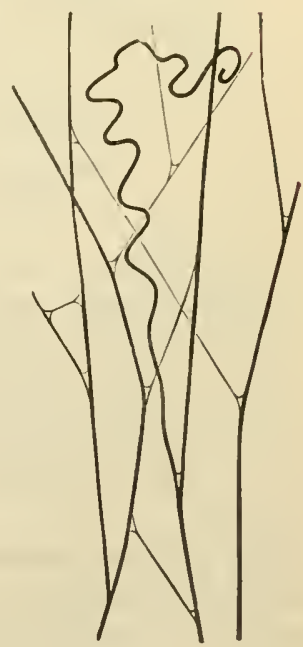

Fig. 73.-White AND ELASTIC FIBRES OF AREOLAR TISSUE.

$A$, bundles of white fibres partly unravelled. B, elastic fibres.

As Macallum has shown, this reaction is due to the presence of ehlorides in the intercellular substance, whereas the cell-protoplasm contains none.

Besides the white fibres of connective tissue here described, fibres of a different kind (fig. 73, B) may be made out in the preparations; these are the elastic fibres. They are especially well seen after treatment 
with acetic acid, and after staining with magenta, or, in sections, with orcein; but they can be detected also in the fresh preparation. They are characterised by their distinct outline, their straight course, the fact that they never run in bundles, but singly, and that they branch or join neighbouring fibres. If broken by the needles in making the preparation, the elastic recoil causes them to curl up, especially near the broken ends. Besides these histological differ ences, the two kinds of fibres differ also in their chemical characters. Thus the white fibres are formed of a material (collugen) which is dissolved by boiling in water yielding gelatin, and by peptic digestion. but is not dissolved by tryptic digestion: whereas the substance of which the elastic fibres are composed (elastin) resists for a long time the action of boiling water and peptic digestion, although it is dis. solved by tryptic digestion. Moreover, the white fibres swell and

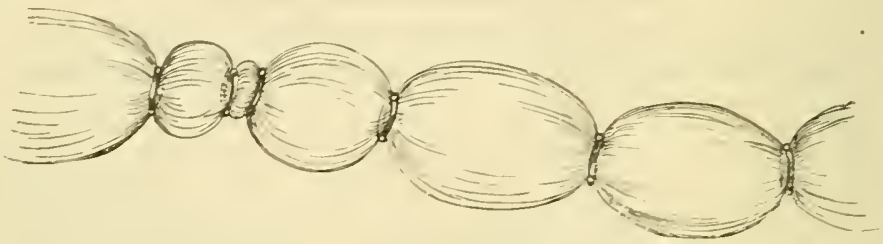

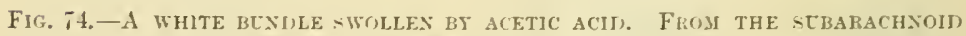
TINSEE AT THE BASE OF THE BRAIS. (Toldt.)

become indistinct under the action of acetic acid; the elastic fibres are unaltered by this reagent. Elastic fibres appear to have a sheath which is more resistant to reagents than the rest of the fibre.

The bundles of white fibres which have becn swollen out by acid sometimes exhibit constrictions at irregular intervals (fig. 74). These are in many instances due to elastic fibres coiling round the white bundles.

The cells of areolar tissue.-Several varieties of connective tissue cells are distinguished, viz.: (1) Lamellar cells, which are flattened and often branched (fig. $75, c, c^{\prime}$ ) and may be united one to the other by their branches, as in the cornea. Sometimes they are unbranched and may lie along the fibril-bundles and even themselves show a fibrillar appearance. Some anthors have inferred from this that these cells are transformed into white fibril-bundles and have termed them "fibroplasts"; but the fibrillation which they exhibit is not of the same character as that of the white fibres, and is probably a form of cytomitome, such as is seen in many protoplasmic cells. In certain situations the lamellar connective-tissue cells 


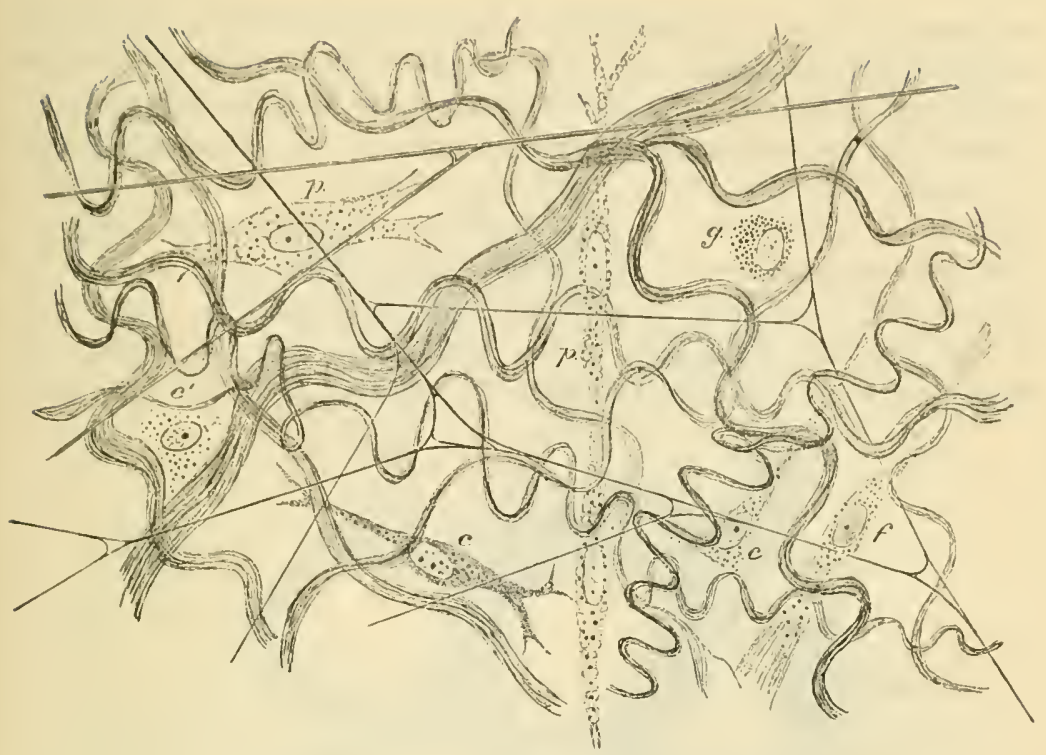

Fig. 75. - Subcutaneods tissue From a young Rabbit, PReparen as directed IN $§ 1$. Highly magnified.

The white fibres are in wavy bundles; the elastic fibres form an open network. $p, p$, plasma-cells ; $g$, granule-cell ; $c, c^{\prime}$, lamellar-cells ; $f$, fibrillated-cell.

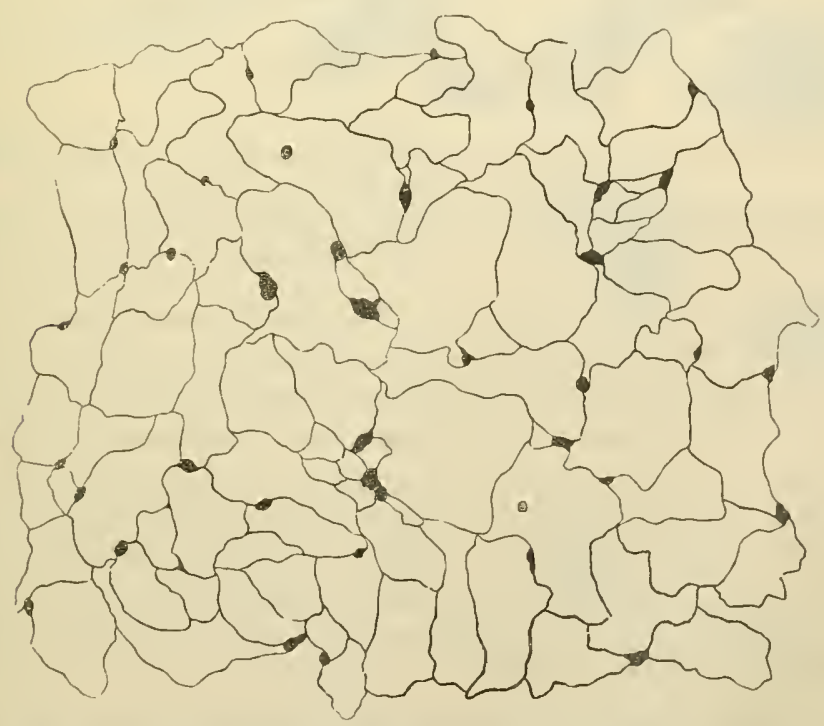

Fif. 76, - EPJThelioid CELLS OF CONNFCtive tisSUE Frou the SURFACE OF AN APONEurosis. (Nitrate of silver preparation.) 
are greatly flattened out, especially when they lie upon the surface of aponeuroses and they are there joined edge to edge like the cells of an endothelium (fig. 76. The apparent cell-spaces in silver preparations have of course in all cases a similar arrangement to that of the cells). (2) Plasma cells (fig. 75, p), which are composed of a soft muchvacuolated protoplasm, rarely flattened, but otherwise varying greatly in shape and size. (3) Granular cells (g) (Mast-zellen of Ehrlich, clasmatocytes of Ranvier), usually spheroidal or ovoidal in shape, and formed, like the plasma-cells, of soft protoplasm, but thickly occupied with albuminous granules, which are deeply stained by gentian violet

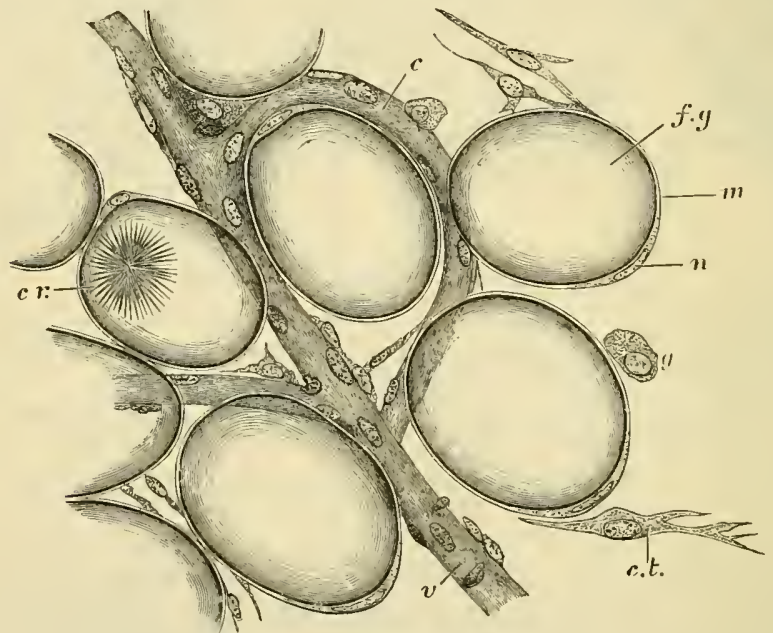

Fig. 77.--A Few Cells from the MaRgiN of a fat LOBUle. Highly magnified. From a photograph.

f. $g$. fat-globule distending a fat-cell; $n$, nucleus; $m$, membranous envelope of the fat. cell; c. $r$. bunch of crystals within a fat-cell ; $c$, capillary vessel; $v$, venule ; c.t. connective-tissuc cell; $g$, granular cell ; the connective-tissue fibres are not represented.

and by other basic aniline dyes. (4) Migratory leucocytes may also be seen here and there in the areolar tissue (wander-cells). (5) In the middle coat of the eye in mammals, and in some parts of the skin, some of the connective-tissue cells are filled with granules of pigment (pigment-cells).

These are much more extensively present in lower vertebrates, especially in amphibia and fishes, where they exhibit amoboid changes which result in the pigment being at one time diffused over a considerable area and at another time restricted to the immediate neighbourhood of the nucleus. The changes thus produced cause alteration in the general colour and shade of the integument, where such pigment cells are very numerous, and serve the purpose of protective adaptation of the animals to their environment.

The cells lie in spaces in the ground-substance, between the bundles of white fibres. In some parts of the connective tissue the white 
bundles are developed to such an extent as to pervade almost the whole of the ground-substance, and then the connective-tissue corpuseles become squeezed into the interstices, flattened lamellar expansions of the cells extending between the bundles, as in tendon (see next Lesson).

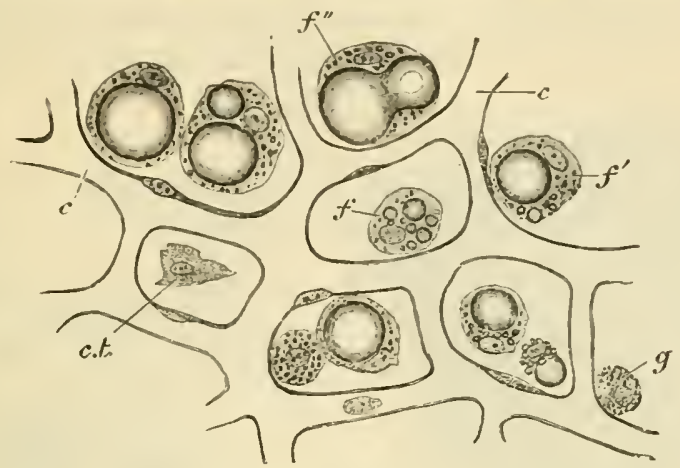

Fig. 78.-Deposition of fat in CONNective-tissCe Cells.

$f$, a cell with a few isolated fat-droplets in its protoplasm; $f^{\prime \prime}$, a cell with a single large and several minute drops; $f^{\prime \prime}$, fusion of two large drops; $g$, granular cell, not yet :xhibiting any fat-deposition; c.t., flat connective-tissue corpuscle; $c, c$, network of capillaries.

The cells and cell-spaces of areolar tissue come into intimate relation with the cells lining the lymphatic vessels and small blood-vessels. This connection can best be seen in silvered preparations; it will be again referred to in speaking of the origin of the lymphatics.

Adipose tissue consists of vesicles filled with fat (figs. 77,79 ) and collected into lobules, or into tracts which accompany the small bloodvessels. The vesicles are round or oval in shape, except where closely packed, when they become polyhedral from mutual compression. The fat-drop is contained within a delicate protoplasmic envelope (fig. $i 7, m$ ) which is thickened at one part, and here includes an oval flattened nucleus. The fat is stained black by osmic acid; a deep yellow colour by Sudan III.; and an intense red by Scharlach $\mathrm{k}$.
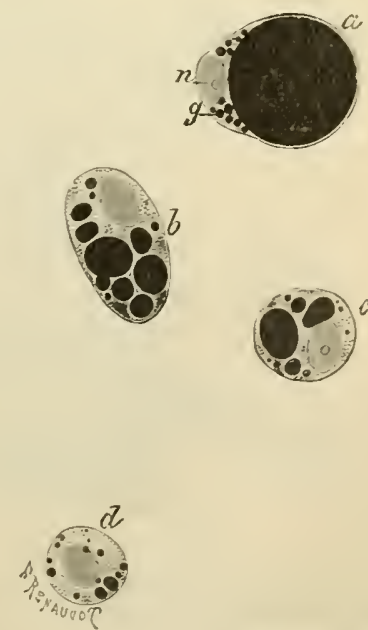

FIG. 79.-FAT-CELLS FROM YOUNG ANI3HA

(Ranvier.) OsMIC ACID PREPARATION.

The drops of fat are stained of an intense black. $n$, nuclcus; $g$, small globules of fat. 
The vesicles are supported partly by filaments of areolar tissue, but chiefly by a fine network of capillary blood-vessels.

The fat when first formed in the embryo is deposited within large granular cells of areolar tissue (fig. 78) similar in general appearance to the "Mast"-cells of Ehrlich; some authorities regard them as of a specific nature, for they are in certain situations collected into large gland-

A

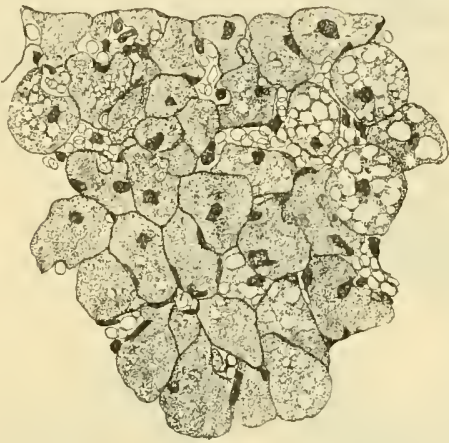

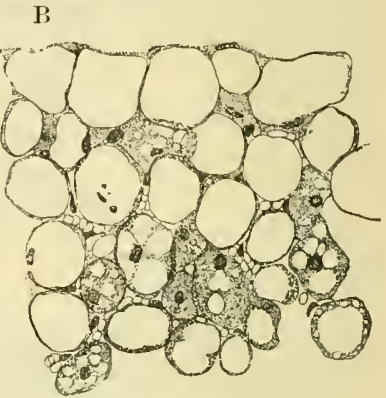

Fig. 80. - Two stages of Formation of anipose tissue. (H. Batty Shaw.)

In $\mathrm{A}$ the tissue is formed of a gland-like mass of cells, in some of which the cytoplasm is occupied by fat globules (looking white in the sections). $\ln \mathrm{B}$ the fat fills many of the cells.

like masses (fig. 80) abunlantly supplied with blood-vessels, which gradually become transformed into fat-cells by the deposition of fat in the cell-protoplasm. Fat is, however, also laid down in ordinary

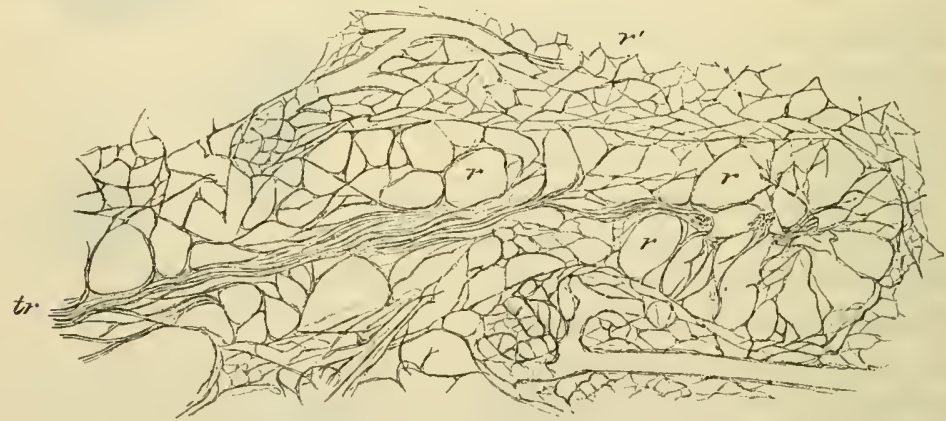

Fig. 81.-ReTiforu tissue From a LYMPH-GLAND. Moderately magnified.

tr, a trabcculum of connective tissue; $r, r^{\prime}$, retiform tissue, with more open meshes at $r$ and denser at $r^{\prime}$.

branched cells of connective-tissue. The fat appears to be produced by a transformation of albuminous granules which the cells contain into droplets of fat. As the droplets increase in size they run 
together into a larger drop, which graclually fills the cell more and more, swelling it out so that the cell-protoplasm eventually appears mercly as the envelope of the fat-vesiele.

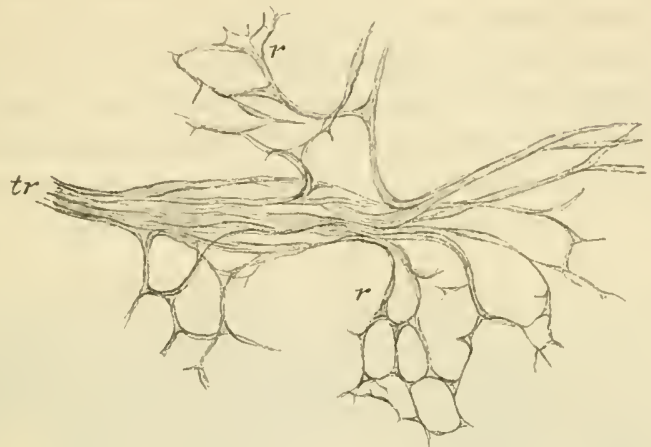

Fig. 82.- PORTION OF THF ABOVE, MORE HIGHLY MAGNIFIED, showing the continuity of the retiform tissue $r, r$, with the connective tissue of a trabeculum, $t r$.

Fat is found most abundantly in subcutaneous areolar tissue, and under the serous membranes; especially in some parts, as at the back of the peritoneum around the kidneys, under the epicardium,

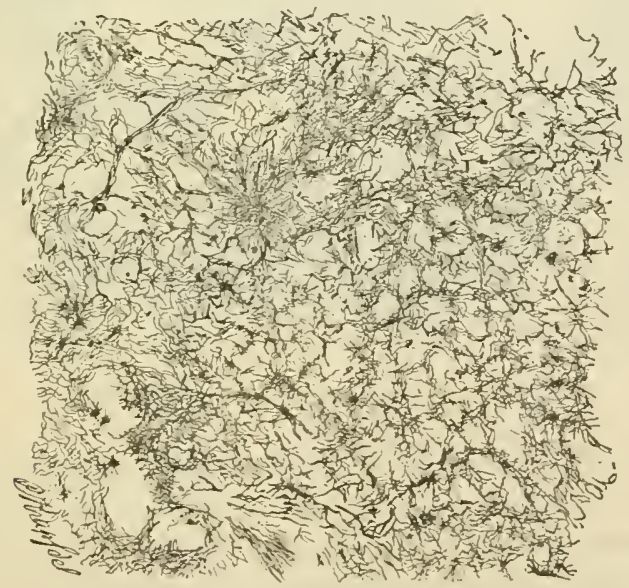

Fig. 83. - Reticclud of bone-siarrow. (Enderlen.)

and in the mesentery and omentum. The yellow marrow of the bones is also principally composed of fat. There is no adipose tissue within the carity of the cranium.

Retiform or reticular tissue (figs. $81,82,83$ ) is a variety of connective tissue in which the intercellular or ground-substance has largely 
disappeared or is replaced by fluid. There are very few or no elastic fibres in it, but a dense network of white fibres, the meshes of which vary in size, being very small and close in some parts; more open and like areolar tissue in other parts. In some places where the tissue occurs the fibres are enwrapped by flattened branched connective-tissue cells, and until these are removed it is not easy to see the fibres. Chemical differences between the fibres of retiform tissue and those of ordinary areolar tissue have been described by Mall, but microscopically the fibres of the two tissnes are indistinguishable and are found in continuity with one another (see figs. 82, 84). This

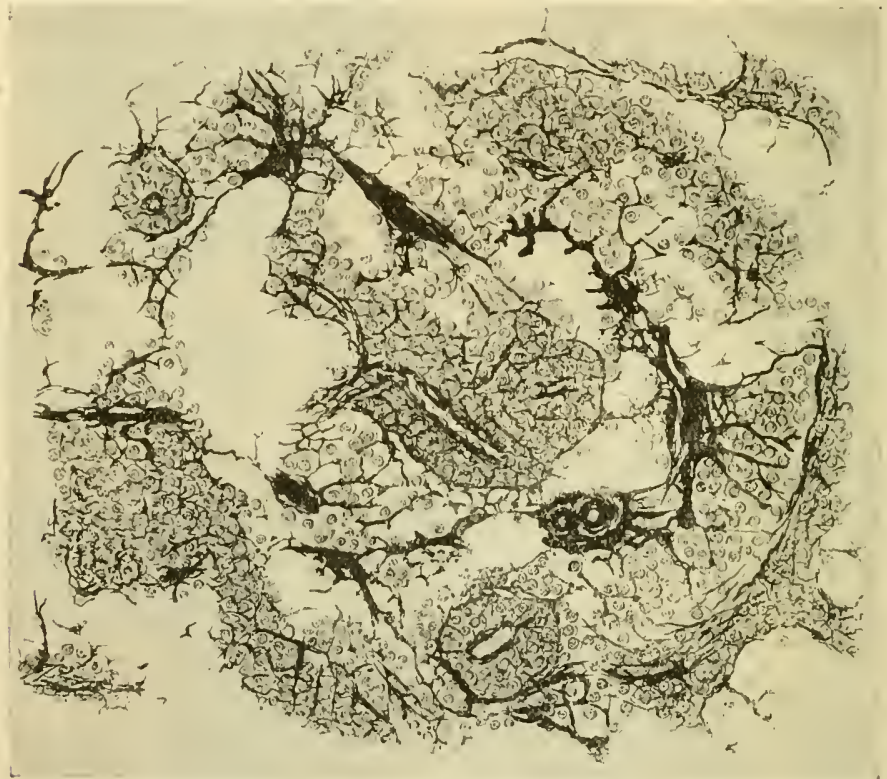

Fig. 84.-LYMPHOID TISSUk OF A LYMPH-GLAND.

tissue forms a fine framework in many organs, supporting the proper elements and extending into all the interstices between the coarser connective tissue bundles. It can best be shown by dissolving the cells of the tissue by tryptic digestion and subsequently staining the fibres forming the reticulum (p. $67, \$ 5)$. In this way it may be demonstrated in lymph-glands, in the spleen, liver, bone-marrow (fig. 83), mucons membranes, and many other parts.

Lymphoid or adenoid tissue is reticular tissue in which the meshes of the network are largely occupied by lymph-corpuseles (fig. 84). This is by far the most common condition of a retiform tissue, and 
is met with in the lymph-glands and allied structures, and also in parts of the alimentary mucous membrane, and in some other situations.

Basement-membranes (membrunce proprice) are homogeneous-looking membranes, which are found forming the surface layers of connectivetissue expansions in many parts, especially where there is a eovering of epithelimm, as on mucons membranes, in secreting glands, and elsewhere. They are generally formed of flattened conneetive-tissue cells joined together to form a membrane; but in some cases they are evidently formed not of cells, but of condensed ground-substanee, and in yet other eases they are composed of elastic substance; the name basement-membrane is therefore used to denote structures of an entirely different nature.

Jelly-like connective tissue, although occurring largely in the embryo, is found only in one situation in the aclult-viz. forming the vitreous humour of the eye. It is composed mainly of soft, fluid, ground-substance, with cells scattereil here and there through it, and with a few fibres which interlace throughout the tissue and confine the fluid of the ground-substance within their meshes; thus conferring upon the tissue its jelly-like character. All embryonie connective-tissue is in the first instance of this jelly-like nature (see p. 82). 


\section{LESSON X.}

\section{THE CONNECTIVE TISSUES (continued).}

\section{ELASTIC TISSLE. FIBROUS TISSUE. DEVELOPIENT OF CONNECTIVE} TISSUE.

1. TEASE ont as finely as possible a small shred of elastic tissue (ligamentum nuclire of the ox or ligamentum subflavm of man) in glycevine and water, slightly coloured by magenta. Cover and cement the preparation. Note the large well-defined fibres constantly branching and uniting with one another. Sketch a small part of the network. Note the existence of bundles of white fibres amongst the elastic fibres.

2. Examine a thin transverse section of ligamentum nuchæ which has been hardened in 2 per cent. solution of bichronate of potash. The section is to be stained with hrmalum and mounted in Canada balsam or dammar by the usual process, or simply in glycerine and water. Observe the grouping of the fibres and their angular shaje.

3. Pinch off the end of the tail of a dead mouse or rat, draw out the long silk-like tendons and put them into salt solution. Take one of the threads, which should be nearly three inches long, and stretch it along a slide, letting the ends dry firmly to the glass but keeping the middle part wet. Put a piece of hair on either side and corer in salt solution. Observe with a high power the fine wavy fibrillation of the tendon. Draw. Now run dilute acetic acid $(0.75$ per cent.) under the cover-glass, watch the tendon where it is becoming swollen or the acetic acid. Notice the oblong nucleated cells comiug intu view between the tendon-bnndles. sketch three or four cells in a low. Lastly, lift the cover-glass, wash away the acid with distilled water, place a drop of Ehrlich's hrmatoxylin or carmalum solution on the tendons, and leave the preparation until it is deeply stained; then wash away the stain aud mount the preparation in faintly acidulated glycerine.

4. Take another long piece of tendon, and after washing it in distilled water, stretch it upon a slide as before, fixing the ends by allowing them to dry on to the slide. Put a drop of nitrate of silver solution (1 per cent.) on the niddle of the tendon, and leare it on for five minutes. Then wash off the silver nitrate with distillerl water, and expose the slide to direct sunlight. In a very few numutes the silvered part of the tenclon will be brown. As soon as this is the case, dehydrate the tendon with absolute alcohol in situ upon the slide, run off the alcohol, and at once put a drop of clove oil on the preparation. In a minute or two the clove oil can be replaced by xylol balsam or dammar and the preparation covered.

5. Stain, with magenta solution, a thin section of a tendon which has been hardened in 70 per cent. alcobol. Mount in dilute grlycerine and cement at once.

6. For developing comnective tissue study sections of the umbilical cord at different periods. Fix with formol. Stain with acid fuchsine and hæmatoxylin. 
Elastic tissue is a variety of connective tissue in which the elastic fibres preponderate. It is found most characteristically in the ligamentum nuchie of quadrupeds and the ligamenta subflava of the vertebre, but the connective tissue of other parts may also have a

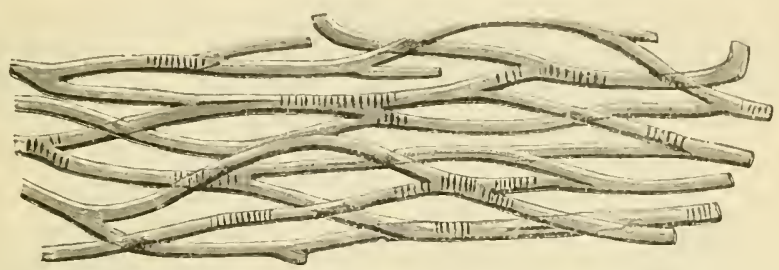

Fig. 85. -Elastic fibres From the Liganentum NuCh. OF THF ox, SHOWING TRANSVERSE MARKINGS (IN THE FIBRES.

considerable development of elastic fibres. It occurs in an almost pure form in the walls of the air-tubes, and uniting the cartilages of the larynx. It also enters largely into the formation of the lungs and of the walls of the blood-vessels, especially the arteries.

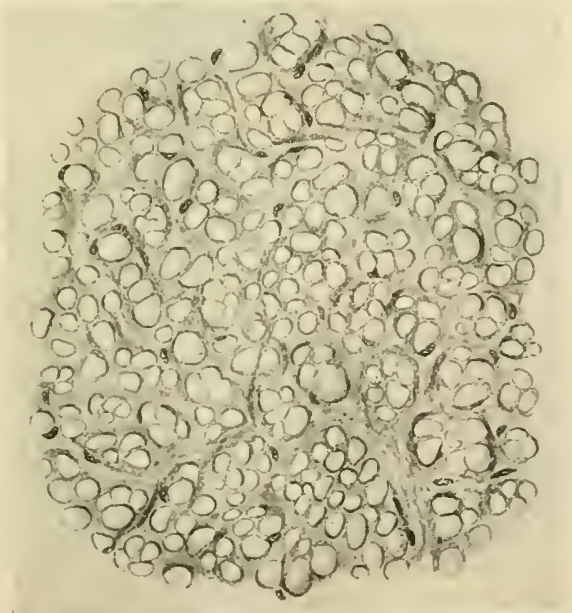

Fig. 86.-CROSs-SECTION OF ELASTIC FIBRES FROM THE LIGAMENTUM NUCH OF THE OX.

In the ligamentum nuchæ most of the fibres are very large (figs. $85,86)$. They often exhibit cross markings or even transverse clefts. When dragged asunder, they break sharply across. They constantly branch and unite, so as to form a close network. In transverse section they are seen to be separated into small groups or bundles (fig. 86) by intervening septa of areolar tissue. 
Elastic tissue does not always take the form of fibres, but may occur as membranes (e.g. in the blood-ressels). Sometimes the fibres are very small, but their microscopic and chemical characters are always very marked (see p. 70).

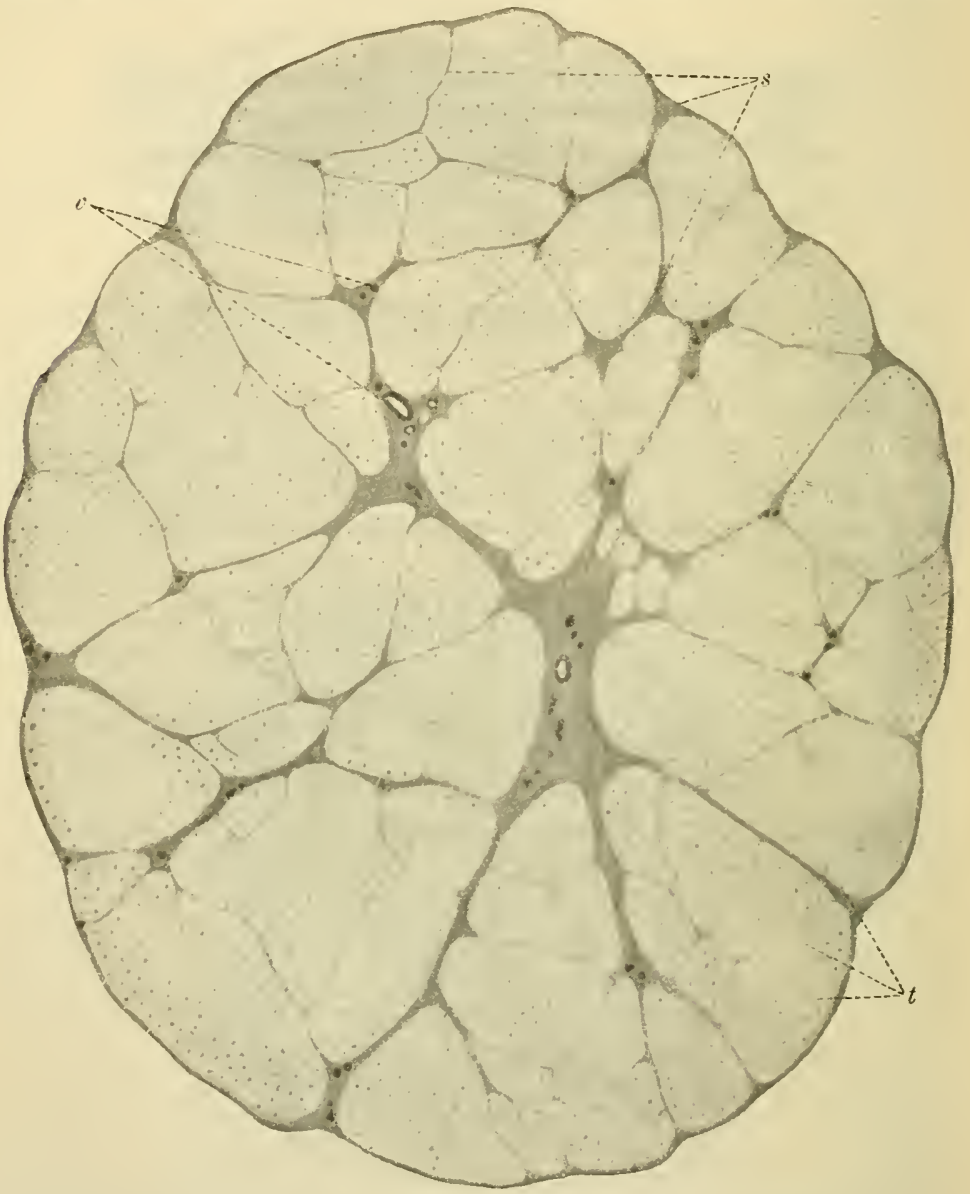

Fig. 87.-Section of teNdon, human. (Sobotta.) $\times 32$.

$t$, tendon-bundles; $s$, septa of areolar tissue; $v$, vessels.

Fibrous tissue is almost wholly made up of bundles of white fibres running in a determinate direction. These again are collected into larger bundles, which give the fibrous appearance to the tissue. The bundles are constantly uniting with one another in their course, although their component fibres remain perfectly distinct.

The interspaces between the larger bundles are occupied by areolar 
tissue (fig. S7, s; fig. $88, c, d, e$ ) in which the blood-vessels and lymphatics of the fibrous tissue are eouveyed. The interstices between the smallest bundles are oceupied by rows of lamellar conucetive-tissuc

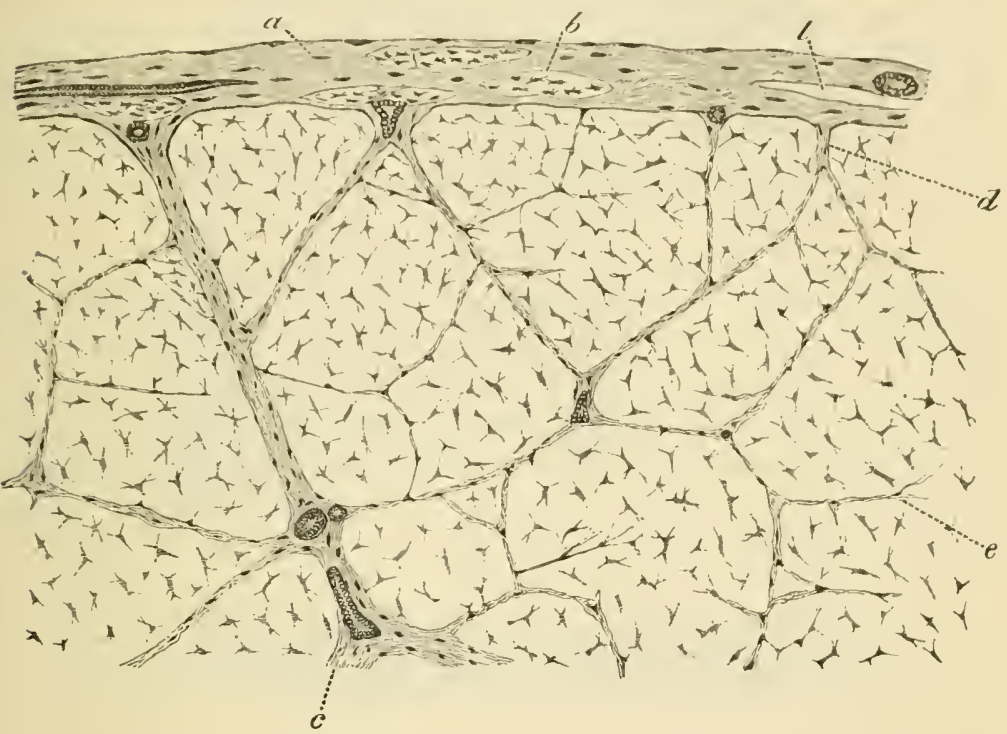

Fig. 88. - Part of a large texdon ix transverse section. More highly magnified.

$a$, areolar sheath of the tendon, with the fibres for the most part running transversely ; but with two or three longitudinal bundles, $b ; l$, lymphatic cleft in the sheath ; immediately over it a blood-vessel is secn cut across, and on the uther side of the figure a small artery is shown cut longitudinally ; $e$, large sej,tum of areolar tissue ; $d$, smaller septum; $e$, still smaller septum. The irregularly stellate bodies are the tendon-cells in section.

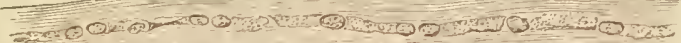

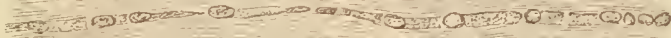

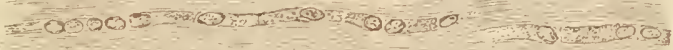

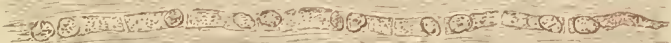

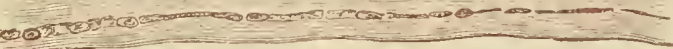

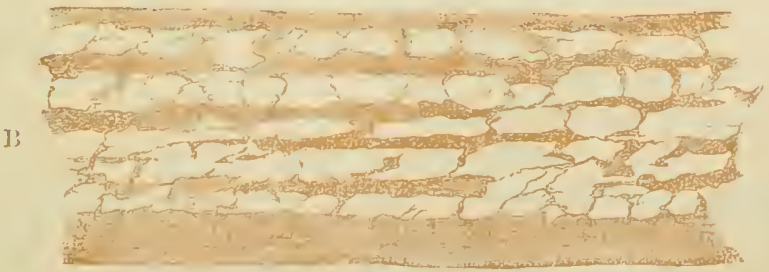

FIG. 89. - TENDON OF MOUSE'S TAIL (175 diameters); SHOWING CHAINS OF' CELLS BETWEEN THE TENDON-BUNDLES.

A, stained with hæmatoxylin. B, stained with silver nitrate, showing the cell-spaces. 
corpuscles (tendon-cells), which, from being squeezed up between three or more bundles, become flattened out in two or three directions. In transverse section the cells appear somewhat stellate (fig. 88), but when secn on the flat they appear lamellar (fig. 89), and from this aspect their general shape is square or oblong. They lie, as before said, in rows between the tendon-bundles, and the nuclei of adjacent cells are placed opposite one another in pairs (fig. 90). The cell-spaces. correspond in general figure and arrangement to the cells which occupy them.

Fibrous tissue forms the tendons and ligaments, and also certain membranes, such as the dura mater, the fibrous pericardium, the fasciæ of the limbs, the fibrons covering of certain organs, etc. It is found wherever great strength, combined with flexibility, is concerned. It receives a few blood-ressels, disposed longitudinally for the most part, and contains many lymphatics. Both blood-ressels and lymphatics run in the areolar tissue which separates and surrounds the tendonbundles. Tendons and ligaments also receive nerve-fibres, which, in

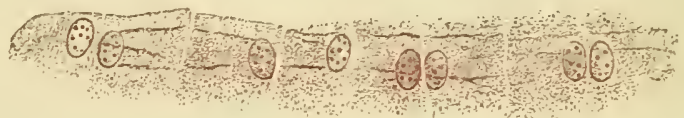

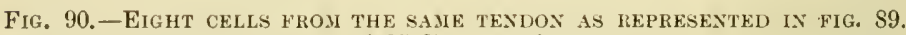
( $\$ 25$ diameters.)

The dark lines on the surface of the cells are the optical sections of lamellar extensions directed towards or away from the observer.

some cases, end in localised ramifications within fusiform enlargements of the tendon-bundles (organs of Golgi), while others terminate in cnd-bulbs or in simple Pacinian corpuscles. These will be described along with the modes of ending of nerve-fibres.

Development of connective tissue.-Connective tissue is developed in and from the cells of the mesoderm (mesenchyme) of the embryo. In those parts which are to form connective tissue, there may frequently be seen a clear space separating the cell-layers which are already formed, this clear space being permeated with fibres which appear to be produced from the cells bounding the space. Presently branching mesenchyme cells, which are derived from the bounding celllayers, are found forming a syncytium within the clcar space (fig. 91, m). In the meshes of the reticular syncytium is a muco-albuminous semifluid intercellular substance (ground-substance). The connective-tissue fibres, both white and elastic, are deposited in this ground-substance, the elastic substance appearing in the form of granules (fig. 95, g), which subsequently become connected together into elastic fibres or 


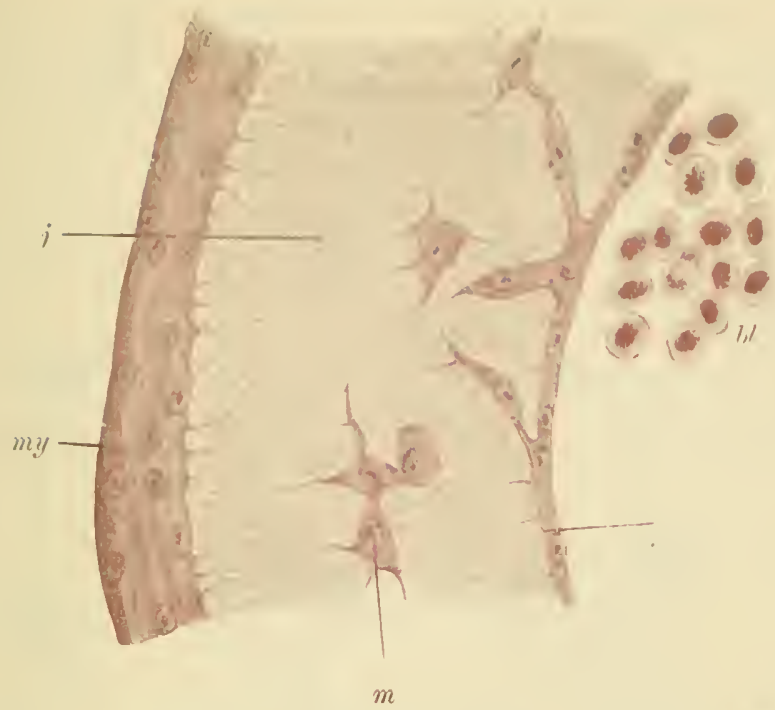

Fig. 91. - Developing CONNective tissue in heart OF CHICK-EMBrio of 48 HOURs. (Szili.)

$m y$, cells forming myocardium; $j$, jelly formed of reticulum with enclosed fluid; $e$, endothelium (mesothelium) of heart; $m$, mesenchyme cells in jelly; $b l$, blood-corpuscles.

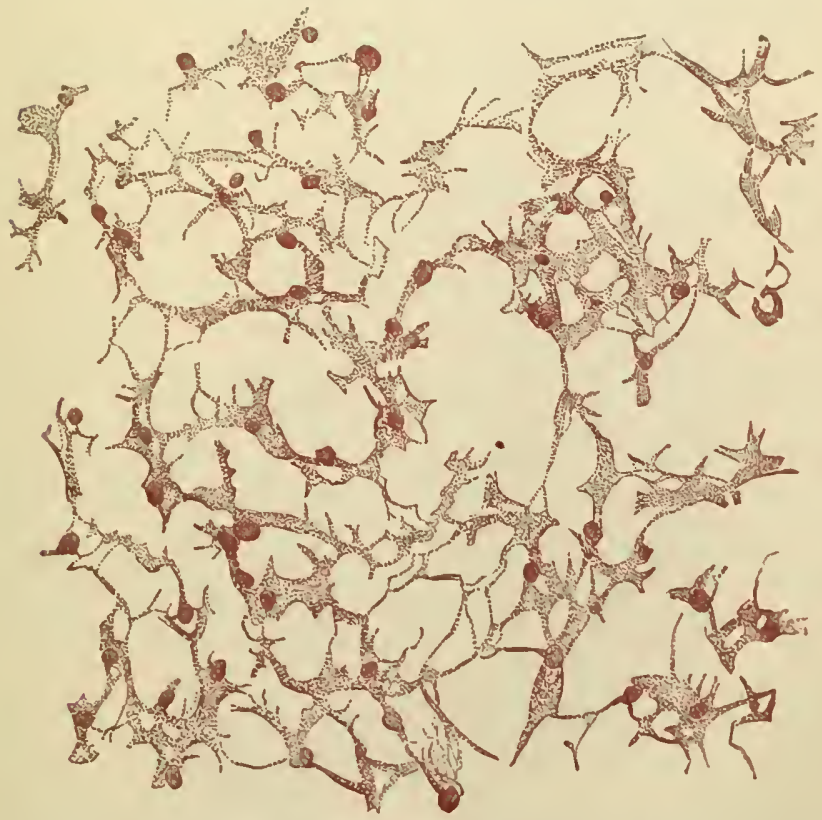

Fig. 92.-Developing CoNNectite tissue From the UMBILICAL CORD OF A HUMAN EMBRYO 21 MM. LONG. (Minot.) $\times 540$. 


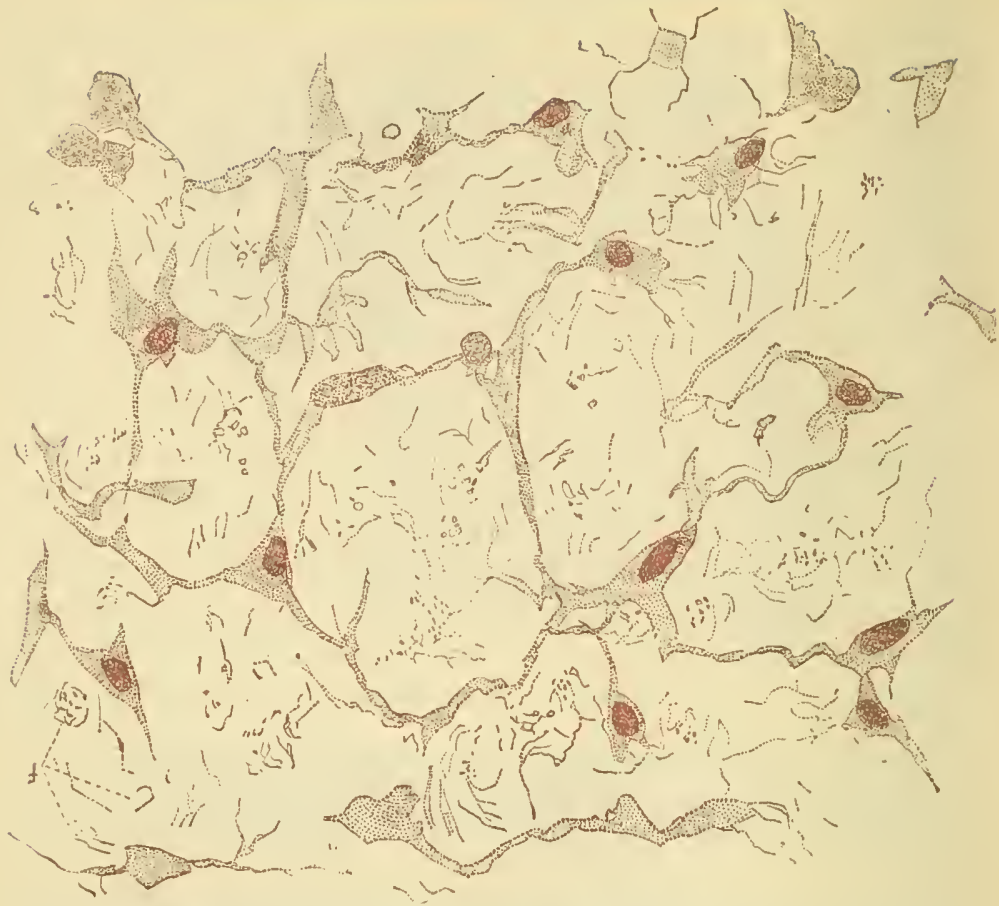

Fig. 93.-Developing conNective tissue from the oMbilical cord of a THREE MONTHS' hUMAN EMBRTO. (Minot.) $\times 511$.

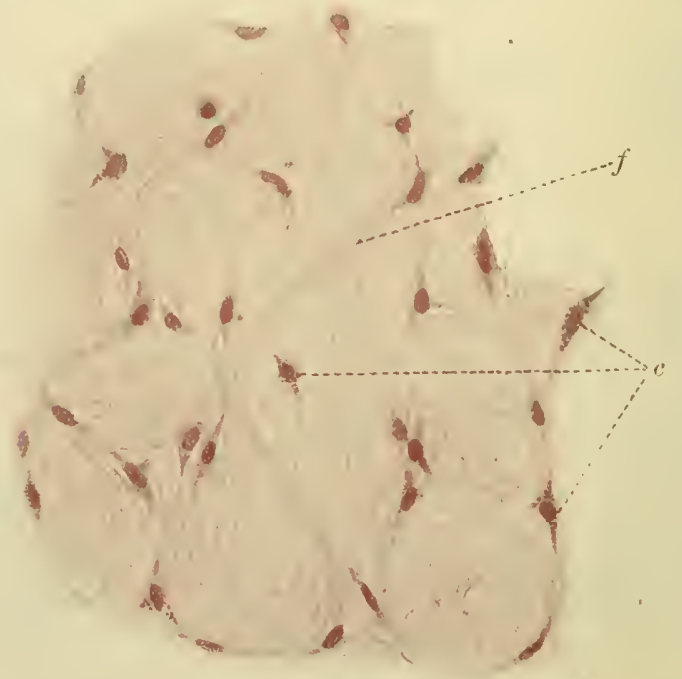

Fig. 94. -Jelly OF WhaRTON FROM UMBILICAL CORD OF NEW-BORN CHILD. (Sobotta.) $\times 280$.

$f$, connective-tissue fibres; $c$, cells. 
lamine, as the case may be, the white fibres appearing at first in the form of very fine bundles, which afterwards become gradually larger (fig. 93); so that in fibrous tissue the whole ground-substance is eventually pervaded by the bundles, and the cells of the tissue become squeezed up into the intervals between them. Before any considerable development of fibres has taken place, the embryonic connective tissue has a jelly-like appearance; in this form it oceurs in the umbilical cord, where it is known as the jelly of Wharton (fig. 94).

There has been always a considerable difference of opinion as to the origin of the fibres of connective tissne, some histologists holding that they are formed within the protoplasm of cells, which gradually lose

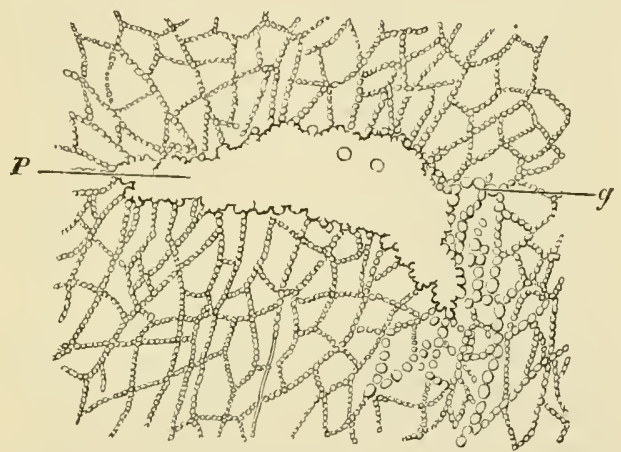

Fig. 95.-Development of Elastic tissue by Deposition of Fine grandles. (kanvier.)

$g$, fibres being formed of rows of 'elastin' granules; $p$, flat plate-like expansion of elastic substance formed by the fusion of 'elastin' granules.

their cell-characters as the fibres become developed within them; others taking the view that the fibres, both white and elastic, are extracellular formations. While there is no doubt that they are produced under the influence of the cells, for they first appear in close proximity to those structures, it scems on the whole probable that the fibres are deposited in the ground-substance and not actually in the cell-protoplasm, so that they are rather to be looked upon, like the ground-substance itself, as formed by a process of secretion than by one of direct cell-transformation. 


\section{LESSON XI.}

\section{THE CONNECTIVE TISSUES (continued).}

\section{ARTICULAR CARTILAGE. SYNOVIAL MEMBRANES.}

1. Cut two or three very thin tangential slices of the fresh cartilage of a joint, mount them in salt solution, and examine with the high power. Observe the form and grouping of the cells. Look at the thin edge of the section for spaces fiom which the cells have dropperl out. Measure two or three cells and their nuclei, and sketch one or two groups. Now replace the salt solution by water and set the preparation aside for a little while. On again examining it, many of the cartilage cells will be found to have retracted away from their containing capsules.

2. Make other sections of the cartilage (1) from near the middle, (2) from near the edge. Place the sections for two or three minutes in acetic acid (1 per cent.), wash them with water, and stain with dilute hæmalum or carnalum solution. When stained monnt in dilute glycerine and cement the cover-glass. In (2) look for branched cartilage cells.

3. Study vertical sections of articular cartilage from an end of bone which has been fixed and decalcified, and mount the sections in glycerine and water, or, after staining with hæmalım, in dammar or xylol balsam. Sketch the arrangement of the cells in the different layers.

4. Brush a fresh joint with distilled water; drop 1 per cent. nitrate of silver solution over it; after five minutes wash away the nitrate of silver and expose in water to rlirect sunlight. When browned, place in spirit for half an hour or more, and then with a razor wetted with spirit cut thin sections from the surface and mount in xylol balsam or dammar after passing through clove oil. The cells and cell-spaces show white in the brown ground-substance.

5. To study the structure of the synovial membrane mount other slices from the silvered preparation of the joint (\$4) just beyond the limits of the articular cartilage, and also look for small fringerl projections of the membrane. Snip then off with scissors and mount as before.

6. The superficial flexor tendons of the foot of the ox or sheep run in grooves formed by the deep flexors, and these grooves are lined, and the tendons which pass through them are covered by vaginal synovial membranes. To show the structure of these treat one of the superficial flexor tendons with silver nitrate in the nımner recommended for the joint, $\$ 4$, and after hardening in spirit cut sections from the surface and mount them in balsam or dammar varnish.

Cartilage or gristle is a translucent bluish-white tissue, firm, and at the same time elastic, and for the most part found in connection with bones of the skeleton, most of which are in the embryo at first represented entirely by cartilage. Three chief varieties of cartilage are 
distinguished. In one, which is termed liyaline, the matrix or groundsubstance is almost elear, and free from obvious fibres; in the other two, which are termed filmo-cartilage, the matrix is everywhere pervaded by connective-tissue fibres. When these are of the white variety, the tissue is white fitro-curtiluye; when they are elastic fibres, it is yellow or elustic fibro-curtiluge.

Hyaline cartilage oceurs principally in two situations-namely (1) covering the ends of the bones in the joints, where it is known as articular cartilage; and (2) forming the rib-eartilages, where it is known

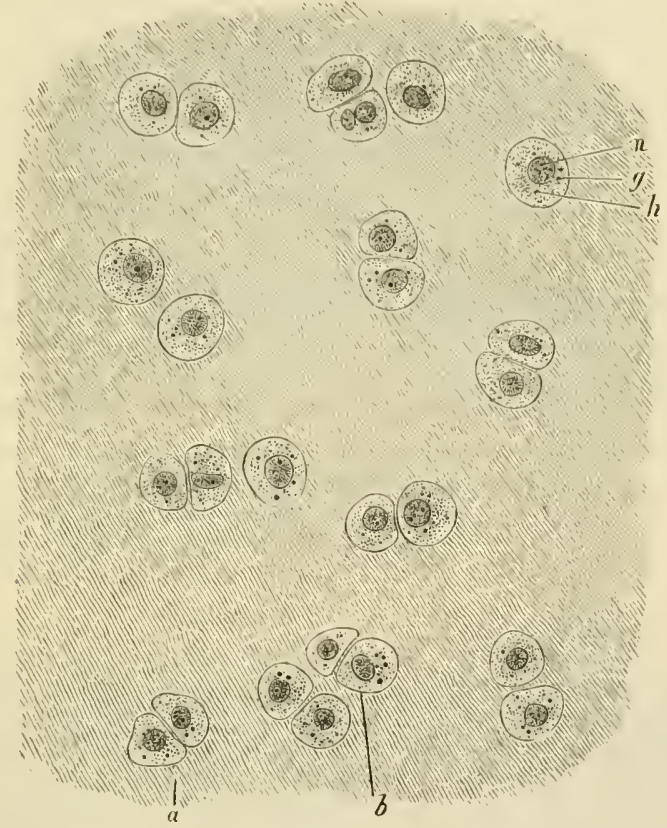

Fig. 96. - Articular cartilage from hean of Metatarsal bone of aupUTATED FOOT, hUMAN (OSMIC ACID PREPARATION). THE CELL-BOdies ENTIRELY FILL THE SPACES IN THE MATRIX. (310 diameters.)

$a$, group of two cclls; $b$, group of four cells; $h$, protoplasm of cell, with $g$, fatty granules; $n$, nucleus.

as costal cartilage. It also forms the cartilages of the nose, of the external auditory meatus (but not the pinna), most of those of the larynx, and the eartilages of the windpipe; in these places it serves to maintain the shape and patency of the orifices and tubes.

Articular cartilage.-The cells of articular cartilage are generally seattered in groups of two or four throughout the matrix (fig. 96). The latter is free from obvious fibres, exeept at the extreme edge of the cartilage, where the connective-tissue fibres from the synovial 
membrane extend into it; and here also the cartilage-cells are often branched, and offer transitions to the branched connective-tissue corpuscles of that membrane (transitional cartilage, fig. 97). By long maceration in brine, however, evidence of a fibrous structure may be

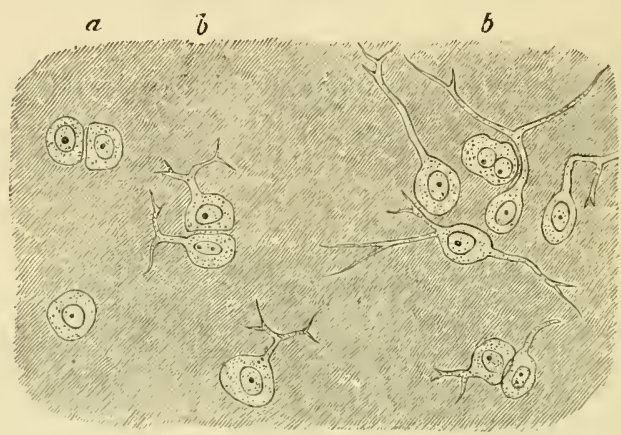

FIG, 97.-BORDER OF ARTICULAR CARTILAGE SHOWING TRANSITION OF CARTILAGE CELLS INTO CONNECTIVE-TISSUE CORPUSCLES OF SYNOVIAL MEMBRANE. From head of metatarsal bone, hUMAN. (About 340 diameters.)

$a$, ordinary cartilage-cells ; $b, b$, with branching processes.

obtained, even in the matrix of true hyaline cartilage. Some histologists also describe fine communications in the matrix uniting the cartilage-cells with one another, but these are of doubtful occurrence in vertebrate cartilage, although they

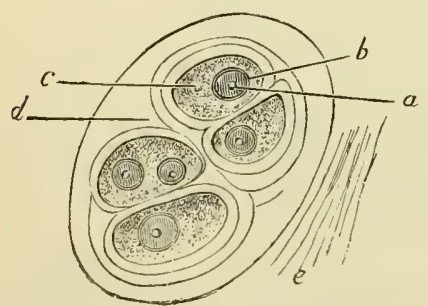

Fig. 98.-A GROUP OF CARTILAGE-CELLS SHOWING THE CAPSULAR OUTLINES IN THE MATRIX SURROUNIING THE GROUP. (Rauvier.)

$a$, nucleolus ; $b$, nucleus; $c$, cytoplasm of a ccll $; d$, capsular lines in pericellular matrix ; $e$, fibrils in cartilage matrix. unquestionably exist in the cartilage of cephalopods.

The matrix immediately around the cartilage-cells is often marked off from the rest by a concentric line or lines, this part of the matrix, which is the latest formed, being known as the capsule of the cell (fig. 98). The cells are bluntly angular in form, the sides opposite to one another in the groups being generally flattened. The protoplasm is very clear, but it may contain droplets of fat; and with a high power fine interlacing filaments and granules have been observed in it. During life the protoplasm entirely fills the cavity or cell-space which it occupies in the matrix; but after death, and in consequence of the action of water and other agents, it tends to shrink away from the capsule. The nucleus is round, and shows the usual intranuclear network. 
In vertical section (fig. 99) the deeper eell groups (c) are seen to be arranged vertically to the surface, the more superficial ones $(a)$ parallel to the surfice; whilst in an intermediate zone the groups are irregu-

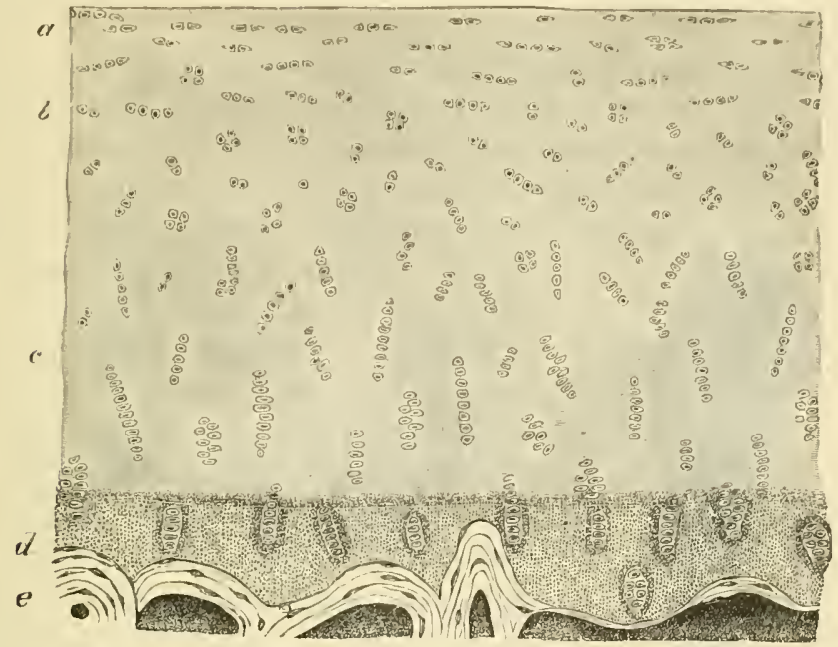

Fig. 99.--VERTICAL SECTION OF ARTICULAR CARTILAgE COVERING THE LOWER END OF THE TIBIA, HUMAN. (Magnified about 30 diameters.)

$a$, cells and ccll-groups flattened conformably with the surface; $b$, cell-groups irregu. larly arranged; $c$, cell-groups disposed perpendicularly to the surface; $d$, layer of calcified cartilage ; $e$, bone.

A

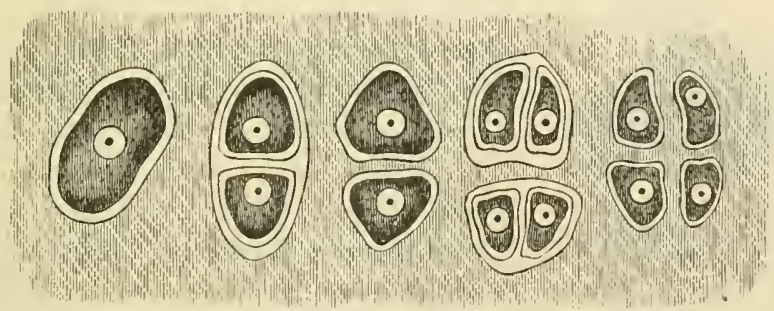

Fig. 100.-Plan of the nultiplication of cells of cartilage. (Sharpey.) $A$, cell in its capsule; $B$, dirided into two, each with a capsule; $C$, primary capsulc disappeared, secondary capsules coherent with matrix; D, tertiary division; $\mathrm{E}$, secondary capsules disappeared, tertiary cohercnt with matrix.

larly disposed $(b)$. In the deepest part of the cartilage, next to the bone, there is often a deposit of calcareous salts in the matrix (calcified cartilage, $d$ ).

The disposition of the cells of cartilage in groups of two, four, eight, etc., is apparently due to the fact that these groups have originated 
from the division of a single cell first into two, and these again into two, and so on (fig. 100). The division of the cartilage-cell, like that of most other cells, is mitotic.

It would seem that the matrix is formed of successive portions, which are deposited around each cartilage-cell as the so-called 'capsules,' each newly formed portion soon blending in its turn with the previously formed matrix, whilst a new capsule is formed within it. The most newly formed portions of matrix stain with hæmatoxylin more deeply than the rest, and in some cartilages this gives the

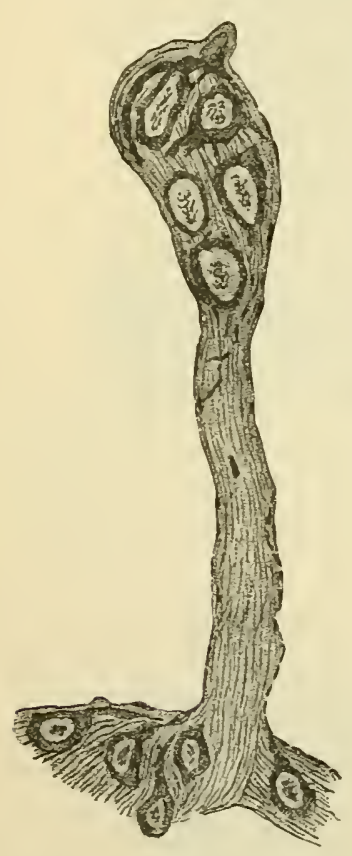

FIg. 101.- Til.les of STxotiaL MEMBRANE. (Hammar.) appearance of rounded balls of darkly stained matter surrounding each cell or cell-group (chondrin-balls, Mörner).

Embryonic cartilage is characterised by the cells being usually more sharply angular and irregular; they are even in some cases markedly branched, like those which occur at the junction of cartilage and synovial membrane in the adult. The cells are also more closely packed, the matrix being in relatively less amount than in later life.

Development. - Cartilage is formed in the embryo from mesenchyme similar to that which gives origin to other forms of connective-tissue. Each cell forms a capsule around itself, and the blended capsules compose the first matrix. Cartilage sometimes remains in this condition thronghout life; it is then termed parenchymatous cartilage. This can be seen in the mouse's ear; where also the cartilage cells become filled with fat. Cartilage grows at first partly by interstitial expansion (accompanied by cell multiplication and by formation around and between the cells of intercellular substance), partly by apposition at the perichondrium, the connective tissue becoming here transformed into cartilage. At a later period of growth the increase in size and change in shape of cartilages are due almost entirely to the agency of the perichondrium.

\section{Sycovial Membianes.}

The synovial membranes are often compared with the serous membranes. They are indeed, like the latter, connective-tissue 
membranes which bound closed eavities moistened with fluid, but they are not connected with the lymphatic system, nor is the fluid (synovia) which moistens them of the nature of lymph. Moreover, there is either no endothelial liming, or it occurs only in patches, in place of the continuous lining which we find in the serons membranes. Long villus-like projections ocenr in many parts; they are often corered by small rounded cells, and probably serve to extend the surface for the secretion of synovia. The blood-vessels of synovial membranes are numerous, and approach close to the inner surface of the membrane. They are well seen in preparations from an injected limb. 


\section{LESSON XII.}

\section{THE CONYECTIEE TISSUES (continued).}

\section{COSTAL CARTILAGE. FIBRO-CARTILAGE.}

1. MAKE transrerse and tangential sections of a rib-cartilage, which may either be fresh. or may hare been preserved in spirit or formol. Stain them with hæmalum or carmalum (if fresh. after treatment with acetic acid as in Lesson XI. $\$ 2$, or ther may be placed for an hour or two in 5 p.c. osmic acid), and mount in glycerine. Sketch a part of a transwerse section under a low power and a cell-group from one of the tangential sections under a high power. Notice especially the arrangement of the cells, somewhat concentric near the surface but radial near the centre. The costal cartilages tend to become ossified near the mirldle in most animals, but in man when ossification occurs it is the superficial layer which is invaded.

2. Make sections of the cartilage of the external ear (pinna), either fresh or after hardening in alcohol. Nlount in dilute glycerine faintly coloured with magenta, or stain with orcein and mount in balsam. If from the $o x$, notice the very large reticulating elastic fibres in the matrix. Notice also the isolated granules of elastin, and around the cartilage-cells an area of clear ground-substance. If from the mouse or rat there is very little matrix and no elastic fibres, and the cells are almost in contact (parenchymatous cartilage); they also contain fat (staining with osmic acid).

3. Mount a section of the epiglottis in the same way. Notice the closer network of much finer fibres in its cartilage.

4. Cut sections of white fibro-cartilage (intervertebral disk or semilumar cartilage of kuee), which has been hardened in picric acid, followed by spirit, or in spirit only. Stain the sections with dilute hremalum or carmalum. Mount in dilute alycerine. Observe the wary fibres in the matrix and the cartilage-cells lying in clear areas often concentrically striated. Look for branched cartilage-cells. sketch three or four cells and the adjoining fibrous matrix.

Costal cartilage.--In the costal cartilages the matrix is not always so clcar as in the cartilages of the joints, for it more often happens that fibres become developed in it. The cells are generally larger and more angular than those of articular cartilage, and collected into larger groups (fig. 102). Near the circumference, and under the perichondrium or fibrous corering of the cartilage, they are flattened and parallel to the surface, but in the deeper parts they have a more irregular or a radiated arrangement. They frequently contain fat. The cartilages of the larynx and windpipe and of the nose resemble on the whole the costal cartilages, but the 
study of them may be deferred until the organs where they oceur are dealt with.

Elastic or yellow fibro-cartilage occurs in only a few situations. These are, the cartilage of the external ear and that of the Eustachian tube, and the epiglottis and cartilages of Santorini of the larynx. The matrix is everywhere pervaded with well-defined branching fibres, which unite with one another to form a close network (figs. 103, 104). These fibres resist the action of acetic acid, and are stained deeply

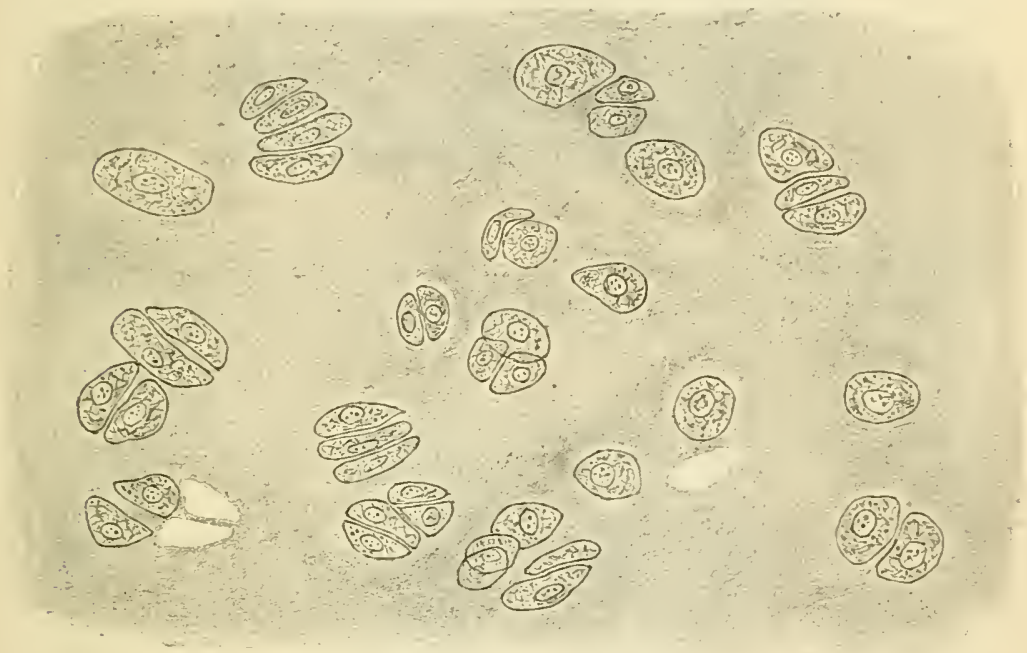

Fig. 102.-Section of RiB-CARTILAGe, SHOWINg CELLS ANI CELL-GROCPS IN AN INDISTINCTLY FIBROES MATRIX.

Two or three empty cell-spaces are seen from which the cells have dropped out in preparing the section.

by magenta; they are evidently elastic fibres. In the ox they are very large, but smaller in man, especially in the cartilage of the epiglottis. They appear to be developed, as with elastic tissue elsewhere (see p. 82), by the deposition of granules of elastin in the matrix, which at first lie singly, but afterwards become joined to form the fibres.

White fibro-cartilage is found wherever great strength combined with a certain amount of rigidity is required: thus we frequently find fibro-cartilage joining bones together, as in the intervertebral disks and other symphyses. But in these cases the part in contact with the bone is always hyaline cartilage, which passes gradually into the fibro-cartilage forming the bulk of the symphysis. Fibrocartilage is often found lining grooves in which tendons run, 


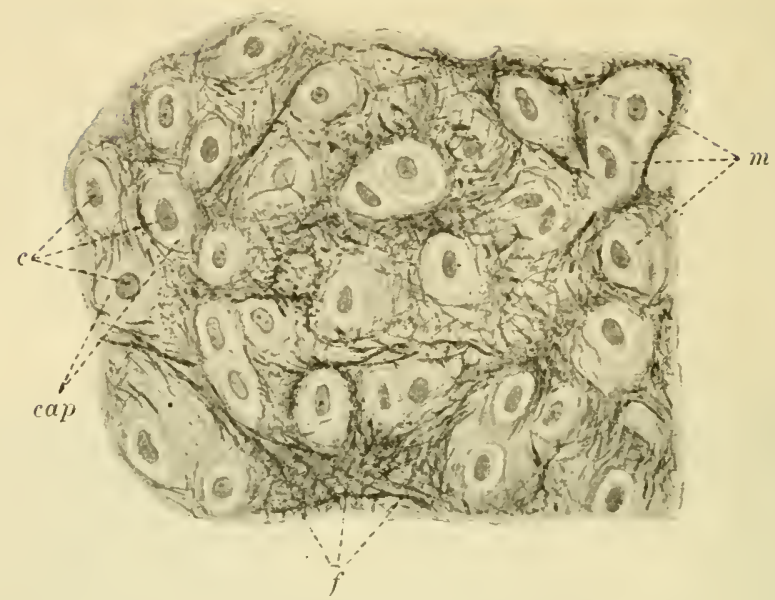

Fig. 103.-Sectios of elastic Cartilage OF Ear, hUMax. (Sobotta.) $\times 230$. $c$, cartilage cells; cap, their capsules; $m$, clear matrix around cells and cell-groups; $f$, elastic fibres.

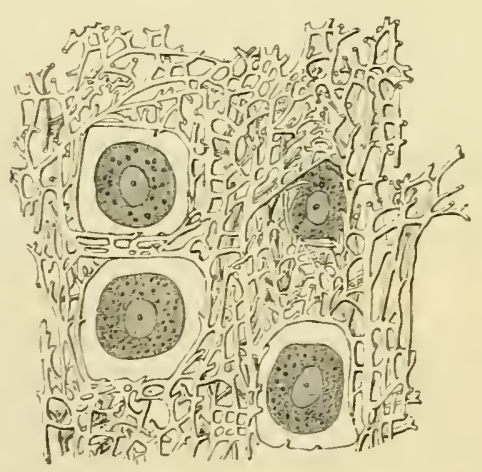

Fig. 104.-Section of the elastic Cartilage of the Ear. (R. Hertwig.) Highly magnified.

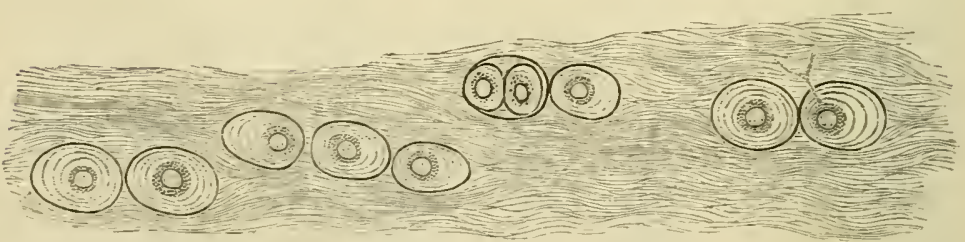

FIG. 105. -WHITE FIBRO-CARTILAGE FROM AN INTERTERTEBRAL DISK, HCMAN. Highly magnified.

The concentric lines around the cells indicate the limits of deposit of successive capsules. One of the cells has a forked frocess which extends beyond the byaline area surrounding the cell, amongst the fibrcs of the general matrix. 
and it may be found in the tendons themselves. It is also employed to deepen eup-shaped articular surfaces; and in the case of the interarticular cartilages, such as those of the knee and lower jaw, to allow greater freedom of movement whilst diminishing the liability to dislocation. Under the microscope white filbro-cartilage looks very like fibrous tissue, but its cells are eartilage cells, not tendon-cells (fig. 105). They are rounded or bluntly angular and surrounded by a concentrically striated area of clear cartilage-matrix. In some parts of the intervertebral disk many of the cells are branched, and may be looked upon as transitional forms to connective-tissue corpuscles. 


\section{LESSON XIII.}

\section{THE CONAECTIVE TISSUES (continued).}

\section{BONE; STRUCTLRE AND DEVELOPMENT.}

1. Is thin sections of hard bone made by grinding, ${ }^{1}$ observe the Haversian canals, lamellæ, lacumæ, canaliculi, etc. IIake a sketch first under a low and afterwards under a high power.

2. With fine forceps strip off a thin shred from the superficial layers of a bone which has been decalcified in 5 p.c. commercial sulphurous acid and afterwards washed with water for 24 hours. It may be kept in dilute alcohol. Mount the shred in water. Observe the fibrous structure of the lamellie. Look for perforating fibres or the holes from which they have been dragged out. Sketch a small piece of the thin eige of a lamella.

3. Stain with dilnte magenta and hæmalum solution, or with methyl-blue and eosin, very thin sections of compact bone which has been fixed with 10 p.c. formol (1 to 3 days) and then decalcified in sulphurons acid as above. Mount in dilute glycerine, cementing at once. Look for fibres of Sharpey piercing the circumferential lamellæ. The elastic perforating fibres are more darkly stained than the others. Notice the stainerl nuclei of the bonecorpuscles in the lacunæ. In the thinnest parts of the sections try to make out the blood-ressels and other structures in the Haversian canals.

4. Mount in xylol balsam or dammar a section of a feetal lower jaw which has been stained in bulk and embedded in paraffin. Find the part where the lower jaw-bone is becoming ossified, and carefully study the appearance which it presents. The bone is prolonged in the form of osteogenic fibres which are covered with osteoblasts.

5. Intramembranous ossification may also be studied in the parietal bone of a foetus which has been preserved in Müller's fluid. A piece of the growing edge is scraped or brushed free from its investing membranes, and from most of the cells which cover and conceal it, and is mounted in glycerine with or without previous staining with carmalum.

6. Mount in balsam or dammar sections of a foetal limb (which may have been stained in bulk). The bones will be found in different stages of ossification, those of the digits being least developed. Make sketches illustrating the three chief stages of endochondral ossification. Notice the peculiar terminal ossification of the third phalanx.

Bone is a connective tissue in which the ground-substance is impregnated with salts of lime, chiefly phosphate, these salts constituting about two-thirds of the weight of the bone. When bones are macerated this earthy matter prevents the putrefaction of the animal matter. When bones are calcined they lose one-third of their weight, owing to the destruction of the animal matter; when steeped in acid

${ }^{1}$ It is best to purchase these. 
the earthy salts are dissolved and only the animal matter is left. This, like areolar and fibrous tissue, is converted into gelatine by boiling.

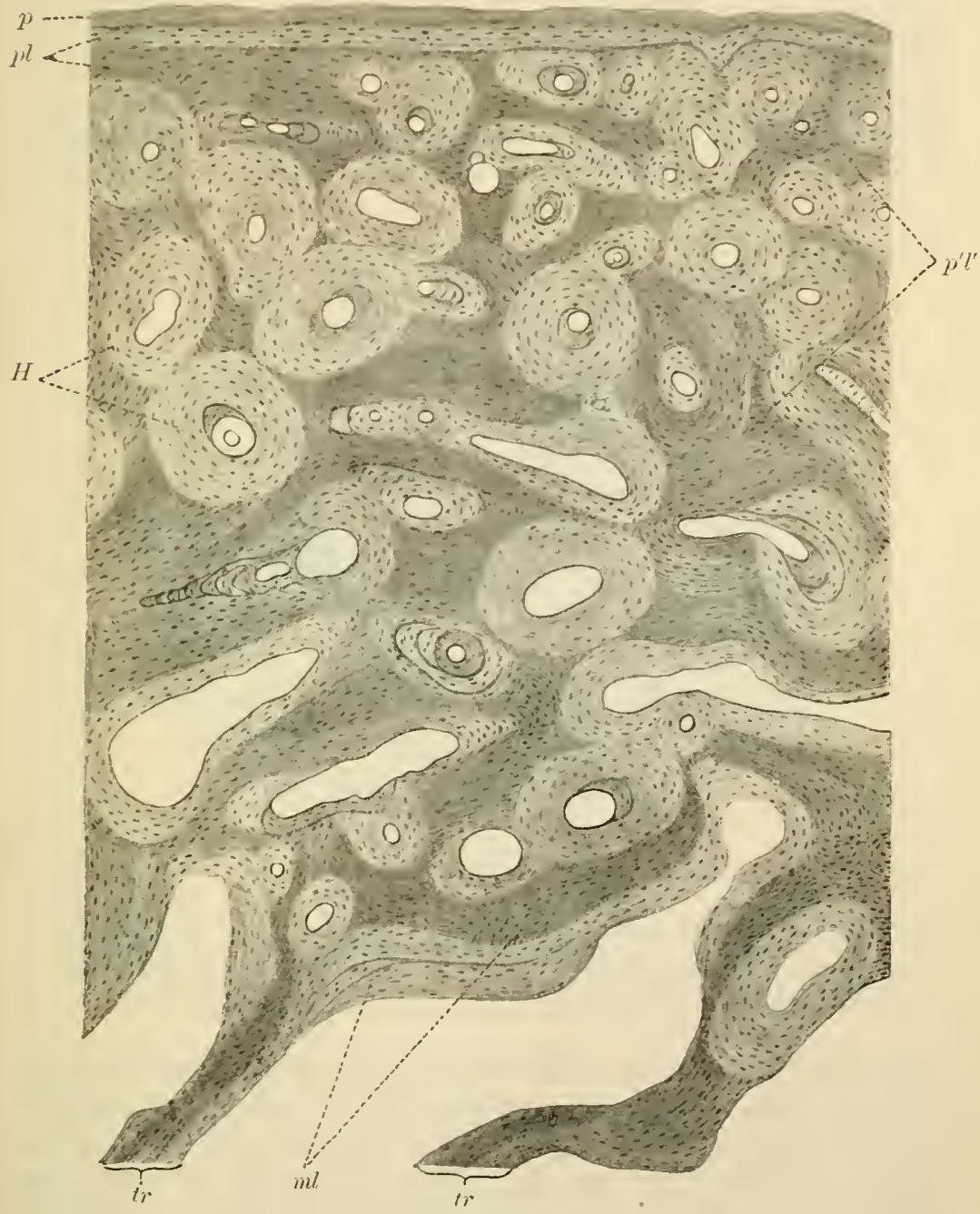

Fig. 106.-Section of a decalcified humas Radies. (Sobotta.) $\times 48$.

$\varphi$, periosteum; $p l$, periosteal bony lamellæ; ' $p^{\prime} l$, deeply seated lamellæ parallel witl periosteal surface; $H$, Harersian systenis; $t r$, $t r$, trabeculæ of spongy substance; ml, lamellæ bounding medullary spaces.

Bony tissue is either compact or cancellated. Compact bone is dense, like ivory; cancellated is spongy with obvious interstices. The outer layers of all bones are compact, and the inner part is generally 
cancellated, but the shaft of a long bone is almost entirely made up of compact substance, except along the centre, which is hollow and filled with marrow. The interstices of cancellated bone are also occupied by nuarrow. Externally bones are covered except at the joints by a vascular fibrous membrane, the periosteum.

True bone is always made up of lamelle, and these again are composed of fine fibres lying in a calcified ground-substance. Between the lamellie are branched cells, the bone-corpuscles, which lie in cell-spaces or lacunc. The ramified passages which contain the cell-processes are termed canaticuli.

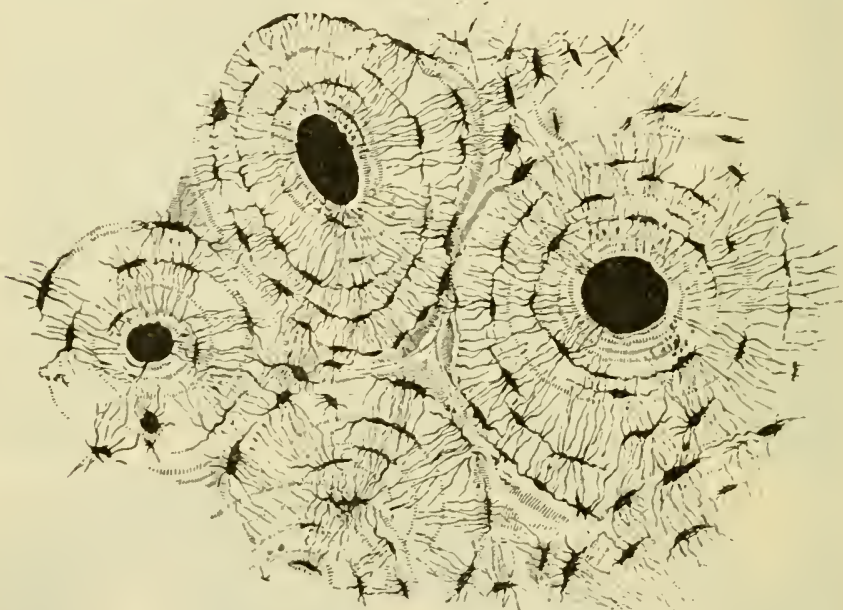

Fig. 107.-Trassterse section of compact tisste (of hejercs). (Sharpey.) Magnified about 150 diameters.

Thrce of the Harersian canals are sec1, with their eoncentric rings; ulso the lacunx, with the canaliculi extending from them across the dircction of the lamellx. The llaversian apertures bad become filled with air and debris in grinding down the section, and therefore alpcar black in the figure, which represents the object as viewed by transmitted liglit.

In cancellated bone the blood-vessels run in the interstices supported by the marrow. In compact bone they are contained in little canalsthe Haversian canals - which everywhere pervade the bone. These canals are about $0.05 \mathrm{~mm} .\left(\frac{1}{500}\right.$ inch) in diameter, but some are smaller, others larger than this. Their general direction is longitudinal, i.e. parallel to the long axis of the bone, but they are constantly united by transversely and obliquely running passages. In a section across the shaft of a long bone they are seen as small rounded or irregular holes (fig. 106). When the section has been made by grinding, the holes get filled up with air and debris, and they then look black by transmitted light, as do also the lacunæ 
and canaliculi (fig. 107). Most of the lamella in compact bone are disposed concentrically around the Haversian canals; they are known as the Haversian lamellie, and with the included canal form what is known as a Haversian system. The lacunæ of a Haversian system communicate with one another and with the Haversian canal, but not as a rule with the lacunæ of adjacent Haversian systems. The angular interstices between the Haversian systems are generally

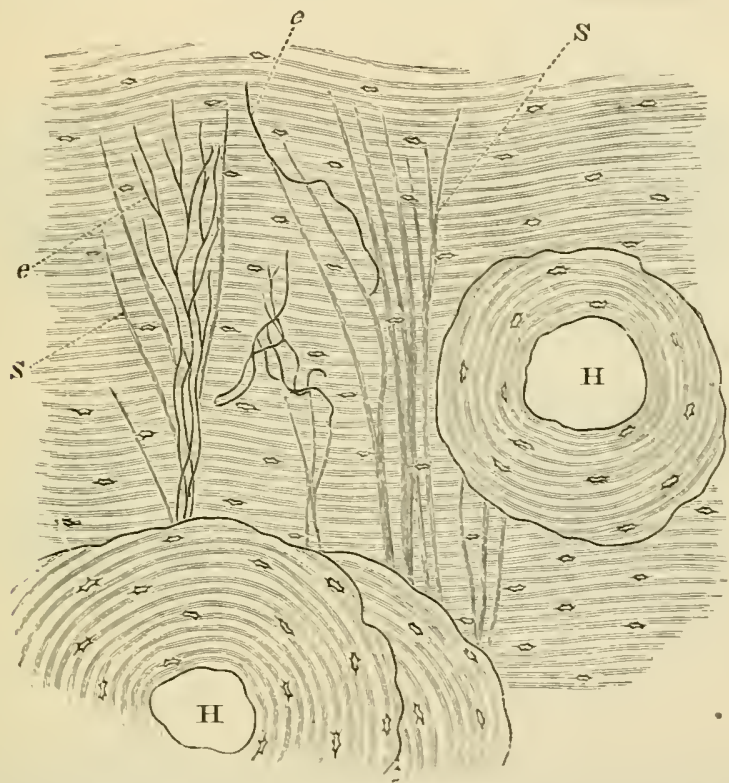

Fig. 108. - Transterse section of Decalcifien humax tibia, From Near the SERFACE OF THE SHAFT.

Н, Н, Haversian canals, with their systems of concentric lamelle; in all the rest of the figure the lamellat are circumferential; s, ordinars perforating fibres of Sharpey; $e$, e, elastic perforating fibres. Dramn under a power of about 150 diameters.

occupied by bony substance which is fibrous but not lamellar. Besides the lamellæ of the Haversian systems there is a certain thickness of bone at the surface, immediately underneath the periosteum, which is composed of lamellæ arranged parallel with the surface; these are the circumferential or periosteal lamellce (fig. $106, p l)$. They are pierced here and there by simple canals for blood-vessels, the so-called Volkmann's cunals, which are proceeding from the periosteum to join the system of Haversian canals, and also by calcified bundles of white fibres and by elastic fibres which may also be prolonged from the periosteum. These are the per forating fibres of Sharpey (fig. 108). 
The lamellæ of bone are fibrous in structure. This may be seen in shreds torn off from the superficial layers of a decalcified bone (fig. 109). The fibres (decussating fibres of Sharpey) often cross one another in adjacent lamellæ, and in the Haversian systems they run in some lamellæ concentrically, in others parallel with the Haversian canal. In shreds of lamellæ which have been peeled off from the surface the perforating fibres may sometimes be seen projecting from the surface of the shred, having been torn out of the deeper lamellie

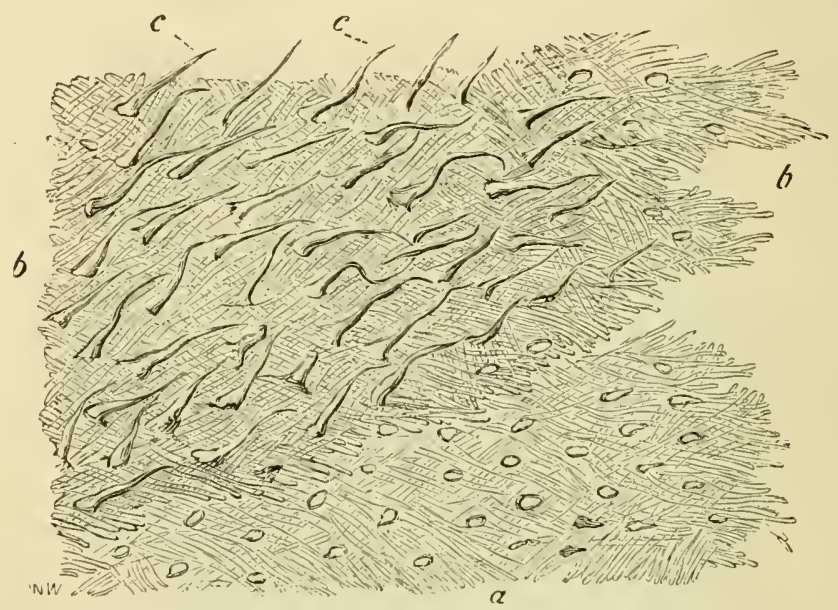

Fig. 109. - LAMELL. TORN OFF FROM A DECALCIFIED hUMAN PARIETAL BONE AT SOME DEPTH FROM THE SURFACE. (Sharpey.)

$a$, lamelle, showing decussating fibres; $b, b$, thicker part, where several lamella are superposed; $c, c$, jerforating fibres; the fibrils which eompose them are not shown in the figure. Apertures through which perforating fibres had passed are seen, especially in the lower part, $a$, of the figure. Magnitude as seen under a power of 200 diameters, but not drawn to seale. (From a sketch by Allen Thomson.)

(fig. 109, c, c). When tendons or ligaments are inserted into bone, their bundles of white fibres are prolonged into the bone as perforating fibres.

The lacunse are occupied by nucleated corpuscles, which send branches along the canaliculi (fig. 110). They have a special lining layer different in chemical composition from the rest of the bone, being much more resistant to the action of strong chemical solvents such as hydrochloric acid (Neumann). The dentinal tubules of the teeth have a similar lining layer.

The Haversian canals contain one or two blood-capillaries and nerrous filaments, besides a little connective tissue; and the larger ones may also contain a few marrow-cells. There are also cleft-like lymphatic spaces running with the vessels, their cells being connected 
through canaliculi with branches from corpuscles within the neighbouring lacune of the osseous sulbstance (fig. 111).

The periosteum may be studied in torm-off shreds, in preparations stained in situ with silver nitrate, and in stained sections from an unmacerated bone which has been decalcified. It is a fibrous membrane composed of two layers, the inner of which contains many elastic fibres. In the outer layer numerous blood-vessels

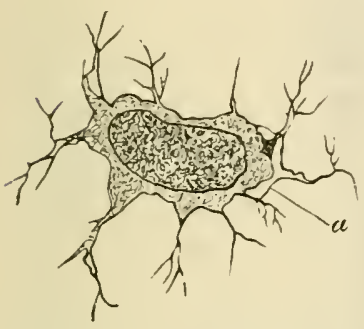

F1G. 110.-A BONE-CELL ISOLATEN AND HIGHLY MAGNIFIED. (Joseph.)

$a$, proper wall of the lacuna (Neu. mann's lajer), where the corpuscle has slirunkell away from it.

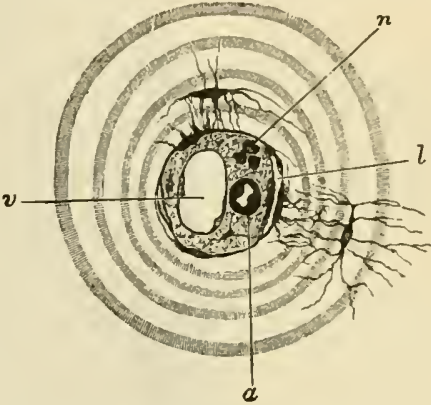

Fig. 111. - SECTION OF A HAVERSIAN CANAL, SHOWING ITS CONTENTS. (Highly magnified.)

$a$, small arterial capillary vessel ; $v$, large venous capillary; $n$, pale nerve-fibres cut across; $l$, cleft-like lymphatic vessel; one of the cells forming its wall cornmunicates by fine branches with the branches of a bone-corpuscle. The substance in which the vessels run is connective tissue with ramified cells; its finely granular appearance is probably due to the cross-section of fibrils. The canal is surrounded by several concentric lamellet.

ramify and send branches to the Haversian canals of the bone. The periosteum ministers to the nutrition of the bone, partly on account of the blood-vessels and lymphatics it contains, partly, especially in young animals, on account of the existence between it and the bone of a layer of osteoblasts or bone-forming cells, a remainder of those which originally produced the bone. It also serves to give attachment to muscular filores.

The marrow of bone has been already studied (pp. 38, 39).

\section{DEVELOPMENT OF BONE.}

True bone is essentially formed in all cases by an ossification of connective tissue. Sometimes the bone is preceded by cartilage, which first becomes calcified, and this is then invaded, and for the most part removed, by an embryonic tissue which re-deposits bony matter in the interior of the cartilage. This is intracartilaginous or endochondral ossification. At the same time layers of bone are being formed outside the 
cartilage underneath the periosteum. The whole bone thus formed is termed a cartilage-bone. Sometimes the bone is not preceded by cartilage, and then the only process which occurs is one corresponding to the subperiosteal ossification of the cartilage-bone; the ossification is then known as intramembranous, and the bone formed is a membrane-bone.

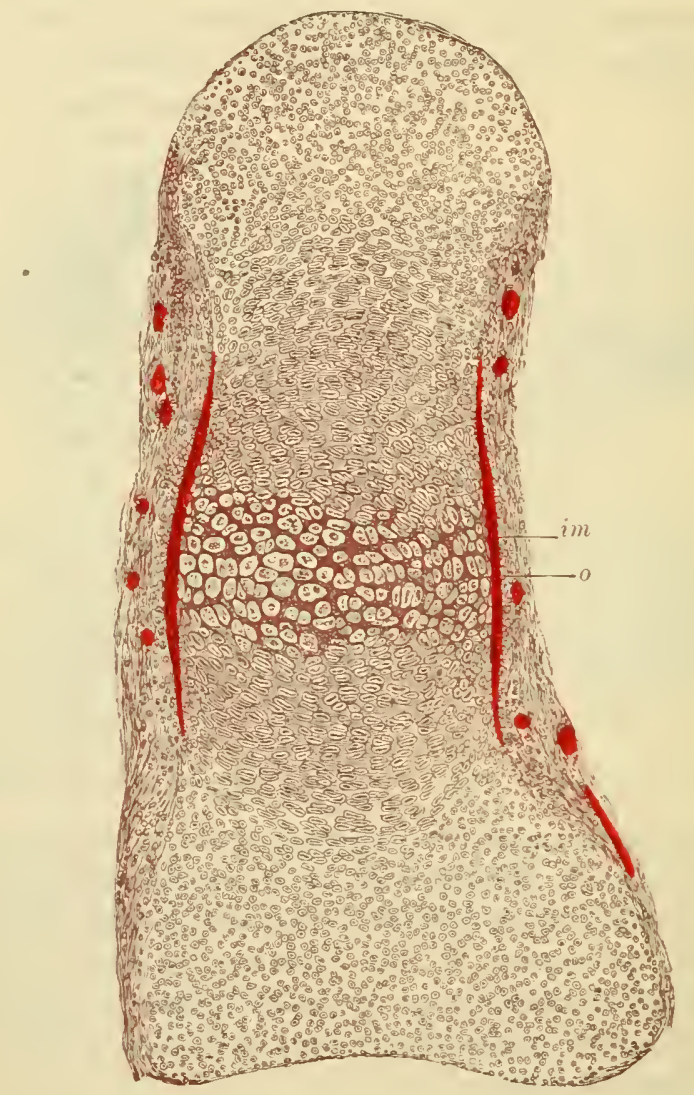

Fig. 112.-SECTION OF PHALANGEAL BONE OF HOMAN FETUS AT THE TIME OF COMMENCING OSSIFICATION. (From a prepalation by F. A. Dixey.) The preparation was stained in bulk with magenta. The drawing is made from a photograph, and is magnified about 75 diameters.

The cartilage cells in the centre are enlarged and separated from one another by stained calcified matrix : im, layer of bone deposited underneath the periosteum; $o$, layer of osteoblasts by which the layer has been formed. Sume of the osteoblasts are already embedded in the new bone as lacunæ. The cartilage-cells are becoming enlarged and flattened and arranged in rows abore and below the ealcified centre. At the ends of the cartilage the cells are small, and the groups are irregularly arranged; the fibrous periosteun is not sharply marked off from the cartilage.

Ossification of cartilage.-This may be described as occurring in - three stages. In the first stage the cells in the middle of the cartilage become enlarged and arranged in rows radiating from the centre 
(fig. 112), and fine granules of calcareous matter are deposited in the matrix. Simultaneously with this the osteoblasts underneath the periosteum deposit a layer or layers of filorous lamella upon the surface of the cartilage, and these lamella also beeome ealcified (fig. 112, $\mathrm{im}$ ). As they are formed, some of the osteoblasts $(0)$ are included between them and become bone-corpuscles.

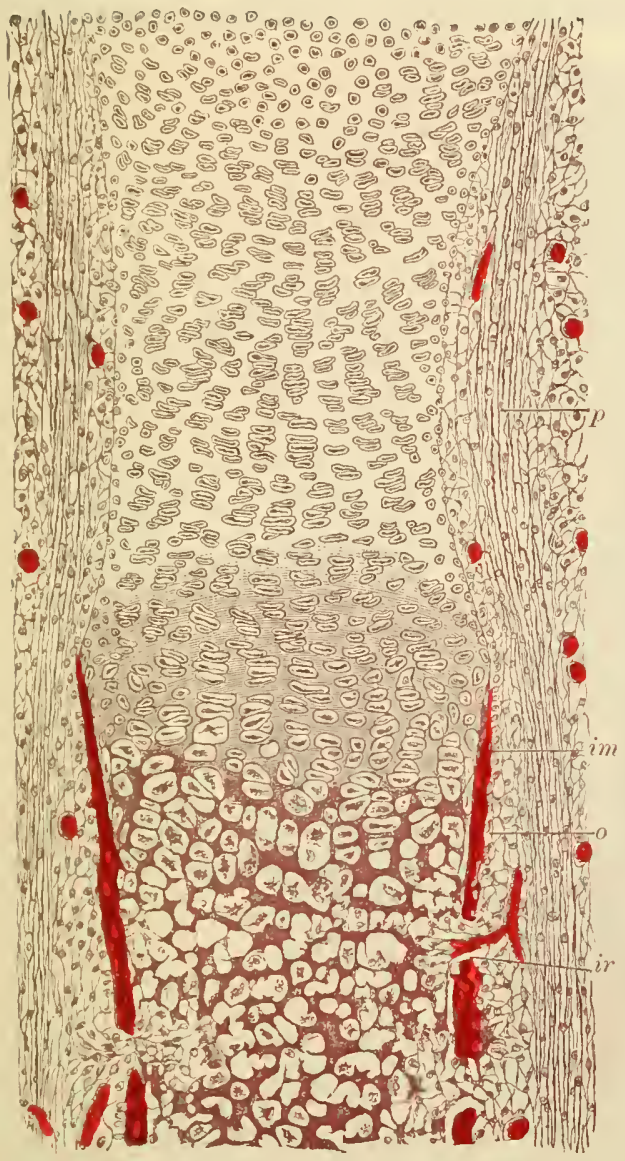

F1G. 113.-SECTION OF PART OF ONE OF THE LIMB-BONES OF A FETAL CAT, AT A MORE ADVANCED STAGE OF OSSIFICATION THAN IS REPRESENTED IN FIG. 112, AND SOMEWHAT MORE HIGHLY MAGNIFIED.

Drawn from a photograph.

The calcification of the cartilageinatrix has advaneed from the centre, and is extending between the groups of cartilage-eells, which are arranged in eharacteristic rows. The subperiosteal bony deposit (im) has extended pari passu with the caleification of the cartilage-natrix. The eartilage cells in the caleified part are mostly slirunken and stellate; in some cases they have dropped out of the spaces. At ir and in two other places an irruption of the subperiosteal tissue, composed of ramified cells with osteoblasts and growing blood-vessels, has perretrated the subperiosteal bouy erust, and has begun to excavate seeondary areolre or medullary spaces: $p$, fibrous layer of the periosteun ; $o$, layer of osteoblasts, soule of them are em. bedded in the osseous layer as bone-eorpuscles in lacumw. The blood-vessels are occupied by bloodeorpuseles. Beyond the line of ossifie advance the periosteum may be noticed to be distinctly ineurved. This incurvation is gradually moved on, the earti. lage expanding belind it until the head of the bone is reached, when it forms the periosteal notch or groove represented in figs. 116 and 119 .

In the second stage some of the subperiosteal tissue eats its way through the newly formed layer of bone and into the centre of the ealcified cartilage (fig. 113, ir). This is freely absorbed before it (fig. 115), so that large spaces are produced which are filled with osteoblasts, and contain numerous blood-vessels which have grown in at the same time. These spaces are termed medullary spaces, and this second stage may be termed the stage of irruption. 
In the third stage of endochondral ossification there is a gradual advance of the ossification towards the extremities of the cartilage, and at the same time a gradual deposition of fresh bony lamellæ and spicules on the walls of the medullary spaces, and on the surface of the new bone under the periosteum. The advance into the cartilage always takes place by a repetition of the same changes, the cartilage-cells first enlarging and becoming arranged in rows, the matrix between the

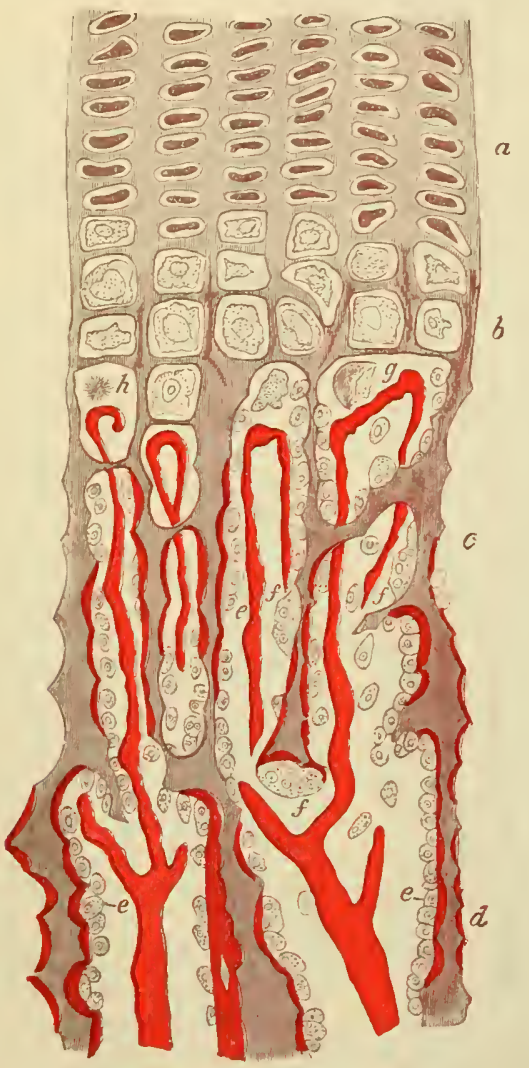

Fig. 114.-PART OF A LONGI. TUDINAL SECTION OF THE DEVELOPING FEMUR OF THE RABBIT. (Klein.) (Drawn under a magnifying power of 350 diameters.)

$a$, rows of flattened cartilage-cells ; $b$, grcatly enlarged cartilage-cells close to the advancing bone, the matrix between is partly calcified; $c$, $d$, already formed bone, the osseous trabecule being covered with ostcoblasts $(e)$ except here and there, where an osteoclast $(f)$ is secn eroding parts of the trabe. culæ; $g, h$, cartilage-cells which have become shrunken and irre. gular in shape. From the middle of the figure downwards the trabecula, which are formed of calcified eartilage-matrix, are becoming covered with secondary osseous substance deposited by the osteoblasts. The vascular loops at the extreme limit of the bone are well shown, as well as the abrupt disappearance of the cartilage-cells.

rows becoming calcified, and then the calcified cartilage becoming excavated from behind by the osteoblastic tissue so as to form new medullary spaces (fig. 114). The walls of these are at first formed only by remains of the calcified cartilage-matrix (fig. 114,c), but they soon become thickened by lamellæ of fibrous bone which are deposited by the osteoblasts, and between which bone-corpuscles become included, as in the case of the subperiosteal bone. The latter advances pari passu with the endochondral calcification, but beyond this the uncalcified 
cartilage grows both in length and brearth, so that the ossification is always advancing into larger portions of cartilage; hence the endochondral bone as it forms assumes the shape of an hour-glass, the cylindrical shape of the whole bone being maintained by additions of periosteal bone to the outside (see fig. 116). The absorption of the calcified cartilage-matrix appears to be effected, as is the case with absorption of bony matter wherever it occurs, by large multi-nucleated

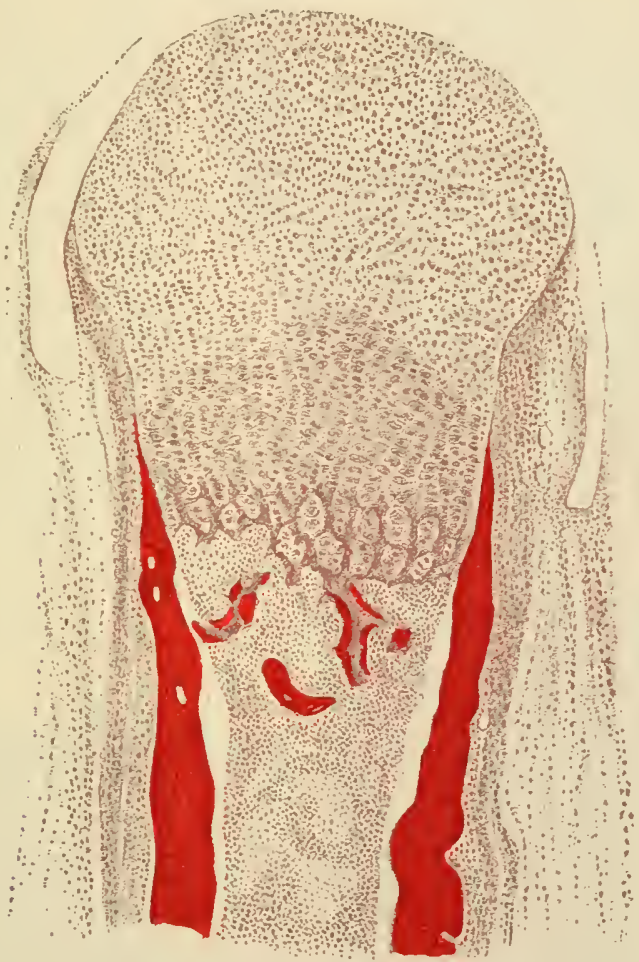

FIG. 115. - LONGITUDINAL SECTION THROLGH PART OF A PHALANX OF A SIX MONTHS' HUMAY EMBRTO, (Kölliker.)

The calcified cartilage is completely absorbed almost to the limit of advancing calcification. The osseous substance on either side is periosteal bonc. The embryonic

marrow has shrunk somewhat away from it.

cells (fig. 114, $f, f$ ) which are termed osteoclasts. They are cells of the same nature as the myeloplaxes of the marrow, and are found on surfaces where absorption of bone is taking place, whereas the osteoblasts are always found covering surfaces where bony deposit is proceeding (fig. 117).

The bone which is first formed is more reticular and less regularly lamellar than that of the adult, and contains no Haversian systems. 
The regular lamellæe are not deposited until some little time after birth, and their deposition is generally preceded by a considerable

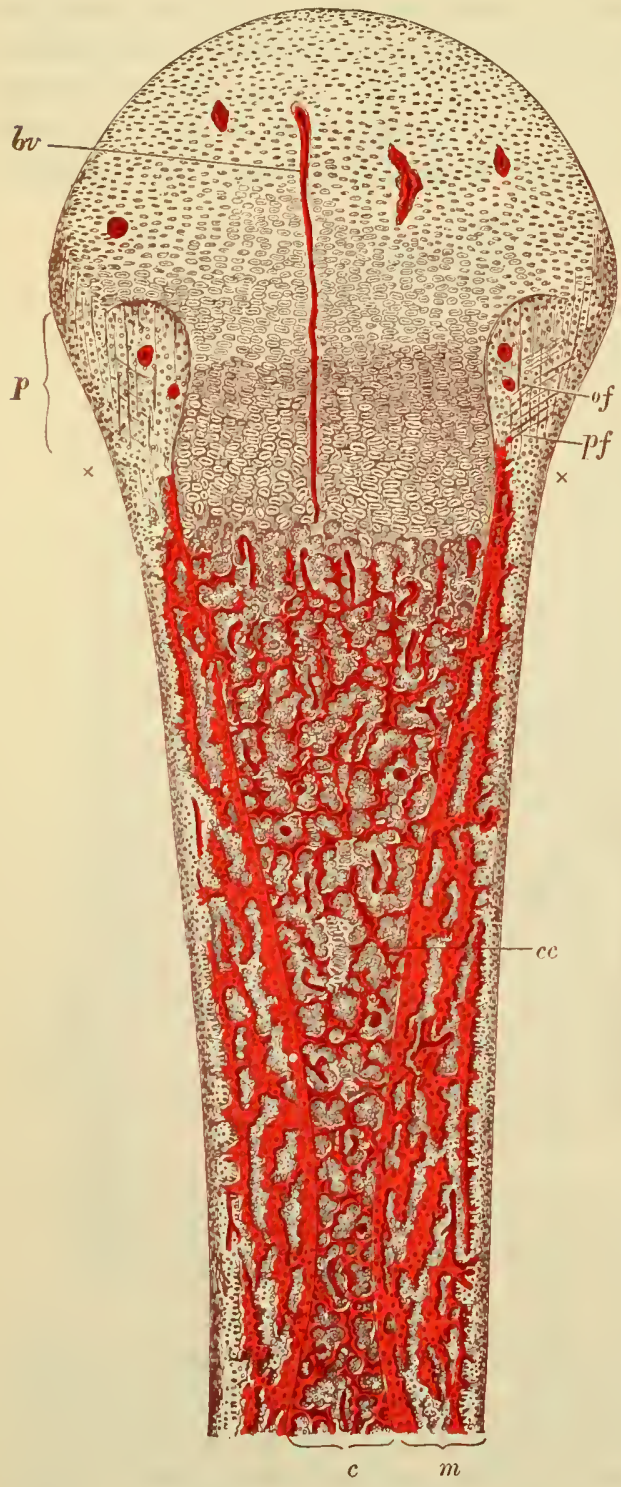

Fig. 116.--LoNgitudinal SECTION THROUGH THE UPPER HALF OF THE DECALCIFIED HUMERUS OF A FETAL SHEEP, AS SEEN CNDER A MAGNIFYING POWER OF ABOUT 30 DLAMETERS.

$c$, the part of the shaft which was primarily ossified in cartilage; what remains of the primary bone is represented dark, enveloped by the clear secondary deposit. The areolre of the bone are occupied by embryonic marrow with osteoblasts, and blood-vessels variously ent. One long straight vessel $(b v)$ passes in advance of the line of ossification far into the cartilaginons head, most of the others loop round close to the cartilage. At one or two places in the older parts of the bone elongated groups of eartilage-cells (cc) may still be seen, which have hitherto cseaped absorption. $m$, the part of the bone that has been ossified in membrame, that is to sity, in the ostcoblastic tissuc under the periosteum. It is well marked off from the eentral portion, and is bounded, peripherally, by a jagged edge, the projeetions of which are indistinctly seen to be prolonged by bunches of osteo. genic fibres. A row of osteoblasts covers the superficial laser of the bone. 'The subperiosteal layer is prolonged above into the thickening $(p)$ which encroaches upon the cartilage of the head of the bone, and in which arc scen amongst numerous osteoblasts and a few blood-vessels, the straight longitudinal osteogenic fibres $(o f)$, and some other fibres ( $p f)$ crossing them, and perhaps representing fibres of Sharpey. The calcareous salts having been removed by au aeid, the granular ossific deposit passing up between the rows of cartilage-cells is not seen in this specimen; it would have extended as far as a line joining the marks $x \times$. Obscrte the general tendency of the osseons trabecule and the vascular channels between them to radiate from the original centre of ossification. This is found to prevail more or less in all bones when they are first formed, although the direction of the trabeculse may afterwards becomc rodified in relation with varying physiologieal eonditions, and cspeeially as the result of pressure in different directions.

amount of absorption. It is about this time also that the medullary canal of the long bones is formed by the absorption of the bony tissue which originally occupies the centre of the shaft. 
Intramembranous ossification. - In this variety of ossification (fig. 120), the bone is not preceded by cartilage at all, and therefore no endochondral bone is formed, but the calcification occurs in a sort of embryonic fibrous tissue which contains numerous osteoblasts and blood-ressels. The fibres of this tissue (osteogenic fibres), which, like those of fibrous tissue, are collected into small bundles, become inclosed in a calcareous matrix, produced by the deposition of lime salts in the ground-substance of the connective tissue; and as the fibres grow, the calcification extends further and further, so that bony

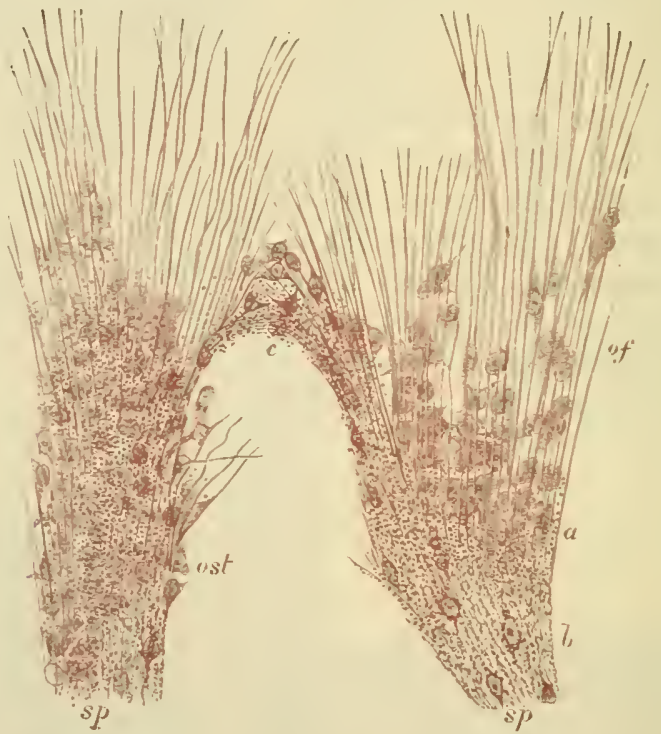

Fig. 120. -PART OF THE GROWING EDgE OF THE DETELOPING PARIETAL BONE OF A FETAL CAT, $1 \frac{1}{2}$ INCH LONG.

sp, bony spicules, with some of the osteoblasts embedded in them, producing the lacunr; of, osteogenic fibres prolonging the spicules, with osteoblasts (ost) between them and applied to them; $a$, granular calcific deposit occurring in the ground. substance between the fibres; $c$, union of two adjacent spicules.

spicules are formed, which, as they become thickened, run together to form reticular layers, leaving spaces filled with osteoblasts around the blood-vessels. The osteogenic fibres are corered with osteoblasts, and as the bone forms, some of these become left as bone-corpuscles within lacunæ. 'Thus in every particular the development of these bones resembles that of the subperiosteal layer of endochondral bone; which is also to be considered as an instance of intramembranous ossification, although taking place on the surface of cartilage. Moreover, it is the same subperiosteal tissue which, in endochondral ossification, deposits the true or secondary bone upon those parts of 
the ealeified eartilage-matrix which have eseaped absorption; and this must also, therefore, be reckoned as developed according to the same type. In faet, even in intracartilaginous ossification, very little of the calcified eartilage-matrix eventually remains; this being almost wholly absorbed and either replaced by true or fibrous bone which has been formed by osteoblasts, or swept away to form the medullary and other eavities.

With reference to the origin of the osteoblasts, it las been thought by some anthors that they are derived from the blood-vessels, and are in fact lencocytes which have wandered out of the vessels and have taken on the special osteogenic function. Another and a more probable riew regards them as modified connective tissue cells formed within the periostem and merely accompanying the vessels into the interior of the ossifying cartilages. They have also been thought to be formerl by division and alteration of the cartilage-cells. 


\section{LESSON XIV.}

\section{STRUCTURE OF STRIATED MUSCLE.}

1. TAKE a shred of muscle from a recently killed mammal, and on a dry slide carefully separate long pieces of muscular fibres (single fibres if possible) and stretch them out, keeping them moist during the process by breathing on the slide. Put a drop of serum on the cover-glass before placing this over the preparation. Study first with a low, then with a high power. Sketch all the appearances to be seen in a small piece of a fibre, focussing carefully the most superficial layer's. Notice the oval nuclei immediately under the sarcolemma. 'Then allow a little dilute acetic acid to run unler the coverglass and watel its effect.

2. Prepare some fibres of frog's muscle in the stme way, but mount in salt solntion instead of serum. Notice the nuncular substance shrinking away here and there from the sarcolemma, which then becomes distinctly visible. Sketch a piece of sarcolemma bridging across an interval thus producerl.

3. Study transverse sections of muscle which has heen harlened in alcohol or formol and stained. Mount in dammar varnish or xylul halsam. Examine the section of a fibre first with a low and then with a high power. Sketch the appearances which are seen.

In each of the above preparations measme the diameter of some of the fibres.

Sections of muscle-spindles may be searched for in the transverse sections of muscle.

4. Place in 1 per cent. osmic acid a small shred of manmalian muscular tissue which has been stretched mpon a cork. After 24 homrs, when it will be deeply stained, wash it in water and with needles break the fibres up in glycerine as finely as possible. Cover and examine with a high power.

5. Cut off the head of a small garlen beetle or wasp, and bisect the trunk with scissor's so as to expose the interior. Notice two kinds of muscular tissue, the one belonging to the legs greyish in colour, the other attached to the wings yellowish. Preparations of both kinds of muscle are to be made in the same way as living mammalian muscle (\$1), but it is better to momnt them in a drop of white of egg. In both preparations the dark-looking air-tubes or trachece form prominent objects ranifying amongst the fibres. Ohserve the structure of the two kinds of muscle so far as it can be made out in the fresh preparation. If the preparation is male quickly, waves of contraction will probably be observed passing along the fibres.

6. Make another preparation of the leg-muscles, momting the muscle in rinegar. (Alcohol-hardened muscle of insect or crab may be used for this purpose.) Notice that the nuscular substance swells pp somewhat and becomes clearer, whilst the sarcoplasm-network, with its lines and dots, comes more distinctly into view. In a well-teased preparation of alcohol. hardened muscle, the fibres will be frequently found breaking across into disks. Make careful drawings from this preparation.

7. Rollett's method. Cut off the head of an insect (wasp, small beetle), bisect the trunk and place in 90 per cent. alcohol for from 24 to 48 hom's 
or more. 'Then take a small piece of each kind of muscle, and place in strong glycerine for some hours. Wash thoroughly with water and transfer to 1 per cent. chloride of gold solution: leave the pieces of muscle in this from 15 to 30 minutes aecorling to their size. From the gold solution they are transferred to formie acid (1 part of the strong acid to 3 of water), and kept in the dark for 24 hours, but they may be kept longer withont disadvantage. The musele is then teased in glycerine. Some of the fibres will be found after this method to have their sarcoplasm darkly stainel, and to show, therefore, the appearance of a network both in longitndinal and transverse view : others, on the other hand, have the sareous elements of the fibrils or sarcostyles stained, whilst the sareoplasm has remained colomrless.

Voluntary muscle is composed of long cylindrical fibres, measuring on an average about $0.05 \mathrm{~mm}$. in diameter $\left(\frac{1}{500}\right.$ inch) in mammalian

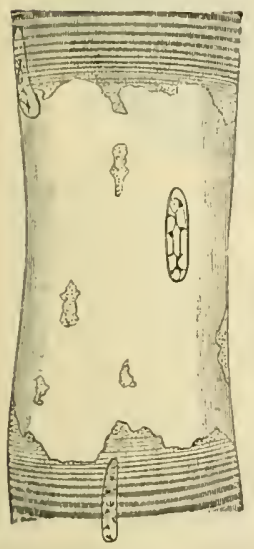

FIG. 121.

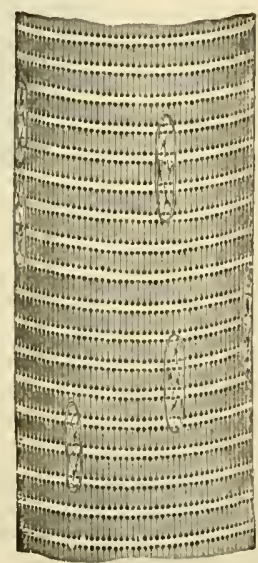

FIG, 122 .

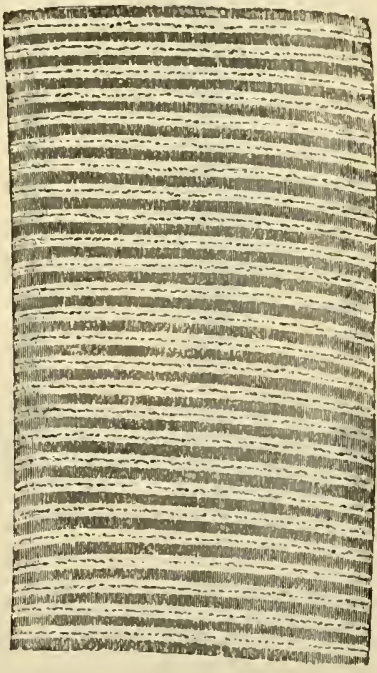

FIG. 123 ,

Fig. 121. - SAROOLEMMA OF MAMMALIAN MUSCLE HIGHLY MAGNIFIED.

The fibre is represented at a flitee where the museular substanee has become ruptured and has shrunk away, leaving the sareolemma (with a nueleus adhering to it) elear. The fibre had been treated with serum acidulated with acetic acid.

FIG. 122. -MISCULAR FIBRE OF A MAMMAL EXAMINED FRESH IN SERUM, HIGHLY MAGNIFJED, THE SURFACE OF THE FIBRE BEIXG ACCURATEL F FOCUSSED.

The nuelei are seen on the flat at the surface of the fibre, and in profile towards the edge.

Fig. 123.-PORTION OF A MEDIUM-SIZED HUMAN MUSCULAR FIBRE, SHOWI.NG ThE INTERMEDIATE LINE (DOBIE'S LINE) MENTIONED IN THE TEXT. (Sharpey.)

muscles, and often having a length of an inch or more. Each fibre has an elastic sheath, the sarcolemma, which incloses the contractile substance. The sarcolemma is seldom distinct, unless the contained substance becomes broken (fig. 121). 
The contractile substance of the fibre is characterised by the alternate dark and light stripes which run across the length of the fibre; hence the name, cross-striated or striped muscle. On focussing, it can be seen that the stripes pass through the whole thickness of the fibre; they may therefore be looked upon as representing alternate disks of dark and light substance. If the fibre be very carefully focussed, rows of apparent granules are scen lying in or at the boundaries of the light streaks, and very fine longitudinal lines may, with a good microscope, be detected uniting the apparent granules (fig. 122). These fine lines, with their enlarged extremities the granules, are more conspicnous

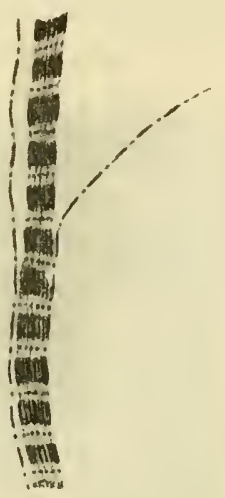

Fig. 124.-Siall Portion of A MUSCLE FIBRE OF CRAB SPLITTING UP INTO FIBRILS. (From a photograph.)

Jagnified 600 diameter's.

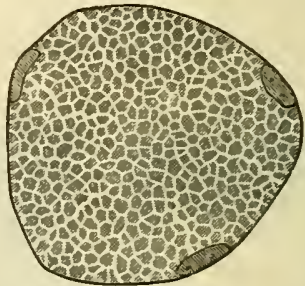

Fig. 125.-SECTION OF A MUSCULAR FIBRE, SHOWING AREAS OF COHNHEIM.

Three nuclei are seen lying close to the sarcolemma.

in the muscles of insects. They indicate the divisions between the longitudinal elements (firvils or sarenstyles) which compose the fibre, and in preparations treated with dilute acid they appear to form part of a fine network, which pervades that substance, and serves to unite the granules both transversely and longitudinally. This network, which is sometimes very distinct in preparations of muscle treated with chloride of gold, is, however, a network in appearance only : in reality it is the optical expression of the interstitial substance which lies between the fibrils. This substance is termed sarcoplasm.

On examining the transverse section of a fibre with a high power, it is seen to be subdivided everywhere into small angular fields, Cohnheim's areas (fig. 125), which are themselves again divided up. The smallest divisions represent sections of the fibrils of which the fibres are composed, and into which they may be split after death, especially after being hardened in certain reagents, e.g. chromic acid 
or osmic acid. The larger areas represent groups of fibrils. These areas of Colmheim are usually polyhedral, but they may be elongated, and disposed either radially, or concentrically with the circumference of the section. The interstitial substance or sarcoplasm lies between them and can be made visible by treatment with dilute acid or by staining with chloride of gold (figs. 127, 128, and 129). It is sometimes in relatively large amount, but in most museular fibres is reduced to a very fine interstitium.

An ill-clefined clear line is sometimes seen rumning transversely across the fibre in the middle of each dark band. This is termed Hensen's line.

If instead of focussing the surface of the fibre it be observed in its depth, an appearance different from that shown in fig. 12:2 is frequently visible, namely, a fine dotted line (Dobie's line), bisecting each clear stripe (fig. 123); this appearance is often considered to represent a membrane (Krause's membrane), which subdivides the fibrils at regular intervals (see p. 116). But the membrane of the individual fibrils or sarcostyles is rarely, if ever, visible in an intact mammalian fibre, and it is certain that the appearance of such a line in the middle of the clear stripe of an intact fibre is in most cases due to interference, caused by the light being transmitted between disks of different refrangibility.

Haycraft has suggested that the cross-striation of voluntary muscle is due to refractive effects prodnced by a varicosity of the component fibrils, basing his view upon the fact that in impressions of the fibres made in soft collodion all the cross-striations which are observed in the fibre itself are reproduced. There is no doubt that a well-marked cross-striated appearance can be produced in homogeneous fibrils by regularly-occurring varicosities, and many of the appearances observed in muscle may, as Haycraft contends, be referred to this canse. But even when a fibre or fibril is stretched so that it exhibits no variensities, the cross-striations are still perfectly distinct. Moreover, in view of the entirely different manner in which the substance of the dark and clear stripes behave to nauy staining reagents, and especially to chloride of gold when applied as directed in $\$ 7$, the fact being that very definite structural appearances can under these circumstances be made ont, the homogeneity of the muscle-fibril camnot be admitted. This inference is strongly confirmed by the microchemical work of A. B. Macallum, who has shown that the potassium salts of the muscle are mainly accumulated in the sarcous elements.

Nuclei.-Besides the sarcolemma and striated substance, a muscular fibre also exhibits a number of oval nuclei which have the usual structure of cell-nuclei: their chromatin often has a spiral arrangement. Sometimes there is a little granular substance (protoplasm) at each pole of the nucleus; each nucleus with the adjacent protoplasm has then been spoken of as a muscle-corpuscle. But the protoplasm which is adjacent to the nuclei is in all probability continuous with the 
sarcoplasm between the fibrils; both being the remains of the original undifferentiated protoplasm of the cells from which the muscular fibres are dereloped. In mammalian muscle the nuclei nsually lie imme-

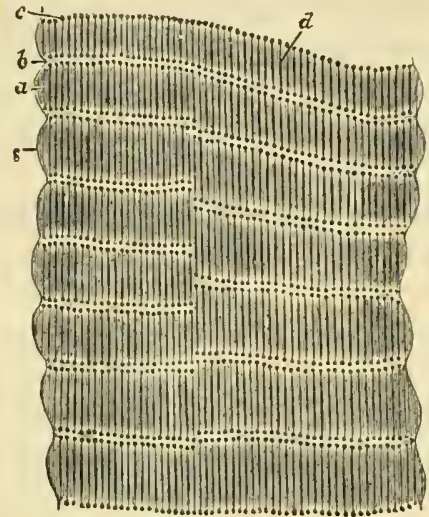

Fig. 126.-Livisg itscle OF water-BeEtle (DYTISCUS YARGIXAI.IS.) (Highly maguified.) $s$, sarcoleınua ; $a$, dim stripe; $b$, bright stripe; $c$, row of dots in bright stripe, which seem to be the enlarged ends of rod-shaped particles, $d$, but are really expansions of the interstitial sarcoplasu which appear in the living muscles as fine dark lines with dot-like enlargements upon them.

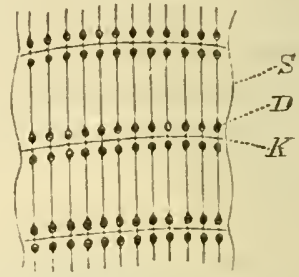

Fig, 127.--PoRTION OH LEG-3ILSCLE OF INSECT TREATED WITH DILETE ACID.

S, sarcolemma; $D$, dot-like enlargement of sarcuplasm ; $K$, Krause's membraue. The sareous elements are dissolved or at least rendered intisible by the acid.

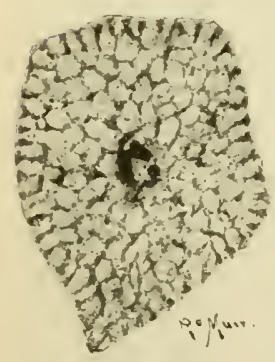

FIG. 128.

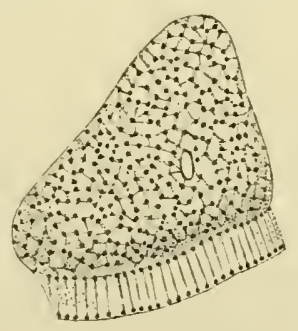

A

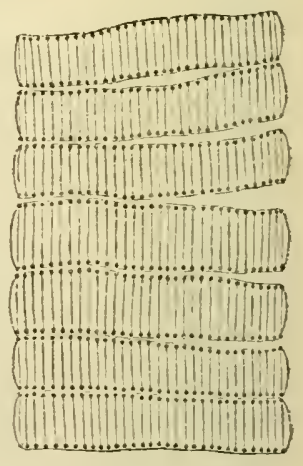

B

FIG. 129.

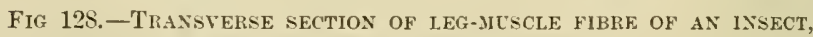
STAINED WITH GOLD CHLORIIE

The sarcoplasm is here stained, and appears in the form of a network, in the meshes of which lie the sections of the fibrils. Notice the mottled appearance of the sections of the sareostyles or fibrils, indicating a porous strueture, as in the wing fibrils (see fig. 132). The central protoplasm (with a mucleus) is also cvident. (From a photograph.)

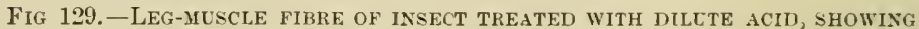
A TENDENCY TO BREAK ACROSS INTO DISKS.

The sareoplasm is in the form of fine lines. The ordinary dark strines of the fibre hare disappeared in the acid. A, a disk seen partly in section and exhibiting the reticular arrangeruent of the sarcoplasm; $B$, longitudinal view of fibre. 
diately under the sarcolemma (figs. 121, 122, 125), in frog's muscle they are seattered throughout the substance of the fibre; in insect muscle they occupy the middle of the fibre, embedder in gramular protoplasm (fig. l:sis). Some animals, such as the rabbit, have, besides muscles of the ordinary type of structure, which in this animal are pale in colour, others of a deep red colour. These red muscles were found by Ranvicr to exhibit certain differences both in structure and function. One difference of structure is that the nuclei, which are numerous, are not confined to the surface, but are scattered throughout the substance of the fibres. The fibres in question also contain more sarcoplasm than the ordinary fibres, and their blood. vessels have a peculiarity of strueture which will be afterwards noticed. Here and there, in all mammals, amongst the ordinary fibres are some in which the muclei are distributed through the thickness of the fibres; this is the case also, as just remarked, with all the muscular fibres of the frog. In muscles which are in constant activity, such as the diaphragm and the dorsal fin muscles of Hippocampus, the protoplasm (sarcoplasm) of the fibres is present in relatively large proportion, and this is also the case with the wing muscles of insects.

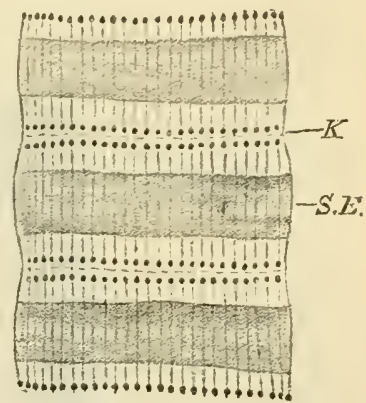

FIG. 130. - LEG-MUSCLE FIBRE OF INSECT, STAINEN WITH GOLD CHLORIDE BY ROLLETT'S METHOJ),

$K$, line formed by membrancs of Kiause: S.E., dark stripe formed by sarcous elements. The sarenplasm hias the arpearance of longi. tudinal lines.

The transverse section of a muscle shows the fibres to be nearly cylindrical in figure. Between the fibres there is a certain amount of areolar tissue, which serves to support the blood-vessels and also unites the fibres into fasciculi; the fasciculi are again united together by a larger amount of this intramuscular comective tissue (endomysizum.)

Ordinary or leg-muscles of insects.-In the muscles of insects the stripes are relatively broad, and their structure can be more readily seen than in mammals. In the living fibres from the muscles which move the legs, the sareoplasm presents a striking appearance of fine longitudinal lines traversing the muscle, and enlarging within the light stripes into rows of dots (fig. 126). This is still better seen in fibres and portions of fibres which have been treated with dilute acid (fig. 127). In separated disks produced by the breaking across of muscle-fibres, the surfaces of the disks show a network with poly hedral meshes in some insects (fig. 129, A), one formed of lines radiating 
from the centre of the fibre in others. The nuclei, with some inclosing protoplasm, lie in the middle of the fibre.

Wing-muscles of insects. - The wing-muscles of insects are easily broken up into fibrils (sarcostyles), which also show alternate dark and light strix (fig. 131).

The sarcostyles are subdivided at regular intervals by thin transverse disks (membranes of Krause) into successive portions, which may be

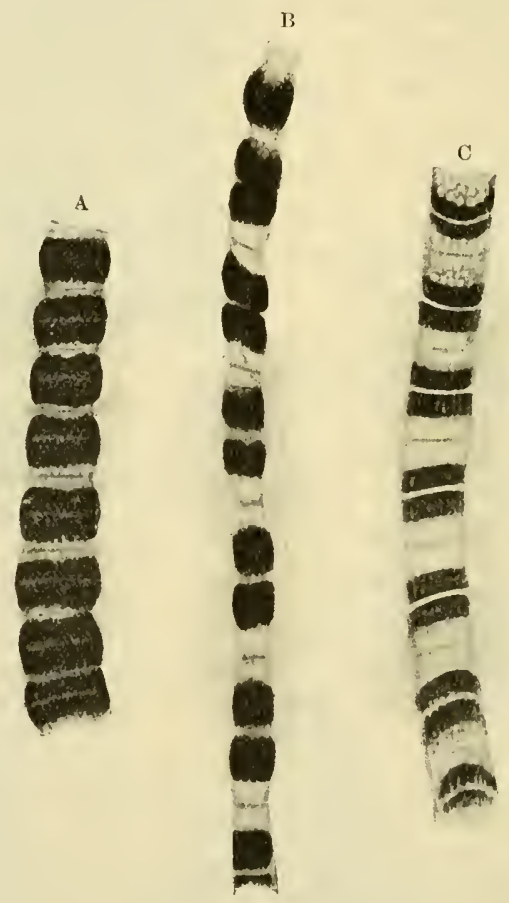

Fig. 131.-Fibrils OF THE WING-MUSCles OF A WASP, PREPARED BY ROLLET's METHOD. Highly magnified. (From photographs.)

A, a contracted flbril. B, a stretched fibril, with its sarcous elements separated at the line of Hensen. C, an uncontracted fibril, showing the porous structure of the sarcous clements.

termed sarcomeres. Each sarcomere is occupied by a portion of the dark stria of the whole fibre (sarcous element): the sarcous element is really double, and in the stretched fibre separates into two at the line of Hensen (fig. 131, B). At either end of the sarcous element is a clear substance (probably fluid or semi-fluid) separating it from the membrane of Krause: this clear substance is more evident the more the fibril is extended, but diminishes, even to complete disappearance, in the contracted muscle (fig. 131, A). The cause of this change is 
explained when we study more minutely the strueture of the sareous element. For we find that each sarcous element is pervaded with longitudinal canals or pores, which are open in the direetion of Kranse's membranes, but closed at the middle of the sarcous element (fig. 132). In the contracted muscle, the clear part of the muscle-substance has disappeared from riew, but the sarcous element is swollen and the surcomere is thus shortened: in the uncontracted muscle, on the other hand, the clear part occupies a eonsiderable interval between the sarcons element and the membrine of Krause, the sarcomere being

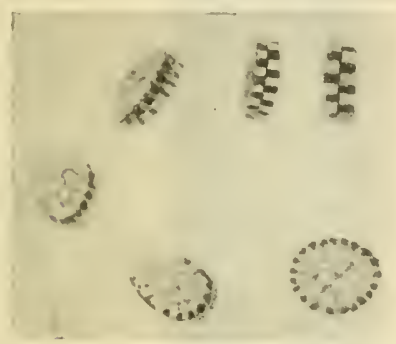

Fig. 132. - Isolated SARCOUS ELEUIENTS OF A WING-HUSCLE, SHOWING THE TUBULAR OR POROUS STRUCTURE. (Magnified 2300 diameters.)

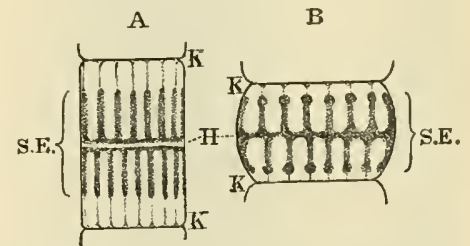

Fig. 133.-Diagray of A SARConere iN A MODERATELY EXTENDED CONDITION, $A$, AND IN A CONTRACTEI CONDITION, B.

$\mathbf{K}, \mathbf{K}$, membranes of Krause ; $H$, line or plane of Hensen ; S.E., poriferous sareous element.

Some are seen in profile; others on the flat.

lengthened and narrowed. The sareous element does not lie free in the middle of the sarcomere, but is attached at either end to Krause's membrane by very fine lines, which may represent fine septa, running through the clear substance (fig. 133); on the other hand, Krause's membrane appears to be attached laterally to a fine membrane which limits the fibril externally.

The planes of sarcous elements set side by side in a muscle-fibre form the dark stripe (the so-ealled principal disk) of the musclesubstance of ordinary muscle-fibres (fig. 130). But in the wing-muscles of insects the sarcous elements of the fibrils less constantly lie in continuous planes, and the whole fibre is therefore very indistinctly and irregularly cross-striated, although each individual fibril is markedly so (fig. 131). As already stated, the sareous elements are remarkable for containing a large proportion of potassium salts (Macallum).

Sometimes in the ordinary (leg) muscles of arthropods what look like letached dot-like portions of the sarcous element are seen within the clear stripes, lying usually near Krause's membrane. The rows of such dots have been termed accessory dishs. Most muscles show no accessory disks, but the sarcoplasmic enlargements between the fibrils (fig. 127, D) are often mistaken for them. 
Muscle in polarised light.-When muscle-fibres are examined with polarised light between crossed Nichol's prisms, the sarcous elements (which form the dark stripe) are seen to be doubly refracting (anisotropous), while the clear substance (forming the light stripe) is singly refracting (isotropous). In contracted parts of the muscle the (anisotropous) sarcous elements are seen to have increased in bulk, while the isotropous substance of the clear stripe has correspondingly diminished in amount (fig. 134, B).

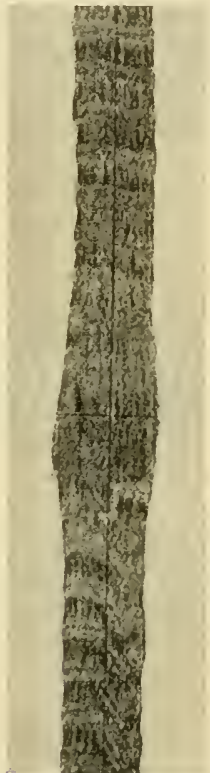

A

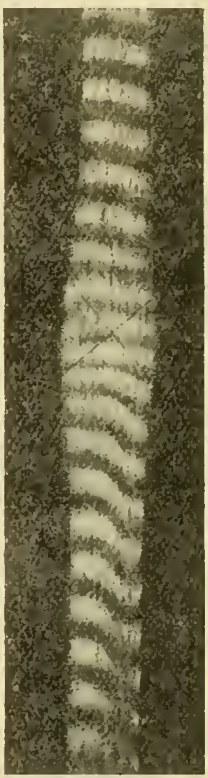

B

Fig 134-Leg-MCSCLE FiBRe OF CHRYSOJIELA COERCLEA WITH (FIXED) CONTRACTION WAVE PHOTOGRAPHED UNDER POLARISING MICROSCOPE. ${ }^{1}$

A, with uncrossed Nichols; B, with crossed Nichols.

F. Merkel described a reversal of the stripes during contraction, i.e. a transference of the anisotropous substance of the dark stripe from Hensen's line to Krause's membrane, the place of the dark stripes thus becoming occupied by clear material, that of the light stripes by dark. He further described this condition as being precerled by an intermediate stage in which the fibril shows homogeneity of shading. No doubt in the ordinary musclefibres of artbropods, when we observe the so-called 'fixed' waves of contraction, there is an apparent blurring of the cross-striation of the fibre just where the rnuscle is passing from extension to contraction, but this appearance is explicable by the unequal pull of the contracted parts of the fibrils upon those which are not yet contracted. The contraction in each fibre starts from the nerve-ending, which is at one side of the fibre, and spreads first across the fibre and then tends to pass as a wave towards either end. But the one sile always has a start in the progress of this wave, and the fibrils must thus receive an unequal pull, so that they are shifted along one another and the line of cross-striping is broken up. That no transference of anisotropous substance really occurs is at once clear from the appearance

${ }^{1}$ I am indebted to Professor Engelmann for these two photographs. 
of the contracting fibre under polarised light (fig. 134, B), and the study of the isolated fibrils of wing-muscle gives no support to the theory of reversal, although it is widely held by German authors. That the apparent reversal is not real is also illustrated by fig. 135, which represents a legr nuscle fibre of an insect in process of contraction. 'The clark bands of the contraction-wave are seen to be really dite to accumulations of sarcoplism. These accumulations appear as dark lines which obscure the continuity of the fibrils, and by contrast cause the whole of the sarcomeres between them to appear light.

Mechanism of contraction.Comparing the structure of the sarcomere with that of the protoplasm of an anceboid cell we fiud in both a framework (spongioplasm, substance of sarcous element) which incloses in its meshes or pores a clear, probably fluid substance (hyaloplasm, clear substance of sarconere). In both instances also the clear substance or hyaloplasm, when the tissue is subjected to stimulation, passes into the pores of the porous substance or spongioplasm (contraction), whilst in the absence of such stimulation it tends to pass out from the spongioplasm (formation of pseudopodia, resting coudition of muscle). The effect of stimulation appears in both structures to be the production of a change in surface tension (perhaps between the hyaloplasm and spongioplasm); this change being demonstrably accompanied in muscle by a difference in electric potential. In all probability such an electric

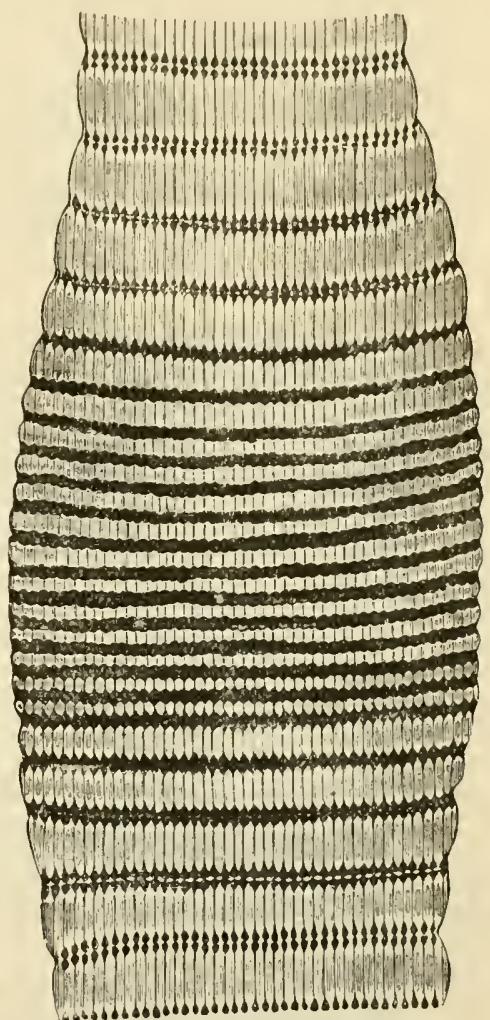

Fig. 135. - WAVE OF contraction PAssing OVER A LEG-MUSCLE FIBRE OF DYTISCUS. Highly magnified. clange occurs in all protoplasm. Thus both the movements of cell-protoplasm and those of muscle seem brought about by like means, although at first sight the structure of muscle is quite dissimilar from that of protoplasm. We have already noticed that the movements of cilia are susceptible of a somewhat similar explanation. 


\section{LESSON XV.}

\section{CONNEXION OF MUSCLE WITH TENDON; BLOOD- IESSELS OF MUSCLE; CARDIAC MUSCULAR TISSUE; DEVELOPMENT OF MUSCLE; PLAIN IUSCULAR TISSUE.}

1. To study the comnexion of muscle with tendon, a frog is killed by destruction of the brain and spinal cord, and placed in about a litre of water raised to a temperature of $55^{\circ} \mathrm{C}$. It is left in this for 15 minutes, the water gradually cooling. It is then easy to dissociate the muscular fibres in large numbers. To observe their attachment to the tendon-bundles a fine longitudinal shred must be snipped off with scissors at the tendinous attachment, and dissociated upon a slide in a drop of water. It will usually be found that the muscular substance is retracted from the end of the sarcolemma tube, which is firmly cemented to the tendon-bundle. The structure may be brought more distinctly into view by adding to the dissociated fibres a drop of a weak solution of iodine in salt solution or in serum (iollised serum). ${ }^{1}$

2. The blood-ressels of muscle. These are studied in longitudinal and transverse sections or in flattened-out pieces of injected muscle. It will be noticed that the capillaries are very numerous, and form a network with oblong meshes. In the red muscles of the rabbit, small dilatations are seen on the transverse cords of the network.

3. The muscular tissue of the heart is studied in sections of that organ (see Lesson XXVII.) aud also in teased preparations. To prepare the latter, place a small piece of heart-muscle in 33 per cent. alcohol for a few days; stain in picro-carmine solution for some hours or clays; and tease in dilute glycerine.

4. Tear off a small shred of the muscular coat of a piece of cat's intestine which has been for 48 hours or more in $\frac{x}{8}$ per cent. bichromate of potash solution or in 33 per cent. alcohol. Hold the shred with forceps in a drop of water and fray it ont with a needle. In this process many cells will be set free and can be found with a low power. The preparation may then be covered and examined with a high power. Sketch one of the cells. Then allow dilute hrematoxylin solution to pass under the cover-glass and lastly a drop of glycerine. Sketch another cell after staining. Measure two or three cells and their nuclei.

Ending of muscle in tendon.-A small tendon-bundle passes to. each muscular fibre and becomes firmly united with the sarcolemma, which extends over the end of the fibre (fig. 136). Besides this immediate attachment, a further connexion is established by the

${ }^{1}$ This method is the one given by Ranvier (Traité Technique, p. 395). The muscle-endings may also sometimes be well seen at the extremities of the tendons which are removed from the mouse's tail in the manner described in Lesson $\mathrm{X}$. 
faet that the areolar tissue between the tendon-hundles is continuous with that which lies between the muscular fibres.

Blood-vessels of muscle.-The capillaries of muscular tissue are very numerous. They run, for the most part, longitudinally, with transverse branches, so as to form long oblong meshes (fig. 137). No bloor-vessels ever penetrate the sareolemma. In the red muscles of the rabbit, the transverse capillaries have small dilatations upon

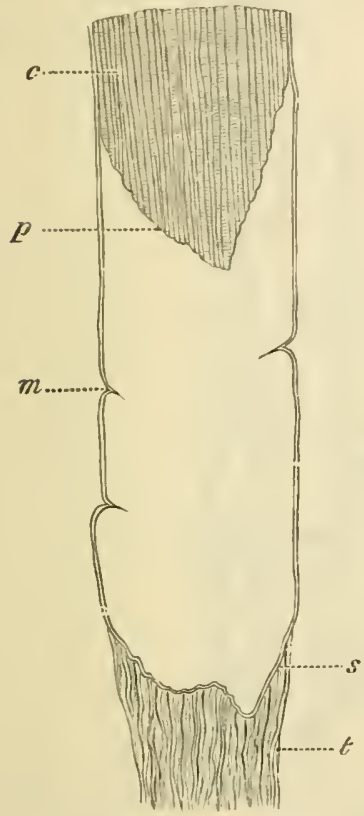

Fig, 136.-Termination of a mescClar fibre iN tENDON. (Ranvier.)

$m$, sarcolemma; $s$, the same membrane passing over the end of the filmre; $p$, extremity of muscular substance, $c$, retracted from the lowcr end of the sarcolemma-tule: $t$, a tendon-bundle passing to be fixed to the sarcolcmma.

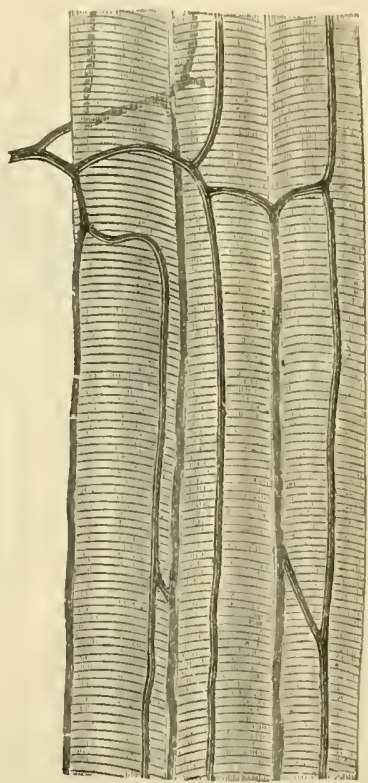

Fig. 137.-Capillari vessel.s of MUSCLE.

them (fig. 138). Associater with this and other pecnliarities of structure (see p. 115), it is found that the red museles have a much slower rate of contraction, and a much longer period of lateney than the ordinary muscles.

Lymph-vessels, although present in the connective-tissue sheath (perimysinm) of a muscle, do not penetrate between the component fibres.

The motor nerves of voluntary muscles pierce the sarcolemma 
and terminate in ramified expansions known as end-pletes or motor end-organs; the sensory nerves end in groups of specially modified muscle fibres known as muscle-spindles (see Lesson XIX.).

Development.-- Voluntary muscular fibres are developed from embryonic cells of the mesoderm (muscle-plate), which become elongated, and the nuclei of which become multiplied, so as to produce long slender multi-nucleated fusiform or cylindrical embryonic fibres. According to most recent authorities the embryonic fibres are not formed by the growth of a single cell, but by the joining together

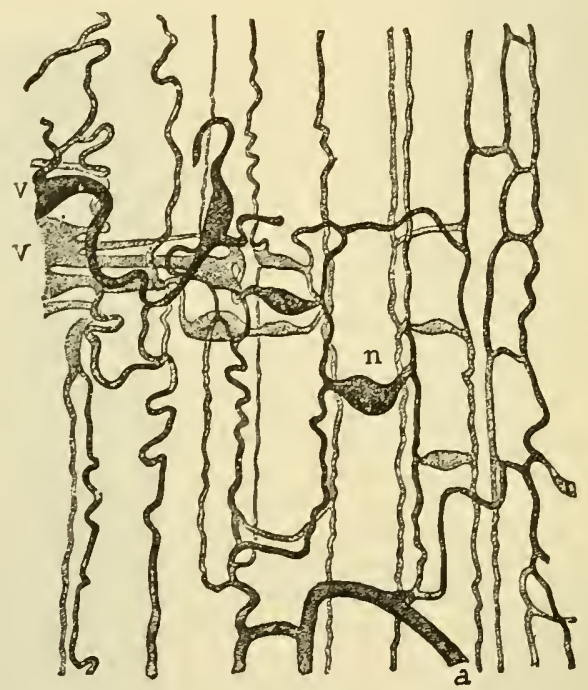

Fig. 138. - VASCULAR NeTWORK OF A RED MUSCle (SEMI-TENDINOSUS) OF THE RABBIT. (Panvier.)

$a$, arteriole ; $v, v$, venules; $n$, dilatation on transverse branch of capillaries.

end to end of a number of cells of the muscle-plate (or even of more than one muscle-plate), so as to produce a syncytium, within which the striated fibrils make their appearance. These appear at first along one side of the fibre, the change gradually extending around the circumference and also penetrating towards the centre; but the protoplasm at the middle of the fibre, to which the nuclei are presently confined, and at the side opposite to that at which the differentiation began, remains for some time unaltered in character (fig. 139). Eventually the change in structure extends to these parts also, and the nuclei pass gradually to occupy their ordinary position under the sarcolemma, which has by this time become formed. The sarcolemma is believed to be produced, not by the muscle-fibre itself, 
but by the mesenehyme or connective-tissue cells between the filres, since it is directly continuons with the connective-tissue bundles of the tendon and of the interstitial tissue.
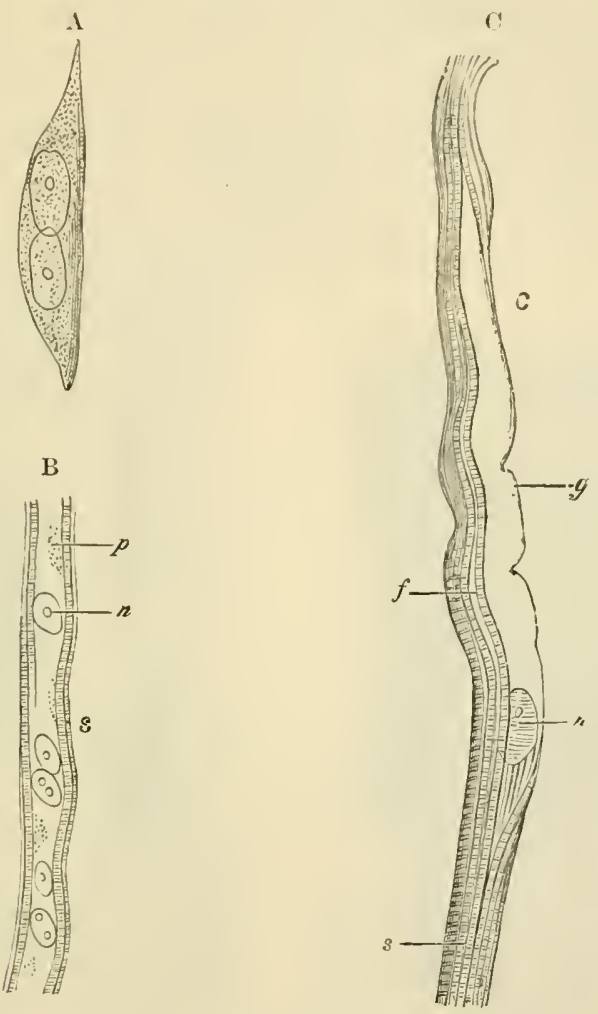

Fig. 139.-Developing júscular fibres.

A, elongated cell with two nuclei. A striation is begiming in the protoplasm along one side of the eell; from foetal sheep. (Wilson Fox.)

B, from human fietus of two months. (Ranvier.) p, central protoplasm with several nuclei, $\imath$, scattercd in it; $s$, commencing sarcolemma, with striated muscular substance dereloping inmediatcly bencath it.

C, from human fetus of three months. (Ranvier.) The contractile substance, $s, f$, now almost incluses the unaltered protoplasm, $g$; only one nucleus, $n$, is represented.

\section{CARDIAC MUSCLE.}

The muscular substance of the heart is composed of transversely striated muscular fibres, which differ from those of voluntary muscle in the following particulars, viz.:- - their striations are less distinct; they have no sarcolemma, although there is a thin superficial layer of non-fibrillated substance; they branch and unite by their branches and also at the side with neighbouring fibres, and their 
nuclei lie in the substance and often near the centre of the fibres. In man and many mammals the fibres are marked off into a series of short cylindrical cells (figs. 140, 141) joined together end to end and side to side, each corresponding to one of the nuclei. The junctions of these cells may be seen in longitudinal sections appropriately stained; they come also distinctly into view in sections of the fresh tissue stained with nitrate of silver. They appear to be bridged across by fine fibrils, continued into the cells above and below the lines of junction (fig. 143). These lines have usually been regarded as intercellular spaces separating the constituent cells of the tissue from one another

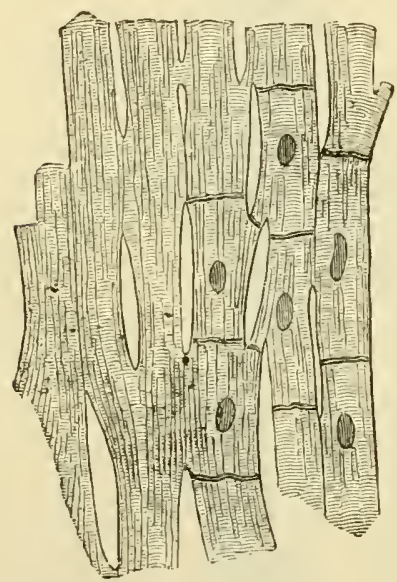

Fig. 140.-MUSCULAR FIBRES FroM THE HEART, MAGNIFIED, SHOWING THEIR CROSS-STRIÆ, DIVISIONS, AND JUNCTIONS. (Schweigger-Seidel.)

The nuclei and cell-junctions are only represented on the right-liand side of the figure.
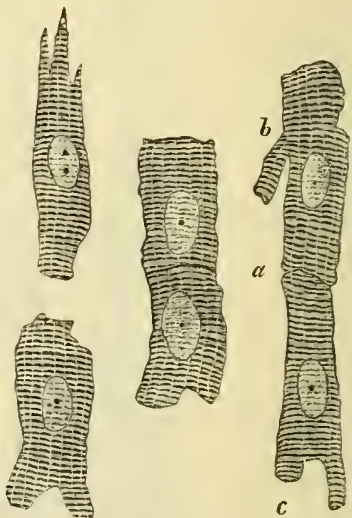

Fig. 141.-Six juscular fibre-CELls FROM THE HEART. (Magnitied 425 diameters.)

$\alpha$, line of junction between two cells; $b, c$, branching of cells. (From a drawing by J. E. Neale.)

(Schweigger-Seidel). But recent authorities (Przewosky, v. Ebner, M. Heidenhain) are inclined to regard the cardiac muscular tissue as forming a syncytium, the cells being all continuous both laterally and longitudinally, and the apparent intercellular lines being special differentiations. These, according to v. Ebner, are due to localised contractions, but, according to Heidenhain, represent portions of the fibres at which growth in length occurs (analogous to the suture-lines between the flat bones of the cranium). As against this view of the structure of the heart-muscle, and in favour of that of SchweiggerSeidel, must be set the silver-staining of the supposed cell-junctions, and the fact that it is easily possible in some animals to separate the fibres after maceration into short nninucleated fragments as in fig. 141. 
The short non-nucleated lengths of fibres (fig. 142), which Heidenhain regards as fatal to the eellular theory, may be parts of cells lying in other planes of the myocardium, which are inserted between those belonging to the plane ineluded in the longitudinal seetion. On the other hand, the continuity of the muscular fibrils within the masses of Purkinje's fibres under the endoeardiun in the sheep, the fibrils around one eell being freely continued around the neighbouring cells (see fig. 304, p. 252), is in favour of the syneytial theory. Further,

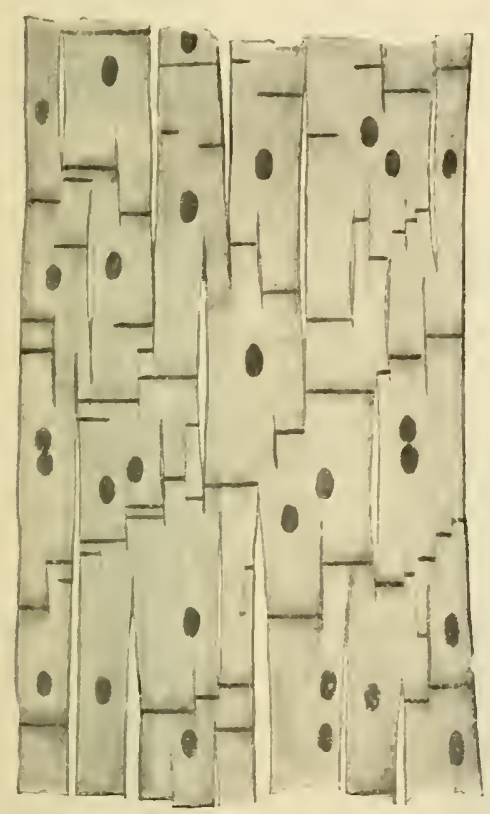

Fig, 142.- Diagray of Segmentatiox OF HEART MCSCLE. (M. Heidenhain.) PARTS OF THE SEgIENTS CONTAIN ONE OR TWO NCCLFI, BUT SOME ARE QUITE SMALL AND NON-NLCLEATED.

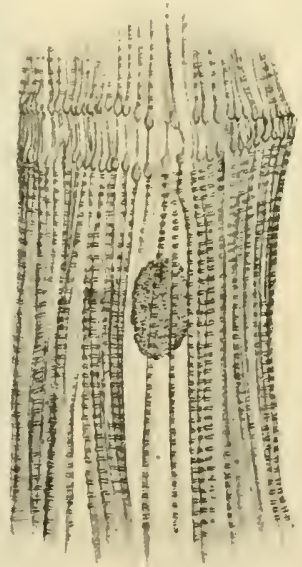

Fig. 143.-PORTION OF CARDIAC ILSCLE EXHIBITING CONTINUITT OF FIBRILS Ackoss Jujctional lixe. (Przewosky.) Highly magnifierl.

in many vertebrates, ineluding some mammals, no cell-territories can be made out in the myoeardium, whilst in others, and especially in man and some mammals, althongh definite cell-territories ean be shown to exist in the adult condition, they are absent in young animals. We must therefore conelude that both eonditions may occur.

The explanation of these differenees appears to lie in the fact that in all heart-muscle at a certain period of development the cells form a syncytium within which the contractile fibrils are developed, and only in mammals is a differentiation of the syncytium into cells produced; the lines of junetion being even here bridged across by the musele-fibrils. 


\section{Non-striated, Shooth or Plain Muscle.}

Involuntary or plain muscular tissue is composed of long, somewhat flattened, fusiform cells (fig. 144), which vary much in length. Each cell has an oval or rod-shaperl nucleus, which shows the usual intramuclear network and commonly one or two nucleoli. The cell-substance

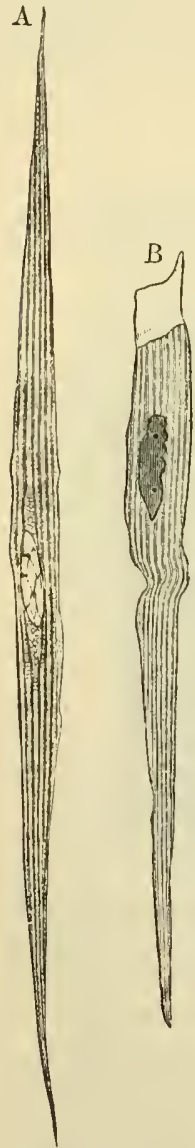

FIG. 144.

FIG. 144.-MUSCULAR FIBRE-CELLS FROM TIE MUSCULAR COAT OH THE SMALL INTESTINE, HIGHLY HAGNIFIED.

$A$, a comllete cell, showing the nucleus with intra-nuclear network, and the longitudinal fibrillation of the cell-substance, with finely vacuolated protoplasm betwcen the fibrils; 13 , a cell broken in the process of isolation; a delicate external layer projects at the broken end a little beyoud the striated substance of the cell.

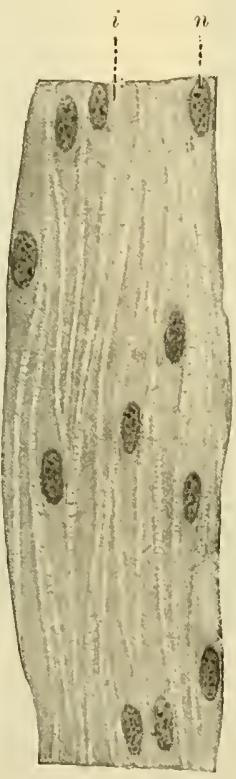

FIG. 145, - MUSCLE-CELLS OF INTESTINE. (Szymonowicz.) Magnified 530 diameters.

The fibres are represented in longitudinal section; and the interstices between them are seen to be bridged across by fine fibrils. $i$, interstice; $n$, nucleus.

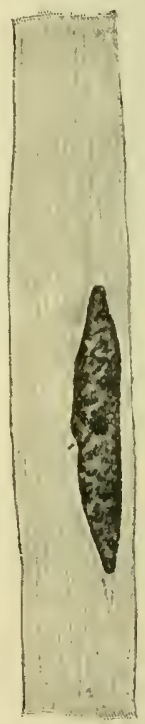

Fig, 146. - PlatiN MUSCle FIBRE, SHOWING NUCLEUS, CENTRIOLE, AND CYTOPLASM WITH FIBRILs. (Lénhossek.)

is fincly fibrillated, but does not exhibit cross-striæ like those of voluntary muscle. There appears, as in cardiac muscle, to be a delicate non-striated external layer, probably a stratum of undifferentiated protoplasm, certainly not a true sarcolemma. Next to this, in some smooth muscle, is a layer containing coarser fibrils (boundary fibrils of M. Heidenhain). There is a little intercellular substance 
which can be stained by nitrate of silver, and which is hridgerl across by filaments passing from ecll to cell (fig. 145). Some authoritics, however, deny that the involuntary cells are thus connected, and hold that the appearance of bridging fibres is due to intercellular connective tissue. It is however difficult to understand how the contractions are propagated from cell to cell if there is no sort of continuity between the cells.

Plain muscular tissue is found chiefly in the walls of hollow viscera ; thus it forms the muscular coat of the stomach and intestines, and oceurs abundantly in the muscular coat of the gullet, although it is here intermixed with cross-striated muscle; it is found also in the mucous membrane of the whole alimentary caual from the asophagus downwards; in the trachea and its ramifications; in the urinary bladder and ureters; in the uterus and Fallopian tubes; in the prostate; the spleen and lymphatic glands; the muscle of Miiller in the orbit, and in the ciliary muscle and iris. The walls of gland-ducts also contain it; and the middle coat of the arteries, veins and lymphatics is largely composed of this tissue. It occurs in the skin, both in the secreting part of the sweat glands, and in small bundles attached to the hairfollicles; in the scrotum it is found abundantly in the subcutaneous tissue (dartos), and it also occurs in the areola of the nipple.

Development.-According to the observations of C. M'Crill, the smooth muscle of the alimentary canal (pig) is developed from the syncytium of mesenchyme cells which surrounds the entoderm. Some of these cells become elongated and spindle-shaped while retaining their inter-comexion. Myofibrils are developed in their protoplasm. These are not confined to the limits of a single cell, but extend over two or even a large number of cells. The myofibrils are of two kinds, coarse and fine, varying in relative number in different parts. The distinction is seen even in the fully formed muscle, which retains its syncytial character, and is not formed of completely separated cclls.

In certain situations smooth muscle is formed from epithelium, as with the muscular tissue of the sweat glands (Ranvier) and that of the iris (Nussbaum, Szili). 


\section{LESSON XVI.}

\section{STRUCTURE OF NERVE-FIBRES.}

1. TEase a piece of fresh nerve rapidly in salt solution (or by the method of semidesiccation, afterwards mounting in salt solution), injuring the fibres as little and obtaining them as long and straight as possible. Study the medullated fibres, carefully noticing all the structures that are visible-viz., nodes of Ranvier, nucleus of primitive sheath, double contour of medullary sheath, medullary segments, etc. Meastre the diameter of half a dozen fibres. Draw a short length of a fibre very exactly.

2. Prepare a piece of sympathetic nerve in the same way. The nerves passing to the spleen are well adapted for the study of non-medullated fibres. They may also be found amongst the medullated fibres of the ordinary nerves. The nuclei may be stained by gentian violet.

3. Separate (in dilute glycerine) into its fibres a small piece of nerve or nerve-root that has been twenty-four hours in 1 per cent. osmic acid. The nerve shonld have been moderately stretched on a piece of cork by means of glass pins before being placed in the acid. Keep the fibres as straight as possible and only tonch them near their ends with the needles. Sketch two portions of a fibre under a high power, one showing a node of Ranvier and the other a nucleus of the primitive sheath. Look for fibres of Remak. Measure the length of the nerve-segments between the nodes of Ranvier.

4. Mount in xylol balsam or dammar sections of a nerve which has been hardened in picric acid and alcolol, or fixed with osmic acid and hardened in alcohol. The sections may be stained with picro-camine or hæmatoxylin. The nerve should be pinned out straight upon a cork with glass pins before being placed in the hardening solutions. Examine the sections first with a low and afterwards with a high power. Notice the lamellar structure of the perineurium, the varying size of the nerve-fibres, the axis cylincler in the centre of each fibre, etc. Measure the diameter of five or six fibres, and sketch a small portion of one of the sections.

5. Study sectious of splenic nerve placed as soon as possible after death in Flemming's solution.

6. Teased preparations and sections from nerves which, some days previously, have been cut nearer the spinal cord. The nerves should have been prepared with osnuc acid, as in $\$ 3$. Notice the breaking up of the myelin of the medullary sheath, varying in degree according to the length of time the section has been made previously. In preparations from the central cut end of the nerve prepared by Cajal's reduced silver method ${ }^{1}$ new fibres may be seen budding from near the extremities of the undegenerated fibres of the stump.

Nerve-fibres are of two kinds, medullated and non-medullated. The cerebro-spinal nerves and the white matter of the nerve-centres are

\footnotetext{
${ }^{1}$ See Appendix.
} 
composed of medullated fibres; the sympathetic nerves near their peripheral distribution are largely made up of non-medullated fibres.

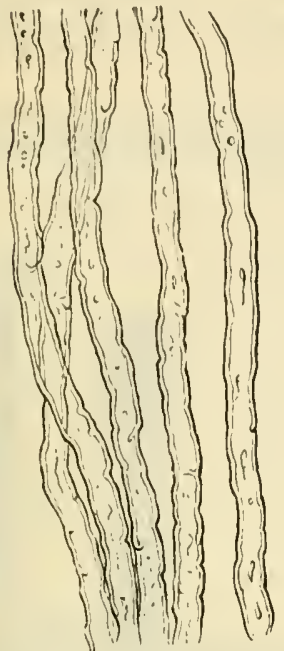

Fig. 147. - White OR Medulated NERVE-FIBRES, SHOWING THE SINCOUS OUTLINE AND DOUBLE CONTOURS.

Fig, 148.-Portions of Two NerveFIBRES STAINED WITH OSMIC ACID, FROM A YOUNG ANIMAL. (Diagrammatic.)

$R, R$, constrictions of Ranvier, with axiseylinder passing through. $a$, neurolemma of the nerve : $c$ opposite the middle of the segment, indicates the nucleus and proto plasm lyiug hetween the primitive sheath and the medullary sheath. In $A$ the nodes are wider, and the intersegmental sub. stance more apparent than in $\mathrm{B}$.

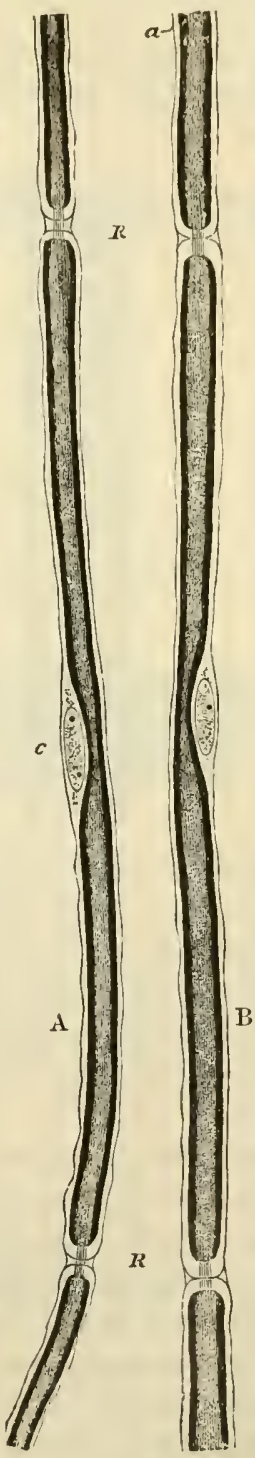

Fig. 148.

The medullated or white fibres are characterised, as their name implies, by the presence of the so-called medullary sheath or white substunce. This is a layer of soft substance, physically of a fatty 
nature, which encircles the essential part of a nerve-fibre, viz., the axis-cylinder. Outside the medullary sheath is a delicate but tough homogeneous membrane, the primitive sheath or nucleated sheath of Schuann, but this is not present in all medullated fibres, being absent in those which are within the nerve-centres. The primitive sheath is known as the neurolemma. ${ }^{1}$

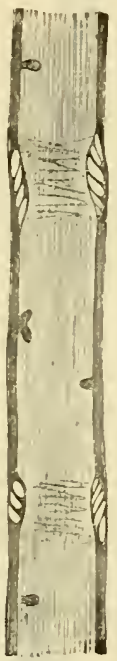

Fig. 149. - A SIALL PART OF A HEDLLLATED FIBRE. (Highly magnified.)

The fibre looks in optical section like a tubehence the term tubular, formerly applied to these fibres. Two partial breaches of continuity (medullars clefts) are seen in the medullary sheath, which at thesc placesexhibits a tendency to split into lamine. The primitive sheath is here and there apjarent outside the mednllary sheath, and the delicate stria which are visible in the middle of the fibre indicate the fibrillations of the axis eylinder.

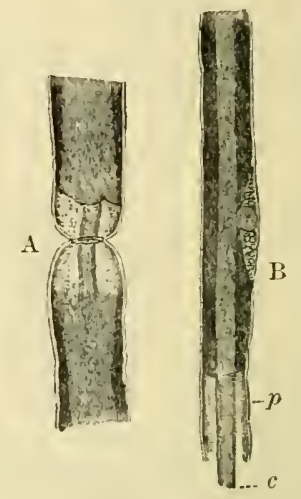

FIG. 150.-Two PORTIONS OF MEDCLLATED NERVE-FIBRES, AFTER TREAT. YEXT WITH OSMIC ACID, SHOWING THE AXIS-CYLINDER AND THE MEDULLARY AXD PRIMITIVE SHEATHS. (Key and Retzius.)

A, node of Ranvier. B, middle of an internode with nucleus. $c$, axis-cylinder projecting; $p$, primitive sheath, within which the medullary sheath, which is stained dark by the osmic acid, is broken away for a short distance.

The medullary sheath is composed of a highly refracting fatty material (myelin), which gives a characteristic dark contour and tubular appearance to the nerve-fibres (fig. 147). It affords a continuous investment to the axis-cylinder, except that, as was shown by Ranvier, in the peripheral nerve-fibres it is interrupted at regular intervals. At these places the neurolemma appears to produce a constriction in the nerve-fibre, and the interruptions of the medullary sheath are accordingly known as the constrictions (Ranvier) or nodes (figs. 148, 151), the latter term being applied from the resemblance which they bear to the nodes of a bamboo. It is, however, uncertain whether the constriction is

'Often termed "neurilemma," a name formerly applied also to the sheath of Henle (see p. 136). 
entirely oceupied by the neurolemma itself or partly by a special band (constricting bend of Ranvier) of a material which resembles intereellular substance in its reaction to nitrate of silver (fig. 16\%). The length of nerve between two suecessive nodes is termed an internode; in the middle of each internode is one of the nuclei of the

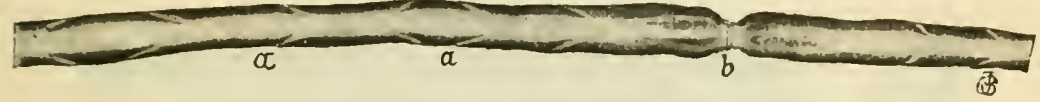

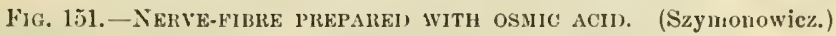

b, constriction of Ranvier. The intervals between the medulliry segments appear as elear oblique lines, a, a.

neurolemma. Besides these interruptions the medullary sheath shows a variable number of oblique clefts (Lantermann) (figs. 149, 151), subdividing it into irregular portions, which have been termed medullery segments; but there is some reason to believe that the clefts are artificially produeed. At the clefts there is an appearance of spiral fibres in the medullary sheath, especially after treatment of the nerve

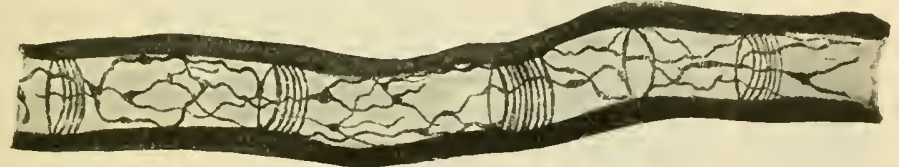

Fig. 152.-SPIRAL AND RETICUlar FiBrils IN THE SHEATH OF A NeRveFIBRE, (Golgi.)

with certain reagents (Golgi) (fig. 152); it is, however, possible that this appearance does not represent any pre-existing strueture. A reticular appearance has also been deseribed in the medullary sheath (neurokerutin network of Kühne), and ean be readily seen in nerve fibres fixed in alcohol and treated with ether, but it varies greatly in aspect, and is perhaps produced by the action of the reagents

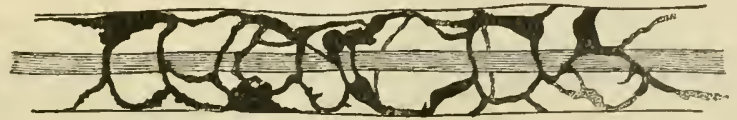

Fig. 153.- Recticular apprarance ix the jedlilary sheath or a NERVE-FIBRE. (Gedoelst.) (From the guinea-pig.)

employed to show it (figs. 152, 153). By other modes of fixation (e.g. picrie acid) the medullary sheath seems to have a rod-like structure (fig. 155); this again may be due to the manner in which certain of its constituents are coagulated by the reagent. Osmic acid stains the medullary sheath black (figs. 151, 154, 156). 
The axis-cylinder, which runs along the middle of the nerve-fibre, is a soft transparent thread which is continuous from end to end of the nerve. On account of the peculiar refractive nature of the medullary sheath it is difficult to see the axis-cylinder in the fresh nerve except at the nodes, where it may be observed stretching across the interruptions
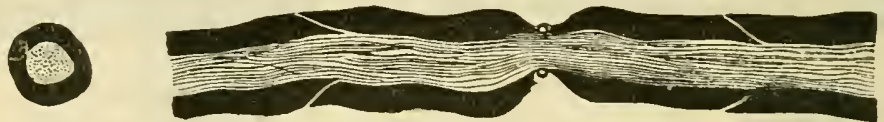

FIG. 154.-LONGITUDIXAL AND TRAXSVERSE SECTION OF MEDLLLATED NERTEFIBRE OF FROG (OSMIC ACID AXD ACID FCCHSINE). (After Biedermamn.)

The longitudinal section shows one node of Ranvier and two of Lantermann's clefts. The fibrillar structure of the axis-eylinder is shown in both longitudinal and transrerse section.

in the medullary sheath: it may also sometimes be seen projecting from a broken end of a nerve-fibre. It is longitudinally striated, being made up of exceedingly fine fibrils (newrofitrils, fig. 15t). They are

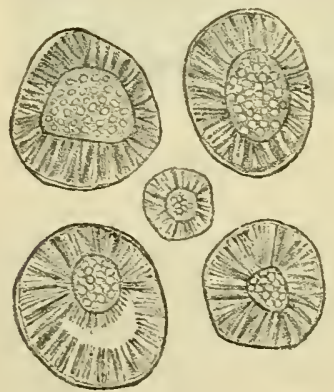

Fig. 15. - SECTION ACRONS FIVE NERTEFIBREs. (Magnified 1000 diameters.)

The nerve was hardened in picric acid and stained with picro-carmine. The radial striation of the medullary sheath is very apparent. In one fibre the rays are broken by shrinkage of the axis-cylinder. The fibrils of the axis.crlinder aj'pear tubular. (From a photograph.)

those which are passing to the skin and to the voluntary muscles; the smallest are those which are distributed to the viscera and bloodressels by way of the antonomic nerves. ${ }^{1}$ As shown by Gaskell, the

${ }^{1}$ This term has been introdnced by Langley to include both the nerves of the sympathetic system and also the analogous nerves which proceed from the cranial and sacral regions for the innervation of certain involuntary muscles and secreting glands. 
anterior roots of the last one or two cervical nerves, of all the thoracic, of the first and second lumbar, and of the second and third sacral nerves contain besides the ordinary large medullated fibres a bundle of very small medullated fibres which are destined for the

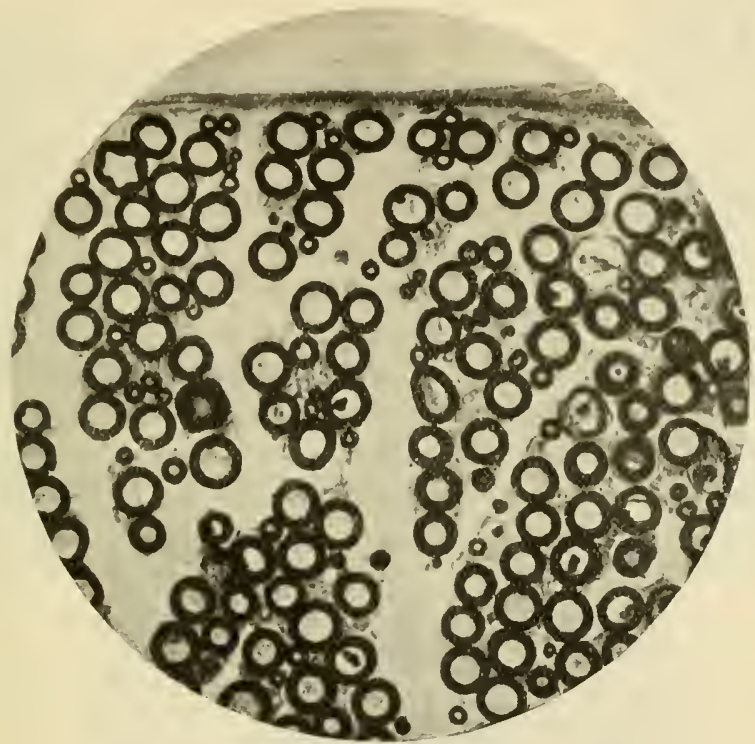

Fig. 15̃6. - SECTION OF THE SCIATIC NERVE OF A CAT, SHOWING THE VARIATIONS IN SIZE OF ITS CONSTITUENT FIBREs. (Magnified 300 diameters.) The nerve was fixed with osmic acid.

viscera and blood-vessels, and which for the most part pass to the sympathetic system. The roots of some of the cranial nerves (the spinal accessory, vagus, glossopharyngeal, and facial) contain similar fine medullated fibres.

Non-medullated fibres.-Intermingled with the medullated fibres there may always, even in the cerebro-spinal nerves, be found a certain

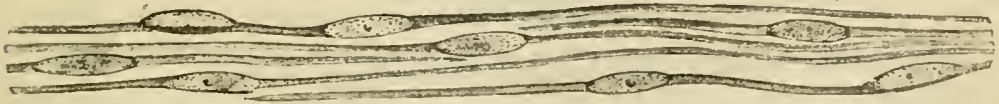

Fig. 157.-Non-mendllated Nerve-Fibres. (Magnified 400 diameters.)

number of pale fibres devoid of the dark double contour which is characteristic of the presence of a medullary sheath. These are the grey or non-medullated fibres, also called, after their discoverer, fibres of Remak (fig. 157). They frequently branch, which the medullated 
fibres rarely do except near their termination, and they are beset with numerous nuclei which perhaps belong to a delicate sheath, but this is not certain, and undoubtedly both in longitudinal view and

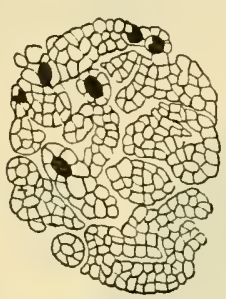

Fig. 158.-SECTION ACROSS NON-MEDULLATED FIBRES FROM THE SPLENIC NERVE of THE ox. (Tuckett.) in cross section the nuclei seem to lie in the substance of the fibres. The sympathetic nerves, as they approach their peripheral distribution, are largely made up of fibres of this nature, but many of the fibres contained in the sympathetic nerves possess a thin medullary sheath, and have the usual structure of medullated fibres.

Structure of the nerve-trunks.-In their course through the body the nerve-fibres are gathered up into bundles or funiculi, and the funiculi are again united together to form the nerves which we meet with in dissection. The connective tissue which unites the funiculi and invests the whole nerve, connecting it to neighbouring

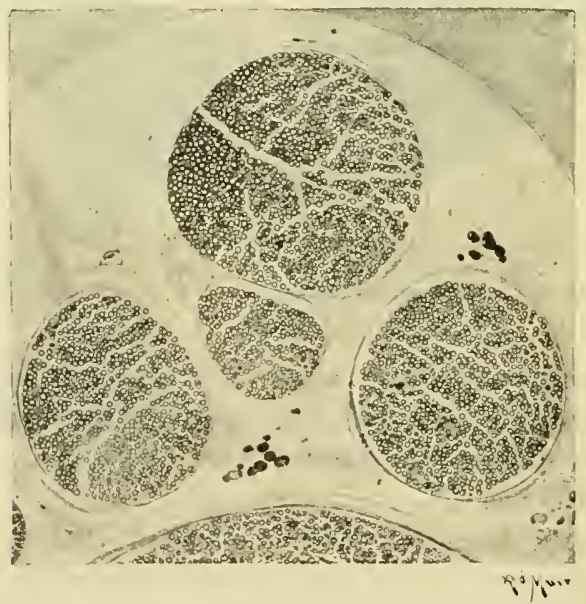

Fig. 159.-SECtion of PART OF a NERVE-TRUNK FIXEI) WITH OSMIC ACID. (From a photograph.) Magnified 40 diameters.

Three small funiculi and a small part of a larger funiculus are shown. The fat-cells in the epineurium are staincd black by the osmic acid.

parts and conveying to it blood-vessels, lymphatics, and even nervefibres destined for its coats, is termed the epineurium; it frequently contains fat-cells: That which ensheaths the funiculi is known as the perineurium (figs. 159 to 161). It has a distinctly lamellar structure (fig. 160), the lamellæ being composed of connective tissue covered by flattened epithelioid cells (fig. 162, A). Between 
the lamella are elefts for the conveyance of lymph to the lymphatics of the epineurium. The delicate comnectire tissue which lies between the nerve-fibres of the funiculus is the endoneurium. It assists in

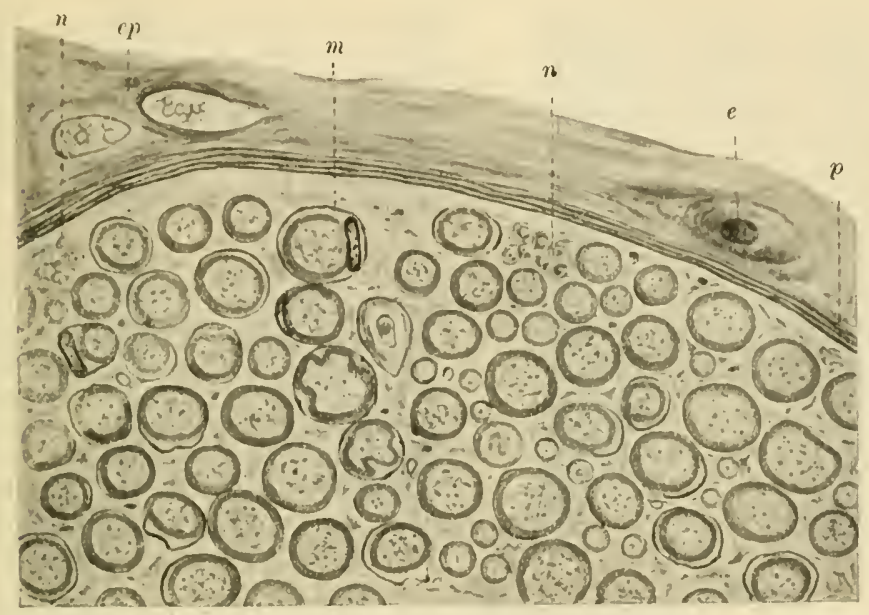

Fig. 160.- Section of PART OF A funiculus of THE SCIATIC NERVE OF A CAT Fixen With Fleming's solution. Magnified 400 diameters.

$c p$, epineurium with blood-vessels ; $e$, section of an end-bulb; $n$, perineurium ; $m$, medullated fibre cut at the level of a nueleus; $n, n$, bundles of non-medullated filures.

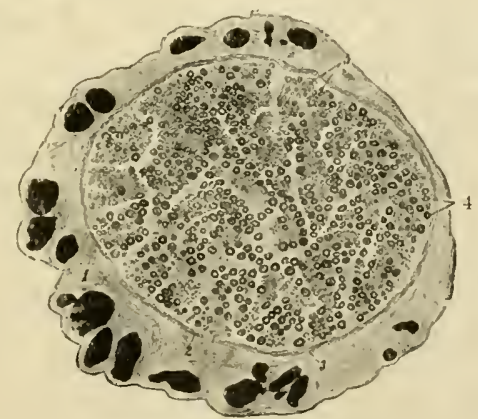

Fig. 161.-SECTION OF THE THORACIC SYMPATHETIC CORD OF THE CAT. (Fischer.) Osmic preparation.

The nerve is composed in almost equal parts of fine medullated fibres $(3,4)$ derived from the thoracic anterior roots, and grey fibres (5) derived from the sympathetic ganglion-cells. The dark bodies in the cpineurium (1) are fat-cells ; 2, perineurium.

supporting the longitudinally arranged meshwork of blood-capillaries, and its interstices communicate with the lymph-clefts of the perineurium.

All the branches of a nerve, and even single nerve-fibres which 
are passing to their distribution, are invested with a prolongation of the perineural sheath, which is then known as the sheath of Henle.

A

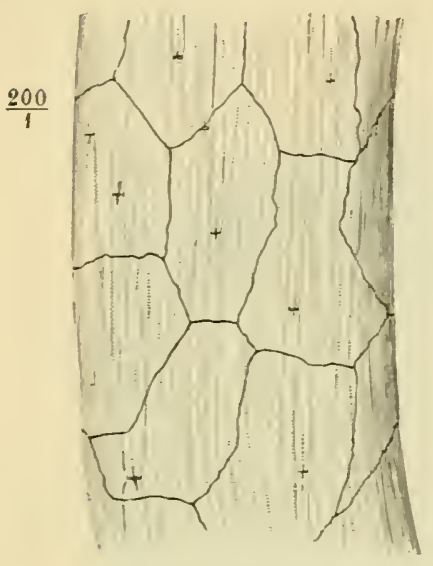

B

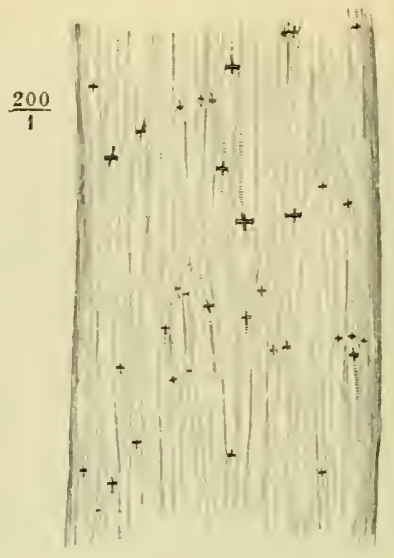

i

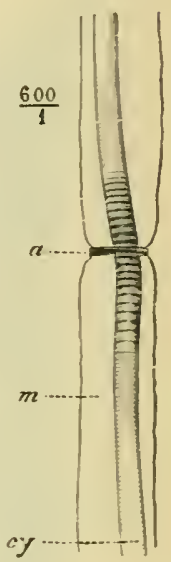

Fig. 162.-Nertes stainen with Silter mitrate. (Ranvier.)

In $A$, the epithelial-like layer of flattened cells belonging to the sheath of Heule is stained. In $\mathrm{B}$, the cross-like markings at the nodes are exhibited. In C, a single fibre is shown more highly magnifed, with Fromann's transterse markings of the axiscylinder. $a$, constricting band; $m$, nedullary sheath; $c y$, axis-cylinder.

The nerve-trunks themselves receive nerve-fibres (nervi nerrorum) which ramify chiefly in the epineurium and terminate within this in end-bulbs (Horsley) (fig. 160,e).

The degenerative processes which occur in cut nerve-fibres as well as the subsequent reparative processes will be dealt with after the structure of nerve-cells has been studied (see p. 154). 


\title{
LESSONS XVIT. AND XVIII.
}

\author{
NERVE-CELLS.
}

1. Put a small piece of spinal ganglion into 1 per cent. osmic acid for a few hours. Place in water containing a fragment of thymol for two days or more. Tease in dilute glycerine. Notice the spheroidal ganglion-cells; their large muclei and distinct nucleoli. Many of the cells may still be seen within their nucleated membranous sheath. Look for cells which still retain the axis-crlinder process and for $\mathrm{T}$-shaped junctions of nerve-fibres with this. Fat-cells may be present in the periganglionic connective tissue. These will appear intensely black in osmic preparations.

2. Prepare in the same way a spinal ganglion or the Gasserian ganglion of the skate or cod. Notice the bipolar character of most of the cells.

3. Prepare a piece of sympathetic ganglion as in $\$ \$ 1$ and 2 . If from a rabbit observe that many of the cells are bi-nncleated.

Measure two or three cells in each of the above preparations.

4. Mount stained sections of ganglia, both spinal and sympathetic. These will serve to show the arrangement of the cells and fibres in the ganglion and the nucleated sheaths around the nerve cells.

The ganglia may be fixerl and hardened in saturated solution of corrosive sublimate or of picric acid or in 10 per cent. formol. They may either be stained in bulk or sections cut from paraffin and stained on the slide by Nissl's method. Ehrlich's methylene blue method, Golgi's silver chromate method, or Cajal's silver reduction method, especially the last namerl, are all useful for showing the cells and their comections with nerve-fibres. These methods are described in the Appendix.

5. Place a portion of the grey matter from a piece of spinal cord in 33 per cent. alcohol. After macerating for two days or longer in this fluid, a little of the grey matter may be shaken up in a test-tube with water so as to break it up into fine fragments. Allow these to subside, decant off the water and substitute a dilute solution (1 to 500) of metlyylene blue or solution of picrocarmine. When it appears sufficiently stained some of the debris is pipetted off and examined under a low power of the microscope; at first without a cover-glass so that the cells may, if necessary, be separated from the rest of the tissue. Mount in water with a thick hair under the coverglass. Notice the large branching cells, some with a mass of pigment near the nucleus. Observe the fibrillation of the cell-processes. Many axiscrlinders will be seen in this preparation deprived wholly or partially of their nedullary sheath, and their fibrillar structure can then also be well seen. Carefully sketch these appearances. To keep the methylene blue preparation the stain must be fixed with picrate of ammonia, after which a mixture of glycerine and picrate of ammonia may be used for mounting. If picrocarmine is used the specimen is simply preserved in dilute glycerine. Similar preparations may be made from the grey matter of the cerebral cortex and cerebellar cortex. 
6. Examine sections of spinal cord, medulla oblongata anil brain stained by methylene blue (Nissl's methoul), to exhibit the angular particles within the nerve-cells.

7. Examine sections of parts of brin, spinal cord and ganglia prepared by Cajal's method, to exhibit the nemo-fibrils in the cells and cell-processes.

8. Examine the nerve-cells and nemroglia-cells in sections from the spinal cord, cerebrum, or cerebellum of a small animal, e.g. young lat or kitten, frepared by Golgi's method. The spetions must be momteil in thick xylol balsam or dammir varnish, withont a cover-glass, and dried rapidly on a war'm plate.

9. Examine sections of spinal cord (lmmbar enlargement) and corresponding spinal ganglia from an animal in which the sciatic nerve had been cut about three weeks before it was killed. 'The sections are to be stained by Nissl's method. Many of the anterior horn nerve-cells and of the ginglioncells on the side of the lesion will exhibit the chromatolysis or breaking down of the Nissl granules, which is characteristic of cells the axoms of which have been severed. They may be compared with the normal cells on the intact side.

Nerve-cells, neurocytes or neurones.-Nerve-cells occur in the grey matter of the nerve centres, and in little groups on the course of certain of the peripheral nerves, these groups often causing nodular enlargements of the nerves, which are known as ganglia. The most conspicuons ganglia are those which are found upon the posterior roots of the spinal nerves, upon the roots of some of the cranial nerves, and upon the trunk and principal branches of the sympathetic nerve. Minute ganglia are also found very numerously in connection with the nerves which are supplicd to glands and involuntary museular tissue, as in the salivary glands, heart, alimentary canal, bladder, uterus, etc.

Nerve-cells vary much in size and shape; many are large, some being amongst the largest cells met with in the body, but others are quite small. All nerve-cells possess at least one process, the axon, which becomes either a non-medullated fibre or the axiscylinder of a medullated fibre. If other processes are present they are always branched almost from their commencement at the cell-body, and they are therefore termed dendrons (dendrites). The mucleus is generally large, clear, and spherical, with a single large and distinct nucleolus; there may also be a network of chromatin, but this is not always to be seen. The cytoplasm is fibrillated, the fibrils passing into the processes; they are known as neuro-fibrils (p. 132), and are believed to be the actual conductors of nerve-impulses. It also contains pecnliar angular particles (Nissl gramules) staining deeply with methylene blue, but the size, number, and arrangement of these in different cells vary greatly (fig. 163). The granules also vary in number and size with the physiological condition of the cells; thus it is fom 
A

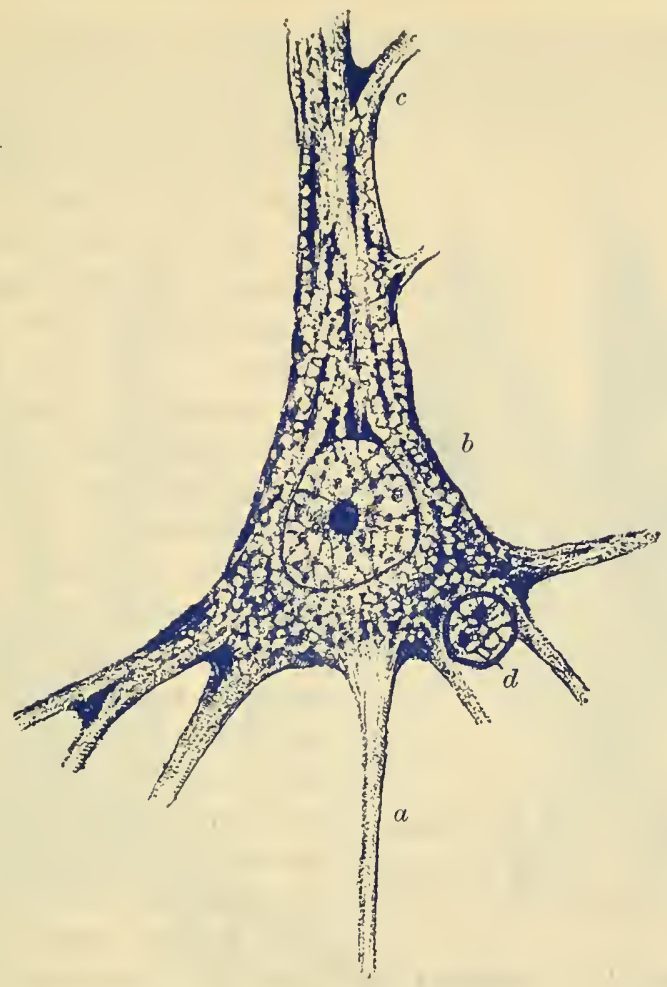

B

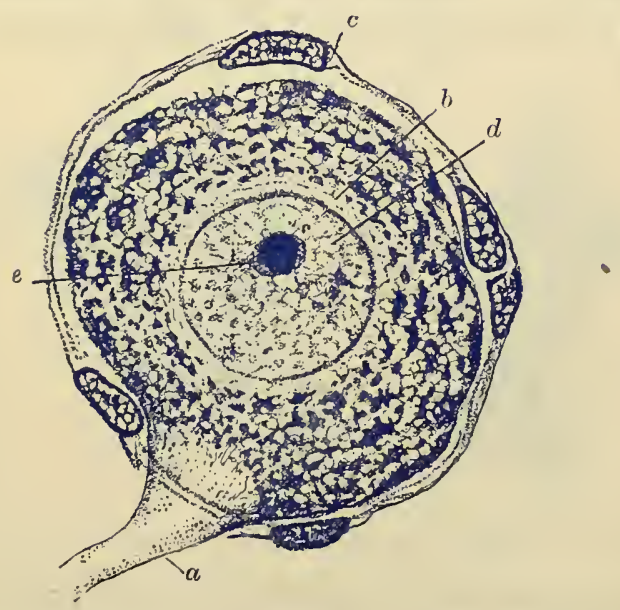

Fig. 163.-MULtipolar AND UNipolar tyPES OF NERTE-CELL.

A, Large pyramidal cell of cerebral cortex, human. Nissl method. (Cajal.) a, axon; $b$, cell-body; $c$, apical dendron; $d$, placed between two of the basal dendrons points to the nucleus of a neuroglia cell.

$B$, Unipolar cell from spinal ganglion of rabbit. Nissl method. (Cajal.) $a$, axon; $b$, circummuclear zone, poor in granules; $c$, capsule; $d$, network within nucleus; $e$, nucleolus. 
that nerve-cells which have been fatigued by prolonged activity (fig. 164), and also those the axis-cylinder process of which has been cut

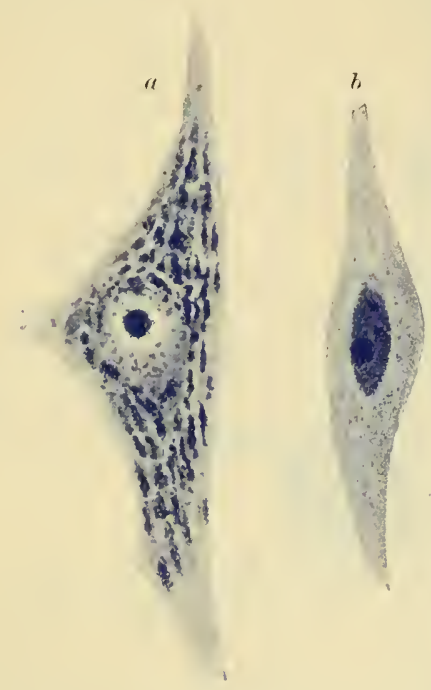

Fig. 164.-Two MOTOR NERVE-CELLS FROM THE DOG.

$a$, normal; $b$, after a period of prolonged activity. (Photographed from preparations by Dr, Gustav Mann.)

(fig. 165), show the Nissl granules beconing disintegrated; they may even disappear for a time from the cell. A similar result is found to occur after the action of poisons which especially affect the nervous system. The Nissl granules of the nerve-cell appear to consist chemically mainly of nucleoproteid; they contain organically combined iron (Macallum). Many nerve-cells have also a clump of pigmentgranules, containing lecithin, at one side of the nucleus. This is especially marked in certain localities (locus cœruleus, locus niger), and is more frequent in man than in the lower animals. The pigment also tends to increase in amount as age advances.

As already stated, the body of every nerve-cell is traversed by fine fibrils (neuro-fibrils) continuous with those in the axis-cylinder of the issuing nerve and with similar

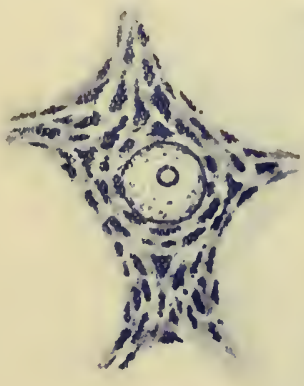

A

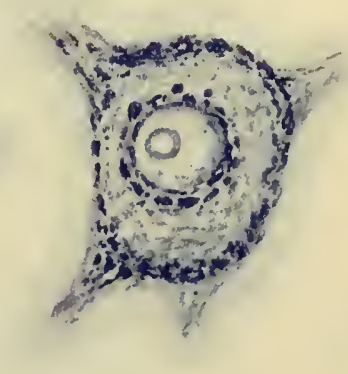

B

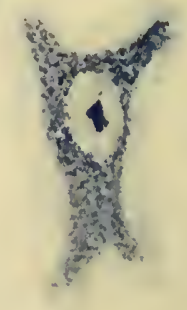

C

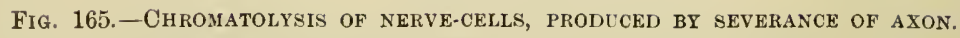

(Diagrammatic.)

A, Nissl granules normal; B, commencing chromatolysis, the cell and nucleus swollen and the granules beginning to disintegrate (the nucleus is usually close to the periphery at this stage); $\mathrm{C}$, advanced condition of chromatolysis, the cell and nucleus shrunken. 
fibrils in their dendrons. They were noticed by Max Schultze, but their course and connections were first accurately described by Apáthy in the nerve-cells of certain anuelids. They can be seen without any difficulty in the nerve-cells of vertebrates (fig. 166) by the employ-

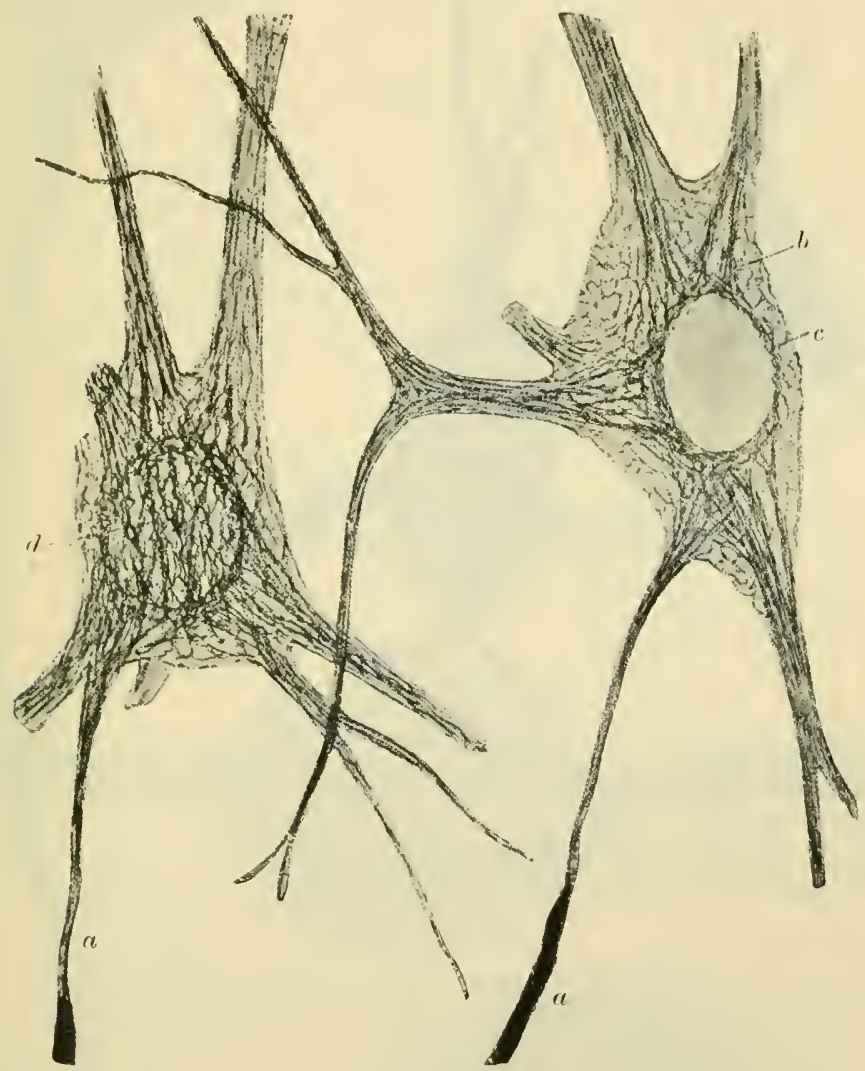

Fig. 166. - NERVE-CELLS OF KITTEN (FROM THE ANTERIOR CORPORA QUADRigeMiNa) SHOWING NEURO-FIBRILS. (Cajal.)

", axon; $b, c, d$, various parts of the intracellular plexus of fibrils.

ment of the silver reduction method of Cajal. The neuro-fibrils are said to present variations in thickness according to the condition of activity of the animal at the time of death.

Most, if not all, nerve-cells show a delicate superficial reticulum (fig. 167), described by Golgi, which is generally regarded as composed of neuro-fibrils, but, according to J. Turner, may be an investment derived from neuroglia-cells. Golgi has also described another network 
of fibrils with somewhat larger meshes (deep reticulum of Golgi) (fig. 168) in the deeper parts of the cell. According to some authorities both
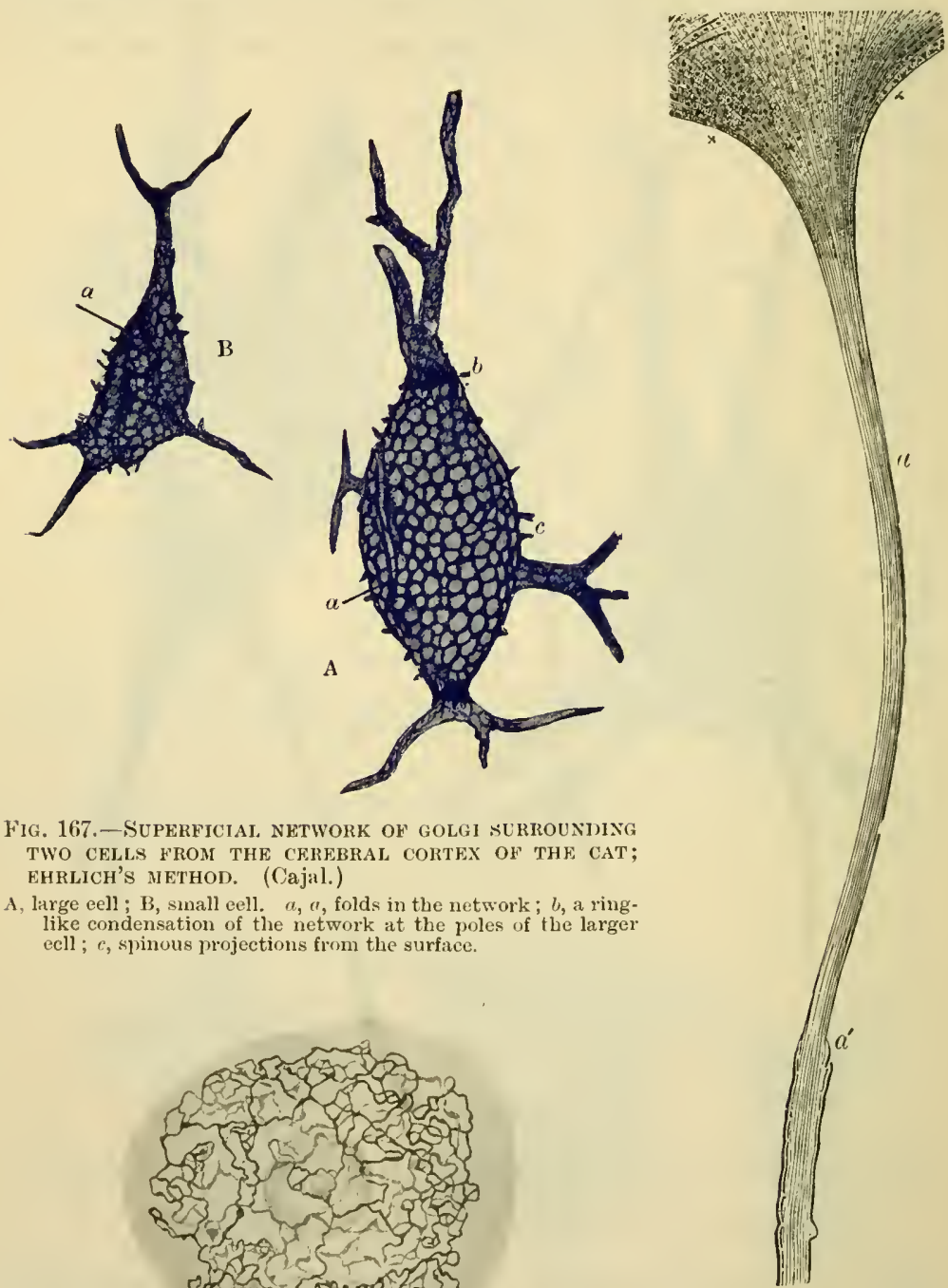

Fig, 167.-SUPEREICIAI, NETWORK OH GOLGI SURIRONDING TWO CELLS FROM THE CEREBRAL CORTEX OF THE CAT; EHRLICH'S METHOD. (Cajal.)

$A$, large eell ; B, sinall eell. $a, ~ "$, folds in the network ; $b$, a ringlike condensation of the network at the poles of the larger ecll; $c$, spinous projections from the surface.

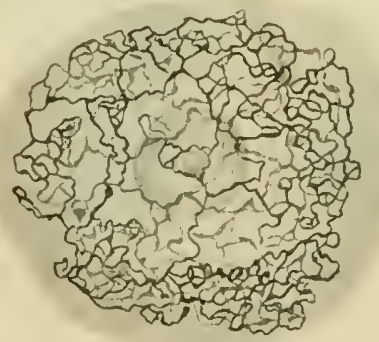

Fig. 169. - AXIS-CYLINDER PROCESS OF A NERVECELL FRO\$ THE SPINAL CORD. (M. Schultze.)

FIG. 168.-NERVE-CELL FROM SPINAL GANGLION, SHOWING $\times \times$, portion of the cell-body, NETWORK AROUND THE NUCLEUS. (Golgi.) out of which the fibrils of the axis-cylinder process, $u$, arc seen to emerge. At ' ${ }^{\prime}$ ', this proeess dequires a medullary sheath. (Highly magnified.) 
superficial and deep networks are in continuity throughout the cell, and receive and are prolonged from the nenro-fibrils of an entering axon on the one hand, and with those of the axis-cylinder process of the nerve-cell, and also of the dendrons, on the other hand. Other authorities regard these networks as distinet from the neuro-fibrils, which they suppose to run independently throngh the nerve-cell borly. entering it by way of the dendrons and emerging in the axon.

'TROPHOSPONGIUM OF NERVE-CEIL.S. - Entirely distinct from the fibrils is a system of fine canaliculi, which has been described by E. Holmgren, permeating the cytoplasm of the nerve-cell body for the purpose of subserving its nutrition by conveying plasma into its substance (see fig. 4, p. 4). These channels are stated by Holmgren to be occupied by branching processes of other (connective-tissue or neuroglia) cells. In the very large nerve-cells from which the nerves of the electric organs of Malapterurus arise blood-vessels penetrate into the eytoplasin.
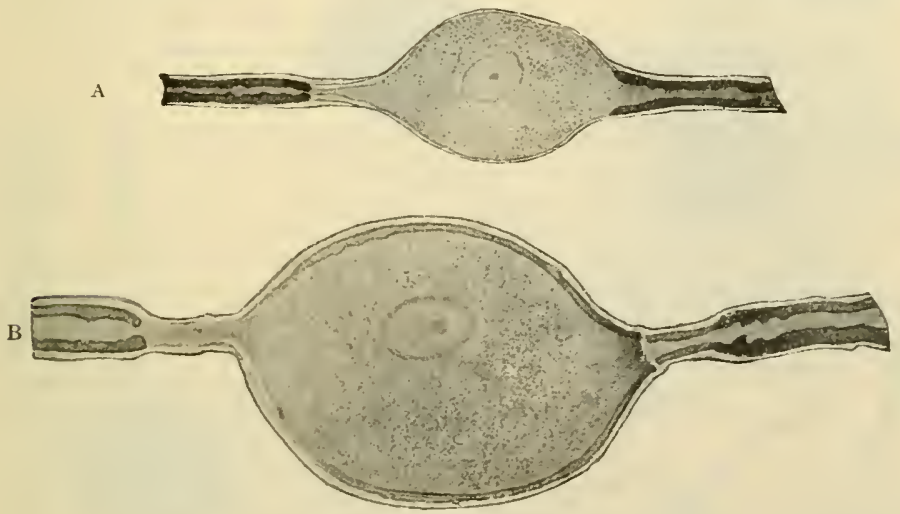

Fig. 170.-TWo BIPOLAR GANGLION CELls (FISH). (Holmgren.)

In $B$ the medullary sheath is continued as a thin layer over the cell-body.

Processes of nerve-cells. - As already intimated the processes are of two kinds. The tirst is that known as the axis-cylinder process (Deiters) or nerve-fibre process, so called because it becomes the axis-cylinder of a nerve-fibre (fig. $169 a, a^{\prime}$ ); in the case of the non-medullated fibres, it becomes the nerve-fibre itself. It is also termed the neuruxon or simply the axon.

Probably no nerve-cell is without this process. The place where it arises from the body of the nerve-cell (cone of origin) is marked off from the rest of the cell-substance by absence of Nissl granules (see fig. 163). The other processes of the nerve-cell are those which were termed by Deiters the protoplasmic processes; they are now nsually termed the 
dendrons or dendrites and are generally multiple, whereas the axon is generally single. The dendrons are characterised by the fact that as soon as they leave the cell they begin to branch dendritically, whereas the axis-cylinder process does not branch until near its

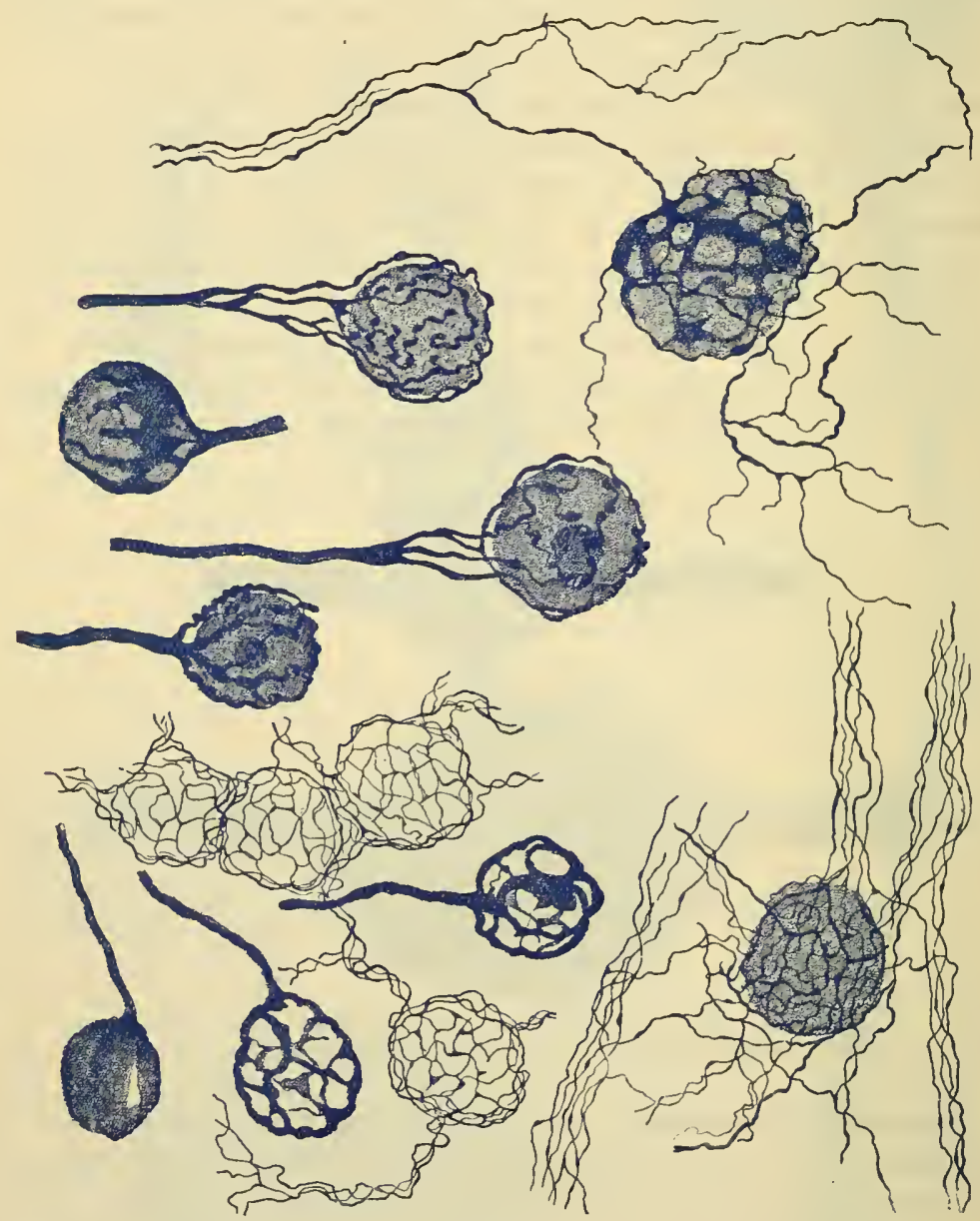

Fig. 171.- TARIOUS FORNS OF PERICELLULAR ENDING OF ENTERING NERVE FIBRES IN THE TRAPEZOID NUCLEUS OF THE CAT. (Edinger, after Veratti.)

termination, with the exception of a few fine lateral offshoots, which are sometimes given off in its course. Dendrons may be absent; the cell is then adendric. Most nerve-cells have only one nerve-fibre process (unipolar), but some have two or more (bipolar, multipolar). The dendrons contain Nissl's granules, but the axons do not. 
The shape of the cell depends largely on the number of processes, and the manner in which they come off from the eell. If there is but one chief proeess the cell is generally nearly spherical. This is the case with most of the cells of the spinal ganglia (fig. 163, B); in these the single process, after a short course, divides into two fibres, which pass the one centrally the other peripherally (fig. 178). When there are two main processes from a nerve-cell they often go off in opposite directions from the cell, which is thus rendered somewhat spindle-shaped (fig. 170), but oceasionally they emerge at the same part. When there are three or more processes, the cell becomes irregularly angular, as in the motor-cells of the spinal cord and the pyramidal cells of the cerebral cortex.

In some eases where there appear to be two fibres connected with a cell, one of them is derived from another nerve-cell elsewhere, and is passing to end in a ramification which envelops the cell-body. In certain situations the ramification is coarse and forms a calyx-like investment to the cell-body: this investment may be so intimately united to the body of the second cell that it appears to be rooted into the external layer (fig. 171); in other places the pericellular fibrils are very fine and form a felt-work

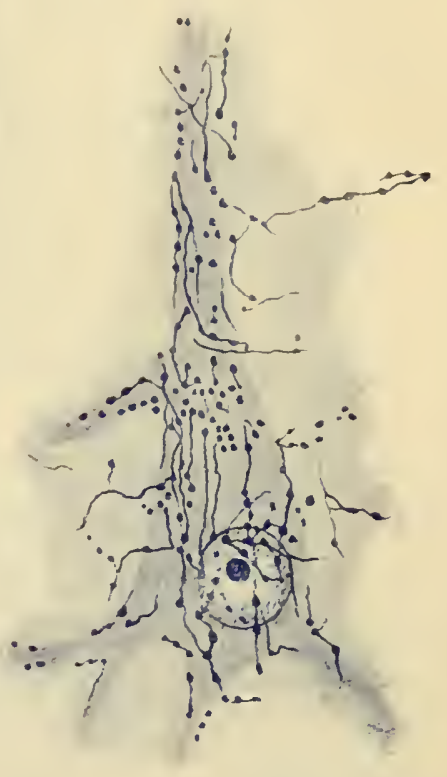

Fig. 172.-PERICELlular NeURo-Fibrils AROUND A LARGE PYRAMIDAL CELL OF THE HUMAN CORTEX CEREBRI. ${ }^{1}$ Methylene blue preparation.

over the cell-body (fig. 172), the fibrils eoming in contaet with the surface of the cell and sometimes ending in small button-like enlargements or varicosities.

In preparations made by Golgi's ehromate of silver method the nerve-cells and their processes are coloured black by a deposit of redueed silver, so that the processes can be traced for a considerable distance from the body of the cell, in fact in many instances as far as their remotest ramifieations. It is found by the employment of this method that the axis-cylinder process is not always an unbranched process, as was formerly supposed, but that it usually, if not invariably,

${ }^{1} \mathrm{I}$ am indebted to Dr. J. Turner for the drawing here reproduced. 


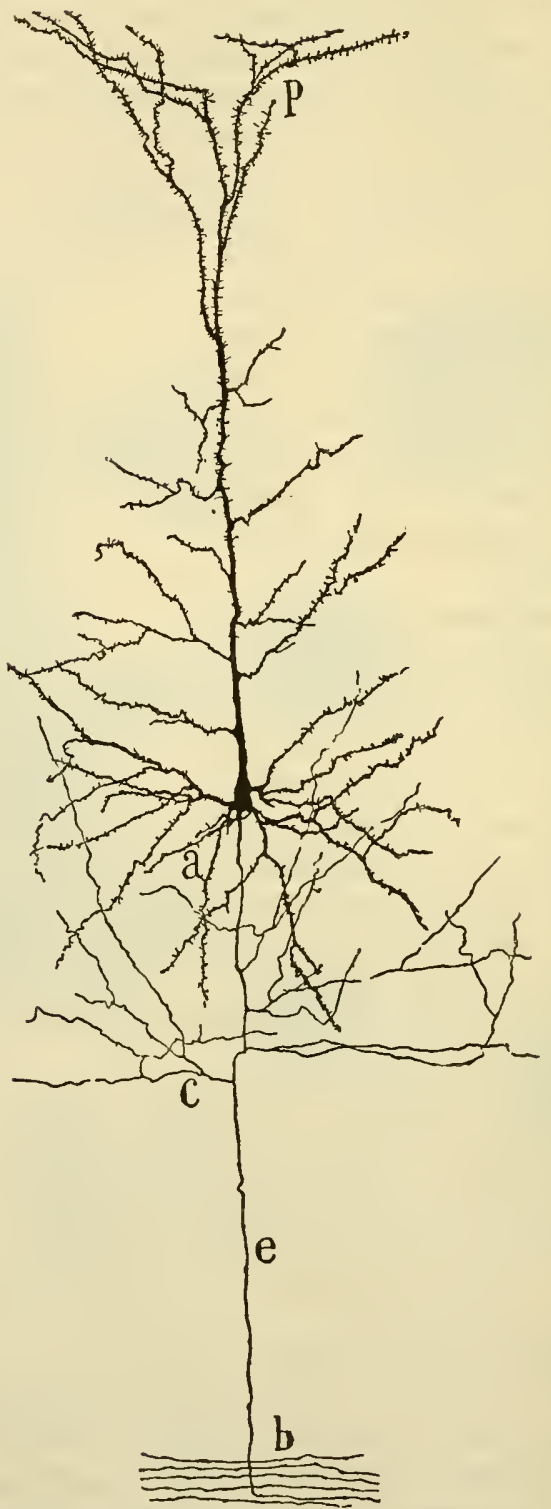

Fig. 173. - A pyramidal cell of the cortex cerebri of the rabBit. (Cajal.)

$a$, basal dendrons; $p$, apical dendron ramifying near surface ; $e$, axon ; $c$, its collaterals ; $b$, fibres of white matter of brain. 


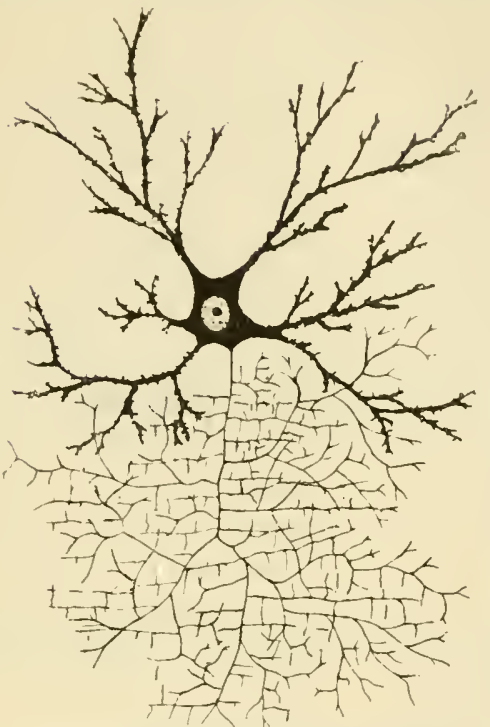

Fig. 174.-CELI. OF TYPE II. OF GOLGI, WITH SHORT AXON RAMIFYING IN THE ADJACENT GREY MATTER.

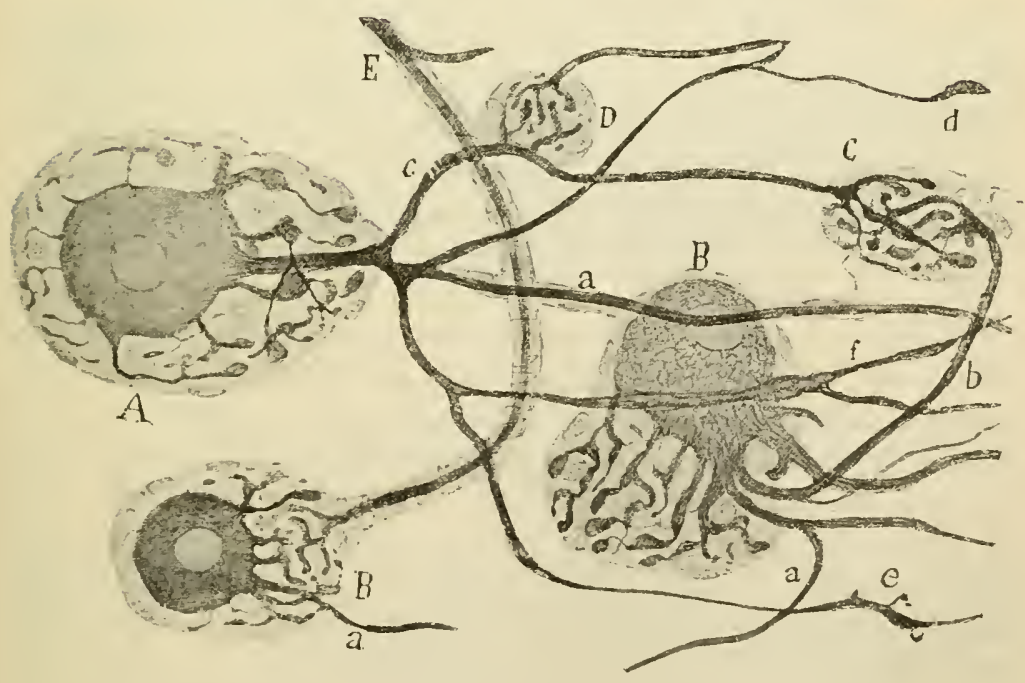

Fig. 175.-SYNAPTIC CONNECTIONS OF STMPATHETIC CELLS FROM THE SUPERIOR CERVICAL GANGLION OF MAN. (Cajal.)

The cells (A, B) show well-marked intracapsular dendrons. C, D, synapses between dendrons outside the cell-capsules; $\mathrm{E}$, a fibre, which is itself surrounded by a fine spirally wound fibril, passing to a cell and forming a synalse with the cell-dendrons within the capsule. $a, a$, axons; $b, c, d, e, f$, extra-capsular dendrons. 
gives off fine lateral branches (collaterals), which themselves tend to ramify in the adjacent nerve-substance (fig. 173). And although the

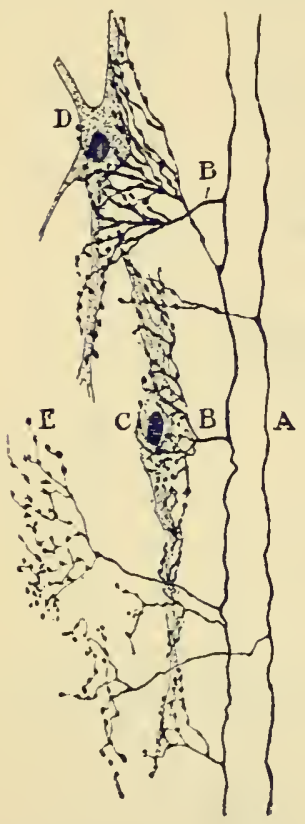

F1G. 176.-ARBorisation of COLLATERALS FROM THE POSTERIOR ROOT-FIBRES AROLNII CELLS IN THE POSTERIOR HORI OF GREY MATTER. (Cajal.)

A, fibres of posterior column derived from posterior root; $\mathrm{B}$, collaterals ; C, D, nerre-cells in grey matter surrounded by the arborisations of the collaterals; $\mathrm{E}$, an arborisation shown separately. main part of the axiscylinder process usually passes on and becomes part of a long medullated nerve-fibre (cell of type I. of Golgi, fig. 173), this is not always the case, for in another type of nerve-cell within the nerve-centres (cell of type II. of Golgi, fig. 17t) the axis-cylinder process breaks up almost immediately into an arborescence. Moreover, the long process of type I. (which becomes the axis-cylinder of a long nerve-fibre) ultimately ends in a similar manner, that is to say, in a terminal ramification or arborescence, as will be seen in studying the endings of nerve-fibres, and the structure of the central nervous system.

Neurone theory. - Each nerve-cell is generally regarded as an anatomically independent element (nerve-unit, neurone), and the connection of one nerve-cell with another is believed to be effected through the medium of the terminal arborisations of the dendrons or axons. Such arborisations from different cells may interlace with one another (as in the olfactory glomeruli, in the retina, and in the sympathetic ganglia) (fig.

$175)$, or a terminal arborisation from one cell may embrace the body or the cell-processes of another cell; as with the cells of the spinal cord (fig. 176) and the cells of the trapezoid nucleus of the pons Varolii (fig. 171) and in many other places. The term neuro-synapse may be applied to these modes of junction. By them nerve-cells are linked together into long chains of neurones, the physiological path being uninterrupted, although the anatomical path is, as above indicated, believed to be interrupted at the synapses.

The doctrine of the anatomical independence of the nerre-cell is known as the "neurone-theory" (Waldeyer). It is supported by the appearances of chromate of silver preparations of nerve-cells. In these the reduction of the silver is strictly confined to single cells, which become stained with all their 
processes; and these processes, when demonstrated by this method, are never found in continuity either with the processes or with the bodies of other. nerve-cells. Moreover many of the facts relating to nerve-degeneration can be more reatily interpreted by this theory than by one which assumes the existence of direct continnity between the nerve-units. But it las been shown by Apáthy that in amnelius (the nervous system of which was formerly supposed to offer a typical example of isolated, linked "neurones"), the fibrils are in fact continuous from cell to cell and are not interrupted at the symapses; it is therefore possible that the same may prove true for vertebrates also, in which case the doctrine of independent units would require modification. We may at any rate assume the truth of the hypothesis so far as the nutrition of all the processes of the nerve-cell to their remotest termination is concerned, independently of the question whether there is or is not anatomical continuity of nerve-fibrils from one unit to the other; for there are many examples in both animal and plant cells of such interlependence by means of fibrils, combined with trophic independence.

\section{STRUCTURE OF G.ANGLIA.}

In the ganglia (fig. 177) each nerve-cell has a nucleated sheath which is continuous with the neurolemma of the nerve-fibre with which the

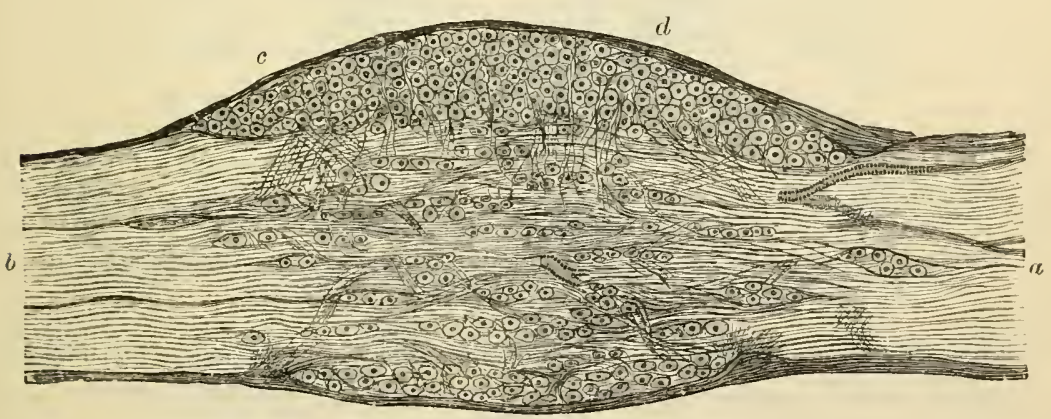

Fig. 177.-LONGITUDiNAL SECTION THROUGH THE MIDDLE OF A GANGLION ON THE POSTERIOR ROOT OF ONE OF THE SACRAL NERVES OF THE DOG, AS SEEN UNDER A LOW MAGNIY'TING POWER.

$a$, nerve-root entering the ganglion; $b$, fibres leaving the ganglion to join the mixed spinal nerve; $c$, connective-tissue coat of the ganglion; $d$, principal group of nervecells, with fibrcs passing down from amongst the cells, to unite with the longitudinally coursing nerve-fibres by T-shaped junctions.

cell is connected. In the spinal ganglia, and in many of the corresponding ganglia on the roots of the cranial nerves of mammals and of most other vertebrates, the cells have only one issuing process, the axis-cylinder process, which soon acquires a medullary sheath and then passes with a somewhat convoluted course to some little distance from the cell-body, where, still within the ganglion, it divides into two, one fibre passing to the nerve-centre, and the other towards the periphery. 
The branching is T-shaped or Y-shaped, and alwars occurs at a node of Ranvier (figs. 178, 179). The neuro-fibrils of the central and peripheral branches retain their individuality in the common trunk and are traceable into a neuro-fibril network within the cell-body. These spinal ganglion-cells have, as a rule, no dendrons, but some show

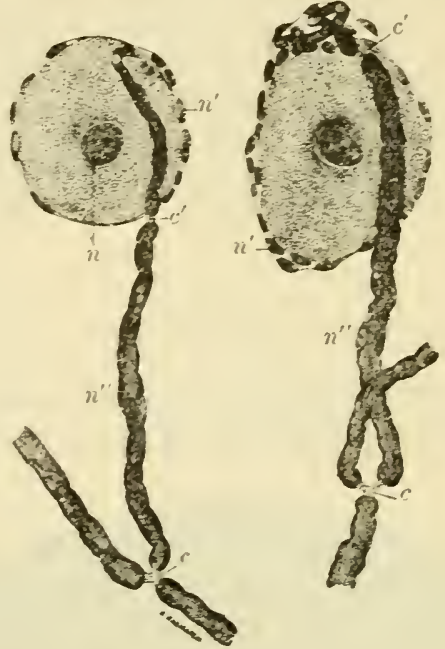

Fig. 178.-Two SPINAL GANGLION-CELls, SHOWING BIFCRCATION OF THEIR SERTE-FIBRE PROCESSES. (Pantier.)

$n$, nucleus of one of the cells; $n$; nuclei of capsules; $n^{\prime \prime}$, nuclei of Schwann's sheath; $c, c, c^{\prime}, c^{\prime}$, constrictions of Ranvier.

short dendrons terminating in bulbous enlargements (fig. 182) either within the cell-capsule or immediately outside it (Huber, Cajal).

The origin of the axon is not always simple, but may be multiple, the several parts forming at first a plexus close to the cell, eventually joining to produce a single axon. This multiple condition tends to become accentuated with age (fig. 183). The intracapsular dendrons also occur in sympathetic ganglia (Cajal) (figs. 175, 185).

Two chief types of cells occur in the spinal ganglia, one large and clear, the other small and staining almost uniformly dark (fig. 179). As was first shown by Dogiel, the cell-body of the spinal ganglion-cell is partially invested by the convoluted ramifications of a fine afferent nerve-fibre, derived either from one of the other cells of the same ganglion or from a cell in a neighbouriug sympathetic ganglion (fig. 180). Similar afferent fibres forming pericellular plexuses als', occur in the sympathetic ganglia (fig. 186).

In the sympathetic ganglia the nerve-cells usually have several dendrons and one axon; this usually becomes a non-medullated nerve- 


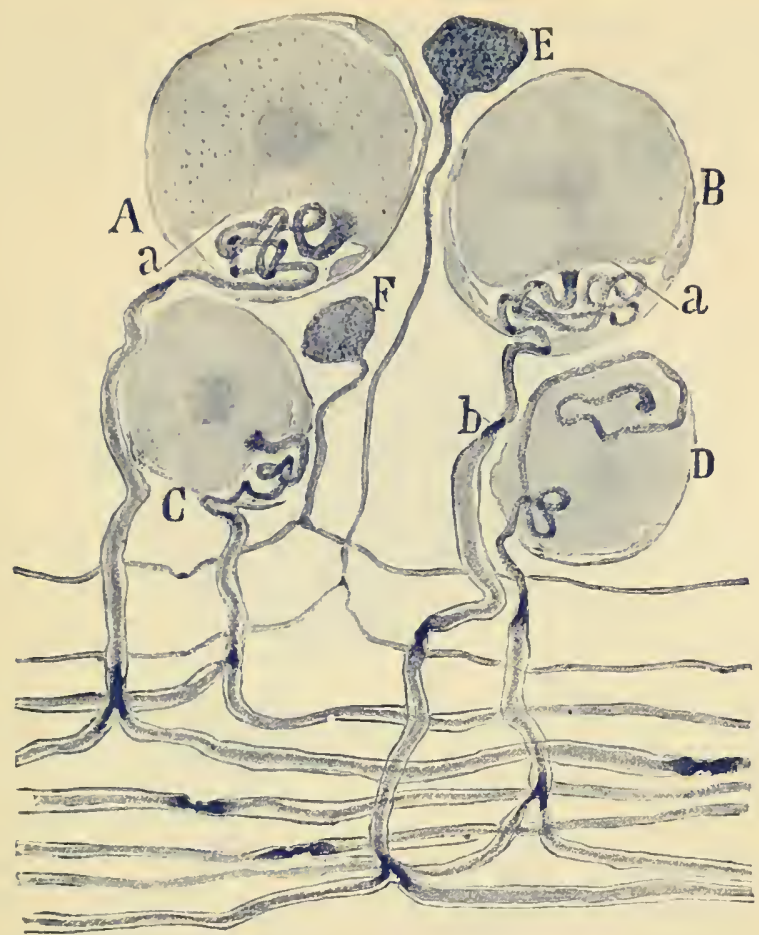

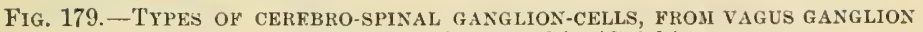
OF CAT. (Ehrlich's method.) (Cajal.)

A, B, large cells with much convoluted commencement of axon ; C, D, smaller cells ; E, F, smallest cells, staining darkly and without convolutions.

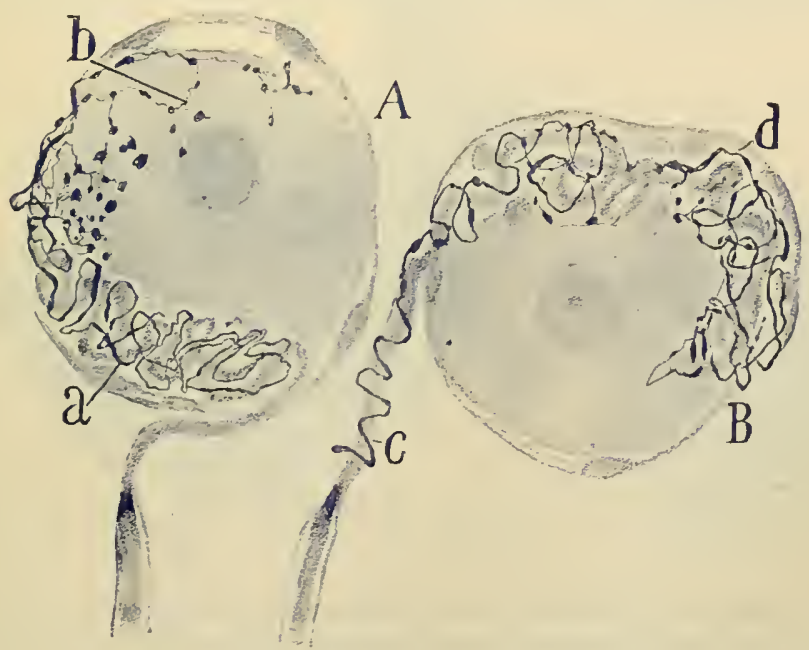

Fig. 180.-Pericellular arborisations in spinal ganglion-cells. (Cajal.)

In $\mathrm{A}$ the arborisation extends over the cell-body; in $\mathrm{B}$ it is limited to the axon. $a, b, c, d$, afferent fibre. 


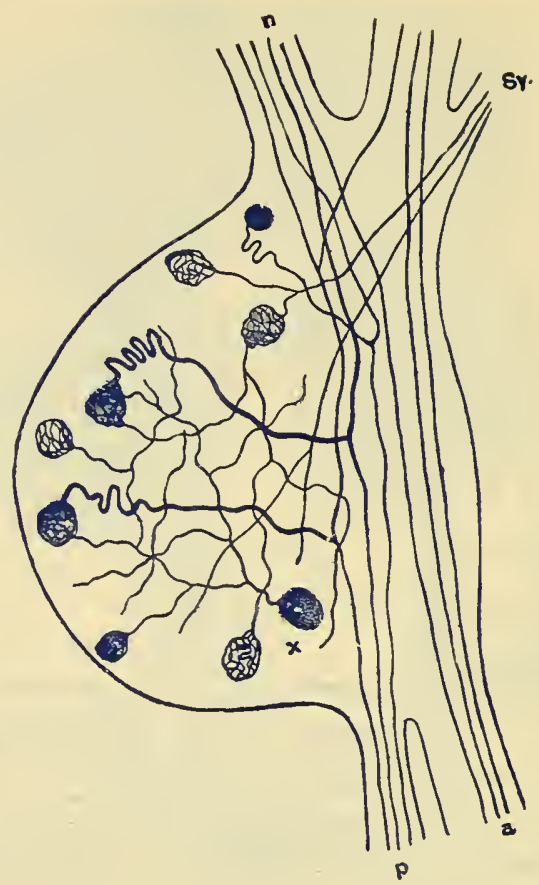

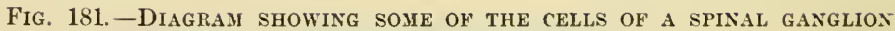
AND THEIR CONNECTION WITH NERVE-FIBRES. (Uogiel.)

$a, p$, anterior and posterior root of spinal nerve ; $n$, an issuing nerve bundle ; $8 y$, fibres from sympathetic; $x$, a cell, the axon of which ends in ramifications around the cell-bodies of the ordinary ganglion-cells.
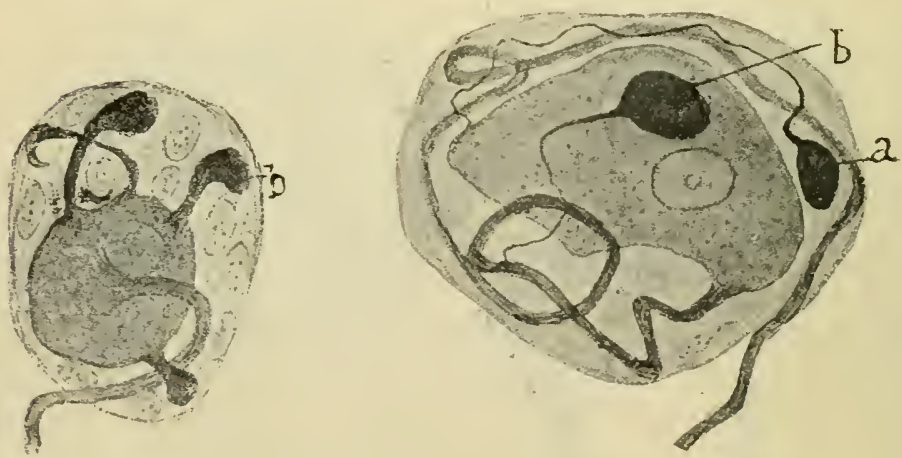

Fig. 182.-Cerebro-spinal Gajglion-CElls, Max. (Cajal.) $a, b$, intracapsular dendrons, with knobbed extremities. 
fibre, but is occasionally finely medullated. In certain animals (rabbit, hare, guinea-pig) the sympathetic cells have each two nuclei (fig. 184). In the frog they are unipolar, but sometimes with a second spiral fibre winding round the issuing axon.

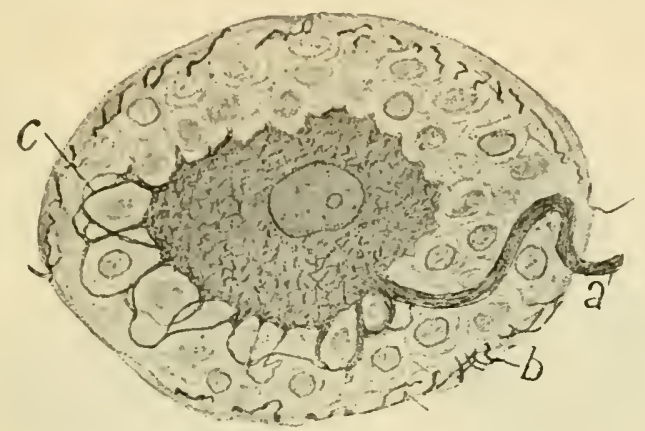

Fig. 183. - Senile type OF Cerebro-SPinal GaNglion-Cell. (Cajal.) $a$, issuing axon ; $b$, part of pericellular plexus; $c$, pericellular loops.

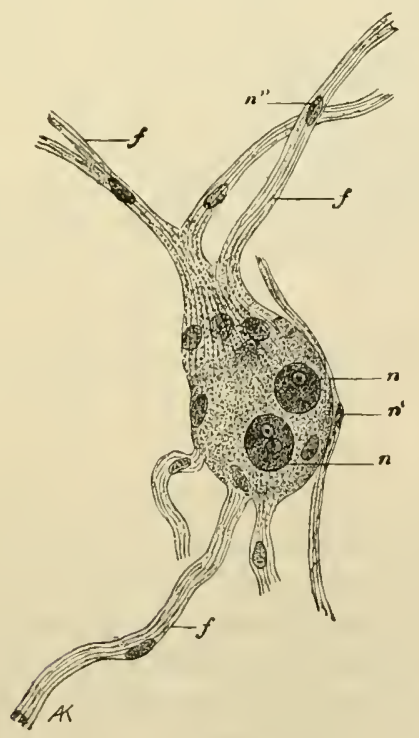

Fig. 184.-A sympathetic NeRve-Cell. (Ranvier.)

$n n$, nuclei of cell; $f, f$, pale fibres issuing from cell ; $\eta^{\prime}, n^{\prime \prime}$, nuclei on fibres.

The cells of ganglia are disposed in aggregations of different size, separated by the bundles of nerve-fibres which are traversing the 
ganglion (fig. 177). The ganglion if large is inclosed by an investing capsule of connective tissue which is continuous with the epineurium and perineurium of the entering and issuing nerve-trunks.

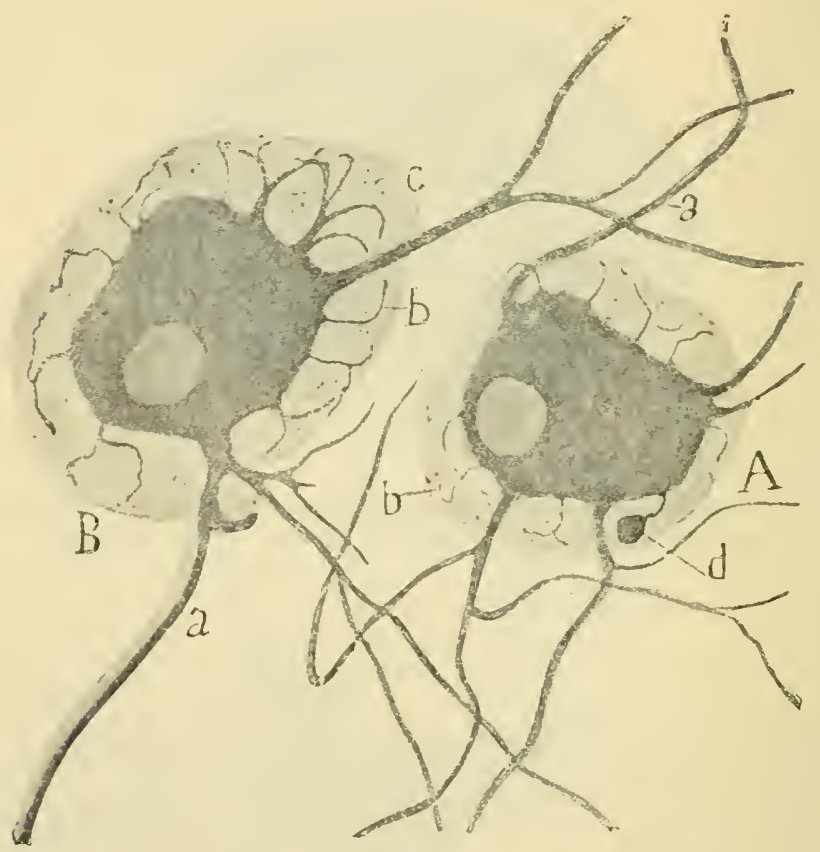

Fig. 185.- -Two sympathetic celis, Mas. (Cajal.)

$a, a$, axon; $b, c$, intracapsular dendrons ; $d$, knob-like ending of an intracapsular dendron.

\section{DEGENERATION AND REGENERATION OF NERVE-EIBRES AND NERVE-CELLS.}

Since each nerve-fibre is the process of a nerve-cell, when a nerve is cut, the separated part degenerates. Its axis-cylinder becomes broken up and disappears, the nuclei of the neurolemma multiply, and the medullary sheath undergoes a process of disintegration into droplets of fatty substance which stain intensely like fat itself in a mixture of bichromate of potash and osmic acid which does not stain the medullary sheath of normal fibres. The change which results in the fibres was described by $\mathrm{A}$. Waller in 1850 , and is known as Wallerian degeneration (fig. $187, \mathrm{~A}$ to $\mathrm{C}$ ). In man and mammals these changes begin $2 t$ to 48 hours after section of the nerve, and proceed rapidly, so that by the 
third day the nerve-fibres cease to conduct impulses. When a peripheral nerve is eut, all the nerve-fibres distal to the point of section must degenerate, becanse all have grown from and are processes of nerve-cells in or near the nerve-centre - the afferent fibres from the cells of the ganglion on the posterior root, the efferent fibres from the cells of the anterior horn of the spinal cord.

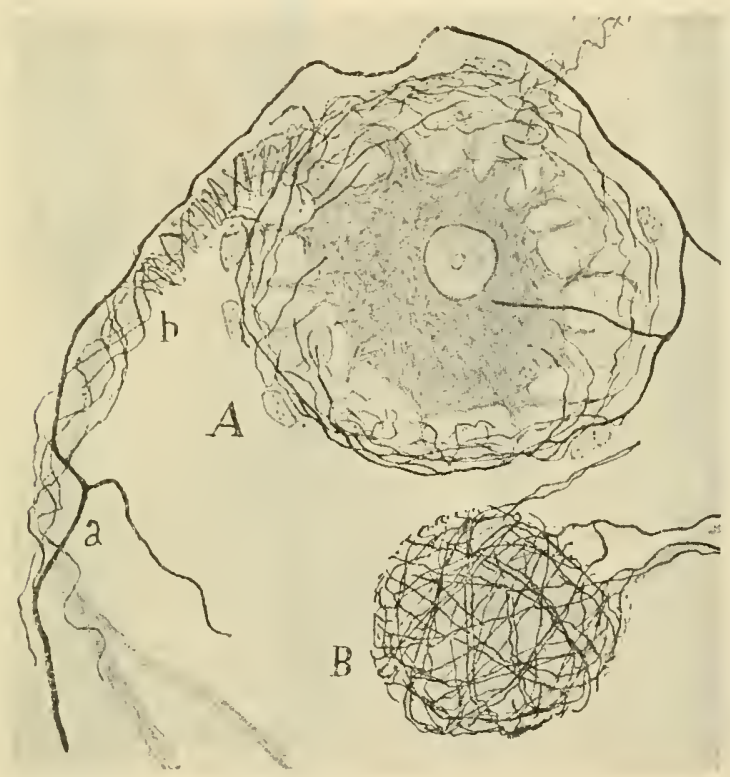

Fig. 186. - TWO CELLS IROM A SYPATHETIC GANGLION OF MAN SHOWING THE TERMINATION OF AFFERENT FIBRES WITHIN THE CELI-CAPSUI.. (Cajal.)

A, large ; B, small eell. $a, b$, afferent fibres surrounding a dendron and passing into eapsule.

Waller supposed that no changes are produced centrally to the injury when a nerve is cut, nor indeed is there any obvious immediate alteration in the nerve-fibre itself between the injury and the cellbody, although it is stated that the fibrils of the axis-cylinder disappear for a time. But it was found by Nissl that degenerative changes oceur in the cell-body of every cell, whether motor or sensory, the axis-cylinder of which has been severed. ${ }^{\mathrm{I}}$ These changes become

${ }^{1}$ But section of the posterior root-fibres central to the ganglia does not entail degeneration of the ganglion cells from which they arise. Nor does section of a spinal nerve always entail degeneration of the anterior horn cells from which its motor fibres arise (Van Gehuchten). Why these apparent exceptions occur is not understood. 
apparent a few days after section of the nerve-fibre and consist in a disintegration of the chromatin granules, associated at first with a general swclling of the cell-body and nucleus, which passes to the periphery of the cell. After a time the disintegrated chromatic substance becomes in great measure removed and the cell-body and

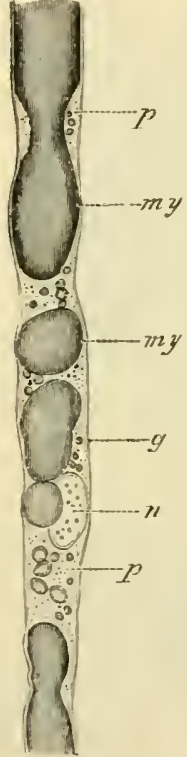

A
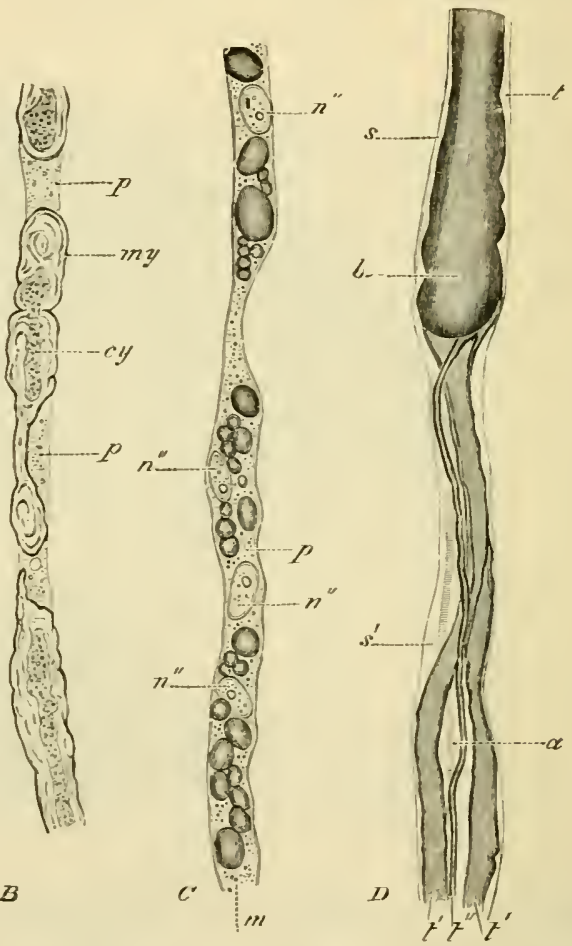

FIG. 1ST.-DEGENERATION AND REGENERATION OF NERTF-FIBRES IN THE RABBIT. (Ranvier.)

$A$, part of a nerse-fibre in which degeneration has commenced in consequence of the section, fifty hours previously, of the trunk of the nerve higher up; my, medullary sheath becoming broken up into drops of myelin; $p$, granular protoplasmic substance which is replacing the myelin: $n$, nucleus: $g$, neurolemma. $B$, another fibre in which degeucration is proceeding, the nerve having been cut four days previously; $p$, as before; $c y$, axis-cylinder partly broken up, and the pieces inclosed in portions of injelin, mu. $C$, more advanced stage of degeneration, the medullary sheath having almost disappeared, and being replaced by protoplasm, $p$, in which, besides drops of fatt substance, $m$, are nmmerous nuclei, $n^{\prime \prime}$, which have resulted from the division of the single nucleus of the interuode. $D$, commencing regener. ation of a nerre-fibre. Several small fibres, $t^{\prime}, t^{\prime \prime}$, hare spronted from the somewhat bulbous cut $e n d, b$, of the original fibre, $t ; a$, an axis-cylinder which has not ret acquired its medullars shenth: $s, z$, neurolemma of the original fibre. $A, C$, and $D$ are from osmic preparations; $B$, from an alcohol and carmine preparation.

nuclens become shrunken in volume. This process of disintegration and disappearance of chromatin may be termed Nissl degeneration: it 
is also known as chromatolysis. It is brought abont not only by section of the axon, but also as the result of excessive fatigue of the intact cell (fig. 164), and of the action of a large number of drugs and poisons.

The chromatolysis may be persistent or may be recovered from. Sometimes it is followed by almost complete atrophy of the cellbody, and when this is marked there may be a secondary Wallerian degeneration of the part of the nerve-fibre still attached to the cell. The chromatolysis is accompanied by changes in the neurofibrils of the cells, which stain differently and become granular (Marinesco).

Regeneration.-After a certain lapse of time, especially if the cut ends of the nerve are in apposition, continuity between them may become re-established. But when such regeneration takes place in the cut nerve, it is effected not by a re-establishment of connection between the degenerated fibres and the fibres of the central stump, but by an outgrowth of new fibres from the stump (figs. 187, D ; 188), which endeavour to find their way to the periphery along the course of the degenerated fibres. If they succeed in doing so, the continuity and conducting power of the nerve become ultimately restored. This may not happen for three months or more, according to the length of nerve cut off and the nature of the severance, although the process begins within a few days of the injury in man. Some investigators have attempted to show that regeneration may take place independently in the peripheral part of the cut nerve, but the evidence offered is not conclusive, although changes occur in the peripheral part preparatory to the down-growth of new fibres into it (Mott, Halliburton and Edmunds). There appears, however, to be no union of the downgrowing fibres with regenerated fibres in the peripheral part. The recent investigations of Cajal have shown conclusively that whenever continuity is re-established it is invariably due to the growth of fibres from the central stump of the cut nerve. These down-growing fibres are usually terminated by a button-like swelling similar to that which characterises the growing fibres of the embryonic nerves (incremental cone), and they may also exhibit numerous lateral ramifications (figs. 188, 189). Even when the cut central stump is turned backwards and fixed amongst the muscles or under the skin a certain number of newly-budded fibres may find their way from it into the degenerated peripheral part of the nerve.

If regeneration fail to establish itself, the central end of the cut fibre and the cell-body from which it takes origin undergo slow atrophic changes resulting from disuse. These atrophic changes may ultimately extend to other links in the cell-chain, so that even 
remote cells in the same physiological path may eventually become atrophied (Gudden's atrophy).

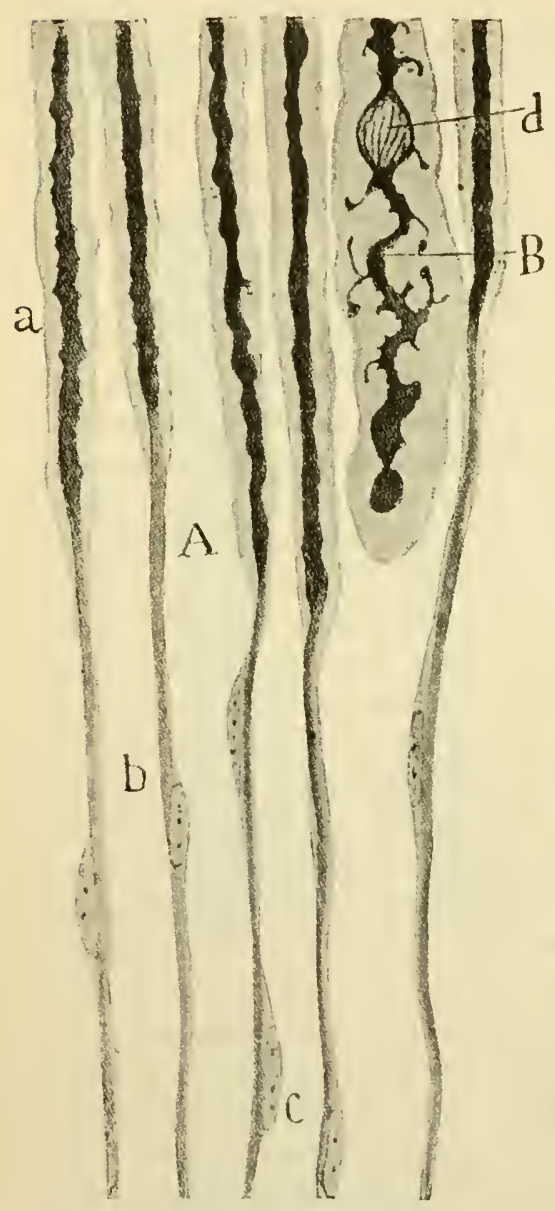

Fig. 188. - FIBRES FROM THE CENTRAL CUT END OF SCIATIC NERVE (OF YOUNG RABBIT) CUT 10 DAYS BEFORE DEגTH. (Cajal.)

A, fibres showing down-growth of axis-eylinders (b) whieh are invested by flattened mueleated eells; $\boldsymbol{u}$, intact part still my. elinated. B, a fibre, the axis-eylinder of which has not grown down with the rest, but which shows various degenerative appearanees, sueh as buds from the axiseylinder and at $d$, a separation of the fibrils.

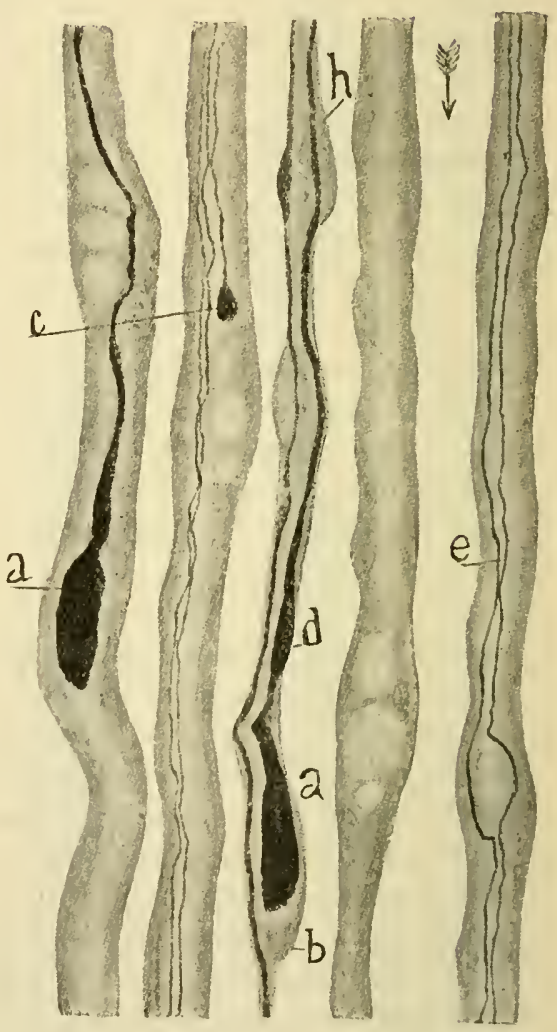

FIG. 1ऽ9. - FROM THE PERIPHERAL ENI) OF A NERVE CUT 78 DATS BEFORE DEATH. (Cajal.)

It, c, enlarged growing cnds of axis-eylinder sirouts whieh have grown down from the eentral eut end into the old sheaths of the cut nerve-fibres (myelin drops are still visible within the sheaths). The middle fibres $(h)$ are interstitial (not in old sheaths), they show a new formation of a nueleated sheath The fibre $d$ has an enlarged end, $a$, with sheath $b$; $e$, very fine fibres within an old sheath; to the left of it, an old sheath withont nerve-fibres. 
No regeneration of cut nerve-fibres ever occurs in the brain or spinal cord, although the process of degeneration of fibres which are eut off from their cell-bodies occurs in the same manner as at the periphery, and the Nissl degeneration also takes place in the cell-bodies. Both in the nerve-centres and in the peripheral nerves (if regeneration fail to oceur), the place of the degenerated nerve-fibres beeomes eventually oceupied by strands of fine fibres, somewhat similar to the fibres of cicatricial tissue. These strands stain deeply with carmine and remain unstained by osmic acid and by the W'igert-Pal method, and are thus differentiated from the surrounding normal medullated nerves.

\section{NEUROGLIA.}

In the brain and spinal eord the nerve-cells and nerve-fibres are supported by a peculiar tissue which has been termed the neuroglia. It is composed of cells and fibres, the latter being prolonged from and

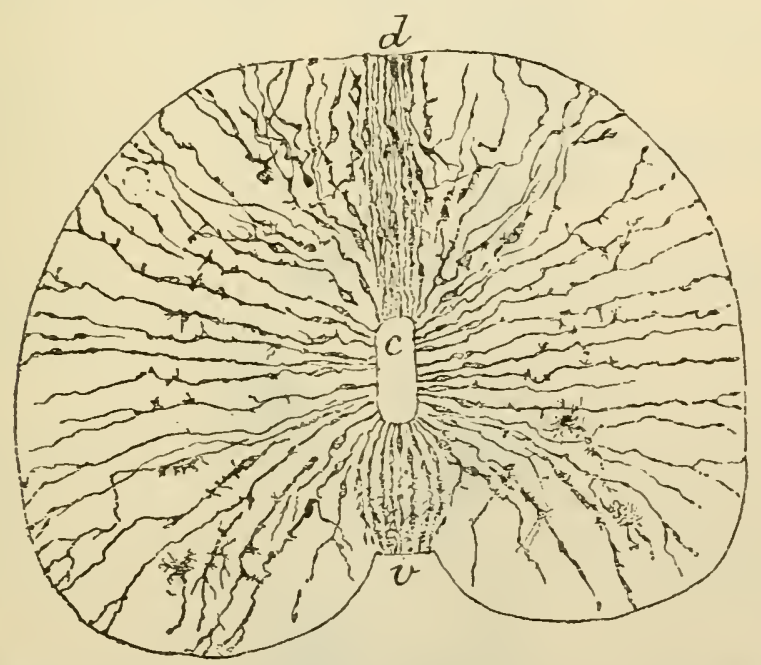

Fig. 190.-SEctiox OF SPINAL CORD OF EMBRYO CHICK, SHOWING NEUROGLIA FIBRES PROLONGED FROS THE EPITHELICM OF THE CENTRAL CANAL. (Cajal.)

$d$, dorsal ; $v$, ventral surface; $c$, central canal from which the neuroglia cclls and fibres are seen to radiate to the periphery of the cord. Solne detached neuroglia cells are also represented.

through the cells. Of the fibres some are radially disposed. These start partly from the lining layer of the central canal of the spinal cord and the ventricles of the brain, where they are originally if not permanently continuous with the eiliated epithelium eells lining 


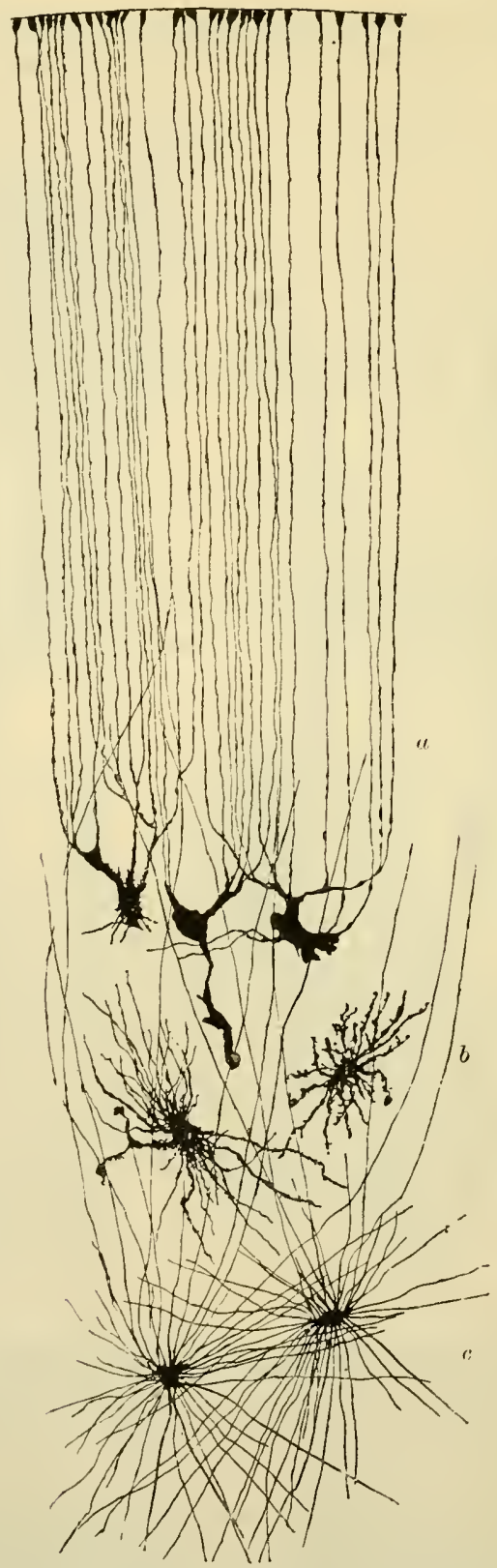

Fig. 191.-Neuroglia cells of the cerebellum. Golgi method. (G. Retzius.) $a$, cells with long parallel processes extending to surface; $b$, arborescent cells; $c$, "spider" cells. 
these cavities. They course in a radial direction, slightly diverging as they proceed, and constantly branching, towards the surface of the organ, where they end in enlargements attached to the pia mater (fig. 191, $\iota$ ). The radial neuroglia cells and fibres are best seen in the embryo before the nervous elements are fully developed (fig. 190); when first distinct they are termed spongioblasts (His).

Other neuroglia-fibres are prolongations or cell-processes of branching neuroglia-cells (glirt-cells). The cells are stellate in shape (fig. 192), and their fine processes pass as neurogliafibres between the nerve-cells and nerve-fibres, which they aid in supporting. There appear to be two kinds of these neuroglia-cells differing from one another in the character of their processes (Andriezen). In the one kind the processes branch re-

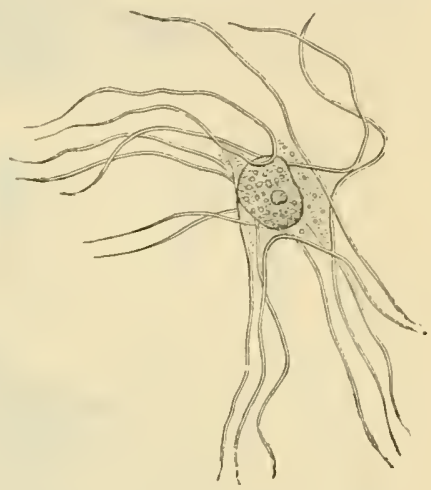

Fig. 192.-NEUROGLIA CELL FROM SPINAL CORD. (Ranvier.)

Isolated after maceration in 33 p.c. alcohol. peatedly (arborescent cells) (fig. 191, b) ; in the other kind they remain unbranched from their origin in the cell-body to their termination (spider-cells) (fig. 191, c).

Some anthorities (e.g. Weigert) have thought that the fibres of the neuroglia are inter- not intra-cellular, although it is admitted by all that they are formed originally by the neuroglia-cells.

\section{DEVELOPMENT OF NFRVE-CELLS AND NERVE-FIBRES.}

All nerre-cells in the body are developed from the cells of the neural groove and neural crest of the early embryo; the neural groove closing to form the neural canal (fig. 193), the cells of which form the spinal cord and brain, and the neural erest giving off at intervals sprouts which become the germs of the spinal ganglia. The cells which line the neural canal are at first all long columnar cells, but amongst these, and probably produced by cell-division from some of these (fig. 194,g), rounded cells (neuroblasts) make their appearance, the remaining elongated cells forming the spongioblusts. Soon from each neuroblast a process begins to grow out (fig. 194, $n$, and fig. 195). This is the axon, and it is soon characterised by an enlarged extremity (incremental cone) (fig. 196, $h, h$; fig. 197, $\mathrm{B}, c$ ). As it grows, it may emerge from the antero-lateral region of the canal and become the axis-cylinder of a motor nerve or anterior root-fibre. The dendrons of 
the cell appear somewhat later than the axon. The axis-cylinder processes of some of the neuroblasts remain within the nerve-centre, and are developed into commissural, association, and intercentral fibres.
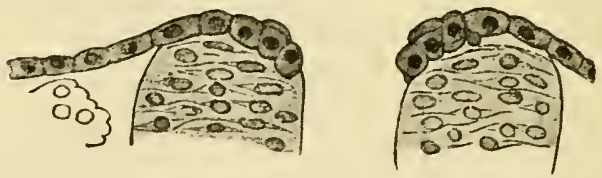

A.

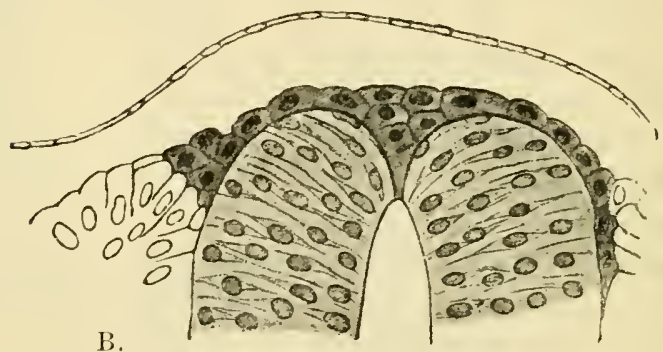

Fig. 193. - Closure of NEURAL CANAL OF HUMAN EMBRYo, SHOWING THE CELLS OF THE NELRAL CREST BECOMING SEPARATED TO FORM THE GERMS OF THE: SPINAL GANGLIA. (Jénhossek.)

A, canal still open; B, canal closed.

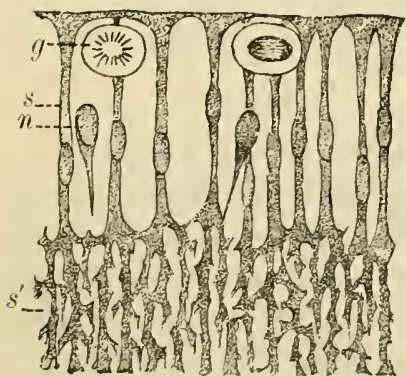

FIG. 194.

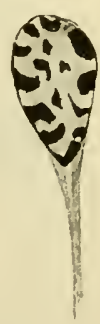

F1G. 195.

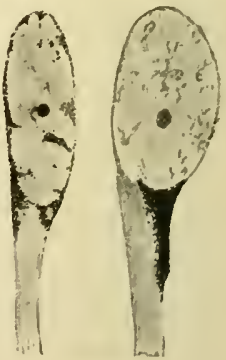

Fig. 194.-SECTION OF NEURAL EPITHELIU
ighly magnificd view of part of a section, at the time of the first differentiation of the neuroblasts, showing, $s^{\prime}$, spongework formed of the outer ends of columnar epithelium cells, 8 ; g, rounded "germinal cells" in process of division (probably to form neuroblasts); $n$, a lieuroblast.

Fig. 195.-Neuroblasts FroM a PIG-EMBRYo, SHOWING THREE STAGeS OF DEVELOPMENT. (Gurwitsch, after Scott.) (Highly magnified.)

The spronts from the neural crest contain the neuroblasts from which the posterior root-fibres are developed. Axons grow out from these neuroblasts in two directions, so that the cells become bipolar (fig. 198). 
One set of processes, forming the posterior root-fibres, grow into the postero-lateral portion of the spinal eord and ramify in the developing grey matter ; the other set, containing the afterent fibres of the spinal nerves, grow towards the developing anterior roots, and eventually mingle with them to form the mixed nerves. As development proceeds, the bipolar ganglion cells become gradually transformed in most

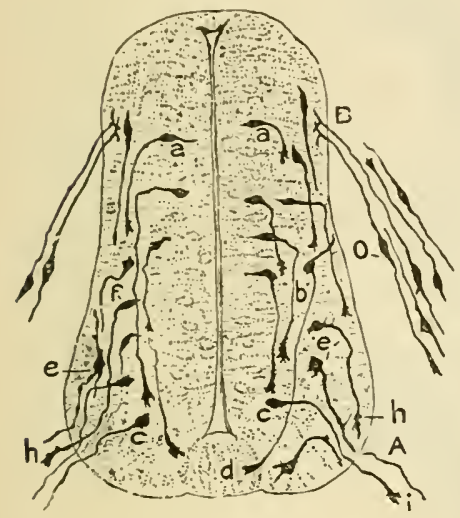

FIG. 196.

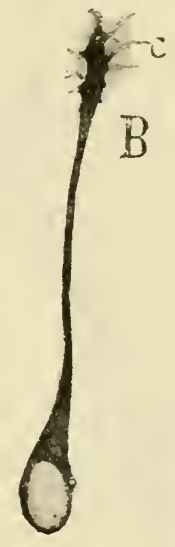

$\mathrm{B}$

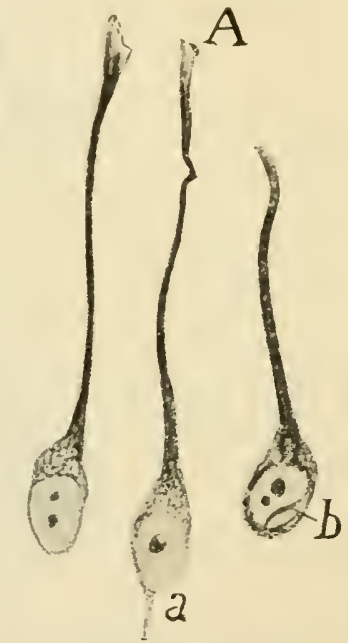

FIG. 197.

FIG. 196. - SECTION OF SPINAL CORD OF CHICK OF THIRD DAY OF INCCBATION. (Cajal.)

A, anterior root-fibres formed by outgrowths of motor neuroblasts, $c, e$; $\mathrm{B}$, posterior root-fibres formed br ingrowths of bipolar sensory neuroblasts, $o$, in ganglion rudi. ment; $a$, early neuroblasts; $b$, neuroblast giving rise to a commissural nerve-fibre, $d ; h, i$, enlarged ends of growing axons; $e, e$, neuroblasts of which the dendrons are beginning to appear.

Fig. 197.-NeUroblasts from the spiNal cord of a third-DAY CHICk EMBRYYo. (Cajal.)

A, three neuroblasts, stained by Cajal's reduced silver method, showing a network of neuro-fibrils in the cell-body; $a$, a bipolar cell. B, a neuroblast stained by the method of Golgi, showing the incremental cone, $c$.

vertebrates, by a shifting of the two axons, into unipolar cells (fig. $198, h, i, j$; fig. 199); but in some fishes the cells remain permanently bipolar (fig. 170). This is also the case with the ganglion-cells of the eighth cranial nerve (ganglion of Scarpa and ganglion of the cochlea).

The ganglia on the sympathetic and on other peripheral nerves are developed from small masses of neuroblast-cells which separate off from the germs of the spinal ganglia and give origin to axons and dendrons much in the same way as do the neuroblasts within the central nervous system. 
The manner in which the medullary sheath and neurolemma of the nerve-fibres are formed is not well understood. It is usually assumed that they are also ectodermic in origin and are developed

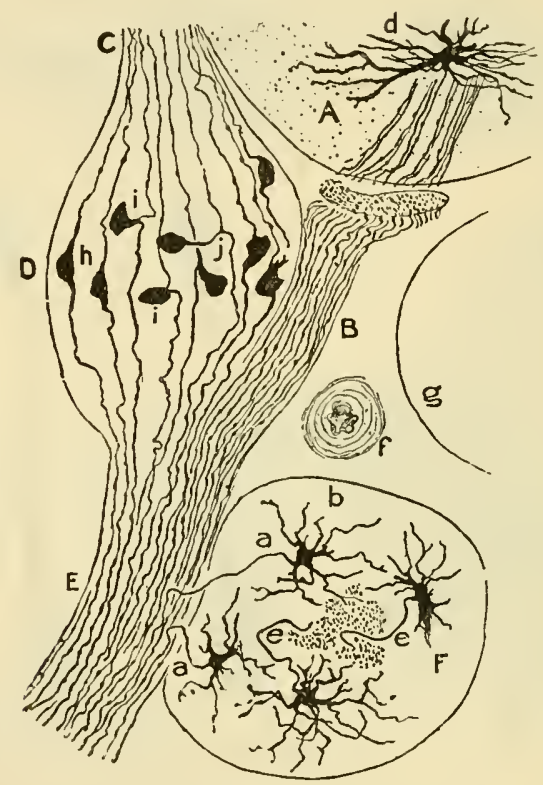

Fig 198. - SíiNal AND SYMPATHETIC GANGLiA AND PART OF SPINAI, CORD OF CHICK OF SEVENTEENTH DAY OF INCUBATION. (Cajal.)

$A$, antero-lateral part of spinal cord with $d$, a motor nerve-cell ; the fibres of the anterior root are seen emerging and passing to $B$ (the eom eetion appears interrupted in the seetion); C, yosterior root formed of fibres which have grown from the ganglion-eells in D, spinal ganglion; E, mixed spinal nerve; F, sympathetie ganglion; $a, a$, axons of sympathetie cells, passing to join the spinal nerve; $b$, dendrons of these cells; $c$, axons passing to the sympathetic cord; $h$, eells of spinal ganglion still bipolar; $i$, $i$, bipolar eells beeoming transformed into unipolar; $i$, unipolar cell with T-junetion; $f$, section of an artery; $g$, body of vertebra.

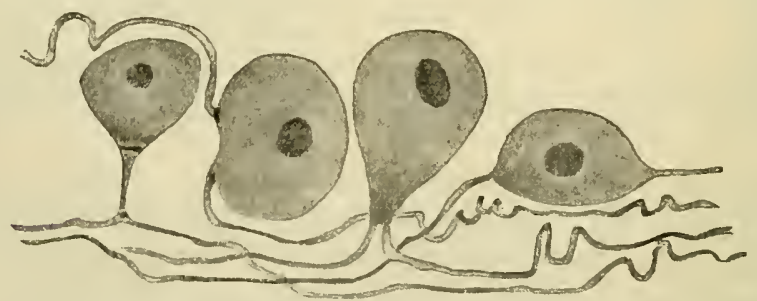

Fig. 199. - SPINAL GANGLION-CELLS SHOWING TRANSITIONS FRON BIPOLAR TO UNIPOLAR CONDITION. (Holmgren.)

from ectoderm cells which grow out from the embryonic central nervous system along the axis-cylinder processes of the neuroblasts. But this is by no means clear. It is more probable that the medullary 
substance is formed by the axis-cylinder itself, and that the nenrolemma with its nuclei is derived from extrinsic cells, perhaps of mesodermic origin.

The neuroglia-cells appear to be developed from ectorlerm cells (spongioblasts) of the wall of the neural canal, which, in place of giving off axon and dendrons like the neuroblasts, send ont a number of tine processes in all directions from the cell to form the fibres of the neuroglia. It is held by some authorities that the nemroglia has a double origin, some of the eells being developed from ectoderm and others from mesorterm.

Some neurologists are of opinion that the nerve-fibres do not grow out from single nerve-cells in the manner above described, but are formed of chains of cells which emerge from the neural ectorlerm or from the ganglionrudiments, and join end to end into a syncytium, which gradually lengthens out into the nerve-fibre, the nuclei of the syncytium becoming the nuclei of the sheath of Schwann, and the protoplasm of the syncytium becoming clifferentiated into axis-cylinder,' medullary sheath, and nenrolemma as - development advances. Others, whilst agreeing that the axis-cylinders grow ont as cell processes from the neuroblasts of the neural canal and ganglia, describe those outgrowing processes as surrounded by other neural ectoderm cells-lemmal cells-which accompany them in their progress through the tissues, multiplying as they proceed, and forming eventually the nucleated sheath of Schwann of the medullated nerve. 


\section{LESSON NIX.}

\section{MODES OF TERMINATION OF NERTE-FIBRES.}

1. SHell out a Pacinian corpuscle from a piece of cat's mesentery either fresh or after having been kept for two or three days in $\frac{1}{20}$ per cent. chromic acid or in 5 per cent. formol. Clear it as much as possible of adhering fat, but be careful not to prick or otherwise injure the corpuscle itself. Mount in water or saline with a thick hair to prevent crushing with the cover-glass. Sketch the corpuscle under a low power, and afterwards draw under a high power the part of the core where the nerve enters and the part where it terminates. Notice the fibrous structure of the lamellar tunics of the corpuscle and the oval nuclei belonging to flattened epithelioid cells which cover the tunics. The distinct lines, which when seen in the fresh corpuscles are generally taken for the tunics, are really the optical sections of these flattened cells.

Pacinian corpuscles may be observed in sections of skin; tactile corpuscles and end-bulbs may also be seen in certain parts of the integument.

2. Study the corpuscles of Grandry and of Herbst in sections of the skin covering the duck's bill.

3. Nount in dilute glycerine sections of a rabbit's cornea which has been stained with chloride of gold by Klein's metlod. Notice the arrangement in plexuses of the darkly-stained nerve-fibres and fibrils, (1) in the connectivetissue substance, (2) under the epithelium, and (3) between the epithelial cells. Make one or two sketches showing the arrangement of the fibrils.

4. Spread out a small piece of muscle which has been stained with chloride of gold by Löwit's method, or with hæmatoxylin by Sihler's method, and examine it with a low power to find the nerve-fibres crossing the muscular fibres and distributed to them.

The pieces of muscle may advantageously be thinned out for observation by pressure upon the cover-glass. Search thoroughly for the close terminal ramifications (end-plates) of the axis-cylinders immediately within the sarcolemma.

These nerve-endings as well as others elsewhere can also be displayed in preparations made by Ehrlich's, Golgi's or Cajal's methods (see Appendix).

Modes of ending of sensory nerve-fibres.-Nerve-fibres which are distributed to sensory parts end either in special organs or in free terminal ramifications, these last being usually in epithelia. Within the special organs the actual nerve-ending is also generally ramified.

Nerve-endings in special connective-tissue organs.--Three chief kinds of these special organs are usually described, represented in man by Puciniun corpuscles, tactile corpuscles, and end-bulbs. The type is the same in all: a lamellated connective-tissue capsule enclosing a core of a soft material which appears to be composed of nucleated protoplasmic cells; the capsule being an expansion of the perineurium, and the core of the endoneurium of the nerve. Within the core the axis- 
cylinder terminates either simply or by a more or less eomplex arborescence. The varlations which oceur are ehiefly due to the complexity of the capsule, which is simplest in the end-bulbs and most complex in the Paeinian corpuscles. In the tactile çorpuscles

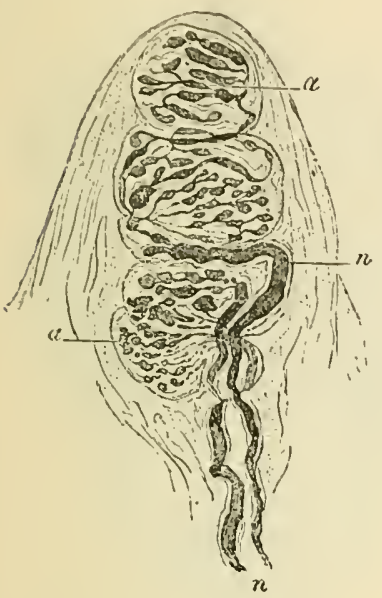

FIG. 200.

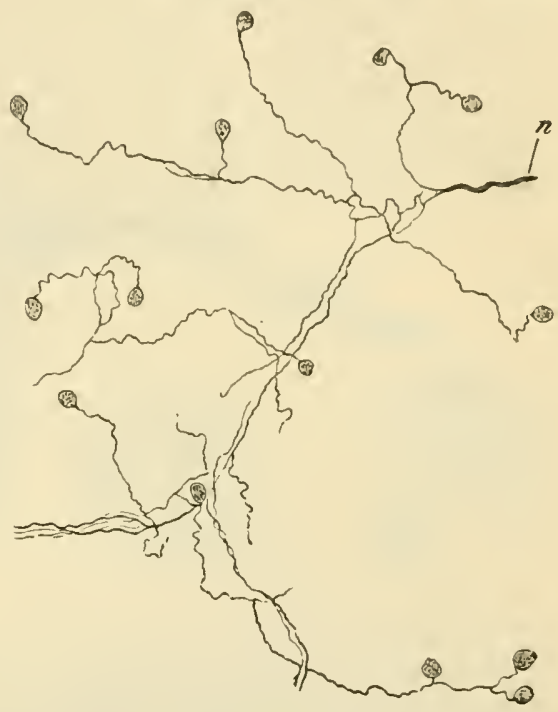

FIG. 201.

Fig. 200. - Tactile corpuscle within a PAPILla OF THE SKIN OF THE HAND. STAINED WITH CHLORIDE OF GOLD. (Ranvier.)

$n$, two nerve-fibres passing to the corpuscle; $n$, $a$, varicose ramifications of the axiscylinders within the corpuscle.

Fig. 201.-END-BULbs AT THE TERIINATIONS OF NERVES IN THE HUMAN CONJUNCTIVA, AS SEEN WITH A LENS. (Lougworth.)

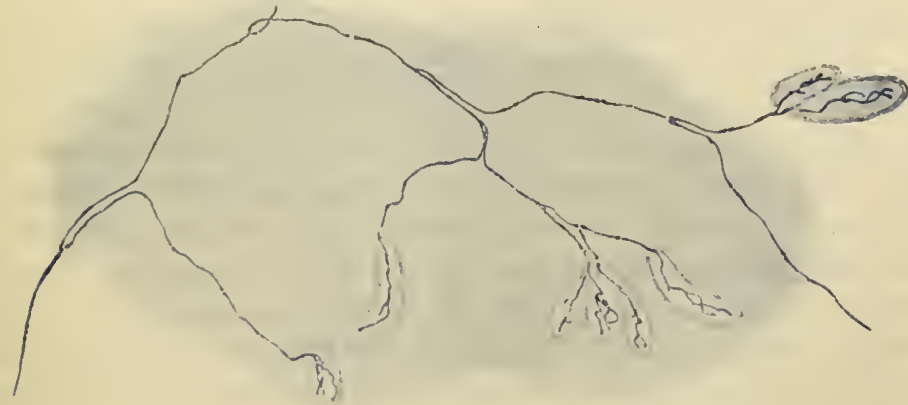

Fig. 202.-A IEDCLLATED FIBRE TERMINATING IN SEVERAL END-BULBS IN THE HUMAN PERITONEUM. (Dogiel.) Methylene blue preparation. Low power. 
and end-bulbs the connective-tissue sheath of the medullated fibre expands to form a bulbous enlargement, which is cylindrical or spheroidal in the end-bulbs and ellipsoidal in the tactile corpuscles. In both kinds of end-organ as the nerve-fibre enter's (which in the tactile corpuscle only happens when it has reached the distal part,

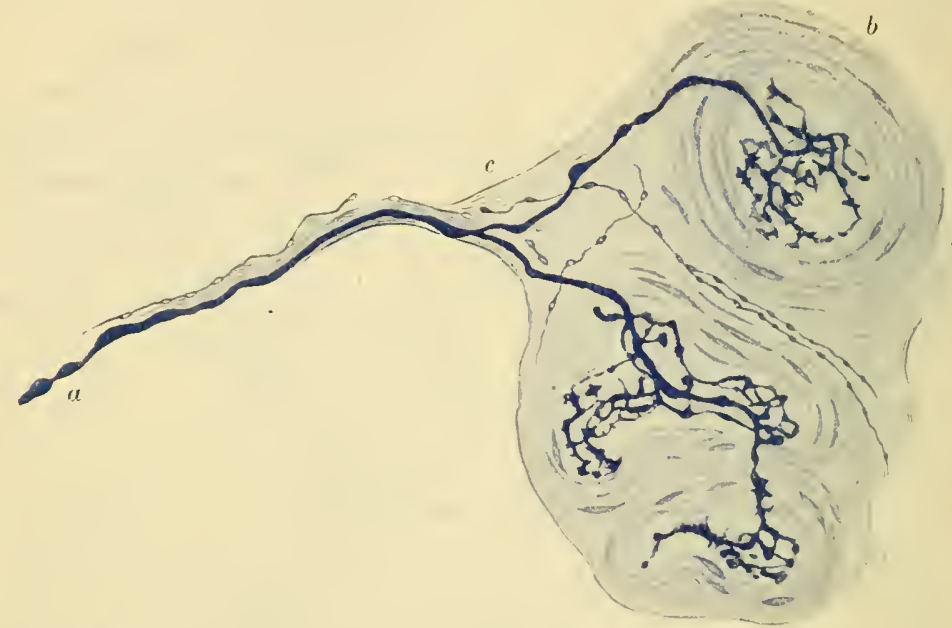

Fig. 203.-END-bUlas from the hedan peritoneum, (Dogiel.) More highly magnified. Methylene blue preparation.

$a$, medullated fibre; $b$, nucleated lamellated capsule of end-bulb; $c$, non-medullated fibres, probably destined for the capillaries which surround the end-bulbs.

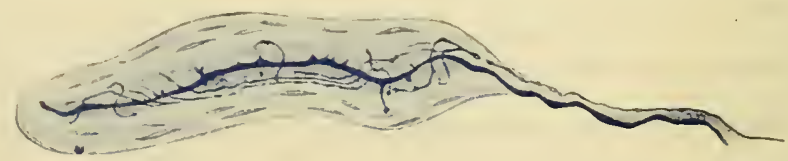

Fig. 204.-END-BULB FROM THE CENTRAL TENDON OF THE DIAPHRAGM OF THE DOG.

(Dogiel.) Showing besides the main medullated fibre terminating by an arborescence within the core, a second very fine medullated fibre, forming a more delicate arborescence around the ending of the nain fibre in the outer part of the core. Methylene blue preparation.

after having wound spirally once or twice round the corpuscle) it loses its sheaths and is prolonged as an axis-cylinder only; this generally ramifies and its branches terminate after either a straight or a convoluted course within the organ; but it sometimes remains almost unbranched (see figs. 200 to 205). Tactile corpuscles occur in some of the papillæe of the skin of the hand and foot, in sections of which they can be studied (see fig. 2ii). End-bulbs are found in the conjunctiva of the eye, where in most animals they have a cylindrical or oblong shape, but in man they are spheroidal (fig. 201). 
They have also been found in papillie of the lips and tongre, in serous nembranes, in tendons and aponeuroses, and in the epineurium of the nerve-trunks; and somewhat similar sensory end-organs (yenitul rorpuscles) also occur in the integument of the external genital organs of both sexes (fig. 205). Similar bodies of larger size are also met with in the neighbourhoor of the joints (articular corpuscles). In the skin covering the bills of certain birds (e.g. duck), a simple form of end-organ (corpuscle of Gramlry, fig. 206) ocenrs, consisting of two or more cells arranged in rows within a capsnle, with the axis-cylinder terminating in flattened expansions (tactile disks) between the cells.

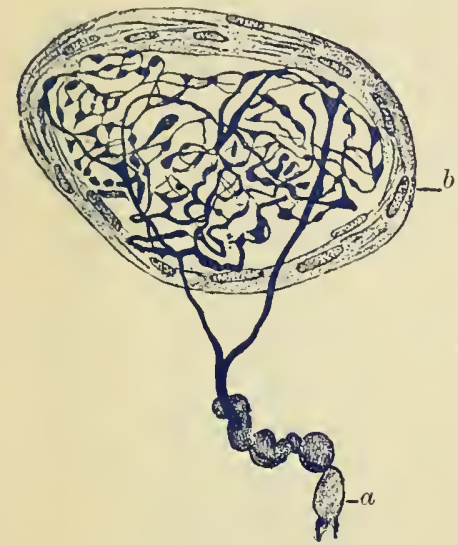

FIG. 205. - END-BULB FROM THE GLANS PENIS, SHOWING ENDING OH AXIS-CYLINDER. Methylene blue preparation. (Dogiel.)

$a$, medullated nerve-fibre; $b$, sheath of end-bulb.
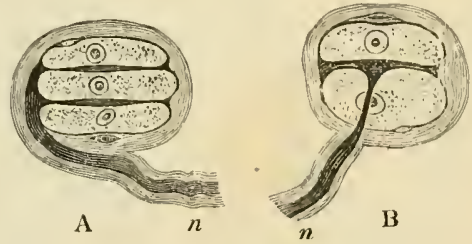

Fig. 206.-TACTILE CORPUSCLES FroM THE DUCK's TONGUE. (Izquierdo.)

$A$, composed of thrce cells, with two interposed disks, into which the axis-cylinder of the nerve, $n$, is observed to pass; in $B$ there is but one tactile disk inclosed betwecn two tactile cells.

The Pacinian corpuscles are larger, and have a more complex structure, than the tactile corpuscles and end-bulbs (fig. 207). They are composed of a number of concentric coats arranged like the layers of an onion, and inclosing the prolonged end of a nerve-fibre. A single medullated nerve-fibre goes to each Pacinian corpuscle, encircled by a prolongation of the perineurium (sheath of Henle), and within this by endonenrium; when it reaches the eorpuscle, of which it appears to form the stalk, the lamellæ of the perineurium expand into the tunics of the eapsule. The nerve passes on, piercing the tunies, surrounded by endoneurium, and still provided with medullary sheath, to reach the central part of the corpuscle. Here the endoneurium is prolonged to form a core of cylindrical shape, along the middle of which the nerve-fibre, now deprived of its medullary and primitive sheaths, passes in a straight course as a simple axis-cylinder (figs. 
$\left.20 \pi, n^{\prime} ; 208, c . f\right)$ to terminate at the farther end of the core, either in an arborisation or in a bulbous enlargement. In its course through the core it may give off lateral ramifications, which penetrate to all parts of the core, and themselves end in fine branches.

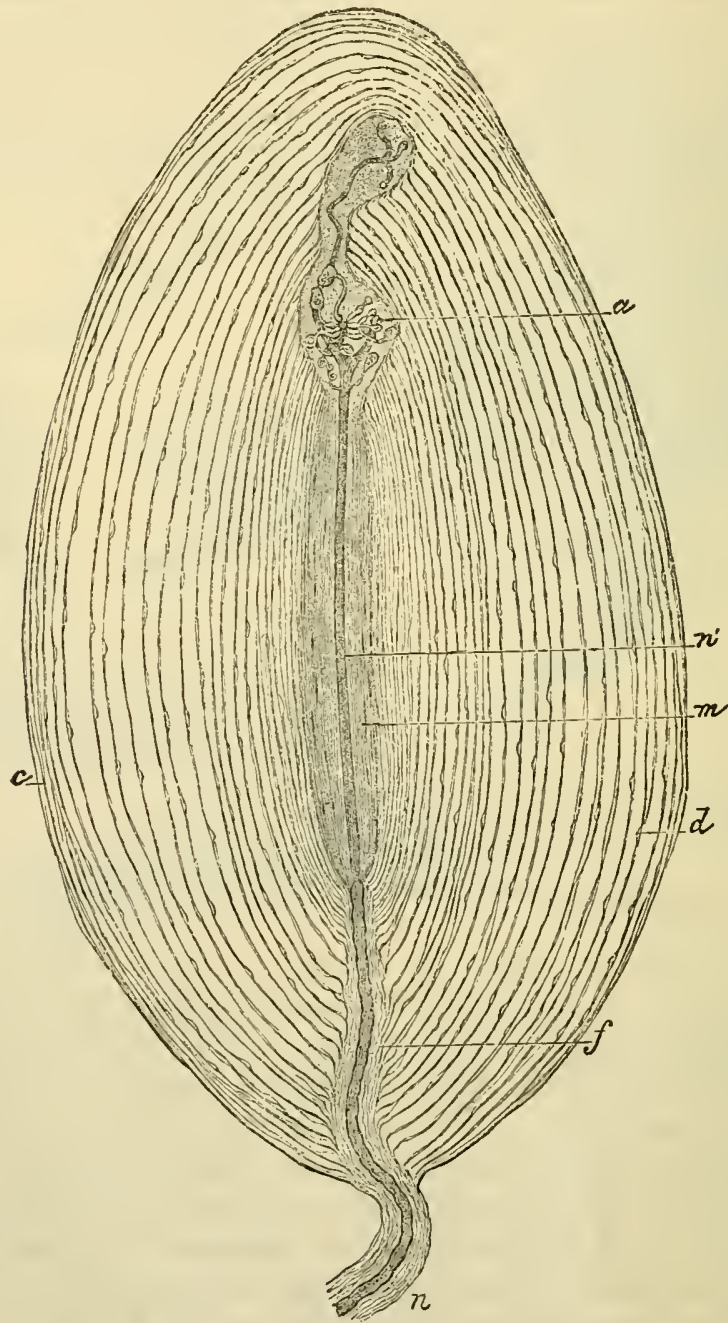

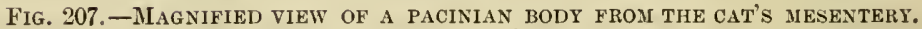
(Ranvier.)

$n$, stalk of corpuscle with nerve-fibre, inclosed in sheath of Henle, passing to the corpuscle; $n^{\prime}$, its continuation through the core, $m$, as axis-cylinder only; $a$, its terminal arborisation; $c, d$, sections of epithelioid cells of tunics, often mistaken for the tunics themselves; $j$, channel through the tunics which expands into the core of the corpuscle. 
Besides the medullated fibre, which is always very conspicunus, it has been shown that both the Pacinian and Herbst corpuscles receive in addition a fine non-nedullated nerve-fibre, which arborizes over the onter surface of the core. A similar arrangement also obtains in Grandry's corpuscles, where the tactile cells are surrounded with such an arborization (Dogiel and others).

The tunics of the capsule are composed of connective tissue, the fibres of which for the most part run eircularly. They are covered

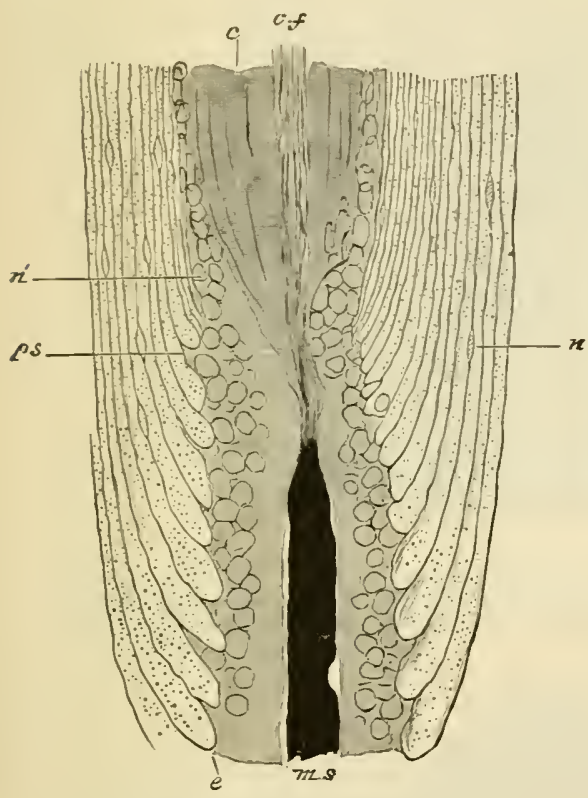

Fig. 208.

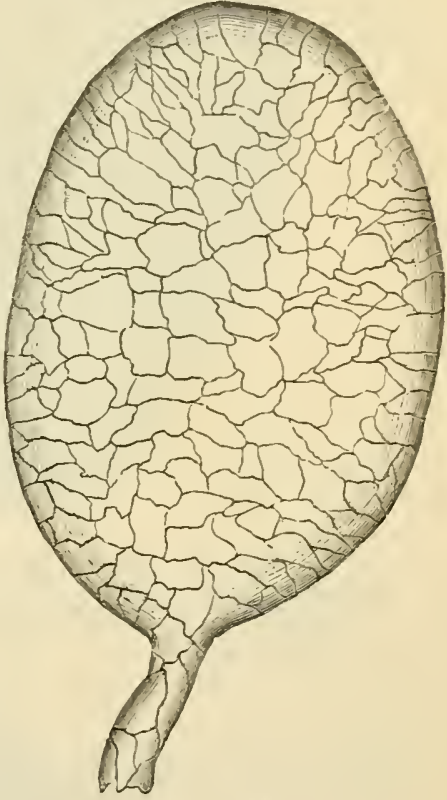

FIG. 209.

FIG. 208. -PART OF PACIXIAI BODY, SHOWIYG THE IERTE-FIBRE ENTERIXG THE CORE. FroM AX OSMIC ACID PREPARATION.

$m s$, entering nerve-fibre, the medullars sheath of which is stained darkly, and ends abruptly at the core, $c ; p s$, prolongation of primitive sheath or neurolemma passing towards the outer part of the core; $c . f$, axis-cylinder passing through the core as the central fibre; $e$, some of the inner tunics of the corpuscle, enlarged where they abut against the canal through which the nerre-fibre passes -the dots within them are sections of the fibres of which they are composed; $n$, nuclei of the tunics; $n^{\prime}$, nuclei of the endoneurium-cclls, continued by other's in the outer part of the core.

Fig. 209.-Pacinias corplscle Fron the Cat, StaiNed With SILTER NITRATE.

on both surfaces with a layer of flattened epithelioid cells (fig. 209), and here and there cleft-like lymph-spaces can be seen between them like those between the layers of the perineurium.

Pacinian corpuscles occur in many parts, e.g. in the deeper layers of the skin of the hands and feet, in the periosteum of some bones, in the neighbourhood of tendons and ligaments, in the connective tissue 


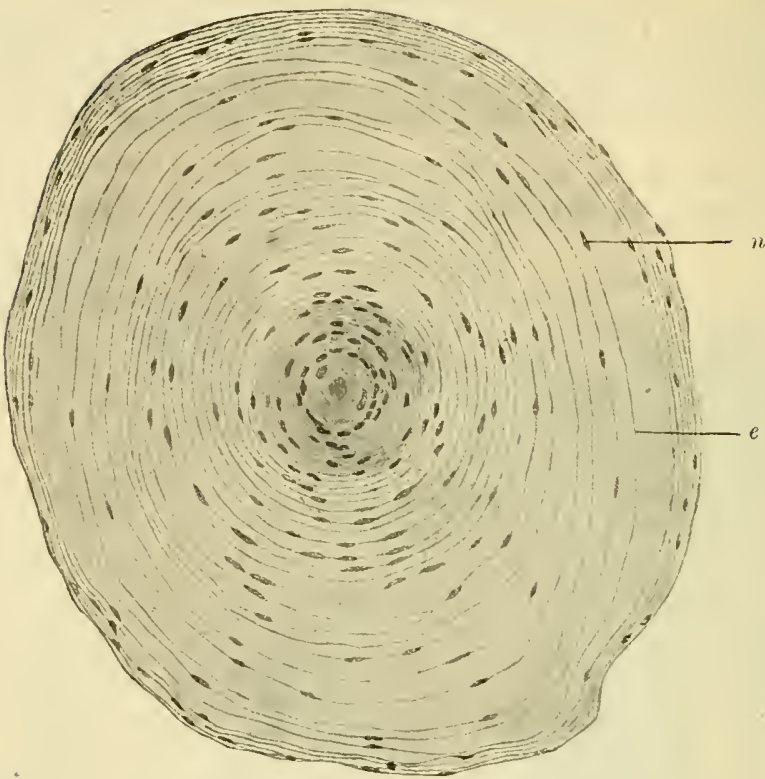

Fig, 210. - Sechion of Pacinian corpuscle. (Szymonowicz.)

$e$, one of the layers of epithelioid cells; $n$, nucleus of epithelioid cell. It is seen that the tunics are very closely packed around the core, in the middle of which the axial-fibre is cut across.

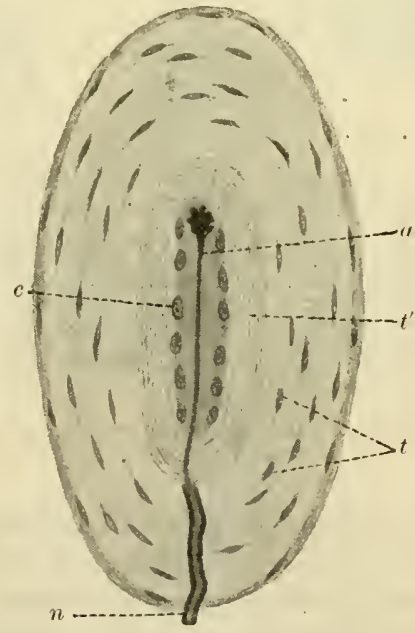

Fig. 211.-Herbst colipuscle of DUCK. (Sobotta.) $\times 380$.

$n$, medullated nerve-fibre; $a$, its axis-cylinder, terminating in an cnlargement at end of core; $c$, nuclei of cells of core ; $t$, nuclei of cells of outer tunics; $t^{\prime}$, inner tunies. 
at the back of the abdomen, and (in the cat) very numeronsly in the mesentery, where they are most easily got for observation.

A simple form of Pacinian corpuscle with fewer tunics and a core formed of regularly arranged cells occurs in birds (corpuscles of Ilerbst, fig. 211).

Although most of the nelve endings in connective-tissue structures are enclosed within lamellated capsules, nerves are found to end in some situations in arborisations between the bundles of connectivetissue fibres. This has been shown by Dogiel to occur in intermuscular

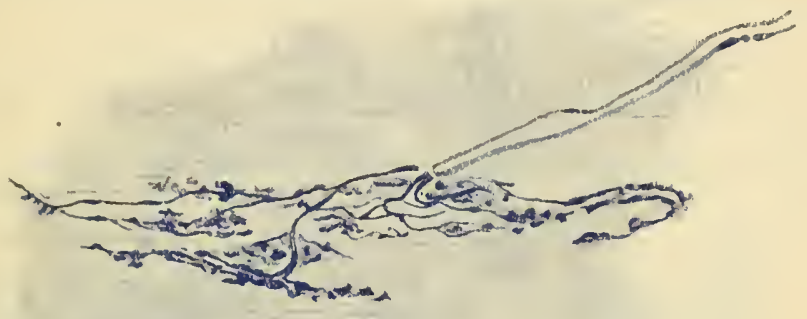

FIg. 212. - TERMINAL ARBORISATION FROM THE INTERMUSCULAR CONNECTIVE TISSUE OF THE RECTUS ABDOMINIS OF THE RABBIT. METHYLENE BLUE PREPARATION. (Dogiel.)

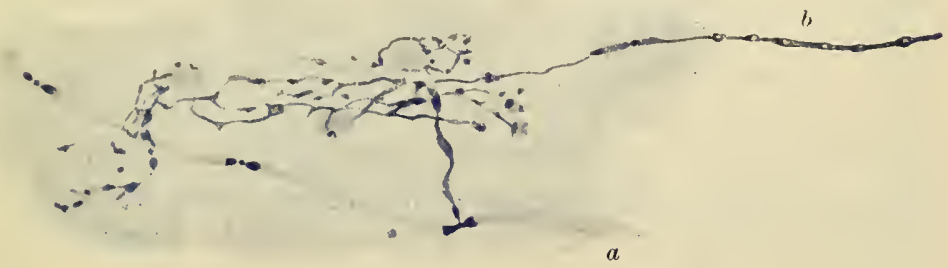

FIG, 213.-TERMINAL ARBORIS.TTON FRON THE SLPERFICIAL LAYER OF THE Peritoneum OF the RABbit. Methylene blue plieparation. (Dogiel.)

$a$, medullated fibre; $b$, fibre comnecting the arborisation with another one not herc represented.

connective-tissue septa (fig. 212); and in serous membranes (fig. 213) ; in the latter such arborisations may be quite superficial and placed just below the endothelium.

Organs of Ruffini.-These, which resemble long cylindrical end-bulbs, are composed of connective-tissue bundles, within which the axiscylinders of the nerves ramify, and end in flattened expansions. They 
occur commonly in the subcutaneous tissue of the human finger (fig. 214). Other end-bulb-like organs, spheroidal, oval, or cylindrical in form, have been described by Ruffini under the name of Golgi-Mazzoni corpuscles; they appear to be varieties of the ordinary end-bulb of W. Krause. They occur in tendons and in the subcutaneous tissue of the pulp of the finger.

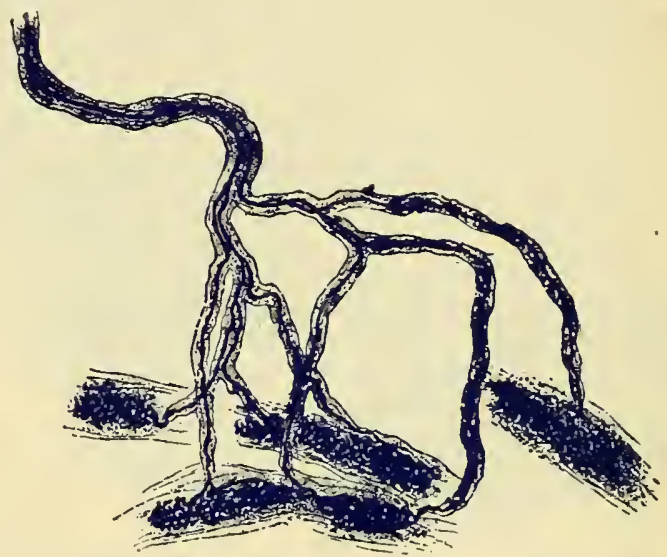

FIG. 214. - A NERVE FIBRE IS SHOWN DIVIDING INTO SEVEN SECONDART FIBRES TO WHICH ARE ATTACHED FIVE ORGANS OF RUFFINI. (Barker, after Ruffini.)

Organs of Golgi.-A special mode of nerve-ending is met with in many tendons, near the points of attachment of the muscular fibres. The tendon-bundles become somewhat enlarged and split into a number of smaller fasciculi, and the nerve-fibres-one, two, or even more in number-pass to the enlarged part, and penetrating between the fasciculi of the tendon lose their medullary sheaths, while the axiscylinders end in a terminal arborisation, beset with irregular varicosities. The structure (fig. 215) is enclosed within a fibrous capsule continuous with the areolar tissue covering the bundles of the tendon; and between the capsule and the organ proper is a lymph-space, similar to that which is found in the muscle-spindle (see p. 179).

Free nerve-endings. - When sensory nerve-fibres terninate in epithelium, they generally branch once or twice in the subepithelial connective tissue on nearing their termination. The sheaths of the fibres then successively become lost, first the connective tissue or perineural sheath, then the medullary sheath, and lastly the neurolemma, the axis-cylinder being alone continued as a bundle of primitive fibrils (fig. 216). This branches, and with the ramifications of the axis-cylinders of neighbouring nerve-fibres forms a primary plexus. 
From the primary plexus smaller branches come off, and these form a secondary plexus nearer the surface, generally immediately under the epithelium if the ending is in a membrane covered by that tissue. Finally, from the secondary plexus nerve-fibrils proceed and form

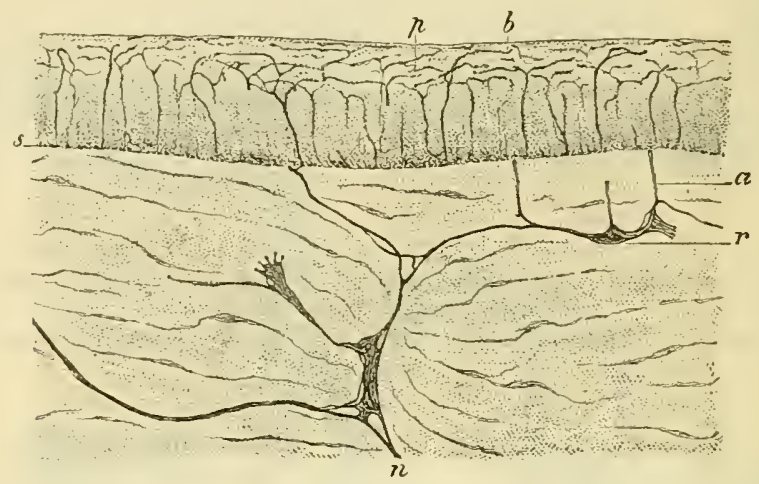

Fig. 217.- Vertical Section OF CORNEA STAINED With CHLORIDE OF GOLD. (Ranvier.)

$n, r$, primary plexus in connective tissue of cornea ; $a$, branch passing to subepithelial plexus, $s ; p$, intraepithelial plexus; $b$, terminations of fibrils.

terminal ramifications amongst the tissue cells (fig. $217, p, l)$, the actual ending being generally in free varicose fibrils $(b)$. This mode of ending is characteristically seen in the cornea of the eye, but can also be rendered evident in other cpithelia (fig. 218). The fibrillar

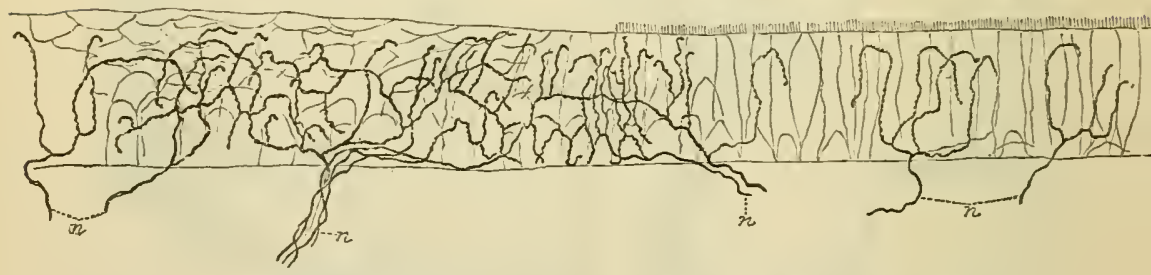

Fig. 21S. - INTRA-EPITHELIAL NERVE-TERMINATIONS IN THE LARYNX:

Golgi METHOD. (G. Retzius.)

On the left the epithelium is stratified and on the right ciliated colummar. $n$, nerve-fibres in corium.

structure of the ramifications of the axis-cylinders is very apparent in some of the preparations figured.

In some situations the nerve-fibrils within a stratified epithelium terminate in flattened or crescentic expansions which lie in the interstices of the deeper epithelium cells, to some of which they are applied. 
These expansions are known as tactile disks; they are characteristieally developed in the skin of the pig's snout (fig. 219), and are also found in the onter root sheath of hairs and in the deeper parts of the epidermis in various parts. With appropriate treatment it may be shown that they consist of a fine network of neuro-fibrils (fig. 220).

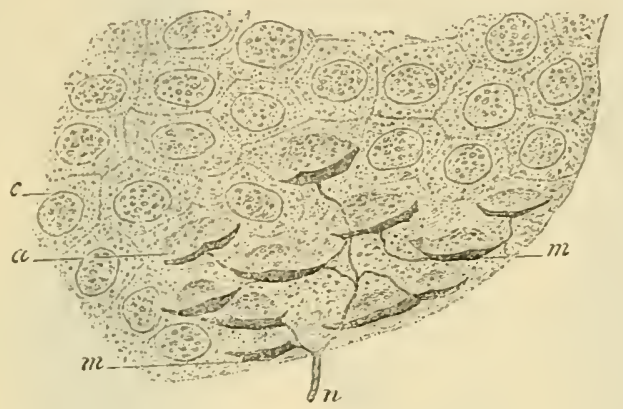

Fig. 219.-ENDING OF NERve IN TACTILE DISKS IN THE PIG'S SNOUT, (Ranvier.)

$\eta$, medullated fibre; $m$, terminal disks or menisci; $e$, cells of the Malpighian lajer of the epidermis; $a$, somewhat modified cell to which a tactile disk is applied.

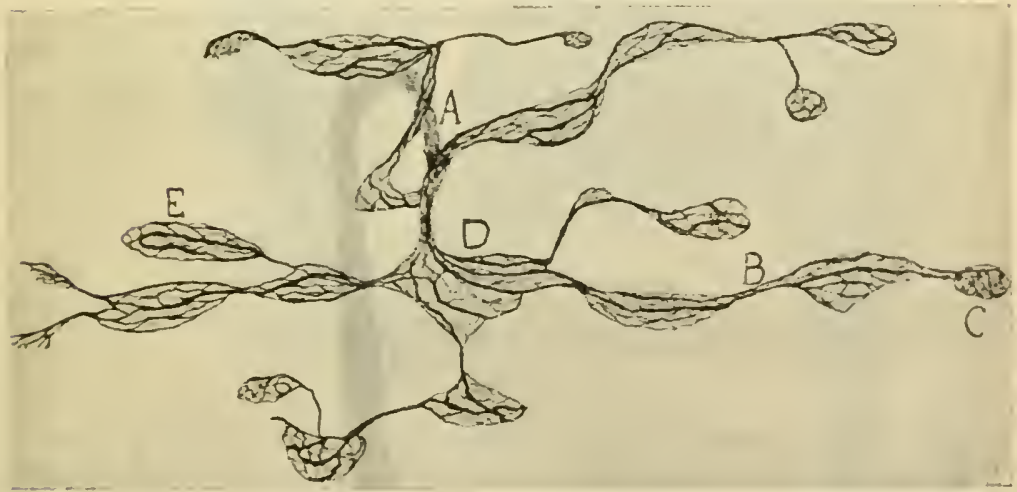

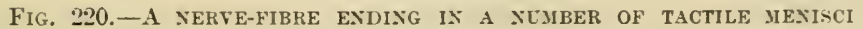
FROM A TACTILE HAIR, RABBIT. (Cajal and Tello.)

$A$, point of ramification of axis-crlinder of uerre-fibre; $B$, isthmus between two menisci ; C, terminal meniscus; D, large meuiscus at branching of severa] divisions of the nerve-ending.

Sensory nerves of museles. - The sensory nerves of museles end in peculiar organs which were termed by Kühne muscle-spindles. Their structure has recently been specially investigated by Rutfini, 
Huber, and Dogiel; and also by Sherrington, who has shown that the large medullated nerves which they receive (about three

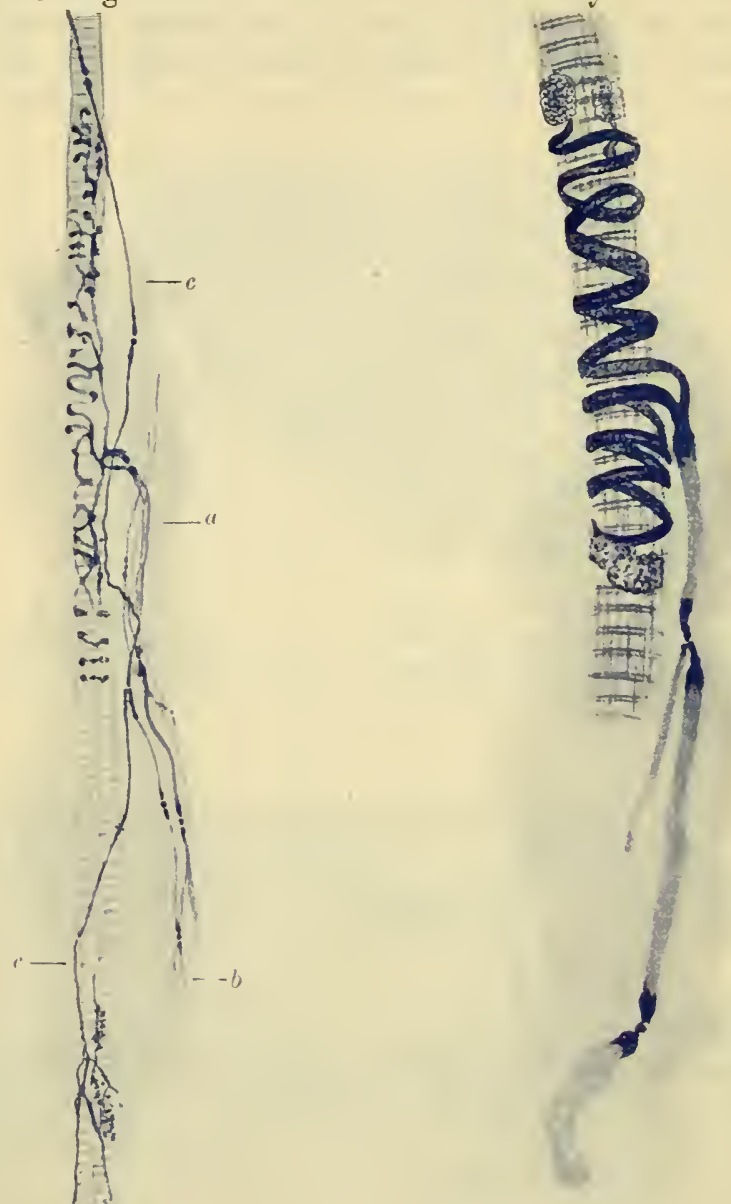

FIG. 222.

Fig. 221.-Nerte-exdixgs UPON THE INTRAFUSAL MUSCLEFIBRES OF A MLSCLE-SPINDLE OF THE RABBIT; MODERATELY MAGNIFIED. METHYLE.TE BLCE PREPARATION. (Dogiel.)

a large medullated fibre coming off from "spindle" nerve and passing to end in an anmulo-spiral termination on and between the intrafusal fibres; $b$, a fine medullated fibre coning off from the same stem and dividing. Its branchcs, $c$, pass towards the ends of the muscle-fibres and terminate in a number of small localised arborisa. tions, like end-plates.

FIG. 221.

FIG. 222. - AX ANXtLO-SPIRAL EXDING OF INTRAFCSAL FIBRE ; HIGHLY MAGNIFIED. METHYLEE BLUE PREPARATION. (Dogiel.) 
or four such fibres entering each spindle not far from its equator), are derived from the posterior root-ganglia.

The muscle-spindle is a fusiform body, from 0.75 to $4 \mathrm{~mm}$. long, and from 0.08 to $0.2 \mathrm{~mm}$. in diameter; it lies parallel with the general direction of the fibres of a muscle. It consists of a lamellated connective-tissue sheath externally, within which is a bundle (intrafusal bundle) of from two to twelve peculiar muscle-fibres. These form an axial mass with some connective tissue and the nerve-fibres; between this axial bundle and the sheath is a lymphatic periaxial space, bridged

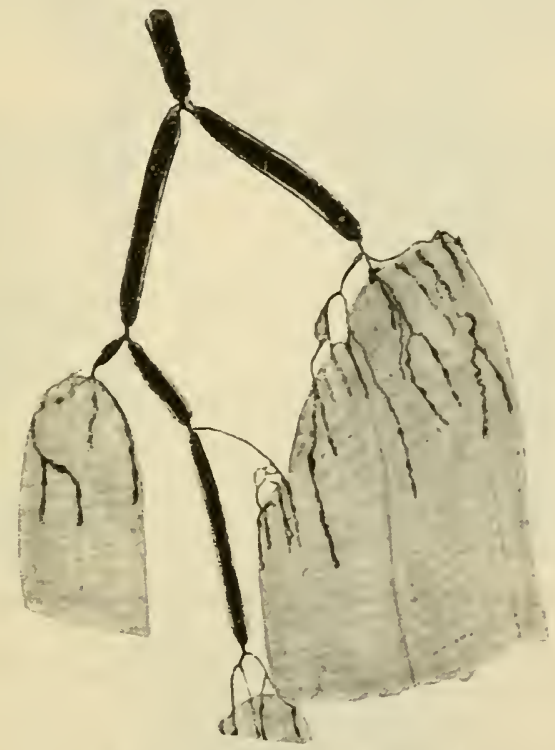

FIg. 223.-SENSORT NERTE TERMINATING IN ARBORISATIONS AROLND THE ENDS OF MUSCLE-FIBRES. (Ceccherelli.)

across by filaments of connective tissue. The intrafusal muscle-fibres are somewhat like embryonic fibres in appearance, being smaller than the ordinary fibres of the muscle and having a relatively large number of nuclei with surrounding protoplasm, as in the red variety of muscle. At the proximal end of the spindle they are usually only two or three in number, but they become cleft as they pass through it; at the distal end they may terminate in tendon bundles. The nerve-fibres which pass to the spindle are mostly of large size; they divide after reaching the intrafusal bundle, but retain their medullary sheath for a time, although eventually terminating as axis-cylinders merely, which wind in a spiral manner around the intrafusal muscle fibres (figs. 221, 222), 
which they clasp by flattened encircling branches (annulo-spiral endings). Other, much finer, medullated fibres also pass to the spindle and terminate in neighbouring parts of the intrafusal bundles in flower-like or plate-like expansions (fig. 221). According to some observers these fine fibres are prolonged from the annulo-spiral endings of the coarser fibres; but Dogiel states that they may run independently to the intrafusal bundle. No motor nerve-fibres appear to pass into the spindles, unless the fine fibres above mentioned are to be so regarded, nor do the muscle-fibres of the spindle undergo atrophy on section of the motor nerve-roots, as is the case eventually with the ordinary muscle-fibres. It is not uncommon to find two or three spindles close together or even

$A$

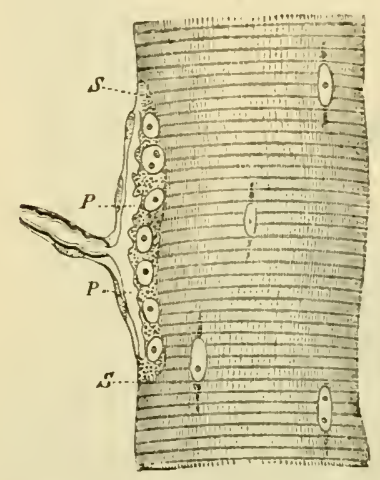

B

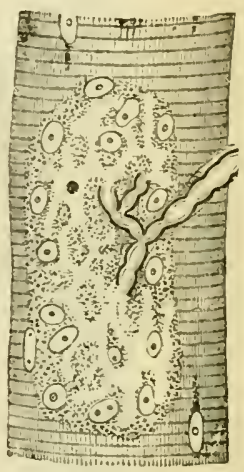

Fig. 224. -Nerte-exdixg in yesctlar Fibre of a lizard (Lacerta viridis). (Kühne.)

$A$, end-plate seen edgeways; B, from the surface ; $s, s$, sarcolemma ; $p, p$, expansion of axis-cylinder. In $\mathrm{B}$ the expansion of the axis-cylinder appears as a clear network brauching from the divisions of the wedullated fibres.

inclosed in a common sheath. Muscle-spindles are few in number in the eye-muscles, and have not yet been found in the muscles of the tongue, but otherwise their occurrence is general.

In the frog both motor and sensory nerves may terminate in and between the same muscle-fibres, but at different parts of the fibre. It is not known whether the muscle-tibres of the spindles also receive motor nerves in mammals.

Another kind of ending of sensory fibres in muscle has been described by Ceccherelli, in the form of an arborisation of nerve-fibrils around the ends of the muscle-fibres which are inserted into tendon (fig. 223).

Ending of motor nerves.-The motor nerves to muscles terminate in fine ramifications of the axis-cylinder ; in striated (voluntary) muscles the ramification is localised in special organs termed motor end-organs, or, less correctly, end-plates. 


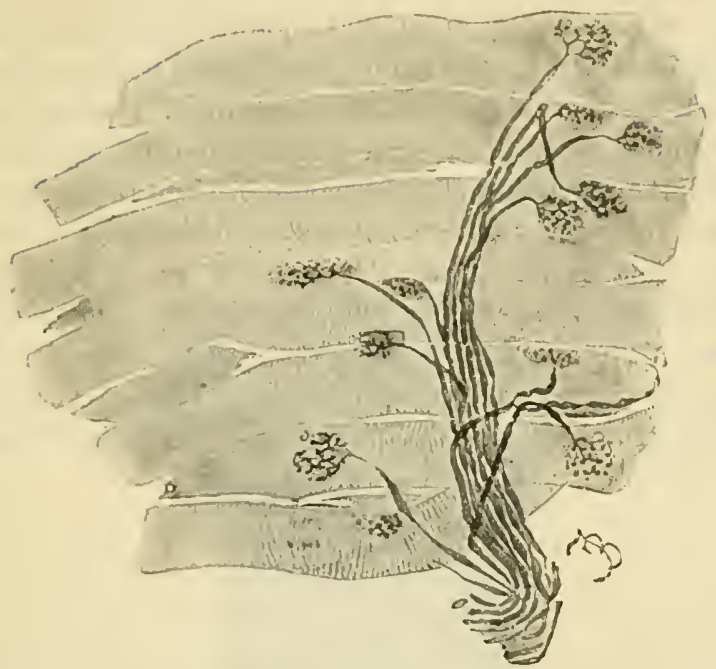

Fig. 225.-Motor YERTE-ENDINGS IN THE ABDoniNal, MUSCles OF A RAT. Gold preparation. Magnified 170 diameters. (Szrmonowicz.)

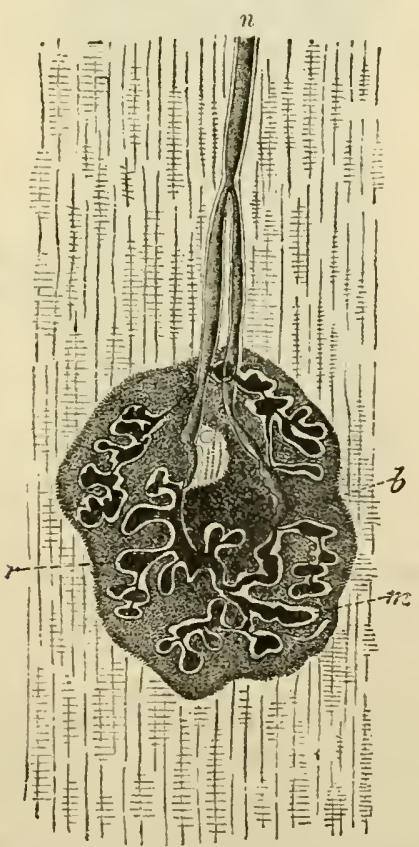

Fig. 226.-Motor Exd-orgax on a lizard, gold preparation. (Kühne.) $n$, nerve-fibre dividing as it approaches the end-organ ; $r$, ramification of axis-cylinder upon, $b$, granular bed or sole of the end.organ $m$, clear substance surruunding the ramifications of the axis-cylinder. 
In voluntary muscle, the nerves, which are always medullated, terminate, as just stated, in special end-organs (figs. 224 to 226). A medullated fibre will branch two or three times before ending, and then each branch passes straight to a muscular fibre. Having reached this, the neurolemma of the nerve-fibre is continued into the sarcolemma of the muscle, the medullary sheath stops short, and the axis-cylinder ends in a close terminal ramification with varicose expansions upon its branches. This ramification is embedded in a layer of granular nucleated protoplasm (sole) (fig. 226, b), probably a development of the sarcoplasm of the muscle. In some cases the ramification is restricted to a small portion of the muscular fibre, and forms with the granular bed a slight prominence (eminence of Doyere). This is the case in insects

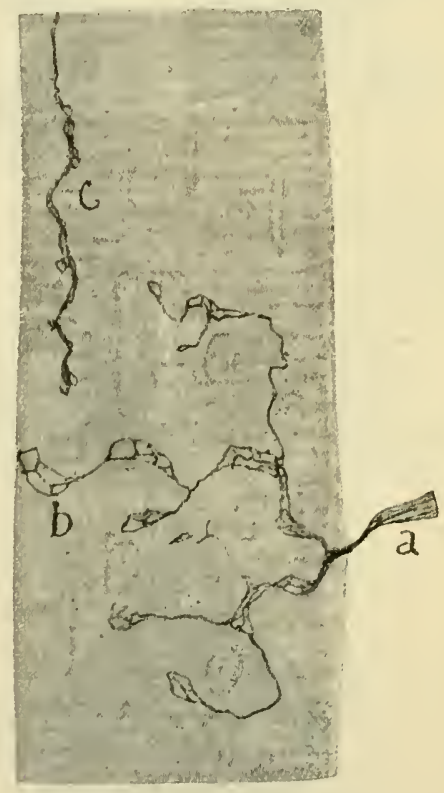

Fig. 227.-ENding of Motor Nerves in Rabit's Muscle. Reduced SILVER METHOD. (Cajal.)

$a$, axis-cylinder of entering nerve; $b, c, d$, parts of terminal ramification showing network of neuro-fibrils.,

and mammals. In the lizard the ramification is rather more extended than in mammals, whilst in the frog it is spread over a considerable length of the fibre. The ramification shows a fibrillar structure (fig. 227), which is especially evident at the enlargements. In mammals there appears to be only one end-plate to each fibre, while in reptiles there may be several. The end-plate is covered, externally 
to the sarcolemma, by an expansion of the sheath of Henle of the nerve-fibre (telolemma).

In involuntary muscle, both plain and cardiac (fig. 228), the nervefibres, which near their termination are entirely non-medullated, end in plexuses. The primary plexuses are generally furnished with ganglioncells in abundance. Such gangliated plexuses are best developed in

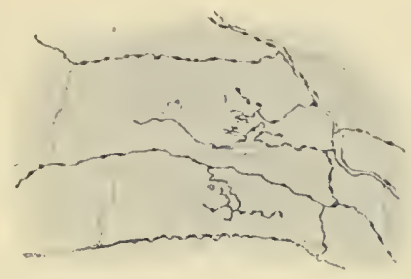

Fig. 228.- Ending of Nerve-fibres in cardiac muscle. (Smirnow.)

connection with the intestine. From the cells of these plexuses other nerve-fibres pass which form secondary plexuses and terminal ramifications amongst the contractile fibre-cells, to the surface of which the endings of the branches, often slightly enlarged, are applied (Huber and de Witt). 


\section{LESSON XX.}

\section{STRUCTURE OF THE LARGER BLOOD-TESSELS.}

1. Sectioss of a medium-sized peripheral artery and rein, e.g. popliteal or radial. In this preparation the limits of the vascular coats can be well seen and also the differences which ther present in the arteries and veins respectively. The sections may be stained with hæmalum and eosin or with orcein, and mounted in dammar or xylol balsam.

‥ Mount in xylol balsam or dammar a thin slice cut from the inner surface of a large artery which, after having been cut open longitudinally and washed with distilled water, has been rinsed with nitrate of silver solution and then with distilled water and exposed to the sunlight. The vessel should then be hardened in alcolool, or it may be exposed in this to the light. This preparation will show the outlines of the epithelium-cells which line the ressel. A similar preparation may be marle from a large vein.

3. A piece of an artery which has been macerated for some days in 33 per cent. alcohol is to be teased so as to isolate sone of the muscular cells of the middle coat and portions of the elastic layers (networks and fenestrated membranes) of the inner and middle coats. The tissue may be stained cantiously with diluted hæmalum, and glycerine afterwards added. The muscular cells are recognisable by their irregular outline and long rodshaped nuclei. Sketch one or two and also a piece of the elastic network or of fenestrated membrane. The fenestrated menlbrane is best obtained from one of the arteries of the base of the brain ; it is also well seen in the arteries within the kidney.

4. Transverse sections of aorta and carotid. Notice the differences in structure between these and the section of the smaller artery.

5. Transverse section of rena cava inferior. Notice the comparatively thin layer of circular muscle, and outside this the thick layer of longitudinal muscular bundles in the adventitia.

Make sketches from 1, 4, and 5 uncer a low power, from 2 and 3 under a high power.

An artery is usually described as being composed of three coats, an inner or elastic, a mildle or muscular, and an external or areolar (fig. $229, b, c, d)$. It is, however, more correct to describe the wall of an artery as being mainly composed of muscular and elastic tissue, lined internally by a parement epithelium (endothelium), and strengthened externally by a layer of connective tissue (adientitia).

The inner coat (tunica intima) is lined by a thin layer of parement epithelium (endothelium), the cells of which are somewhat elongated in the direction of the axis of the vessel (fig. 230), and form a smooth lining to the tube. After death they become easily detached. 
The endothelimn is the essential layer in all blood-vessels. It is always the first part to be developed, anl in some it remains as the only layer of the ressel. This is the case with all true cappllaries and with certinin veins,

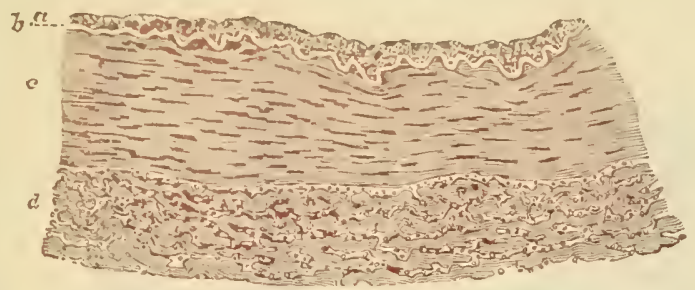

Fig. 229. -Traxsverse SEction OF PART OF THE WALL OF THE POSTerior TIBIAL ARTERT. (75 diameters.)

$a$, epithelial and subepithelial layers of inner coat; $b$, elastic layer (fenestrated mem. brane) of inner coat, appearing as a bright line in section; $c$, muscular liyer (middle coat); $d$, outer coat, consisting of connective tissue bundles. In the interstices of the bundles are some connective-tissue nuclei, and, especially near the muscular coat, a number of clastic fibres cut across.

and also with the lacunar spaces or sinusoids, which, as Minot has pointed out, take the place of capillaries in certain parts (e.g. in the liver, the medulla of the suprarenal capsules and the Wolffian body of the embryo);

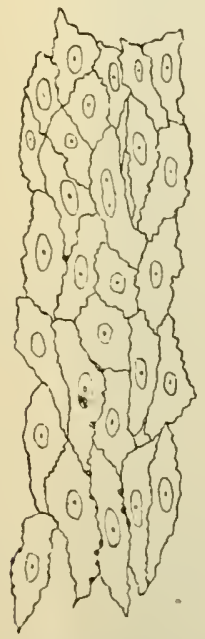

Fig. 230.-EPITHELIAL LAYER LINIXG THE POSTERIOR TIBIAL ARTERT. (250 diameters.)

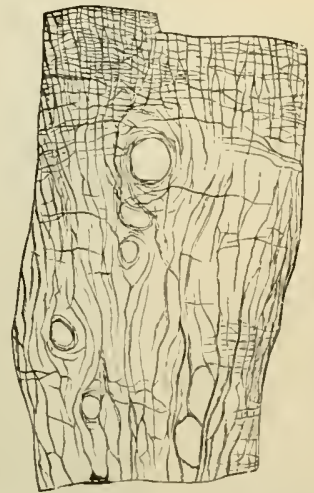

Fig. 231.-PORTION OF FENESTRATED MEJBRANE OF HENLE FROM AY ARTERT. (Toldt.)

it is also true of the sinuses of erectile tissue, as well as the sinus-like blood-vessels which are met with in invertebrates. In some structures the endothelial layer of the blood-vessels is imperfect, viz. : in the capillaries and 
blood-sinuses of the spleen, the placental mucous membrane of the pregnant uterus, and probably the sinusoids (capillaries) of the lirer : in these places

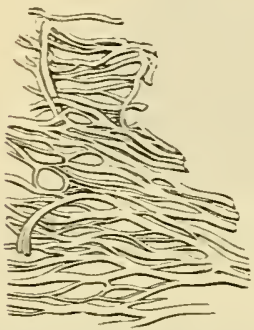

FIG. 232.-ELASTIC SETWORK OF ARTERY. (Toldt.)
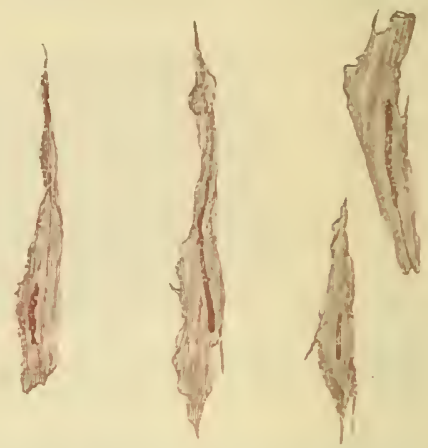

Fig. 233.-MICSCCLAR FIBRE-CELLS FROY SEPERIOR THYROID ARTERY. (310 diameters.)

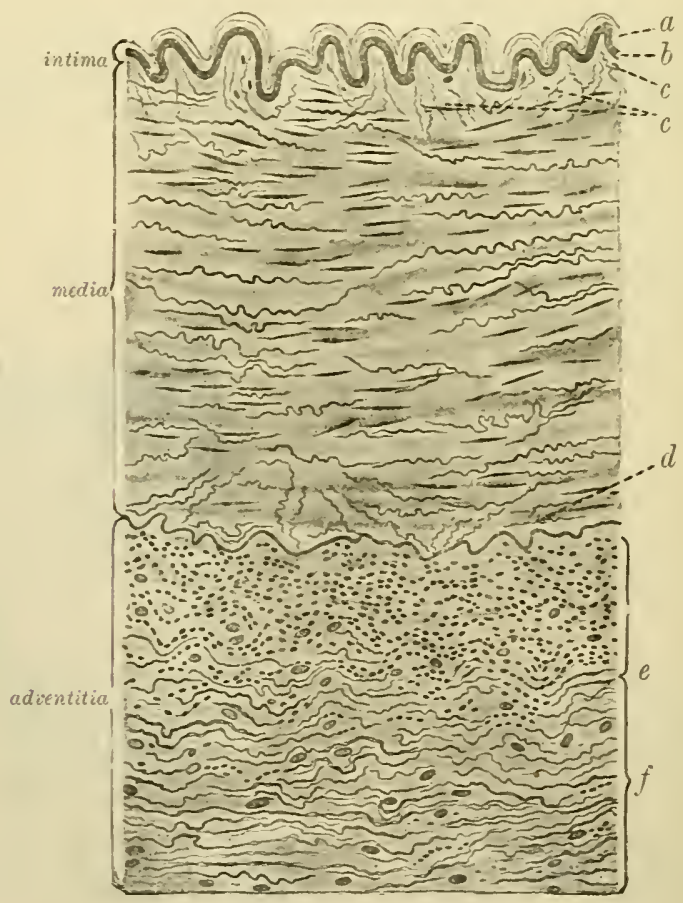

Fig. 234.-Section of the Livgeal ARTERT. (Grünstein.)

$a$, epithelium and subenithelial lajer of inner coat; $b$, its elastic laser; $c, c, d$, inner. most and outermost lajers of middle coat, with elastic fibres passing obliquely to join the elastic lajers which bound that coat; $\epsilon$, innernnost rart of outer coat or adrentitia, showing many elastic fibres cut across ; $f$; outer rart of adrentitia. 
the blood finds its way into the interstices of the organ and comes in direct contact with the tissue-cells.

Next to the endothelium eomes an elastic layer in the form either of elustic neturorks (fig. 232) or of a fenestruted membrane (fig. 231). In some arteries there is a layer of fine comnective tissue intervening between the epitheliun and the fenestrated mensbrane (subepithelial layer).

The mildle cout (tunica media) consists mainly of circularly disposed plain muscular fibres, but it is also pervaded in most arteries by a network of elastic fibres which are connected with the fenestrated

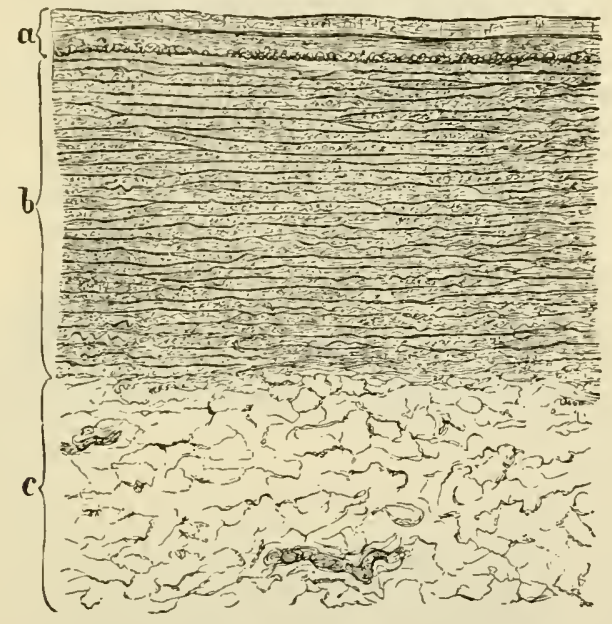

Fig. 235.--Section OF ThORACIC AORTA AS SEEN UNDER A Low POWER. (Toldt.)

$a$, the inner coat consisting of threc layers, viz.: 1. Epithelium seen as a fine line. 2. Subepithelial layer. 3. Elastic layers. In the outer part of the inner coat, at its junction with the middle, a layer of longitudinal museular fibres is represented as cut across. $b$, middle eoat with alternating lajers of muscle aud elastic membranes; c, outer coat with two vasa vasorur.

membrane of the inner coat and are sometimes almost as much developed as the muscular tissue itself. This is especially the case with the larger arteries, such as the aorta and the carotid and its immediate branches, but in the smaller arteries of the limbs the middle coat is composed almost purely of muscular tissue. The muscular fibres are comparatively short, with long rod-shaped nuclei, and are often irregular in shape (as in fig. 233), especially if the middle coat contains much elastic tissue.

The outer coat is formed of connective tissue with a good many elastic fibres, especially next to the middle coat. The strength of an artery depends largely upon this coat; it is far less easily cut or torn 
than the other coats, and it serves to resist undue expansion of the vessel. Its outer limit is not sharply marked, for it tends to blend with the surrounding connective tissue; hence it has been termed tunica adventitia.

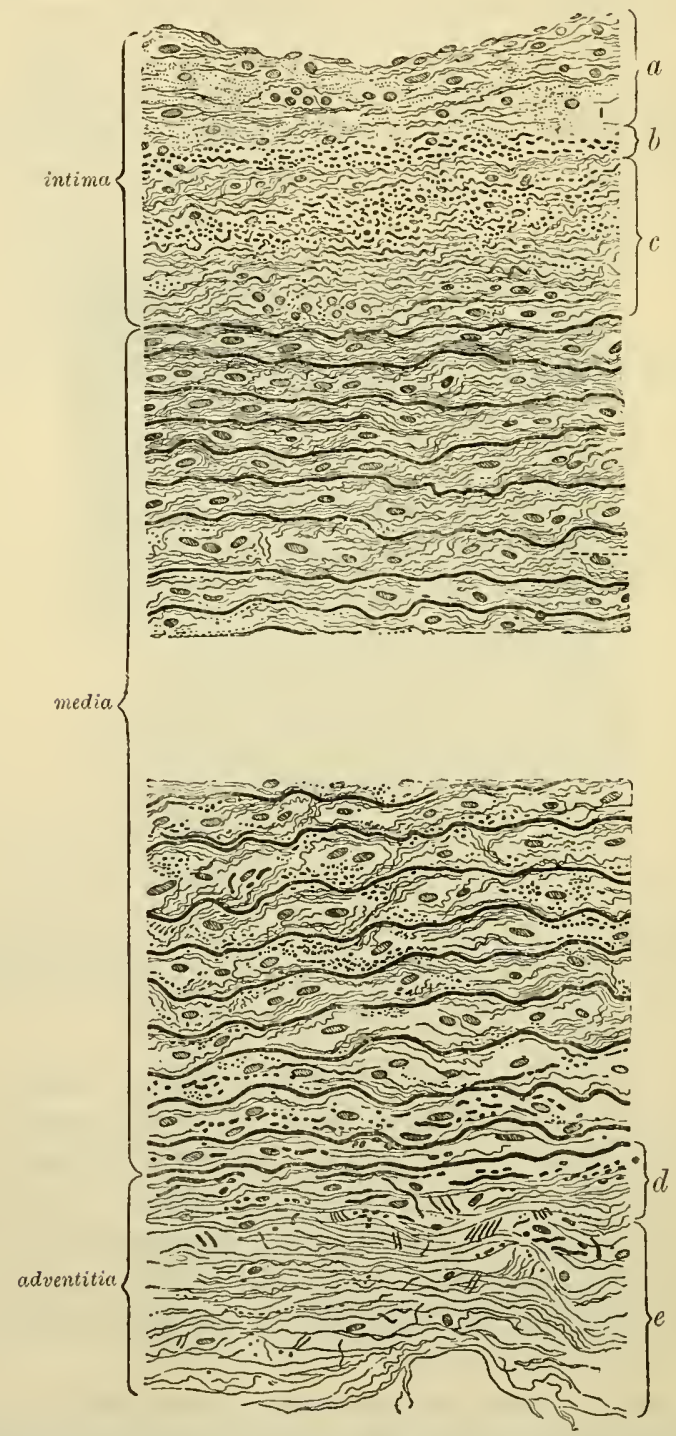

Fig. 236.- Section of aORTa More Magnified. (Grünstein.)

$a$, epithclial and subepithelial layers of inner coat; $b, c$, outer layers of inner coat containing many fine elastic fibres; $d, e$, parts of outer coat. 
Variations in structure.-The aorta (figs. 235, 236) differs in some respects in structure from an orlinary artery. Its inmer coat contains a consideralile thickness of subepithelial connective tissue, but the elastic layers of this coat are chiefly composed of fine fibres, and are not especially marked off from those of the middle coat, so that the inner and middle coats appear blended with one another. On the other hand, there is a very great development of elastic tissue in the middle coat, forming membranous layers which alternate with layers of the muscular tissue. A good deal of connective tissue also takes part in the formation of the middle coat, making this coat musually strong. The immer and middle coats constitute ahmost the entire thickness of the wall, the onter coat being relatively thin.

The other variations which occur in the arterial system have reference chietly to the development and arrangement of the muscular tissue. Thus in many of the larger arteries there are a few longitudinal muscular fibres at the immer bomdary of the middle coat, and in some arteries amongst the circular fibres of the middle coat. This is the case in the aorta. In the part of the umbilical arteries within the umbilical cord there is a complete layer of longitudinal fibres internal to the circular fibres and another external to them, whilst the amount of elastic tissue is very small. Longitudinal fibres are also present in some other arteries (iliac, superior mesenteric, splenic, renal, etc.), external to the circular fibres, and therefore in the outer coat of the artery.

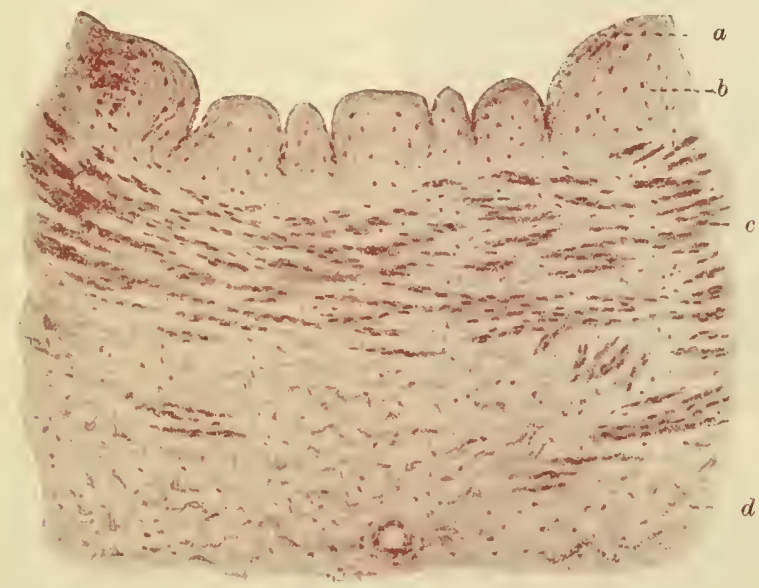

FIG. 237.-TRANSVERSE SECTION OF PART OF THE WALL OF ONE OF THE POSTERIOR TIBIAL VEINS (HAN). About 200 diameters.

$a$, epithelial, and $b$, subepithelial layers of inncr coat; $c$, middle coat consisting of irregular liyers of museular tissue, alternating with connective tissue, and passing somewhat gradually into the outer connective tissue and elastic coat, $d$.

The veins (fig. 237) on the whole resemble the arteries in structure, but they present certain differences. In the internal coat the same layers may be present, but the elastic tissue is less developed, and may be quite inconspicuous; it seldom takes the form of a complete membrane. The epithelium cells are less elongated than those of the arteries. The middle coat $(c)$ contains less elastic tissue and also much less muscular tissue, being partly occupied by bundles of white 
connectire-tissue fibres. These are continuous with those of the external coat, which is relatively better developed in the veins than in the arteries, so that, although thinner, their walls are often stronger.

Many of the reins are provided with valves, which are crescentic folds of the internal coat strengthened by a little fibrous tissue:

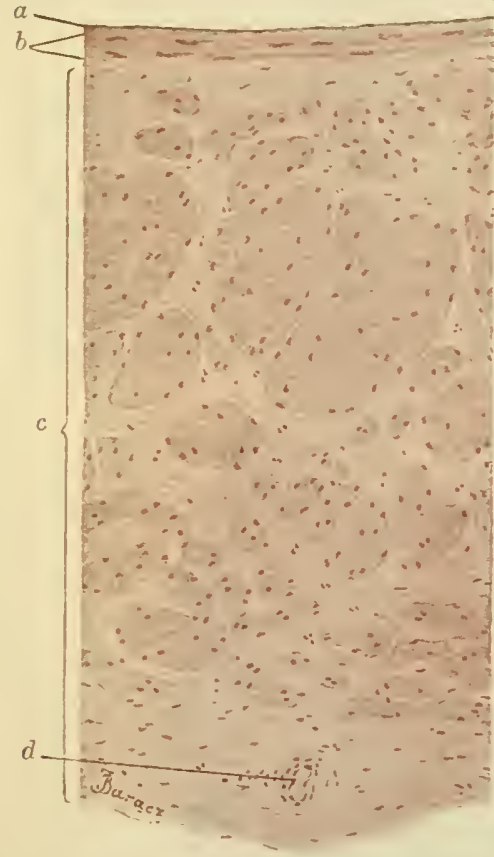

Fig. 238.-TRANSTERSE SECTION OF THF. INFERIOR TEXA CATA OF THE DOG. (Szymonoricz.) Magnified 150 dia. meters.

$a$, intima; $b$, thin laser of circular muscle; $c$, thick adrentitia with longitudinal muscular buudles; $d$, a vas vasis.

a few muscular fibres may be found in the valve near its attach. ment. The layer of the inner coat is rather thicker and the epithelium-cells are more elongated on the side which is subject to friction from the current of blood than on that which is turned towards the wall of the ressel.

Variations in different veins.The reins vary in structure more than do the arteries. In many reins longitudinal nuscular fibres are found in the immer part of the middle coat, as in the iliac, femoral, umbilical; the umbilical vein within the umbilical cord having three muscular larers like the corresponding arteries; it has a well-developed internal elastic layer. In other reins, longitudinal fibres occur external to the circularly disposed fibres, and may be described as belonging to the outer coat. This is the case with the abcominal and especially the hepatic portions of the inferior vena cara (fig. 238), and to a less extent with the hepatic veius and the portal rein and its tributaries. In the superior reua cara, in the upper part of the inferiol rena cara and in the jugular, subclavian and innominate reins muscular fibres are almost entirely absent in the middle coat, and there are but few in the adrentitia. The reins of the pia mater, brain and spinal cord, retina, and bones, and the venous sinuses of the dura mater and placenta have no muscular tissue.

It is only the larger reins, especially those of the limbs, that possess valres. They are wanting in most of the reins of the riscera (although occurring abundantly in some of the tributaries of the portal vein), in those within the craninm and rertebral canal, in the veins of the bones, and in the umbilical rein. 


\section{LESSON XXI.}

\section{S.ULLER BLOOD-TESSELS AND LYMPH-VESSELS. SEROUS MEMBRAMES. MICROSCOPIC STUDY OF TIIE CIRCULA- TION. DEVELOPUENT OF BLOOD-I'ESSELS.}

1. TAKE a piece of pia mater which has been fixed with 2 per cent. bichromate of potassiun and stained with hrmatoxylin, and separate from it some of the small blond-ressels of which it is chiefly composed. Mount the shreds in dilute glycerine, or after dehydrating with alcobol and passing through clove oil they can be mounted in dammar or xylol balsam. The structure of the small arteries can be studied in this preparation, the nuclei of the epithelium and of the muscular coat being brought distinctly into view by the stain. The veins of the pia mater possess no muscular tissue. Capillary vessels which have been dragged out from the brain in removing the pia nater may also be seen in this preparation. Sketch two small arteries of different sizes, giving also their measurements.

2. Mount in dammar or xylol balsam a piece of the omentum of the rabbit, stained with silver nitrate. The nembrane should be stretched over a cork or a ring of mood or rulcanite, rinsed with distilled water, treated for five minutes with 1 per cent. nitrate of silver solution, again washed and exposed to sunlight in spirit. When stainerl brown, the preparation is removed from the light and placed in oil of cloves. Pieces may now be cut off from the membrane and mounted in balsam or dammar: they should include one or more blood-vessels.

This preparation is intended to show the epithelium of the smaller bloodvessels and accompanying lymphatics, and also the epithelium of the serous membrane. Sketch a small piece showing the epithelium of the vessels.

3. Mount in balsam or dammar a piece of the central tendon of the rabbit's diaphragn which has been prepared with silver nitrate, the plemal surface laving been first brushed to remove the superficial epithelium and thus enable the nitrate of silver more readily to penetrate to the network of underlying lymphatic vessels. Observe the lymphatic plexus under a low power; sketch a portion of the network. If the peritoneal surface is focussed, the epithelium which covers that surface will be seen, and opposite the clefts between the radially disposed tendon-bundles stomata may be looked for in this epithelium.

4. Examine sections of the thoracic duct. These may be made in the same way as sections of the blood-vessels.

5. Open the abdomen of a freshly killerl frog, preferably a male, and remove the abdominal viscera, taking care not to injure the membrane or septum at the back of the abdomen, which lies over and between the kidneys and separates the peritoneal cavity from the cisterna lymphatica magna, a large lymph-space in which the aorta and vena cava are contained. Cut ont the kidneys along with as much as possible of the above septum; rinse with distilled water; and place in a watch-glass of 1 per cent. silver nitrate for 5 minutes. Rinse again in distilled water and expose in tap water to the light. When slightly browned snip off a portion of the membranous septum, float it flat on a slide, drain off the superfluous water and 
allow it to dry ; then add a drop of xylol balsam or dammar and cover the preparation.

6. Kill a frog by destroying the brain, and study the circulation of the blood in the mesentery. It can also be studied in the web of the frog's foot, and in the lung and tongue of the frog or trad, or in the tail of the tadpole or of any small fish. But for observing the phenomena attending conmencing inflammation and the emigration of lencocytes from the ressels, the mesentery is the most convenient object. The frog can be immobilised with curari or by placing it in water in which chloroform or ether has been shaken up: a lateral incision is made in the abdominal wall, a loop of intestine drawn ont, and laid over a ring of cork which is fixed to a glass plate and corered with a thin piece of glass. The membrane nust be kept wet with salt solution. ${ }^{1}$

The coats of the small arteries and veins are much simpler in structure than those of the larger vessels, but they contain at first all
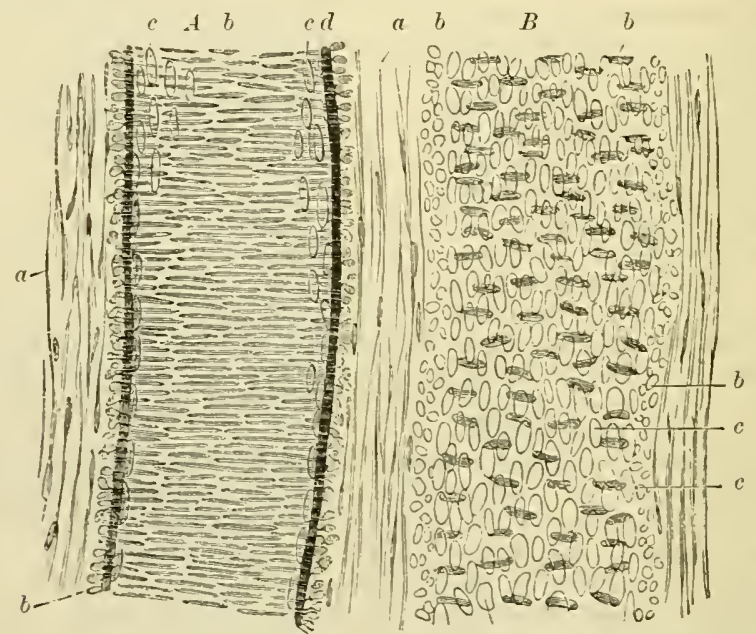

Fig. 239.-SMall arteri, $A$, with correspondivg vein, $B$, treated with ACETIC ACID. (Kölliker.) (Magnified 350 diameters.)

$a$, external coat with elongated nuclei; $b$, nuclei of the transwcrse muscular tissue of the middle coat (when seen endwise, as at the sides of the ressel, their outline is circular); $c$, nuclei of the epithelium-cells ; $d$, elastic layer of the inner coat.

the same elements. Thus there is a lining endothelium and an elastic layer, the two together forming an inner crat; a middle coat of circularly disposed plain muscular tissue; and a thin adrentitia. The same differences are found between the smaller arteries and reins as with the larger, the walls of the veins being thinner and containing far less muscular tissue (fig. 239), and the lining epithelium-cells, much

1 For details of the methods of studying the circulation and also of injecting the blood-vessels, see $A$ Course of Practical Histology. 
elongated in both vessels, are far longer and narrower in the small arteries than in the eorresponding veins (fig. 241).

In the smallest vessels it will be found that the clastic layer has entirely disappeared in the veins, and the muscular tissue is eonsiderably reduced in thickness in both kinds of vessel. Indeed, it is soon represented by but a single layer of eontractile cells, and even these no longer form a complete layer. By this time also, the outer coat as well as the elastic layer of the inner coat have disappeared both from arteries and veins. The vessels are reduced, therefore, to the condition of a tube formed of pavement-epithelium cells, with a partial covering of circularly disposed museular cells.

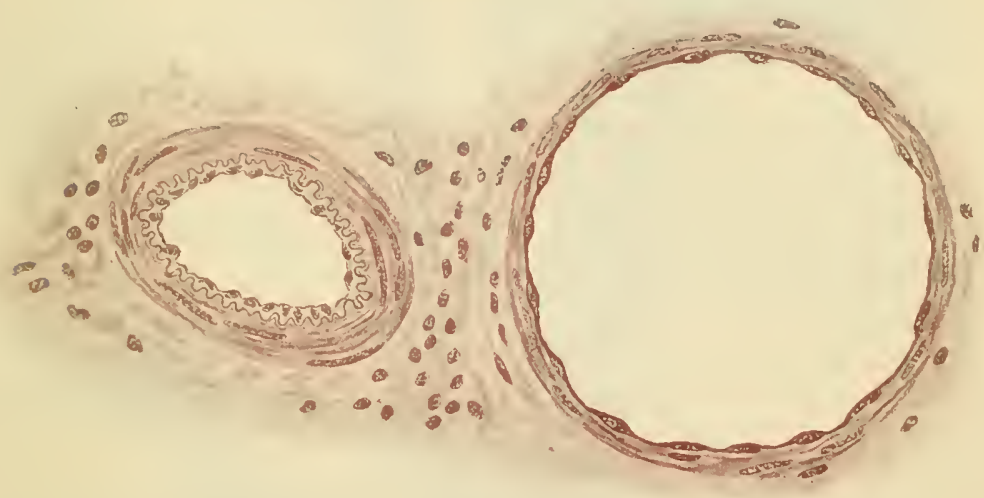

Fig. 240.-Transverse Section of a small artery AND vein.

Magnified 250 diameters.

Even in the smallest vessels, which are not capillaries, the differenees between arteries and veins are still manifested. These differenees may be enumerated as follows:- The veins are larger than the corresponding arteries; they branch at less acute angles; their museular cells are fewer, and their epithelium-cells less elongated; the elastic layer of the inner coat is always less marked, and sooner disappears as the vessels become smaller.

Capillary vessels. - When traced to their smallest branches the arteries and veins eventually are seen to be continued into a network of the smallest blood-vessels or capillaries. The walls of these are composed only of flattened epithelium-cells (fig. 242) continuous with those that line the arteries and veins; these eells can be exhibited by staining a tissue with nitrate of silver. The eell-outlines are not shown in developing capillaries; in these, silver nitrate stains the whole 
wall. This is the case also with the capillaries of the villi, those of the choroid coat of the eye (Eberth), and those of the kidney-glomeruli (Ranvier): in all these places the walls are formed of a syncytium.

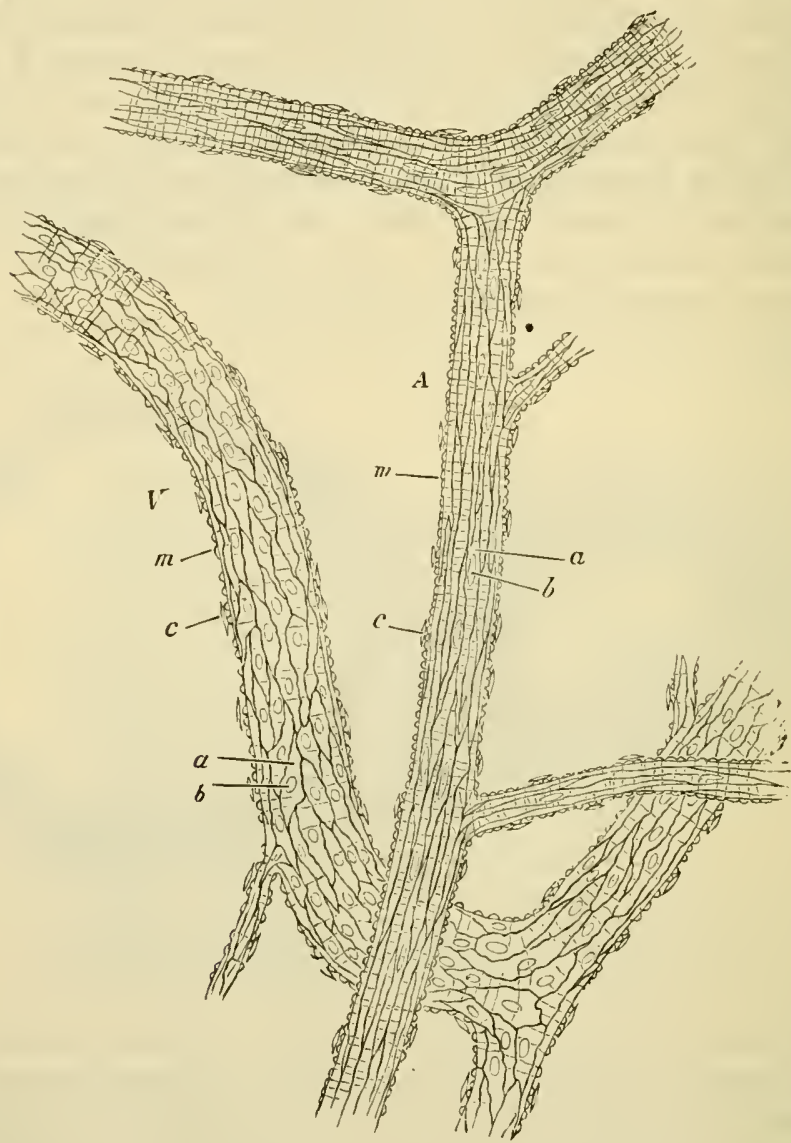

Fig. 241.-A shall arteri, $A$, ani vein, $\boldsymbol{V}$, from the subcutaneous conNECTIVE TISSUE OF THE RIT, TREATEN WITH NITRATE OF SILVER, WITH SUBSEQUENT STAINING OF NUCLEI. 175 diameters.

$a, a$, epithelial cells with $b, b$ their nuclei $; m, m$, transverse markings due to staining of substance between the nuscular fibre-cells; $c, c$, nuclei of comnectivc-tissue corpuscles attached to exterior of ressel.

The eapillaries vary somewhat in size and in the closeness of their meshes; their arrangement in different parts, which is mainly determined by the disposition of the tissue-elements, may best be studied in injected preparations, and will be described when the structure of the several organs is considered.

In the transparent parts of animals, the blood may be seen flowing 
through the capillary network from the arteries into the veins. The current is very rapid in the small arteries, somewhat less rapid in the veins, and slow in the capillaries. The eurrent is fastest in the centre of the vessels, slowest near the wall (inert layer). In this layer the leucocytes are carried along by the stream and may be observedespecially where there is commencing inflammation of the part, as in

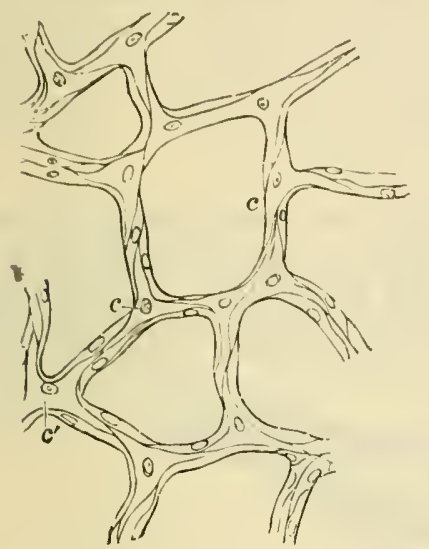

Fig. 242.-CAPILLARY VESSELS FROM THE BLADDER OF THE CAT, MAGNIFIED.

The outlines of the cells are stained by nitrate of silver.

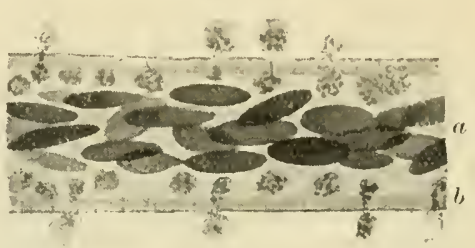

Fig. 243. - BLOOD FLowing THROUGH A SMALL VEIN OF THE FROG'S MESENTERY.

The mesentery had been cxposed for a short time, so that there was commencing inflammation and many of the white corpuscles are observed sticking to and even passing through the vascular wall. $\alpha$, central rapid layer containing the coloured corpuscles; $b$, outer slower layer (inert layer) containing the white corpuscles.

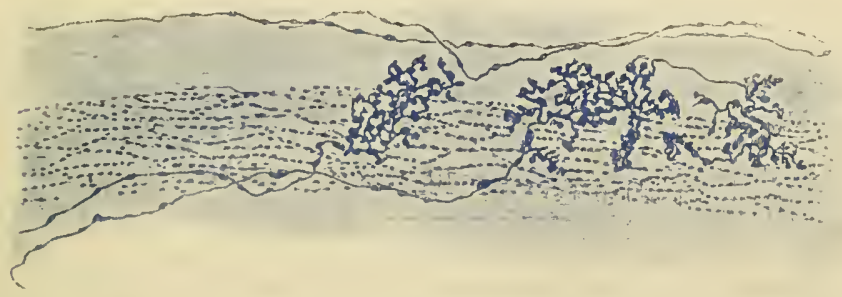

Fig. 244.-ENDING OF SENSORY NERVE-FIBRES IN ARBORESCENCES IN THE WALL OF A SMALL ARTERY. (Dogiel.)

The endothelium-cells of the vessel are outlined by dotted lines and the outlines of the muscular fibres are faintly indicated.

the mesentery in consequence of exposure-to adhere to the inner surface of the blood-vessels, and here and there to pass through the coats of the small vessels, and appear as migratory cells in the surrounding connective tissue (fig. 243). The blood-platelets are also to be seen in the inert layer, and show a tendency to adbere to the wall and to one another in commencing inflammation. 
Vessels and nerves of the blood-vessels.-The larger arteries and veins yossess blood-vessels (vasa vasorum) and lymphaties, both of which ramify chiefly in the external coat. Nerves are distributed to the muscular tissue of the middle coat, after forming a plexus in the onter coat. Most of the nerves are non-medullaterl. But there are a certain number of medullated fibres intermingled with the non-medullated and passing to end in localised arborescences (fig. 244) partly in the adventitia, jartly in the intima. These medullated fibres are doubtless afferent; the majority of the non-medullated are probably efferent (vaso-motors). In the aorta of man and in some of the larger trunks Pacinian corpuscles are here and there met with. The capillary vessels also receive nerve-fibres, which form a fine plexus of fibrils in close contact with the endothelium-cells of which the walls of these vessels are composed. Small cells are found at intervals in connection with these plexuses, but whether they are of the nature of nerve-cells or not is uncertain.

Development of the blood-vessels. - The blood-vessels are developed in the connective tissue or in the mesenchyme which precedes it, the first vessels being formed in the vascular area which surrounds the early embryo. Their development may be studied in the embryo

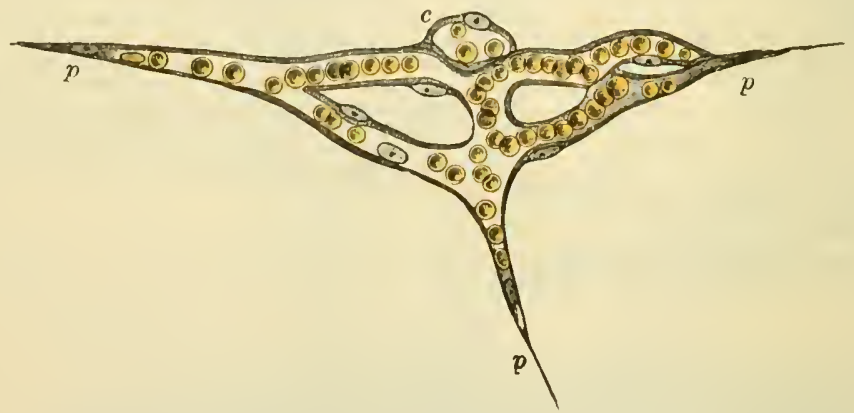

F1G. 245.-Isolated CAPILlaty NeTWORK ForMed BT the JUNCtion OF A HOLLOWED-OUT SYNCYTIUM, CONTAINING COLOURED BLOOD-CORPUSCLES IN A CLEAR FLUUD.

c, a hollow eell the eavity of which does not yet eommunicate with the network; $p, p$, pointed eell processes, extending in different directions for union with neighbouring capillaries.

chick or mammal, in the omentum of the new-born rabbit, or in the serous membranes and subcutaneous connective tissue of fotal animals. They are originally developed from cells (vaso-formative cells or angioblasts) which become hollowed out by vacuolation: coloured blood-corpuscles may be formed within them (see Development of Blood-corpuscles, Lesson II.). The cells branch and unite with one another to form a syncytium, and their cavities extend into the branches. In the meantime their nuclei multiply and become distributed along the branches, cell-areas being at a later stage marked out around the nuclei. In this way intercommunicating vessels-capillaries containing blood-are produced (fig. 245). 
These presently become connected with previously formed vessels, which extend themselves by sending out spronts, at first solid, and afterwards hollowerl out. ${ }^{1}$ Even the larger blood-vessels appear first to be developed in the same way as the eapillaries, in so far that the epithelium is first formed and the muscular and other tissues are subsequently added; but whether they are formed as clefts in the mesoblastic tissue, which become bounded by flattened cells, or whether as a hollowed-out syncytium has not been definitely ascertained.

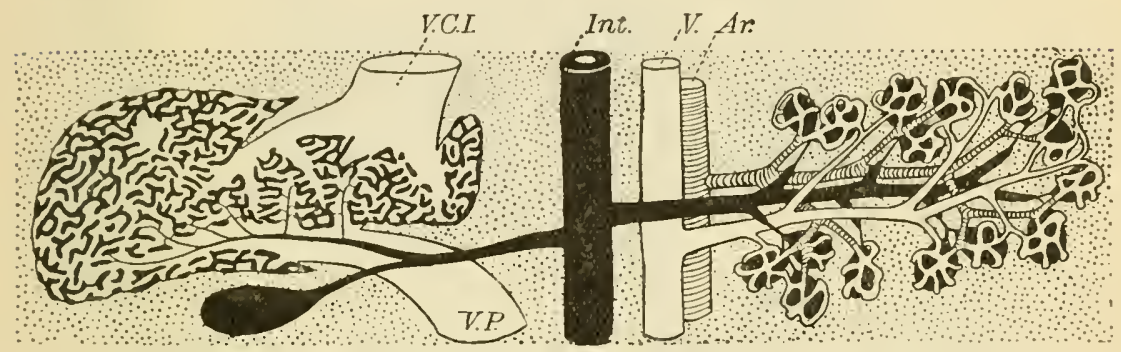

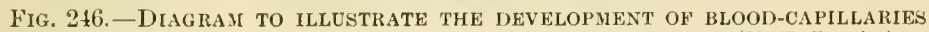
(RIGHT SIDE), AND SINUSOIDS (LEFT SIDE) RESPECTIVELY. (F. T. Lewis.)

Int, intestinal entoderm with outgruwth on the left to form the liver and gall-bladder, and on the right to form the pancreas. V.C.I., vena cava inferior; V.P., vena portæ; $V$., vein and $A r$, artery supplying pancreas. It is seen that the sinusoids or apparent enpillaries of the liver are formed by the breaking up of a large blood-space into channels by the growth into it of cell-columns derived from the hepatic outgrowth of the entoderm.

Sinusoids. - These are sinus-like blood-spaces between the cells of a tissue, which may when fully developed bear a superficial resemblance to blood-capillaries, but which differ essentially from them both in their mode of development and in their relationship to the connective tissue, as well as to the tissue-elements of the organs in which they occur. Whereas capillary blood-vessels are developed amongst and between the tissue-elements and are connected with and grow from neighbouring capillaries which are themselves surrounded by areolar tissue, sinusoids make their first appearance in the form of comparatively large bloodspaces connected with the venous (or arterial) system. Into these, the walls of which are formed only of a single layer of endothelial cells, the tissue-elements of the developing organ (Wolffian body, liver, suprarenals, blood-glands, etc.) grow, invaginating the thin wall and forming cell-trabeculæ within the sinus (figs. 246, 247), so that

${ }^{1}$ Many authorities consider that new blood-vessels are exclusively formed by sprouts from pre-existing vessels, and regard the appearances above described as being due to retrogressive development of an already formed vascular network (see footnote, p. 37). 
the cells of the organ are directly in contact with the invaginated endothelium, and are only separated by this from the blood contained within the sinus. But the connection may become yet closer than this, for, as happens in the liver, the invaginated endothelium may

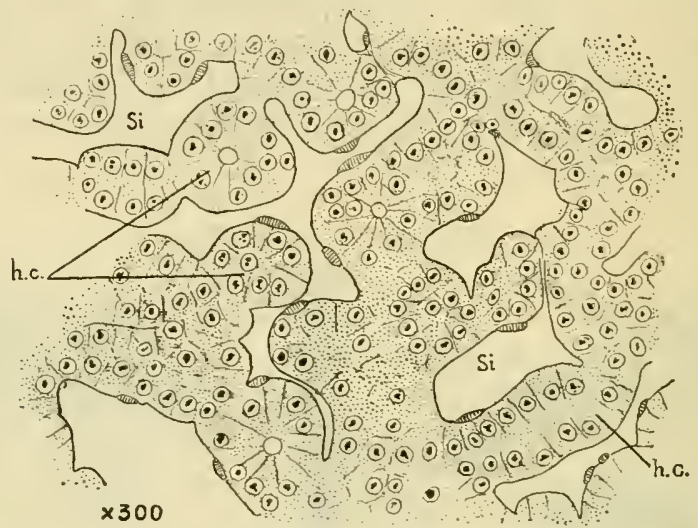

Fig. 247.-Liver OF EMBRYO-CHICK OF ELEVEN DAYS. (C. S. Minot.) h.c., hepatic cylinders; si, sinusoids.

become defective, so that the blood within the sinus comes into actual contact with the cells of the organ, and runs into the interstices between them. As development proceeds these interstices may come to resemble blood-capillaries in general arrangement and shape; but the resemblance is only superficial, and the intimate relationship between the blood and the tissue-elements, which are both enclosed within the original sinus, is usually maintained. The distinctive character of sinusoids was first recognised by Minot.

\section{LYMPHATICS OR LYMPH-VESSELS.}

To the lymphatic system belong not only the lymphatic vessels and lymphatic glands, but also the carities of the serous membranes, which are moistened with lymph and are in open communication with lymphatic vessels which run in their parietes.

The larger lymph-vessels somewhat resemble the veins in structure, except that their coats are much thinner and valves much more numerous. In lymphatics of smaller size, the wall of the vessel is formed, first, by a lining of pavement-epithelium cells (lymphatic endothelium), which are elongated in the direction of the axis of the vessel; and, secondly, by a layer of circularly and obliquely disposed muscular fibres. In the smallest vessels (so-called lymph-capillaries, which are generally considerably larger than the blood-capillaries), 


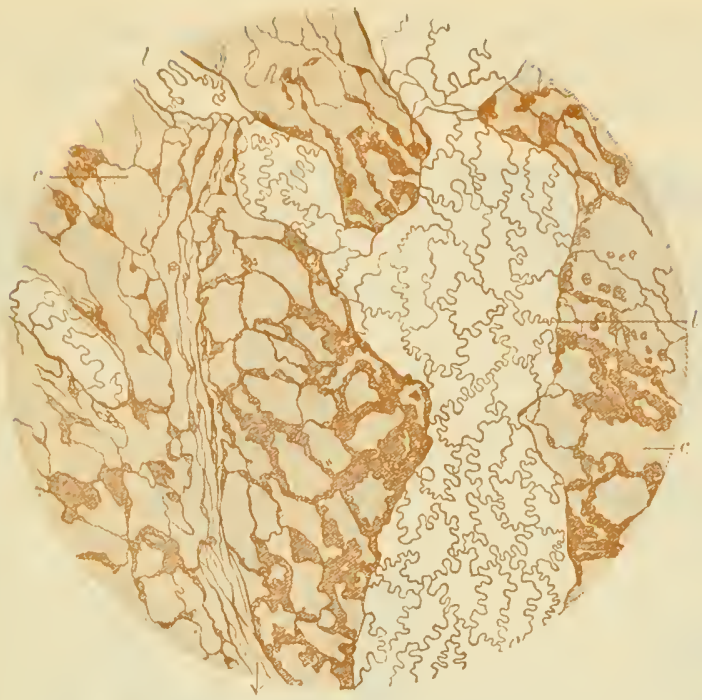

Fig. 248. - A SMALL PART OF THE lyMPhatid plexus OF THE PLeURAL LATER OF THE DIAPHRAgM. Magnified 110 diameters. (Ranvier.)

l, lymphatics with characteristic epithelium : $c$, cell-spaces of the connective tissue here and there abutting against the lymphatic.

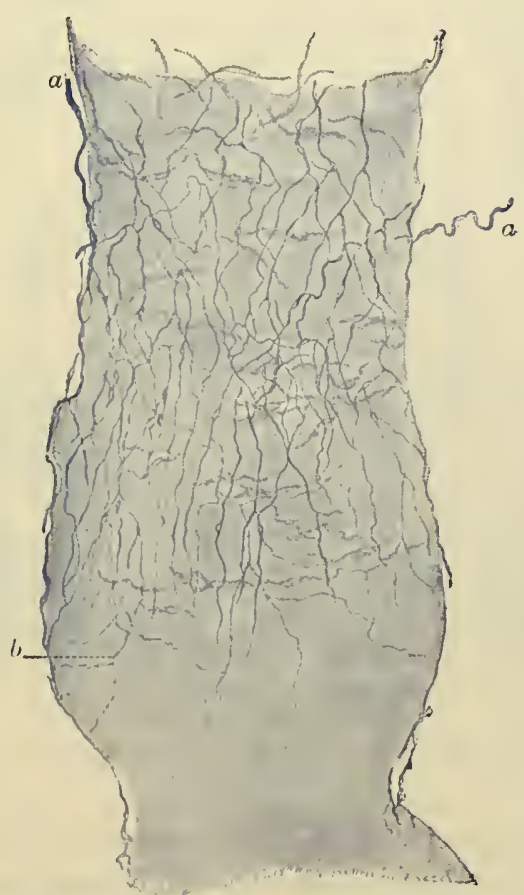

Fig. 249, - Nerves of a LyMPhatic Vessel, ShOWN BY METHYLENE BLUE, (Dogiel.)

$a, a$, non-medullated fibres passing to the vessel; $b$, part of their terminal ramification. 
there is nothing but the epithelium remaining, and the cells of this are frequently not more elongated in one direction than in another, but have a characteristic wavy outline (fig. 248).

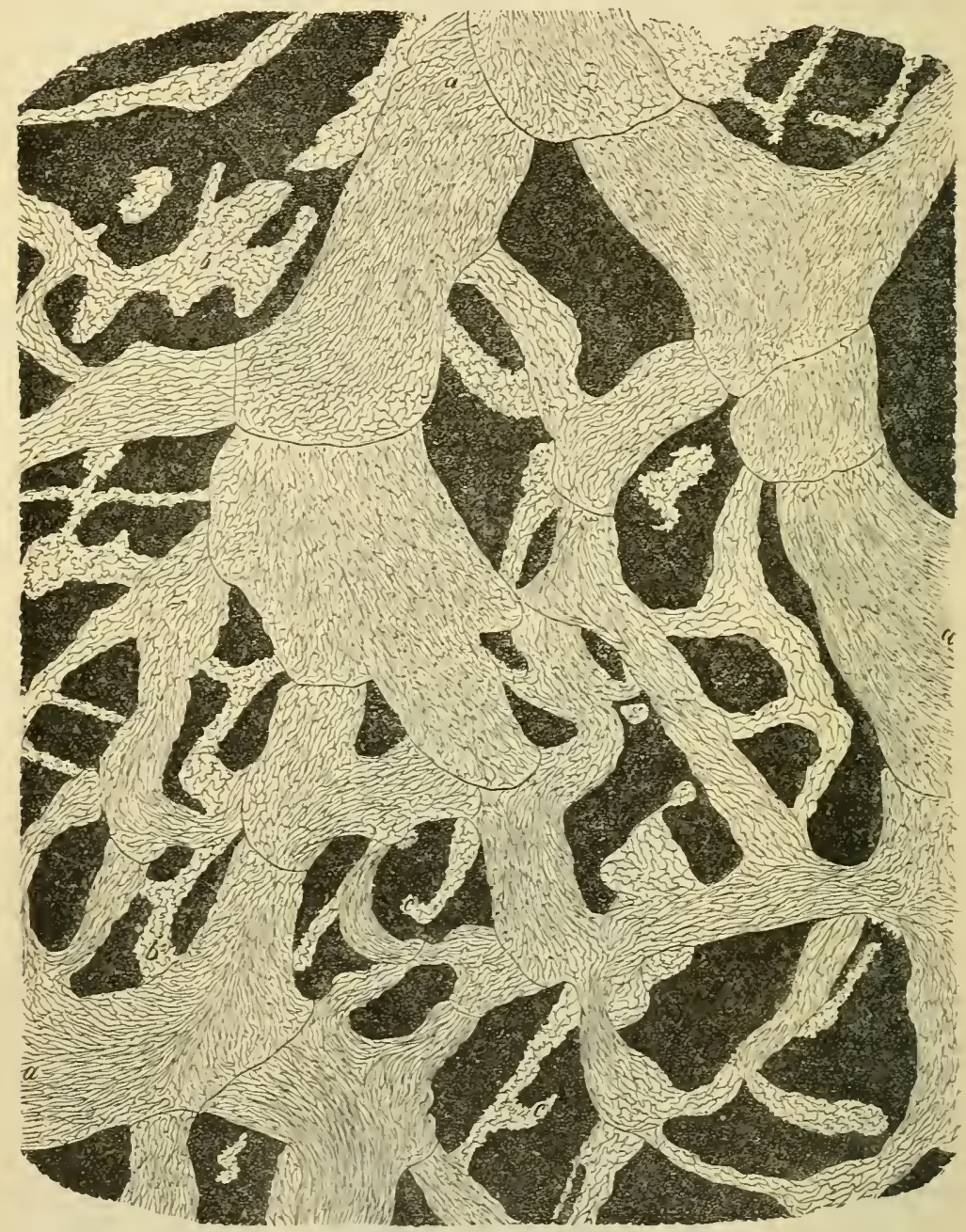

Fig. 250. - LTMPHATIC PLEXCS OF CEATRAL TENDON OF DIAPHRAGM OF RABBIT, PLECRAL SIIIE. (Klein.)

$a$, larger vessels with lanceolate cells and numerous ralves; $b, c$, lymph-capillaries with wavy-bordered cells.

The lymphatics receive numerous nerve-fibres, which are nonmedullated, and which end in a ramification of the finest fibrils, which are distributed to the coats of the vessel (fig. 249). 
Lymphatics begin either in the form of plexuses, as in serous membranes (fig. 250), or of lacunar interstices, as in some of the viscera, and all transitions occur between the two.

In order to show their structure, it is usual to stain a tissue with nitrate of silver; for exhibiting their distribution they may be injected by sticking the nozzle of an injecting cannula into any tissue which contains them, and forcing coloured fluid under gentle pressure into the interstices of the tissue.

In silver preparations it may be observed that the lymphatics always appear in the form of clear channels in the stained groundsubstance of the connective tissue, and that their walls are in close connection with the cells and cell-spaces of that tissue (fig. 248). But, except in the case of the serous membranes, no open communication is observable between the lymphatic vessels and the interstices of the connective tissue, although from the readiness with which they can be injected from the latter there must be a ready means of passage of the interstitial lymph into the commencing lymphatics. The lymphatic vessels were originally described by Klein, and more recently by Retterer, as being developed from hollowed-out cells in the same manner as the blood-vessels, and by Gulland as becoming formed at the periphery as clefts in the connective tissue, which later form a connection with the venous system. But the investigations of Ranvier, recently confirmed by Lewis and others, tend to show that the lymphatic trunks grow out from the venous system, and gradually penetrate into the peripheral parts of the embryo.

\section{Serous Menbrayes.}

The serous membranes, which may be conveniently studied in connection with the lymphatic system, are delicate membranes of connective tissue which surround and line the internal cavities of the body, and are reflected over many of the thoracic and abdominal viscera; in passing to which they form folds (such as the mesentery), within which blood-vessels, lymphatics, and nerves are conducted to the viscera.

The inner surface is lined by a continuous layer of pavementepithelium (endothelium) (fig. 251), which is very distinct in nitrate of silver preparations. In some places there are apertures in the epithelium which lead directly into subjacent lymphatic vessels. These apertures are called stomata, and are sometimes surrounded by special cells (fig. 251, B). They are numerous upon the peritoneal surface of the diaphragm, but are present in most serous membranes. They are nowhere better studied or more easily seen than in the peritoneal membrane at the back of the abdominal cavity in the 
frog. This membrane lies between and at the sides of the kidneys, and serves to separate the peritoneal cavity from the large lymphspace just behind it. If the membrane is prepared by the nitrate of silver method the stomata and the cells which surround them on either side of the membrane are well shown.

The pavement-epithelium of the serous membrane rests upon a homogeneous basement-membrane, which is especially well marked

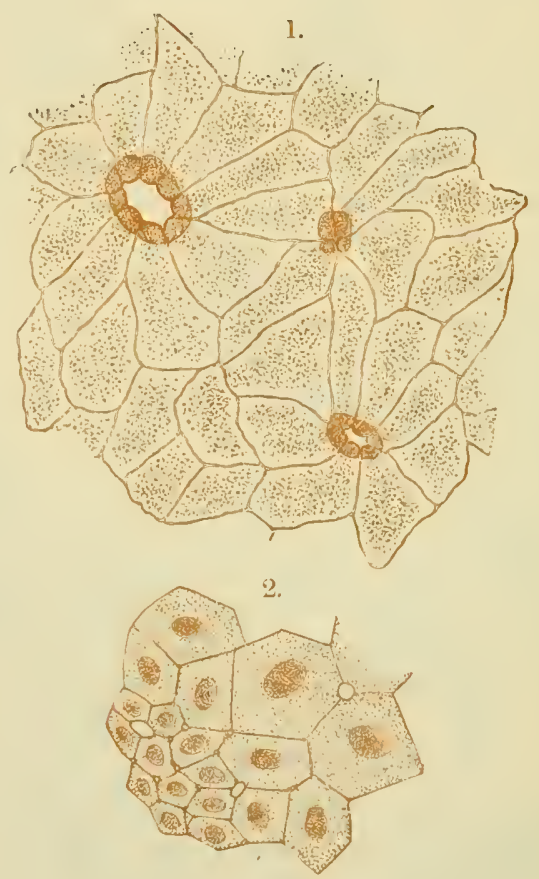

FIG. 251.

1. EPITHELIUM FROM THE POSTERIOR PART OF THE FROG'S PERITONEUM, SHOWING THREE STOMATA LEADING INTO THE CISTERNA LYMPHATICA MAGNA. (v. Ebner, after Schweigger Seidel and Dogiel.)

2. A PORTION OF EPITHELIUM From the PERITONEAL SURFACE OF THE RABBit's DIAPHRAGM. THREE PORES ARE VISIBLE BETWEEN THE EPITHELIUM CELLS. (v. Ebner, after Ludwig and Schweigger Seidel.)

in the serous membranes of man. The rest of the thickness of the membrane is composed of connective tissue, with a network of fine elastic fibres near the inner surface.

The cavities of the serous membranes are originally formed in the embryo as a cleft in the mesoderm (pleuro-peritoneal split, cœlom) which becomes lined with epithelium, outside which the cœlomic wall eventually becomes differentiated into the serous membrane. 


\section{LESSON XXII.}

\section{LYMPH-GLANDS. TONSILS. THYMUS.}

1. Sectross of a lymph-gland which has been hardened either in formol or potassium bichiomate, or in chromic acid or picric acid followed by alcohol, stained in bulk, and embedded in paraffin. Or the sections may be stained with hematoxylin and eosin. Notice (1) the fibrous and muscular capsule, with trabecula extending inwards from it throngh the cortex and anastomosing with one another in the nedulla, (2) the dense lymphoid tissue (artenoid tissne of some authors) forming large masses in the cortex (cortical uodules) and romded cords in the nierlulla (medullary cords). Notice also the clearer chamel or lymph-sinus which everywhere intervenes between the fibrous tissue and the lymphoid tissue. Observe the fine fibres and branched cells which bridge across this channel.

Make a general sketch under a low power of a portion of the cortex together with the adjoining part of the medulla, and under a high power drawings of small portions of cortex and medulla.

The retiform tissue of the lymph-glands has already been studied (p. 75).

2. Sections of a hremal lymph-gland. These may be readily found in the neck of the $\alpha x$, in the neighbourhood of the large blood-vessels. Stain with eosin and hamatoxylin or with éosin and methylene blue. Notice that the chammels around the lymphoid nodules (or some of them) contain blood instead of lympl.

3. In sections of tonsil prepared similarly to those of the lymphatic gland, notice the large amount of lymphoid tissue, partly collected into nodules. Observe also that the stratified epithelium, which covers the mucous membrane here as elsewhere in the mouth, is infiltrated with lymphcorpuscles. The tonsil is beset with pit-like recesses, with mucus-secreting glands opening into the pits.

4. Lymphoid nodules of mucous membranes. In other mucous membranes besiles that of the back of the month and pharynx, collections of lymphoid tissue occur which resemble those of the tonsils; such nodules form the solitary glands of the stomach and intestines and the agminated glands of the small intestine, and are also found in the trachea and bronchial tubes and in the oesophagus. They may be studied later in sections of those parts.

5. Sections of the thymus gland of an infant or young animal. Notice that the nasses of lymphoid (?) tissue which form the lobules of the gland are separated by septa of connective tissue, and that the lobules show a distinctiun into two parts, cortical and medullary. There are no lymph-paths. Observe the differences of structure of the cortex and medulla, and especially notice the concentric corpuscles in the mednllary part.

Make a sketch of one of the lobules under a low power and of a small part of the medulla under a high power, including one or two conceutric corpuscles. Measure the latter.

\section{LYMPH-GLANDS.}

Structure of a lymph-gland.-A lymph-gland (lymphatic gland) is composed of a framework of fibrous and plain muscular tissue, which 
incloses and supports the proper glandular substance, but is everywhere separated from it by a narrow channel, bridged across by cells and fibres, which is known as the lymph-channel. The framework consists of an envelope or capsule (fig. 252, c), and of trabecule (tr), which pass at intervals inwards from the capsule, and after traversing the cortex of the gland, divide and reunite with one another to form a network of fibrous bands. At one part of the gland there is usually a depression (hilus), and at the bottom of this the medulla comes to the surface and its fibrous bands are directly continuous with the capsule.

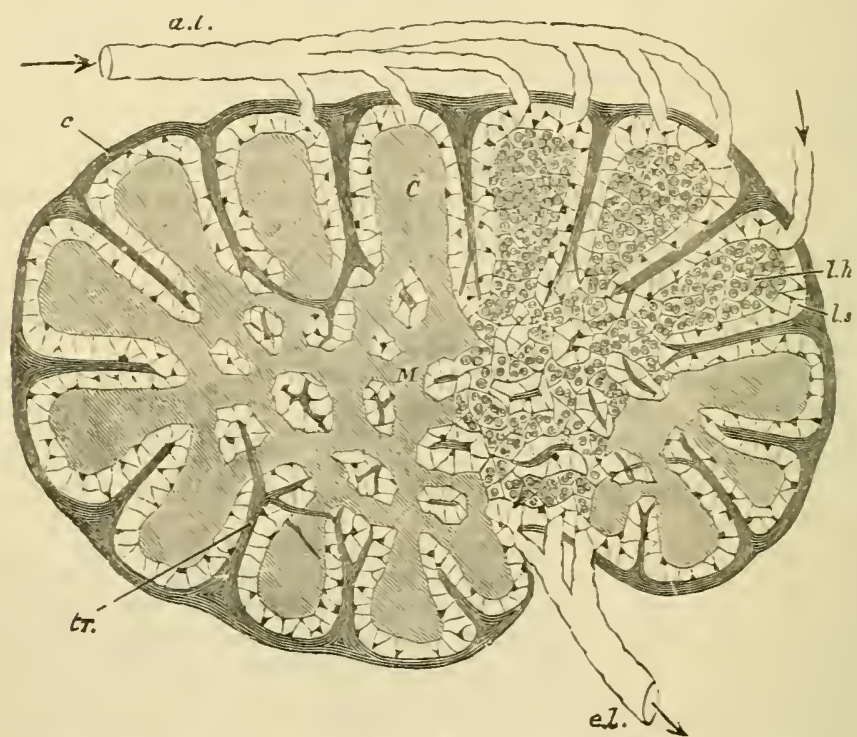

FIG. 252.-DIAGRAMMATIC SECTION OF LIMPH-GLAND. (Sharper.)

a.l. afferent, e.l. efferent 1 rmphatics; $C$, cortical substance; $M$, reticulating cords of medullary substance; l.h. lymphoid tissue; $\ell .8 .1 \mathrm{ym}, \mathrm{h}$-sinus; $c$, capsule sending trabeculæ, $t r$, into the substance of the gland.

The proper glandular substance (l.h.) is composed of lymphoid tissue, i.e. a fine reticulum with the meshes thickly occupied by lymphcorpuscles. It occupies all the interstices of the gland, forming comparatively large rounded masses in the cortex (lymphoid nodules, $C^{\prime}$ ), which may be two or three deep, and smaller reticulating cord-like masses (lymphoid cords, $M$ ) in the medulla.

The cells which bridge across the lymph-channel in the medulla (fig. $254, c$ ) are branching nucleated cells which often contain pigment, so that this part of the gland has a dark colour. Some may contain disintegrating erythrocytes. The lymph-channel is bridged across not only by these branched cells, but also by fibres derived from the 
capsule and trabeculie, which pass to the lymphoid tissue and become lost in its reticulum. But the fibres are often completely concealed by the cells.

Afferent lymph-ressels (fig. 252, a.l.) enter the lymph-channels after ramifying in the capsule, and the lymph is conveyed slowly along the channels of the cortical and medullary part towards the hilus, taking up many lympli-corpuscles in its passage. At the hilus it is gathered up by an efferent vessel or vessels (e.l.) taking origin in the lymph-sinuses of the medulla.

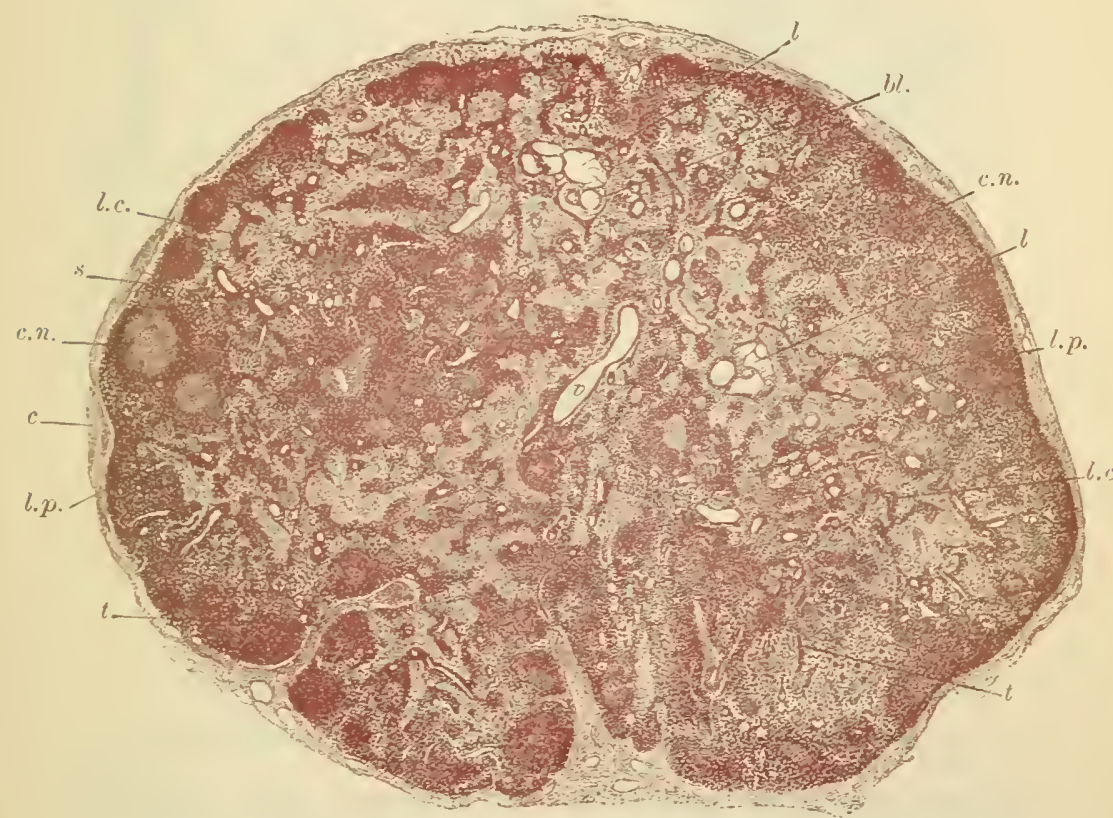

Fig. 253.-SECTION OF A LIMPH-GLAND FROM THE SIECK OF AN EIGHT YEAR OLD CHILD. (v. Ebner.) $\times 13$.

c, capsule; c.n, cortical nodules, some with germ-centres; l.c, 1 rmphoid cords of redulla (dark); $l . p$, lymph-path (light); 8 , cortical sinus ; $t$, trabeculæ; $v$, rein; $l$, efferent lymph-vessels, accompanying and partly surrounding blood-vessels, $b l$.

The efferent lymphatics al ways contain many more lymph-corpuscles than those which enter the gland, for lymph-corpuscles are constantly being formed by mitotic division of the pre-existing cells in the glandular substance, especially in the clearer centre of each cortical nodule (germ-centre of Flemming); they gradually find their way into the lymph-channel.

The leucocytes of the germ-centres frequently show in sections peculiar darkly-coloured bodies-the stainable-bodies of Flemming-the origin of which has not been determined. 
An artery passes into each gland at the hilus; its branches are conveyed at first along the fibrous cords, but soon become surrounded by the lymphoid cords, where they break up into capillaries (fig. $254, d$ ). The blood is returned by small veins, which are conducted along the fibrous trabeculæ to the hilus.

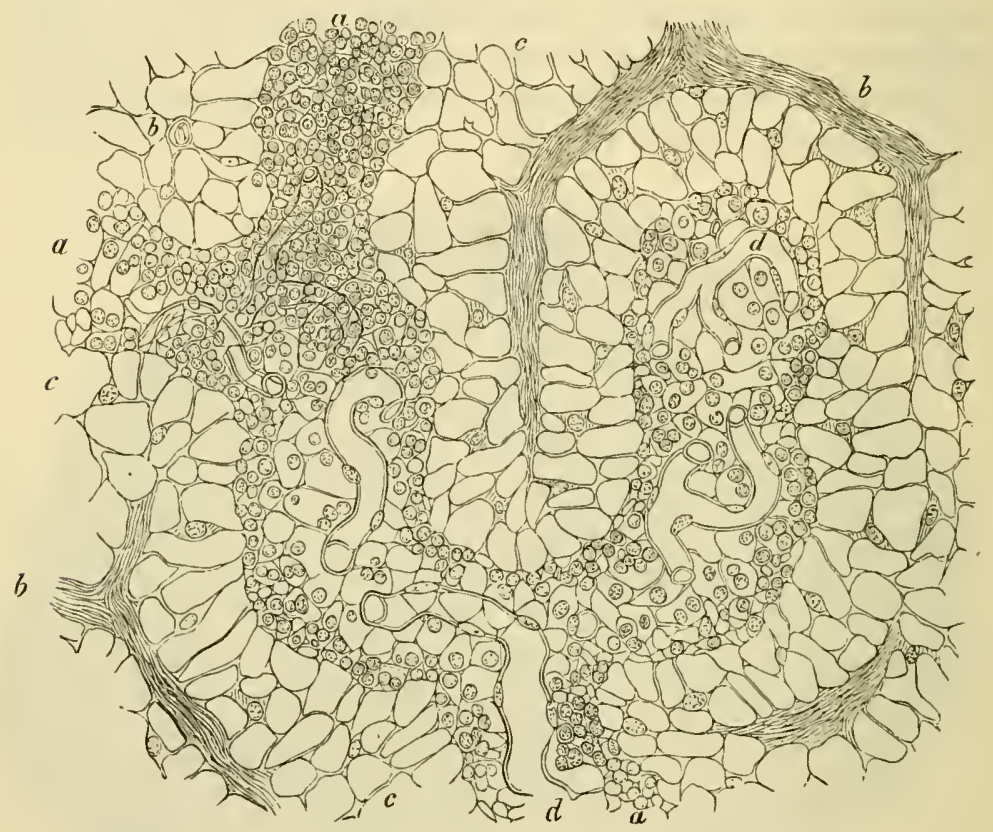

Fig. 20̃4.-SeCtion OF THE MEDULLARY SUBSTANCE OF A LyMPH-gLAND. 300 diameters. (Recklinghausen.)

$a, a, a, 15$ mphoid cords ; $c$, lymph-sinus ; $b, b$, trabecula ; $d, d$, capillary blood-vessels.

In some lymph-glands the fibrous trabecula are very slightly developed, so that the gland seems in section to be almost uniformly a mass of lymphoid tissue, pervaded by lymph-channels and with clearer rounded nodules (germ-centres) scattered about, especially in the cortex (fig. 253). This is the case with most of the lymph-glands of man and some other animals. In other animals, such as the dog and ox, the trabeculæ are very well developed and contain much muscular tissue.

Nerve-fibres pass to lymph-glands and appear to be distributed chiefly as non-medullated fibres to the plain muscular tissue of the blood-vessels and trabeculæ.

Ordinary lymph-glands are confined to mammals, but Vincent and Harrison have found hæmal lymph-glands in birds.

Hæmal lymph-glands.-In many animals a certain number of lymphglands are observable which have a red colour. Some of these on 
section show that what corresponds to the peripheral lymph-channel in ordinary lymph-glands is in them occupied by blood. Others have the greater part of the interior occupied by large sinuses filled with blood; but some parts have the ordinary structure of a lymphgland. The names hemal glands and hemal lymph-glunds (Robertson) have been given to these organs. The blood passes into the sinuses from the arterial capillaries, which probably, as in the spleen, become incomplete, and open into the tissue interstices, from which at other

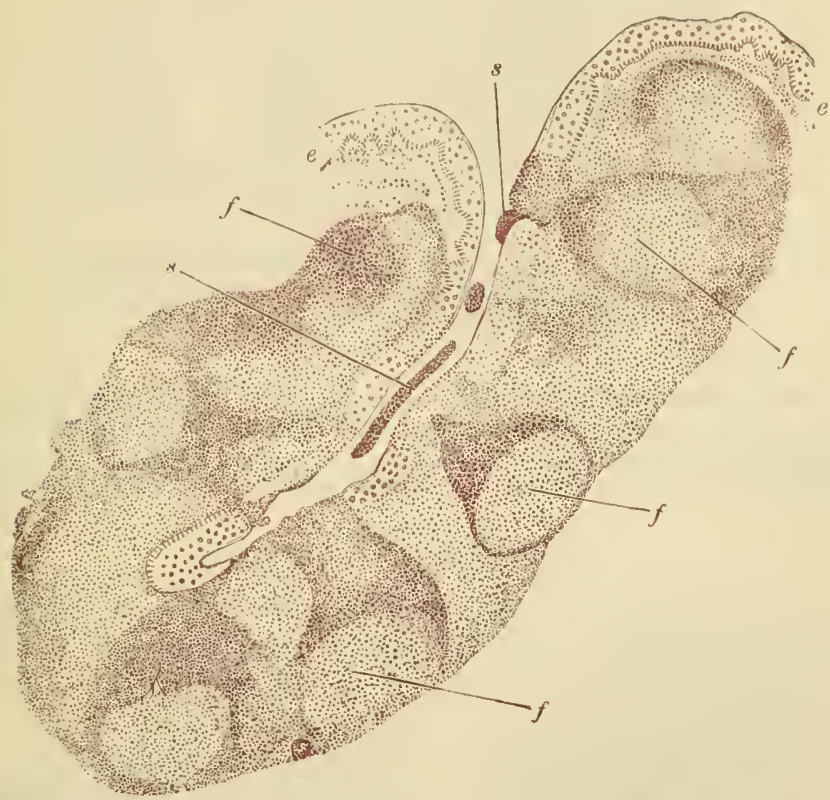

Fig. 255.-SECTION THROUgh ONE OF THE CRYPTS OF THE TONSIL. (Stöhr.)

$e, e$, stratified epithclium of surface of mucous membrane, continued into crypt; $f, f$, follicles or nodules of the lymphoid tissue, which is elsewhere diffuse; some show clear "germ-centres"; opposite each nodule numbers of lymph-cells are passing through the epithelium; $s$, masses of cells which have thus escaped from the organ to mix with the saliva as salivary corpuscles.

parts the small veins in like manner arise. Like the spleen these hæmal glands show cells (phagocytes) which contain red bloodcorpuscles in various stages of transformation into pigment.

Some hæmal glands are said by Weidenreich to have no lymph. channels, but this statement requires confirmation.

\section{The Tonsils.}

The tonsils are two masses of lymphoid tissue placed one on each side of the pharynx, into which they project. They are covered on the free surface with the stratified epithelium of the mucous membrane, 


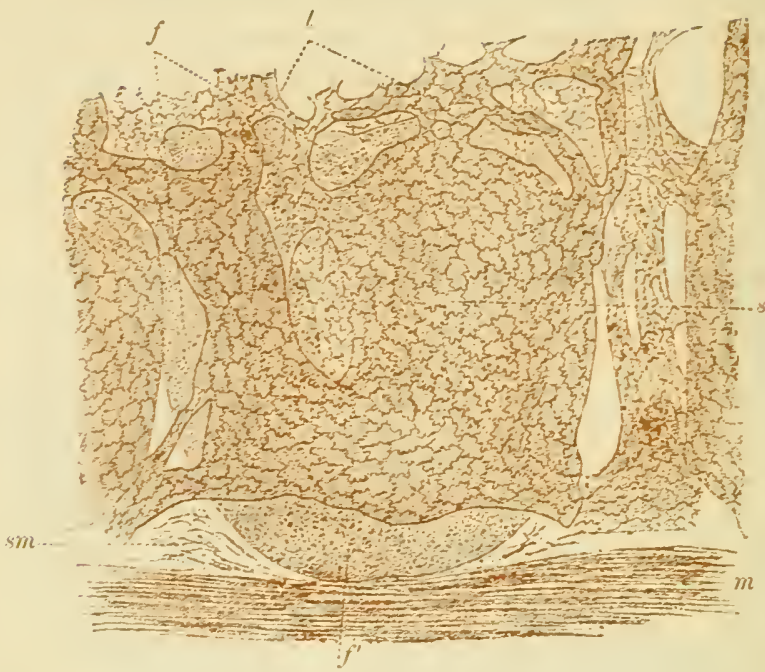

Fig. 256. -LYMPHATICS OF A PEYER'S PATCH, INJECTED WITH SILVER NITRATE; CAT. (Kölliker.) Magnified 85 diameters.

$f$, a lymphoid nodule or follicle ; $f^{\prime}$, its base, resting upon the muscular coat, $m$; $s . m$, submucosa ; $l, 15 \mathrm{mph}$-ressels ; 8 , sinus-like enlargement of lympl-vessel surrounding follicle.

A

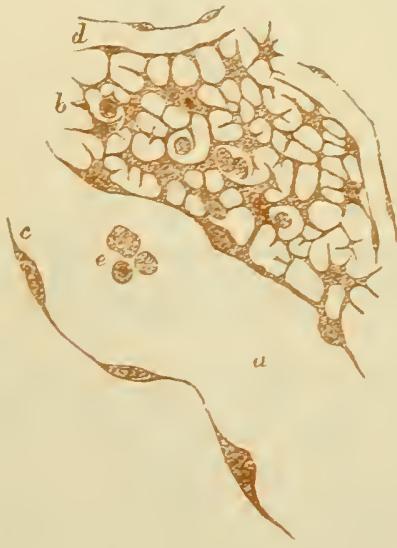

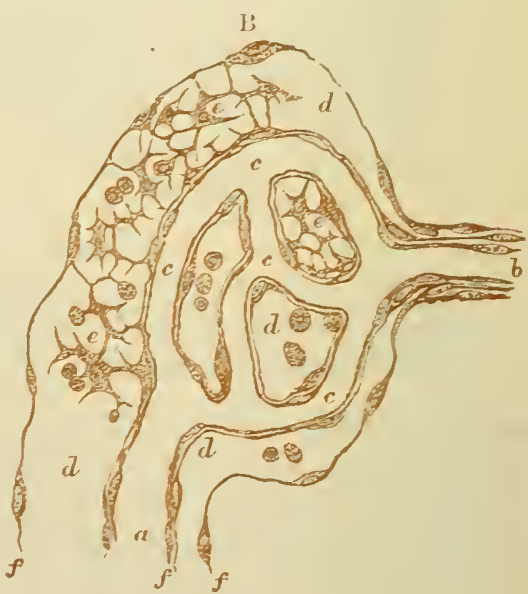

FIG. 25\%.-DEVELOPISg LYMPHOID NODCLES FROM THE GCIXEA-PIG'S OMENTEM. (Klein.)

A, perilymphatic nodule; $a, 15$ mphatic ; $c$, its endothelium; $e$, lymph-corpuscles ; $b$, accumulation of $15 \mathrm{mph}$ oid tissue on one side of it; $d$, blood-capillaries withiu this.

$B$, endolymphatic nodule consisting of an enlarged lymphatic vessel, $d$, within which is a capillary network $c, c$, an artery, $b$, and a vein, $a ; e$, lymphoid tissue within the lymphatic, its branched cells being joined to and derived from the ljmphatic endothclium $f$. 
and this surfice is pitted with apertures which lead into recesses or crypts in the substince of the organ (fig. 255). These recesses are all lined by a prolongation of the stratified epithelium, and into them the ducts of numerous small mucous glands open. The tonsils are composed almost entirely of lymphoid tissue, which, besides being diffused over the whole organ, is at intervals aggregated into nodules, in which the lymph-cells are more closely arranged than elsewhere. In the clear centre (germ-centre) of some of these nodules active multiplication of the lymph-cells by mitosis is constantly proceeding, and is, in fact, the cause of the formation of nodules in the tissue, as in other organs in which lymphoid tissue occurs. Even the epithelium which covers the tonsils is infiltrated with lymph-corpuscles (Niöhr), and these may also wander out on to the free surface, and become mingled with the saliva as salivary corpuscles.

The lymphoid tissue is highly rascular, and contains many lymphatics.

The mucous membrane of the neighbouring part of the pharynx and of the back of the tongue and that of the upper part of the pharynx near the orifices of the Eustachian tubes shows crypts and masses of lymphoid tissue similar in structure to those of the tonsils.

\section{OThER LyMPHOID ŚTRUCTURES.}

Lymphoid tissue occurs in many other parts of the body in addition to the Iymphatic glands and tonsils, although it may not, as in these structures, constitute the bulk of the organ. Thus it is found in many mucous membranes, such as those of the intestine and of the respiratory tract, both in a diffuse form and also collected into nodular masses which arc like the cortical nodules of a lymphatic gland, and may, like these, be partially surrounded by a lymph-sinus. In the intestine such nodules constitute the so-called solitary glands and Peyer's patches. The lymphatics form plexuses of large sinus-like ressels which to a large extent enclose the nodules (fig. 256). In the spleen a large amount of lymphoid tissue is found ensheathing the smaller arteries, and also expanded into nodular masses (Mulpighian corpuscles of the spleen). All these structures will be studied subsequently. Lymphoid tissue also occurs in considerable amount in the serous membranes, especially in young animals; in the adult it is here mostly replaced by adipose tissue.

Development of lymphoid tissue.-Lrmph-glands are developed in connection witl plexuses of lywph-vessels, an accumulation of retiform tissue and lymph-cells taking place either external to and around the lymphatics (jerilymphatic formation); or some of the lympliatics are dilated 
into a sinus or sinuses and the formation of lymphoid tissue occurs within it (endolymplutic formation) (fig. $257, \mathrm{~A}$ and $\mathrm{B}$ ). When there is a development of lymphoid tissue mutsile the lympliatic vessels this may form a considerable accumulation before the formation of lympl-paths within the tissue. Blood-vessels are early developed amongst the lymphatic plexuses, and by these, according to Gulland, the first lyuph-cropuscles of the lymphoid tissue are bronght to the gland.

The marginal sinns is prorluced by the fusion of a number of lymphvessels which surromol the accumulation of lymphoid tissue, while in the situation of the future hilus other lymph-vessels grow intn the glandular substance and form channels which subdivide it up into cords and nodules (Kling). The branched cells of the lymph-path are said to be derived from the lymphatic endothelimm.

The axillary glants were found by stiles to increase in number and size luring lactation, riminishing again after lactation has ceased. In the developing tonsils Gulland occasionally found nests of epithelial cells detached from thie surface epithelium, somewhat like thrse found permaneutly in the thymus.

\section{Thryus.}

The thymus gland is an organ which in man is found only in the embryo and during infancy. It is composed of a number of lobules (fig. 258) varying in size, which are separated from one another by septa of connective tissue, along which the blood-ressels and lymphatics pass to and from the lobules. Each lobule shows

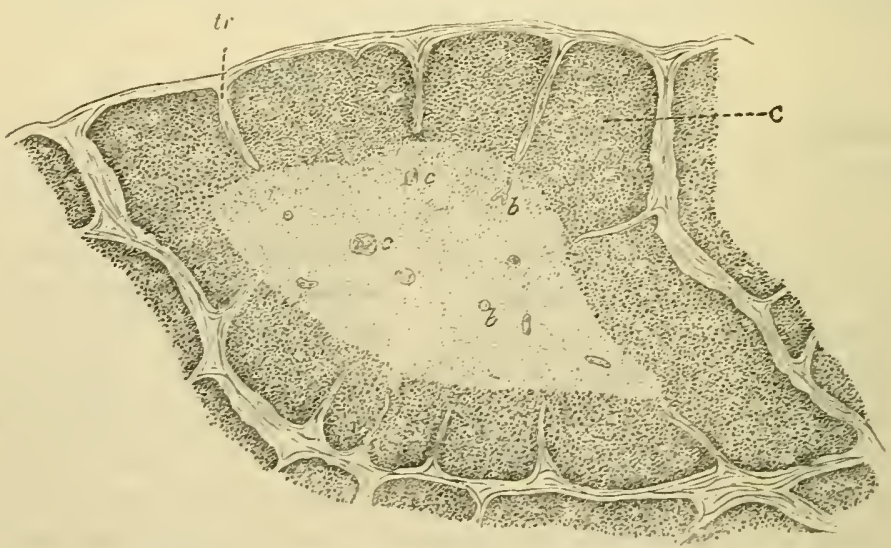

FIG. 258. - 1 LOBCLE OF THE THYMCS OF A CHILD, AS SEEX UXDER A LOW POWER

$c$, cortex; $c$, concentric corpuscles within medulla ; $\iota$, blood-vesscls; $t r$, trabecula.

plainly, when examined with a low power, a distinction into an outer cortical and an inner medullary portion. The cortical part of the lobule is imperfectly divided into nodules by trabeculæ of connective tissue. It is highly vascular, and is superficially similar in structure to the lymphoid tissue of the lymph-glands and tonsils, with which it also agrees in exhibiting numerous indications of indirect cell- 
division, but without definite germ-eentres. Besides lencocytes it contains a number of peculiar granular cells. The medulla is more open in its texture, and its reticulum is formed by large transparent, branched cells (fig. 259), which are sumetimes masserl together and then resemble epithelium-cells. The medulla contains fewer lymphcorpuscles than the cortex and has a clearer aspect. Connective tissue fibres are not wholly absent from it. Within the medulla, but not

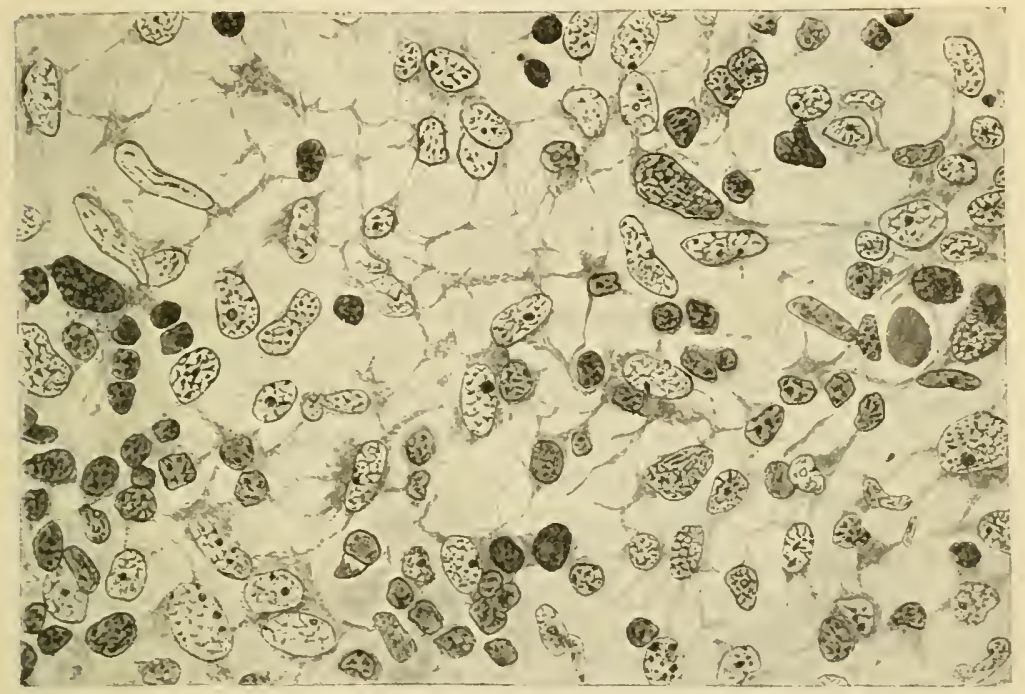

Fig. 259.-SECTION OF MEDULLA OF THYMUS, SHOWING BRAXCHED (EPITHELIAL) CELLS OF RETICELEM AND A CERTAIN NCMBER OF LYMPHOID CELLS IN THE MESHES. (Hammar.)

in the cortex, are found peculiar concentrically striated bodies (the concentric corpuscles of Hussul, figs. 258, 260), which are "nests" of flattened epithelial cells arranged concentrically around one or more central cells, which have often undergone a degenerative process. Sometimes these corpuscles are compound, two or three being grouped together and similarly enclosed by flattened cells. They represent part of the remains of an epithelial tube, which forms the thymus rudiment of the early embryo and is derived from certain of the branchial elefts. According to the observations of Hammar the reticulum of the gland is also derived from this epithelium, and Stöhr believes that the apparent lymphoid cells of the gland have a similar origin. The inference drawn by J. Beard from his observations in Elasmobranchs that the thymus is the original seat of 
formation of leucocytes in the embryo, appears from more extended investigations to be incorrect.

Nucleated red blood corpuscles (erythroblasts), similar to those found in red marrow, have also been describerl in the thynıus (J. Schaffer), and occasionally cysts lined by ciliated epithelium are found. In some animals islands of striated muscular cells are seen in the medulla. Multinucleated giant-cells are also found (Watney).

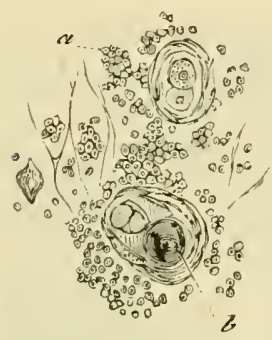

Fig. 260.-ELeMents OF THE ThYMUS. 300 diameters. (Cadiat.)

$a$, Iymph corpuscles; $b$, concentric corpuscle.

The lobules, the cortex especially, are abundantly supplied with capillary bloodvessels. In man the arteries penetrate to the junction of cortex and medulla, and give off most of their capillaries radially into the cortical nodules. Veins pass away both from the surface of the lobules and to a less extent directly from the medulla. The mode of distribution of the lymphatics has not been definitely ascertained, but none are scen within the lobules. Nevertheless, large lymphatic ressels, containing many lymphoeytes, issue from the interstitial connective tissue of the thymus, but in what way they are connected with the lobules has not been ascertained.

In the human subject the thymus gland undergoes after childhood a process of retrogression, its lobules ceasing to grow and becoming surrounded and concealed by a quantity of adipose tissue which develops in the interstitial connective tissue of the gland. Eventually the lobules atrophy. 


\section{LESSON XXIII.}

\section{STRUCTURE OF THE SPLEEN, SUPRARENAL CAPSULES, THIROID BODY, AND PITUITARY BODY.}

1. Sectioss of the spleen hardened in Miiller's fluid or formol and stained with hrematoxylin and eosin. Notice the trabeculae extending into the substance of the organ from the capsule. Notice also that the glandular substance is of two kinds, (1) lymphoid tissue accumulated aromnd the small arteries and here and there massed to form lymphoid nodules-the Malpighias corpuscles-and (2) a tissue-the red pulp-consisting of a reticulum of fibrils aud branching cells : this tissue contains blood in its interstices.

Sketch part of a section uncler a low power and a small portion of the pulp uniler a high power.

2. Sections across a suprarenal capsule hardened in 2 per cent. bichromate of potassium. In sections not otherwise stained, notice the deep brown coloration of the medulla (action of the chromic salt). Stain other sections with eosin and hematoxylin. Examine first with a low power, noticing the general arrangement and extent of the cortical and medullary parts of the organ, and making a general sketch which shall include both. Afterwards sketch carefully moler the high power a group of cells from each part of the organ.

3. Sections of the thyroid borly stained with eosin and hæmatoxylin. Notice the vesicles lined with cubical epithelium and filled witl a "colloid" substance which becomes stained with hrematoxylin. Sketch one or two vesicles. Measure several vesicles. The sections will probably also include one or more parathyroids.

4. Sections (antero-posterior) throngh the pituitary body. Notice the (epithelial) anterior lobe separated by a cleft from the (nervous) posterior lobe. (The anterior part of the posterior lobe is also covered by an epithelial layer.)

5. Injected preparations of these organs may also be studied: the spleen is usually naturally injected with blood.

\section{THE SPLEEN.}

The spleen is the largest of the so-called ductless glands. It appears to be functionally connected with the blood, white blood-corpuscles being formed and coloured blood-corpuscles being submitted to destruction within it.

Like the lymph-glands, the spleen is invested with a fibrous and muscular cupsule (fig. 261), which is however stronger and has far more plain muscular tissue; outside the capsule is a covering derived from the serous membrane. The capsule sends bands of trabecula 
into the organ, and these join with a network of similar trabeculæ which pass into the gland at the hilus along with the blood-vessels. In the interstices of the framework thus constituted lies a soft pulpy substance containing a large amount of blood, and therefore of a deep red colour, dotted within which are here and there to be seen small round bodies, whiter than the pulp in the fresh organ but darker in

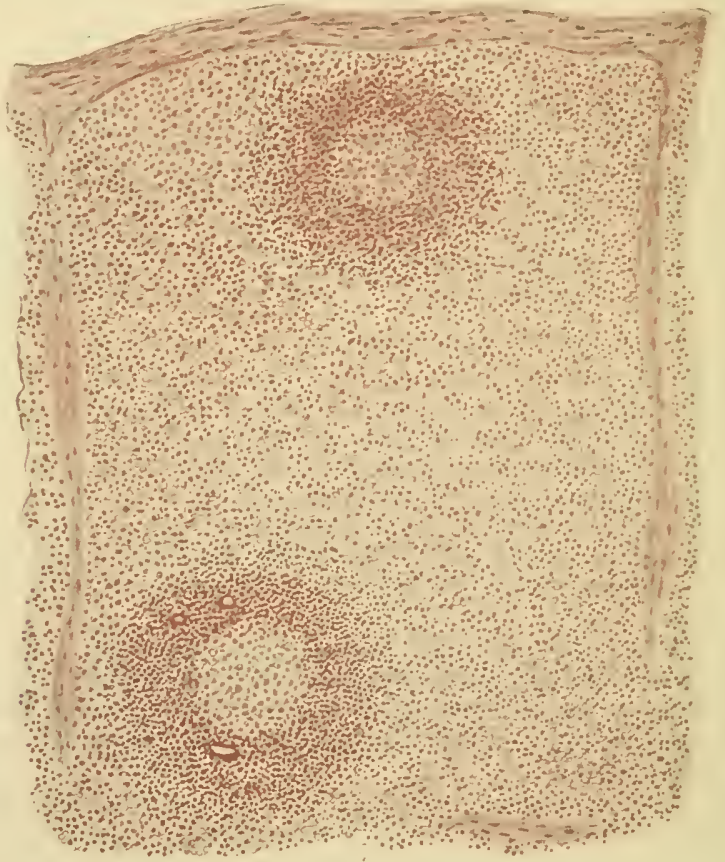

Fig. 261. - VERTICAL SECTION OF A PORTION OF THE MONKEY'S SPLEEN, AS SEEN WITH A LOW POWER.

stained sections, the Mulpighian corpuscles of the spleen. These are composed of lymphoid tissue which is gathered up into masses which envelop the smaller arteries, whilst the red pulp which everywhere surrounds them and which forms the bulk of the organ is composed (Carlicr) of a close network of connective tissue fibrils (fig. 262), partly covered by flattened and branched cells (fig. 263). Passing into the pulp and communicating with its interstices are capillary bloodvessels which are connected with the terminations of the arteries; whilst in other parts venous channels-characterised in the human spleen by an encirclement of reticulum-fibres, possibly of an elastic nature (fig. 264 ), and by the presence of a layer of highly characteristic, 


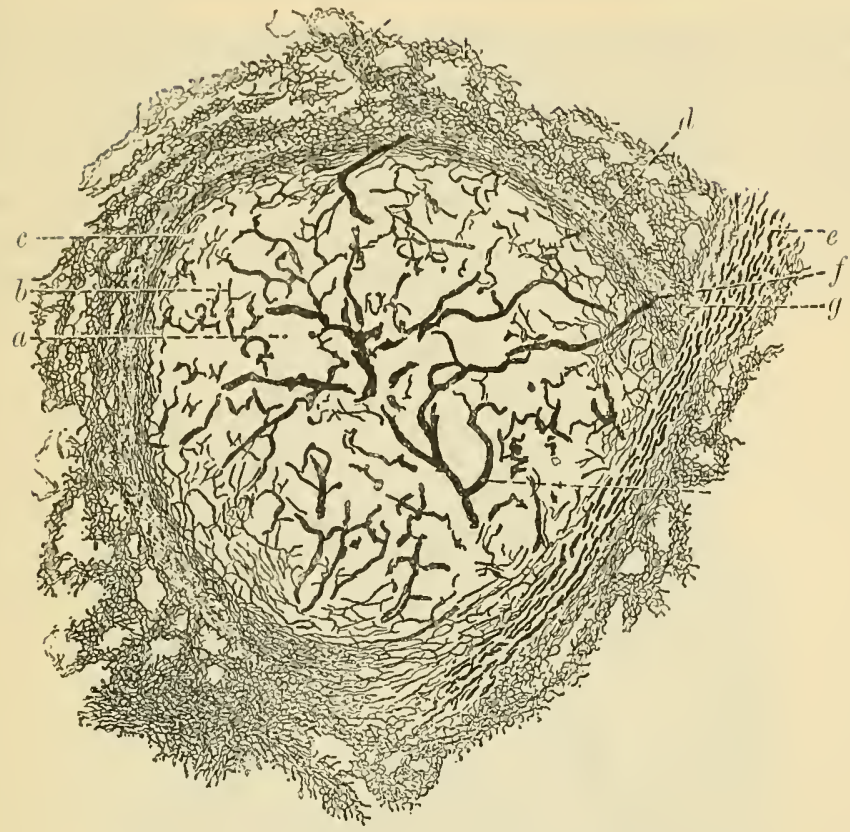

Fig. 262.-Reticulum of spleen, golgi Method. (Oppel.)

$a$, Malpighian corpusclc; $b$, part of its reticulum : $c$, condensed reticulum at its margin : $d$, more open tissue next to this; $e$, wall of arteriole; $f$, capillaries of Malpighian corpuscle; $g$, reticulum of arteriole expanding into that of the Malpighian corpuscle.

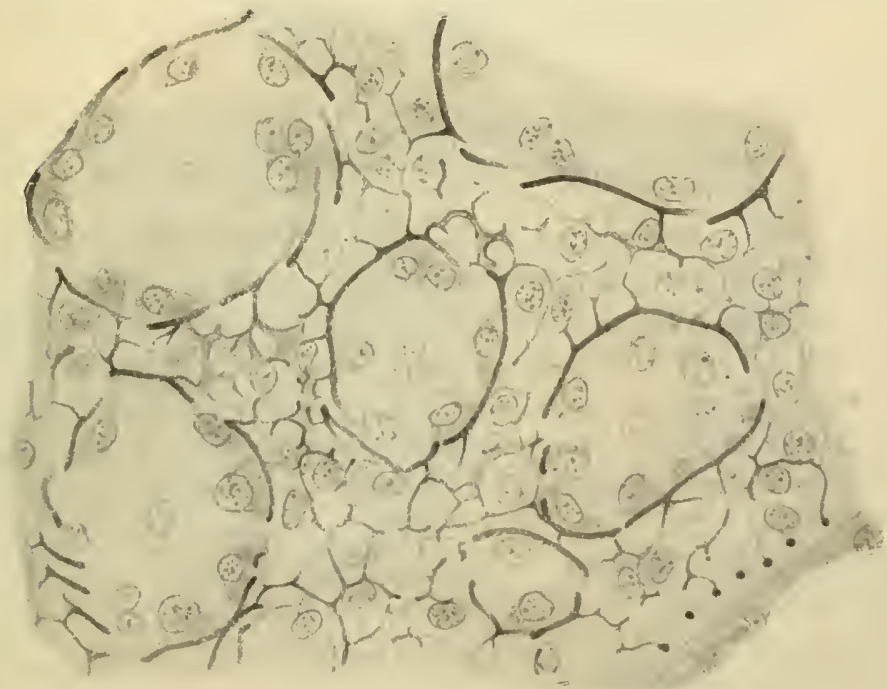

Fig. 263,-Syall veins of SPleks pUlP with Reticular tissue. (Hoyer.) The reins, which are invested by encircling fibres, show gaps in thcir walls whereby they communicate with the interstices of the pulp. 
comparatively thick and prominent endothelium-cells, which exhibit a longitudinally striated structure-course through the pulp and bring the blood which has passed into its interstices from the arterial capillaries towards the larger veins of the organ, which run in the trabecula, and are by them conducted to the hilus. The arteries, which are also at first conducted from the hilus along the trabeculæ into the interior of the organ, presently leave the trabeculæ, and their

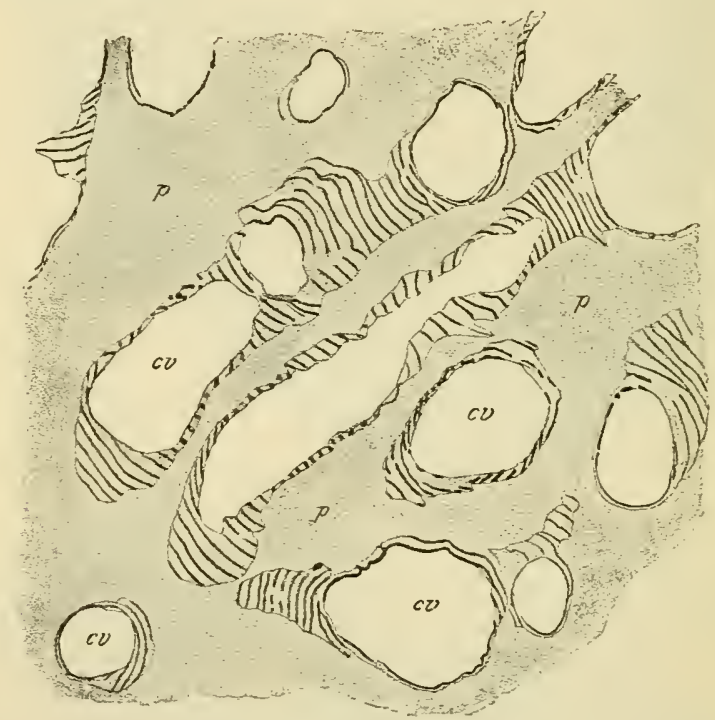

Fig. 264.-VENous SPACES OF SPLEEN PULP, SHOWING THE ENCIRCLING FIBRES iN their WaLls. MLAN. (v. Ebner.)

$c v$, capillary reins; $p$, pulp (the tissue elements are not represented).

external coat becomes gradually converted into a thick sheath of lymphoid tissue which invests then in the remainder of their course, and in places becomes swollen into the Malpighian corpuscles already mentioned. The small arteries distribute a few capillaries to the Malpighian corpuscles, and then break up into pencils of capillary vessels which open into the interstices of the pulp. ${ }^{1}$

The Malpighian corpuscles frequently but not always show a clearer central nodule or gerin-centre, characterised by the presence of numerous mitoses; and the stainable bodies of Flemming (see p. 205) are also seen in them.

\footnotetext{
${ }^{1}$ It is right to state that many authorities hold that the arterial capillaries open into the venous sinuses and that the blood-system of the spleen is therefore a closed one, the blood-corpuscles passing into the pulp-interstices by diapedesis.
} 


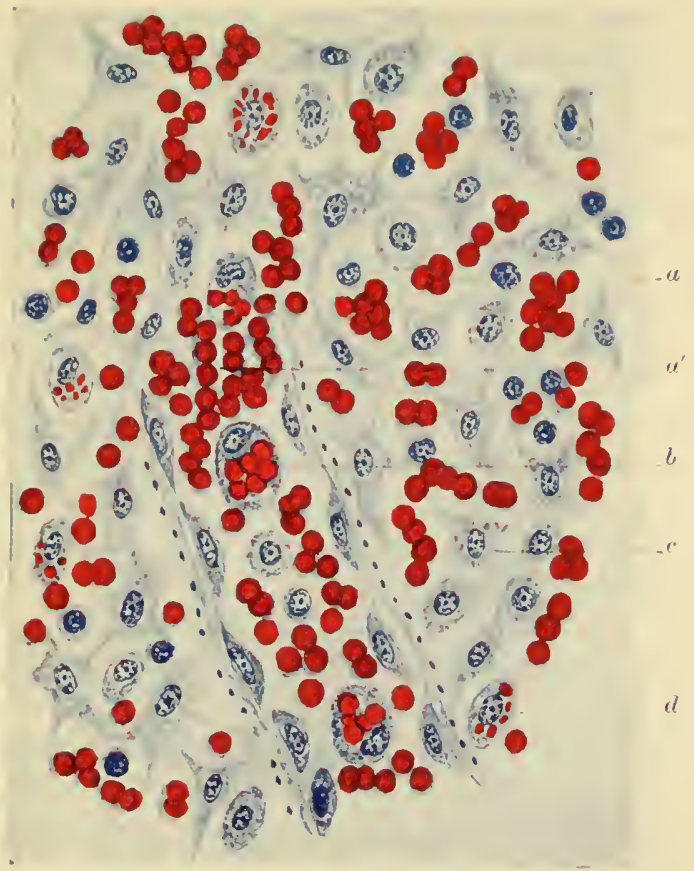

Fig. 26.̆. - THIN SECTION OF SPLEEN-PULP OF CHILD, HIGHLY MAGNIfIED, SHOWING THE APPARENT MODE OF ORIGIN OF A SMALL VEIN IN THE INTERSTICES OF THE PULP. Magnified 400 diameters.

$a$, blood in pulp; $a^{\prime}$, blood in vein; $b$, phagocyte in vein ; $c$, branched eell of pulp; $d$, splenic cell.

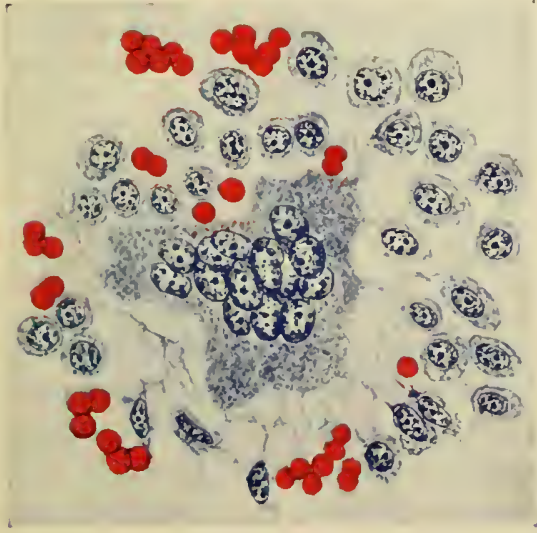

Fig. 266.-A GIANT CELL FRoM THE SPLEEN OF A KITTEN. Magnified 400 diameters.

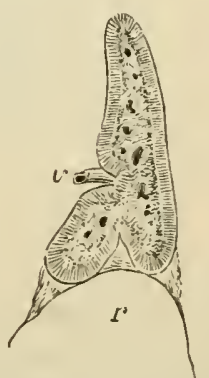

Fig. 267.-A VERTICAL SECTION OF THE SUPRARENAL BODY OF A FETUS, TWICE THE NATURAL SIZE, SHOWING THE DISTINCTION BETWEEN THE MEDCLLART AND COR. TICAL SUBSTANCK. (A. Thomson.)

$v$, issuing vein ; $r$, summit of kidney. 
The special cellular elements of the spleen-pulp are of three kinds, viz. (1) peculiar, large, amœboid phagocytic cells, (2) megukaryocytes or giant cells, and (3) brunched and generally fattened cells which assist in forming the spongework. The pulp also contains all the corpuscular elements of blood. The phagocytic cells are frequently found to contain coloured blood-corpuscles in their interior in varions stages of transformation into pigment. They occur both in the interstices of the pulp and in the venous sinuses and veins, where they are often filled with erythrocytes (fig. 265). The giant cells are most frequent in young animals (fig. 266) : their function has not been ascertained. The branched cells of the spongework are probably of the same nature as the enclothelium cells of the terminal capillaries and veins of the pulp. They are connected with one another and with the endothelial cells of the small vessels by branches. The phagocytic spleen cells are perhaps derived from them.

Nucleated coloured corpuscles are found in the embryo, and occasionally after birth, in the spleen-pulp. The blood of the splenic vein is very rich in lencocytes.

The lymphatics of the spleen run partly in the trabeculæ and capsule, and partly in the lymphoid tissue ensheathing the arteries. They join to form larger vessels which emerge together at the hilus. There are no lymphatics in the spleen pulp.

The nerves, which are numerous and mostly non-medullated, are distributed to the muscular tissue of the arteries and to that in the capsule and trabeculie.

Mall states that the distribution of the trabeculæe and of the blood-vessels within the spleen is such as to indicate a differentiation of the pulp into divisions which he terms "spleen lobules," each of which has its own arteriole and venule, and in which, the pulp is arranged in columns or cords surrounded by venous spaces. It must, however, be understood that there is nothing of the nature of partitions separating such lobules: to all appearance the pulp is in continuity thronghout the organ.

\section{The Suprarenal Capsules.}

The suprarenal capsules (adrenals) belong to the class of bodies known as ductless glands, but they are entirely different in structure and function from the spleen and lymphatic glands. A section through the fresh organ (fig. 267) shows a cortex which is striated vertically to the surface, and of a yellowish colour, and a medulla which is soft and highly vascular, and of a dark-red colour. The whole organ is invested by a fibrous cupsule which sends fibrons septa inwards through the cortical substance (fig. 268,a), subdividing this for the most part 
into columuar groups of cells (sona fusciculutu, c). Immediately underneath the capsule, however, the groups are more rounded, and the cells tend to assume a columnar form (cona glomerulost, $b$ ), whilst next to the medulla they have a reticular arrangement (ana reticularis, $d$ ).

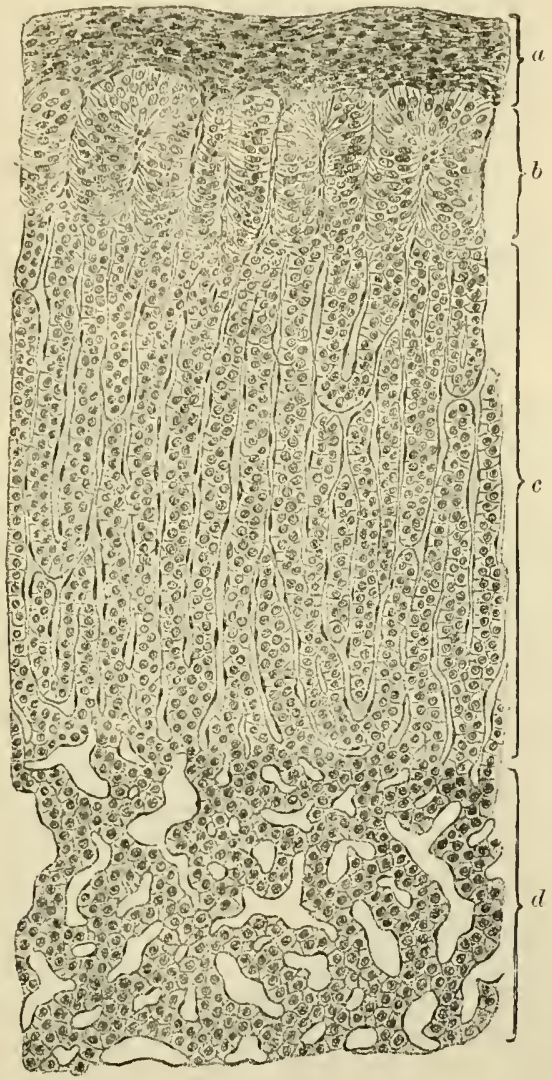

Fig. 268.-Vertical SEUTioN OF CORTEX OF SUPRARENAL OF DOG. (Böhm and v. Davidoff). Magnified about 150 diameters.

$\{a$, capsule ; $b$, zona glomerulosa ; $c$, zona fasciculata ; $d$, zona reticularis.

The cells which form the cortical substance are, for the most part, polyhedral in form; each contains a clear round nucleus, and there are often yellowish oil-globules in their protoplasm. No arteries and veins penetrate between these cells, both these and the lymphatics of the cortex running in the fibrous septa between the columns of cells, which they surround with a capillary network. In the zona reticularis the capillaries widen out and oceupy the spaces between the cell-. columns (fig. $268, d$ ). The lymphatics communicate with fine canals between the cells of the cortex. 
The cells of the medulla (fig. 269) are more irregularly disposed. They are supported by a network of elastic fibres. They lie in very close relation to the large capillary blood-spaces (sinusoids) which

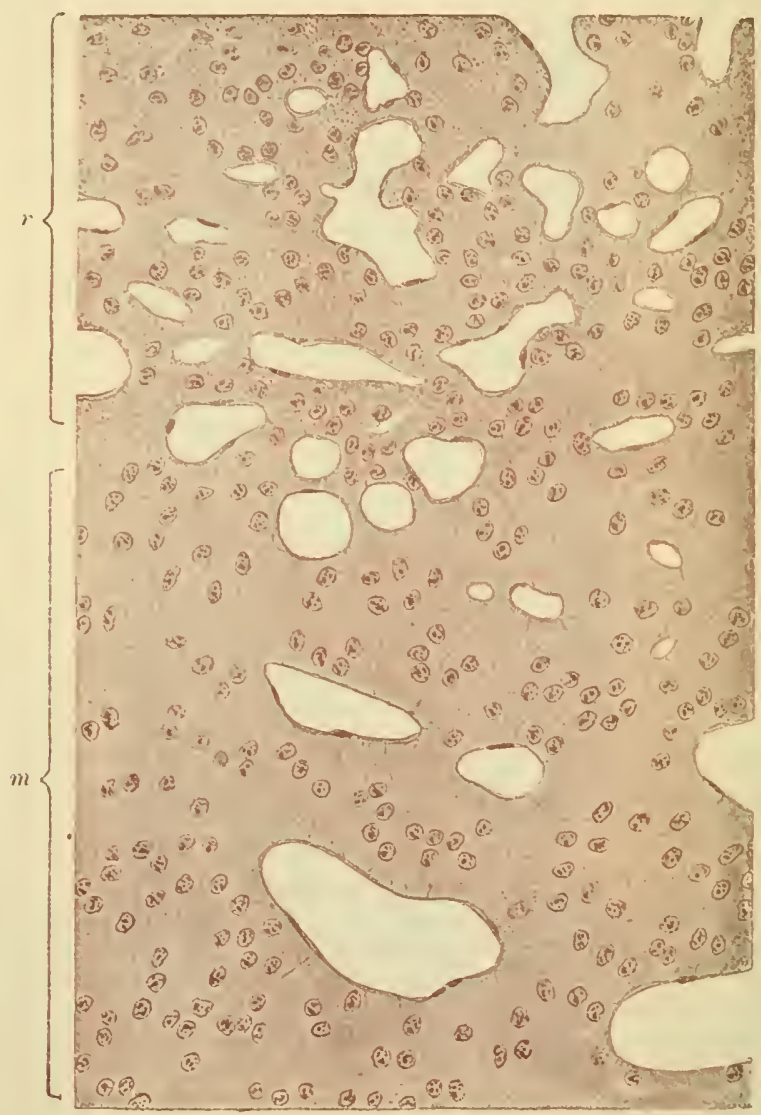

FIg. 269. - SECTION SHOWING ZONA RETICULARIS OF CORTEX, $r$, AND MEDULLA, $m$, OF sUPRARENAL OF DOG. (Szymonowicz.) Magnified $38+$ diameters.

pervade the medulla and they probably pour a secretion directly into the blood. Their protoplasm is granular ; in some animals it contains a brownish pigment, but in man the dark red colour of the medulla is due to the blood contained in the large sinusoid spaces by which it is pervaded, and which receive the blood after it has traversed the capillaries of the cortex. A few arterioles pass straight to the medulla through the cortex. One large vein usually passes out at 
the hilus in the anterior surface of the glaurd. Investing the larger reins are longitudinal bundles of plain muscular fibres; but most of the veins have only an endothelium. Numerous nerves, after traversing . the cortieal substance, are distributed throughout the medulla, where they form a close plexus provided here and there with ganglion-eells. The cells of the medulla are charaeterised by staining brown by ehromie acid and its salts, provided the organ is fresh (chromophil or chromattin eells).

The medulla of the suprarenal capsule is developed from cells which become detached from the rudiments of the sympathetic ganglia, and are therefore of ectodermal origin. The cortex is developed from mesoderm.

\section{The Thyrold Body.}

The thyroid body consists of a framework of connective tissue inclosing numerous spherical or oval vesicles (fig. 270) which are lined

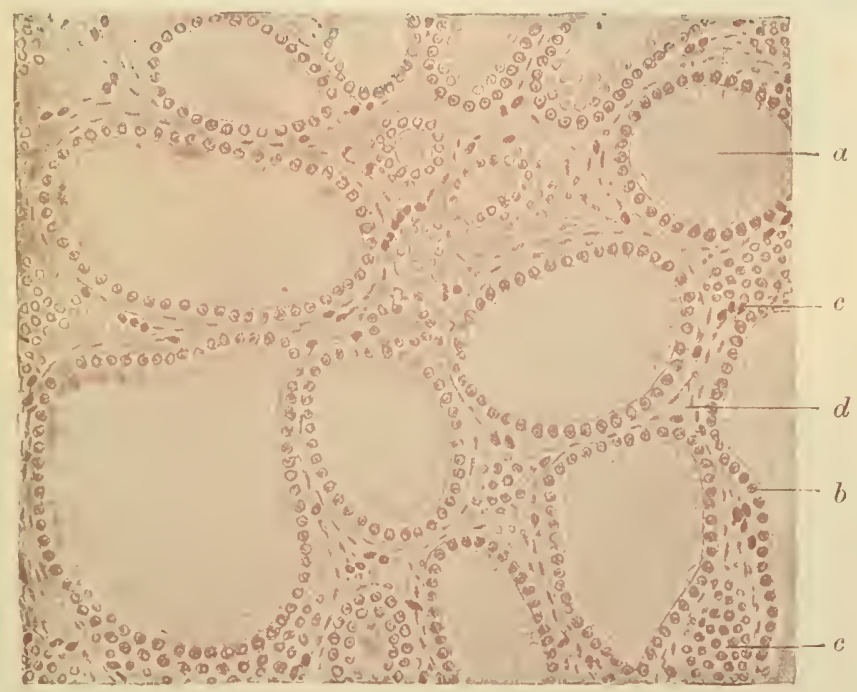

Fig. 270.-SFCtion OF HUMAN THYRoID. (Szymonowicz.) Magnified about 180 diameters.

a: vesicle occupied by colloid, which has partly shrunk away from the cpithelium; $b$, epithelium of a large vesicle; $c, c$, elithelium of vesicles which are cut tangentially; $d$, interstitial connective tissue.

with eubical epitbelium-cells; these often contain granules of a fatty character. The cavities of the vesicles are usually occupied by a peculiar viscid liquid (colloid) which is coagulated by alcohol and which then becomes stainer with hæmatoxylin. A similar material 
has been found in the lymphatics of the gland, and may often be detected also in the interstices of the connective tissue.

The blood-vessels of the thyroid are numerous and give a deep red colour to the organ. The capillaries form close plexuses round the vesicles (fig. 271 ), and even extend between the lining epithelium cells.

Parathyroids. - In close proximity to or embedded in the substance of the thyroid are always to be found four small glandular organs

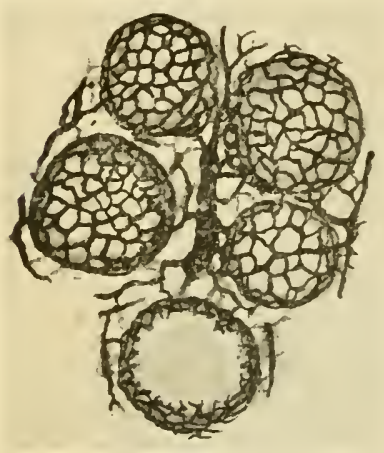

Fig. 2:1.-THYROID OF DOG INJECTED.

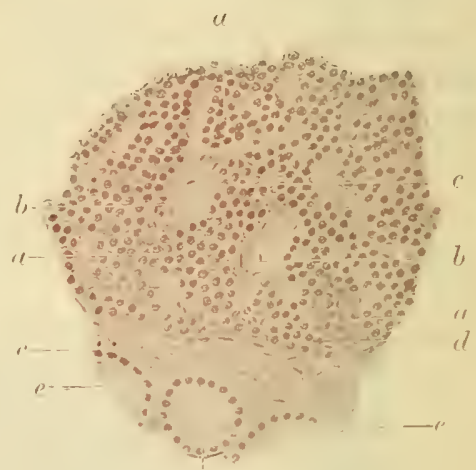

Fig. 2:2.-PARATHYROID OF HONKET. (Tincent and Jolly.)

a, parath rroid tissue; b, blood-ressels ; $c$, connective tissue; $d$, junction of parathyroid with thyroid; e, thyroid vesieles; $\epsilon^{\prime}$, colloid.

of different structure from the thyroid proper, although somewhat resembling its embryonic condition (fig. 272). These bodies, one of which usually lies on the lateral and one on the mesial surface of each lateral lobe, are formed of columns of granular epithelium-cells, with a very vascular connective tissue between the columns. If left after removal of the thyroid, they are stated to undergo hypertrophy, and to develop a vesicular structure (Vincent and Jolly). Besides these bodies, there is also frequently to be found in connexion with the thyroid a small mass of lymphoid tissue which resembles the thymus tissue in structure, and, like it, contains concentric corpuscles.

\section{CAROTID AND COCCYGEAL GLANDS.}

These are minute glandular organs without ducts, lying respectively at the bifurcation of the carotid artery and in front of the apex of the coccyx. They are composed of polyhedral cells, with numerous bloodcapillaries between them. In the carotid gland the cells are collected 


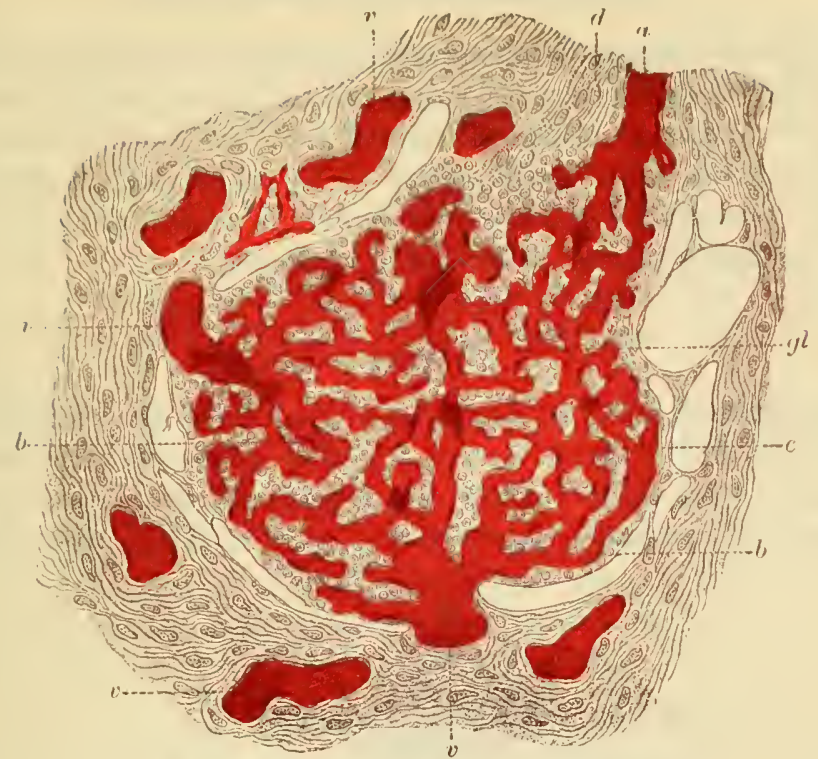

Fig. 273.-A CLUMP OR CELL-BALL FrOM THE CAROTIN GLANI, INJECTED. (Schaper.)

$a$, arteriole; $\imath$, venules; $c$, sinus-like capillary within nodule; gl, group of gland eells; $c$, boundary of nodule surrounded by lymph space; $d$, inter-nodular conneetive tissue of gland.

1 .

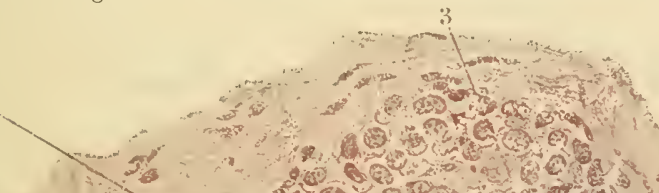

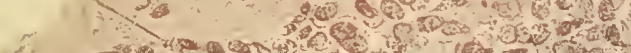

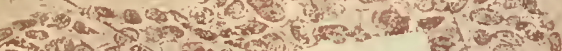
(1)

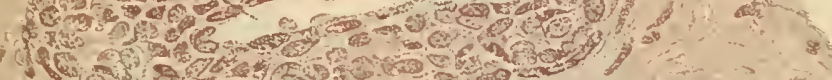

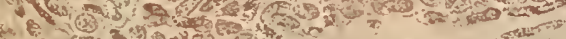

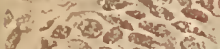
-

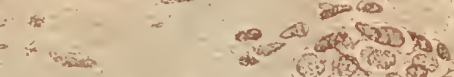
3e. b $\rightarrow$ a

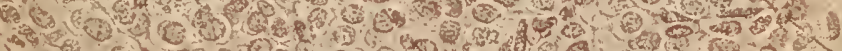

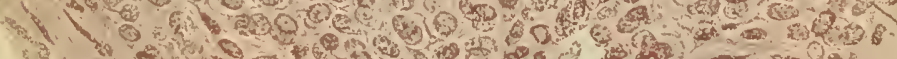

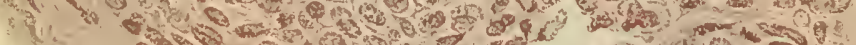

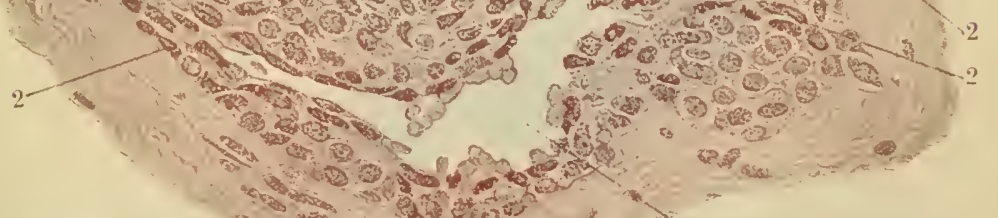

Fig. 274.-Section OF COCCYGEAL GLAND, (Walker.)

1, blood-spaees; 2 , epithelium ; 3 , connective tissue. 
into spheroidal clumps, in the coccygeal gland into irregular nodules. The blood-vessels, at least in the coccrgeal gland, have a sinusoidal character (Walker). Amongst the cells are some which stain dark brown with chromic acid like those of the medulla of the suprarenal capsules (chromophil cells). A certain number of such cells occur also, according to Kohn, in sympathetic ganglia.

\section{The Pitlitary Body.}

The pituitary body or gland (hypophysis ceretri) is a small reddish mass which lies in the sella turcica, and is connected with the third ventricle by the infundibulum. It consists of two lobes, a larger anterior and a smaller posterior (fig. 275). The anterior labe is

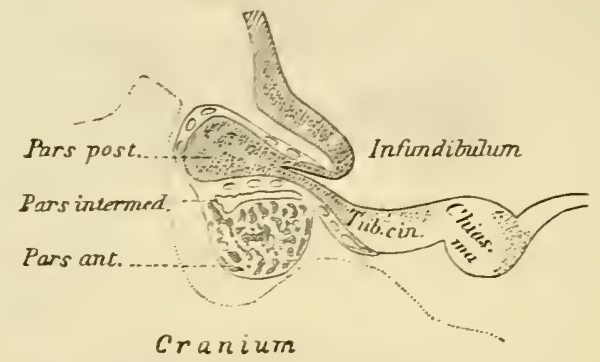

FIG. 275.-SECTIOX THROCGH HYPOPHYSIS. (Edinger.)

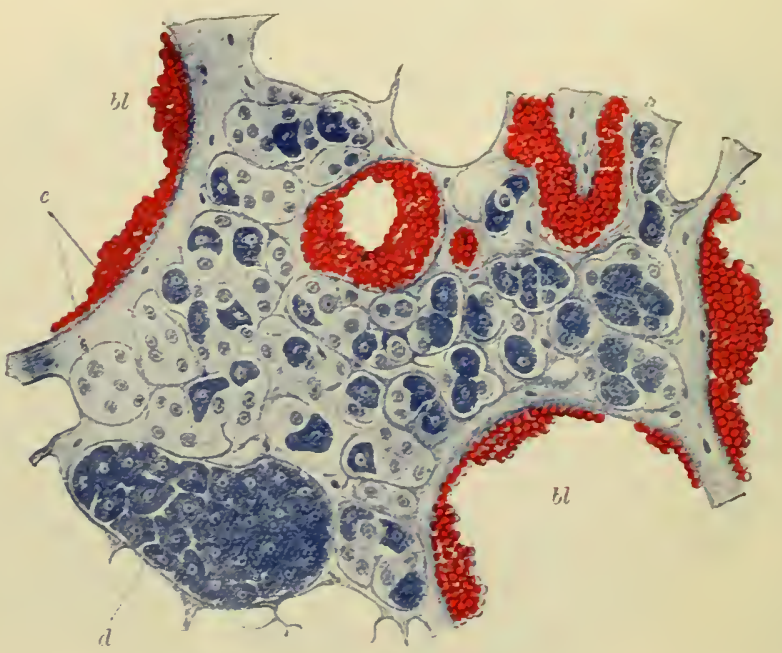

FIG. 2ija.-Sectios of ANTERIOR LOBE OF HYPOPHYSIS OF OX. (Dostoiewsky.) $b l$, hlood-sinuses ; $c$, cell-strands containir g clear cells; $d$, strands of darker granular cells. Other strands contain both kinds of cell. 
originally dereloped as a hollow protrusion of the buccal epithelium. It consists of a number of tubules, which are lined by epithelium and mited by connective tissue. In some of the tubes the epithelium is ciliated, and occasionally a colloid substance is found in them, but for the most part the lumen of the tubules has become obliterated in the adult, and they. present the appearance of solid cell-masses between which are numerous large venous capillaries, perbaps sinusoids. Some of the cells are clear, others darkly granular in appearance (fig. $275 \mathrm{~A}$ ).

The posterior lobe of the pituitary body, which is developed from the infundibulum of the third ventricle, consists chiefly of vascular connective tissue and neuroglia, but it also includes masses of cells of an epithelial character (pars intermedia), which are continuous with those of the anterior lobe. It is partly separated from the anterior lobe hy a cleft-like space containing glairy fluid. In man the posterior lobe is stated to contain no cells in the adult of distinctly nervous character, but it receives many nerve-fibres which arise from large cells in the grey matter just behind the optic chiasma, some of which penetrate into the glandular substance. 


\section{LESSONS XXIV. AND XXV.}

\section{THE SKIN.}

1. Sections of skin from the palmar surface of the fingers. The skin is hardened in picric acid or formol, followed by alcohol. The sections are made vertical to the surface, and should extend down as far as the subcutaneous tissue. Notice the layers of the epidermis and their different behaviour to staining fluids. Notice also the papilla projecting from the corium into the epidermis and look for tactile corpuscles within them. In very thin parts of the sections the fine intercellular channels in the deeper parts of the epithelium (see Lesson VII.) may be seen with a high power. The convoluted tubes of the sweat-glands are visible here and there in the deeper parts of the corium, and in thick sections the corkscrew-like channels by which the sweat is conducted through the epidermis may also be observed. Make a sketch showing the general structure under a low power, and other sketches to exhibit the most important details under a high power. Measure the thickness of the epidermis and the length of the papillix.

2. Sections of the skin of the scalp, vertical to the surface and parallel to the slope of the hair-follicles, and others parallel to the surface, and therefore across the hair-follicles. Stain and mount in the same way as in the last preparation. Examine also the structure of the hairs.

In these preparations the details of structure of the hairs and hair-follicles, together with the sebaceous glands and the little muscles of the hair-follicles, are to be made ont.

3. Vertical sections of the nail and nail-bed. To cut such hard structures as the nail it is best, after fixing with picric acid or formol followed by 75 p.c. alcohol, to soak the tissue in strong gum arabic for a few days, then place it in an appropriate position upon a cork or upon the object-carrier of a microtome, and plunge the whole into 70 per cent. alcohol. This renders the gum hard, and enables sections to be cut of sufficient fineness. A plane iron should be used with the microtome, since the hardness of the nail will turn the erge of a razor. To remove the gum the sections are placed in water for a few hours; they may then be stainerl and mounted. Notice the ridges (not papillæ) of the corium, projecting into the epidermis. Observe also the distinction of the epidermis into Malpighian layer and nail proper.

4. Mount a section from a portion of skin in which the blood-vessels have been injected, and notice the distribution of the capillaries to the sweatglands, to the hair-follicles, and to the papillary surface of the corium.

5. The cells which compose the nails and hairs can be isolated by warming a small piece of nail or lair in strong sulphuric acid; after this treatment they are readily separated from one another by pressure upon the coverglass.

6. Sections of mammary gland during lactation. The gland may be fixed in Zenker's fluid (see Appendix) and the sections stained with hrmatoxylin and eosin.

The skin is composed of two parts, epidermis and cutis vera (fig. 276).

The epidermis, or scarf skin, is a stratified epitbelium (fig. 277). It is composed of a number of layers of cells, the deeper of which are 
soft and protoplasmic, and form the rete mucosum of Malpighi, whilst the superficial layers are hard and horny, this horny portion sometimes

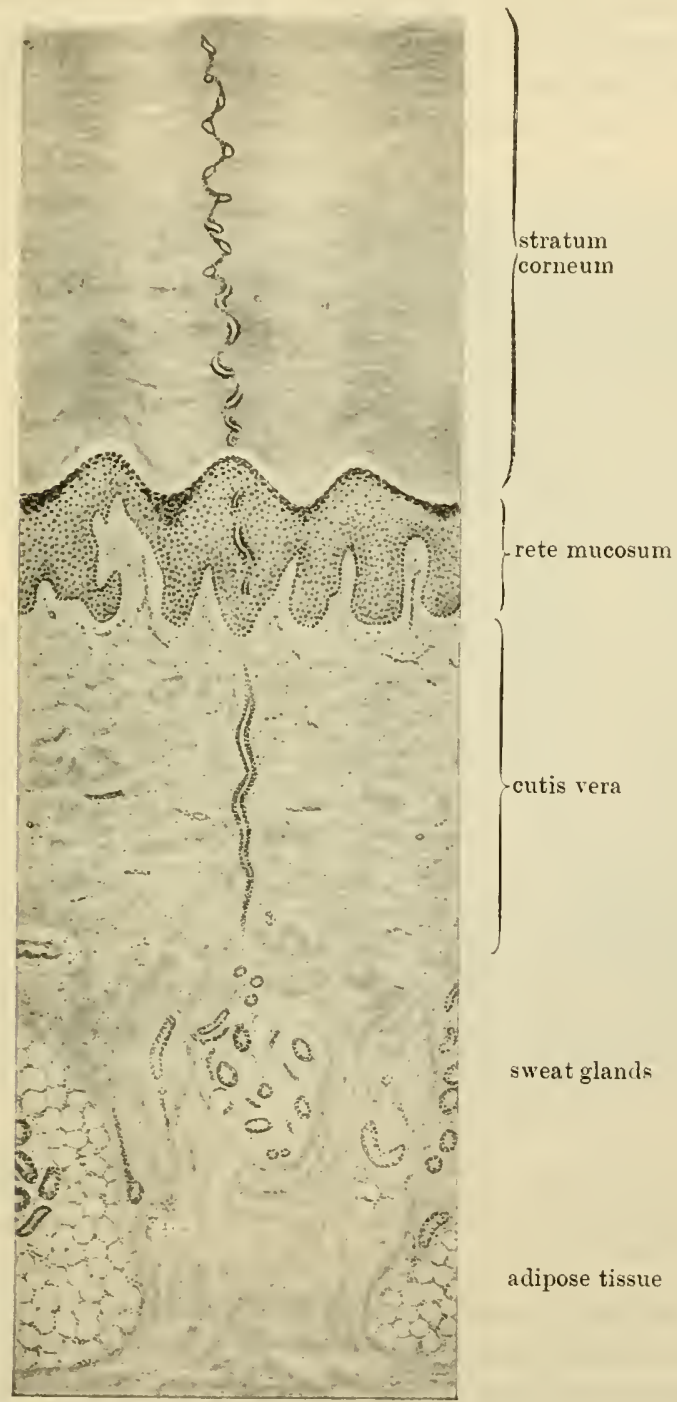

Fig. 276. - Vertical SECTION THROUGH THE SKIN OF THE SOLE OF THE FOOT. Magnifed about 25 diameters.

constituting the greater part of the thickness of the epidermis. The deepest cells of the rete mucosum, which are set on the surface of the cutis vera, are columnar in shape. In the coloured races of mankind 
these cells contain pigment-granules. In the layers immediately above them the cells are polyhedral. Between all these cells of the rete mucosum there are fine intercellular clefts which separate the cells from one another, but are bridged across by fibres which pass from cell to cell, and also through the substance of the cells (Ranvier, Delépine). The intercellular channels serve for the passage of lymph,

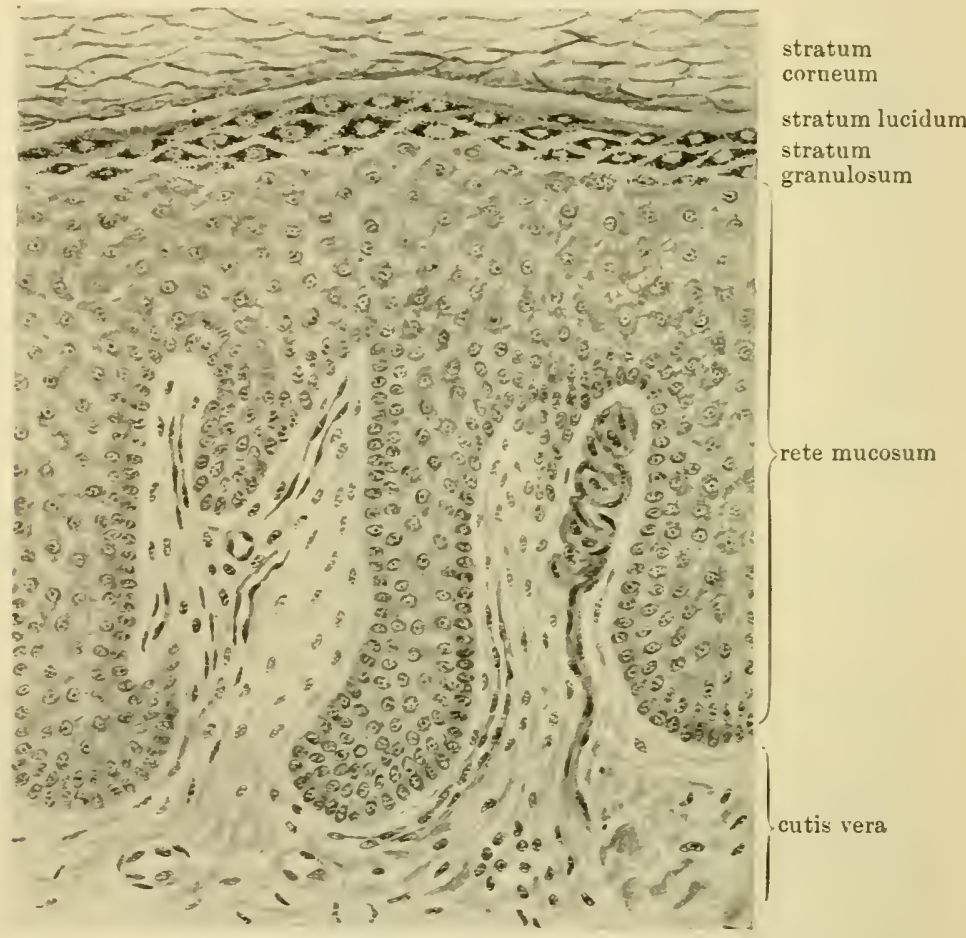

Fig. 2\%.-TERTICAL SECTION THROCGH THE SKIN OF THE PALMAR SIDE OF THE FIXGER, SHOWIYG TWO PAPILLE (ONE OF WHICH CONTAINS A TACTILE CORPCSCLE) AND THE DEEPER LAYER OF THE EPIDERMIS. Magnified about 200 diameters.

and witbin them occasionally lymph-corpuscles may be found, often having a stellate figure from becoming shaped to the interstices.

The superficial layer of the rete mucosum is formed of somewhat flattened cells filled with granules or droplets of a material (eleidin) which stains deeply with carmine and hæmatoxylin (stratum granulosum, fig. 277 ; fig. 278). This is not sharply marked off from the cells of the rete mucosum which lie next to it, for many of these show similar granules, although they less completely fill the cell. 
Superficial to the stratum granulosum is a layer in which the celloutlines are indistinct and the cells contain flakes or larger droplets of a hyaline material (kerato-hyalin), which stain less intensely than the granules in the last layer, and which tend to run together. This layer has a clear appearance in section, and is known as the stratum lucidum. Immediately superficial to the stratum lucidum is the horny part (stratum corneum) of the epidermis. It is composed of a number of layers of epithelium cells, the nuclei of which are no longer visible. These cells near the surface take the form of thin horny scales

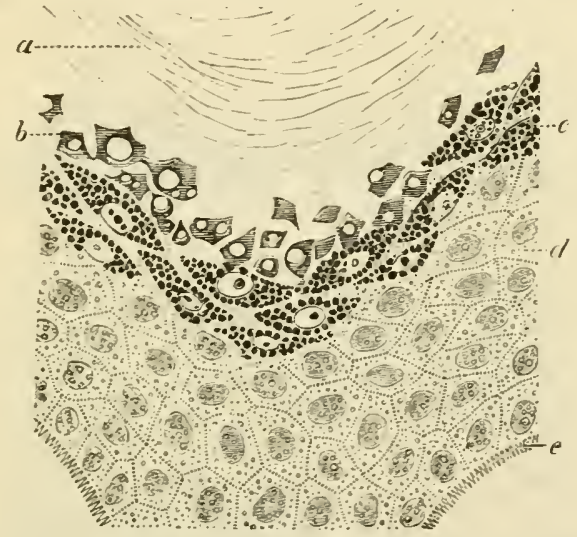

Fig. 278. - PORTION OF EPIDERMIS FROY A SECTION OF THE SKIN OF THE FINGER, COLOLRED WITH PICROCARMINE. (Ranvier.)

$a$, stratum corneum; $b$, stratum lucidum with flakes of kcrato-hyalin; $c$, stratum granulosum, the cells filled with drops of eleidin; $l$, prickle-cells; $e$, dentate projections by which the deepest cells of the epidermis are fixed to the cutis vera.

which eventually become detached (fig. $279, s$ ). In certain parts which have a thick epidermis and are not covered with hair (e.g. the palms and soles), the superficial part of the epidermis is a layer mainly formed by a number of greatly swollen cells $(s w)$, forming collectively what has been termed the exitrichicl layer. In the embryo in the second and third month of intrauterine life it covers the whole body, but is thrown off where hairs are developed.

The growth of the epidermis takes place by a multiplication of the cells of the deeper layers. The newly formed cells, as they grow, push towards the surface those which were previously formed, and in their progress the latter undergo a chemical transformation, which converts their protoplasm into horny material : this change seems to occur just at and above the stratum granulosum (see fig. 278). The granules which occupy the cells of the stratum granulosum are composed, as already stated, of a substance termed eleidin, which according to 
Ranvier becomes chemically altered and transformed into the keratin of the more superficial strata.

No blood-ressels pass into the epidermis, but it receives nerves which ramify between the cells of the rete mucosum in the form of fine varicose fibrils (fig. 279). In some parts these are enlarged at their extremity and along their course, into menisci which lie between

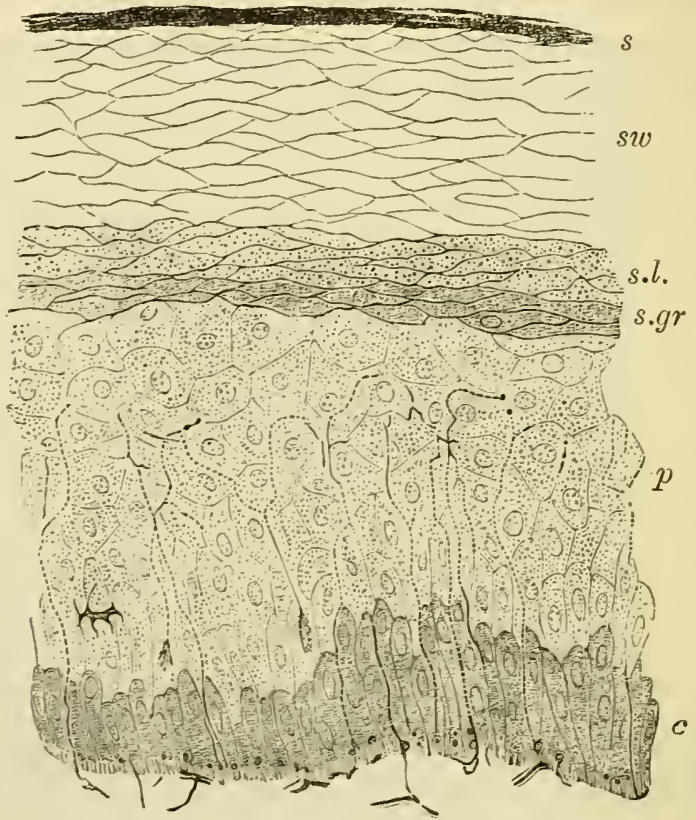

Fig. 279. - Sectios of EPInfruis. (Ranvier.)

s, superficial horny scales; $s v$, swollen horny cells; $s . L$, stratum lucidum; $p$, pricklecclls, several rows deep; $c$, elongated cells forming a single stratum near the corium ; 8.gr, stratum granulosum of Langerhans, just below the stratum lucidum. Part of a plexus of nerve-fibres is seen in the superficial layer of the cutis vera. From this plexus fine varicose nerve-fibrils may be traced passing up between the epithelium. cells of the Malpighian layer.

the deeper epidermis cells. Such terminations are seen in the skin over the pig's snout (fig. 219) and in the root-sheaths of hairs. They also occur in the skin in the neighbourhood of the entrance of the sweat-ducts into the epidermis (Ranvier) (fig. 280).

The cutis vera or corium is composed of dense connective tissue, which becomes more open and reticular in its texture in its deeper part, where it merges into the subcutaneous tissue. It is thickest over the posterior aspect of the trunk, whereas the epidermis is thickest on the palms of the hands and soles of the feet. The superficial or vascular layer of the corium bears microscopic papillce, which project up 
into the epidermis, which is monlded over them. These papillæ for the most part contain looped capillary vessels, but some, especially those of the palmar surface of the hand and fingers, and the corresponding part of the foot, contain tactile corpuscles, to which medullated nerve-fibres pass (fig. 277).

In some parts of the body (scrotum, penis, nipple, and its areola), involuntary muscular tissue occurs in the deeper portions of the cutis vera, and, in addition, wherever hairs occur, small bundles of this tissue are attached to the hair-follicles.

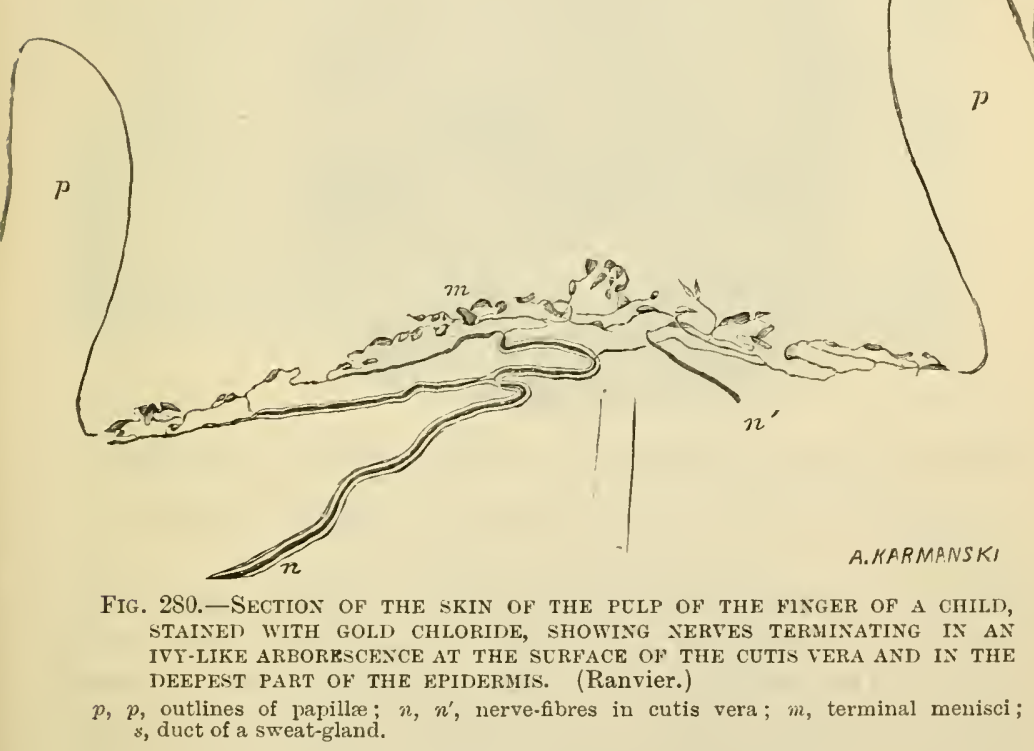

The blood-vessels of the skin are distributed almost entirely to the surface, where they form a close capillary network, sending up loops into the papillæ (fig. 281). Special branches are also distributed to the various appendages of the skin, viz. the sweat-glands and hair-follicles, with their sebaceous glands and little muscles, as well as to the masses of adipose tissue which may be found in the deeper parts of the cutis.

The lymphatics originate near the surface in a network of vessels, which is placed a little deeper than the blood-capillary network. They receive branches from the papillæ, and pass into larger vessels, which are valved, and which run in the deeper or reticular part of the corium. From these the lymph is carried away by still larger vessels, which course in the subcutaneous tissue.

The appendages of the skin are the nails, the hairs, with their 
sebaceous glands, and the sweat-glands. They are all developed as thickenings and downgrowths of the Malpighian layer of the epidermis.

\section{THE NAILS.}

The nails are thickenings of the deeper part of the stratum corneum developed over a specially modified portion of the skin (fig. 282), which

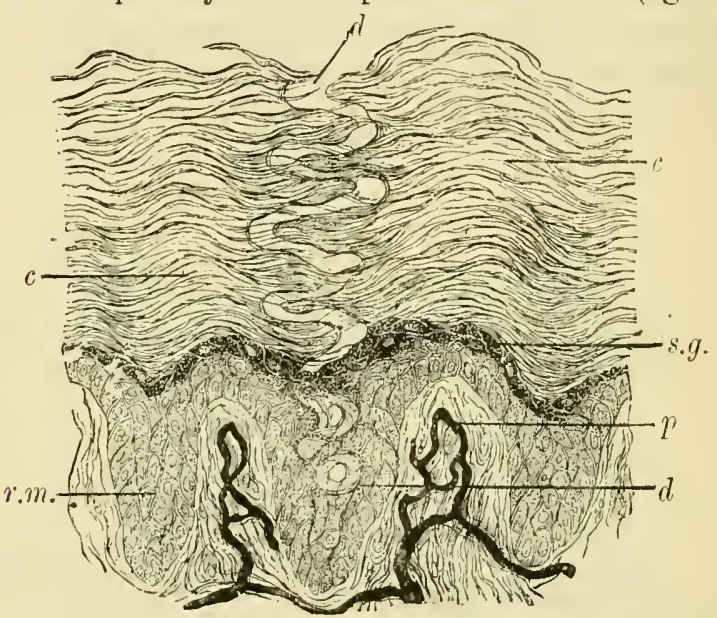

Fig. 281.-Duct OF a sweAT-gLAND PASSING THROtgh THE EPIDERMIS. Magnified 200 diameters. (Heitzmann.)

$p$, papillæe with blood.vessels injected; $r . m$., rete mucosurn between the papillæ; $c, c$, stratum corneum; s.g., stratum granulosurn; $d$, $d$, sweat-duct passing through epidermis.

is known as the bed of the nail, the depression at the posterior part of the nail-bed from which the root of the nail grows being known as the nail-groove. The part of the bed which occupies the inner or central portion of the groove is termed the nail-matrix, since it is from this part that the srowth of the nail proceeds. The distal part of the nail forms the free border, and is the thickest part of the body of the nail. The substance of the nail (fig. $283, N$ ) is composed of clear horny cells, each containing the remains of a nucleus; it rests immediately upon a Malpighian layer $(B)$ similar to that which is found in the epidermis generally, but destitute of a defined stratun granulosum. Nevertheless, in the more superficial cells both of the bed and matrix there are a large number of granules to be seen, which appear to represent those of the stratum granulosum of the epidermis. These granules are, however, not composed of eleidin, but of a material (onychogenic substance, Ranvier) which stains brown instead of red with carmine; a similar material occurs in the cells which form the fibrous substance and cuticula of the hairs. The corium of the nail-bed 
THE NAILS.

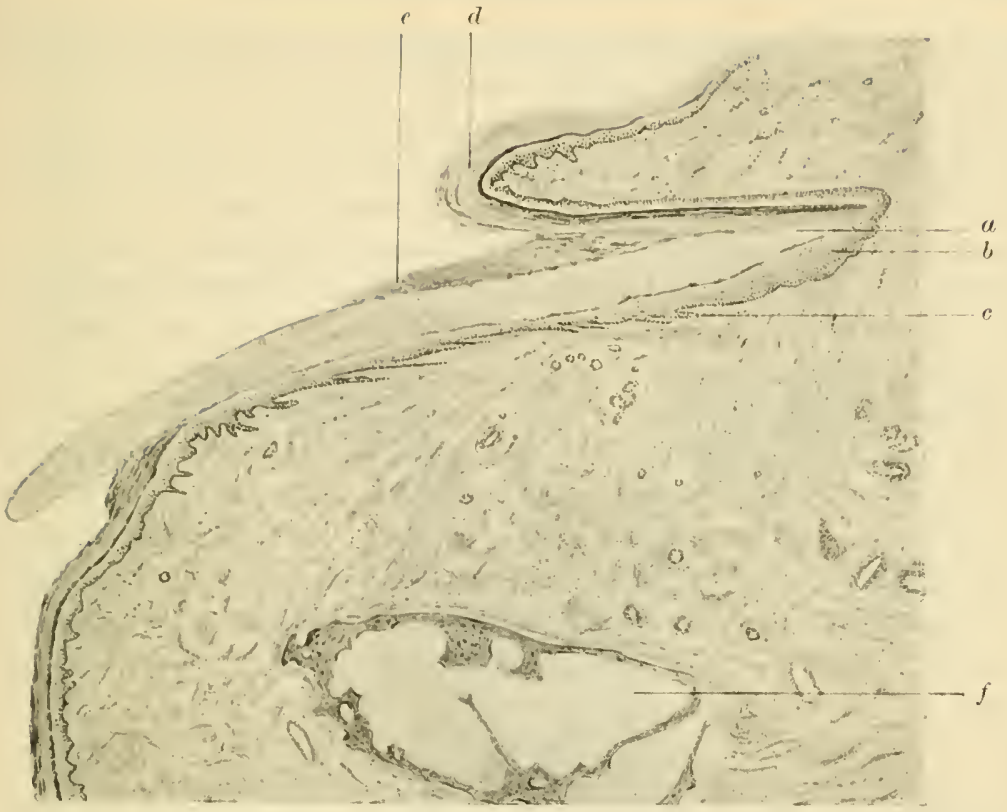

Fig. 282.-ThongtTUdNal SECTION THROUgh THE ROOT OF THE NAIL AND ITS MATRIX. Magnified about 10 diameters.

$a$, root of nail; $b$, Malpighian layer of matrix ; $c$, ridges in dermis of nail-bed ; $d$, epitrichial layer of epidermis ; $e$, eponychium; $f$, bone (terminal phalanx) of finger.

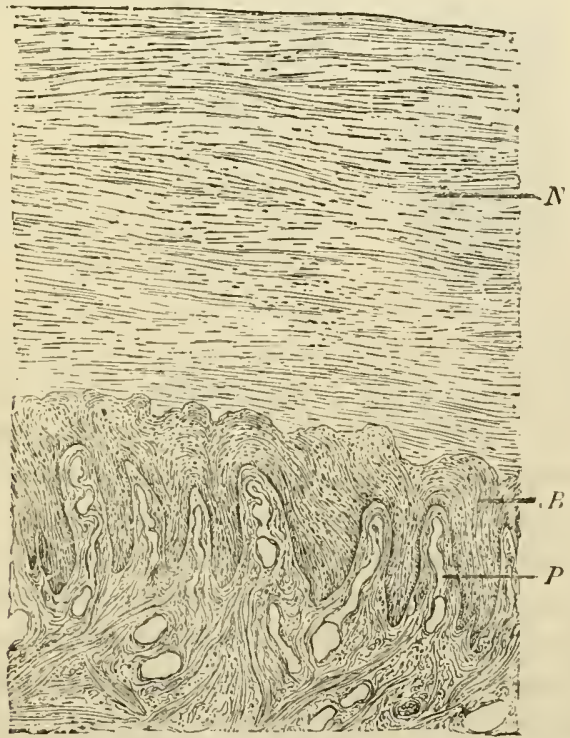

Fig. 283.-Section ACROSS THE NAIL AND NAIL-BED. Magnified 100 diameters. (Heitzmann.)

$P$, ridges with blood-ressels ; $B$, rete mucosum ; $N$, nail. 
is beset with longitudinal ridges instead of the papillæ which are present over the rest of the skin; these, like the rest of the superficial part of the corium, are extremely vascular.

The nail-bed also receives many nerve-fibres, some of which end in Pacinian corpuscles whilst others ramify in the ridges of the corium, and others again penetrate amongst the deeper epithelium cells.

The nails are developed in the fotus at about the third month, the groove being formed at this time in the corium, and the nail rudiment appearing in it as a thickening of the stratum lucidum, which lies over the bed. It becomes free in the sixth month, its free end being at first thin, but as it grows forward over the bed it receives additions on its under surface-at least in the posterior part of the bed-so that after a time the distal end becomes thicker. The epitrichial layer of the cuticle which originally covered the developing nail becomes detached after the fifth month, and, after birth, only remains as the narrow border of enticle (eponychium) which overlies the lunula at the root.

\section{HAIRS.}

The hairs are growths of the epidermis, developed in little pitsthe hair-follicles - which extend downwards into the deeper part of the

A

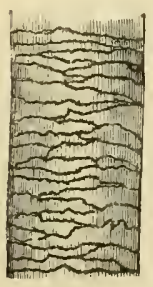

Fig. 2\$4.-Piece of human hair. Magnified.

$A$, seen from the surface; $B$, in optical section. $c$, cuticle; $f$, fibrous substance; $m$, medulla, the air laving been expelled by Cauada balsam. corium, or even into the subcutaneous tissue. The hair grows from the bottom of the follicle, the part which thus lies within the follicle being known as the root (fig. 285).

The substance of a hair is mainly composed of a pigmented, horny, fibrous material (fig.284,f), which can be separated by the action of sulphuric acid into long tapering fibrillated cells, the nuclei of which are still visible. The fibrous substance of the hair is covered by a layer of delicate imbricated scales, termed the hair-cuticle $(c)$. In many hairs, but not in all, the centre is occupied by an axial substance (medull $a, m)$, formed of angular cells which contain granules of eleidin, and frequently have a dark appearance from the presence of minute air-bubbles. The latter may also occur in interstices in the fibrous substance. When they are present, the hair looks white by reflected light. The root has the same structure as the body of the hair, except at its extremity, which is enlarged (fig. 285); this enlargement is com- 
posed mainly of soft, growing cells, and fits over a vascular papilla, which projects up into the bottom of the follicle (fig. 287).

Structure of hair-follicle (figs. 285 to 288 ). - The follicle, like the skin itself, of which it is a recess, is composed of two parts : one epithelial, and the other connective-tissue. The epithelial or epidermic part of the follicle closely invests the hair-root, and is often in great part dragged out with it; hence it is known as the root-sheath. It consists of an outer layer of soft columnar and polyhedral cells, like the

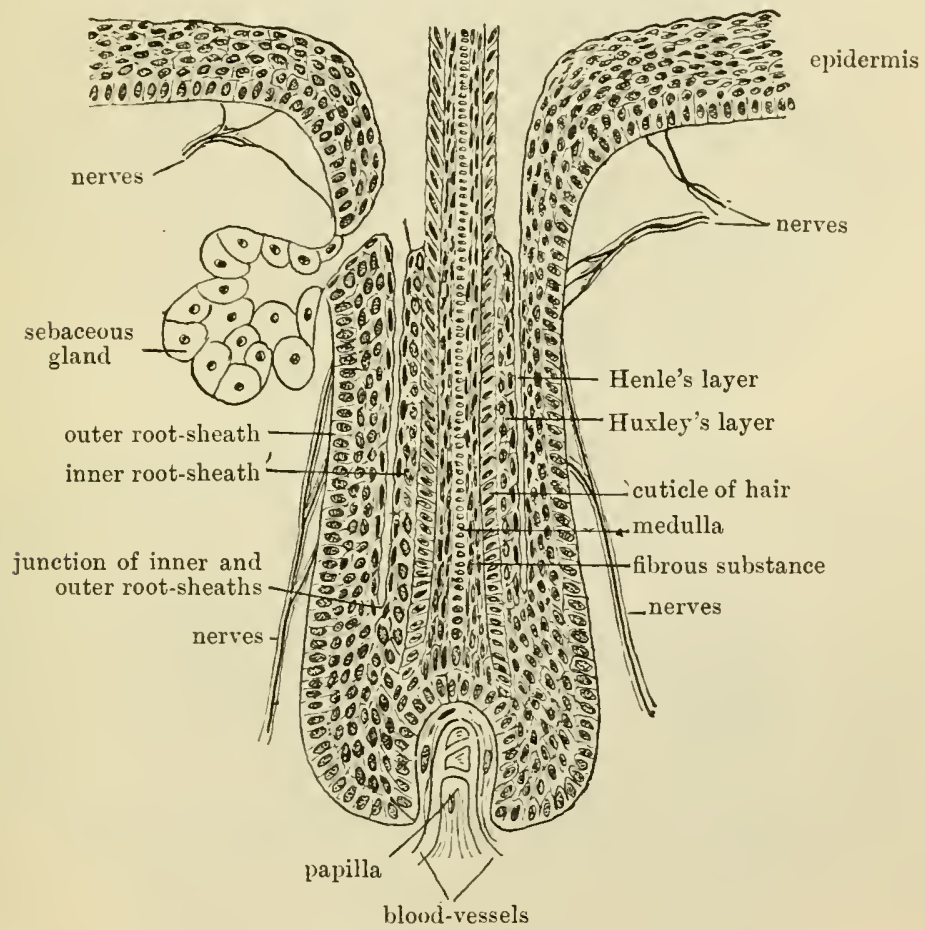

Fig. 285.-Diagray to explain the Formation of a hair. (Maurer.)

Malpighian layer of the epidermis, but without stratum granulosumthe outer root-sheath; and of an inner, thinner, horny stratum next to the hair-the inner root-sheath. The inner root-sheath itself consists of three layers, the outermost being composed of horny, fibrous, oblong cells the nuclei of which are obscure and difficult to make out (Henle's layer), the next of polyhedral nucleated cells containing eleidin (Huxley's layer), and the third-the cuticle of the root-sheath-a layer of downwardly imbricated scales, which fit over the upwardly imbricated scales of the hair itself. In the more superficial part of the hair-follicle the layers of Huxley and Henle are indistinguishable, the cells of both 
being clear and keratinised; even lower down where distinguishable they show a tendency to dovetail into one another. At the bottom of the follicle no differentiation into layers can be made out in the root-sheath, which is here formed by a uniform mass of soft cells surrounding the papilla.
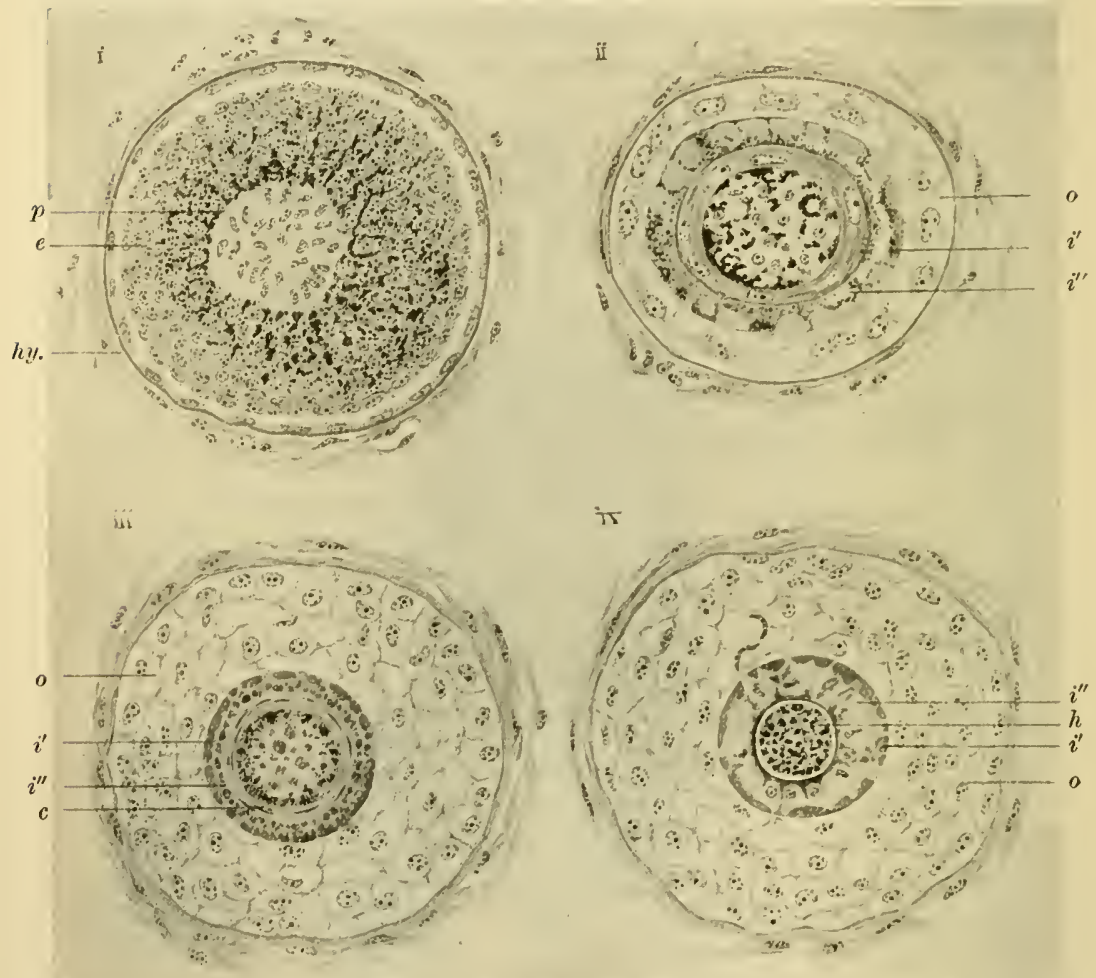

FIG. 286. - SECTIONS ACROSS HAIR-FOLLICLES FroM THE SCALP OF AN INFANT.

I. Through papilla. II. Just ahove papilla, 1Il, About middle of follicle. IV. Near outer part of follicle. In I. :-p, papilla; $\ell$, elithelium surrounding papilla, with pigment in cells; $h y$, hyaline layer of dermic coat with thin outer root-sheatl just within it. In II., III., IV. :-o, outer root-sheath; $i^{\prime}$, layer of Henlc and $i^{\prime \prime}$, layer of Huxley of the inner root-sheath; $c$, cuticle of root-sheath; $h$, hair.

In the greater extent of the follicle the outer root-sheath is several layers deep, but as the bottom of the follicle is approached it becomes thinner and is finally reduced to a single stratum of cells which becomes flattened out into a very thin layer in the papillary part (fig. 286, I.).

The connective tissue or dermic part of the hair-follicle is composed internally of a vascular layer, which is separated from the root-sheath 
by a basement-membrane termed the hyaline layer of the follicle. This inner vascular layer corresponds to the superfieial layer of the eutis vera. Its fibres and cells have a regular circular arrangement around

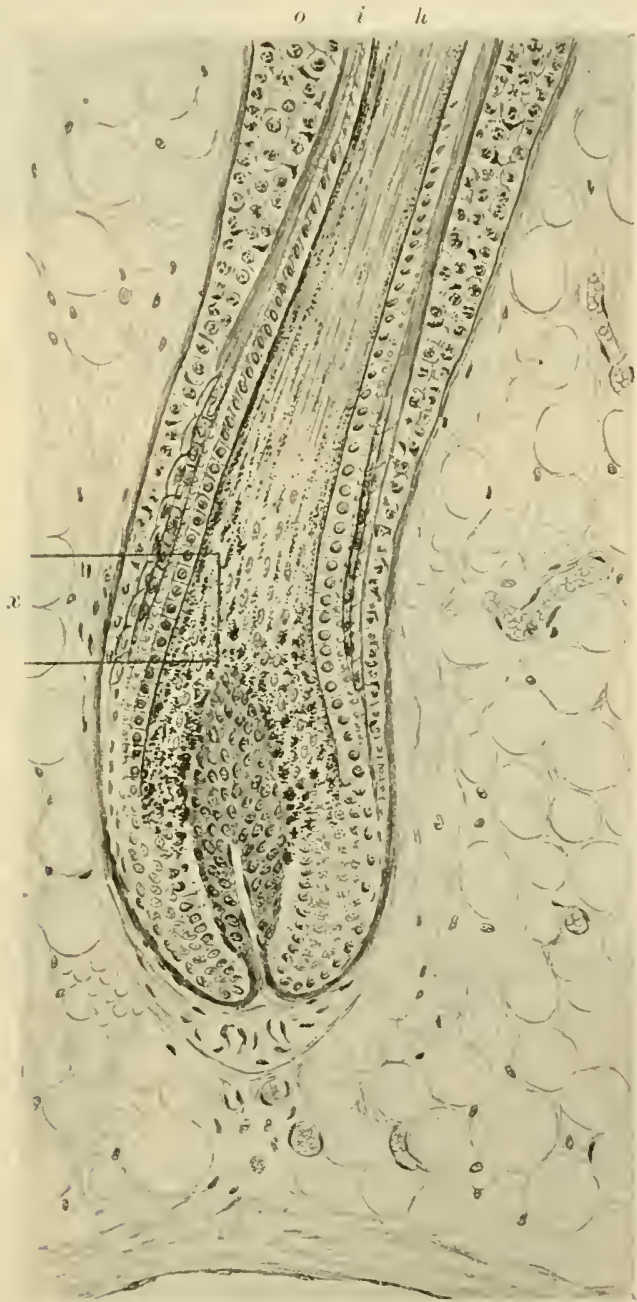

Fig. 287.-Longitudinal section of a hair-follicle. Magnified 200 dimmeters. $o$, outer ; $i$, inner root-sheath; $h$, hair ; $x$, part shown magnified in fig. $28 s$.

the follicle, the cells being flattened against the hyaline layer. Externally the dermic coat of the follicle has a more open texture, eorresponding to the deeper part of the cutis, and contains the larger branches of the arteries and veins. In the large tactile hairs of animals, the 


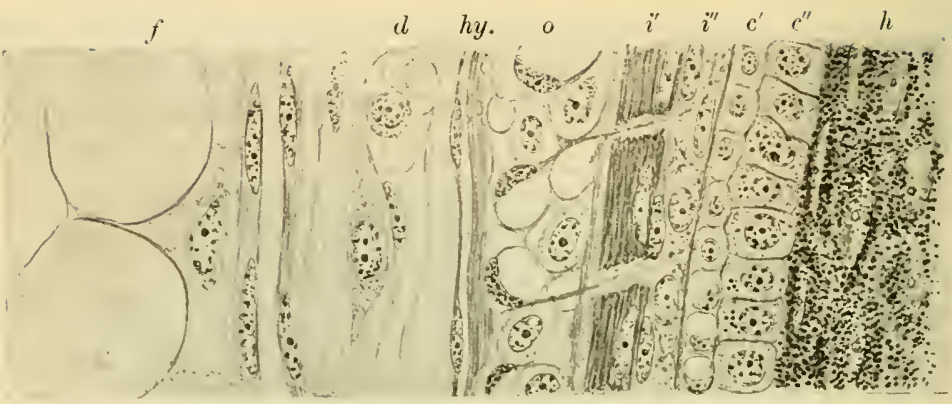

Fig. 288.-A Silall portion of the SECTION SHOWN IN Fig. 287 ENLARgEI) TO EXHIBIT THE STRUCTORE OF THE SEVERAL LATERS.

$h$, hair ; $c^{\prime \prime}$, its cuticle; $c^{\prime}$, cuticle of root-sheath; $i^{\prime \prime}$, Huxley's layer; $i^{\prime}$, Henle's layer; o, outer root-sheath ; $h y$, hyaline layer; $d$, dermic coat; $t$, fat-cells.

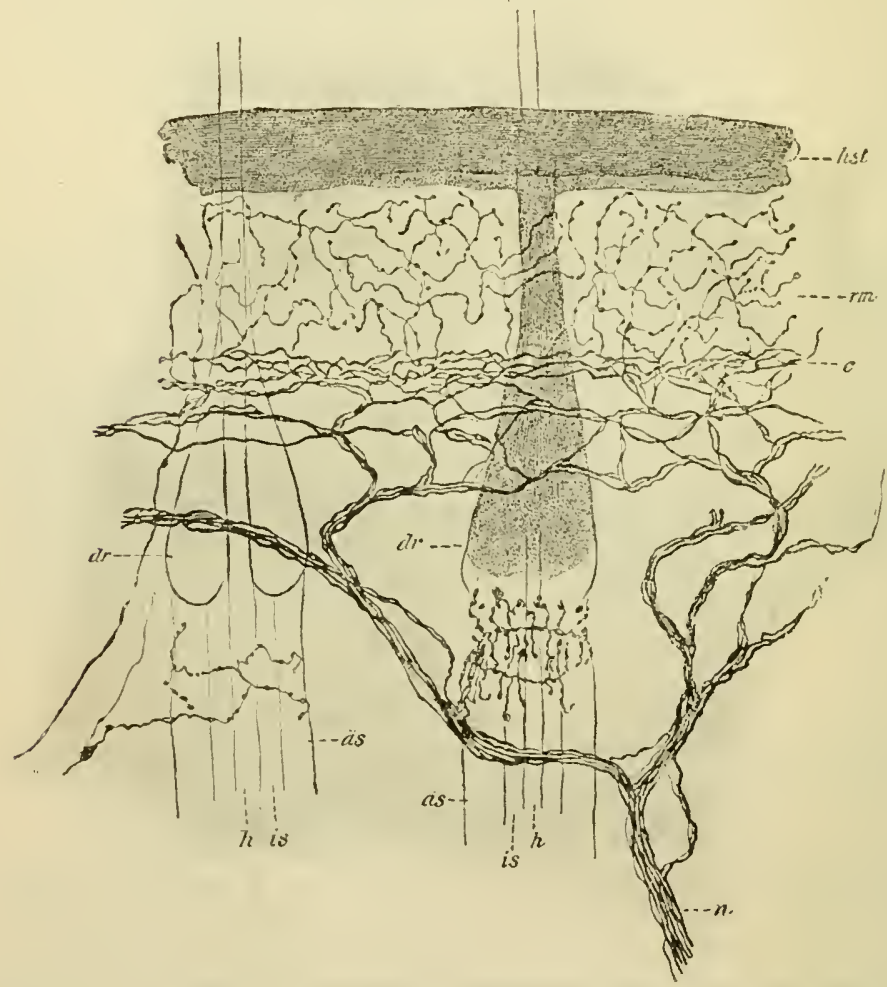

Fig. 289. -Nerves AN] NERVE-ENDINGS IN THE SKIN AND HAIR-Follicles. (G. Retzius.)

$h i s t$, horny straturn; $r m$, rete Malpighii ; $c$, superficial nerve-fibre plexus in the cutis $n$, cutaneous nerve; is, inner root-sheath of hair; $\ddot{a} s$, outer root-sheath ; $h$, hair; $d r$, sebaceous glands. 
veins near the bottom of the follicle are dilated into sinuses, so as to produce a kind of erectile structure.

The hair-follicle receives nerve-fibres which pass into the papilla, and others which enter the root-sheath. These last are derived from the superficial nerves of the corium and form ring-like arborisations in the upper part of the hair follicle. They are especially well developed in the large tactile hairs (whiskers) of animals (figs. 289, 290, 291).

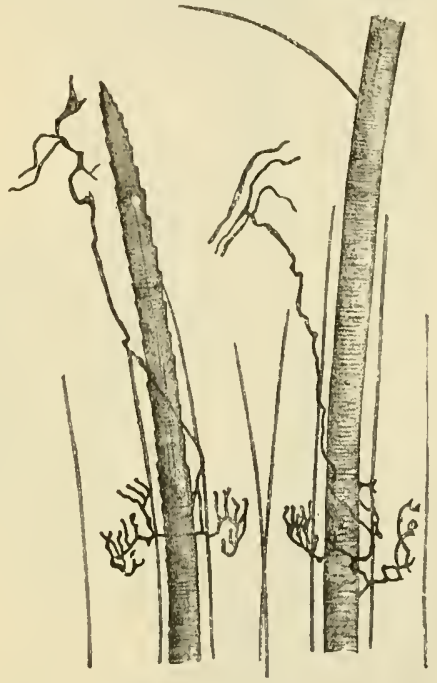

Fig. 290.-Fron A SECTION OF SKIN PIEPARED BY THE CHROHATE OF SILVER METHOD, SHOWING THE UPPER PART OH TWO HAIRS AND THE TERMINAL ARBORISATIONS OF NERVE-HIBRES IN THEIR ROOT-SHEATHS. (T'an Gehuchten.)

The hair grows from the bottom of the follicle by multiplication of the soft cells which cover the papilla, these cells becoming elongated and pigmented to form the fibres of the fibrous substance, and otherwise modified to produce the medulla and cuticle of the hair and the several layers of the root-shcath. The cells which form the medulla of the hair and the inner root-sheath are filled with granules of eleidin, but those which form the fibrous substance and cuticula of the hair have granules which stain brown with carmine, and appear similar to those which are met with in the corresponding cells of the nail-matrix (Ranvier) (see p. 232).

On the side to which the hair slopes a small patch of richly innervated thickented epidermis is usually to be found, dereloped over an enlarged papilla of the cutis vera: while on the opposite side of the hair is a flat area of skin with thickened scale-like epiclermis, which may represent a vestige of the reptilian scale (Pinkus). 
The hair germs when they first appear (as at $a$, fig. 293) are singularly like certain tactile patches which are found in the skin of anphibia and some reptiles, and it is possible that hairs have become rleveloped phylogenetically from these patches. It is well known that the tactile sensibility of many parts of the skin is intimately associated with the hairs, where these occur, although parts devoid of hairs may also have a highly developed sense of touch.

Besides the hair-follicles already described, which are provided with a papilla, from the cells on the surface of which the hair and its inner root-sheath grow (growing hairs, papillated hairs, hairs with hollow bulb),

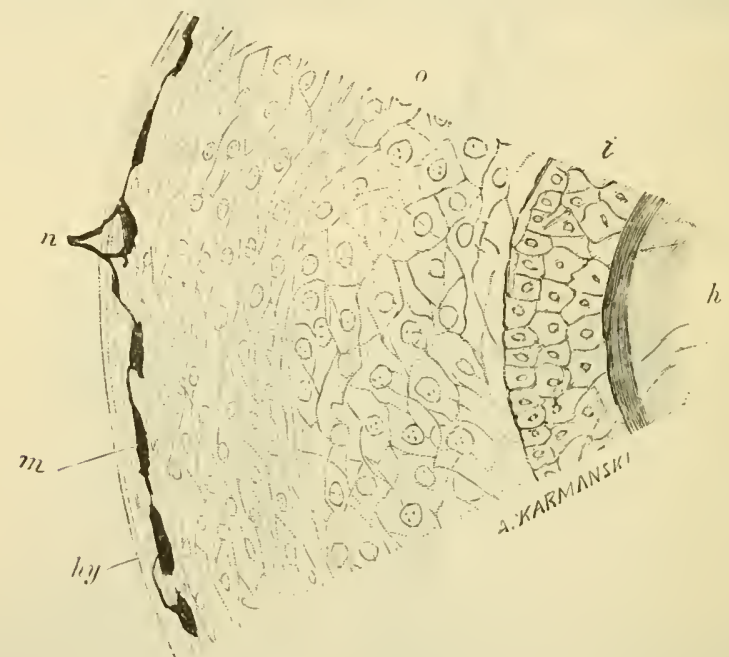

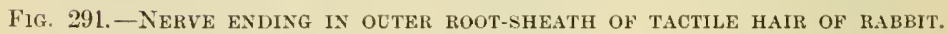
(Ranvier.)

$n$, nerre-fibre; $m$, tactile meniscus; $o$, outer root-sheath ; $i$, inwer root-sheath ; $h$, bair ; $h y$, hyalinie membrane.

there are many hairs which are unprovided with a papilla and the follicle of which ceases at the level of attachment of the arrector pili muscle (club-hairs, non-papillated hairs, hairs with solid bulb). These are hairs which have lost their papilla and have ceased to grow ; they are more easily eradicated than the growing hairs, and tend to fall out spontaneously after a time. In their follicles the whole of the lower part, including the original papilla and the soft growing cells which cover it, have entirely disappeared, the hair being now attached at its sides and below to the root-sheath. A hair which has thus ceased to grow eventually becomes lost, but its place is presently supplied by a new hair, which becomes developed in a down-growth from the bottom of the follicle, a new papilla becoming formed at the extremity of the 
(lown-growth (fig. 292). If not previously detached, the old hair is pushed out from the follicle by the one which replaces it.

The detachment of the non-papillated hairs is preceded by an absorption of the root of the hair and of the investing inner root-sheath.

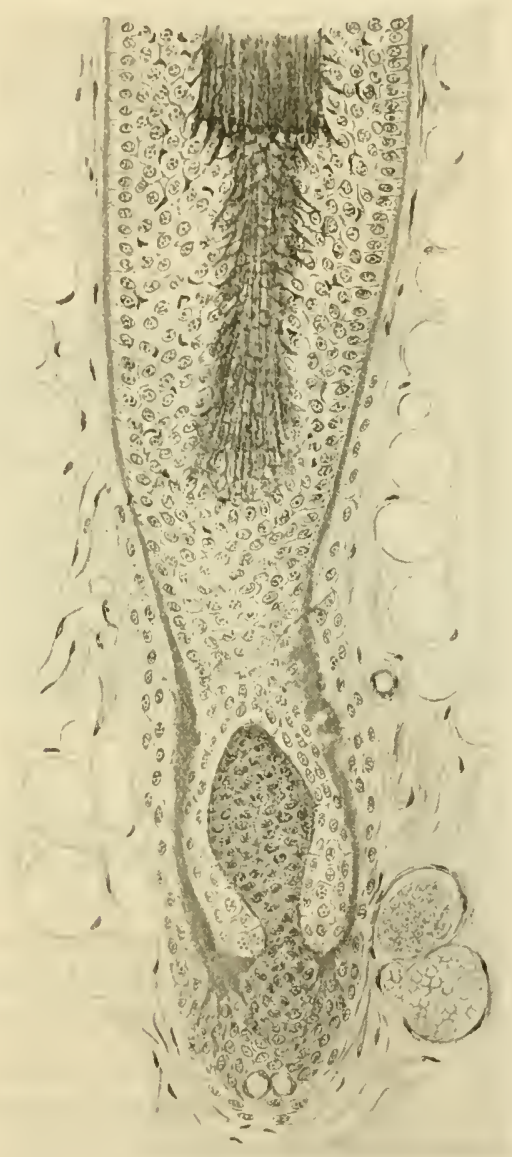

FIG. 292.-LoNgITUTINAL SECTION THROUGH THE FOLLICLE OF A HAIR WHICH HAS CEASED TO GROW AND THE ROOT OF WHICH IS UNDERGOING ABSORP. TIOx. Magnified 200 diameters.

This absorption appears to be effeeted by the cells of the outer sheath, which multiply at the expense of the keratinised parts of the hair root and thus undermine its attachment to the follicle (fig. 292).

The hairs are originally developed in the embryo in the form of small solid down-growths from the Malpighian layer of the epidermis (fig. 293). The hair-germ, as it is called (although it gives rise not only to the hair proper but to the epithelium-cells of the hair-follicle 
also), is at first composed entirely of soft growing cells, the outermost and deepest having a columnar shape; but presently those in the centre become differentiated, so as to produce a minute hair invested by inner root-sheath, its base resting upon a papilla which has become inclosed by the extremity of the hair-germ and which is continuous with the connective tissue of the corium (figs. 294, 295). As the minute hair grows, it pushes its way through the layers of the epidermis, which it finally perforates, the epitrichial layer being thrown off (p. 229). At the same time the follicle grows more deeply into the cutis vera, carrying the papilla down with it.

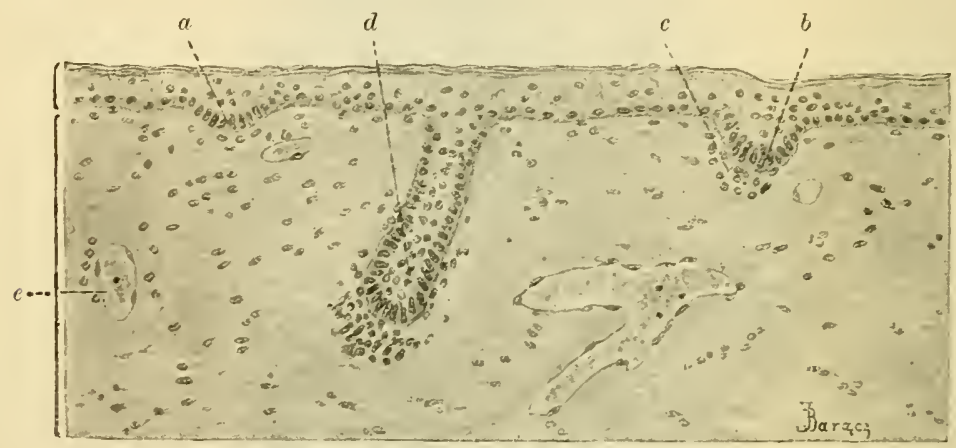

FIG. 293.-HAIR-GERMS IN A SECTION OF THE SCALP OF A HCMAN FETUS.

(Szymonowicz.) Magnified 230 diameters.

$a$, commencing down-growth of epidermis; $b$, further stage of down-growth ; $c$, conncctive-tissue cells beginning to accumulate to produce the dermic coat of the follicle; $d$, hair-follicle more advanced in development; $e$, section of a blood-ressel.

The hair-rudiments begin to appear at the third or fourth month of fotal life; their growth is completed about the fifth or sixth month, and the fine hairs which they form constitute a complete bairy covering termed the lanugo. This is entirely shed within a few months of birth, the new hairs being formed in down-growths from the old hairfollicles in the manner already mentioned.

Hairs grow at the rate of half an inch per month. They are found all over the surface of the body except on the palms of the hands and the soles of the feet, and on the distal phalanges of the fingers and toes. They usually slant, and in the negro the hair-follicles are even considerably curved. On the scalp they are set in groups, as is well seen in a horizontal section.

The hairs of animals are often curiously marked by the arrangement of their medulla, the markings being characteristic of particular species. In some animals, e.g. the nole, the hairs have a raricose form with alternate enlargements and constrictions. In human hair the disappearance of 
the papilla is preceded by its gradual diminution in size, and during this period the root of the hair is becoming grarlually more slenter (Ranvier), so that when such a hair is pulled ont it appears to be of least dianeter near the bulb, insteal of being largest there, as is the case under ordiuary circumstances.

Muscles of the hairs. - A small muscle composed of bundles of plain muscular tissue is attached to each hair-follicle (urector pili); it passes from the superficial part of the corium, on the side to which the hair slopes, obliquely downwards, to be attached near the bottom of the follicle to a projection formed by a localised hypertrophy of the outer root-sheath. When the musele contracts, the hair becomes more erect, and the follicle is dragged upwards so as to cause a prominence on the general surface of the skin, whilst the part of the corium from which the little muscle arises is correspond ingly depressed; the roughened condition known as 'goose skin' being in this way produced. There is always a sebaceous gland in the triangle formed between the arrector pili, the mouth of the hair-follicle, and the epidermis, so that the contraction of the arrector generally causes the secretion of the gland to be extruded.

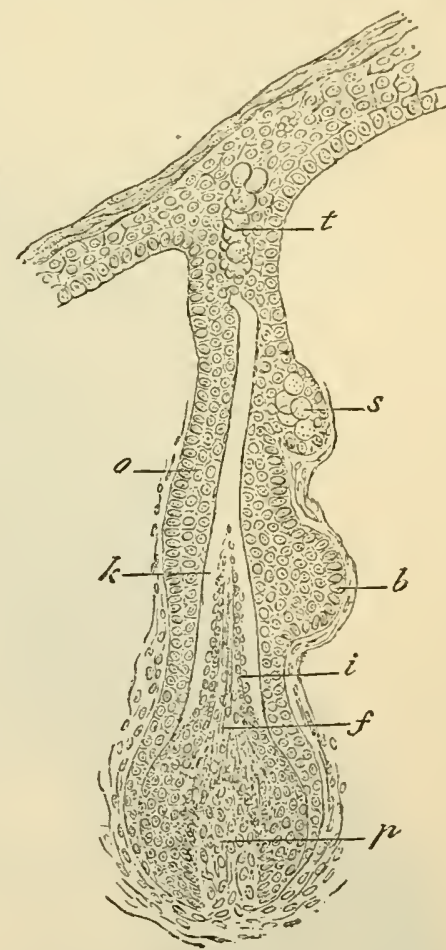

Fig, 294.-DETELOPING HAIR FROM HCMAN EMBRTO OF $4 \frac{1}{2}$ MONTHS. (Ranvier.)

The sebaceous glands (fig. 285) are small saccular glands, the ducts from which open into the mouths of the hair-follicles, but they are also found in a few situations which are devoid of hairs (margin of lips, labia minora, glans, and prepuce). The Meibomian glands of the eyelid may also be regarded as modified sebaceous glands. Both the duct and the saccules are lined by epithelium, which becomes charged with fatty matter. This sebaceous matter is 
discharged into the cavity of the saccule, probably owing to the disintegration of the cells within which it is formed. There may be more than one sebaceous gland attached to each hair-follicle.

The sebaceous glands are developed as outgrowths from the outer root-sheath (figs. 294, 295, s).

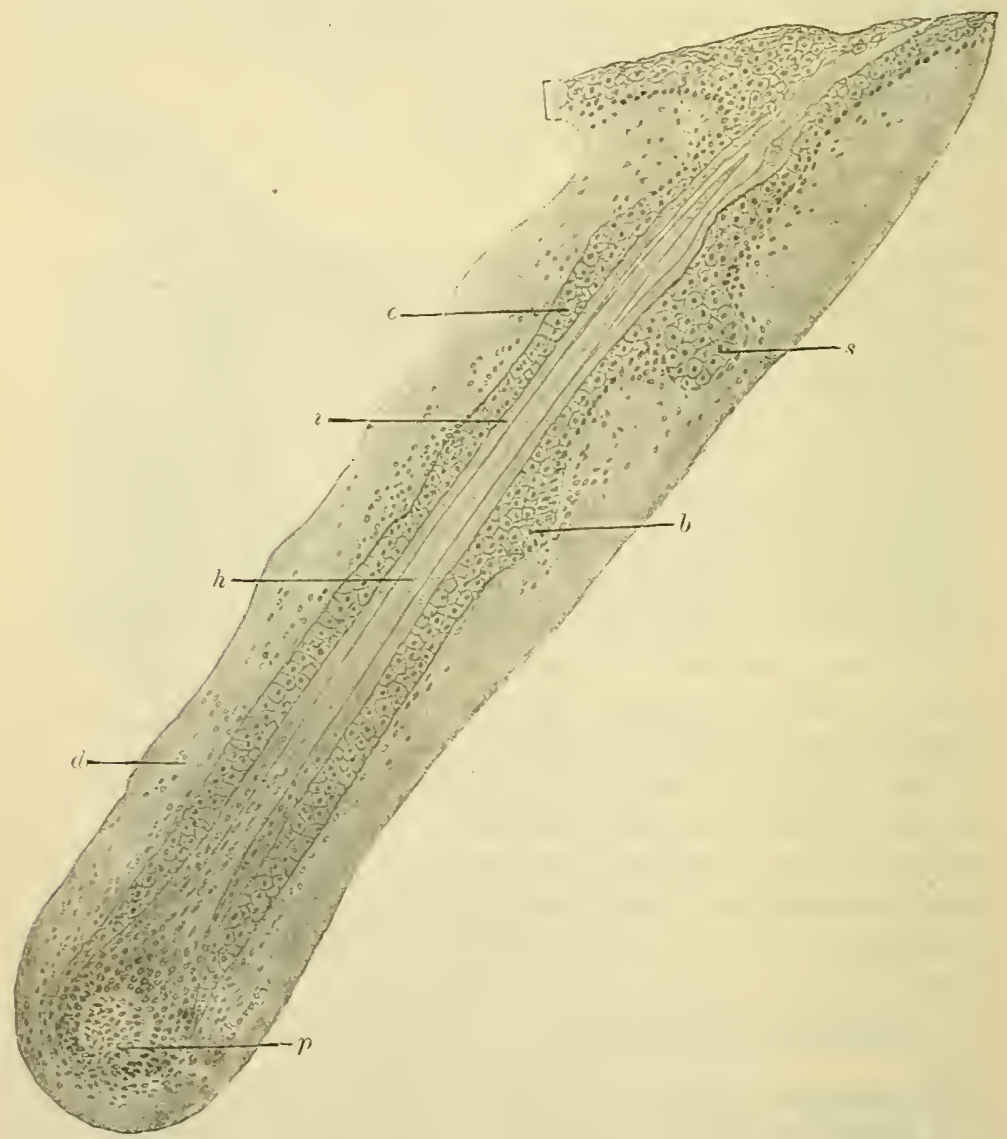

Fig, 295.,-LONGITUDINAL SECTIOX OF A HAIR WITH ITS FOLLICLE FROM A SIX-MOXTHs' HCMAN EMBRYo. (Szymonowicz.) Magnified about 150 diameters.

$\rho$, papilla; $h$, young hair; $i$, inner root-sheath ; $d$, dermic coat of follicle ; $o$, outcr rootsheath; $s$, sebaceous gland rudiment $; b$, projection for insertion of arrector pili.

The sweat-glands are abundant orer the whole skin, but they are most numerous on the palm of the hand and on the sole of the foot. They are composed of coiled tubes, which lie in the deeper part of the integument and send their ducts up through the cutis 
to open on the surface by corkscrew-like chamnels in the epidermis (figs. 276, 281).

The glundular or secreting tule is a convoluted tube composed of a hasement-membrane lined by a single layer of cubical or columnar epithelimm-cells, and with a layer of longitndinally or obliquely clisposed fibres between the epithelium and basement-membrane (fig. 296). 'These fibres are usually regarded as museular, but the evidence on this point is not conclusive. The secreting tube is considerably larger than the efferent tube or duct, which begins within the gland and usually makes several convolutions before leaving the gland to traverse the cutis vera.

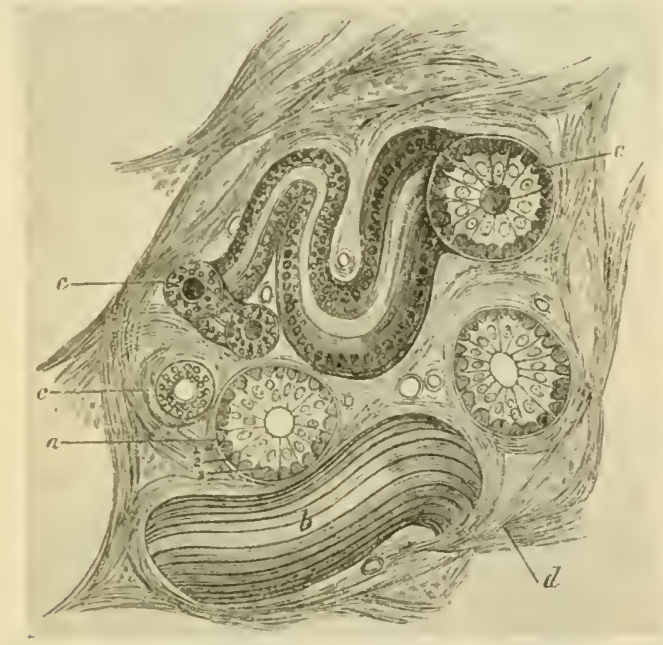

FIG. 296.-SECTION OF A SWEAT-GLAND IX THE SKIN OF MAN.

$a, a$, secreting tube in section; $b$, a coil seen from above; $c$, $c$, efferent tuhe; $d$, intertubular connectire tissue with blood-vessels. 1, basement-membrane;

2 , museular fibres cut across; 3 , secreting epitheliurn of tubule.

The efferent tube bas an epithelium consisting of two or three layers of cells, within which is a well-marked cuticular lining, but there is no muscular layer. The passage through the epidermis has no proper wall, but is merely a channel excavated between the epithelium-cells. Very large sweat-glands oecur in the axilla.

The ceruminous glunds of the ear (fig. 297) are modified sweat-glands. The secretion is of a sebaceons nature, instead of being watery like that of the ordinary sweat-glands.

The sweat-glands are developed, like the hairs, from down-growths of the Malpighian layer of the epidermis into the corium. They are distinguishable from the hair-germs by the fact that the cells of the outermost layer are not columnar in shape, but spheroidal or poly- 
hedral. The sweat-gland germs which are thus formed become eventually coiled up at their extremities and converted into hollow tubes. The muscular fibres of the tubes as well as the secreting epithelium cells are ectodermic structures.

The sweat-glands receive nerve-fibres, and each gland has a special cluster of capillary blood-ressels.

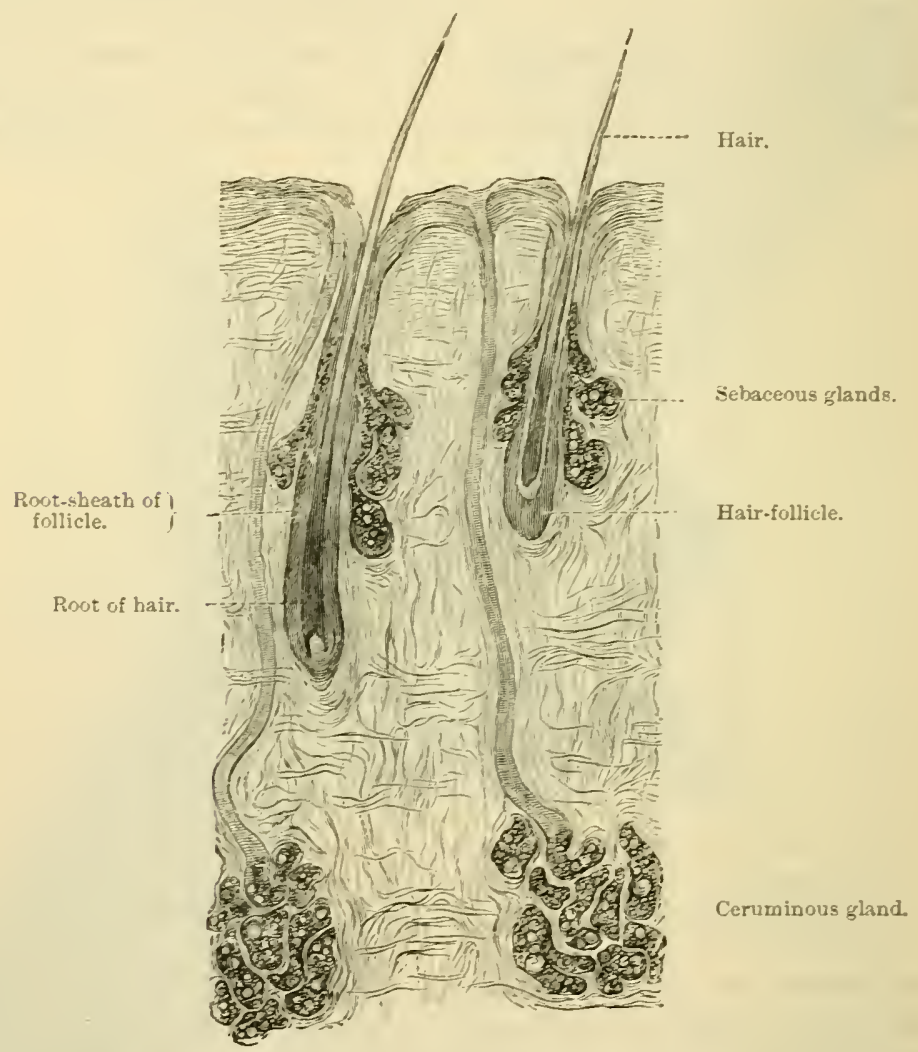

FIG. 297.-SECTION OF SKIS OF ACDITORY MEATLS, INCLCDIXG TWO HAIRFOLLICLES WITH THEIR SEBACEOCS GLANDS ANT TWO CERCMINOLS GLANDS. (Griber.)

\section{The Mambary Glands.}

The mammary glands are compound racemose glands which open by numerous ducts upon the apex of the nipple. The ducts are dilated into small reservoirs just before reaching the nipple. If traced backwards, they are found to commence in groups of saccular alveoli (fig. 298). The walls of the ducts and alveoli are formed of 


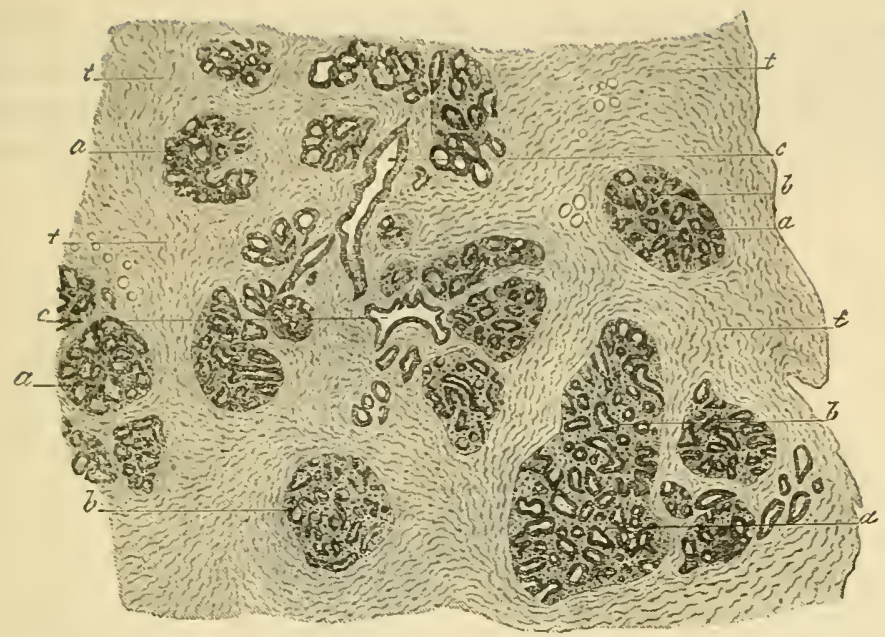

Fig. 298. -SECTION OF MAMMARY GLAND OF WOMAN DCRING LACTATION. (Testut, after de Sinéty.)

$a$, lobule of gland ; $b$, acini lined by cubical epithelium; $c$, duct ; $t$, connectire-tissue stroma.

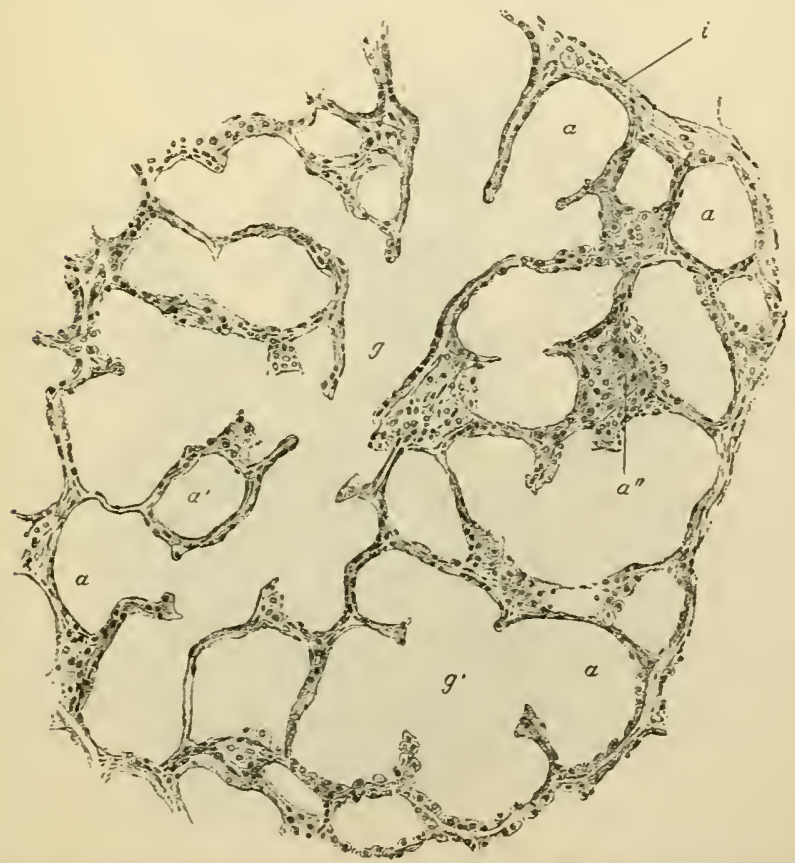

Fig. 299. -SECTION OF MAMMARY GLAND, HEMAN, IN FULL ACTIVITY. (v. Ebner.) $\times 110$.

$a, a^{\prime}, a^{\prime \prime}$, alveoli variously cut, and distended by secretion ; $g, \vartheta^{\prime}$, commencing ducts ; $i$, connective tissue. 
a basement-membrane lined by a simple larer of flattened epithelium (fig. 299). Milk globules may be seen within the alveoli and ducts, and at the commencement of lactation anceboid cells containing fat-particles appear in the secretion (colostrum corpuscles). These are

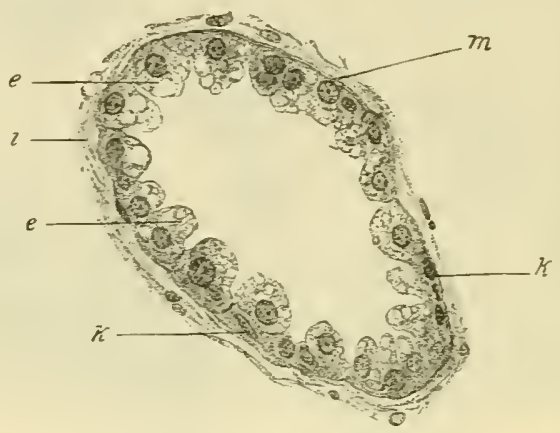

Fig. 300.-Ax alteolts with Fat-Drops ix celts. (v. Ebner.) $\times 360$.

e, cells of alreolus; $k$, cells forming basket-like basement membrane, $m ; i$, connective tissue.

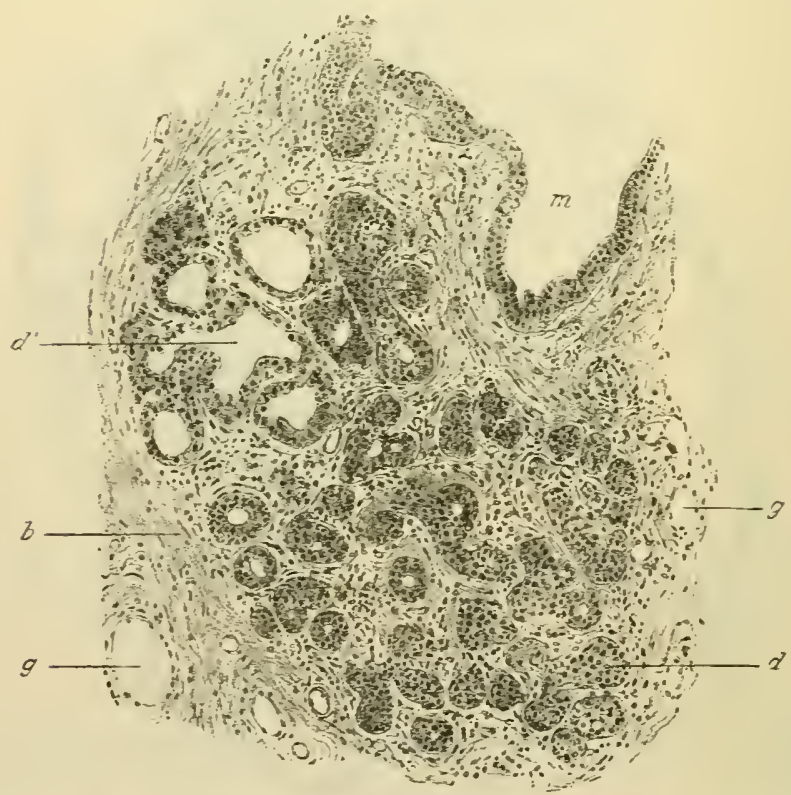

Fig. 301.--SECTIOX FROM THE SAME GLAND As THAT SHOWX IX FIG. 299. (r. Ebner, $\times 110$.

$b$, connective tissue; $d$, undeveloped alreoli; $d^{\prime}$, partially developed alreoli; $g$, bloud-vessels; $m$, portion of larger duct with two-layered epithelium. 
probably emigrated lencocytes similar to the salivary corpuscles of saliva, but some have been looked upon as epithelium-cells or portions of epithelium-cells which bave become detached from the general lining of the alveoli.

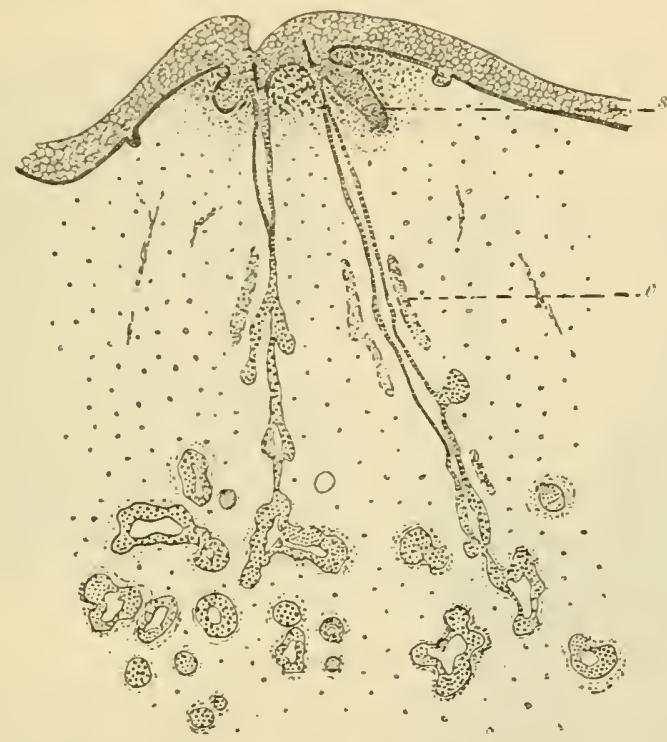

FIG. 302.-SECTION OF DEVELOPING MAMMART GLAND OF HORSE. (C. Hamburger.)

$v$, blood̨-ressels ; s, sebaceous glands.

Development.-The mammary glands are developed in the same manner as the sweat-glands, excepting that the secreting part does not become convoluted and tubular. In the virgin mamma they show very few and small groups of alveoli, but as pregnancy advances the gland ducts bud out extensively, and many more alveoli are formed and undergo enlargement, until the greater part of the connective tissue in the manimary region is permeated by them. In sections of the gland they may be seen in various stages of derelopment (figs. 299, 301). After lactation is over they undergo a process of retrogression. 


\section{LESSON XXVI.}

\section{STRUCTURE OF THE HEART.}

1. Is sections through the wall of the auricle note the relative thickness of the epicardium, myocardium, and endocardimm. Observe the blood-vessels and nerve-fibres under the epicardium, often embedded in fat; here and there a ganglion may be seen under this membrane. Notice also the elastic networks under both the pericardium and endocardium. Make a general sketch from this section.

2. In sections through the wall of the ventricle the same points are to be noticed. The muscular fibres are variously cut. In those which are cut longitudinally, the branching of the fibres and their union both laterally and by their branches may be seen. Notice also that although the fibres are cross-striated this is less distinct than in voluntary muscle, and that the nuclei lie near the centre of each fibre. Transverse markings may also be seen frassing across the fibres between the nuclei; this is usually taken as inclicating a division into cells. The endocardium is very thin, especially over the colummæ carner.

3. Section through one of the valves of the heart. ${ }^{1}$

4. If a portion of endocardium of the sheep's heart is sprear ont on a slide and examined in salt solution, a network of large beaded fibres may be seen with a low power or even with a lens; they are also well seen in sections. These are the fibres of Purkinje ; they are formed of large, square-looking cells, usually containing two nuclei, and having striated muscular substance at their periphery. The fibres of Purkinje maty also be seen in sections.

5. The lymphatics of the heart may be injected with Berlin blue by sticking the nozzle of the injecting syringe into the muscular substance, in the interstices of which the lymphatics arise. These commencing lymphatics lear to efferent vessels which pass under the epicardium towarls the base of the heart.

6. The epithelium which covers the epicardium, and that which lines the endocardium, may be studied in preparations of the fresh organ which have been well rinsed with distilled water; then treated with nitrate of silver, again rinsed, and subsequently exposed to the light and hardened in alcohol. Surface sections are to be made and mounted in xylol balsam or dammar.

The muscular tissue of the heart (myocardium) forms the main thickness of the ventricles and also of parts of the auricles. It is composed of a network of fibres which are formed of uninucleated transversely striated cells, the structure of which has already been studied (Lesson XVII. p. 124).

1 The appearances which are to be studied in sections 1,2 , and 3 can all be obtained in one preparation, viz. a vertical section including a portion of auricle and ventricle and a flap of the intervening auriculo-ventricular valve. 
In the interstices of the muscular bundles there is a little areolar tissne in which run the rery numerous blood-capillities and the lacunar lymphatics.
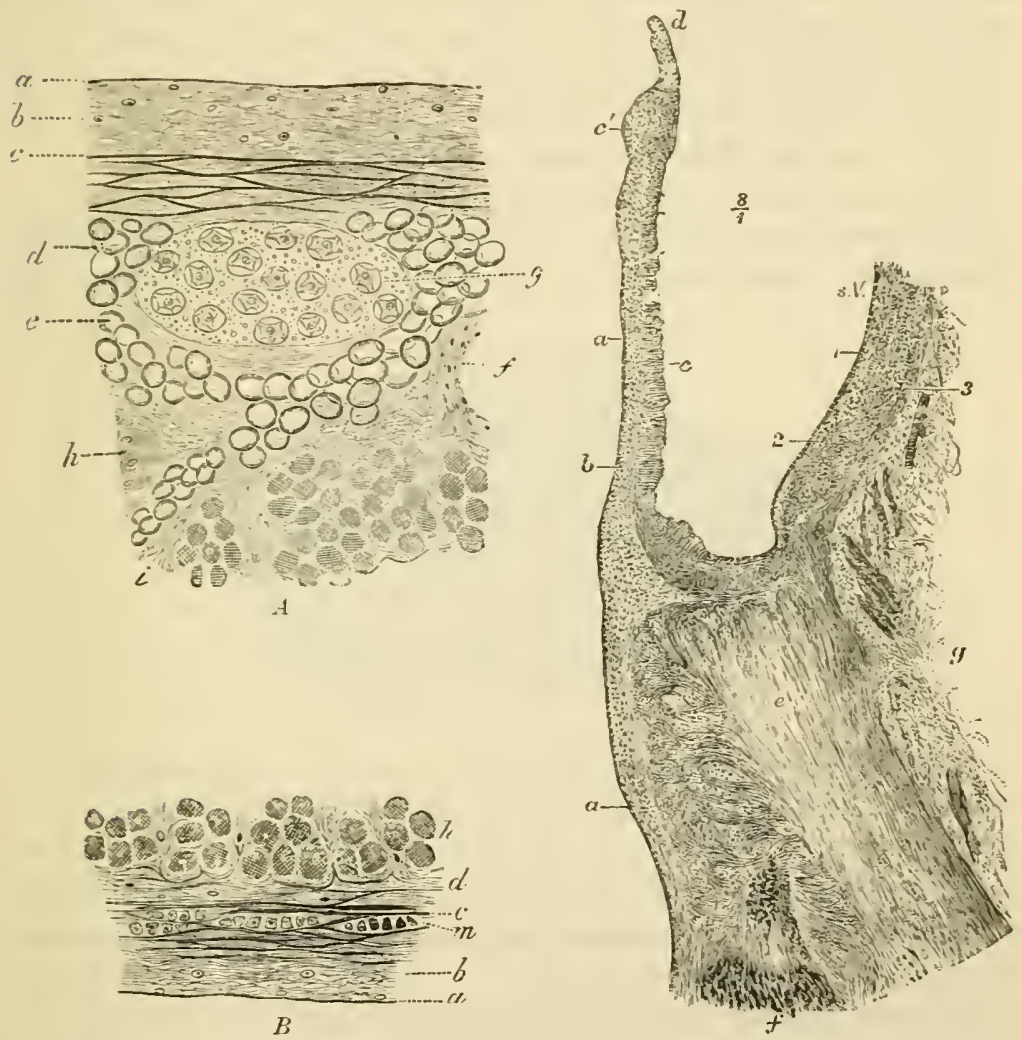

FIG. 303 A, B.

FIG. 303 c.

Fig. 303 A, B. -SECTION OF THE RIGHT AURICLE.

A, Epicardium and adjacent part of the myocardium. $u$, serous epithelium in section; $b$, connectire-tissue layer; $c$, elastic network; $d$, subserous areolar tissue ; $e$, fat; $f$, section of a blood-ressel; $g$, a small ganglion; $h$, muscular fibres of the myocardium ; $i$, intermuscular areolar tissue.

$B$, Endocardium and adjacent layer of the myocardium, $a$, lining epithelium; $b$, connectire tissue with fine elastic fibres; $c$, laser with coarser elastic fibrcs; $d$, sub. endocardial connective tissue continuous with the intermuscular tissuc of the myocardium; $h$, muscular fibres of the myocardiun ; $m$. plain rauseular tissue in the endocardium.

Fig. 303 C. -SECTIOS THROCGH ONE OF THE FLAPS OF THE AORTIC VALNE, AND PART OF THE CORRESPONDIYG SINUS OF VALSALVA, WITH THE ADJOINING PART OF THF VESTRICULAR WALL. (Horsley.)

$a$, endocardium, prolonged over the valve; $b$, sub-cndocardial tissue; $c$, fibrous tissue of the valre, thickened at $c^{\prime}$ near the free edge; $d$, section of the lunula; $c$, section of the fibrous ring; $f$, muscular fibres of the rentricle attached to it; $q$, loose areolar tissue at the base of the ventricle; $s . \mathrm{J}$. sinus of Valsalva; $1,2,3$, iuuer, middle, and outer coats of the aorta. 
The myocardium is covered externally by a laver of serous membrane-the epicurdium (cardiac pericardium fig. 303, $A$ )-composed, like other serous membranes, of connective tissue and elastic fibres, the latter being most numerous in its deeper parts. Underneath the epicardium run the blood-ressels, nerres, and lymphatic vessels of the heart embedded in areolar and adipose tissue, this tissue being continuous with that which lies between the muscular bundles; the free surface of the membrane is covered by serous epithelium.

The endocardium (fig. $303, B$ ) has a structure not very unlike the pericardium. It is lined by a parement-epithelium (endothelium), like that of a serous membrane, and consists of connective tissue with

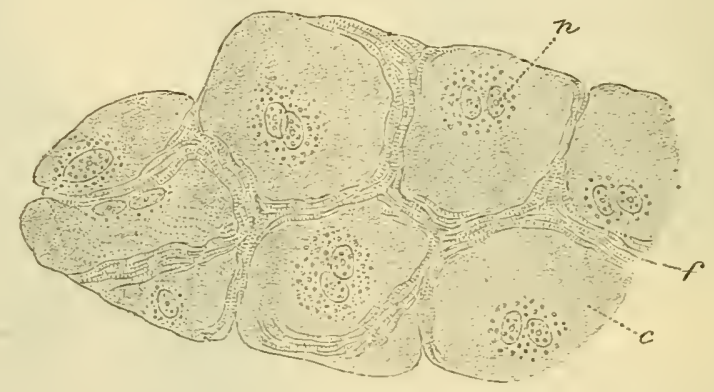

Fig. 304.-FragueNt OF THE Network OF PLRKINJE's FIBREs FROM THE VEATRICULAR ExDOCARDICM OF THE SHEEP. (Ranvier.) $c$, clear cell body; $n$, nuclei; $f$, striated fibrils.

elastic fibres in its deeper part, between which there may, in some parts, be found a few plain muscular fibres. Fat is sometimes met with under the endocardium.

In some animals, e.g. the sheep and ox, large beaded fibres are found under the endocardium. These are formed of clear cells joined both end to end and laterally, and generally containing in their centre two nuclei, whilst the peripheral part of the cell is formed of crossstriated muscular tissue; the chains of cells form the fibres of Purkinje (fig. 304). They appear to be cardiac cells which have undergone differentiation into striated muscle substance only at their periphery, the non-differentiated part of the cell haring continued to grow until it has attained a considerable size. In man distinct fibres of Purkinje are not seen, but the innermost muscular fibres of the ventricles are larger than those which lie more externally: they also undergo development somewhat later (J. B. MacCallum).

A nuscular bundle which shows less differentiation than the rest of the cardiac muscle has been described by Stanler Kent, His and others, running 
in the septum and atfording a bridging connexion between the muscle of the amricles and that of the rentricles. This bundle is commonly believed to serve to propagate the contractions of the auricles to the ventricles and thus to maintain their regularity of rlythm; and it is stated that when the bundle in question is severed experimentally or by disease this propagation is no longer possible, anm the rentricles in consequence beat with a nuch slower rhythu than the auricles. The accuracy of this statement is, however, denied by Kronecker, who regards the regularity of the cardiac contractions as a function, not of the nuscular substance of the heart, but of the nerrefibres, which are distributed to every part of the myocardium.

The valves of the heart are formed of folds of endocardium strengthened by fibrous tissue (fig. 303, C). This tissue forms a thickening near the free edge of the valve $\left(c^{\prime}\right)$. At the base of the auriculoventricular valves the muscular tissue of the auricle may be found passing a short distance into the valve. In the foetus thesc valves are at first entirely muscular.

The nerves of the heart are seen in sections underneath the epicardium of both auricles and ventricles; in the former situation they are connected at intervals with small ganglia (fig. 303, A, g). Their branches pass to the muscular substance, and after dividing into fine fibrils, these end in enlarged extremities, which are applied directly to the muscular tibres (Ranvier). Other nerve-fibres, which are probably afferent, terminate in complex ramifications in the endocardium in connection with small masses of nucleated cclls, forming a kind of endplate (Smirnow).

The blood-vessels of the heart are very numerous, and the veins thinwalled, retaining the capillary structure (endothelium only) in vessels of as much as $0.25 \mathrm{~mm}$. in diameter. They are accompanicd by numerous lymphatic vessels, which also form plexuses under the cardiac pericardium and endocardium. The lymphatics appear to be in free communication with the spaces of the interstitial connective tissue between the muscle-fibres. 


\section{LESSON XXVII.}

\section{THE TRACHEA AND LUNGS.}

1. In sections of the trachea and larynx, notice the epithelium, the basementmembrane (of some thickness in the human trachea), the lymploid tissue of the mucous membrane, the elastic tissue external to this, and, lastly, the fibrous membrane containing the cartilages. In the mucous membrane and submucous areolar tissue look for sections of mucous glauds, ducts of which may be seen opening on the surface. At the back of the trachea notice the plain muscular fibres transversely arranged; there may be larger mucous glands external to these.

2. In sections of lung notice the sections of the alveoli collected into groups (air-sacs). Find sections of bronchial tubes, some cut longitudinally and passing at their extremities into the alveolar passages, others cut across. In each tube notice the ciliated epithelium internally. Next to this the mucous membrane containing numerous elastic fibres and often thrown into folds; then the layer of circular mnscular fibres, and, outside this, loose filurous tissue in which in larger bronchial tubes pieces of cartilage may be seen embedded. Small mucous glands may also be observed in the fibrous tissue sending their ducts through the other layers to open on the inner surface. Notice that the section of a branch of the pulmonary artery always accompanies a section of a bronchial tube.

In the sections of the alveoli observe the capillary vessels passing from one side to the other of the intervening septa; and in places where the thin wall of an alveolus is to be seen in the section, the network of blood-capillaries upon it. Notice within the alveoli nucleated corpuscles which frequently contain dark particles in their protoplasm. They are amoboid cells which have migrated from the blood-ressels and lymphatics, and liave taken in inhaled particles of carbon. They may pass back into the lung tissue, for similar cells are seen in this. Make a sketch of part of the wall of one or more bronchial tubes and of one or two of the alveoli.

3. In sections of a fresh lung the air-cells of which have been filled with a mixture of gelatine and nitrate of silver solution, the epithelium of the alveoli may be studied. The sectious can be made with the freezing microtome, and mounted in glycerine, which should be warmed after the cover-glass is applied in order to melt the gelatine.

4. Mount a section of lung in which the pulmonary vessels hare been injected. Study the general arrangement of the vessels with a low power, and the network of capillaries of the alveoli with a high power. Olserve that the veins rum apart from the arteries. Sketch the capillary network of one or two adjoining alveoli.

\section{The Trachea.}

The trachea or windpjpe is a fibrous and muscular tube, the wall of which is rendered somewhat rigid by $\mathrm{C}$-shaped hoops of cartilage 
which are embedded in the fibrous tissue. The museular tissue, which is of the plain variety, forms a flat band, the fibres of which run transversely at the back of the tube. The trachea is lined by a mucous membrane (fig. 305, $a$ to $d$ ), which has ciliated epithelinm upon its inner surface. The epithelium-cells, which have been already described (Lesson VIII.), rest upon a thick basement-membrane. The corium of

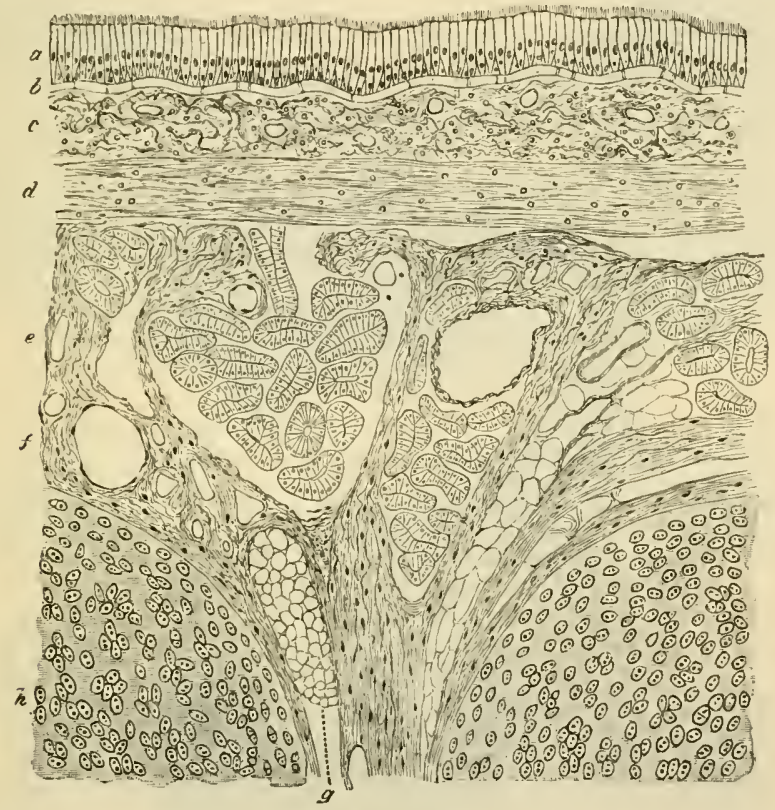

Fig. 305.-LONGITUDINAL SECTION OF THE HUMAN TRACHEA, INCLUDING PORTIONS OF Two Cartilaginous rings. (Klein.) Moderately magnified.

$a$, ciliated epithelium; $b$, basement-membrane; $c$, superficial part of the mucous membrane, eontaining the seetions of numerous capillary blood-vessels and mueh lymphoid tissue; d, deeper part of the mucous membrane, eonsisting majnly of elastie fibres; $e$, submucous areolar tissue, containing the larger blood-vessels, small mucous glands (their ducts and alveoli are seen in section), fat, etc. ; $f$, fibrous tissue investing and uniting the eartilages; $g$, a small mass of adipose tissue in the fibrous layer; $h$, cartilage.

the mucous membrane consists of areolar and lymphoid tissue, and contains numerous blood-vessels and lymphatics. In its deepest part is a well-marked layer of longitudinal elastic fibres $(d)$. Many small glands-mucous and mixed mucous and serous-are found in the wall of the trachea. They may lie either within the mucous membrane or in the submucous areolar tissue (e) or, lastly, at the back of the trachea, ontside the transverse muscular fibres.

The two divisions of the trachea, the bronchi, are precisely similar in structure to the main tube. 
The larynx is also very like the trachea so far as the structure of the mucous membrane is concerned. It is lined by ciliated epithelium, but over the true rocal cords and upon the epiglottis, as well as here and there in the part above the glottis, stratified epithelium is found; and taste-buds may occur in this epithelium, except over the rocal cords. The nerveendings in the epithelium are shown in fig. 218 , p. 176.

The lrmphoid tissue is especially abundant in the mucous membrane of the rentricle of Morgagni (fig. $306, d$ ), and a large number of mucous glands open into this cavity and into that of the sacculus.

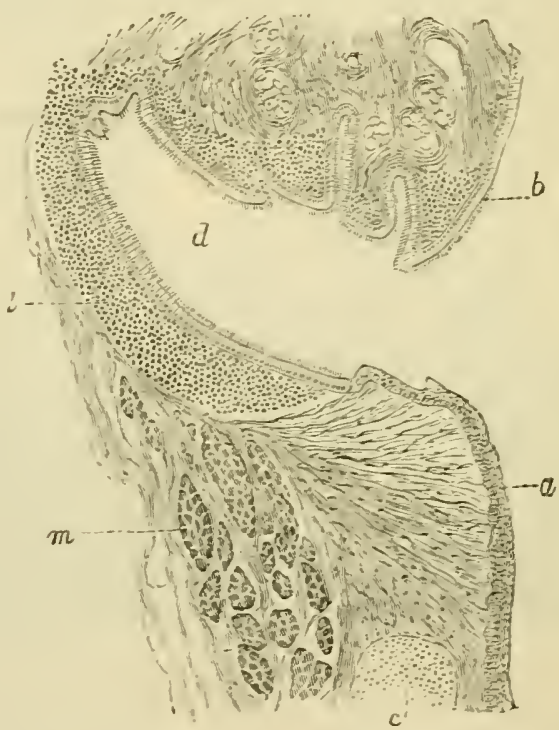

FIG. 30f.-LOSGITCDISAL SECTIOS THROCGH THE VENTRICLE OF THE LARISX oF A CHILD. (Klein.)

$a$, true rocal cord: $b$, ialse racal cord ; $c$, nodule of cartilage; $d$, rentricle of Morgagni ; $i$, lyraphoid tissue; $w$, thyro-arstenuid muscle.

The true rocal cords are composed of fine elastic fibres.

The cartilages of the trachea and the thyroid, cricoid and arytenoid cartilages of the larynx are hyaline; all these are liable to ossify as age adrances. The epiglottis and the cartilages of Santorini and of Irisberg are composed of elastic fibro-cartilage. This is also the case with the uppermost part of the arytenoid and the tip of the rocal process.

\section{The Lexgs.}

The lungs are formed by the ramifications of the bronchial tutes and their terminal expansions, which form groups or lobules of sacculated 
dilatations (uir-sucs, infumdilulu), beset everywhere with small irregularly hemispherical or eubieal bulgings, known as the air-cells or pulmonary alceoli.

The bronchial tubes (figs. 307, 308, 309) are lined (except the

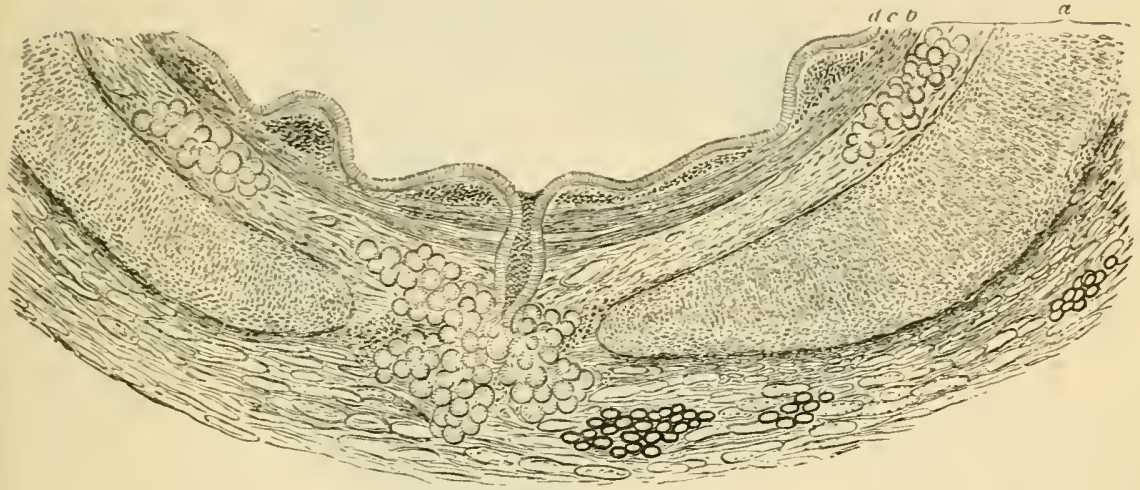

FIG. 307.-PORTIOX of A TRAXSVERSE SECTIOX OF A BRONCHIAL TCBE, HCMAX, 6 My. IS DIAyeter. (F. E. Sichultze.) Mlagnified 30 diameters.

$a$, cartilage and fibrous layer with mucous glands, and, in the outer part, a little fat; in the middle, the duct of a gland opens on the inner surface of the tube; $l$, annular lajer of involuntary muscular fibres; $c$, elastic lajer, the elastic fibres in bundles which are seen cut across; $d$, columnar ciliated epithelium.

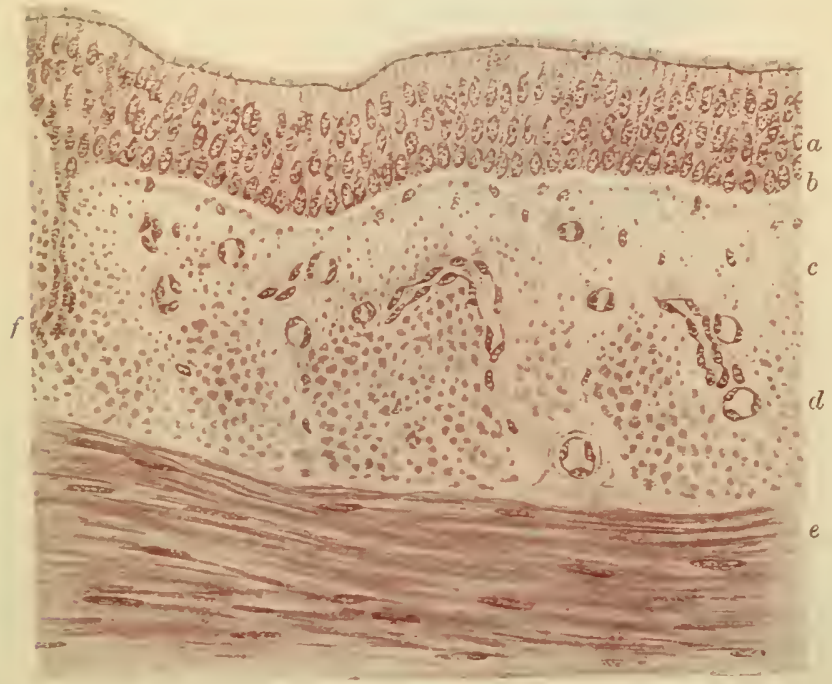

Fig. 308.-Sectiox of PARt of a BRoxchial tCBE. Magnified 200 diameters.

$a$, ciliated epithelium; $b$, basement membrane ; $c$, superficial part of mucous membrane, with fine clastic fibres; $d$, deeper part with numerous coarser fibres ; $e$, plain muscle of bronchus; $f$, duct of gland passing through mucous membrane. 
terminal bronchi) by ciliated epithelium which rests on a basementmembrane. External to this is the corium of the mucous membrane, containing a large number of longitudinal elastic fibres and some

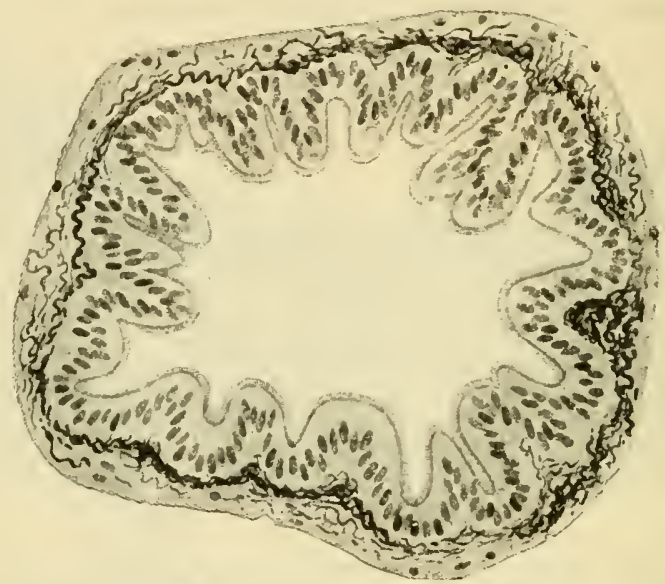

Fig. 309.-Sectiox of a siall broschial tebe, humax. (Sobotta.) $\times \mathbf{2 8 0}$.

The elastic fibres of the mucous membrane are stained.

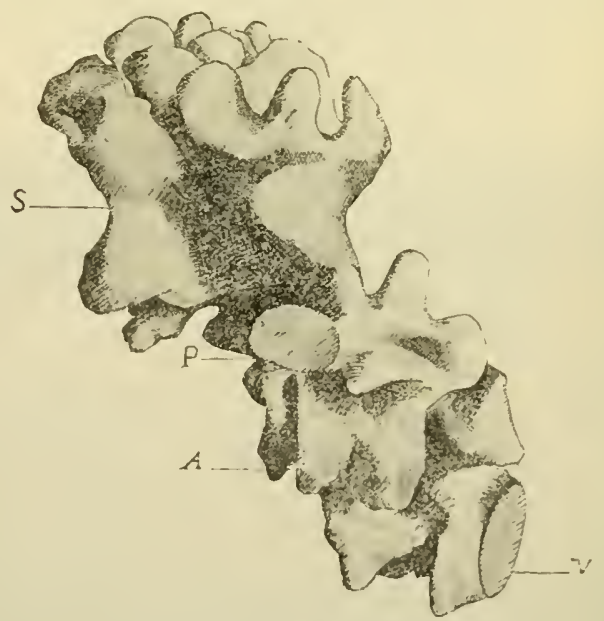

Fig. 310.-CAST OF LOBULE OF DOG'S LUNG SHOWING A SINGLE INFUNDIBCLU I OR AIR-SAC. (W. S. Miller).

$A$, atrium; $r$, vestibule or alveolar duct lcading to atrium (seen in section); $S$, air-sac (infundibulum); $P$, section of the neck of a second air-sac (cut away). The irregular projections on the atrium and air-sac are the alvenli.

lymphoid tissue. Ontside this again is a complete layer of plain muscular fibres encircling the tube. Next comes a loose fibrous layer in which, in the larger tubes (fig. 307), small plates of cartilage are embedded. Mucous glands are also present in this tissue. 
The extremities of the bronehial tubes expand into passages, the respiratory bronchioles, which give off branches, termed alceolur ducts or terminal Ironchioles. The walls of these are beset with alveoli. The terminal bronchioles lead through nearly spherical alveolated dilatations (the atria) into a number of blind and often funnel-shaped

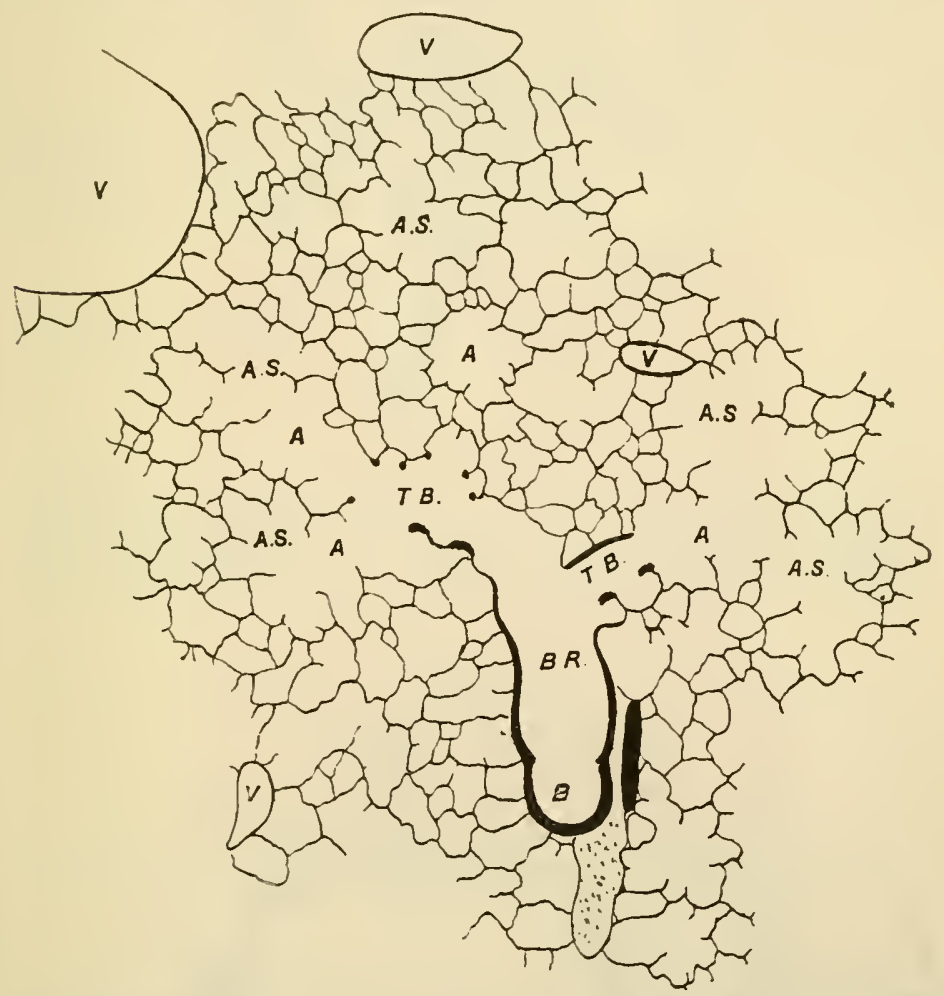

Fig. 311.-SECTION OF CAT'S LENG, OUTLINED With CAMERA LUCIDA.

(W. S. Miller.)

The shading indicates the position of plain muscular tissue. $V$, pulmonary veins; A, atria ; A.S, air-sacs; T. B, terminal bronchioles or alveolar ducts; B. R, respira. tory bronchioles; $\mathrm{B}$, small bronchus.

diverticula completely eovered with alveoli; these are known as the infunditula, alceolar sacs or air-sacs (Waters). The arrangement of these parts, according to the investigations of $\mathrm{T}$. S. Miller, is as follows:-Two or more air-sncs, or groups of alveoli, open into a common chamber (atrium), and three to six atria into an alveolar duct or terminal bronchiole. The latter open into the respiratory bronchioles, whieh are expanded eontinuations of the smallest bronebi. All of these, except the last named, are beset with alveoli.

The epithelium changes in eharacter in the alveolar ducts; from 


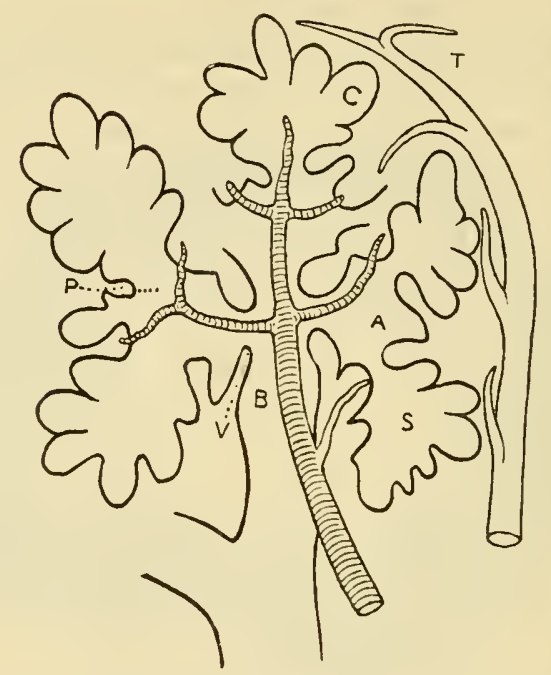

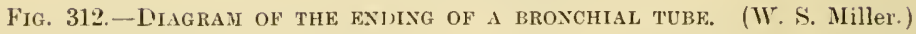

$\mathrm{B}$, terminal bronchiole; $\mathrm{V}$, restibulc; $\mathrm{A}$, atrium ; $\mathrm{s}$, air-sac (infundibulum); $\mathrm{C}$, air-cell (alvcolus); $\mathrm{P}$, ending of pulmonary arteriole; $\mathrm{T}$, commencement of pulmonary venule.

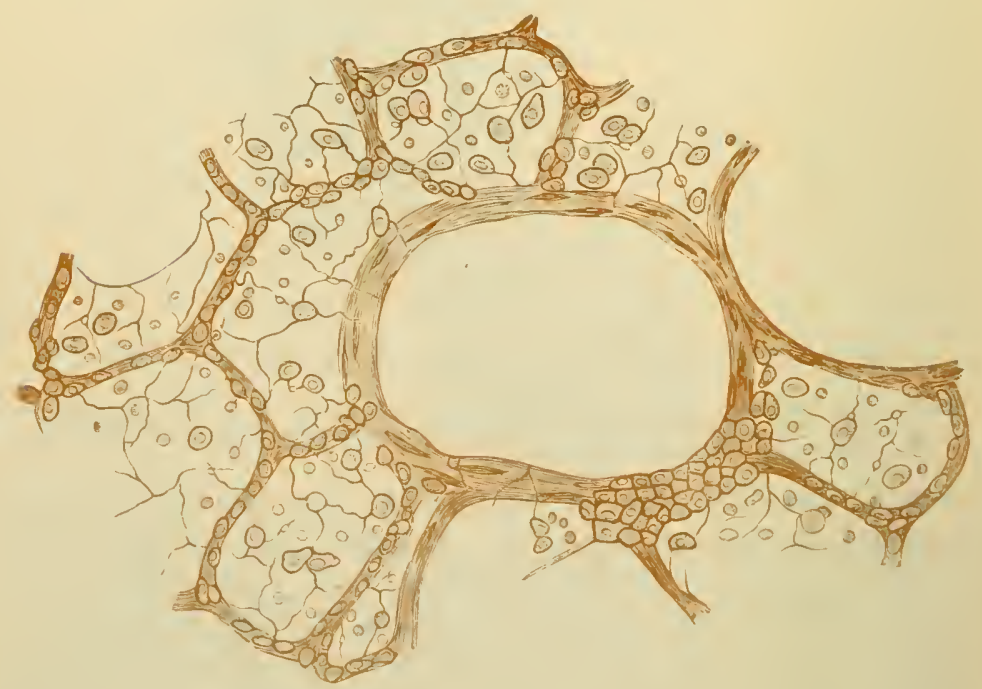

Fig. 313. - SECtion OF PART OF CAT'S LUNG, STAINED With Nitrate OF SILver. (Klein.) Highly magnitied.

Both the cubical and the large flattened cells of the alveoli are shown. In the middle is a section of a lobular bronchial tube, with a patch of cubical epithelium cells at one side. 
columuar and ciliated it hecomes cubical and non-ciliated, and there are patches of the respiratory epithelium (see below) not only in the alveoli which beset the ducts, but also elsewhere in their wall. The plain muscular tissue of the bronchiole is continued on the walls of the alveolar ducts, but not on those of the atria, although some occurs round the mouths of the atria and even of the alveoli.

The alveoli are lined by large irregular flattened cells (fig. 313), which form an extremely delicate layer (respiratory epithelium), separating the blood-capillaries from the air within the alveoli. Amongst the flattened cells are here and there groups of smaller and thicker (cubical) epithelium-cells. The capillary network of the alveoli

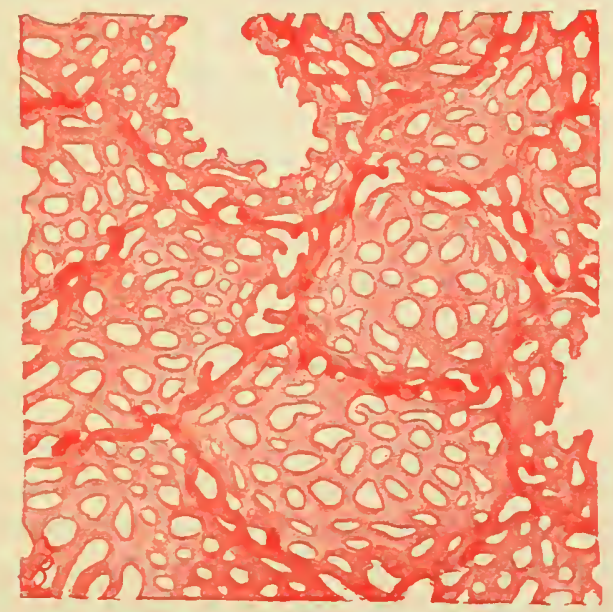

Fig. 314.-SECTION OF INJECTED LExg OF RABBIT. INCLLDING SEVERAL CONTIGCOCS ALTEOLI. (\$zymonowicz.) Magnified 300 diameters.

is very close (fig. 314 ), and the capillary ressels of adjoining alveoli are in complete continuity, the ressels passing first to one side and then to the other of the septa which separate the adjacent alveoli. Outside the epithelium a thin layer of connective tissue (basement membrane?) forms the wall of each alveolus. Elastic fibres are numerous around the mouths of the alveoli, and a certain number course over the wall of each alveolus.

Blood-vessels.-Branches of the pulmonary artery accompany the bronchial tubes to be distributed to the capillary networks upon the alveoli, from which the blood is returned by the pulmonary veins. An arteriole runs with each terminal bronchiole, and, dividing into as many branches as there are atria, is distributed to the capillary networks of all the air-cells with which the bronchiole is connected 
(Miller). From these networks one or two venules collect the blood, usually coursing (independently of the arteriole) on the outer border of the group of infundibula, and unite with other venules to form efferent veins. The venules of the superficial lobules are connected with a vascular network at the surface of the lung underneath the pleura. The veins, pursuing a separate course through the tissue of the lung, join with others to form larger vessels which pass to the root of the lung. Branches from the bronchial arteries are distributed to the walls of the bronchial tubes, and to the connective tissue of the lung. Bronchial veins accompany the bronchial arteries to the larger tubes, but most of the blood brought to the lungs by the bronchial arteries is returned by the pulmonary reins. Connective tissue intervenes everywhere in small quantity between the infundibula (interstitial tissue), and forms a distinct layer, containing much elastic tissue, covering the surface of the lung underneath the serous membrane (subserous tissue). In some animals (e.g. guinea-pig) the subserous layer contains plain muscular tissue, which is especially developed near the lung-apex; it has not been detected in man.

The lymphatics of the lung accompany the bronchial tubes, the branches of the pulmonary artery, and the branches of the pulmonary vein; and they also form a network in the pleura. The atria and air-sacs have no lymphatics in their walls (Miller). The bronchial lymphatics are less superficial than the corresponding blond-vessels. The larger tubes have two plexuses, one within the other outside the cartilages. The smaller have only one set. The lymphatics of the bronchi are connected with those of the arteries and veins by lateral branches curving off at the divarications of the tubes; at these points there is usually an accumulation of lymphoid tissue. The larger arteries and veins have two accompanying lymphatics, the smaller only one. All the lymphatics tend towards the hilus, and enter lymphatic glands at the root of the lung. Those in the pleura have been said to communicate, by means of stomata between the epithelial cells of the serous membrane, with the cavity of the pleura, but this connexion is denied by Miller. The lymphatics of the pleura are furnished with numerous valves.

The pleura, which covers the surface of the lung, has the usual structure of a serous membrane. It is provided with a special network of blood-vessels, which is supplied from the pulmonary vessels of the superficial lobules. 


\section{LESSON XYVIII.}

\section{STRUCTURE AYD DEVELOPMENT OF THE TEETH.}

1. STUDY first with the low power and afterwards with the high power a longitudinal section of a hmman tooth which has been prepared by grinding. It is better to purchase this specimen, for the process of preparation is difficult and terlious without the aid of special apparatus. Examine carefully the enamel, the dentine, and the cement. The dark appearance of the dentinal tubules is due to their containing air in the dried specimen. Measure the diameter of the enamel prisms and of some of the dentinal tubules. Make sketches from each of the tissues.

2. Section of a tooth in situ, which has been decalcified after fixation, and stained. In this section the mode of implantation of a tooth, as well as the structure of the pulp, can be made out. Make a general sketch under a low power, and under a high power draw a small piece of the pnlp showing the processes of the odontoblasts extending into the dentinal tubules.

3. The development of the teeth and the formation of their tissnes are studied in sections made across the snont and lower jaw of foetal and roung animals. The preparations may be stained in bulk or the indiridual sections may be stained.

\section{The Teeth.}

A tooth consists in man of three calcified tissues; the enumel, which is of epithelial origin, the dentine, and the cement or crusta petrosa. The dentine forms the main substance of a tooth, the enamel covers the crown, and the cement is a layer of bone which invests the root (figs. 315 to 317 ).

Enamel is formed of elongated hexagonal prisms (figs. 31s, 319), which are set vertically, or with a slight curvature, upon the surface of the dentine. They are marked at tolerably regular intervals with slight transverse shadings producing an indistinct cross-striated appearance. Sometimes coloured lines run through the enamel across the direction of its prisms. The enamel prisms have when first laid down a fibrous structure, but this becomes obscured after their calcification is complete. C. Tomes has shown that the enamel of the fully-formed tooth contains only an extremely minute proportion of animal matter : practically it is wholly composed of earthy matter (lime salts).

Dentine is constituted of a hard dense substance like bone, but containing no Haversian canals or lacunæ. It is pierced everywhere by fine canaliculi (dentinal tubules, fig. 320), radiating outwards from a 
central cavity which, during life, contains the pulp. The tubules branch at acute angles as they pass outwards ; their branches become gradually finer towards the periphery of the dentine. The dentinal tubules are occupied by processes of the odontoblasts (p. 268).

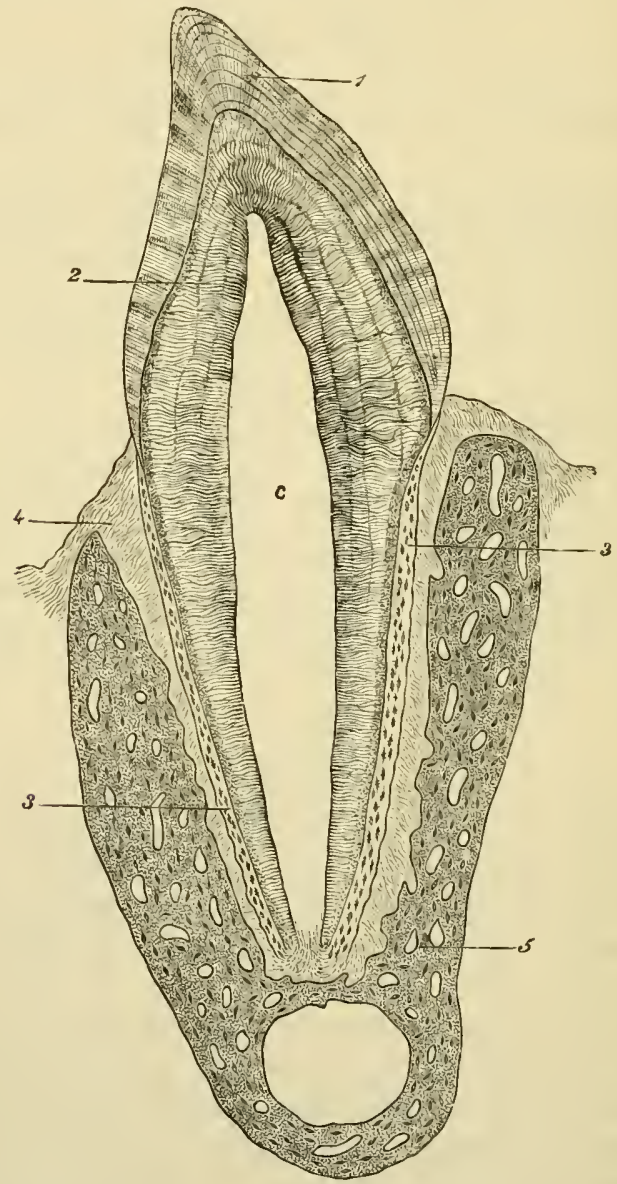

FIG. 315.-VERTICAL SECTION OH A TOOTH IN SITU. (WaIdeyer.)

$c$, is placed in the pulp-cavity, opposite the cervix or neck of the tooth; the part above is the crown, that below is the root (fang). 1, enamcl with radial and concentric markings; \&, dentine with tubules and incremental lines; 3, cement or crusta petrosa, with bone corpuseles; 4 , dental periosteum; 5 , bonc of lower jaw.

The tubules have a proper wall of their own, which can be isolated by steeping a section of tooth in strong hydrochloric acid. In the living tooth they are occupied by protoplasmic fibres (Tomes' fibres), which are prolonged from the superficial cells of the pulp.

The intertubular substance appears for the most part homogeneous, 
but here and there indications can be seen in it of a globular formation. This is especially the case near the surface of the dentine, where the globular deposit and the interglobular spaces may prorluce

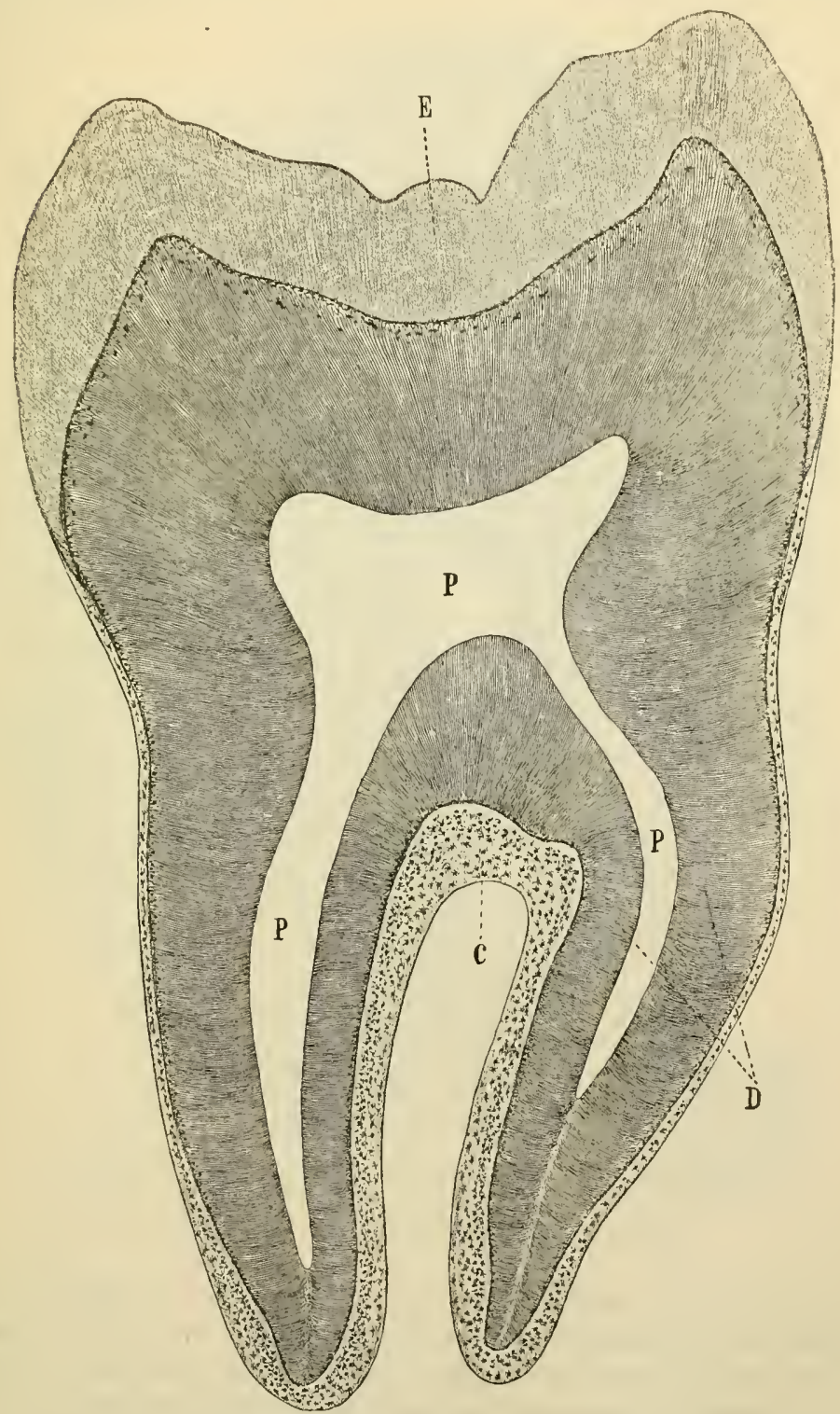

Fig. 316.-Section of Molar tooth. (Sobotta.) $\times 8$.

E, enamel ; D, dentine; C, cement; P, pulp cavity. 
a granular appearance (granular layer, fig. $317, \mathrm{G}$ ), and also in the course of certain lines or clefts which are seen traversing the dentine across the direction of the tubules (interglobular spaces, incremental lines,

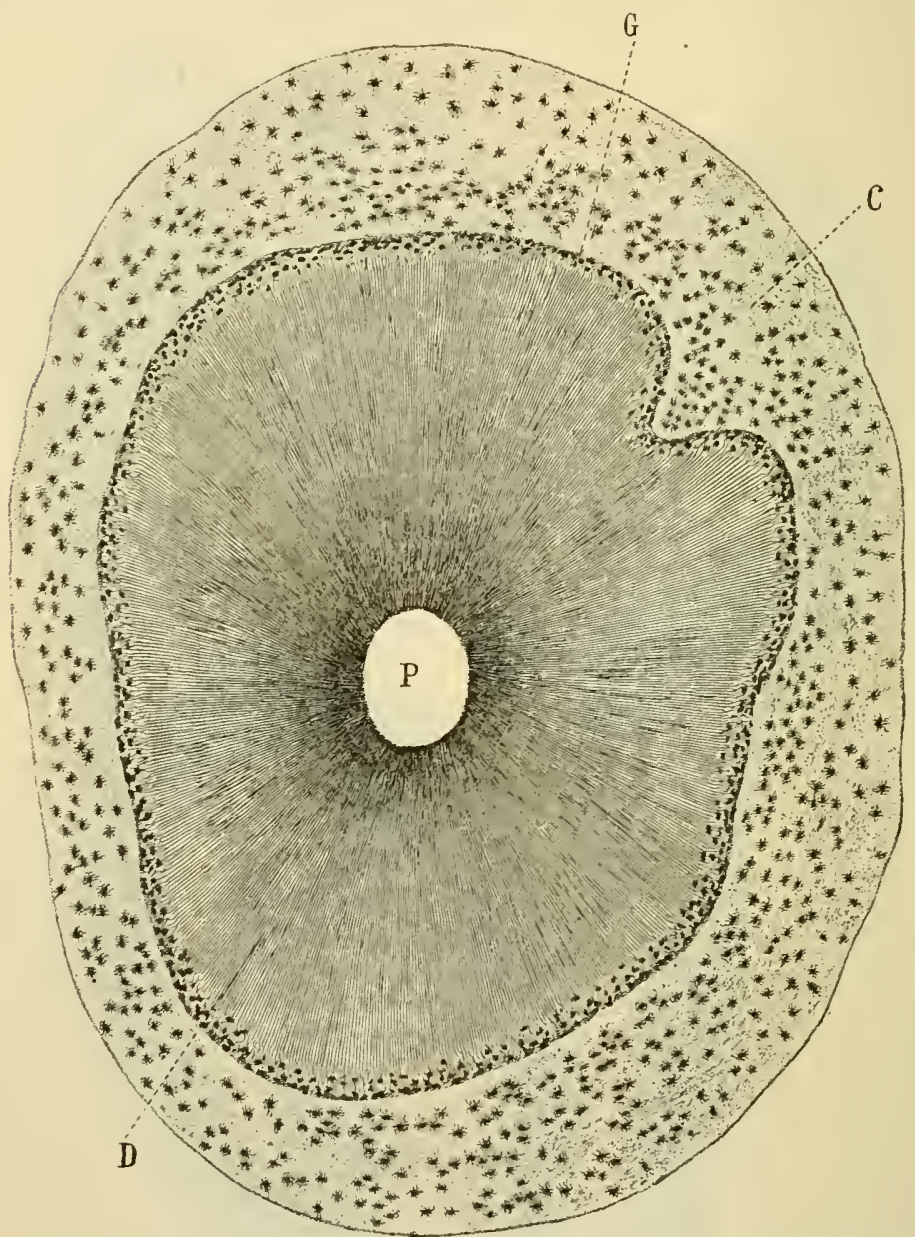

Fig. 317.-Cross-section of RoOT OF CANINE TOOTH, hUMAN. (Sobotta.) $\times 25$.

$D$, dentine ; $G$, its granular layer; C, cement ; P, pulp cavity.

fig. 315, shown magnified in fig. 322). After decalcification the dentine can be separated into lamellæa along these incremental lines.

The animal matter of dentine resembles bone and the connective tissues generally in having its ground-substance pervaded by fibres which yield gelatine on boiling. These fibres, which have been 
especially investigated by v. Ebner and by Mummery, are difficult of demonstration in the fully ealcified dentine; but in developing dentine and in dentine which is attacked by caries they are more easily shown.

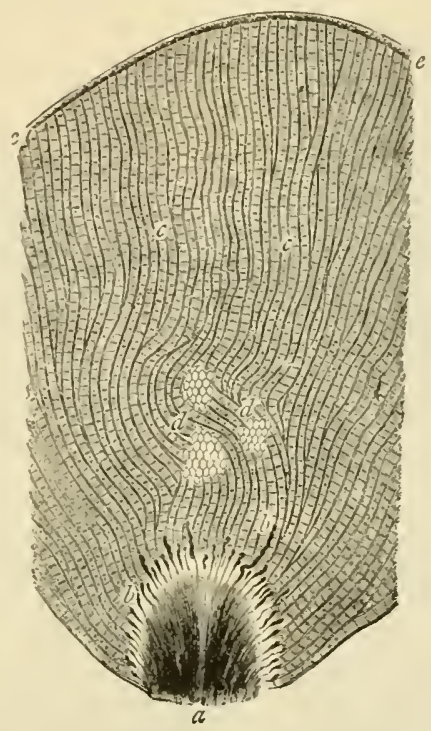

Fig. 318.-Section throtgh the eNamel of A tooth. Magnified 200 diameters. (Rauber.)

$a$, projection of dentine, showing some of its tubules, $b$, penetrating into the enamel; $c$, $c$, enamel fibres cut longitudinally; $d$, $d$, prisms cut transrersely;
$e$, cuticle of the enamel.

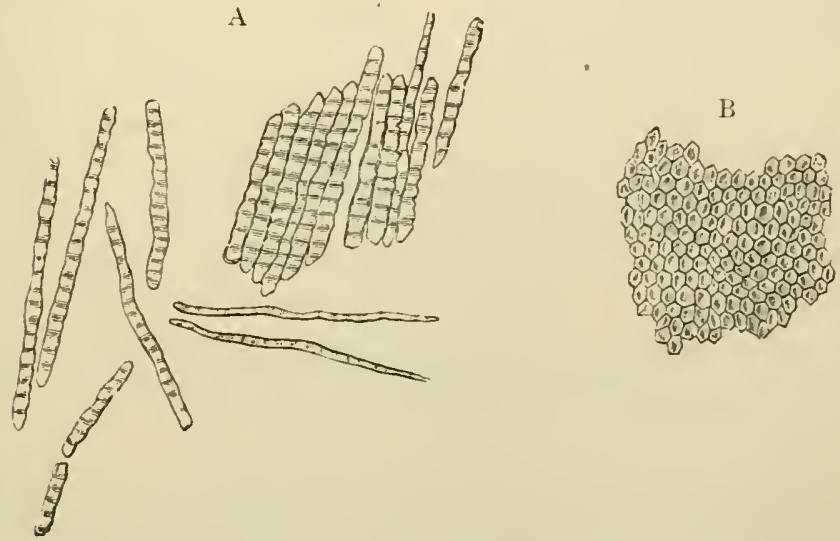

Fig. 319.-Examel PrisMs. Magnified 350 diameters. (Kölliker.)

A, Fragments and single fibres of the enamel, isolated by the action of hydrochloric acid. $B$, Surface of a small fragment of enamel, showing the hexagonal ends of the fibres. 
The pulp (fig. 323) consists of a soft, somewhat jelly-like, connective tissue, containing many branched cells, a network of blood-vessels, and many nerve-fibres which pass into the pulp-cavity along with the bloodvessels by a minute canal at the apex of the fang. The superficial

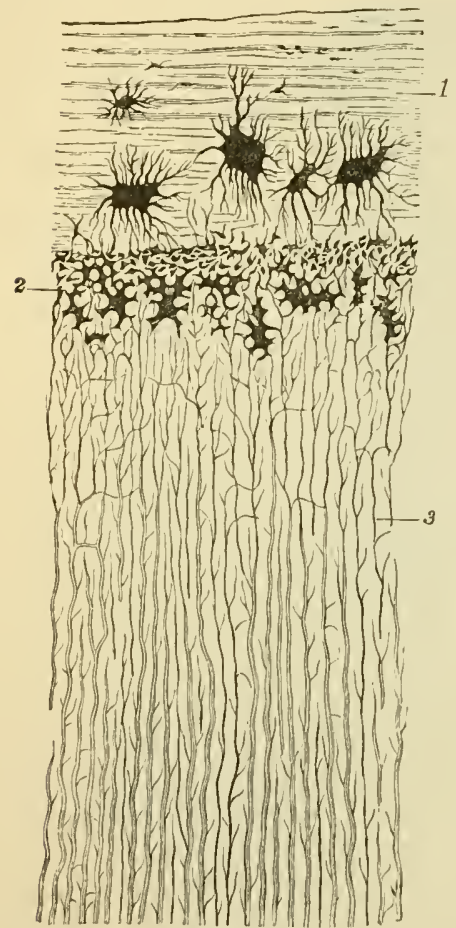

Fig. 320 .

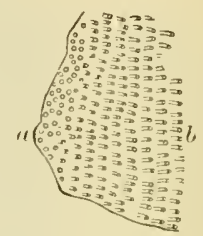

Fit. 321 .

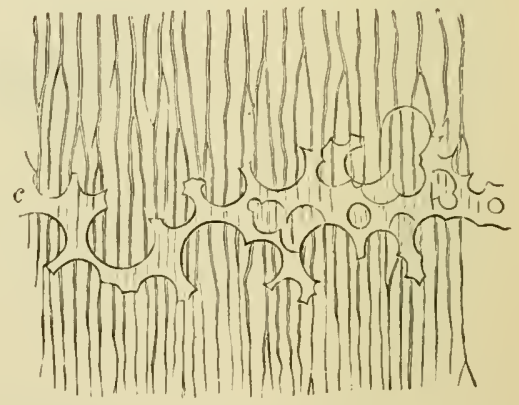

Fig. 322.

Fig. 320.-Section of fasg, parallet to the dextinal tubules. Magnified 300 diameters. (Waldeyer.)

1, cement, with large bone lacuna and indications of lamelle; 2, granular layer of Purkinje (interglobular spaces); 3 , dentinal tubules.

Fig. 321.-Sections of nentinal tubules. Magnified about 300 diameters. (Fraenckel.)

$a$, cut aeross ; $b$, cut obliquely.

Fig. 322.-A SMall PORTion OF DeNTiNe With INTERglobular spaces. Magnified 350 diameters. (Kölliker.)

c, portion of incremental line formed by the interglobular spaces, which are here filled up by a transparent material.

cells of the pulp form an almost continuous layer, like an epithelium (fig. $323, O d, O d^{\prime}$ ). They are known as odontoblasts, from having been concerned in the formation of the dentine. The nerve-fibres are said to pass eventually between the odontoblasts and to end in arborisa- 
tions close to the dentine, but they have not been followed into the dentinal tubules.

The crusta petrosa (fig. 317,320 ) is a layer of lamellated bone, including lacune and canaliculi, but without Haversian canals, at least nol'mally, in the human teeth. It is covered with periosteum (dental perissteum), which also lines the socket, and serves to fix the tooth securely.

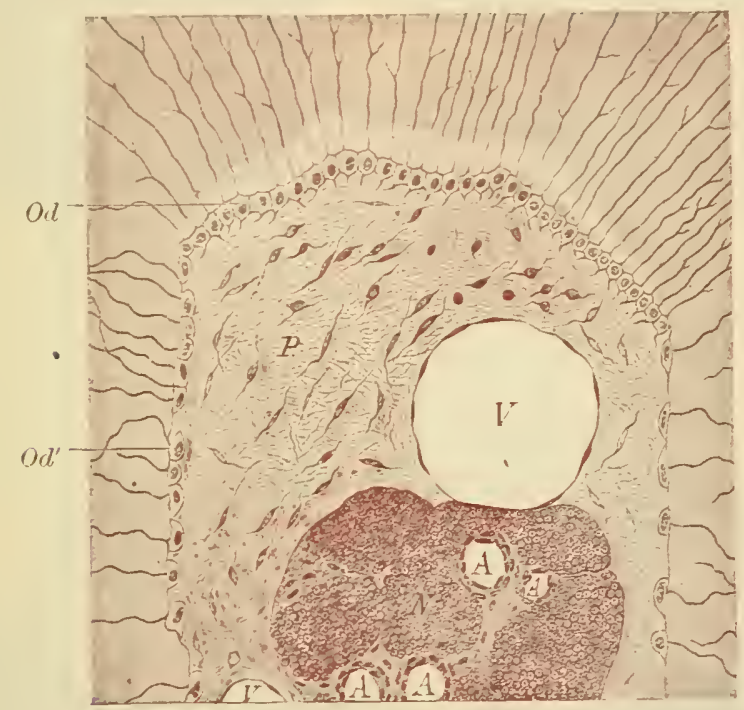

Fig. 323.-SECTION ACROSS THE ROOT OF A YOLAg TOOTH SHOWING THE PULP IX sITC. (Röse.)

$P$, pulp; $F, V$, veins ; $A, A, A$, arterioles ; $N$, nerre bundles ; Od, columnar odontoblasts still depositing dentine; $O d^{\prime}$, flattened odontoblasts which bave ceased to form dentine.

Formation of the teeth. - The teeth are developed somewhat similarly to the hairs. A continuous thickening of the epithelium occurs along the line of the gums, and grows into the corium of the mucous membrane (common dental germ or dental lamina, fig. $324, \mathrm{~A}$ ). At regular intervals there is yet a further thickening and growth from the common germ into the tissue of the mucous membrane, each of these special rudiments, which are ten in number, swelling out below into a flask-shaped mass of cells, the special dental germ (fig. $324, \mathrm{~B}$ ) of a milk tooth. The intermediate parts of the dental lamina long remain, forming a common epithelial strand uniting the several special dental germs to one another and to the epithelium covering the gum (fig. 324, C, D, f). A vascular pupilla is continued from the corium into the bottom of each special 
germ (fig. $324, \mathrm{C}, \mathrm{D}, p$ ); this papilla has the shape of the crown of the future tooth. Each special dental germ, with its included papilla,

$A$
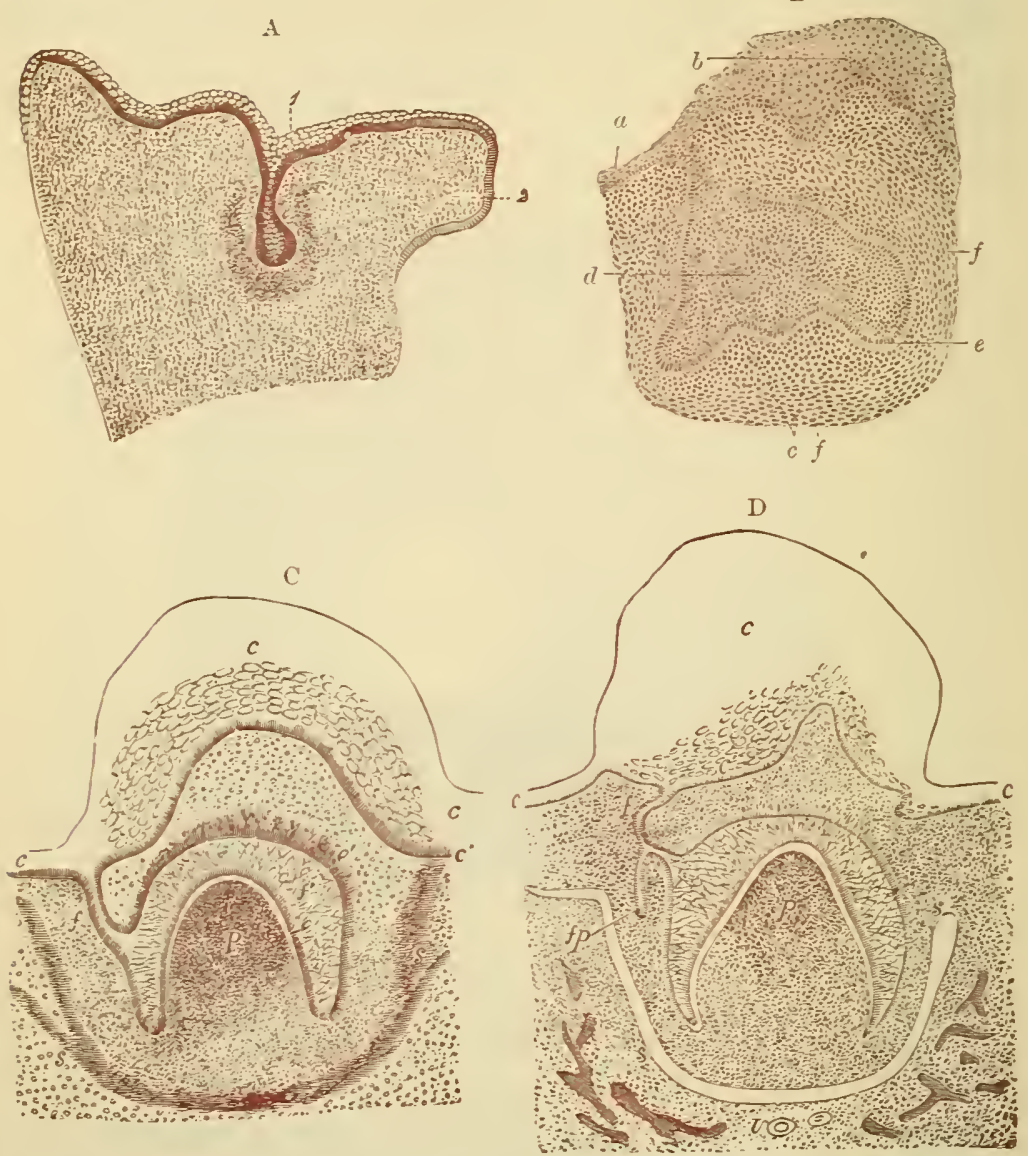

FIG. 324

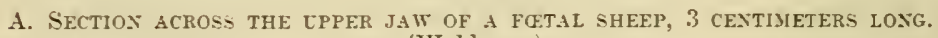
(Waldejer.)

1, cummon dental lamina dipping down into the mucous membrane where it is half surrounded by a horseshoe-shaped more dense-looking tissue, the germ of the dentine and dental sac; ?, palatine process of the maxilla.

B. Sectiox froN FETAL CALY SIMILAR TO THAT :HOWN IN A, BCT PAsSING THROCGH ONE OF THE SPECIAL DENTAL GERMS HERE BECOMING FLASK-SH.APED. (Rōse.)

$a$, epithelium of mouth, thickened at $b$, above special dental germ; $c$, papilla; $d$, special dental germ; $\epsilon$, enamel epitbelium; ;, , dental sac.

C AND D. SEctions AT Later STAges THAN I AND B, THE PAPILLA HaVING BECOME FORMED AND HATIXG BECOME PARTLI SURROUSDED BI THE EPITHELIAL GERM. (Kölliker.)

$c$, epithelium of gum, sketched in outline; $j$, neck of dental germ; $y^{\prime}$, enamel organ ; $e$, its deeper columnar cells; $e^{\prime}$, projections into the corium; $p$, papilla; 8 , dental sac forning. In $\mathrm{D}$, the deutal germ $(j p)$ of the corresponding permanent tooth is seen. 
presently becomes almost entirely cut oft' from the epithelium of the mouth, and surrounded by a vascular membrane-the dental sac. The papilla becomes transformed into the dentine and pulp of the future tooth, and the enamel is deposited upon its surface by the epithelial cells of the dental germ. The root of the tooth, with its covering of cement, is formed at a later period, when the tooth is beginning to grow up through the gum, by a gradual elongation of the base of the papilla. The shaping of this into the form of the root is

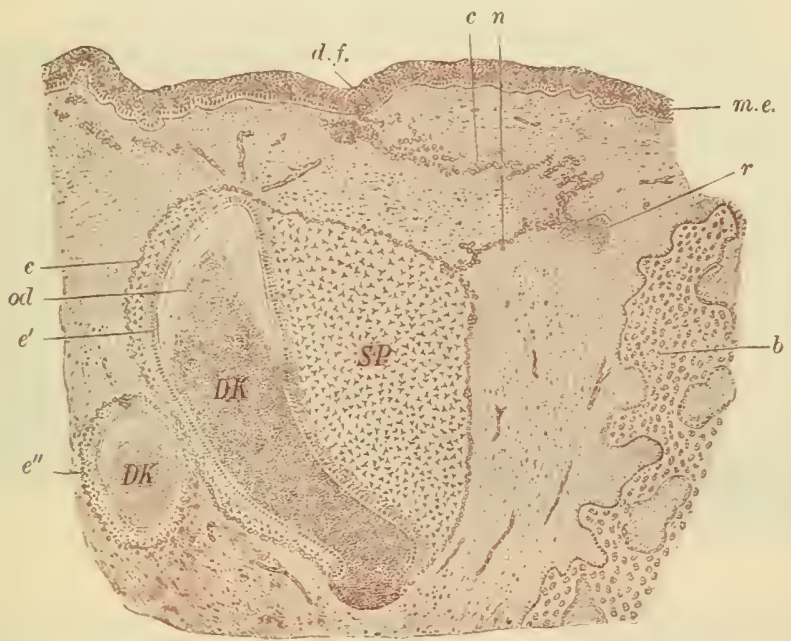

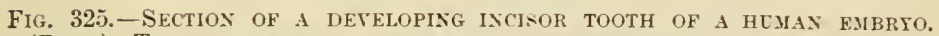

(Rōse.) THE SECTION ALso INCLUDEs THE gERY OF THE ADJACENT TOOTH.

$D K$, dental papilla; od, odontoblasts; $b$, bone of jaw; $e, e^{\prime}$, outer and inner layers of enamcl-organ ; S.P., enamel pulp; $d$. $t$ ' dental furrow; $c$, remains of common dental germ or lamina; $n$, neck or bridge of cells connecting this with the enamel-organ; m.e., mouth-epithelium; $e^{\prime \prime}$, cnamel organ of adjacent tooth-germ; $r$, reserve germ of permanent tooth.

determined by a growth of the epithelium of the edge of the enamel germ, which extends in the form of a fold (the epithelial sheath of r. Brunn) towards the future apex of each fang.

Previously to the deposition of the enamel, the dental germ undergoes a peculiar transformation of its previously polyhedral epitheliumcells into three layers of modified cells. One of these is a layer of columnar cells (ameloblasts, fig. 326, a), immediately corering the surface of the dentine. The enamel-prisms are producer by a fibrous formation (fig. $32 \pi, f$ ) followed by a deposition of calcareous salts; these changes taking place altogether external to the cells (or, as sonie hold, by a direct calcification of their protoplasn). The cells next to the dental sac form a single layer of cubical epithelium (fig. 325, e), and 
nearly all the other cells of the dental germ become transformed into branching corpuscles (fig. $325, S P$; fig. $326, p$ ) communicating by their processes, and thus forming a continuous network. The dental germ, after it is thus modified, is known as the enamel organ.

The dentine of the tooth is formed by calcification of the surface of the papilla. At this surface there is a well-marked layer of odontoblasts (fig. 328 , od, fig. $329, c$ ), and these produce a layer of dentinal matrix which forms a sort of eap to the papilla, and which soon
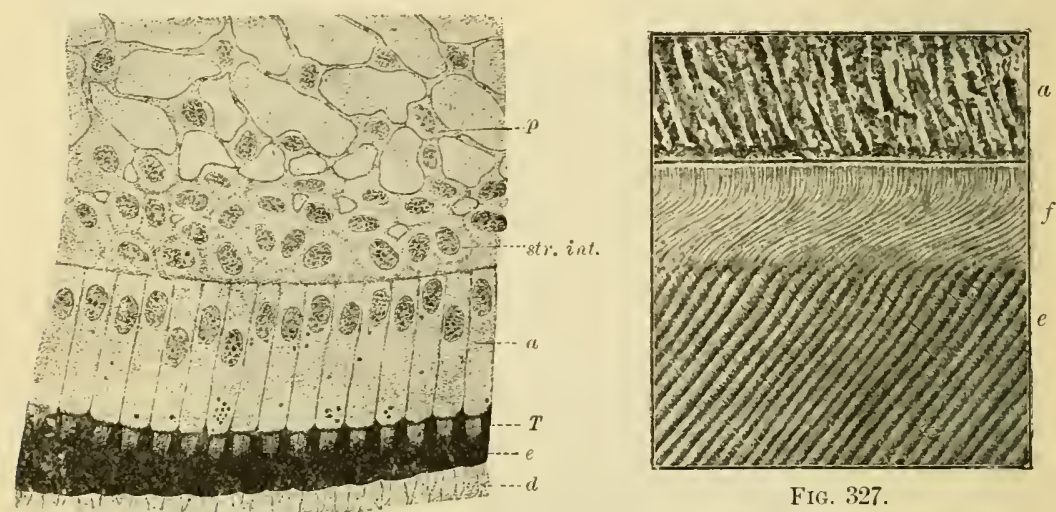

Fig. 327.

FIG. 326.

Fig. 326.-Section showivg the structure of the part of the examel ORGAX WHICH LIES NEXT TO THE DENTINE. (Röse.)

$d$, dentine; $e$, newly formed enamel stained black by osmic acid; $T$, Tomes' processes from the ameloblasts, $a$; str. int., stratum intermedium of enamel.organ; $p$, branched cells of enamel pulp.

Fig. 327.-DEVELOPING ENAMEL SHOWING AMELOBLASTS AND THE FIBROUS SUBSTANCE PRONUCED BY THESE CELLS, WHICH FORMS THE BASIS OF THE EXAJIEL PRISMS. (From a photograph by Leon Williams.)

$u$, portions of the ameloblasts; $f$, fibrous basis of enamel prisms ; $e$, calcified part of enamel.

becomes calcified by the deposition of globules of calcareous matter. Processes of the odontoblasts remain in the dentine as it is forming, and thus the dentinal tubules are produced. Subsequently other layers of dentine are formed within the first by a repetition of the same process, and in this way the papilla gradually becomes calcified. A part, however, remains unaltered in the centre of the tooth, and with its covering of odontoblasts forms the pulp.

The ten milk-teeth are formed in each jaw in the manner described. These, however, become lost within a few years after birth, and are replaced by permanent teeth in much the same way that a new succession of bair occul's. A small outgrowth takes place at an early period 
from the dental germ close to each of the milk-teeth (fig. 324, D, $f p$ ), and this eventually becomes the germ of the corresponding permanent tooth. It gradually enlarges, acquires a papilla, forms an enamel

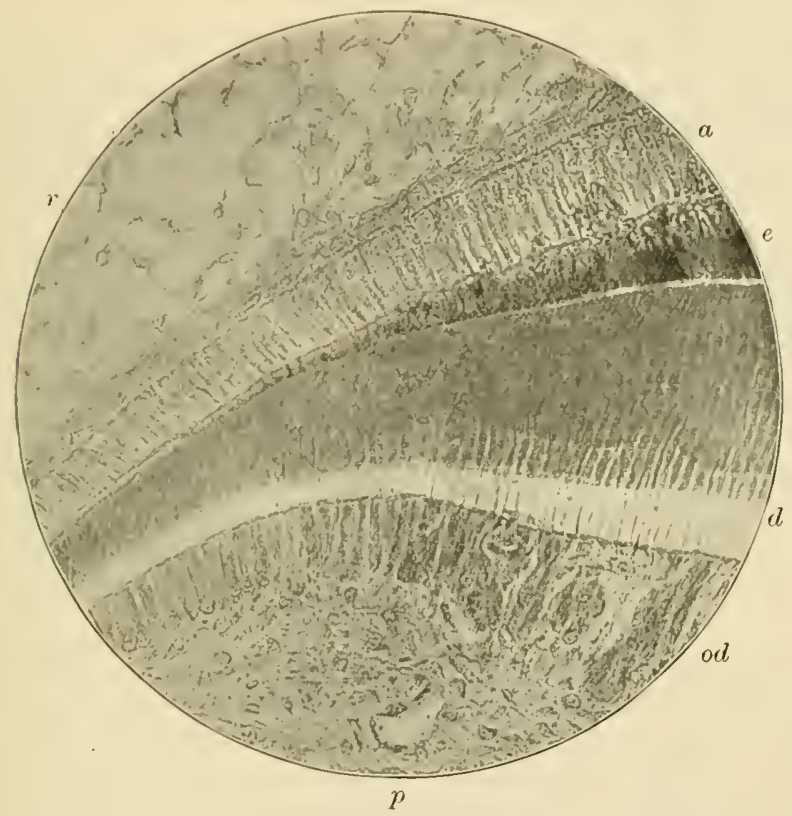

Fig. 328. - SECTION OF PART OF A DEVEloping TOOTH. (From a photograph by Leon Williams.)

$a$, dentine; od, odontoblasts sending their processes into the dentinal tubules; $p$, branched cells of the pulp; $e$, developing enamel; $a$, ameloblasts; $r$, reticulum or spongework of the enamel organ.

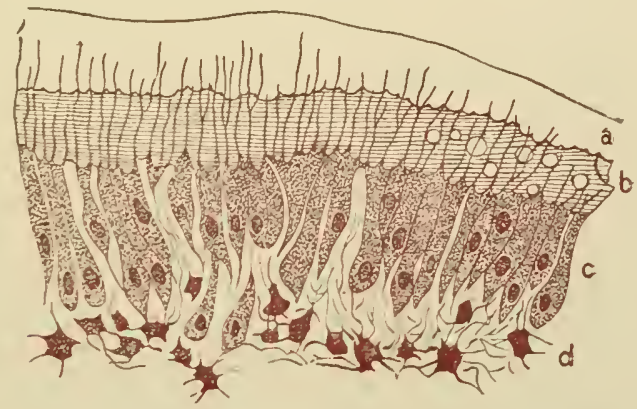

Fig. 329.-PART OF SECTION OF DEVELOPING TOOTH OF YOUNG RAT, SHOWING THE MODE OF DEPOSITION OF THE DENTINE. Highly magnified.

$a$, outer layer of fully calcified dentine; $b$, uncalcified matrix, with a few nodules of calcareous matter: e, odontoblasts with processes extending into the dentine; $d$, pulp. The section being stained, the uncalcified matrix is coloured, but not the calcified part. 
organ: in short, passes through the same phases of development as the germ of the milk-tooth; and when the milk-tooth drops out of the jaw in consequence of the absorption of its roots (by osteoclasts) the permanent tooth grows up into its place.

There are six permanent teeth in each jaw which do not succeed milk-teeth ; these are the permanent molars. They are developed from an extension backwards on each side of the jaw of the original epithelial thickening or common dental germ and by the downgrowth from this into the corium of three successive special germs at comparatively long intervals of time. Within these the tissues of the permanent molars become formed in a manner exactly similar to that in which the milk-teeth are developed. 


\section{LESSON XXIX.}

\section{THE TONGUE ANI THE GUSTATORY ORGANS. THE MUCOUS MEMBRANE OF THE MOUTH. THE PHARYNX AND CESOPHAGUS.}

1. Sectioss of the tongue vertical to the surface, stained with hæmatoxylin and eosin. The sections should be taken from different parts and include all three kinds of papillæ.

2. Sections of injecter tongue.

3. Sections of the papilla foliata of the rabbit, stained with hæmatoxylin and eosin to show the taste-buds in situ.

The cells composing the taste-buds are studied by teasing osmic preparations of the papilla foliata; the nerve-endings are seen in sections of papillit foliatie which have been treated by Golgi's osmic-bichromate silver method.

4. Sections of the pharynx and of the cesophagus stained with hæmatoxylin and eosin.

The tongue is mainly composed of striated muscular fibres, running some longitudinally, and others transversely. It is covered by a mucous membrane, the epithelium of which, like that of the rest of the mouth, is thick and stratified, and conceals microscopic papillæ (fig. 330) like those of the skin. Besides these, the upper surface of the organ is covered with larger papillæ, which give it a rough appearance. These, which are termed the lingual papillae, are of three kinds: (1) About twelve or thirteen comparatively large circular projections, each of which is surrounded by a narrow groove (fossa), external to which the mucous membrane is raised above the general level (vallum) (fig. 331). These papillæ form a $\mathbf{V}$-shaped line towards the back of the tongue; they receive filaments of the glosso-pharyngeal nerve, and have taste-buds in the epithelium which covers their sides, and in that of the side of the vallum. They are known as the circumvallate papilla. (2) All the rest of the papillary surface of the tongue is covered by conical papillce, so named from the conical pointed cap of epithelium which is borne by each; sometimes this cap is fringed with fine epithelial filaments, when they are termed filiform (fig. 332). (3) Scattered here and there amongst the conical papillæ are other larger papillæ, the fungiform (fig. 333). These are very vascular, and lie partly embedded in little depressions of the mucous membrane.

Small tubular glands may be seen between the superficial muscular fibres sending their ducts to the surface. Most of them secrete mucus, 
but those which open into the trenches of the circumvallate papillæ, and a few others elsewhere, yield an albuminous secretion (serous glands, glands of Ebner).

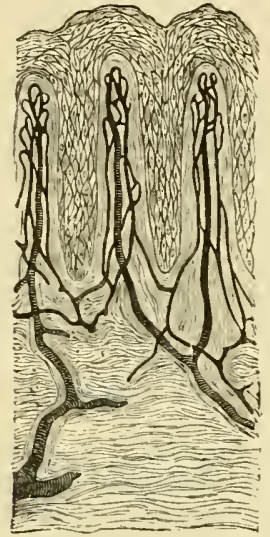

Fig. 330.-SECTION OF MCCOCS MEMBRANE OF MOUTH, SHOWIXG THREE MICROSCOPIC PAPILLE AND STRATIFIED EPITHELIUM. THE BLOOD-TESSELS HAVE BEEN INJECTED. (Toldt.)

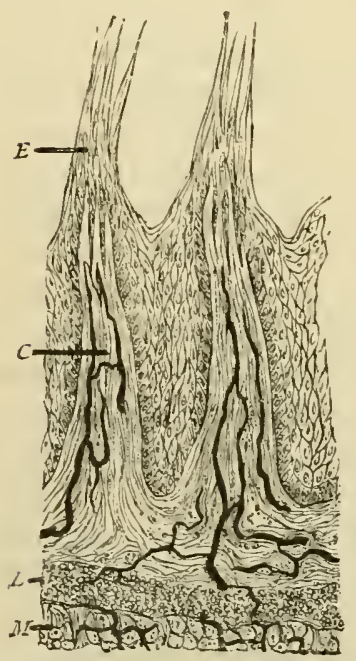

Fig. 332.-SECTION OF TWO FILIFORM PAPILLE, HUMAN. (Heitzmann.)

$E$, epithelium ; $C$, corium ; $L$, lymphoid tissue ; $M$, muscular fibres of tongue.

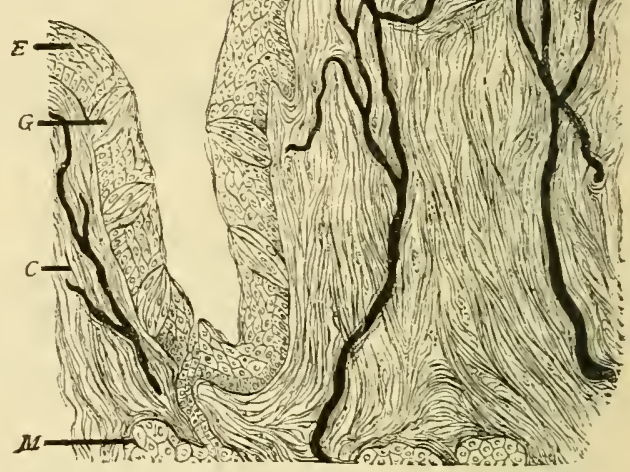

Fig, 331.-Section OF CIRCCMVALLATE PAPILla, HUMAN. THE FIGURE IXCLUDES ONE SIDE OF THF PAPILLA AND THE ADJOINING PART OF THE VALLUM. (Magnified 150 diameters.) (Heitzmann.) $E$, epithelium; $G$, taste-bud; $C$, corium with injected blood-ressels; $M$, gland with duct.

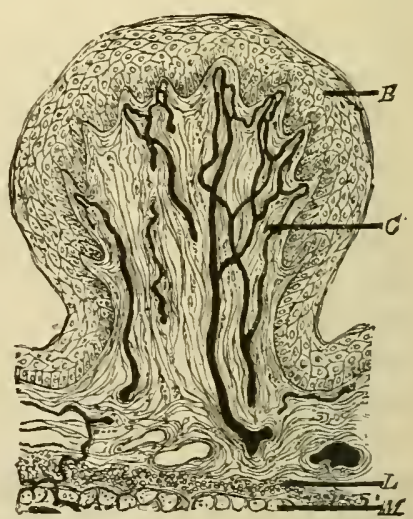

FIG. 333. - SECTION OF FLNGIFORM PAPILLA, HUilax. (Heitzmamn.) (Letters as in previous figure.) 
The mucous membrane at the back of the tongue contains a large amount of lymphoid tissue.

Taste-buds.-The minute gustatory organs which are known as tastebuls or taste-bulbs may be seen in sections which pass through the papilla vallate or the papillæ fungiformes; they are also present here and there in the epithelium of the gencral mucous inembrane of the

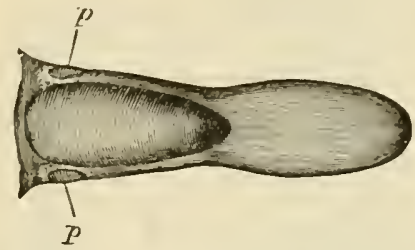

Fig. 334.-TONGUE OF RABBIT, SHOWISg THE SITUATION OF THE PAPILLE FOLIAT.E, $p$.

tongue, especially at the back and sides, and oceur also upon the under surface of the soft palate, and on the epiglottis. But they are most easily studied in the papillæ foliatæ of the rabbit, two small oval areas lyirg on either side of the back of the tongue and marked transversely with a number of small ridges or laminæ with intervening furrows (see

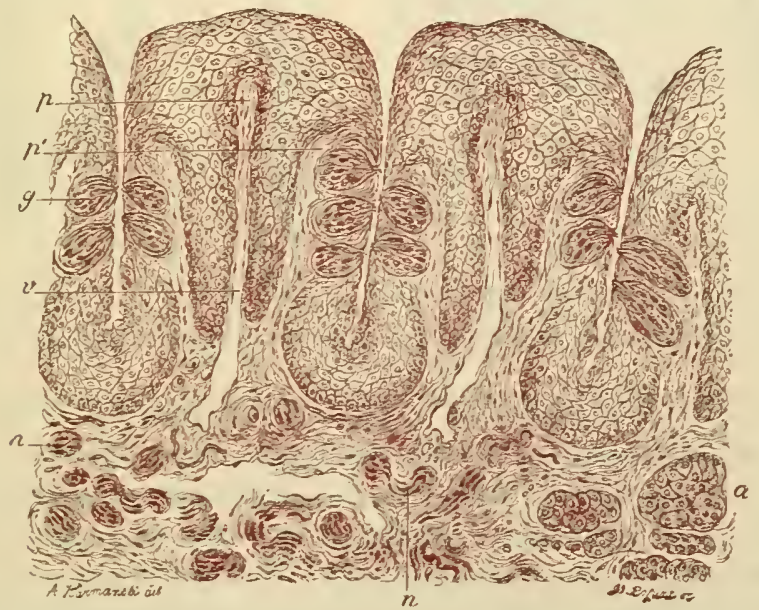

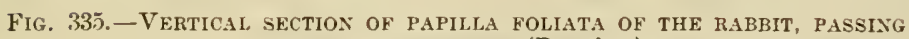
ACROSS THE FOLIE. (Ranvier.)

$p$, central lamina of the coriun; $v$, section across a vein, which traverses the folium; $p^{\prime}$, lateral lamina in which the nerve-fibres run; $g$, taste-bud; $n$, sections of nervebundles; $a$, serous glind.

fig. 334). Sections across the ridges show numerous taste-buds embedded in the thick epithelium which clothes their sides (fig. 335).

The taste-buds are ovoid clusters of epithelium-cells which lie in cavities in the stratified epithelium (fig. 336). The base of the taste- 
bud rests upon the corium of the mucous membrane, and receives a branch of the glosso-pharyngeal nerve; the apex is narrow and comnumicates with the cavity of the mouth by a small pore in the superficial epithelium (gustatory pore, fig. $336, p$ ).

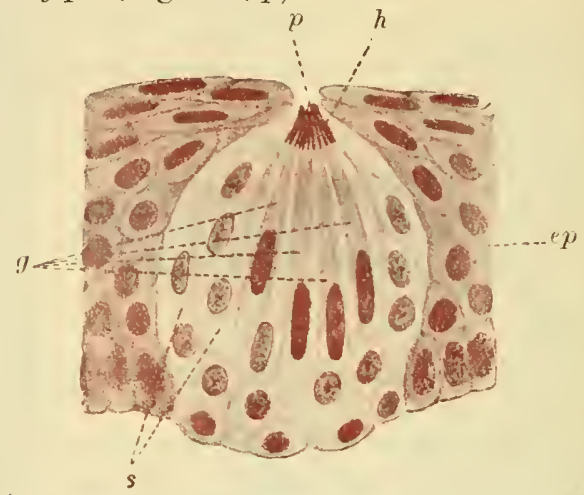

Fig. 336.-A taste-ben Within the stratified EPITHEliUn OF the TONGUE. (Sobotta.) $\times 500$.

$g$, gustatory cells ; $s$, sustentacular cclls ; $e p$, epithelium ; $p$, gustatory pore ; $h$, hairlets.
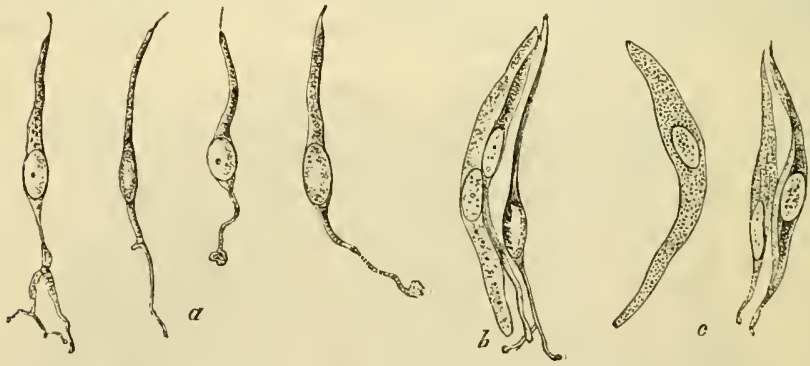

Fig. 337.-VARious Cells from taste-bUd of RABbit. (Engelmamn.) 600 diameters.

$u_{1}$ four gustatory cells from central part; $b$, two sustentacular cells, and one gustatory cell, in connection; $c$, three sustentacular cclls.

The cells which compose the taste-buds are of two kinds, viz.: 1. The gustatory cells (fig. $337, a$ ), which are delicate fusiform or bipolar cells composed of the cell-body or nucleated enlargement, and of two processes, one distal, the other proximal. The distal process is nearly straight, and passes towards the apex of the taste-bud, where it terminates in a small, highly refracting cilium-like appendage, which projects into the gustatory pore above mentioned, but the cell-body does not itself quite reach the pore. The proximal process is more delicate than the other, and is often branched and varicose. The nerve-fibres (fig. 338) terminate in ramifications amongst the gustatory cells (Retzius). 2. The sustentacular cells (fig. 337, c), which are elongated cells, mostly flattened, and pointed at their ends; they lie 
between the gustatory cells, which they thus appear to support, and in addition they form a sort of envelope or covering to the taste-bud. Between the eells of the taste-bud lymph-corpuscles are often seen,

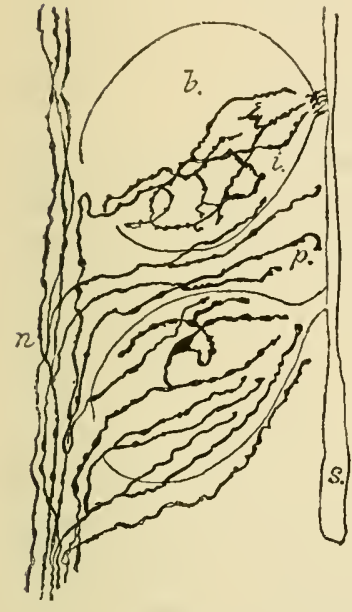

FIG. 338.

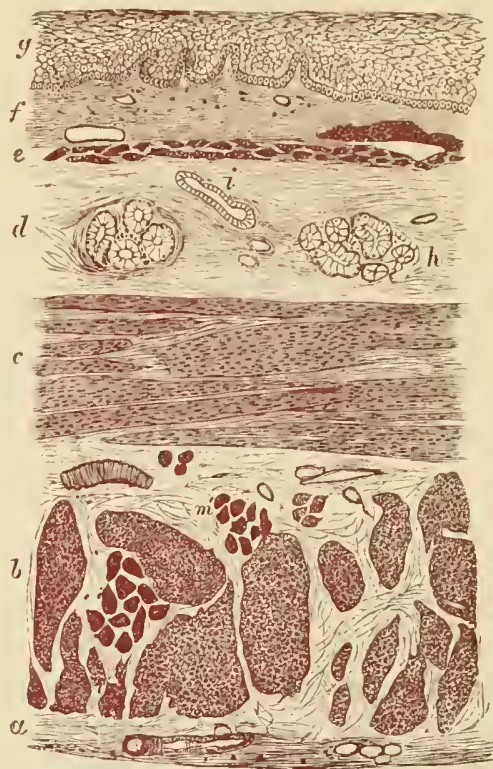

Fig. 339.

Fig. 338.-Nerve-endings in TAste-Buds. (G. Retzius.)

$n$, nerre-fibres ; $b$, taste-buds in outline; $i$, ending of fibrils willin taste-bud; $p$, ending in epithelium between taste-buds; $s$, sulcus into which the gustatory pores open.

Fig. 339.- - Section of the human cesophagus. (Horsley.)

The section is transverse, and from near the middle of the gullet. $a$, fibrous covering; $b$, divided fibres of the longitudinal muscular eoat; $c$, transverse muscular fibres; $d$, submueous or areolar layer; $e$, muscularis mucosæ; $f$, mueous membrane with papillæ; $g$, laminated epithelial lining; $h$, mucous gland ; $i$, gland duet; $m^{\prime}$, striated muscular fibres in section.

having probably wandered hither from the subjacent mucous membrane. Connective tissue fibrils penetrate between the taste-bud and the stratified epithelium in which it is embedded (Drasch).

The mucous membrane of the mouth is lined by a stratified epithelium into which numerous microscopic vascular and, in some parts, nerve-containing papillæ project. The corium is formed of connective tissue and contains within and beneath it a large number of small secretory glands (buccal glands). Most of these secrete mucus, but some are of the mixed type (see under salivary glands, p. 286): this is the case, for example, with the glands of the lips. The ducts of the buccal glands open everywhere upon the surface of the membrane, and the openings of the large ducts belonging to the salivary glands are also seen at certain parts. 
The pharynx is composed of a fibrous membrane which is encircled by striated muscles, the constrictor's, and lined by mucous membrane. The mucous membrane is covered on its inner surface over the upper part of the pharynx with ciliated epithelium, which is continuous with that of the nostrils, and through the Eustachian tube with that of the tympanum. Below the level of the soft palate the epithelium is stratified like that of the mouth and gullet, into which it passes. In certain parts the mucous membrane contains a large amount of lymphoid tissue, and there are numerous glands opening on its surface.

The œsophagus or gullet, which passes from the pharynx to the stomach, consists, like the pharynx, of a fibrous covering, a muscular coat, a lining mucous membrane, and intervening connective tissue (submucous or areolar coat) (fig. 339). The muscular coat is much more regularly arranged than that of the pharynx, and is composed of striated muscle in about its upper third only, the rest being of the plain variety. There are two layers of the muscular coat-an outer layer, in which the fibres run longitudinally, and an inner, in which they have a circular arrangement. The mucons membrane is lined by a stratified epithelium, into which microscopic papillæ from the corium project. The corium is formed of areolar tissue, and its limits are marked externally by a narrow layer of longitndinally disposed plain muscular fibres, the muscularis mucosce. This is separated from the proper muscular coat by the areolar coat, which contains the larger branches of the blood-vessels and lymphatics, and also the mucous glands of the membrane. The ducts of these glands are large and usually pass through a nodule of lymphoid tissue, lymph-cells from which infiltrate the epithelium of the duct and may pass out into the lumen of the duct.

Besides these mucous glands, there are met with both at the upper or laryngeal part of the cesophagus and at the lower or cardiac end a certain number of small tubulo-racemose glands of a different character. They are confined to the mucous membrane, not penetrating the muscularis mucosæ, and their ducts open upon and not between the papilla of the mucous membrane. They closely resemble the cardiac glands of the stomach (see fig. 353, p. 290), and it is frequently found that the epithelium of the surface in the immediate neighbourhood of their ducts is similar to that lining the stomach.

There are two gangliated nerve-plexuses, one in the muscular coat, and one in the submucous coat, like those of the intestine (Klein). 


\title{
LESSON XXX.
}

\author{
THE SALIVARY GLANDS.
}

1. Sectioss of the submixillary gland (dog). The gland may be hardened in alcohol or formol and stained with hematoxylin-eosin or with iron hematoxylin by Heidenhain's method. Notice the acini filled with clear (nncussecreting) cells, the nuclei of which usually lie near the basement-membrane. Notice liere and there, ontside the clear cells, demilumes or crescents of small darkly stained granular-looking (albuminous) cells. Observe also the sections of the ducts with their striated columnar epithelium. If possible find a place where one of the ducts is passing into the alveoli. Sketch under a high power.

2. Study sections of the parotid and sublingual glands preparer in a similar way, and notice the differences between the three glands.

3. Examine small pieces of both submaxillary and parotid gland of the dog fresh in 2 per cent. salt solution. In the submaxillary gland notice that the alveolar cells are swollen ont with large granules or droplets of mucigen, which swell up in water to form large clear vacuoles. Dilute acids and alkalies produce a similar change but more rapidly. The cells of the parotid gland are also filled with granules, but they are smaller. The granules are also swollen up and dissolved by these fluids. Make a sketch from each preparation under a high power.

4. To study the changes which the alveolar cells undergo during secretion, pilocarpine is administered to an animal in sufficient amount to produce copions salivation; after half an hour the animal is killed and its salivary glands are examinerl as in preparation 3. The granules are not seen in preparations that have been in alcohol, but osmic acid preserves them moderately well; they are well seen in sections stained by Muir's eosin-methylene blve method (see Appendix).

The salivary glands may be looked upon as typical of secreting glands in general. They are composed of a number of lobules bound together loosely by connective tissue. Each small lobule is formed of a group of irregularly saccular or tubular alveoli or acini from which a duct passes, and this, after uniting with other ducts, eventually leaves the gland to open upon the surface of the mucous membrane of the mouth.

The alveoli are inclosed by a basement-membrane, which has flattened branched cells on its inner surface, next to the epithelium (fig. 340). It may be shown by teasing the fresh gland substance in water (Langley). This basement-membrane is continued along the ducts. Within it is the epithelium, which in the alveoli is composed of polyhedral cells (fig. 341, a), but in the ducts is regularly columnar, 
except in that part of the duct which immediately opens into the alveoli (junctional part); in this it is flattened $\left(d^{\prime}\right)$. The columnar epithelium of the ducts is peculiar, in that the cells show a distinction into two unequal zones, an outer, larger, striated zone, and an inner, smaller, granular one (fig. $341, d)$.

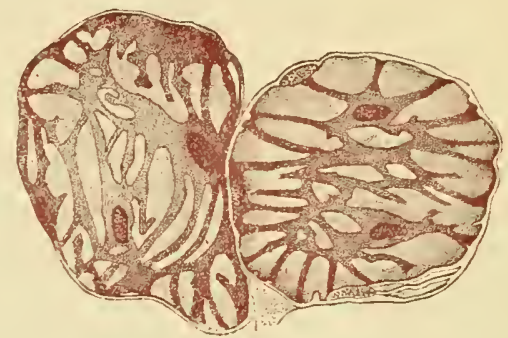

Fig. 340. - MeMbrana propria of two alveoli. (v. Ebner.) $\times 600$.

The preparation is taken from a mucous gland of the rabbit.

The cells of the alveoli differ according to the substance they secrete. In alveoli which secrete mucus, such as all the alveoli of the dog's submaxillary (fig. 341), and some of the alveoli of the same gland in

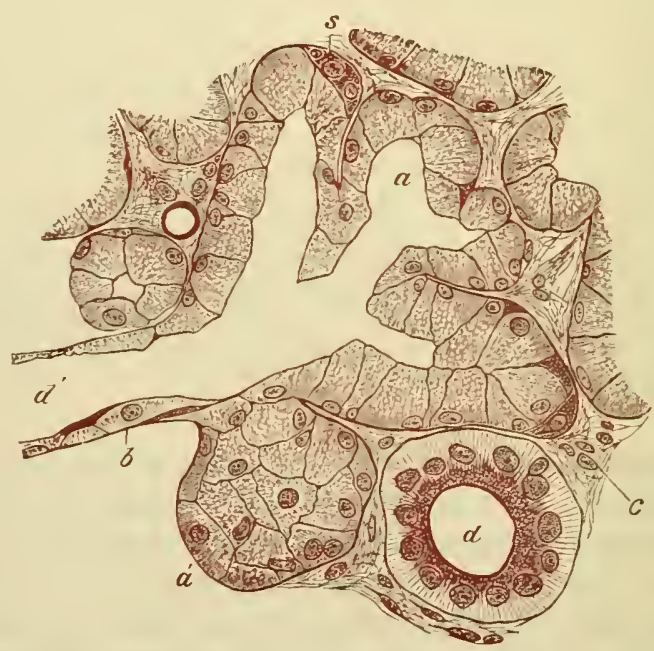

Fig. 3H1. - SECTION OF THE SCBMAXILLARY GLAND OF THE DOG, SHOWING THE COMMENCEMENT OF A DCCT IN THE ALVEOLI. (Magnified 425 diameters.)

$a$, one of the alveoli, several of which are in the scetion shown groupcd around the commencement of the duct $t^{\prime} ; a^{\prime}$, an alveolus, not opened by the section; $b$, basernentmembrane in section; $c$, interstitial connective tissue of the gland; $d$, section of a duet which has passed away from the alveoli, and is now lined with characteristically striated coluinnar cells; $s$, semilunar group of darkly stained eells at the periphery of an alveolus.

man (fig. 344), the cells, if examined in normal saline solution or after hardening with alcohol, are clear and swollen. But if examined rapidly in serum, or in solutions of salt of from 2 to 5 per cent., 
they are often seen to be occupied by large and distinct granules (Langley). These granules can also be rendered visible by certain methods of staining, when it is apparent that they are not present as such in all the cells, but have in many cells become elcar and swollen, and converted into a substance which is known as mucigen (fig. $346, a$ ).

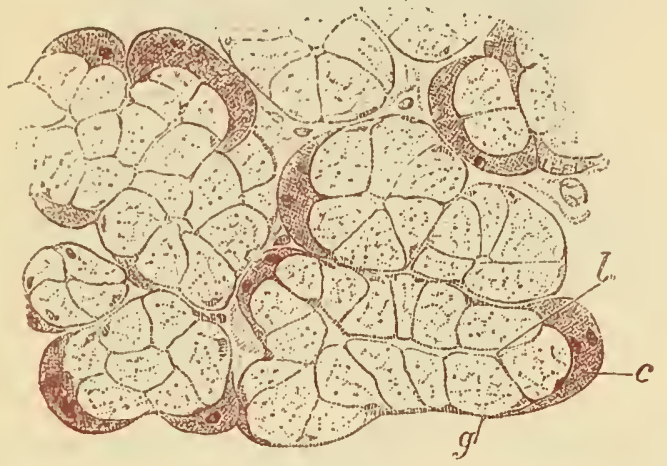

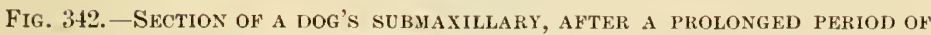
REST. (Ranvier.)

$l$, lumen of alveolus ; $g$, mucus-sccreting cells ; $c$, crescent, formed of alburninous cells.

Similar grantules are seen also in the cells lining the gland ducts; here also they are found to vary in size and number with the condition of activity of the gland (fig. 348). The mucigen is dissolved out of the cell and discharged as mucus into the lumen of the alveolus and

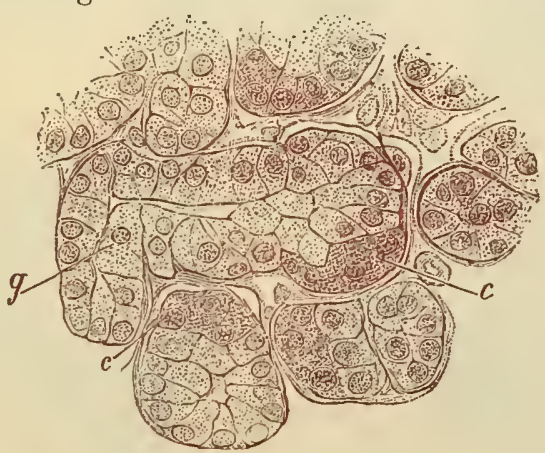

Fig. 343. - SubMaxillary OF DOG, A wTER A PERION OF ACTIVITY. (Ranvier.) The mucus-secreting cells, $g$, have discharged their secretion, and are smaller and stain better; the albuninous cells of the crescents, $c$, are cularged.

into the ducts, when the gland is stimulated to activity. The cells are known as mucous cells. But in most alveoli there are some cells which do not contain mucigen, but small albuminous granules, and these often form crescentic groups which lie next to the basementmembrane (figs. $341, s, 342, c$ ). These are the so-called crescents of 


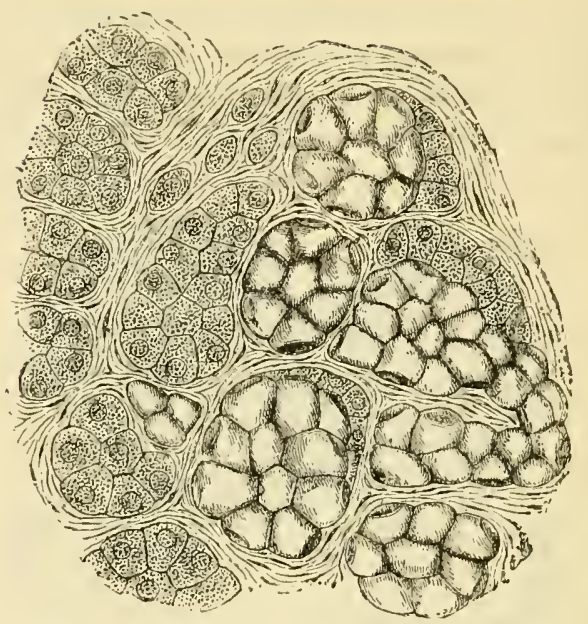

Fig. 344. -SECTION OF PART OF THE HUMAN SUBMAXILLARY GLAND. (Heidenhain.)

To the right of the figure is a groul, of mucous alveoli ; to the left a group of serous alveoli.
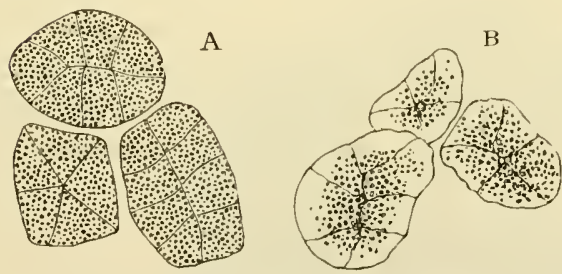

C

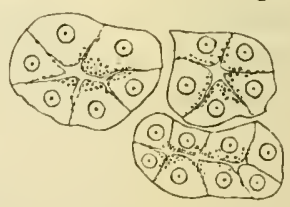

Fig. 345. - Alveoli of a serous gland. A, AT REST. B, AWTER A SHORT PFRIOD OF ACTIVITY. C, AFTER A PROLONGED PERIOD OF ACTIVITY. (Langley.)

In $\mathrm{A}$ and $\mathrm{B}$ the nuclei are obscured by the granules of zymogen.
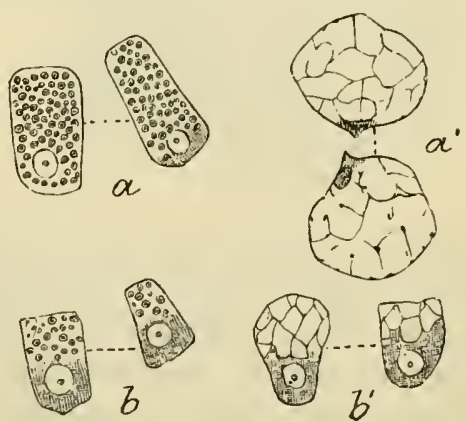

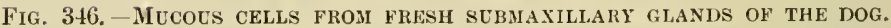
(Laugley.)

$a$, from a resting or loaded gland; $b$, from a gland which has been secreting for some time ; $a^{\prime}, b^{\prime}$, similar cells which have been treated with dilute aeid. 
Gianu: $\approx$ : their constituent eells are known also as marginal or serous cells. Special diverticula pass from the lumen of the alveoli between the mucous cells to penetrate to the crescents and to branch amongst and within their constituent cells; these diverticula are best shown by

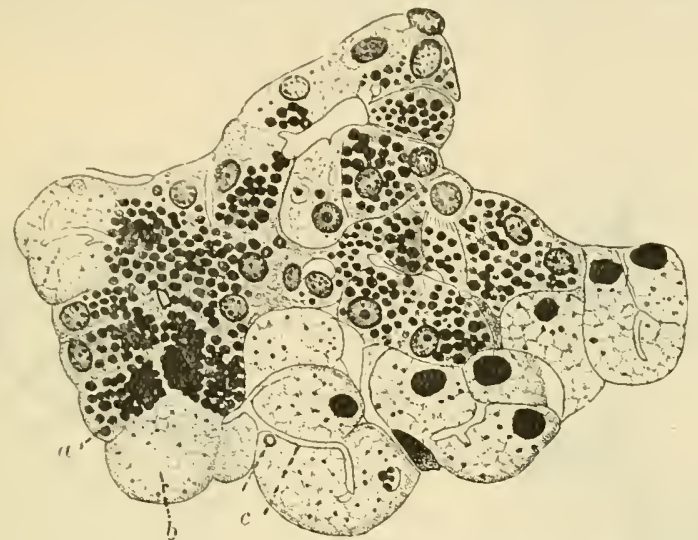

Fig. 347.-SubMaxillary glayd of Rabbit. (E. Müller.)

The cells, which are all serous, are in different functional states, as indicated by the condition and staining of the granules. " cell filled with darkly staining granules ; $b$, clear cell; $c$, secretory canaliculi penetrating into the cells.

the Golgi method of staining (figs. 349, 350). They also oecur in the purely serous alveoli (fig. 347 ), in which none of the cells secrete mucus, but watery or albuminous saliva. In these when the gland has been long at rest the cells are filled with granules, which do not swell with water

A

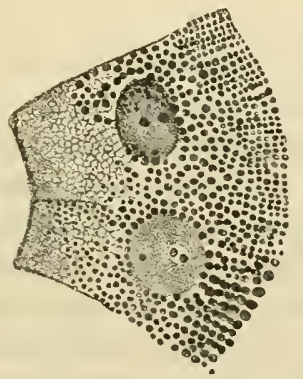

B

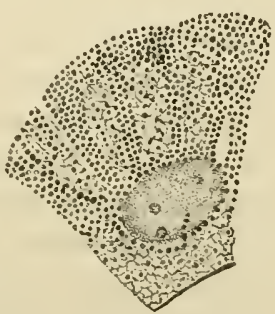

Fig. 34S.-CElls Froy DUCT OF PAROTID.

A, prior to secretion; B, after secretion (Mislawski and Smirnow).

nor form mucin; they appear to be albuminous in nature, and probably yield to the secretion of the gland its ferment (ptyalin) and its albumin. The granular substance within the cell is not the ferment, but the ferment is formed from it when the secretion is poured out. Hence it has been termed zymogen (mother of ferment). As Langley 
showed, the outer part of each cell becomes clear and free from granules after secretion (fig. 345).

In nearly all animals the parotid glands are composed of purely serous alreoli : in man and most animals the submaxillary and sublingual glands have both serous and mucous alveoli or "mixed" alveoli, i.e. alveoli containing both serous and mucous cells. The smaller detached anterior parts of the sublingual gland have purely mucous alveoli.

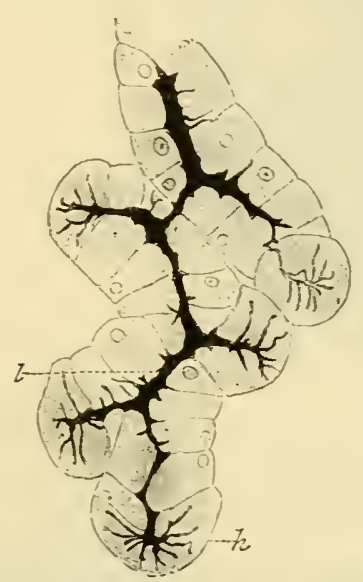

FIG. 349.-ALTEOLI OF HCMAN SUBLISGCAL GLAYD PREPARED BI GOLGI METHOD. (E. Müller.)

$l$, lumen stained, with lateral direrticula passing between mucus-secreting cells ; $h$, longer diverticula penctrating into the "crescent" cells.

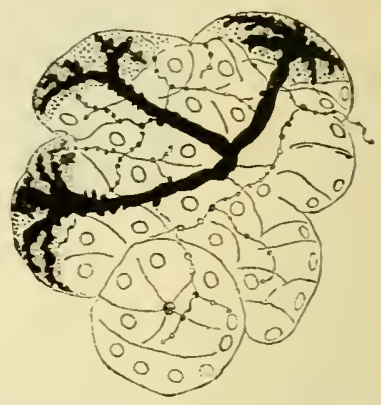

Fig. 350.-Alveoli of the SUBMaxilLART GLAND OF THE DOG. (G. Retzius.) Golgi method.

The extensions of the lumen into the crescents of Gianuzzi are shown, and also the endings of nerve-fibrils.

The largest ducts have a wall of connective tissue outside the basement-membrane, and also a few plain muscular cells. The bloodressels of the salivary gland form a capillary network around each alveolus. The lymphatics commence in the form of lacunar vessels between the alreoli. Lymphoid nodules are occasionally found in the interstitial connective tissue. The nerve-fibres, which are derived both from the cerebro-spinal nerves and from the sympathetic, pass through ganglia before proceeding to their distribution. They ramify as fine varicose fibrils amongst the alveolar cells (fig. 350), and many are distributed to the blood-vessels.

The salivary glands are dereloped as buds from the epithelium of the buccal cavity, at first solid but becoming gradually hollowed out. To begin with they are simple, but undergo ramification as they grow into the mucous membrane and submucous tissue. 


\section{LESSON XXXI.}

\section{THE STOMACH.}

1. Vertical longitudinal sections through the cardia, including the lower end of the nesophagus and the adjacent cardiac portion of the stomach. These are intended to show the abrupt transition of the stratified epithelium of the aesophagus into the colummar epithelium of the stomach, and also the character of the gastric and cesophageal glands in the immediate neighbourhood of the cardia. The sections may be stained with hamatoxylin and eosin.

2. Sections of the fundus of the stomach, cut perpendicularly to the surface of the mucous membrane.

In these sections the general arrangenent of the coats of the stomach is to be studied. Sketches are to be made under a low power illustrating this arrangement, and others under a high power showing the structure of the glands of the mucons menibrane.

Measure the whole thickness of the mucous membrane, the thickness of the muscular coat, the size of the columnar epithelium-cells of the surface, and that of the cells in the deeper parts of the glands.

3. Sections of the nucous membrane of the fundus, cut parallel to the surface.

These sections will show better than the others the arrangement of the cells in the glands.

4. Vertical sections of the mucous membrane from the pyloric region of the stomach. If the section is taken longitudinally through the pylorus, the transition of the gastric glands into the glands of Brumner of the duodenmm will be made manifest. Make a sketch under a low power of one of the glands in its whole length, filling up some of the details with the high power.

5. Study the arrangement of the blood-vessels of the stomach in vertical sections of the wall of an organ the vessels of which have been injected.

The wall of the stomach consists of four coats, which, enumerated from without in, are as follows, viz. : serous, muscular, areolar, or sub. mucous, and mucous membrane (fig. 351).

The serous coat is a layer which is derived from the peritoneum. It is deficient only along the lines of the lesser and greater curvatures.

The musculur cout consists of three layers of plain muscular fibres. Of these the bundles of the outer layer run longitudinally, those of the middle layer circularly, and those of the inner layer obliquely. The longitudinal and circular bundles become thicker and stronger towards the pylorus; at the pylorus itself the circular layer is greatly thickened to form a sphincter muscle. The oblique fibres are only present over the fundus.

The areolar or submucous coat is a layer of areolar tissue, which serves 
to unite the mucous membrane loosely to the muscular coat; in it

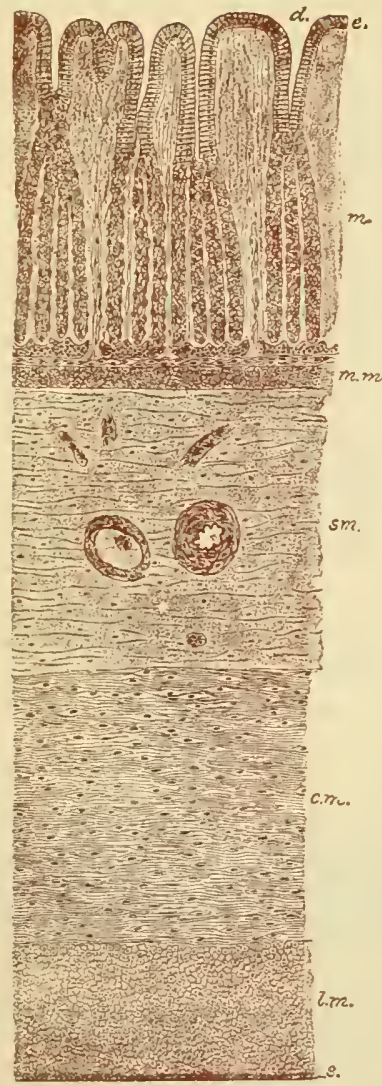

Fig. 351.-DIAgras oF section THROCGH THE COATS OF THE STомАсн. (Mall.)

$m$, mucous membrane; $e$, epithelium $d$, orifice of gland-duct; $m . m_{\text {. }}$, muscu. laris mucosa; sm., submucosa ; c.m., circular muscular layer; l.m., longitudinal muscular layer; $s$, scrous coat.

the organ. The following varieties of gastric glands are met with :-

(1) Glands of the curdia.- These are found in man close to the œsophageal opening or cardia; they are of two kinds: $(a)$ simple tubules, very similar to the crypts of Lieberkühn of the intestine and $(b)$ small tubulo-racemose glands (fig. 353). The secreting tubules of the racemose glands are lined by cells which are granular in appearance and of a short columnar form, and of the same nature throughout the length ressels and lymphatics.

The mucous membrane is a soft thick layer, generally somewhat corrugated in the empty condition of the organ. Its inner surface is covered by columnarshaped epithelium cells, all of which secrete mucus. They are prolonged into the ducts of the glands, but when these divide to form the tubnles the cells become cubical, and lose their mucussecreting character. The thickness of the mucous membrane is due to the fact that it is largely made up of long tubular glands, which open upon the inner surface. Between the glands the mucous membrane is formed of retiform with some lymphoid tissuc. Externally it is bounded by the muscularis mucosce, which consists of an external longitudinal and an imner circular layer of plain muscular fibres.

Gastric glands.-These are formed of a basement-membrane lined with epithelium. Each gland consists of secreting tubules from one to four in number, opening at the surface into a larger tube, the duct of the gland. The duct is in all cases lined by mucnssecreting epithelium of the same character as that which corers the inner surface of the mucous membrane, but the epithelium of the secreting tubules is different from this, and also differs somewhat in the glands of different regions of ramify the larger branches of the blood- 
of the tubule, except near the orifice (duct), where they give place to columnar mucus-secreting eells. Occasionally one or two oxyutic cells may be present in their tubules.

(2) Glemels of the fundus (o.ryntic glands) (figs. 354,355 ). - In these glands the tubules are long and the duct short. The epithelium of the tubules is composed of two kinds of cells. Those of the one kind,

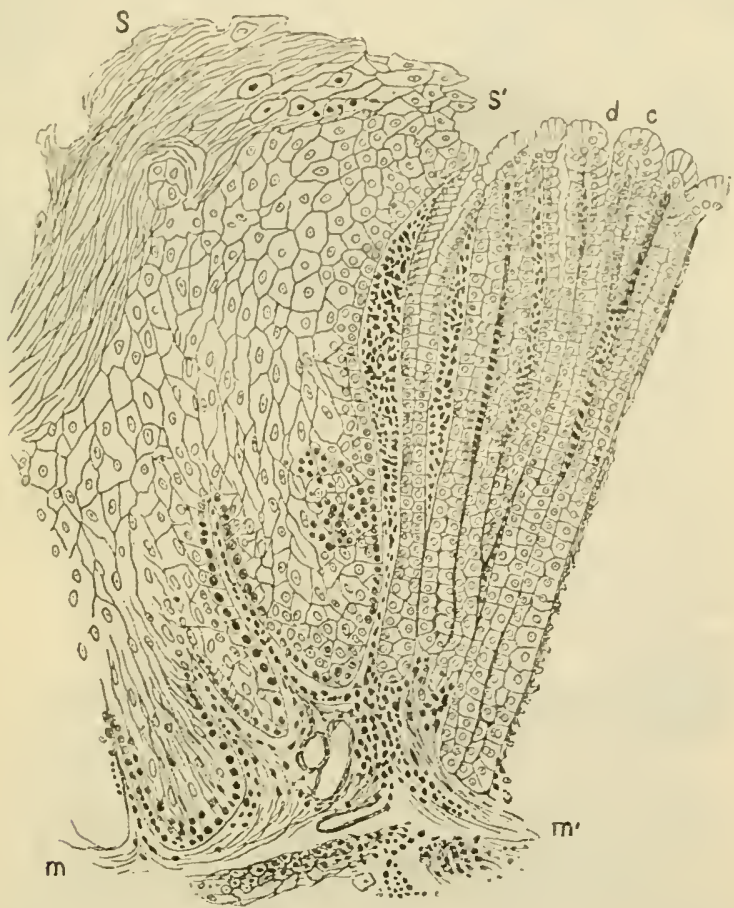

Fig. 352. - SECTION OF THE JUNCTION OF THE GSOPHAGEAL AND GASTRIC MUCOUS MEIBRANE OF' THE KANGAROO. (135̃ diameters.)

$S$, stratified epithelium of cesophagus abruptly discontinued at $S^{\prime} ; c$, columnar epithelium of gastric nucous membrane; $d$, orifices or ducts of cardiac glands; $n$, corium of esophageal mucous membrane scuding payillie into the epithelium; $m^{\prime}$, corium of gastric mucous membrane.

which form a continuous lining to the tubule, are somewhat polyhedral in shape, and in stained sections look clearer and smaller than the others, but in the fresh glands, and with certain methods of staining; it can be seen that they are filled with granules (fig. 355). The granules are most numerous at the inner part of the cell, an outer zone being left clear. After prolonged activity this outer zone increases in size while the granules diminish in number as 
in the analogous cases of the pancreas and parotid glands (Langley). The cells are believed to form pepsin, and are termed the chief cells of the cardiac glands, or from their relative position in the tubule immediately surrounding the lumen, the central cells. Scattered along the tubule, and lying between the chief cells and the basement-membrane, are a number of large spheroidal or ovoidal cells. These are the parietal or cxyntic cells. ${ }^{1}$ Each parietal cell is surrounded and

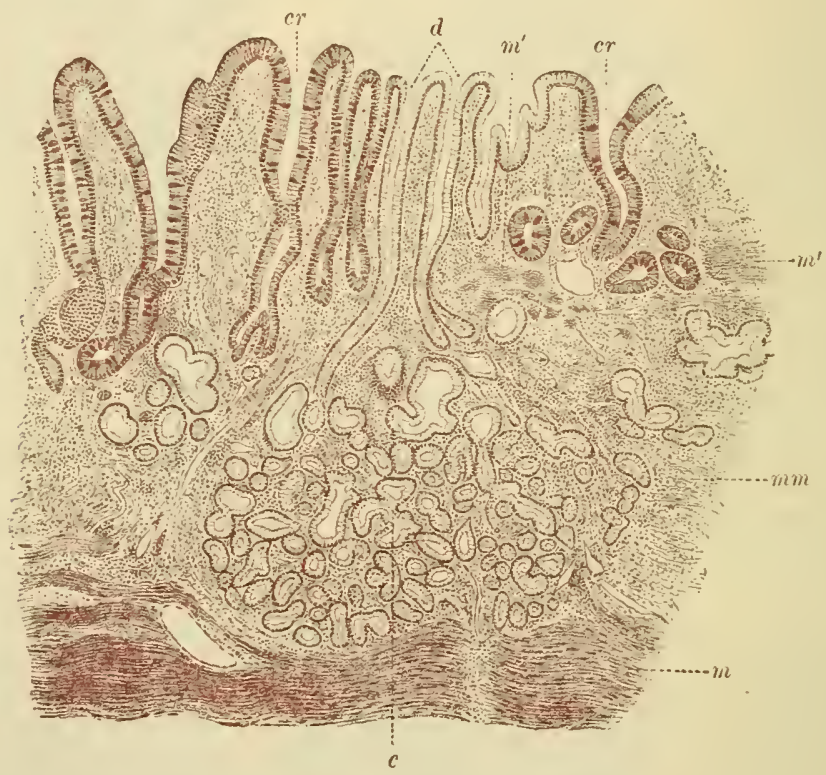

Fig. 35̃3.-Section of human stomach Near the CaRdia. (v. Ebner, after J. Schaffer.) $\times 45$.

$c$, cardiac glands ; $d$, their ducts ; $c r$, glands similar to crypts of Licberkühn, with goblet cells; $m m$, mucous membrane; $m$, muscularis mucosa ; $m^{\prime}$, muscular tissue within mucous membrane.

penetrated by a network of minute passages, communicating with the lumen of the gland by a fine canal, which passes between the central cells (fig. 356); but in the neck of the gland the parietal cells abut against the lumen, being here wedged in between the mucus-secreting cells (fig. $354, \mathrm{~A}$ ).

(3) Glands of the pyloric canal (fig. 357).-In the glands of the pyloric canal the ducts are much longer than in those of the fundus, and the secreting tubules possess cells of only one kind. ${ }^{2}$ These correspond to

I So called because they are believed to produce the acid of the gastric secretion.

${ }^{2}$ In man it is only quite near the pylorus that oxyntic cells are altogether absent. 


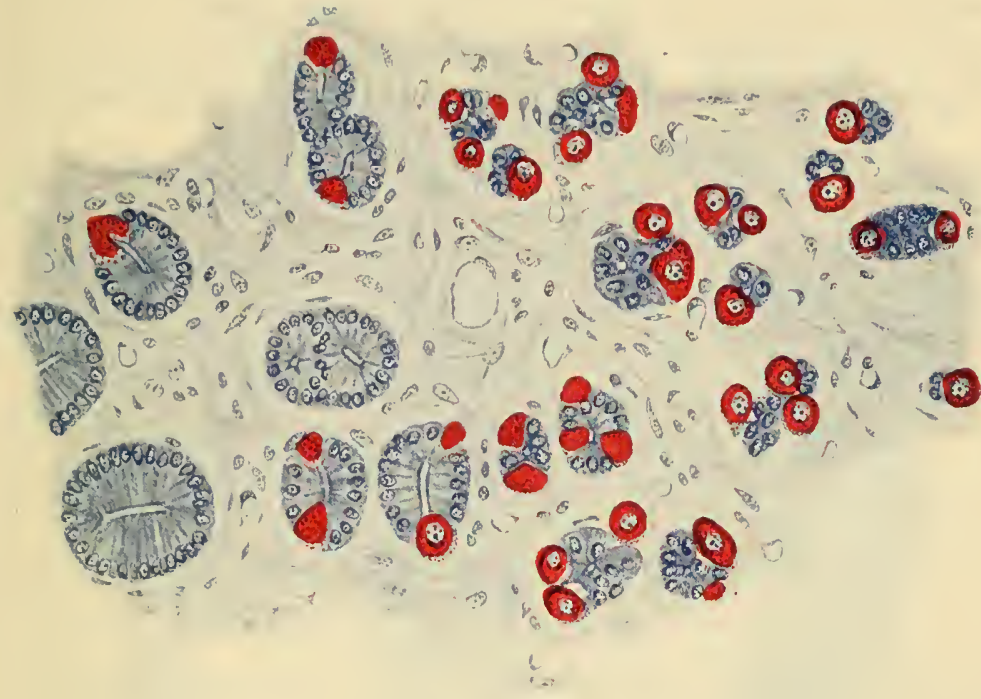

B

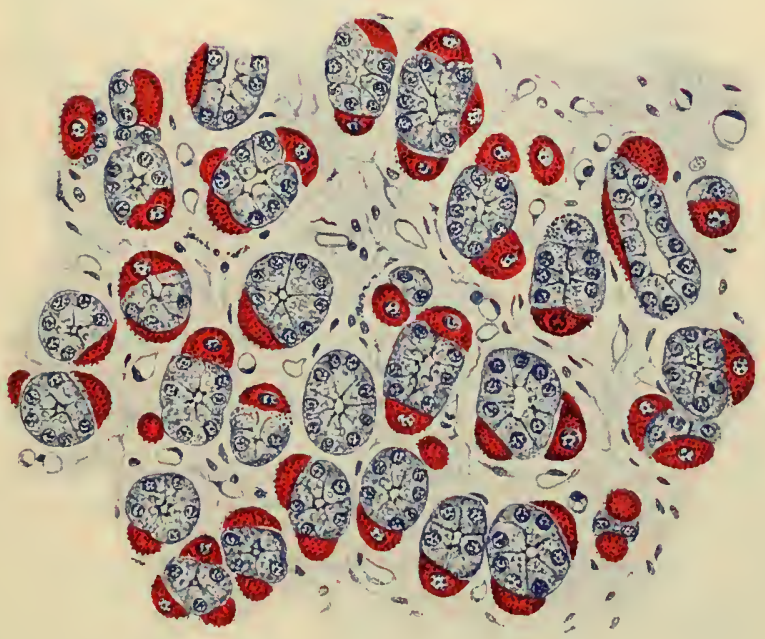

Fig. 354.--SECTIONS OF THE MUCOUS MeMBRANE OF THE FUNDUS OF THE DOG'S STOMACH PASSING ACROSS THE LONG AXIS OF THE GLANDS.

A, Section close to but not quite parallel with the surface, and including on the left the gland ducts and on the right the commencing gland tubulcs. Notice the oxyntic cells beginning to appear between the columnar cells of the ducts.

B, Deeper part of the same section, showing the lumina of the gland tubules surrounded by chief cells, with the oxyntic cells altogether outside them. 
the chief cells of the fundus glands, but are not quite identical with them in appearance, the granules being much less distinct. The cells are of a columnar or cubical shape, and in the fresh condition of a granular appearance; quite unlike the clear columnar epithelium of the

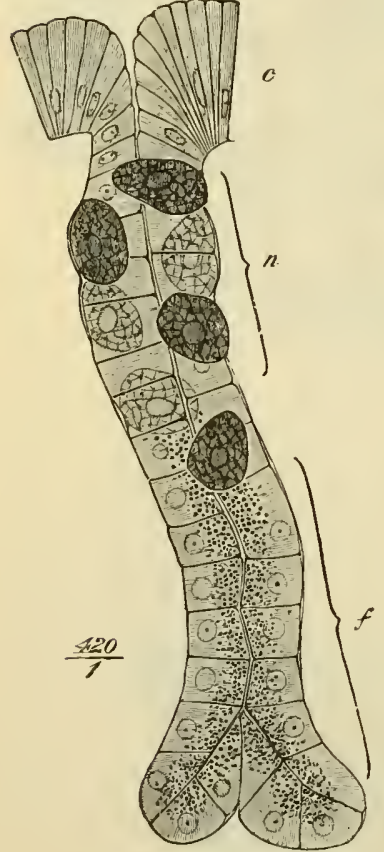

Fig. 355 .

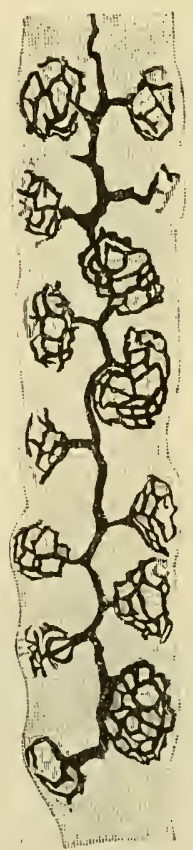

FIG. 356 .

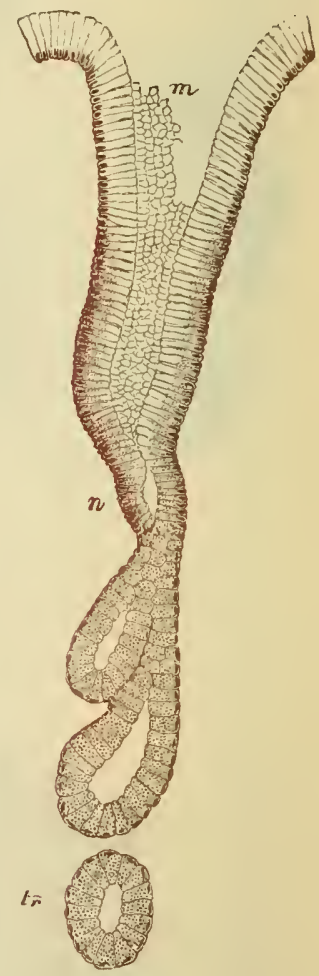

FIG. 357 .

Fig. 355.-A FUNDUS GLAND OF SIMPLE FORM FROM THE BAT'S STOMACH.

Osmic acid preparation. (Langley.)

$c$, columnar epithelium of the surface; $n$, neck of the gland with central and parietal cells; $f$, base, oceupicd only by princijal or central cells, which exhibit the granules aceumulated towards the lumen of the gland.

Fig. 3.36. - A Fundus gland prepared by golgi's Method, Showing the MODE OF COMMUNICATION OF THE PARIETAL CELLS WITH THE GLAND-LUMEN. (E. Müller.)

Fig. 357.-A PYLORIC GLAND, FROM a SECtion OF THE DOG'S stoMACH. (Ebstein.) $m$, mouth; $n$, neck; $t r$, a decp portion of a tubule cut transversely.

surface, which is formed, as elsewhere, of long tapering cells, the outer part of which is filled with mucigen.

At the pylorus itself the gastric glands become considerably lengthened and enlarged, and are continued into the submucous tissue, the muscularis mucosa being here deficient; they thus 


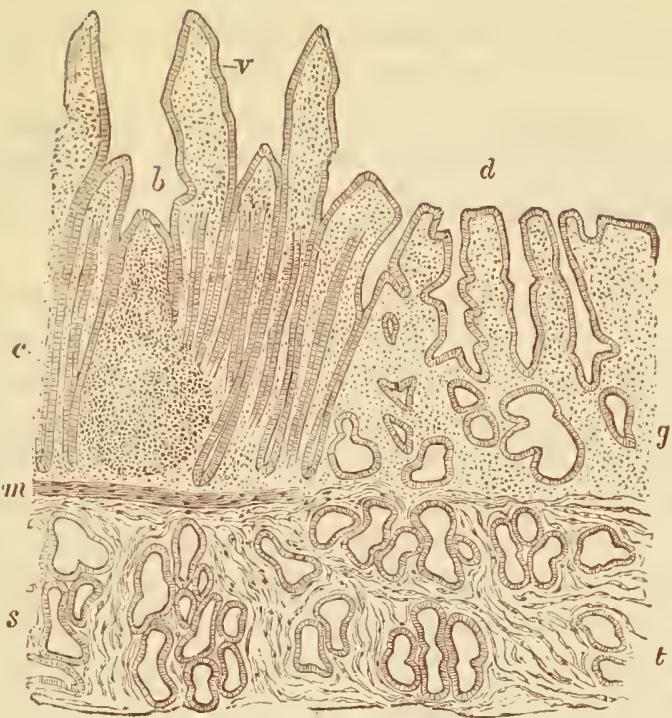

Fig. 358.-SECTION THROUGH THE PYLORCS, INCLUDING THE COMMENCEMENT OF THE DUODENUM. (Klein.)

$r$, villi of duodenum ; $b$, apex of a lymphoid nodule ; $c$, crypts of Lieberkülnn ; $s$, secreting tubules of Brunner's glands; $d$, ducts of pyloric glands of the stomach; $g$, tubes of these glands in inucous membrane; $t$, deeper lying tubes in submucosa, correspond. ing to secreting tubules of Brunner's glands of duodenum; $m$, muscularis mucosæ.

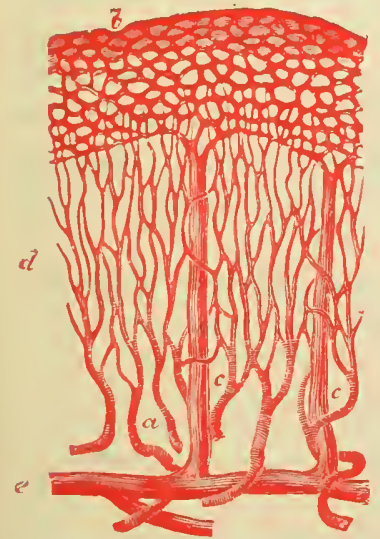

Fig. 359.-PLAX OF THE BLOODVESSELS OF THE STOMACH. (Modified from Brinton.)

$a$, smill arteries passing to break up into the fine capillary network, $d$, between the glands; $b$, coarser capillary network around the mouths of the glands; $c, c$, veins passing vertically downwards from the superficial network; $e$, larger vessels in the submucosa.

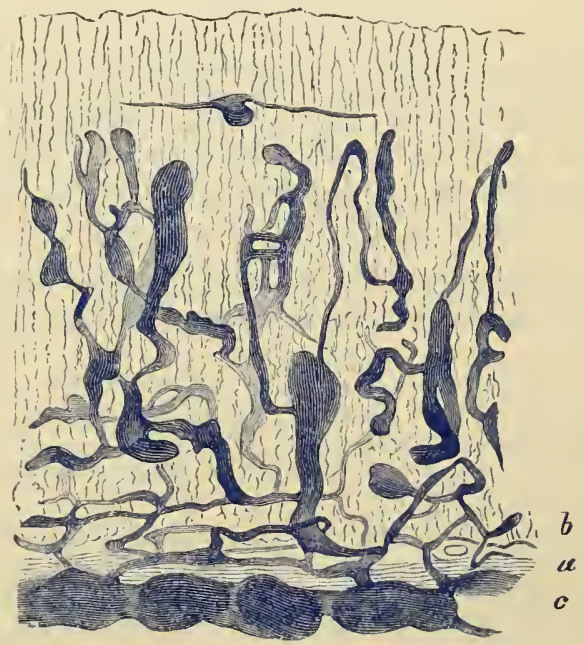

Fig. 360.-LyMPhatics OF THE HUMAN GASTRIC MUCOUS MEMBRANE, INJECTED. (C. Lovèn.)

The tubules are only faintly indicated; $a$, muscularis mucosæ; $b$, plexus of fine vessels at base of glands; $c$, plexus of larger valved lymphatics in submucosa. 
present transitions to the glands of Brunner, which lie in the submucous tissue of the duodenum (fig. 358).

Scattered amongst the ordinary secreting cells of the pyloric glands, cells are seen here and there which stain differently from the rest, and probably have a different function (Stöhr). Uccasionally oxyntic cells are met with in the pyloric glands and even in Brumner's glands in the chodenum (Kaufmann).

The blood-vessels of the stomach are very numerous, and pass to the organ along its curvatures. The arteries traverse the musenlar coat, giving off branches to the eapillary network of the muscular tissue, and ramify in the areolar eoat. From this, small tortuous arteries pierce the muscularis mucosie, and break up into capillaries near the bases of the glands (fig. 359). The capillary network extends between the glands to the surface, close to which it terminates in a plexus of relatively large venons capillaries which encircle the mouths of the glands. From this plexus straight venous radicles pass through the mucous membrane, pieree the muscularis mueosæ, and join a plexus of veins in the submucous tissue. From these reins blood is carried away from the stomach by efferent veins, which aceompany the entering arteries.

The lymphatics (fig. 360) arise in the mucous membrane by a plexus of large vessels dilated at intervals, and looking in sections like clefts in the interglandular tissue. From this plexus the lymph is earried into large valved vessels in the submucous coat, and from these, efferent vessels run through the muscular coat to reach the serous membrane, underneath which they pass away from the organ. The muscular coat has its own network of lymphatic vessels. These lie between the two principal layers, and their lymph is poured into the efferent lymphaties of the organ.

The nerves have the same general arrangement and mode of distribution as those of the intestine (see next Lesson). 


\section{LESSONS XXXII. AND XXXII.}

\section{THE SWALL AND LARGE INTESTINE.}

1. Sectioss of the duodenum, jejunum, and ileum, vertical to the surface. The three parts of the intestine may be embedded in the same parafin block, and the sections stained and mounted together. Choose a part of the ilem which includes a Peyer's patch. Observe the norloles of lymphoid tissue which constitute the patch and which extend into the submucous tissue. Observe the lymphoid cells in the superjacent epithelium. Notice also the sinus-like lymphatic or lacteal ressel which encircles the base of each nodule. In the duodeum study the glands of Brumer in the submucous tissue. Make a general sketch of each section under a low power and draw a villus under the high power. The general arrangement and structure of the intestinal wall is to be studied in these sections.

2. Sections parallel to the surface of the intestine, and therefore across the long axis of the villi and glands of the mucous membrane. In order to keep the sections of the villi together so that they are not lost in the mounting, it is necessary either to embed in celloidin or, if parafin be used, to employ an adhesive method of mounting.

In this preparation, sketch the transverse section of a villus and of some of the crypts of Lieberkiilnn.

3. To study the process of fat-absorption, kill a frog two or three days after feeding with bacon fat. Put a very small shred of the mucous menbrane of the intestine into osmic acid $(0 \div 5$ per cent.) and another piece into a mixture of 2 parts Miiller's fluid and 1 part osmic acid solution (1 per cent.). After forty-eight hours teased preparations may be made from the osmic acirl preparation, in the same mammer as directerl in Lesson VIII., \$ 1. The piece in Miiller and osmic acid may be left for ten days or more in the fluid. When hardened, sections are made by the freezing method and mounted in glycerine.

4. Sections of small intestine the blood-vessels of which have been injected. Notice the arrangement of the vessels in the several layer's. Sketch carefully the vascular network of a villus.

5 . From a piece of intestine which has been stained with chloride of gold tear off broad strips of the longiturliual muscular coat, and mount them in glycerine. It will generally be found that portions of the nervous plexus of Aiterbach remain adhereut to the strips, and the plexus can in this way easily be studied.

From the remainder of the piece of intestine tear off with forceps the fibres of the circnlar muscular layer on the one side, and the mucous membrane on the other sille, so as to leave only the submucous tissue and the muscularis mucosæ. This tissue is also to be mounter flat in glycerine: it contains the plexus of Meissner:

Sketch a small portion of each plexus under a high power. The plexuses can also be studied by the methylene-blue and reduced silver methods (see Appendix).

6. Sections of the large intestine, perpendicular to the surface. These will 
show the general structure and arrangenent of the coats. Sketch under a low power.

7. Sections of the mucous membrane of the large intestine parallel to the surface, and therefore across the glands. Sketch some of the glands and the interglandular tissue under a high power.

8. The arrangement of the blood-vessels of the large intestine may be studied in sections of the injected organ.

The wall of the small intestine consists, like that of the stomach, of four coats (fig. 361).

The serous coat is complete except over part of the duodenun.

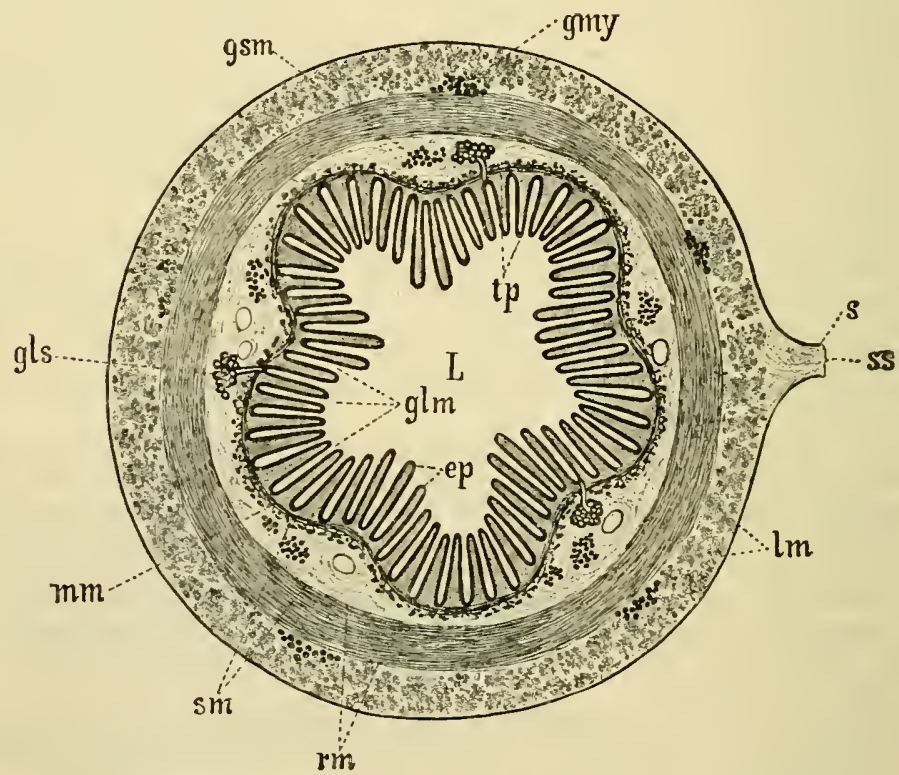

Fig. 361.-Dingram of section of alimentary tube. (Sobotta.)

$L$, lumen ; glm, glands of mucous membrane ; ep, epitbclium; gls, glands in submucosa ; $m m$, muscularis mucose ; $s m$, submucous coat ; $r m$, circular muscular layer ; $l m$, longitudinal muscular layer; $s$, serous coat; $s s$, mesentery; gmy, gauglion of plexus inyentcricus; gsin, ganglion of plexus submucosus.

The muscular coat is composed of two layers of muscular tissue, an outer longitudinal and an inner circular. Between them lies a network of lymphatic vessels and also the close gangliated plexus of nonmedullated nerve-fibres known as the plexus myentericus of Auerbach. The ganglia of this plexus may usually be seen in vertical sections of the intestinal wall (in figs. 365, 369), but the plexus, like the one in the submucous coat immediately to be described, can only be 
properly displayed in preparations made with chloride of gold (fig. 362 ) or methylene blue or by Golgi's method.

The submucous coat is like that of the stomach; in it the bloor-vessels and lacteals ramify before entering or after leaving the mucous membrane, and it contains a gangliated plexus of nerve-fibres-the plexus of Meissner-which is finer than that of Auerbach and has fewer

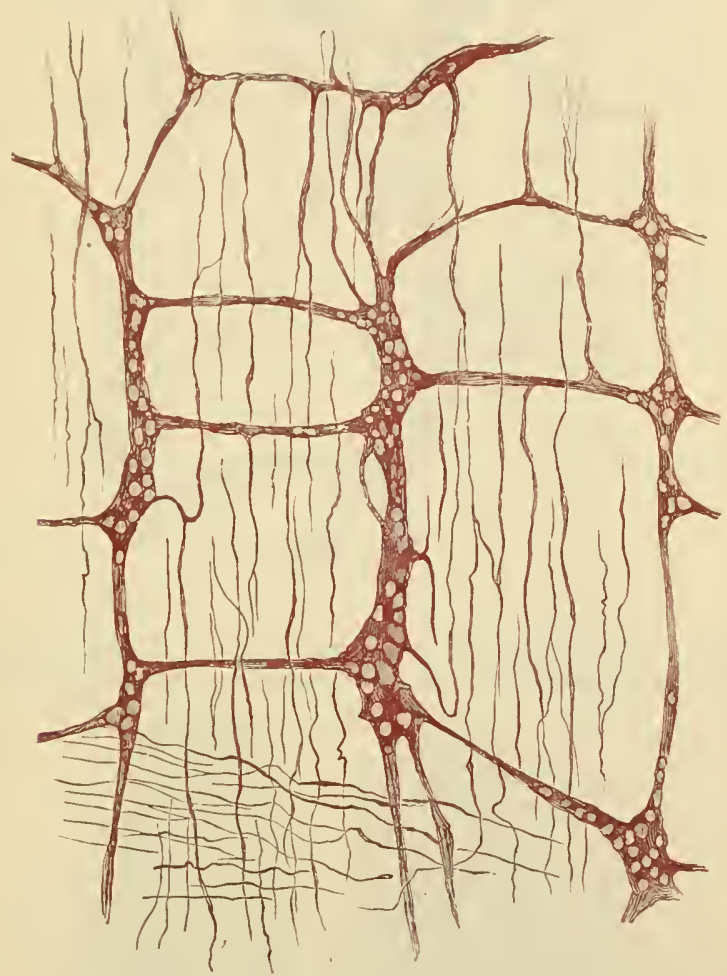

Fig. 362.-AUERbach's PleXUS, From the MUSCUlar COAT OF THE INTESTINE. (Cadiat.)

ganglion cells (fig. 363). Its branches are chiefly supplied to the muscular fibres of the mucous membrane, but also to the glands and villi (fig. 364).

The mucous membrane is bounded next to the submueous coat by a double layer of plain muscular fibres (muscularis mucosee). Bundles from this pass inwards through the membrane towards the inner surface and penetrate also into the villi. The mucous membrane proper is pervaded with simple tubular glands-the crypts of Lieberkiuhn (figs. 365, 366, 369) - which are lined throughout by a columnar 


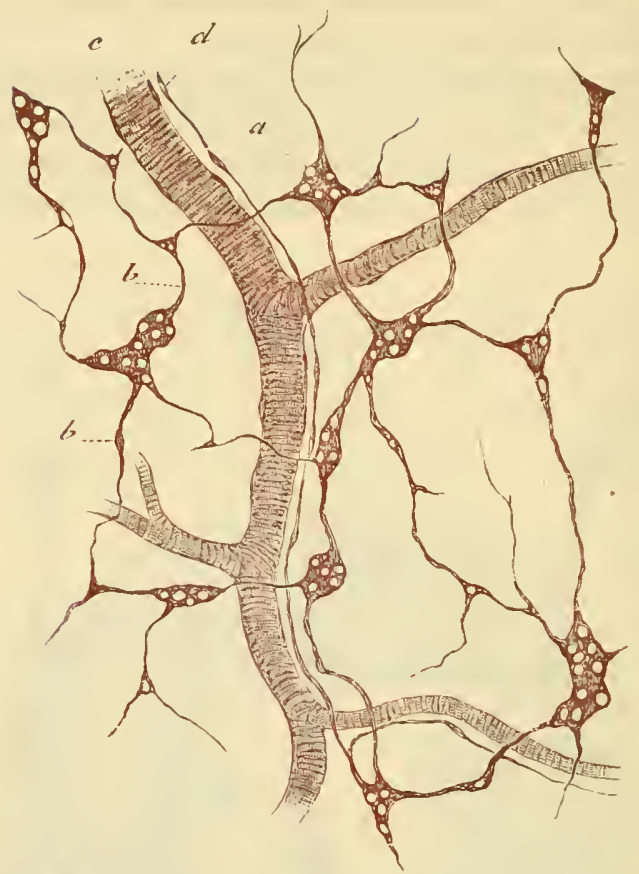

Fig. 363. - MeissNeris Plexus froy the subMucous COAT. (Cadiat.) $a$, gangliou ; $b, b$, nervous cords; $c$, a blood-vessel; $d$, an entering lymphatic nerve.

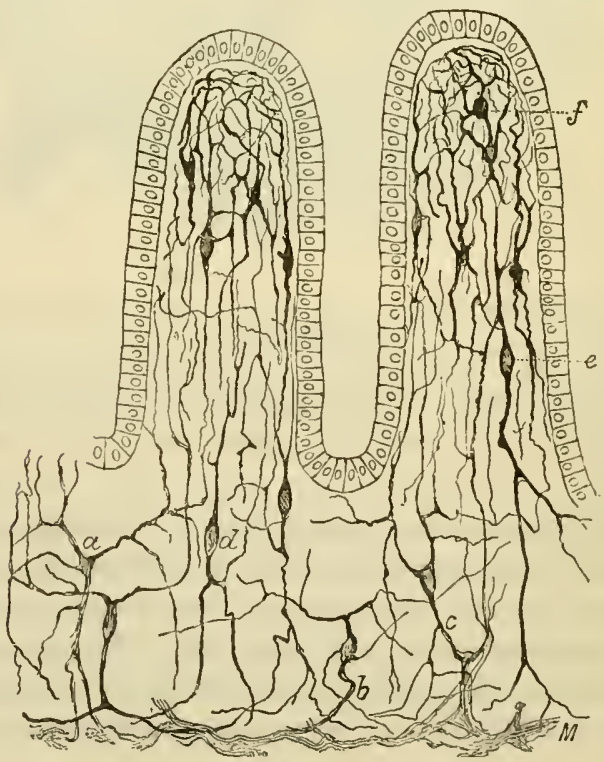

Fig. 364.-Nerves of the Mucous MembraNe of the sMall iNtestive. (Cajal.) $M$, part of Meissner's plexus; $a-f$, small nerve-cells and nervc-fibres in the tissue of the mucous membrane and villi. 
epithelium, with scattered goblet cells, like that which eovers the general surface and the villi. At the fundus of each erypt are a few cells containing well-marked granules (Paneth). The cells of the glands show frequent mitoses, and it is believed that the epithelium of

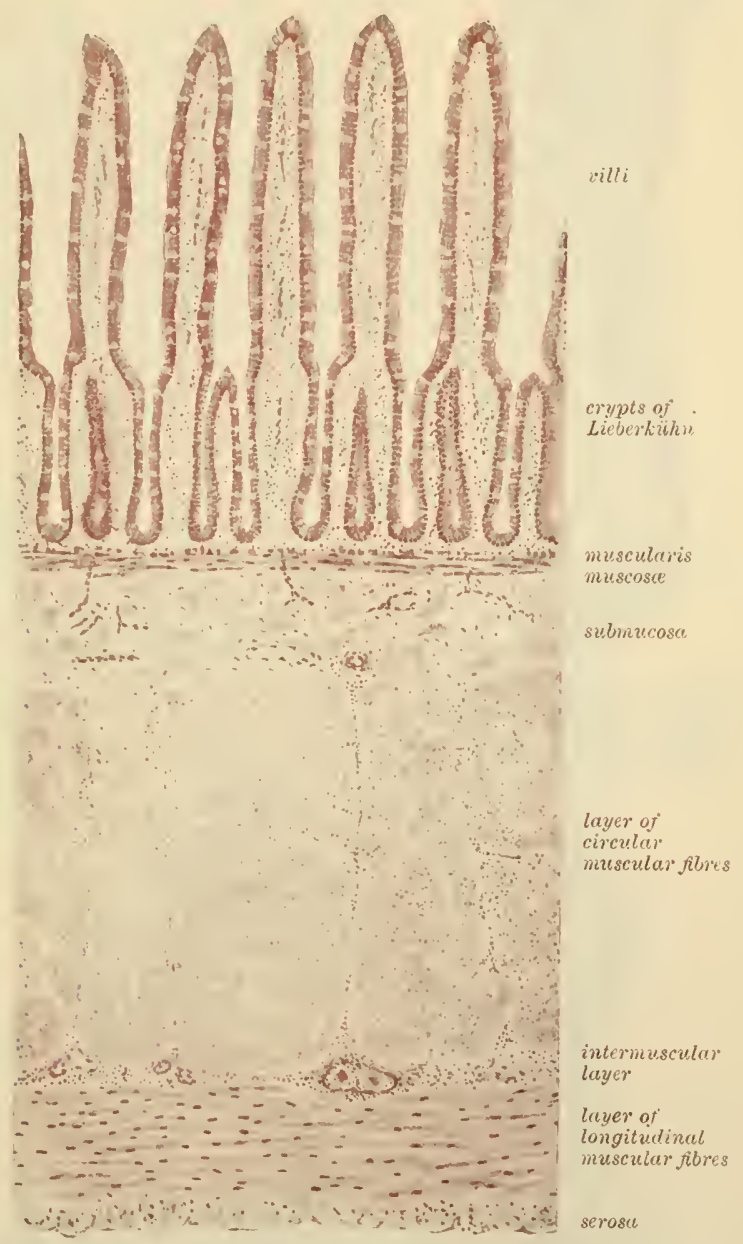

Fig. 365̃.-SEction OF THE SMALl intestine (JejunUM) OF CAT.

(MIagnified about 40 diameters.)

the general surface becomes regenerated from them (Bizzozero). The mueous membrane between these glands is mainly composed of retieular tissue, which contains here and there nodules of lymphoid tissue. These nodules constitute when they oceur singly the so-called solitary glands of the intestine (fig. 368), and when aggregated together 
form the agminuted glands or patches of Peyer (fig. 374). The latter occur chiefly in the ileum.

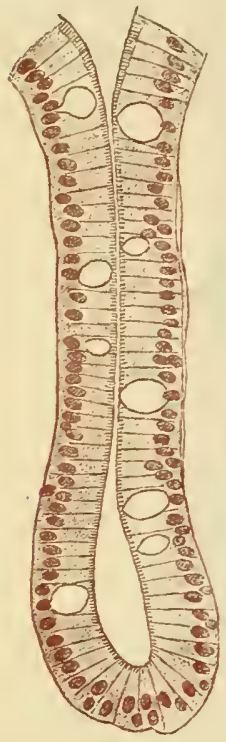

FIG. 366.-A CRYPT OF LIEBERKËHN G'ROIT THE HCMAN INTEATINE. (Flemming.)

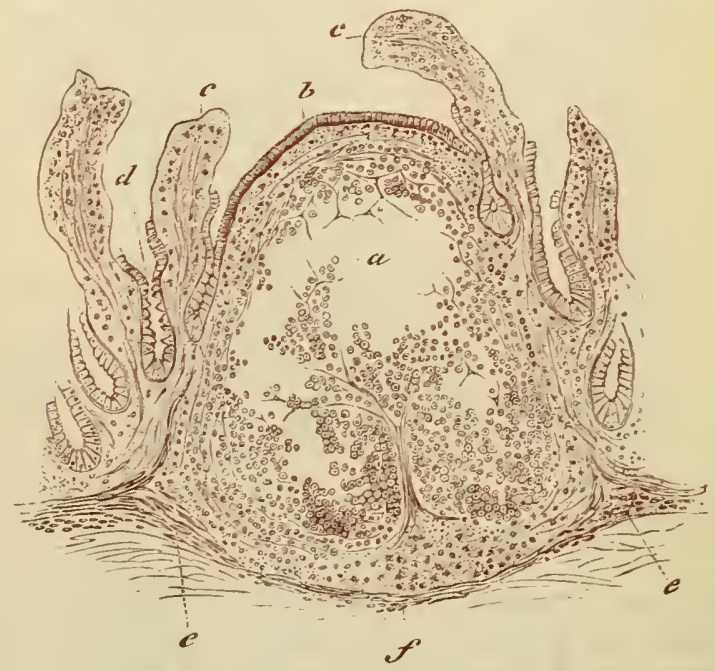

Fig. 368.-SECTION OF THE ILEUM THROUGH A LYMPHOID Nodule. (Cadiat.) $a$, middle of the nodule with the lymphoid tissue partly fallen away from the scction; $b$, epithelium of the intestine ; $c$, villi : their epithelium is partly broken away; $d$, crypts of Lieberkithn; $e, f$, muscularis mucosæ. 
The glands of Brunner, which have been already noticed (p. 294), oecur in the duodenum. They are small tubulo-racemose glands of

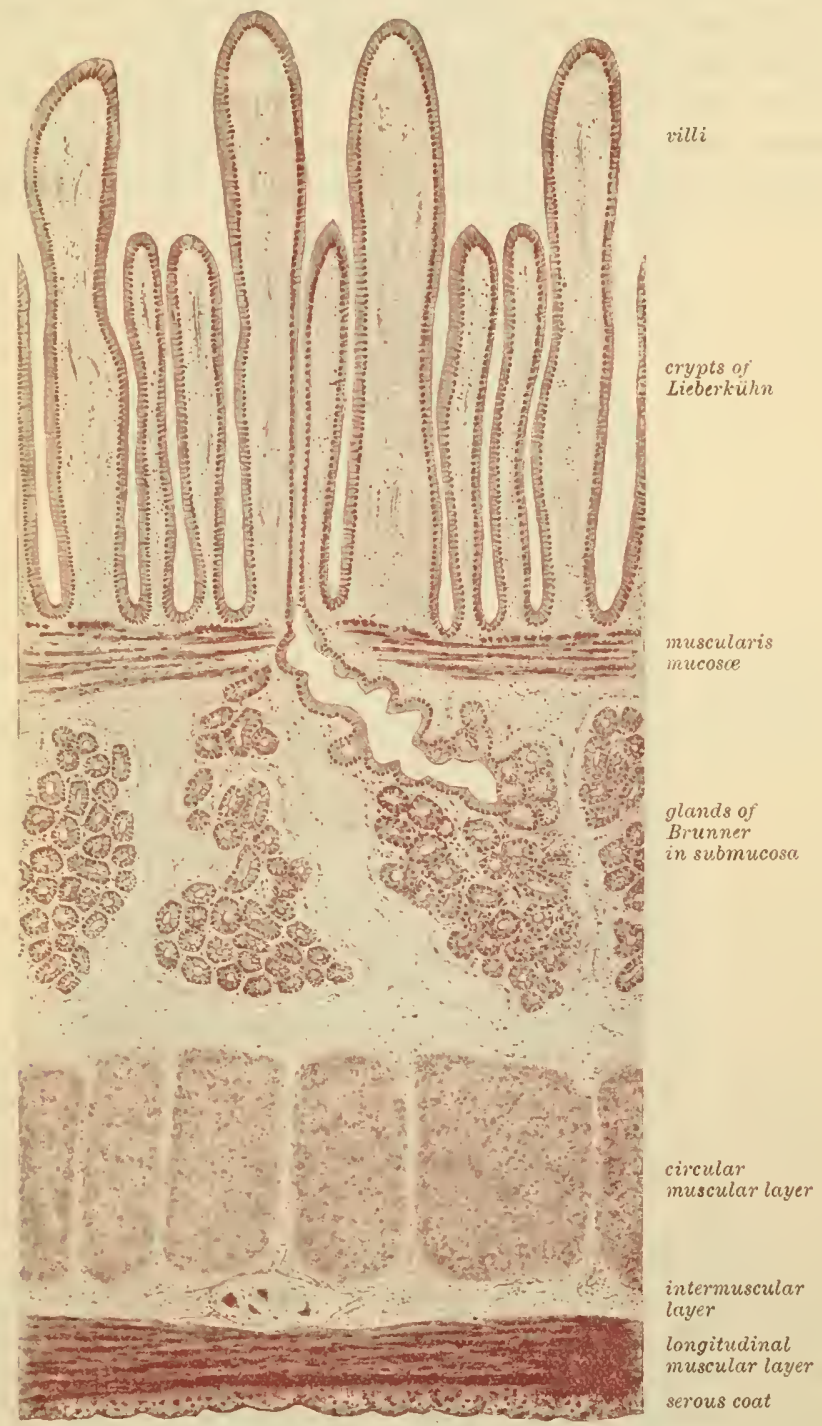

Fig. 369. - Section of duodency of Cat, showing Brunner's glands.

(Magnified about 60 diameters.)

serous character, situated in the submucosa (fig. 369); they send their ducts to the inner surface of the mucous membrane either between the crypts of Lieberkïhn or into them. 
The villi with which the whole of the inner surface of the small intestine is closely beset are clavate or finger-shaped projections of the mucous membrane, and are composed, like that, of retiform tissue covered with columnar epithelium (figs. 370 to 372 ). The characters of this epithelium have already been described (Lesson VIII.). Between and at the base of the epithelium-cells many lymphcorpuscles occur, as well as in the meshes of the retiform tissue.

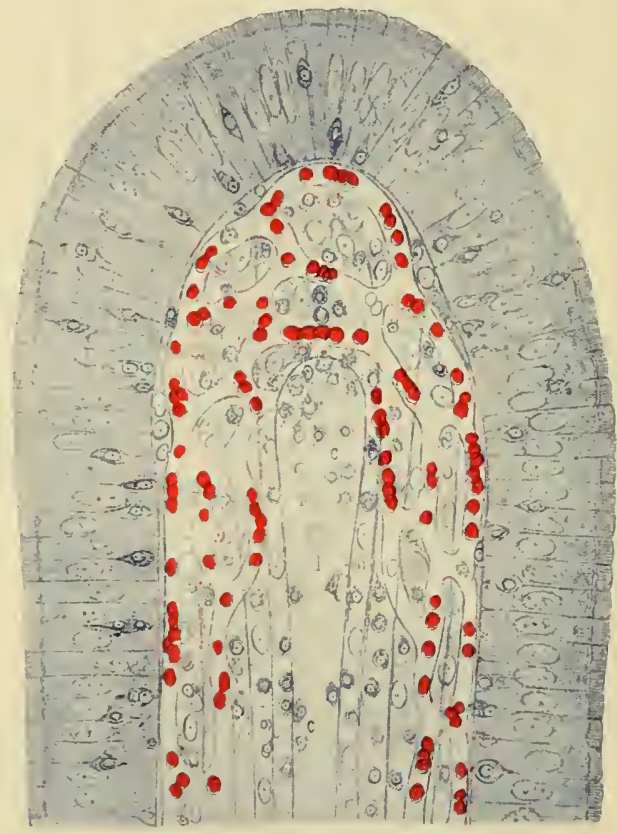

Fig. 370. - LONGITUdINAL SECTION OF A VILLUS FROM A RAT KILLED THREE HOURS AFTER FEEDING WITH BREAD AND WATER.

The columnar epithelium shows numerous lsmph-corpuseles between the cells ; $l$, lacteal, containing lymph-corpuscles, $c$, some partly disintcgrated.

The epithelium rests upon a basement-membrane. In the middle of the villus is a lymphatic or lacteal vessel which may be somewhat enlarged near its commencement, but the enlargement is replaced in some animals by a network of lacteals. Surrounding this vessel are small bundles of plain muscular tissue prolonged from the muscularis mucosæ. The network of blood-capillaries (figs. 370, 373) lies for the most part near the surface within the basement-membrane; it is supplied with blood by a small artery which joins the eapillary network at the base of the villus; the corresponding vein generally arises near the extremity. 


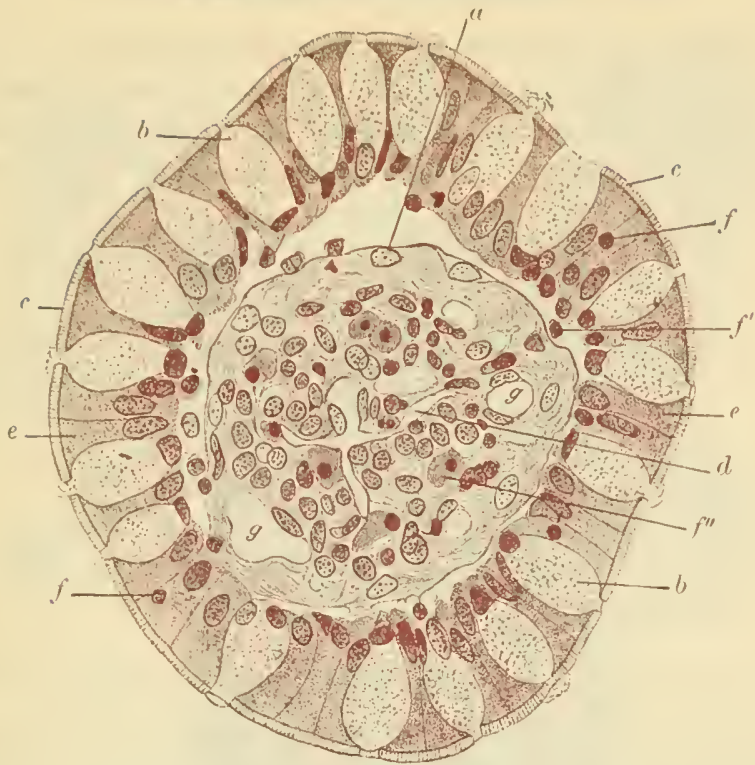

Fig. 371.-Transveise section of a villus, yay. (v. Ebner.) Magnified 530 diameters.

$a$, bascment-membrane, here somewhat shrunken away from epithelium; $b$, gobleteells; $c$, euticula ; $d$, lacteal ; $e$, eolumnar epithelium ; $f$, leucocytcs in epithelium; $f^{\prime}$, leucocy tes below epithelium ; $f^{\prime \prime}$, large leucocytes ; $g$, blood-vessels.

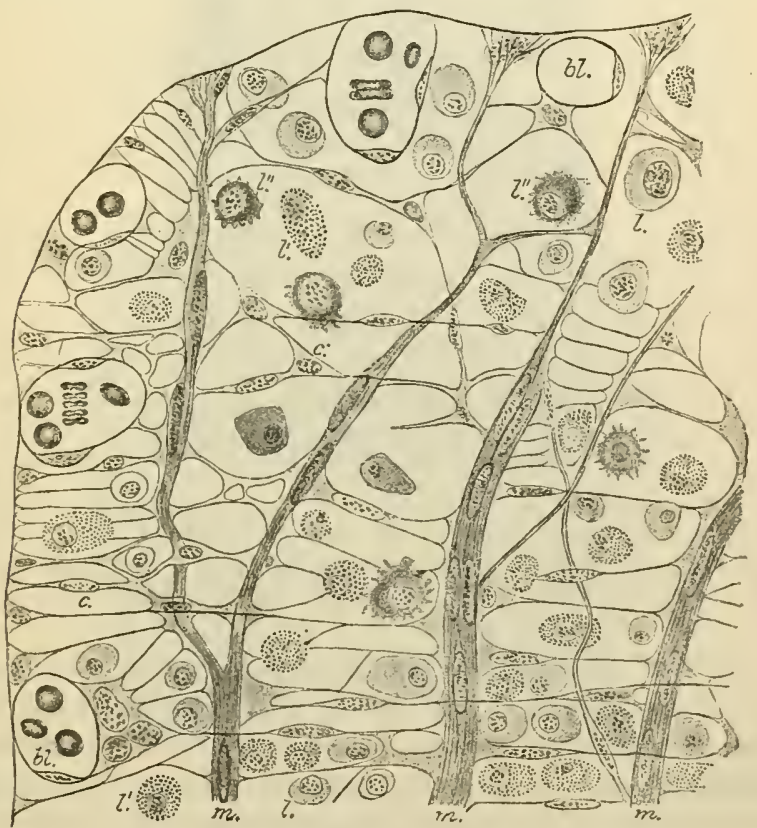

Fig. 372.-PART OH a SECTION THROUgh a villus OF THE DOG, HIGHLY MAGNIFIED, (R. Heidenhain.)

$m$, plain muscle; $l, l^{\prime}, l^{\prime \prime}$, leucocytes, which are seen in Large numbers in the interstices of the reticular tissue; $l l$, vessels; $c$, connective-tissue cells, corering the fibrils of the reticulum. The opithelium of the villus is not represented. 
The lymphatics (lacteals) of the mucous membrane (fig. 374), after receiving the central lacteals of the villi, pour their contents into a plexus of large valved lymphatics which lie in the submucous tissue and form sinuses around the bases of the lymphoid nodules (fig. 256,

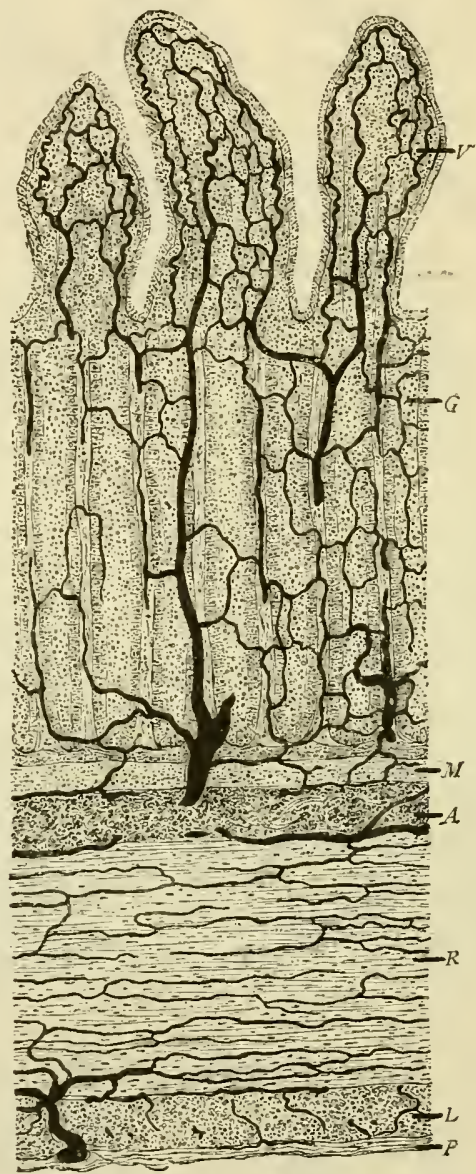

Fig. 373.-SMall intestive (Vertical tRansverse SECtion), With THE BLOOD-VESSELS INJECTED. (Heitzmann.)

$V$, a villus ; $G$, glands of Lieberkühn ; $M$, muscularis mucose; $A$, areolar coat ; $R$, circular muscular coat; $L$, longitudinal muscular coat; $P$, peritoneal coat.

p. 208). From the submucous tissue efferent vessels pass through the muscular coat, receiving the lymph from an intramuscular plexus of lymphatics, and are conveyed away between the layers of the mesentery.

Absorption of fat. - In order to study the process of fat transference in the intestine, it is convenient to stain the fat with osmic acid, which 


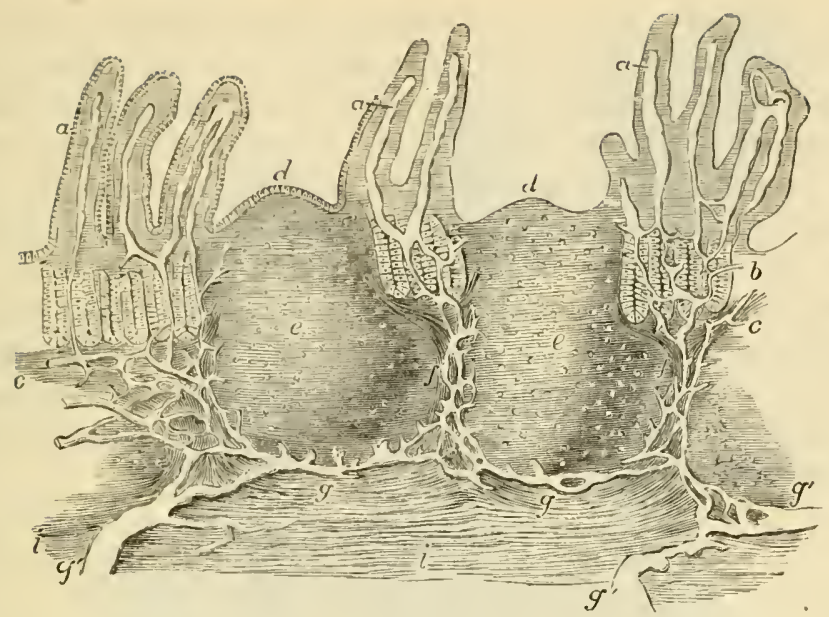

Fig. 374-Vertical section of a portion of a Perer's patch, with the LACTEAL VFSজELS INJECTED. Magnified 32 diameters. (Frey.)

The specimen is from the lower part of the ileum; ", villi, with thcir lacteals left white; $b$, some of the tubular glands; $c$, the miscular layer of the nucous membrane : $d$, cupola or projecting part of the nodule ; $e$, central part; $f$, the reticulated lacteal vesseis occupying the lymphoid tissue betwecn the nodules, joined above by the lactcals from the villi and mucous surface, and passing below into $q$, the sinus-like lacteals under the nodules, which again pass into the large efferent lacteals, $g^{\prime} ; i$, part of the muscular coat.

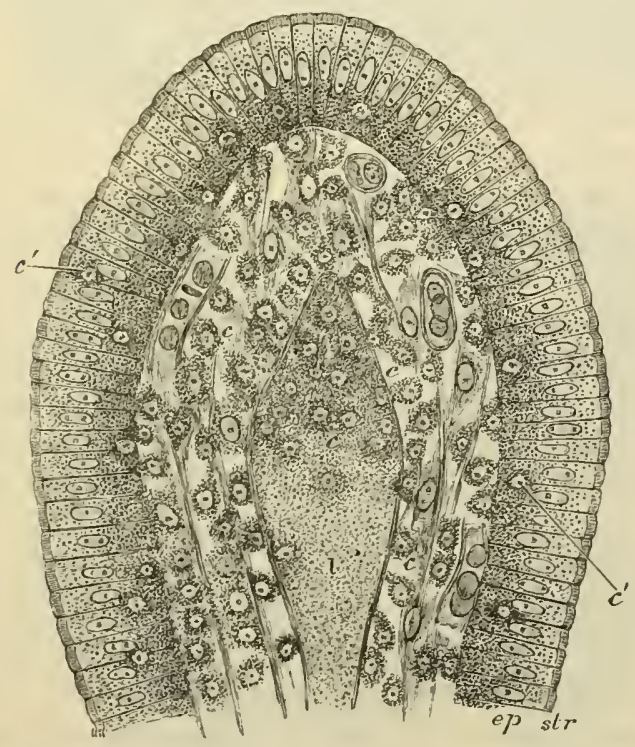

Fig. 375.--SECTION OF THE VILLUS OF A RAT KILLED DURING FAT-ABSORPTION. $\epsilon p$, epithelium; str, striated border; $c$, lencocytes ; $c^{\prime}$, leucocytes in the epithelium ; $l$, central lacteal containing chyle and disintegrating leucocytes. 
colours it black. It can then be observed that in animals which have been fed with food containing fat, particles of fat are present (1) in comparatively large globules within the columnar epithelium-cells ; (2) in fine granules in the interstitial tissue of the villus, but often confined to the amoboid leucocytes, which abound in this tissue; (3) in fine granules within the central lacteal of the villus. The leucocytes are present not only in the reticular tissue of the villus, but also in considerable numbers between and at the base of the epithelium-cells; and they can also be seen in thin sections from bichromate-osmic preparations within the commencing lacteal; in the last situation they are undergoing disintegration (figs. 375,376 ). These observations are easily made in the frog.

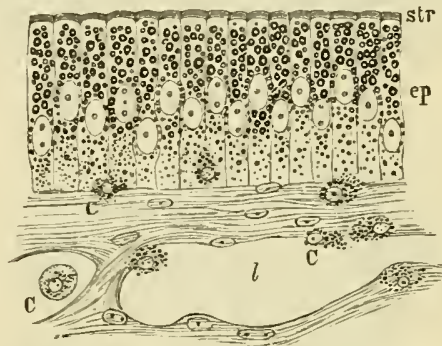

Fig. 376. - Mucots MEMBRANE OF Frog'S INTESTINE DURING FAT-ABSORPTION.

$e p$, epithelium ; str, striated border ; $c$, leucucstes; $l$, lacteal.

Since the leucocytes are amoboid, it is probable from these facts that the mechanism of fat-absorption consists of the following processes -viz. (1) absorption or formation of fat in the colunınar epitheliumcells of the surface; (2) ejection of fat-granules from the epithelium into the tissue of the villus; (3) inception of fat by leucocytes, these taking it up after it has passed out of the epithelium-cells; (4) migration of lencocytes carrying fat particles through the tissue of the villus and into the central lacteal; (5) disintegration and solution of the immigrated leucocytes, and setting free their contents. Since fat-particles are never seen in the striated border of the columnar cell it is probable that the fat first becomes saponified by the action of the digestive juices, and reaches the epithelium-cell in the form of dissolved soap; the fat which is seen and stained by osmic acid within the cells having become re-formed by a process of synthesis.

In some young animals (puppy, kitten) the fat which is undergoing absorption is seen not only in the epithelium-cells and leucocytes, but also in the form of streaks of liquid, stained black by osmic acid, in the interstices of the reticular tissue of the villi. It has probably passed 


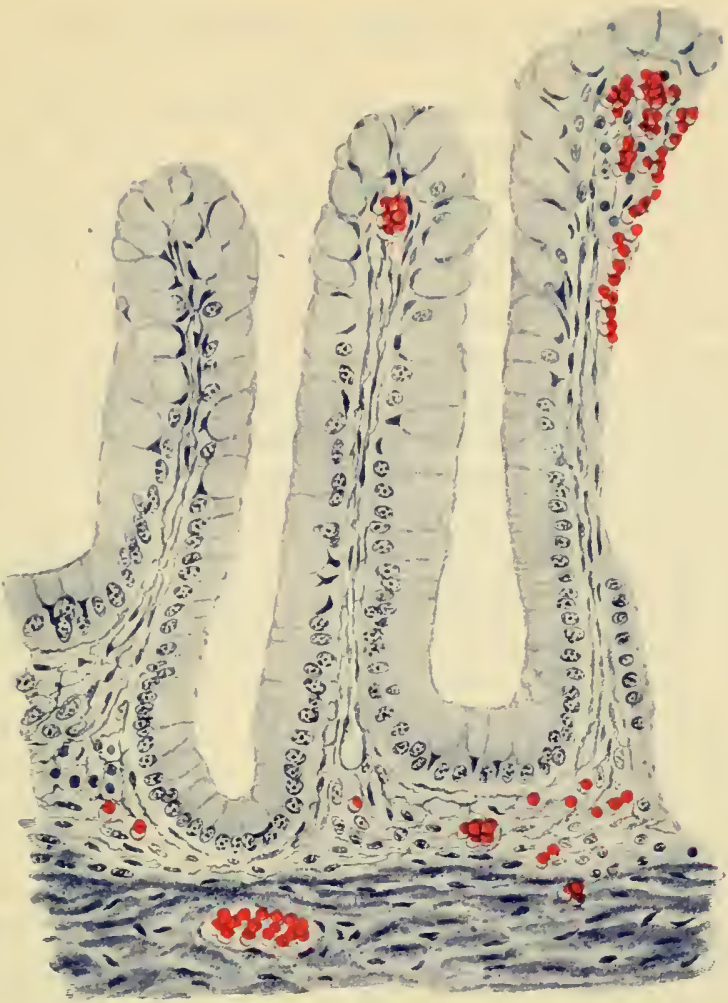

d

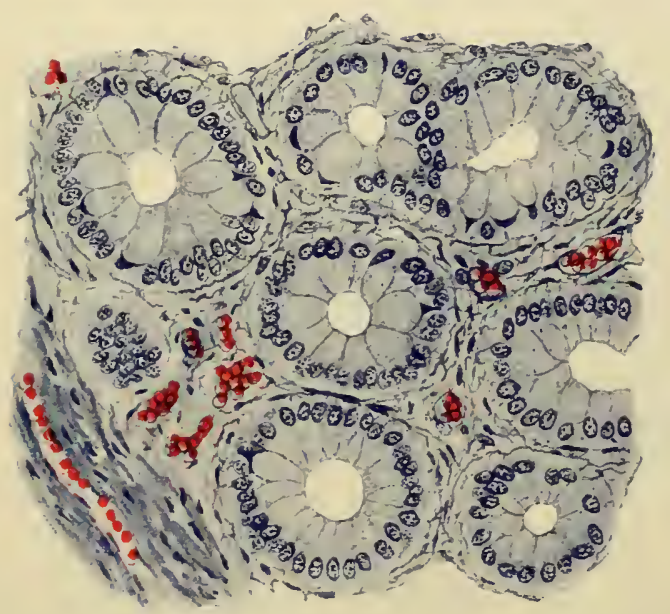

B

Fig. 377.-GLaNdS OF THE LARGE INTESTINe OF CHILD. (300 diameters.) $A$, in longitudinal section; $B$, in transverse section. 
ont from the epithelium in a dissolved condition by a kind of reversed secretion.

The migration of leucocytes into the lacteals of the villi is not a special feature of absorption of fat, but occurs also when absorption of other matters is proceeding (fig. 370); the transference of fat-particles is merely a part of a more general phenomenon of migration of lencocytes which accompanies the process of absorption.

The large intestine has the usual four coats, except near its termination, where the serous coat is absent. In man the muscular coat is peculiar in the fact that along the cxecum and colon the longitudinal muscular fibres are gathered up into three thickened bands which produce puckerings in the wall of the gut.

The mucous membrune of the large intestine is beset with simple tubular glands somewhat resembling the crypts of Lieberkühn of the small intestine, and lined by columnar epithelium similar to that of the inner surface of the gut, but containing many more mucus-secrcting or goblet-cells (fig. 377). The blind extremity of each gland is usually slightly dilated. These glands of the large intestine are not strictly homologous with the crypts of the sniall intestine, for whereas the latter are developed as depressions in the general surface between the villi, the glands of the large intestine are formed by the growing together of villus-like projections of the surface. The interglandular tissue is a reticular tissue and is beset here and there with solitary glands, especially in the crecum. The mucous membrane of the vermiform appendix is in great part of its extent packed full of lymphoid nodules.

The arrangement of the bloor-vessels and lymphatics in the large intestine resembles that in the stomach. The nerves of the large intestine also resenible those of the stomach and small intestine in their arrangement.

At the lower enr of the rectum the circular nuscular fibres of the gut become thickened a little above the anus to form the internal sphincter muscle. In the anal region there are a number of compound racemose mucous glands opening on the surface of the mucous membrane (anal glands). The anus has a lining of stratified epithelium continuous with that of the skin. 


\section{LESSONS XYYIV AND XYXV.}

\section{THE LIVER AND PANCREAS.}

1. Secrioss of liver are to be studied carefully. They may be stained with eosin and hæmatoxyliu; or by eosin and methylene-blue after Mur's methol (see Appendix). Sketcli the general arrangement of the cells in a lobule under the low power; and under the high power make very carefu] drawings of some of the hepatic cells and also of a portal canal. If from the pig, the ontlines of the lobules are observed to be very well narkerl.

Notice that the hepatic cells are in intimate contact with the blood-capillaries or simnsoids. Some cells may be found to contain rell blood-corpuscles; many are filler with ersinophil grannles. Notice in the sinusoid capillaries the large partly detacherl endothelial cells (cells of Kupffer). These also frequenty contain erythrocytes, which appear to be in process of destruction.

2. To observe the glycogen within the liver-cells, kill a rabbit or rat (preferably about six hours after a full meal of carrot), and at once throw a thin piece of the liver into 96 per cent. alcohol. When well hardened the piece nay be embediled in paraftin in the usual way, or sections may be cut with the free hand withont emberlding. Some of the sections so obtained are to be treated with a I per cent. sulntion of iodine in potassium iodide for five minutes; they may then be uounted in a nearly saturated solution of potassium acetate, the cover-glass being cemented with gold size.

3. Presence of iron. Other sections of alcohol-hardened liver are to be treated first with potassium ferrocyanide solution and then with hydrochloric acid and alcohol ( 1 to 10 ), passerl through absolute alcohol into xylol, and mounted in dammar; in these many of the pigment granules will be stained blue (Prussian blue). Or the sections may simply be placed in an aqueous solution of hæmatoxylin ( 1 to 300 ), with or without previous treatment with alcohol containing 10 parts per cent. hydrochloric acid (to set free organically combinel iron), after which they are mounted in the ordinary way (Macallum's methor).

4. Study, first with the low power and afterwards with the high power, a section of the liver in which the blood-vessels have beeu injecterl. Almost invariably the injection will be found to have penetrated into canaliculi within the liver-cells themselves. Make a general sketch of a lobule under the low power and llaw a small part of the network of blood-vessels and intracellular canaliculi nnder the high power.

5. Take a small piece of liver which has been several weeks in 2 per cent. bichronate of potassium solution or Mitller's fluid and plunge it in I per cent. nitrate of silver solntion, changing the fluid after lialf an hour. Leave the piece of liver in the silver solntion overnight. It may then be transferred to alcohol, and after complete dehydration embedded and cut in paraffin in the usmal way and the sections monnted in dammar. In many parts of such sections the bile-canaliculi are stained.

They can also be bronght to view (at the periphery of the lobules) by injection with solution of Berlin blue from the hepatic duct; or, thronghout the whole of the lobule, by injecting abont 60 c.c. of saturated sulphindigotate of sork solution in three successive portions, at intervals of half an 
hour, into the bloor-vessels of an anæsthetized cat or rabbit. Two hours after the last injection the animal is killed, and the blood-vessels washed out with saturated solution of potassium chloride. The organ is then fixed with absolute alcohol. But the chromate of silver methor is easier and surer than the injection methods.

6. Tease a piece of fresh liver in serum or salt solution for the study of the appearance of the hepatic cells in the recent or living condition.

7. Stained sections of pancreas from a gland which has been hardenerl in alcohol, or in formol followed by alcoliol. The sections may be double stained with eosin and hrmatoxylin or with eosin and methylene blue. Notice the islets of Langerlians between the alveoli; largest and most evident in animals which lave been long fasting and also very well marked after the glaud has been stimulated by secretin.

Make sketches under both low and high power.

8. Tease a sruall piece of fresh pancreas in serun or salt solution. Notice the granules in the alveolar cells, chiefly accumulated in the half of the cell which is nearest the lumen of the alveolus, leaving the outer zone of the cell clear.

sketch a small portion of an alveolus under a high power.

9. The ducts of the pancreas, and the termination of nerve-fibres in the alveoli way be seen in preparations made by the folgri methorl.

THE LIVER.

The liver is a solid glandular organ, made up of the hepatic lobules. These are polyhedral masses (fig. 378) about $1 \mathrm{~mm} .\left(\frac{1}{25}\right.$ inch) in

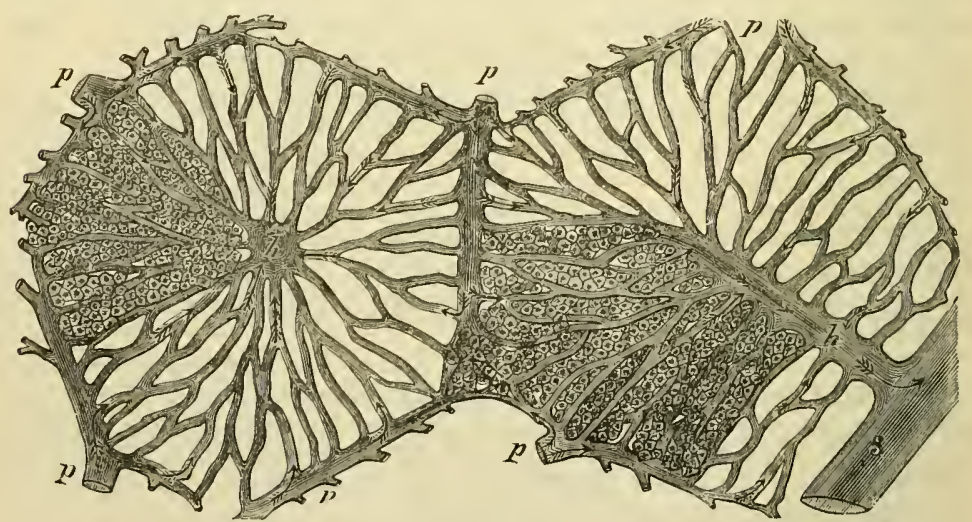

Fig. 378.-DiagRAMMATIC REPRESENTATION OF TWO HEPATIC LOBULES.

The left-hand lobule is represented with the intralobular vein eut across; in the right. hand one the section takes the course of the intralolular vein. $p$, interlubular branches of the portal vein ; $h$, intralobular branches of the hepatic veins; $s$, sub. lobular vein; $c$, capillaries of the lobules. The arrows indieate the direction of the course of the blood. The liver-cells are only represented in one part of eaeb lobule.

diameter, composed of cells, and separated fiom one another by connective tissue. In some animals, as in the pig, this separation is complete, and each lobule is isolated, but in man and most animals it is incomplete. There is also a layer of connective tissue underneath 
the serous covering of the liver, forming the so-ealled cupsule of the organ. Each lobule is penetrated by a fine network of reticular tissue which helps to support the columns of eells within the lobule (fig. 379).

The afferent blood-vessels of the liver (portal vein and hepatic artery) enter it on its under surface, where also the bile-duct passes away from the gland. The branches of these three vessels accompany one another in their course through the organ, and are inclosed by loose comective

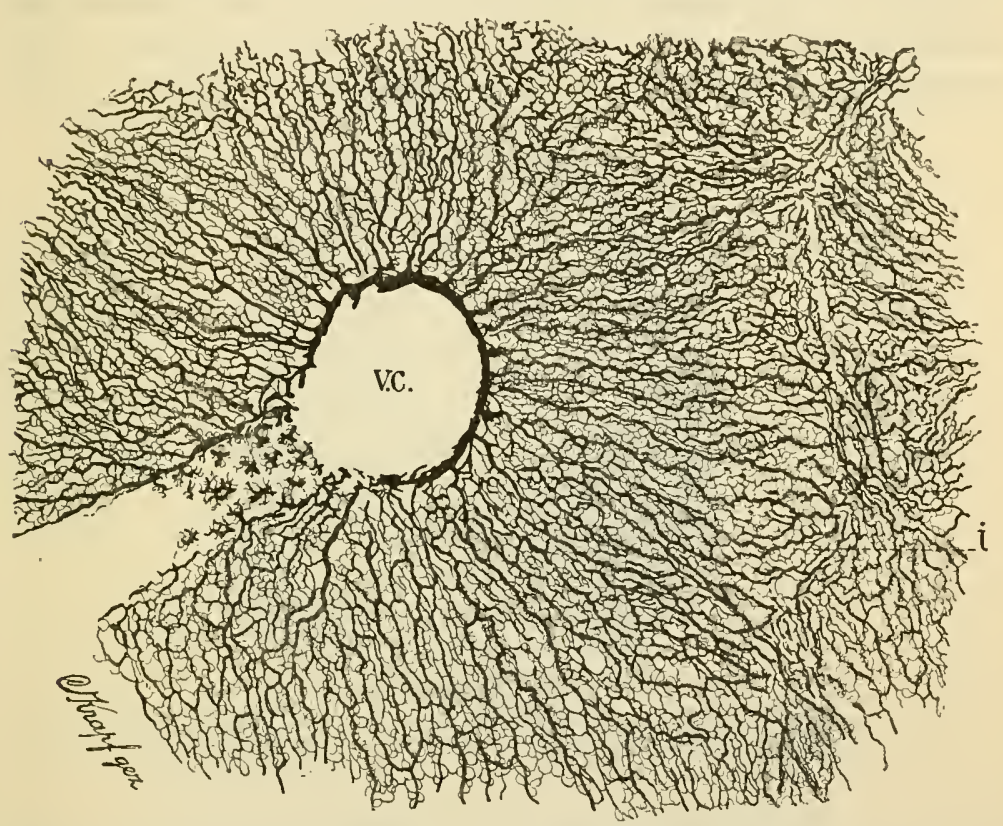

Fig. 379. - Reticuluy of A Liver-Lobule. (Oppel.)

V.C., central vein ; $i$, interlobular interval.

tissue (capsule of Glisson), in which are lymphatie vessels, the whole being termed a portal canal (fig. 380). The smaller branches of the vessels penetrate to the intervals between the hepatic lobules, and are known as the interlobular branches. The blood leaves the liver at the back of the organ by the hepatic veins; the branches of these run through the gland unaccompanied by other vessels (except lymphatics) and can also be traced to the lobules, from each of which they reeeive a minute branch (central or intralobular vein) which passes from the centre of the lobule, and opens directly into the (sublobular) branch of the hepatic vein.

Each lobule is a mass of hepatic cells pierced everywhere with a 
network of sinusoid blood-vessels, the so-called hepatic capillaries (fig. 378 ), which at the periphery of the lobule receive blood from the interlobular branches of the portal vein $(p)$, and converge to the centre of the lobule, where they unite to form the intralobular branch of the hepatic vein. The interlobular branches of the hepatic arteries join this network a short distance from the periphery of the lobule. The blood-capillaries are in direct contact with the liver-cells; indeed, it wonld appear as if the endothelium is deficient, for artificial injections are seen to be in contact with the cells and even pass between their interstices and run into canaliculi within their protoplasm. The endothelium of the blood-vessels (or sinusoids) is in part at least

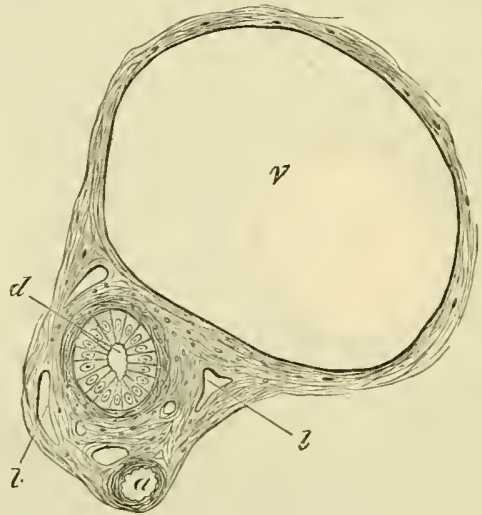

Fig. 380. - SECtion of a PORTAL CANal.

$a$, branch of hejatic artery ; $v$, branch of portal vein; $d$, bile-duct ; $l, l$, lymphatics in the areolar tissue of Glisson's capsule which incloses the ressels.

represented by certain conspicuous cells which occur at intervals on the wall of the sinusoids, and lie in contact with the liver cells. These cells were described by Kupffer. They are phagocytic, like the endothelial cells of the blood-sinuses of the spleen, and ingest erythrocytes, which ean be seen within them.

The hepatic cells, which everywhere lie between and surround the capillaries, are polyhedral, somewhat granular-looking cells, each containing a spherical nucleus. The protoplasm of each cell is pervaded by an irregnlar network of fine canaliculi (fig. 383), which in preparations of injected liver become filled with the injection material, which has passed into them from the blood-vessels (Herring and Simpson). They thus form a system of intracellular canals which probably receive the blood-plasma directly from the vessels. Such canals were conjectured to exist by Browicz, who showed that under 
certain circumstances not only hamoglobin but whole red bloodcorpuscles, and even groups of blood-corpuscles, which are in process of breaking down, are to be found in the interior of the hepatic cells. In the dog's liver hoth hemoglobin and bilirubin may be found in the furm of crystals within the nuclei of the liver-cells (Browicz). It is easy to inject these minute canals from the blood. vessels, and they are clearly shown filled with the injection mass in the preparation of injected liver of rabbit shown in fig. 384 . Besides these plasma-channels, the liver cells may show finc, short

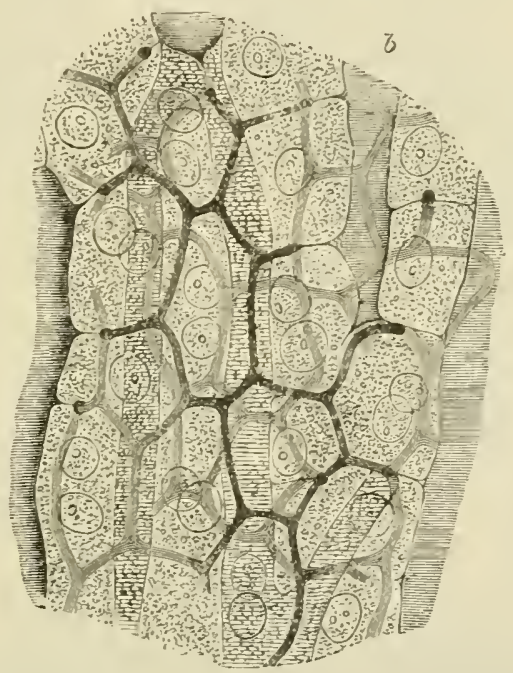

Fig, 381.-SECTION OF RABBit's LIVER WITH THE INTERCELLCLAR NeTWORK OH BILE-CANaLICLLI INJECTEI. Highly magnified. (Hering.)

Two or three layers of eells are represented; $b$, blood-capillaries.

canals which communicate with the intercellular bile-ducts (see below) and generally commence within the cell by a dilatation (secretionvacuoles).

After a meal many of the liver cells may contain fat, and masses of glycogen can also be seen within them (fig. 385) if the liver be hardened in alcohol and treated in the manner described in section 2. The cells also contain pigment-granules, many of which are stained by potassium ferrocyanide and hydrochloric acid, or by pure hæmatoxylin (presence of iron ${ }^{1}$ ).

The ducts commence between the hepatic cells in the form of intercellular bile-canaliculi, which lie between the adjacent sides of the

${ }^{1}$ The iron which is in organic combination can be set free by treatment for a short time with alcohol to which 10 p.c. hydrochloric acid has been added. 
cells, and receive the contents of the secretion-vacuoles above mentioned. They form a network, the meshes of which correspond in size to the cells (fig. 381), and at the periphery of the lobule they pass into the interlobular bile-ducts (fig. 382). In many animals the network of bile-canaliculi is incomplete (G. Retzius).

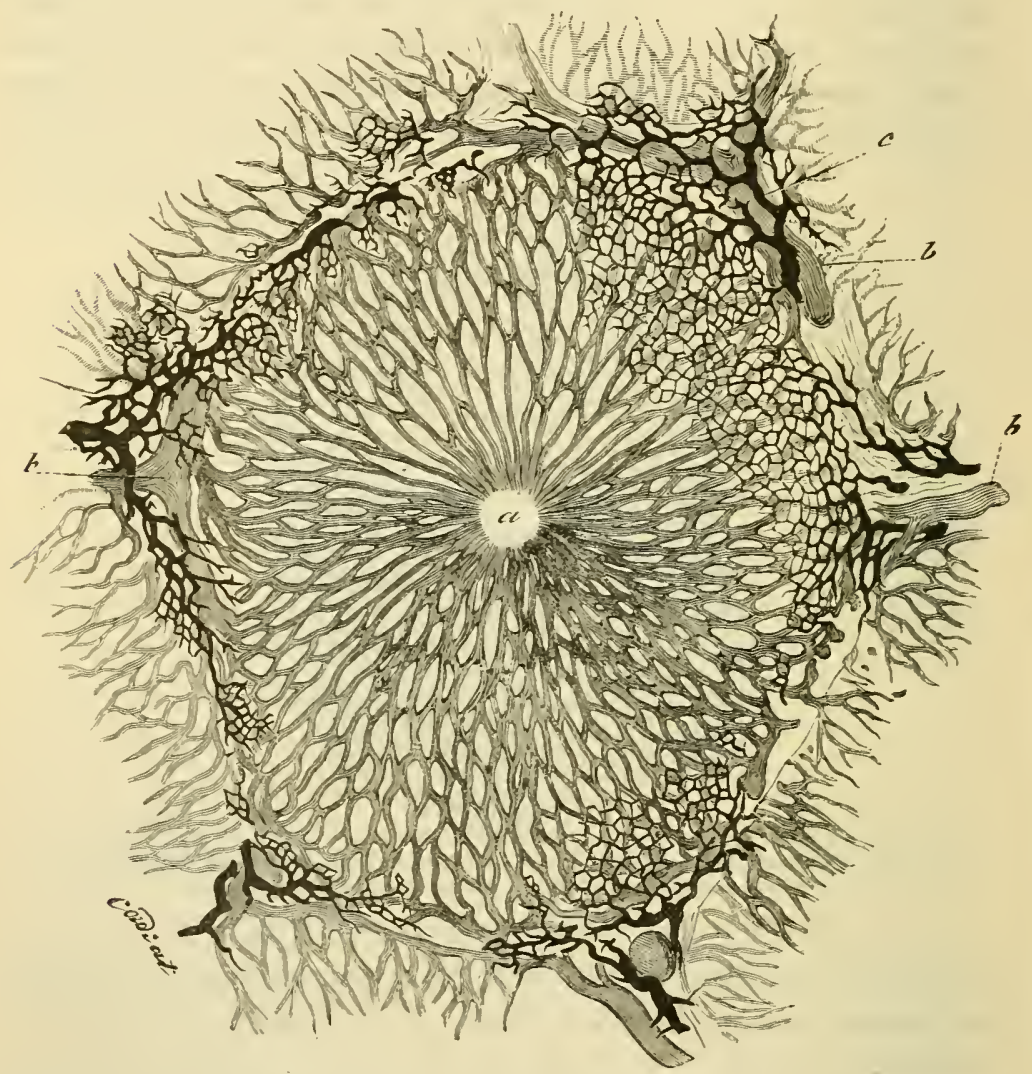

Fig. 382.- LOBCLE OF RABBiT's LIVER: VESSELS AND BILE-DUCTS INJECTED. (Cadiat.)

$a$, central vein; $b, b$, peripheral or interlobular veins ; $c$, interlobular bile-duct. The liver-cells are not represented.

The bile-ducts are lined by clear columnar epithelium (fig. 380, d). Outside this is a basement-membrane, and in the larger ducts some fibrous and plain muscular tissue. Many of the large ducts are beset with small blind diverticula.

The gall-bladder is in its general structure similar to the larger bile-ducts. It is lined by columnar epithelium, and its wall is formed of fibrous and muscular tissue. 
The lymphaties of the liver have been deseribed as commencing as perivascular lymphatic spaces inelosing the eapillaries of the lobules (MacGillavry). But this eannot be so, since there is no spaee between

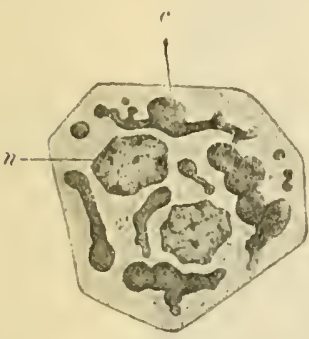

FIG. 383.

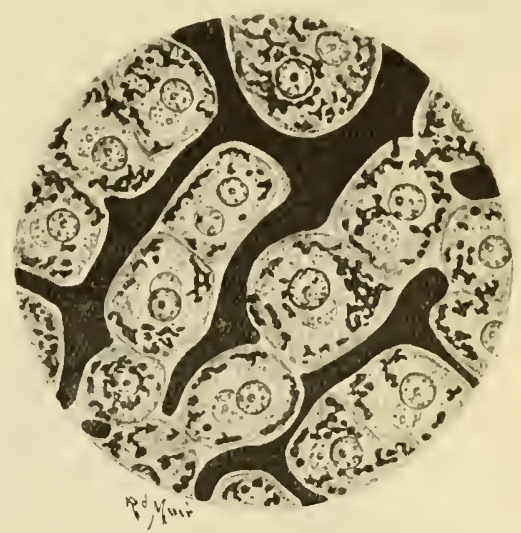

FIG. 384.

FIG. 383, - A CELL FROM THE HUMAN LIVER, SHOWING INTRACELLULAR CANALICULI. (Prowicz.)

FIG. 384.-FroN A SECTION OF RABBIT'S LIVER INJECTED FROM THE PORTAL VEIN, SHOWING INTRACELLULAR CANALICULI COMMUNICATING WITH THE INTERCELLULAR BLOOD-SINUSOIDS.

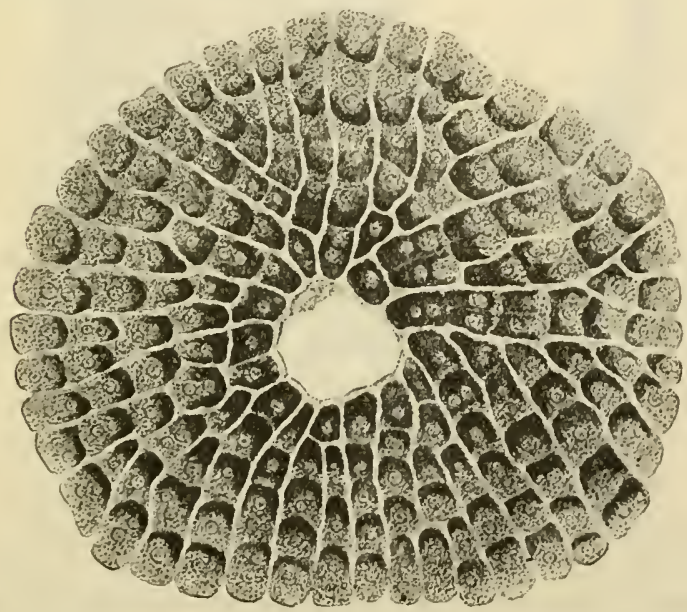

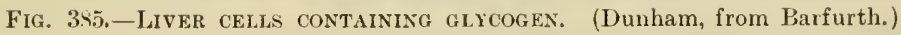

the liver-eells and the sinusoid eapillaries with which they eome into immediate relationship (Herring and Simpson). All that can be positively asserted is that there are numerous lymphatics accompanying the branches of the portal vein, and others, less numerous, aceompanying 
the tributaries of the hepatic veins, but so far as can be ascertained no direct communication exists between the two sets of lymphatics within the lobules, although they communicate freely near their exit from the liver. Most of the lymph passes out by the portal lymphatics.

Nerves are described as ristributed both to the blood-vessels and to the liver-cells.

\section{THF: PANCREAS.}

The pancreas is a tubulo-racemose gland, resembling the salivary glands so far as its general structure is concerned, but differing from

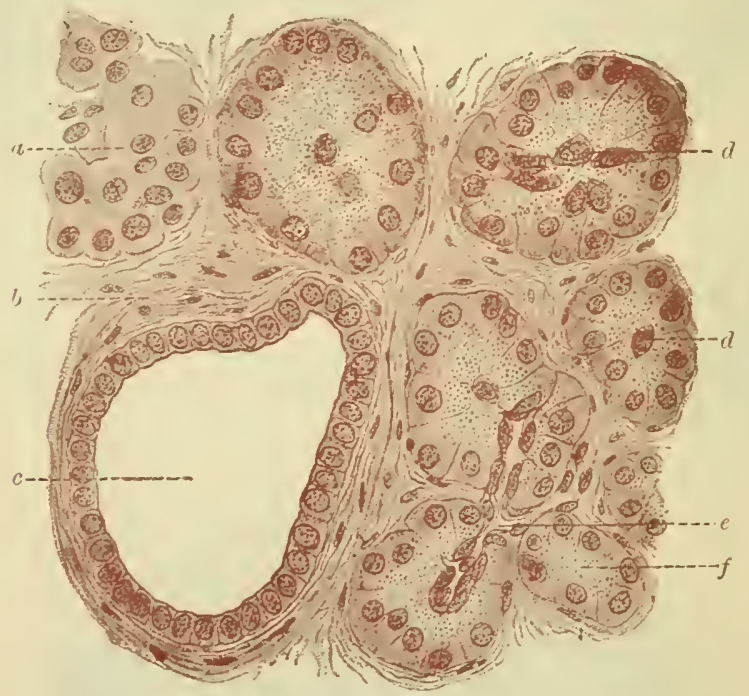

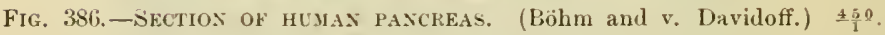

$a$, group of cells in interstitial tissue (islet of Langerhans); $b$, connective tissue ; $c$, larger duct; $n, d$, alveoli with centro-acinar cells ; $e$, small duct passing into alveoli ; $f$, inner branular zouc of alreolus.

them in the fact that the alveoli are longer and more tubular in character. Moreover, the connective tissue of the gland is somewhat looser, and there occur in the glandular substance here and there small groups of epithelium-like cells unfurnished with ducts (islets of Langerhans) (fig. $386 \mathrm{a}$; fig. 387), which are supplied with a close network of large convoluted capillary vessels (fig. 388). Their function is unknown, but their presence is very characteristic of the pancreas. They increase in size during starvation and also as the result of increasing the activity of the gland by injection of secretin (Dale), apparently at the expense of the proper glandular alveoli. The degeneration which they sometimes undergo in cases of diabetes 
mellitus seems to suggest that they are concerned with the influence exerted by the pancreas on the metabolism of carbohydrates.

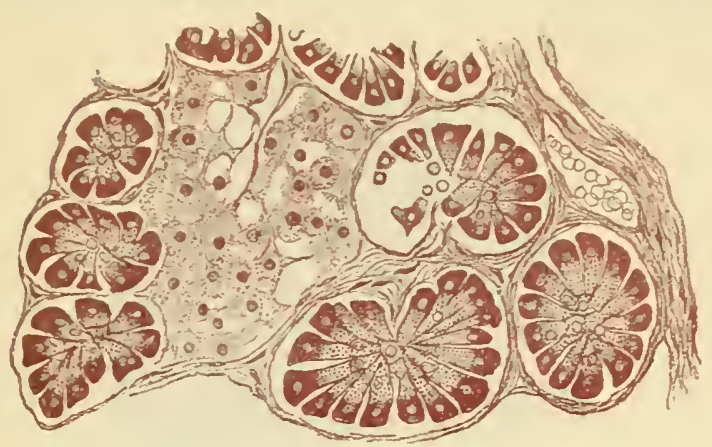

FIG. 3:- - SECTION OF PANCRFAS OF ARMATILLO SHOWIYG SETERAL ALVEOLI ANI A LAKGE INTERALTEOLAR CELL-ISLET. (V. D. Harris.)

The cells of the alreoli are shrunken. but they sbow markedly the two zones, the outer or non-granular stained deeply by hamatoxylin.

The cells which line the alveoli are columnar or polyhedral in shape. When examined in the fresh condition, or in sections stained by certain methods, their protoplasm is seen to be filled in the inner. two-thirds with granules, but the outer third is left clear or: is

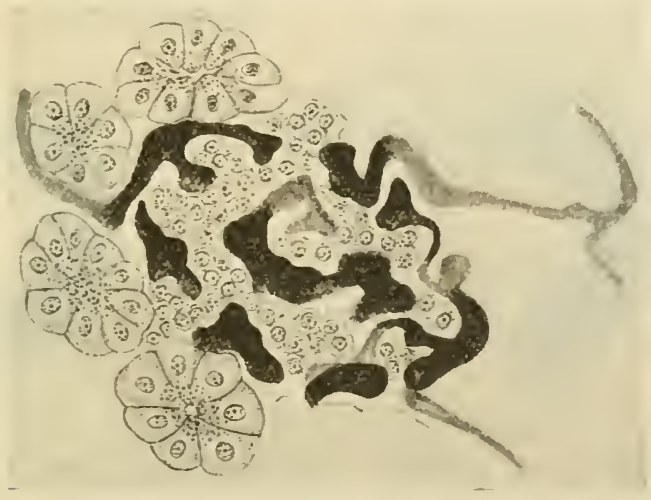

Fig. 388.-INJECTION OF BLOOD-YESOELS OF AX "ISLET" OF THE PAXCREAS. (Kühne and Lea.)

striated (fig. $390, A$; fig. 386 ). After a period of activity the clear part of the cell becomes larger, and the granular part smaller (fig. 390, B). In hæmatoxylin-stained sections the outer part is coloured more deeply than the inner (fig. 38i). 
Pancreas cells frequently exhibit a ronnded mass of granules or fibrils (mitochondria) near the nucleus, which is known as the paranucleus (Nebenkern): this is probably related to the secretory activity of the cells (see p. 5).

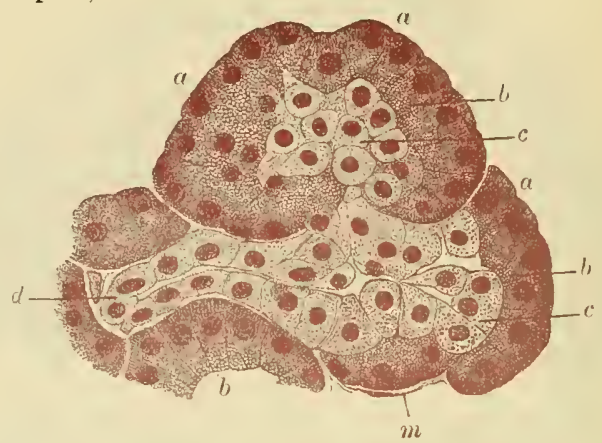

Fig. 389.-From a section of human pancreas. (v. Ebner.) Maguified 530 diameters.

$a, a$, outer zones of alvcolar cells with striated appearance; $b$, inner granular zones; $m$, inembrana propria; $c$, centro-acinar cells, liere occurring in unusually large anount; $d$, junctional part of duct; its epithelium is continuous with the centroacinar cells.

In the centre of each acinus there may generally be seen some spindle-shaped cells (centro-acinar cells of Langerhans-fig. 386, d), the nature of which has not been definitely determined; but they appear to be continued from the cells which line the smallest ducts (fig. $386, e$ )

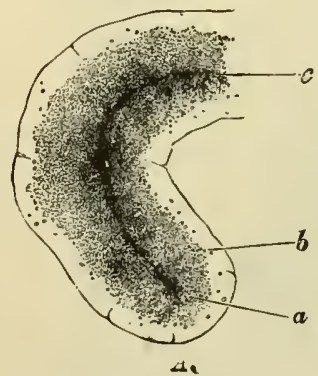

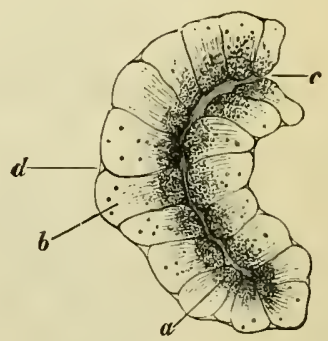

B.

Fig. 390.-PARt of an alveolus of the Rabbit's pancreas. $A$, at Rest; $B$, AFTER ACTIVE SECRETION. (From Foster, after Kühne and Lea.)

$a$, the inner granular zone, which in $A$ is larger and more closely studded with fine granules than in $B$, in which the granules are fewer and coarser; $b$, the outer trans. parent zone, small in $A$, larger in $B$, and in the latter marked with faint striæ ; $c$, the lumen, very obvious in $B$, but indistinct in $A ; d$, an indentation at the junction of two cells, only distinct in $B$.

Sometimes they are much more conspicuous and fill the parts of the alveoli which are nearest to the duct (fig. 389); in these cases the mass of cells which they form is liable to be mistaken for a Langerhans' islet. 
Diverticula from the lumen of the alveolus penetrate between the alveolar cells (fig. 391), as in the salivary glands (p. 285). The pancreas has many nerves, with numerous small nerve-cells distributed upon

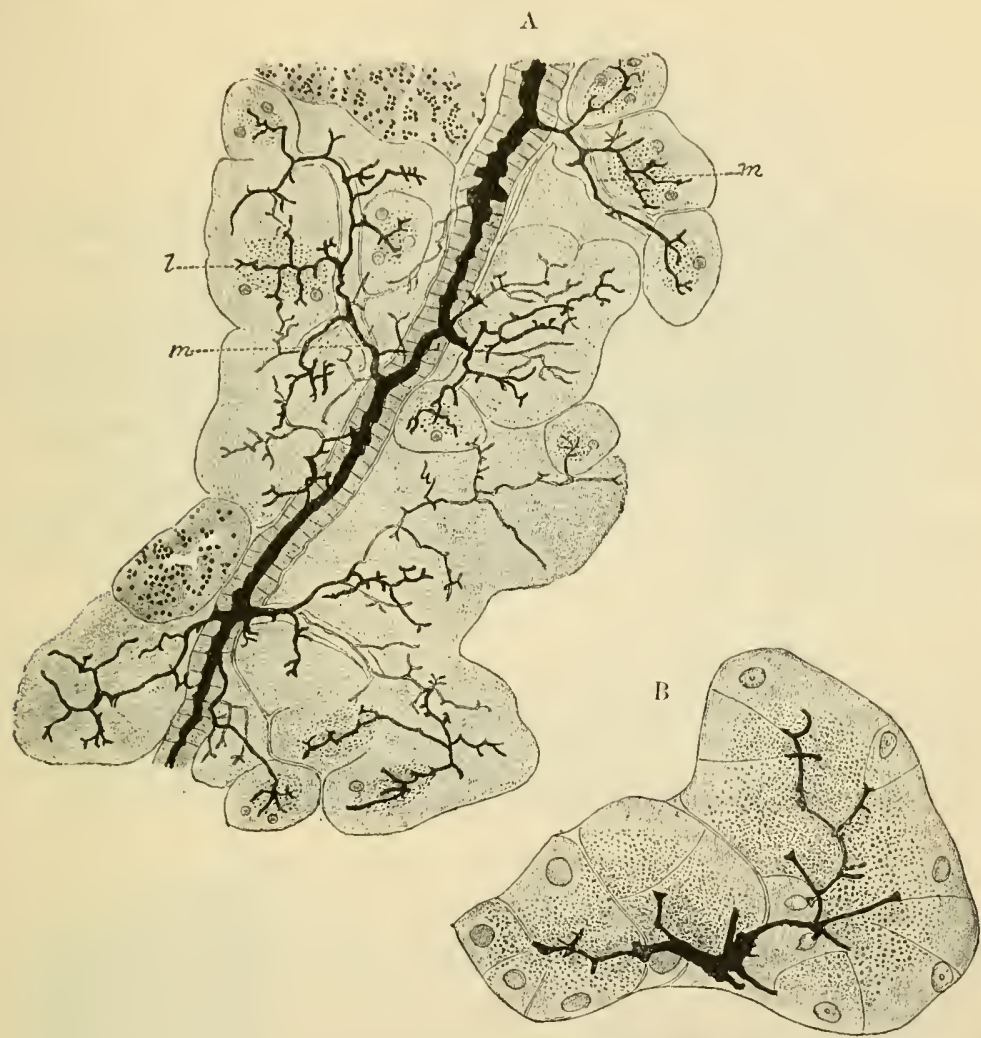

Fig. 391.-A DUCT OF THE PANCREAS With LATERAL DIVERTICUla inTO THE ALVEOLI ; GOLGI METHOD. (E. Müller.)

In $A$ the duct is shown eut longitudinally and giving off ductules, $m$, to the alveoli, where they exteud between the cells $(l)$. In $B$ the details of their termination are shown more highly magnificd.

their course; the nerve-fibrils end by ramifying amongst the cells of the alveoli, as in the salivary glands. In the cat, which has Pacinian bodies in its mesentery, these terminal organs are also found numerously in the substance of the pancreas (V. D. Harris). 


\section{LESSON XXXVI.}

\section{STRUCTURE OF THE KIDNEY.}

1. Sections passing through the whole kidney of a small mamnal, such as a mouse or rat. These sections will show the general arrangement of the organ and the disposition of the tubules and of the Malpighian corpuscles.

2. Thin sections of the kidney of a larger mammal, such as the dog or cat, may next be studied. In some the direction of the section should be parallel with the rays of the medulla, and in others across their direction. The characters of the epithelium of the several parts of the uriniferous tubules and the structure of the glomeruli are to be made out in these sections.

3. Separate portions of the uriniferous tubules may be studier in teased preparations from a kidney which has been macerated in diluted hydrochloric acid (1 to 5 water). This renders it possible to unravel the uriniferous tubules for sone distance.

4. Thick sections of a kidney in which the blood-ressels have been injected. Examine these with a low power of the microscope. Follow the course of the arteries-those to the cortex sending their branches to the glomeruli, tlose to the medulla rapidly dividing into pencils of fine vessels which run between the straight uriniferons tubules of the boundary zone. Notice also the efferent vessels from the glomeruli breaking up into the capillaries which are distributed to the tubules of the cortical substance.

The kidney is a compound tubular gland. To the naked eye it appears formed of two portions-a cortical and a medullury. The latter is subdivided into a number of pyramidal portions (pyrumids of Malpighi), the hase (boundary zone) of each being surrounded by cortical substance, while the apex projects in the form of a papillu into the dilated commencement of the ureter (pelvis of the kidney). ${ }^{1}$ Both cortex and medulla are composed entirely of tubules-the uriniferous tulules-which have a straight direction in the medulla and a contorted arraugement in the cortex; but groups of straight tubules also pass from the medulla through the thickness of the cortex (medullary rays).

The uriniferous tubules begin in the cortical part of the organ in dilatations, each inclosing a tuft or glomerulus of convoluted capillary blcod-vessels (corpuscles of Malpighi), the dilated commencement of the tubule being known as the capsule (fig. 396, 1). The glomerulus is

${ }^{1}$ In many animals (e.g. dog, cat, rabbit, most monkeys) the whole kidney is formed of only a single pyramid, but in man there are about twelve. 
lobulated (figs. 394, 395); the lobules being united by the afferent and efferent vessels and covered by a syncytium reflected from the

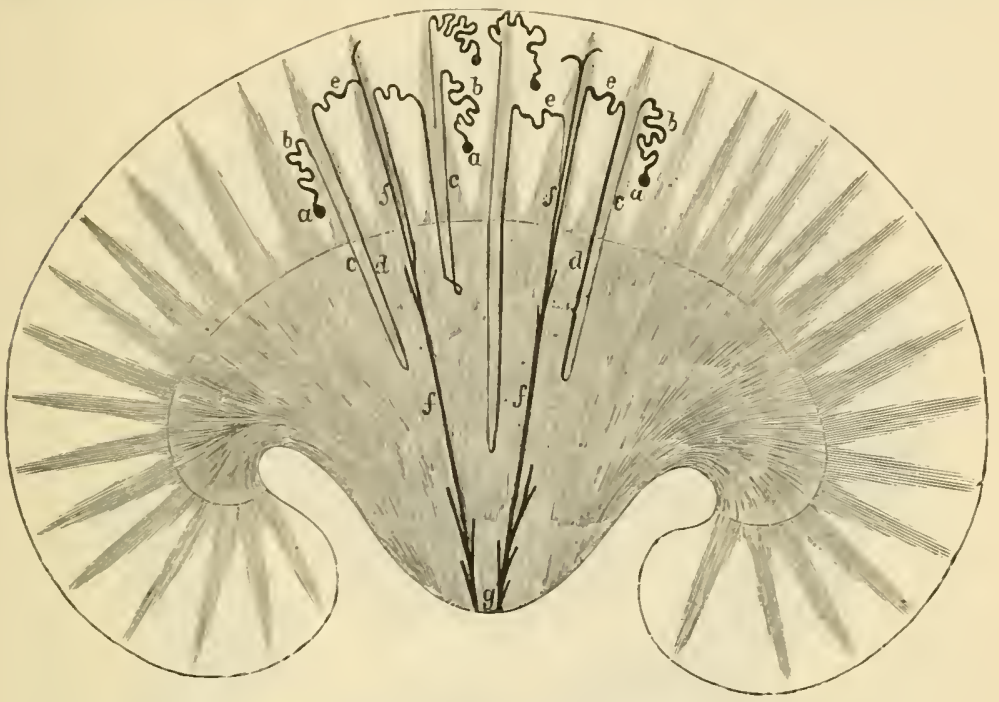

Fig. 392.-DIAGRAM OF THE COLRSE OF THE TCBULES IN A CNIPYRAMIDAL KIDNET, SUCH AS THAT OF THE RABBIT. (Toldt.)

a, MaIpighian bodies ; $l$, first conroluted tubulc ; $c, d$, looped tube of Henle ; $e$, second convoluted; $j$, collecting tube; $g$, ducts of Bellini.

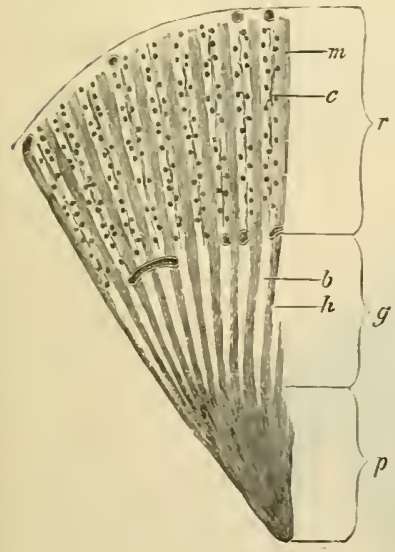

Fig, 393. - SECTION THROtGH PART OF A DOG'S KIDNEY. (Ludwig.)

$p$, papillary, and $g$, boundary zones of the medulla; $i$, cortical larer; $h$, bundles of tubules in the boundary laycr, separated by spaces, $b$, containing bunches of ressels (not here represented), and prolonged into the cortex as the medullary rays, $m$; $c$, intervals of cortex, cornposed chiefly of convoluted tubules, with irregular rows of glomeruli, between the medullary rays.

epithelium lining the capsule. The glomeruli near the medulla are larger than the rest and have more lobules. The capillary-wall in all the glomeruli is a syncytium, showing no cell-outlines in silver preparations (Draseh). 
The tubule leaves the capsule by a neck (2), which is rarely narrower than the rest of the tubule in mammals, but in some animals (e.g. frog)

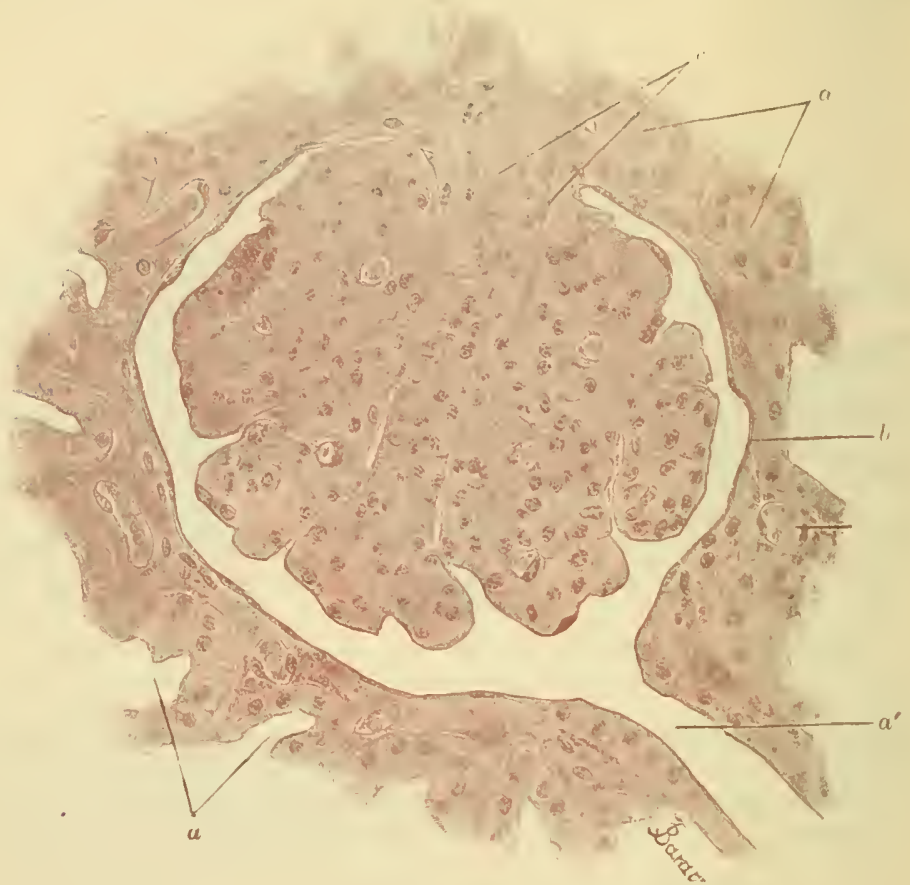

Fig. 394. - A MALPIghian corpuscle From the KIDNEY OF THE MONKEY. (Szymonowicz.) Magnified 350 diameters.

$a, a$, sections of eonvoluted tubules; $a^{\prime}$, commencement of convoluted tube from eapsule ; $b$, erpsule; $c$, afferent and efferent vessels of glomerulus.

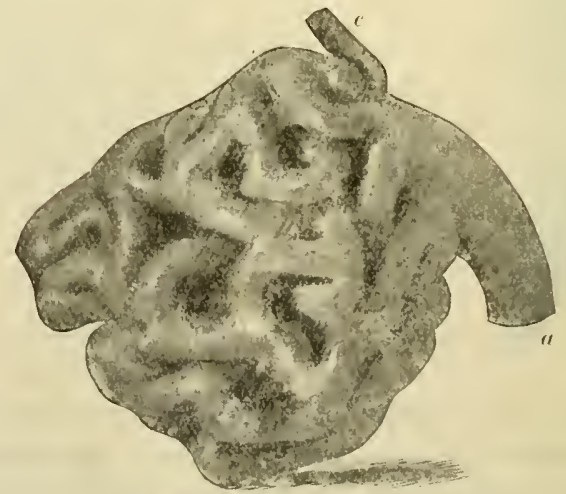

Fig. 395.-MIONEL OF A GLOMERULUS. (Johnson.) r, afferent ;, efferent blood-vessel. 
is long, and has ciliated epithelium; the tubule is at first convoluted (first romcoluled tubule, 3), but soon becomes nearly straight or slightly spiral only (spirul tulule, t), and then, rapidly narrowing, passes down

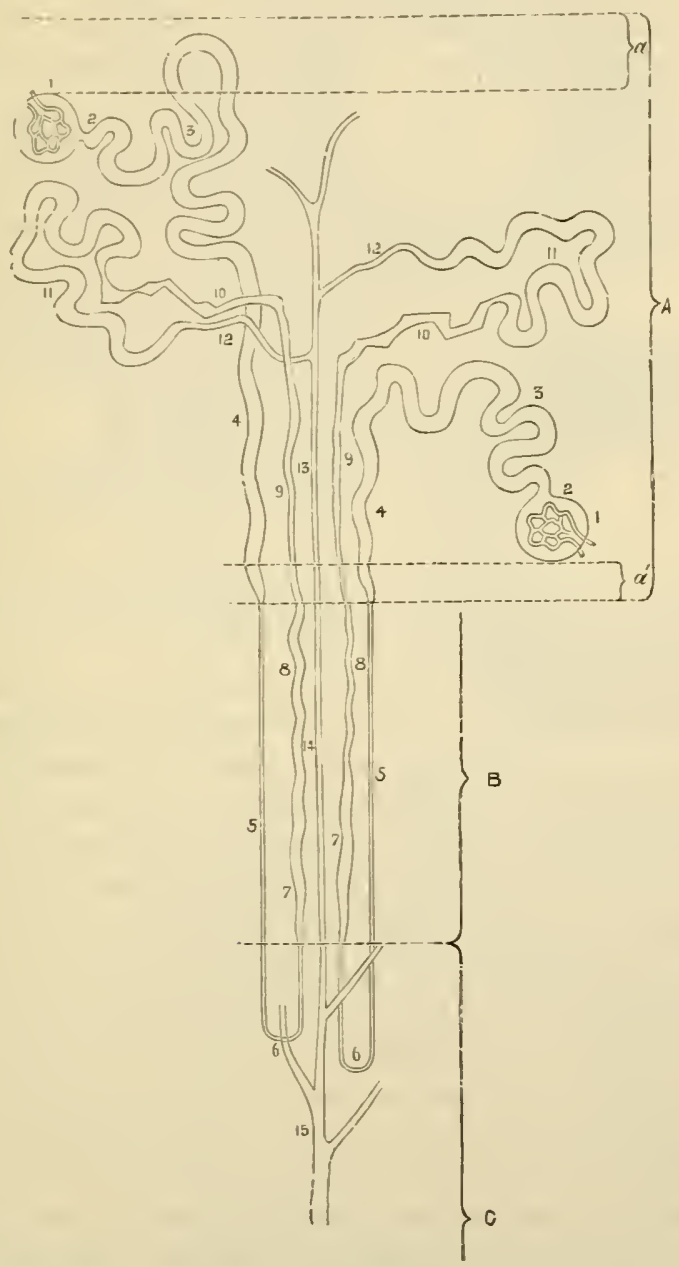

Flg. 396.-Diagay of the colrse of two urixiferots trbeles. (Klein.)

A, cortex; B, boundary zone ; c, papillary zone of the medulla ; $a$, $a^{\prime}$, superfieial and deen lajers of eortex, free from gluneruli. For the explanation of the numerals, see the text.

into the medulla towards the dilated commencement of the ureter as the descending tubule of Henle (5). It does not at onee, bowever, open into the pelvis of the kidney, but before reaching the end of the 
papilla it turns round in the form of a loop (loop of Henle, 6) and passes upwards again towards the cortex, parallel to its former course, and at first somewhat larger than before, but afterwards diminishing in size (ascending tubule of Henle, $7,8,9$ ). Arrived at the cortex it approaches close to the capsule from which the tubule took origin, but at a point opposite to the origin, viz. near the afferent and efferent vessels of the glomerulus (Golgi). It then becomes larger and irregularly zigzag (zigzag or irregular tubule, 10), and may again be somewhat convoluted (second conroluted tubule, 11), eventually; however, narrowing into a small vessel (junctional tubule, 12), which joins a straight or collecting tubule (13). The last-named unites with others to form large collecting

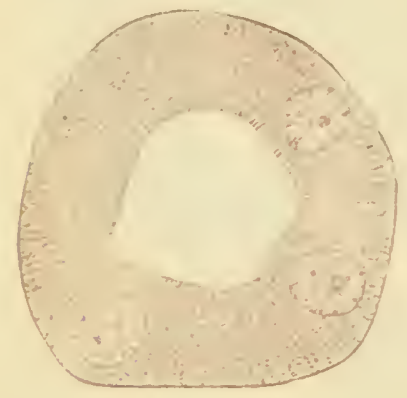

Fig, 397.-Sectiox of a CONTOLETED TCBLLE OF THE RABHIT'S KIDNET, SHOWIXG THE STRCCTURE OF THE EPITHELIt M. (Szymonowicz.) (Magnified 1100 diameters.) tubes which pass through the medullary substance of the kidney (14) to open at the apex of the papilla as the ducts of Bellini (15).

The tubules are throughout bounded by a basement-membrane, which is lined br epithelium, but the characters of the epithelium cells vary in the different parts of a tubule. In the capsule the epithelium is flattened and is reflected orer the glomerulus. In some animals (e.g. mouse) the granular epithelium of the convoluted tube is prolonged a little way into the capsule. In the first comroluted and spiral tubules the epithelium is thick, and the cells are markedly granular, with a tendency for the granules to be arranged in lines perpendicular to the basement-membrane (rodded or fibrillar appearance, fig. 397 ). The granules of the cells are particularly well displayed in sections stained by Muir's method; they are eosinophil, like the granules of secreting cells generally. They often exhibit a brush of cilium-like processes projecting into the lumen (figs. $39 \bar{i}, 400$ ), but these are not vibratile in mammals. In the narrow descending limb of the looped tubules, and in the loop itself, the cells are clear and flattened and leave a relatively large lumen; in the ascending limb they again acquire a granular structure and may nearly fill the lumen. The arrangement of the cell-granules in lines perpendicular to the basement-membrane is still more marked in the sig:ug tubules, and a similar structure is present also in the second concoluted tubules, into which these pass. On the other hand, the junctional tubule has a large lumen and is lined by clear flattened cells, and the collecting tubes have also a very 
distinct lumen and are lined by a clear cubical or columnar epithelium (tig. 398, a).

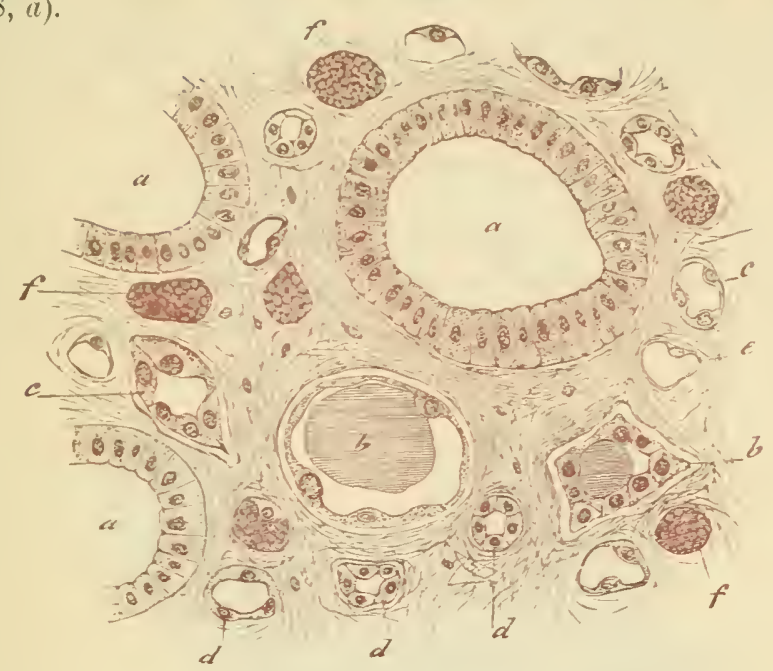

Fig. 398.-Section ACross a PAPIlla of the kidxey. (Cadiat.)

$a$, large collecting tubes (ducts of Bellini); $b, c, d$, tubules of Henle ; $\ell, i$, blood-capillaries.

The following gives a tabular view of the parts which compose a uriniferous tubule, and the nature of the epithelium in each part :-

\begin{tabular}{|c|c|c|}
\hline Portios of Teblize. & Yature of Epithelici. & Position of Trbele. \\
\hline Capsule . & $\begin{array}{l}\text { Flattened, reflecterl over glomerulus, } \\
\text { where its cells form a srncytium. }\end{array}$ & Labyrinth of cortex. ${ }^{2}$ \\
\hline First convoluted tube . & $\begin{array}{l}\text { Cubical, granular, with appearance } \\
\text { of fibrillation ("rodded"), the cells } \\
\text { interlocking. }\end{array}$ & Labrrinth of cortex. \\
\hline Spiral tube & Like the last & $\begin{array}{l}\text { Wedullars ray of } \\
\text { cortex. }\end{array}$ \\
\hline $\begin{array}{l}\text { Small or descending } \\
\text { tube of Henle. }\end{array}$ & Clear flattened cells . & $\begin{array}{l}\text { Boundars zone and } \\
\text { partly papillary } \\
\text { zone of medulla. }\end{array}$ \\
\hline Loop of Henle & Like the last & $\begin{array}{l}\text { Papillary zone of } \\
\text { medulla. }\end{array}$ \\
\hline $\begin{array}{l}\text { Larger or ascending } \\
\text { tube of Henle. }\end{array}$ & $\begin{array}{c}\text { Cubical, granular: the cells some- } \\
\text { times imbricated }\end{array}$ & $\begin{array}{l}\text { Medulla, and medul- } \\
\text { lary ray of cortex. }\end{array}$ \\
\hline Zigzag tube . & $\begin{array}{l}\text { Cells strongly "rodderl": varying } \\
\text { height, lumen small }\end{array}$ & Labyrinth of cortex. \\
\hline Second convoluted tube & $\begin{array}{l}\text { Similar to first convoluted tube, but } \\
\text { cells are longer, with larger nuclei, } \\
\text { and they have it more refractive } \\
\text { aspect }\end{array}$ & Labyrinth of cortex. \\
\hline Junctional tube & Clear flattened and cubical cells & $\begin{array}{l}\text { Labyrinth passing to } \\
\text { medullary rar. }\end{array}$ \\
\hline $\begin{array}{l}\text { Straight or collecting } \\
\text { tube. }\end{array}$ & Clear cubical and columnar cells & $\begin{array}{l}\text { Medullary ray and } \\
\text { medulla. }\end{array}$ \\
\hline Duct of Bellini & Clear columnar cells. & $\begin{array}{l}\text { Opens at apex of } \\
\text { papilla. }\end{array}$ \\
\hline
\end{tabular}

${ }^{1}$ The part of the cortex between and surrounding the medullary rays is so named. 
Blood-vessels. - The renal artery divides into branches on entering the organ, and these branches pass towards the cortex, forming incomplete arches between the cortex and the medulla (fig. 399, a). The branches of the renal vein form similar but more complete

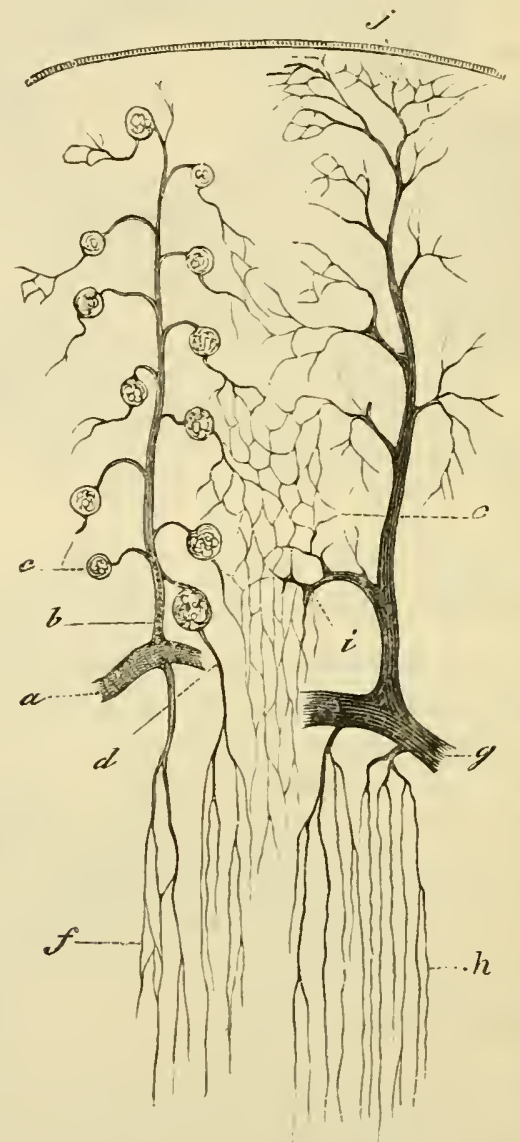

FIG. 399.-VASCLLAR SEPPLY OF KIDNEY. (Cadiat.) Diagrammatic.

u, part of arterial arch; $b$, interlobular artery; $c$, glomerulus ; $d$, efferent vessel passing to medulla as false arteria recta ; e, capillaries of cortex : $f$, capillaries of medulla; $g$, venous arch $; h$, straight veins of medulla $; j$, vena stellula $; i$, interlobular vein.

arches $(g)$.- From the arterial arches vessels pass through the cortex (cortical or interlobular arteries, b), and give off at intervals small arteri oles (ufferent vessels of the gl'meruli), each of which enters the dilated commencement of a uriniferous tubule, within which its capillaries form a glomerulus. From the glomerulus a somewhat smaller efferent vessel passes out, and this at once again breaks up into capillaries, which are 
distributed amongst the tubules of the cortex $(e)$; their blood is collected by veins which rum parallel with the cortical arteries but not in juxtaposition with them: these reins join the venous arches between the cortex and the medulla; they receive blood from certain other veins which arise by radicles having a somewhat stellate arrangement near the capsule (rence stellule, $j$ ).

The medulla derives its blood-supuly from special offsets of the arterial arches, which almost immediately break up into pencils of fine straight arterioles rumning in groups between the straight tubules of the medulla. These arterioles supply a capillary network with

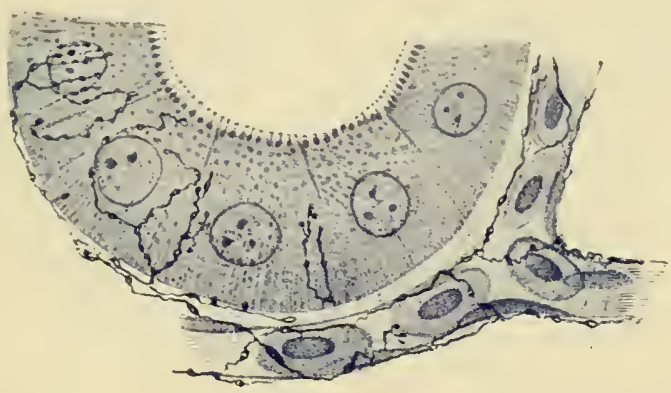

Fig. 400,-NERVE FIBRILS ENDING OVER CAPILLARY BLOOD-TESSELS AND AMONGST THE EPITHELIUM CELLS OF A CONTOLUTED TUBE OF THE F'ROG'S KIDNEY. (SMirnow.)

elongated meshes which pervades the medulla (fig. 399, $f$ ), and which terminates in a plexus of somewhat larger venous capillaries in the papillæ. From these and from the other capillaries the venules of the medulla collect the blood, and pass, accompanying the straight arterioles, into the venous arches between the cortex and medulla. The groups of small arteries and veins (rasn recta) in the part of the medulla nearest to the cortex alternate with groups of the uriniferous tubules, and this arrangement confers a striated aspect upon this portion of the medulla (boundiry zone, fig. 393, $g$ ).

The efferent ressels of those glomeruli which are situated nearest to the medulla also break up into pencils of fine vessels (false vasa recta) which join the capillary network of the medulla (fig. $399, d$ ).

Between the uriniferous tubules, and supporting the blood-vessels. is a certain amount of connective tissue (fig. 400), within which are cleft-like lymphatics.

Nerve-fibrils are descrihed as ramifying amongst the epithelium-cells of the tubules (fig. 400), but most of the nerves to the kidneys are distributed to the blood-vessels. 


\section{LESSON XXXVII.}

\section{STRUCTURE OF THE URETER, BLADDER, AND MALE GENERATIVE ORGANS.}

1. Secrion across the lower part of the ureter. Another section may be taken across the upper part near the pelvis of the kidney.

2 . Section of the urinary bladder vertical to the surface.

In the sections of the ureter and of the urinary bladder, notice the transitional epithelimm resting on a mucous membrane, which is composed of areolar tissue withont glands (in most animals), and the muscnlar coat outside this. In the mreter there is a layer of comnective tissue outside the musenlar coat, and at the upper part of the blarder a layer of serons membrane covering the muscular tissne.

3. Section across the penis (child or monkey). The blood-vessels of the organ should be injected with the hardening fluid so as the better to exhibit the arrangement of the venous spaces which constitute the erectile tissue. Notice the large venous simuses of the corpora cavernosa and the smaller spaces of the corpus spongiosum, in the mildle of which is seen the (flattened) tube of the urethra.

4. Section across nrethra and prostate gland (child or monkey). Notice the glanclular tubes and the plain muscular tissne of the prostate, and the character of the urethral epithelinm.

5. Section of testis and epididymis. The sections may be made from a rat's testis which has been hardened in alcolool; they can be stained with iron-hæmatoxylin. In these sections notice the strong capsule surrounding the gland, the substance of which consists of tubules which are variously cut; and the epithelium of the tubules, which is in different phases of development in different tubules. Observe the strands of polyhedral interstitial cells, much more numerous in some animals, lying in the loose tissue between the tubules; also the lymphatic clefts in that tissue. Notice in sections through the epilidymis the epithelium of that tube.

Sketch carefully under a high power the contents of some of the seminiferous tubules to illustrate the morle of formation of the spermatozoa.

6. Examination of spermatozoa. Spermatozoa may be obtained fresh from the testicle or seminal vesicles of a recently killed nammal and examined in saline solution. Their movements may be studier on the warm stage; to display their structure a very high power of the microscope is necessary. They may be preserved and stained as "film" prejarations, as with marrow (p. 30).

The ureter (fig. 401) is a muscular tube lined by mucous membrane. The muscular coat consists of two layers of plain muscular tissue, an outer circular, and an inner longitudinal. In the lower part there are some longitudinal bundles external to the circular. Outside the muscular coat is a layer of connective tissue in which the blood-vessels and nerves ramify before entering the muscular layer. 
The mucous membrane is composed of areolar tissue and is lined by transitional epithelium (fig. 402).

The urinary bladder has a muscular wall lined by a strong mucous membrane and covered in part by a serous coat.

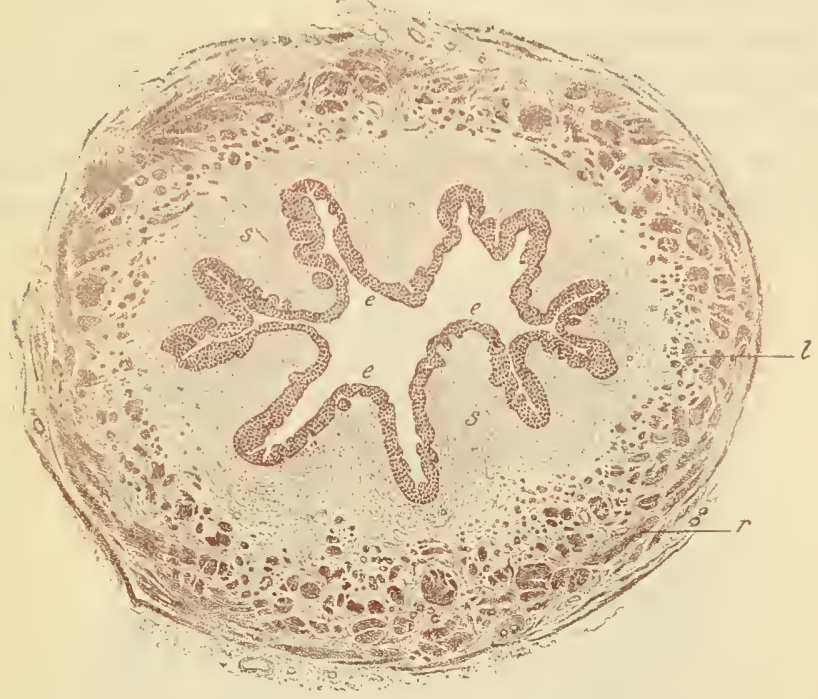

Fig. 401.-SEction ACross THE UPPER PART OF THE URETER. (v. Ebner.) Magnified 14 diameters.

$e$, epithelium ; $s$, mucous mcmbrane; $l$, longitudinal muscle ; $r$, circular muscle.

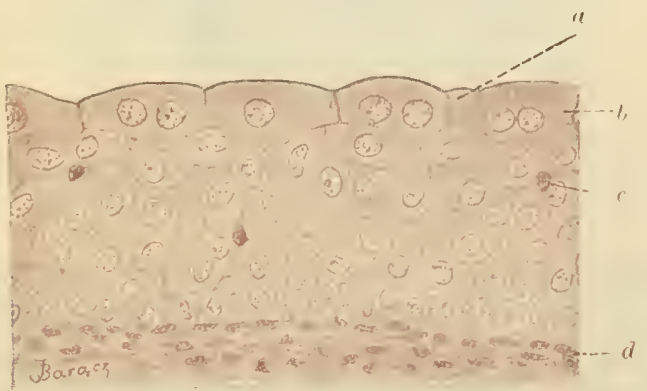

Fig. 402. - SEction OF THE MUCOUS MEMBRANE OF THE BLADDER TO SHOW ITS EPITHELIUM. (Szymonowicz.)

$a, b$, superficial enithelium-cells ; $c$, leucocyte ; $d$, areolar tissue of mucous membrane.

The muscular coat consists of three layers, but the innermost is incomplete. The principal fibres run longitudinally and circularly, and the circular fibres are collected into a layer of some thickness which immediately surrounds the commencement of the urethra. The mucous membrane is lined by a transitional stratified epithelium like that of 
the ureter. The shape and structure of the cells have already been studied (p. 55). Many of the superficial cells have two nuclei.

The nerves to the blarder form gangliated plexuses, and are distributed to the muscular tissue and blood-vessels, but some are said to enter the epithelinm.

The penis is mainly composed of cavernous tissue which is collected into two principal tracts - the corpora carernosa, one on each side, and the corpus spongiosum in the middle line inferiorly. All these are bounded by a strong capsule of fibrous and plain muscular tissue, containing also many elastic fibres and sending in strong septa or trabeculæ

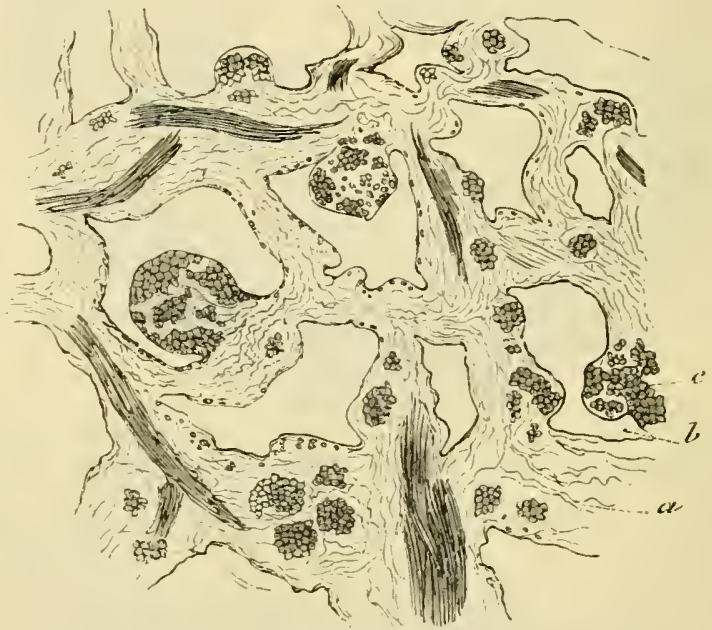

Fig. 403.-Sectiox of erectile tissue. (Cadiat.)

$a$, trabeculæ of connective tissue, with elastic fibres, and bundles of plain muscular tissue, some cut across $(c) ; b$, venous spaces.

of the same tissues, which form the boundaries of the cavernous spaces of the erectile tissue (fig. 403). The arteries of the tissue run in these trabeculæ, and their capillaries open into the cavernous spaces. On the other hand, the spaces are connected with efferent veins. The arteries of the carernous tissue may sometimes in injected specimens be observed to form looped or twisted projections into the cavernous spaces (helicine arteries of Minller), into which they may open directly.

The integument of the penis and clitoris, especially that of the glans, contains numerous special nerve end organs of the nature of endbulbs (see p. 169), and Pacinian bodies are also found upon the nerves. Lymphatic vessels are numerous in the integument of the organ and also in the submucous tissue of the urethra. 
Urethra.-The cross-section of the urethra appears in the midrlle of the corpus spongiosum in the form of a transierse cleft. It is lined in the prostatie part by transitional, bnt elsewhere by columnar epithelinm, except near its orifice, where the epithelinm is stratified. In the female urethra it is stratified throughout. The epithelium rests upon a vascular mucous membrane, which contains longitudinally disposed plain musenlar fibres, and in the memhranous urethra, circularly disposed cross-striated filres. Outside the mucous membranc is a coating of submucons tissue, with two layers of plain muscular tibre-an inner longitudinal and an outer circular. Outside this again

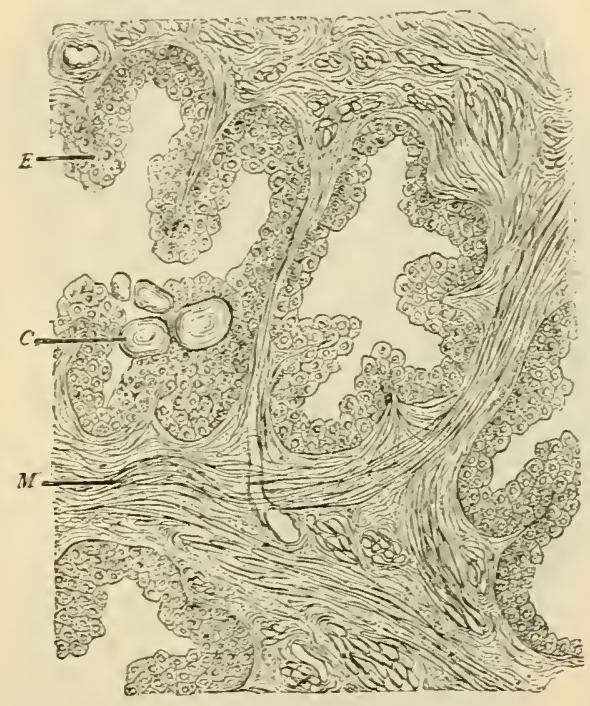

F1G. 404.-SEctios of Prostate. (Heitzmann.)

$M$, muscular tissue: $E$, epithelium; $C$, concretions.

is a close plexus of small reins which is connected with, and may be said to form part of, the corpus spongiosum.

The mucous membrane of the urethra is beset with small mucous glands, simple and compound (glends of Littré). There are also a number of oblique recesses termed lacunce. Besides these small glands and glandular recesses, two compound racemose glands open into the bulbous portion of the urethra (Cruxper's glunds). Their acini are lined by elear columnar cells which yield a mucus-like secretion.

The prostate, which surrounds the commencement of the urethra, is a muscular and glandular mass, the glands of which are composed of tubular alveoli, lined by columnar epithelium, with smaller cells lying between them and the basement-membrane (fig. 404). Their ducts 
open upon the floor of the urethra. In old subjects the tubules often contain colloid or calcareous coneretions. The muscular tissue is of the plain variety.

Blood-vessels and nerves are numerous. The nerves are provided with small ganglia and are distributed partly to the muscular tissue, partly to the glands, and others (sensory) to the capsule, and to the wall of the urethra. The sensory nerves end in plexuses and in peculiar terminal corpuscles like simple Pacinian bodies (Timofeew).

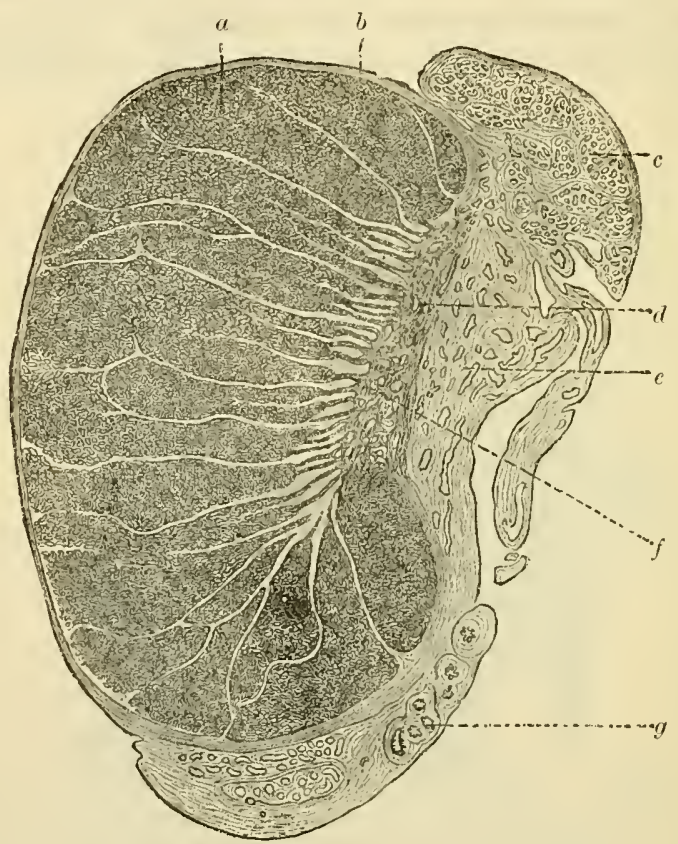

Fig. 405. - SECTION OF HUMAN TESTTS AND EPIDIDYMIS, SOMEWHAT MAGNIFIED. (Bohm and v. Davidoff.)

$a$, glandular substance divided into lobules by sejta of eonnective tissue ; $b$, tunica albu. ginea ; $c$, head of epididymis; $d$, rete testis ; $e$, middle part or bod $y$ of epididymis $; j$, mediastinum giving origin to the septa; /, seetions of the commencing vas deferens.

The testicle is inclosed by a strong fibrous capsule, the tunica albuginea (fig. $405, b$ ). This is covered externally with a layer of serous epithelium reflected from the tunicu vaginalis. From its inner surface there proceed fibrous processes or trabecule, which imperfectly subdivide the organ into lobules, and posteriorly the capsule is prolonged into the interior of the gland in the form of a mass of fibrous tissue, which is known as the mediastinum testis (fig. 405, $f$ ). Attached to the posterior margin of the body of the gland is a mass (epididymis) which when investigated is found to consist of a single convoluted tube, receiving at 
its upper end the efferent ducts of the testis and prolonged at its lower end into a thick-walled muscular tube, the rus deferens, which conducts the secretion to the urethra.

The glandular substance of the testiele is wholly made up of conroluted tubules, which when mnavelled are of very considerable length. Each commenees neit the tuniea albuginea, and after many windings terminates, usually after joining one or two others, in a

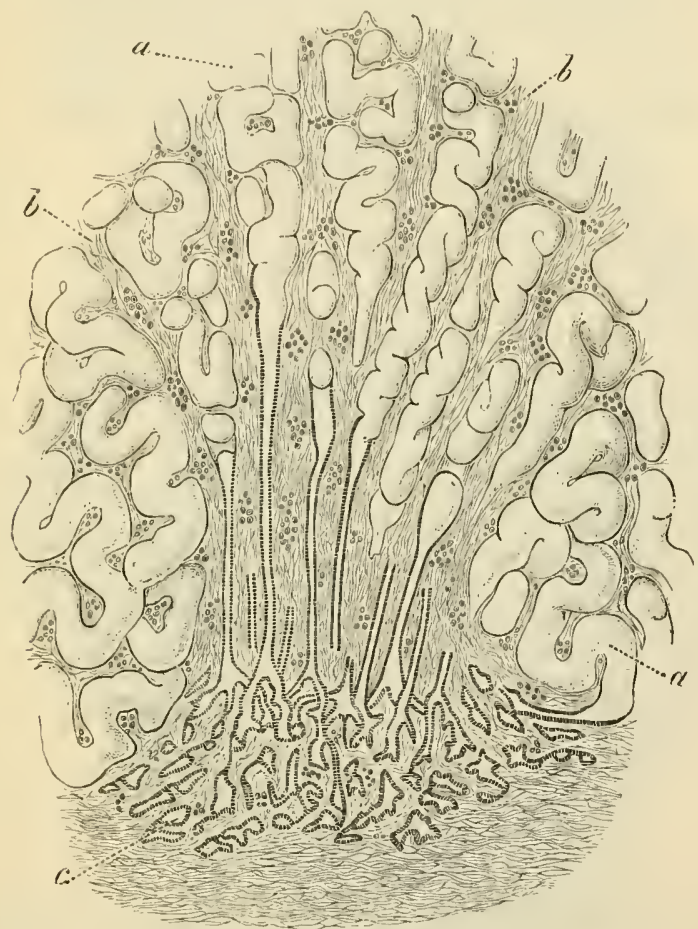

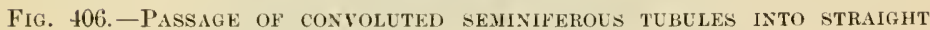
TUBULES AND OF THESE INTO THE RETE TESTIS. (Milalkowicz.)

u, seminiferous tubules; $b$, fibrous stroma eontinued from the mediastinum testis; $c$, rete testis.

straight tubule, which passes into the mediastinum, and there forms, by uniting with the other straight tubules, a network of intercommunicating vessels of varying size, which is known as the rete testis (fig. 406). From the rete a certain number of efferent tubules arise, and after a few convolutions pass into the tube of the epididymis.

The straight tubules which lead from the convoluted seminiferous tubes into the rete testis are lined only by a single layer of clear flattened or cubical epithelium. The tubules of the rete also have a 
simple epithelial lining; both in these and in the straight tubules the basement-membrane is absent, the epithelium being supported directly by the connective tissue of the mediastinum.

The efferent tubules which pass from the rete to the epididymis are lined by columnar ciliated epithelium In man their lumen is irregular in section, and the inner surface pitted with depressions (intra-epithelial glands) lined by short clear non-ciliated cells (J. Schaffer). The tube of the epididymis is lined by long colnmnar cells having at their bases

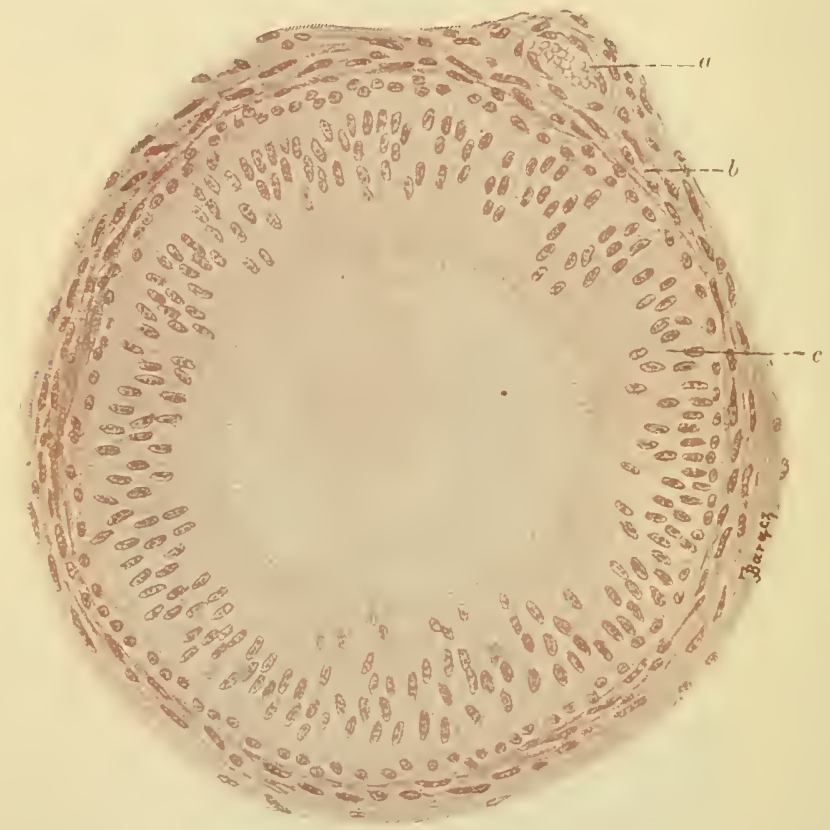

Fig. 407.--Section of THE TUbe of THE ePIDIDYMis. (SZymonowicz.) (Magnitied 300 diameters.)

a, blood-vessel ; $b$, circular unuscular fibres; $c$, epithelium.

smaller cubical cells with spherical nuclei (fig. 407). The columnar cells are provided with what appear to be bunches of cilium-like fibrils projecting into the lumen of the tube. These apparent eilia are, however, not vibratile as was formerly supposed, and are therefore not true cilia (Neumann, Myers-Ward). They appear to vary in development in different cells, and are probably comected in some way with the formation of the secretion of the epididymis and its extrusion into the lumen of the tube. The epididymis cells exhibit eanaliculi in their cytoplasm, which according to Holmgren, communicate with the exterior at the attached border of the cell (fig. 408). The tube of 
the epididymis has a considerable amonnt of plain muscular tissue in its wall (fig. 407).

The res deferens (fig. 109) is a thiek-walled tube, formed of an outer

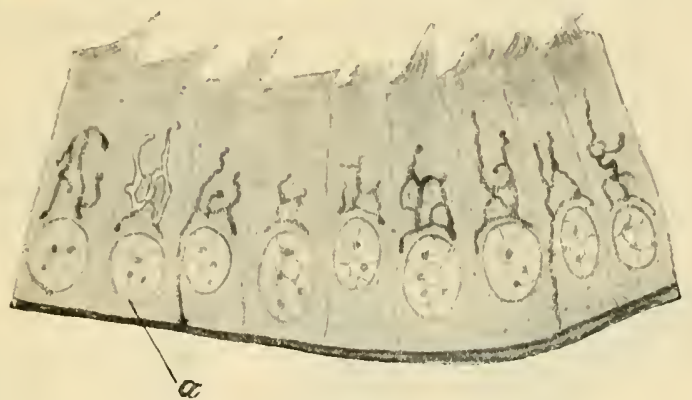

FIG. 408. - CELLS OF EPIDIDYMIS, SHOWING CANALIZATION OH THE CYTOPLASM. (E. Holmgren.)

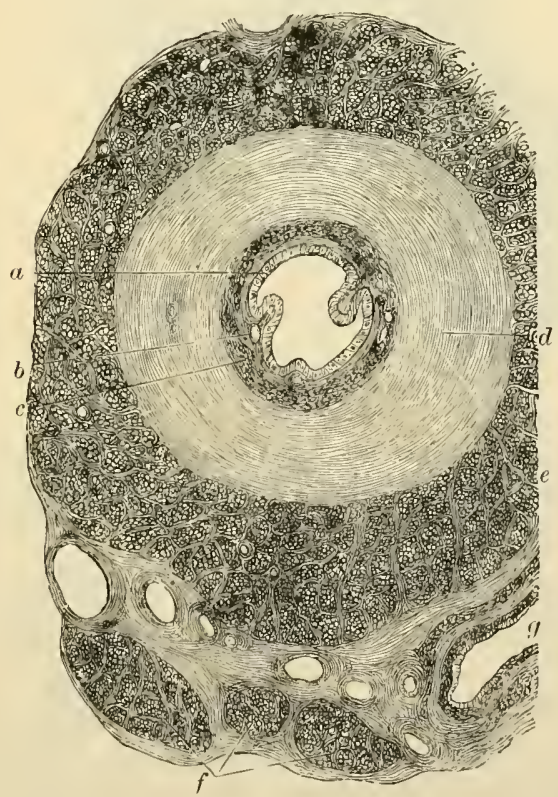

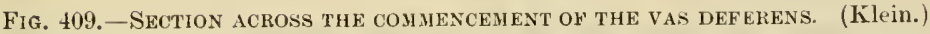
$a$, epithelium; $b$, mueous membrane; $e, d$, $e$, inner, middle, and outer layers of the muscular coat; $f$, bundles of the internal eremaster nutsele; $g$, section of a bloodvessel.

layer of longitudinal bundles of plain muscular tissue; within this an equally thick layer of circular bundles of the same tissue, and within this again a thinner layer of longitudinal muscle. There is a good deal of connective and elastic tissue hetween the muscular bundles. The 
tube is lined by a mucous membrane, the imner surface of which is covered by columnar non-ciliated epithelium.

The ampullce of the vasa deferentia, and the resiculce seminales, are in structure similar to the vas deferens, but their corrugated walls are much thinner and less muscular.

The connective tissue between the tubules of the testis is of very loose texture, and contains numerous lymphatic clefts, which form an intercommunicating system of commencing lymphatic vessels. Lying in this intertubular tissue are strands of polyhedral epithelium-like

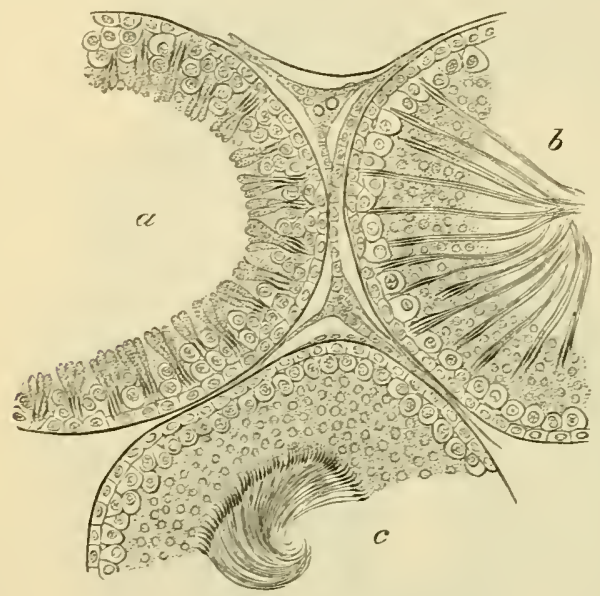

FIG. 410.

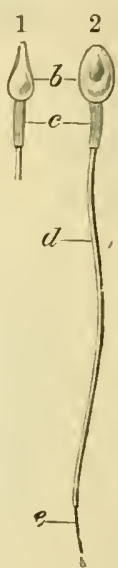

FIG. 411.

Fig. 410.-SECTION OF PARTS OF THREE SEMINIFEROUS TEBELES OF THE RAT. (, with the spermatozoa least advanced in develojment; $b$, more advanced; $c$, containing fully dercloped spermatozoa. Between the tubules are secn strands of interstitial cells with blood-ressels and lymph-sjaces.

Fig. 411.-Humax spermatozoa. 1000. (G. Retzius.)

1 , in profile; 2 , riewed on the flat; $b$, head; $c$, middle jjecc; $d$, tail; $\ell$, end-yiece of the tail, which is described as a distinct part by Retzius.

cells (interstitial cells, see fig. 410) of a yellowish colour; they are much more abundant in some species of animals (cat, boar) than in others. They accompany the blood-ressels before these break up to form the capillary networks which cover the walls of the scminiferous tubules.

The interstitial cells contain in many animals yellowish-brown fatglobules (staining with osmic acid); and also sometimes needle-shaped crystals (proteid). Similar fatty globules may occur in the Sertoli cells of the seminiferous tubules (see above), and have been thought to be derived from those of the interstitial tissue. 
Strueture of the tubules.-The seminiferous tubules are formerl of a thick basement-membrane, and contain several layers of epitheliumcells. Of these layers, the one next to the basement-nuembrane is a

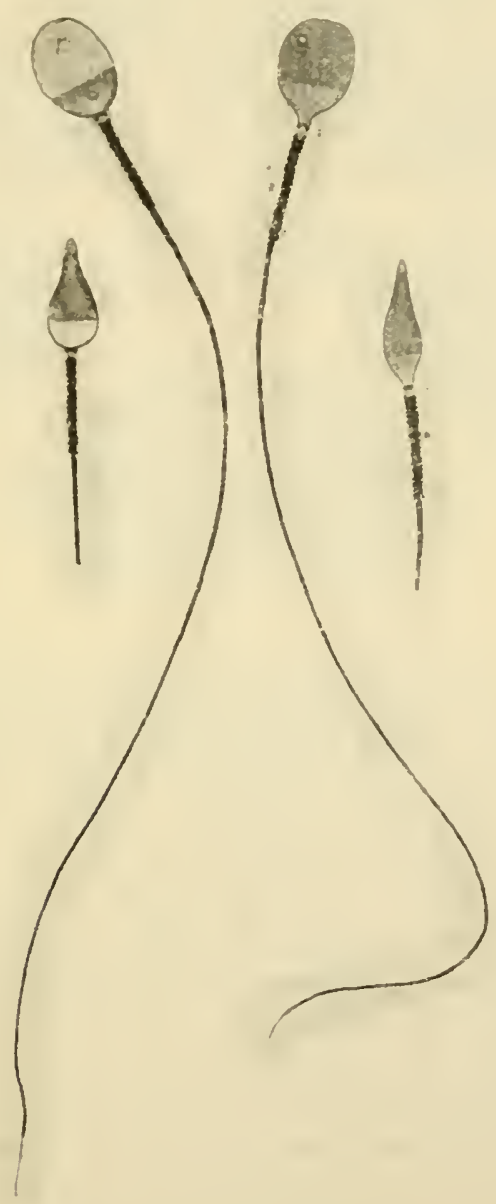

Fig. 412.- Hс3ras a PERMATOZOA OX THE FLAT AND IS PROFILE. (Bramman.) Those on the right still show protoplasm adhering to them. Only the commencement of the tail is represented in the $t w 0$ wich are shown in profile. Magnified 2500 diameters.

stratum of clear cubieal cells (spermatogonia or spermogons, figs. $410,414, a$ ), the nuelei of whieh for the most part exhibit the irregular network which is eharacteristic of the resting condition, but in certain tubules show indications of division. Here and there between the spermatogonia 
some of the lining epithelium-cells are enlarged, and project between the more internal layers, being connected with groups of developing spermatozoa. These enlarged cells are the cells of Sertoli (fig. 414, $a^{\prime}, a^{\prime \prime}$; fig. $41 i)$.

Next to this lining epithelium is a zone of larger cells (spermatocytes or spermocytes, fig. $414, b$ ), the nuclei of which are usually in some stage of hetero- or homo-typical mitotic division; these cells may be two or three deep (as in a, fig. 410). Next to them, and most internal, are to be seen in some tubules (fig. $410, b$ and c) a large
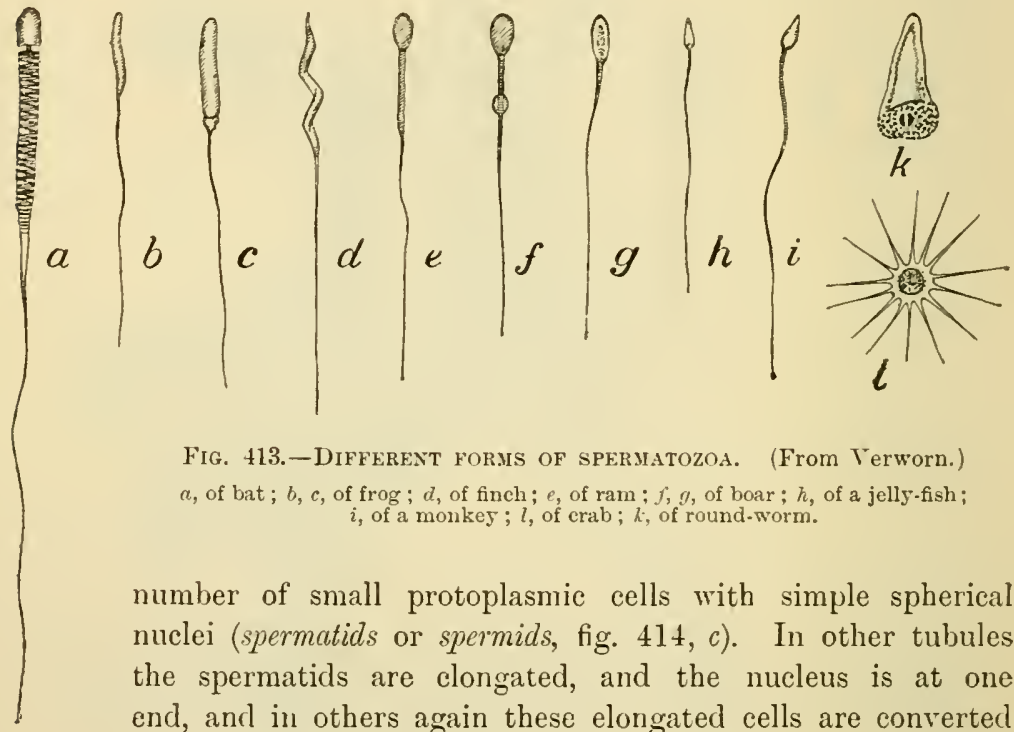

Fig. 413.-Different Foris of SPERMatozod. (From Verworn.) $a$, of bat ; $b$, $c$, of frog ; $d$, of finch; $e$, of ram; $f, g$, of boar; $h$, of a jelly-fish; $i$, of a monkey; $l$, of erab; $k$, of round-worm.

number of small protoplasmic cells with simple spherical nuclei (spermatids or spermids, fig. $414, c$ ). In other tubules the spermatids are clongated, and the nucleus is at one end, and in others again these elongated cells are converted into evident spermatozoa, which lie in groups: their beads projecting between the deeper cells and connected with one of the Sertoli cells of the lining epithclium, and their tails emerging into the lumen of the tubule (fig. $410, b$ ). As they become matured they gradually shift altogether towards the lumen, where they eventually become free $(c)$. During the time that this crop of spermatozoa has been forming, another set of spermocytes has been produced by the division of the spermogonia, and on the discharge of the spermatozoa the process is repeated as before (see diagram, fig. 414).

The spermatozoa.-Each spermatozoon or sperm consists of three parts, a head, a middle part or body, and a long tapering and vibratile tail (figs. 411, 412). In man the head is of a flattened oval shape, somewhat more flattened anteriorly; in some animals it bears a small barb-like projection at its extremity, but this appears to be 


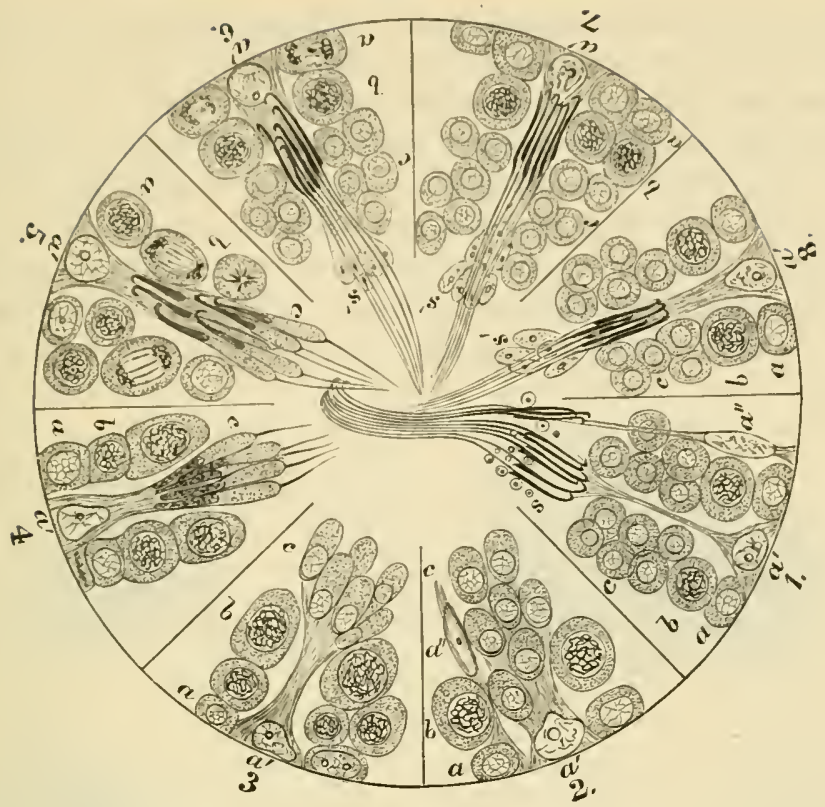

Fig. 414.-Diagray Exhibitixg THE CICLE OF PHASES OF SPERMOGENESIS (RAT).

$a$, lining epithelium-cells or spermatogonia, seen dividing in $6 ; a^{\prime}, a^{\prime \prime}$, Sertoli cells; $b$, spermatocytes, with skein-like nuelear filaments. These cells are seen actively dividing in 5. $c$, spermatids, forming an irregular eolumn or clump in $6,7, \mathrm{~s}$, and $\mathrm{l}$, and connected to an enlarged Sertoli eell, $a^{\prime}$, of the lining epithelium in $2,3,4$, and 5 . In 6,7 , and $S$ advanced spermatozoa of one crop are seen between columns of spermatids of the next erop. $s^{\prime}$, parts of the spermatids which disappear when the spermatozoa are fully formed; s, seminal granules.

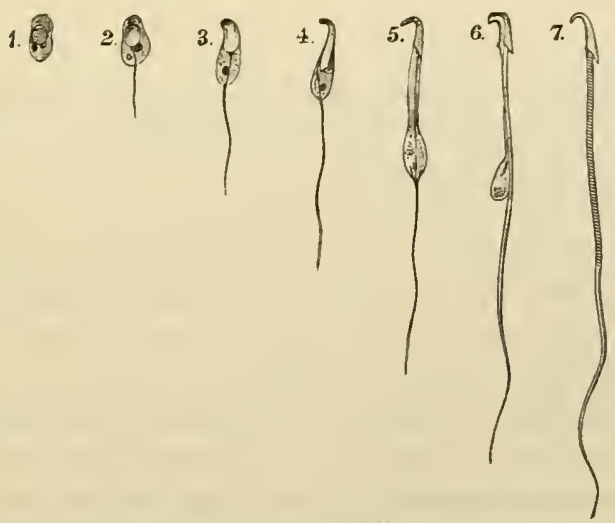

Fig. 415.- SPERMatozoA Froj THE RAT IN DIFFERExt STAGES OF DEVELOPMENT. (H. H. Brown.)

1-6, developing spermatozoa from the testiele; $\vec{\imath}$, a mature spermatozoon from the vas deferens. The remains of the protoplasm of the cell, which is seen in 6 still adhering to the middle piece of the spermatozoon and containing a number of chromatin granules, appears to be thrown off as the spermatozoon matures. 
absent in the human spermatozoon. The apical part is covered by a cap of a somewhat different appearance from the rest-the head-cap. The middle-piece is in man short and cylindrical, and has a spiral fibre passing round it. An axial fibre, itself fibrillated, passes from a knob close to the head right through the body and tail. The tail is the longest part of the spermatozoon, and when examined with the microscope in the fresh condition is seen to be in continual vibratile motion, the action resembling that of a cilium. The extremity of the tail (end-piece) forms a distinct part of the spermatozoon, and in some
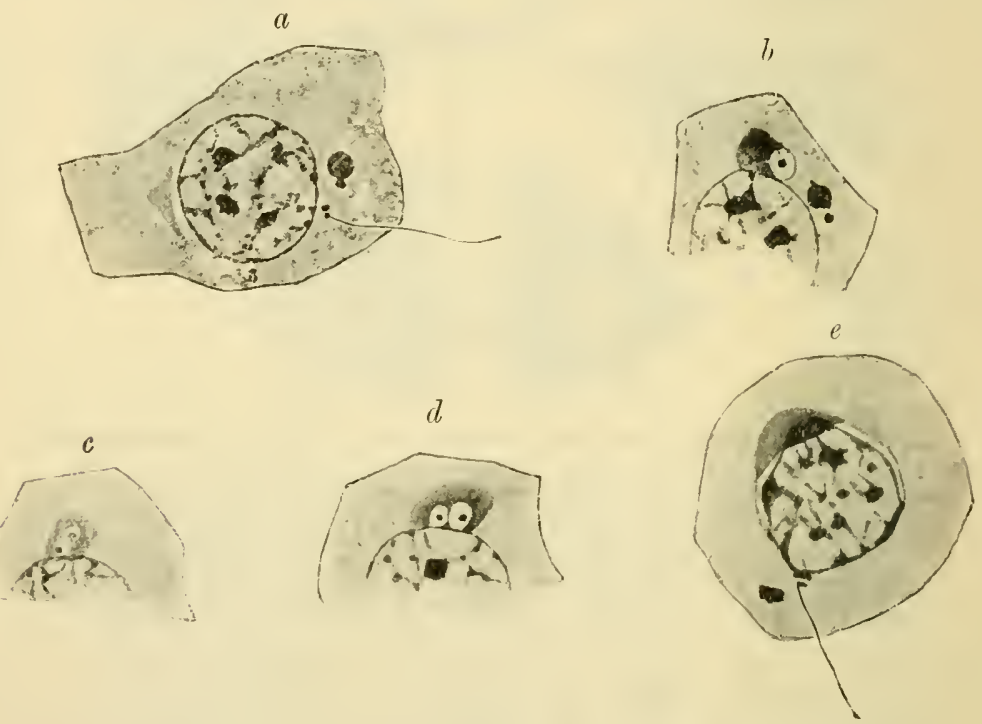

Fig, 416. - Changes in the SPERMatids iN the COURSE OF FORMation OF THE SPERMATOZOA. (Niessing.)

The tail filament is seen (iu $t$ and $e$ ) to extend from the centrosome, which lics close to the nucleus. The head-cap (shown in e) is produced by a transformation of part of the archoplasm which becomes vacuolated $(b, c, l)$.

animals may split into two or three fibrils; these can also sometimes be traced along the whole length of the tail. Human spermatozoa are about $0.05 \mathrm{~mm}$. ( $\frac{1}{50}$ o inch) long, the head and middle-piece each measuring about $\frac{1}{10}$ th of this amount.

In different animals the shape of the head and the extent of middlepiece and tail vary greatly (fig. 413 ). In the rat (fig. 415,7 ) the hearl is long, and is recurved anteriorly ; it is set obliquely on the middlepiece, which is also of considerable extent, and which has a closely wound spiral filament encircling it (H. H. Brown). In the newt the head is long and tapering, and the tail bas a membranous expansion, attached in a spiral manner along its whole length. This has also been 
deseribed in the luman spermatozoon, but its existence here is doubtful. In deeapoils, which possess no cilia, the spermatozoa are stellate and motionless (fig. $413, l$ ); in nematoid worms they are amoboid (fig. $413, k$ ). Sometimes two distinct kinds of spermatozoa are met with in the same species of animal, one kind being far the larger in size (giant spermatozoa) but much less numerous. Such giant spermatozoa have been observed in man.

Although the tail of the spermatozoon is usually classed with oilia, it is obvious that it exhibits far greater complexity and is a much more highly differentiated structure. Spermatozoa also differ from cilia in being highly resistant to putrefaetion and to chemical reagents, even inclucling the strongest acids and alkalies.

Spermogenesis.-The spermatozoa are developed from the small cells (spermatids) which form the innermost stratum of the seminal epithelium, and these are themselves produced by the division of the large spermocytes of the seeond layer. It is probable that fresh spermocytes are formed by division of some of the lining epithelium. cells or spermogons. The cycle of changes therefore which takes place is as follows:- - Division of a lining epithelium-eell or spermogon into two, one of whieh grows larger ("growing eells" of H. H. Brown), becomes a spermoeyte, and passes into the second layer, while the other remains in the first layer. 2. Division of the spermocyte. 3. Further division of the daughter-spermocytes thus produced. The four cells (spermatids) which result from this double division possess only one-half the somatic number of chromosomes in their nuclei, "reduction" having been effected in the final cell-divisions by which the spermatids are produced (see p. 14). 4. Elongation of the spermatids and their gradual conversion into spermatozoa. As they undergo this conversion their grouping becomes more evident, and each group is found to be connected with a cell of Sertoli (figs. 414, $a^{\prime}, 417$ ), which probably minister's to their nutrition. This cell undergoes a gradual process of elongation so that the spermatozoa by the time they are fully developed are brought to the lumen of the tube, in which they then become free. In the meantime other alternate groups of spermatids from which the next crop of spermatozoa will be derived are being formed in the same manner, passing through the same cyele of changes. So that in a longitudinal section even of the same tubule, different phases of development may be observed, and in different tubules of the same testicle every phase may be traced. The accompanying diagram (fig. 414), which is construeterl from drawings by $\mathrm{H}$. H. Brown, illustrates the eycle of changes above deseribed: it is divided into eight parts, each of which sbows 
the condition of the epithelium of a seminiferous tubule at a particular stage.

Each spermatid becomes converted into a spermatozoon in the following manner (figs. 415, 416, 418). The nucleus forms the chief part of the head, while the tail develops as an outgrowth of the centrosome and cytoplasm. The tail-filament appears within the protoplasm, growing ont from the centriole of the cell which lies close

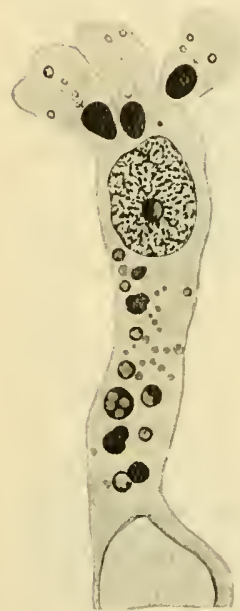

FIG. 417.

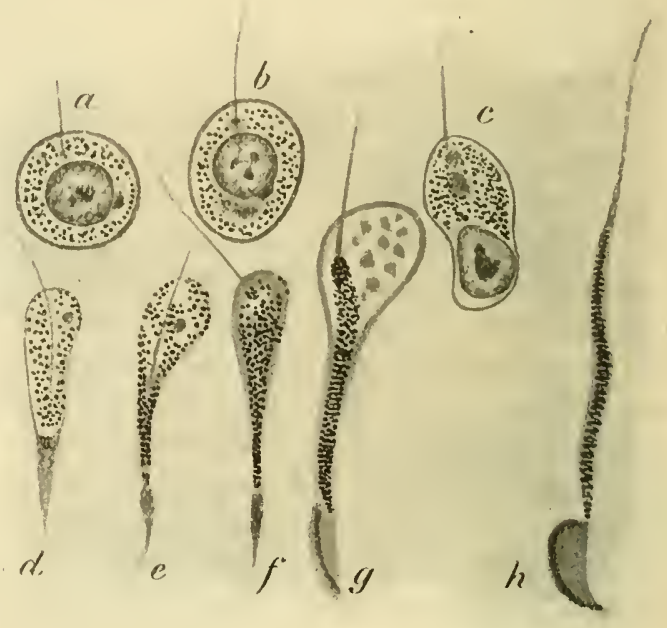

FIG. 418.

Fig. 417.-A Cell of Sertoli with Which THe sperhatids (THReE OF which ARE SHOWN) ARE BEGINNING TO BE CONNECTED : HUIAN. (Bramman.)

The cell contains globules (of nutritive substance) staining with osmic acid, and similar but smaller globules are also seen in the spermatids. "The "ring" formed around the tail filament by one of the particles of the centrosome (see text) is shown in each of these spermatids close to the "bead."

Fig. 418. -STAgES OF SPERMOgENESIS, WITH TRANSFORMATION OF THE GRANULES OR MITOCHONDRIA OF THE SPERMATID INTO THE SPIRAL YIBRE OF THE MIDULE PIECE: MOUSE. (Benda.)

to the nucleus (fig. 416). The centriole is double, and one of its two particles forms an annular expansion or ring which, as development proceeds, moves down the tail-filament until it reaches the place where this leaves the cytoplasm: here it ultimately forms the limit of the borly or middle piece of the spermatozoon. The archoplasm (see p. 8) assists in forming the head of the spermatozoon; a portion (the idiozome of Meves) at an early stage separates from the rest, lying apically to the nucleus. Within this portion vacuoles form (fig. $416, b, c, d)$ which presently run together into a clear non-stainable 
globule which Hattens out orer the nucleus and forms (fig. 416 , e) the hearleap of the spermatozoon; as development proceeds, this may become indistinguishable from the rest of the head. The spiral fibre of the middle piece is developed from mitochondria (see p. 5) in the spermatid (Benda) (fig. 418).

A portion of the protoplasm of each spermatid containing a number of chromatin-particles (seminal granules) becomes detached and disintegrated before the spermatozoon is fully matured (fig. $414, s, s^{\prime}$ ).

A few spermocytes undergo incomplete division, and the resulting spermatids are large (giant spermatids) and contain either one large nucleus or two or more nuclei which ultimately blend to form the head of the spermatozoon. In these cases there are a corresponding number of centrosomes, from each of which a tail-filament may become developed. 


\section{LESSON XXYVII.}

\section{GENERATIVE ORGANS OF THE FEMALE.}

1. Sections of the ovary of the non-pregnant rablit or cat. (If from a pregnant animal the organ may be largely occupied by luteal tissue.) study the sections with a low power, observing the small and large Graafian follicles, each inclosing an orum, scattered through the stroma. Neasure some Graafian follicles of different sizes; make a general sketch of a section under the low power. Then sketch carefully two or more of the follicles with their contents under a high power.

2. Sections across the Fallopian tube. Sketch a section under the low power.

3. Section across the body of the uterus, or across a cornu of a bicorned uterus. Observe with the naked eye the thickness of the muscular and mucous coats respectively. Notice the ciliated columnar epithelium lining the organ and extending into the glands of the mucous membrane. Draw a part of the section mder the low power.

4. Section of the mucous membrane of the vagina. Notice the stratified scaly epithelium which lines it and which is continued over the projecting part of the os uteri.

5. Take the fresh ovary of a recently killed animal and with a needle or fine scalpel-point prick one of the largest and most prominent of the Graafian follicles. The organ must be held just over a slide so that on pricking the follicle the fluid contents may spurt out on to the glass. Examine the drop of liquor folliculi with a low power for the escaped ovum, which will be surrounded by follicular cells. When found place a piece of hair in the drop, cover with cover-glass and examine with high power.

THE OVARY.

The ovary is a small solid organ, composed of a stroma of fibrous tissue, with many spindle-shaped cells, and also containing, near its attachment to the broad ligament, a large number of plain muscular fibres. It is covered by a layer of small columnar epithelium-cells (germinal epithelium, fig. 420,a), between which may here and there be seen a few larger spheroidal cells, with large round nuclei. In the young subject the epithelium occasionally dips down into the subjacent stroma.

The stroma is beset with vesicles of different sizes, the smallest being near the surface of the organ, the larger ones placed more deeply in the stroma, although, as they increase in size, they extend towards the surface. 
These resicles are the Gruffun follicles. Each Gratafiun follicle has a proper wall (theca folliculi) formed of a layer derived from the stroma, and a special inner layer containing large cells: both are highly vascular. Each follicle contains an ovum and epitheliom. In the smallest follieles the ovim is small, and the epithelimm of the follicle is formed of a single layer of cells, which may be flattened against the ovim (fig. 4.21). In somewhat larger follicles the epithelium-cells are in two layers, and these are columnar in shape (fig. $423, \mathrm{E}$ ). In still larger ones, each of these two layers is formed of several strata of cells, and fluid has begm to collect between the layers at one part. Of the two layers, the one which lines the cavity of the folliele is termed the membrana granulosa, while the mass of eells which more immediately surrounds the ovum is known as the cumulus or discus proligerus.

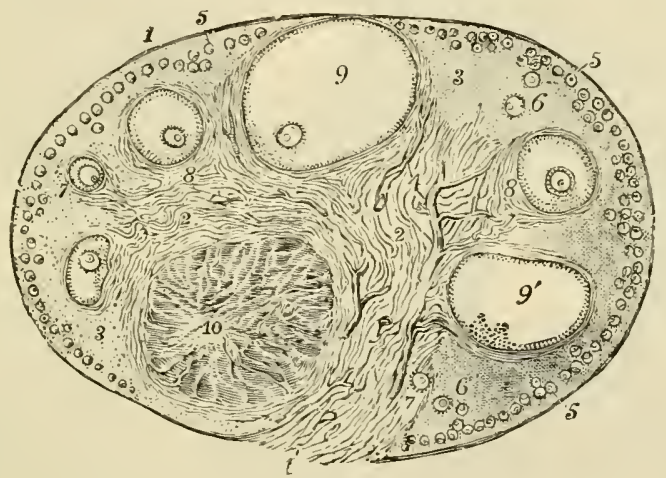

Fig. 419.-Section of the ovari of the Cat. ${ }_{1}^{6} \cdot$ (Schron.)

1 , outer covering and free border of the ovary ; 1 , attached border; 2 , the central ovarian stroma, showing a fibrous and vascular structure; 3 , peripheral stroma; 4, bloodvessels; 5 , Graafian follicles in their earliest stages lying near the surface; $6,7, \delta$, more advanced follicles which are embedded more decply in the stroma; 9 , an almost mature follicle containing the ovum in its deepest part ; $Y^{\prime}$, a follicle frou which the ovum has fallen out in preparing the section; 10, corpus luteum.

In the largest follicles the fluid bas much increased in amount, so that the follicle has become gradually larger and more tense. Finally it reaches the surface of the ovary, and projects from that surface, where it eventually bursts, and the liquor folliculi, with its contained ov'um, is set free. This event is believed to occur usually at some time during menstruation.

Some of the Graafian follicles do not burst, but, after attaining a certain stage of maturity, undergo a process of retrograde metamorphosis and eventually disappear.

The ovarian ova or ovocytes are large spherical cells (fig. 424), about $0.2 \mathrm{~mm}$. ( $\frac{1}{12}$ inch) in diameter. When fully formed, as in the 
largest Graafian follieles, each ovum is surrounded by a thiek transparent membrane (zona pellucila). Within this is the protoplasm of the ovocyte (vitellus), filled with fatty and albuminous granules (yolk gramules). Lying in the vitellus, generally eceentrically, is the large

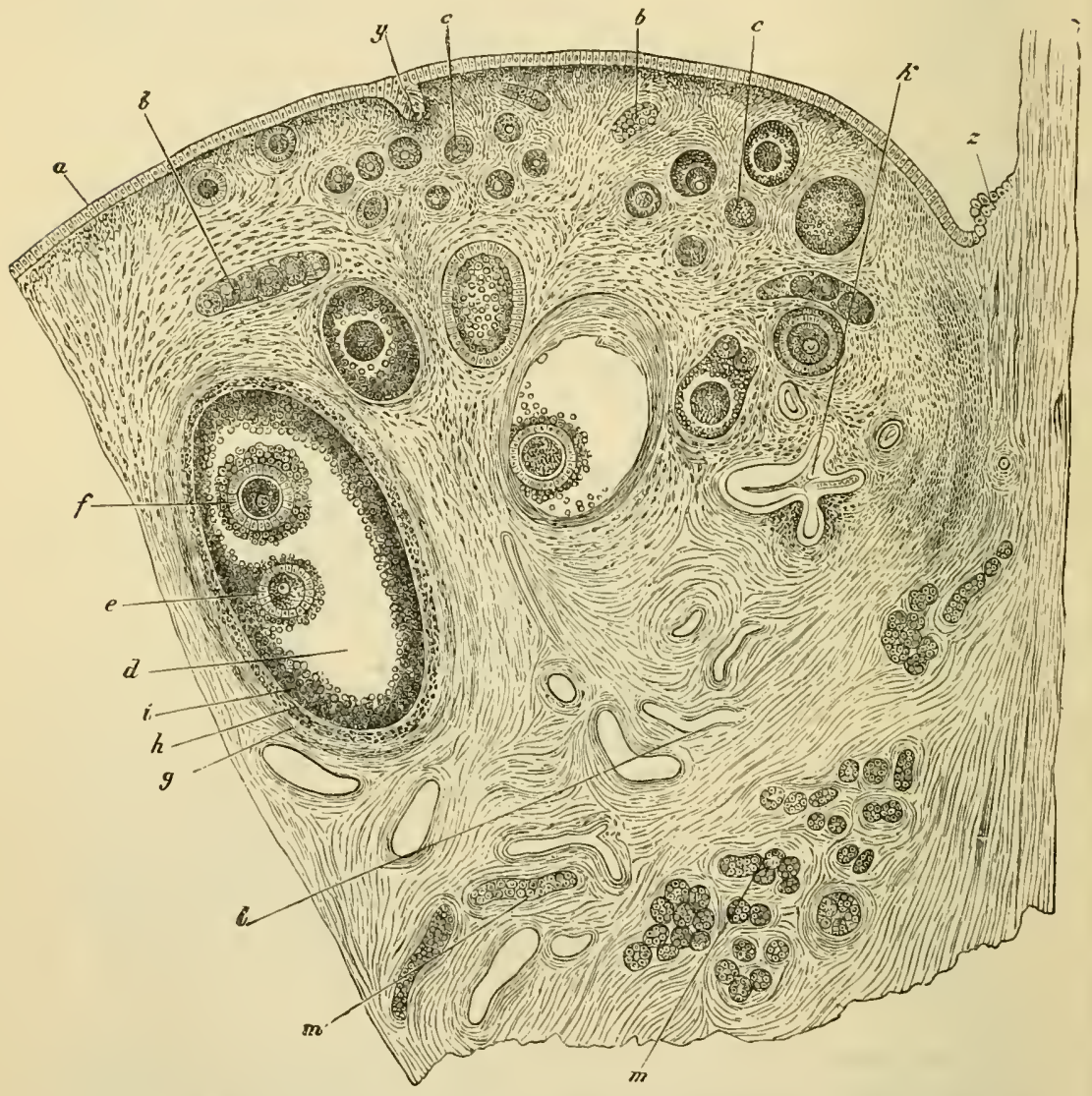

Fig. 420.-Section of the ovary of an adult Bitch. (Waldeyer.)

$a$, germ-epithelium : $l$, remains of egg-tubes; $c$, small follicles ; $d$, more advanced follicle ; $e$, discus proligerus and ovum; $f$, second ovum in the same follicle (this occurs but rarely); $g$, outer tunic of the follicle; $h$, inner tunic; $i$ membrana granulosa; $k$, collapsed retrograded follicle; $l$, blood-vessels; $m$, $m$, longitudinal and transverse sections of tubes of the parovarium; $y$, involuted portion of the germ-cpithelium of the surface; $z$, place of the transition from peritoneal to germinal or ovarian epithelium.

elear round nucleus (germinal vesicle), which may show an intranuelear network, and invariably has a well-marked nucleolus (germinal spot), sometimes more than one.

Oogenesis.-Both the ova and the epithelium of the Graafian follicles 
originate from the germinal epithelium of the embryo. This forms at first a simple layer covering the stroma, but later becomes thickened and multiple. After a time rounded cords of epithelium-eells (eggtubes of Pflugger: fig. $423, A$ ), grow down into the stroma, whilst this

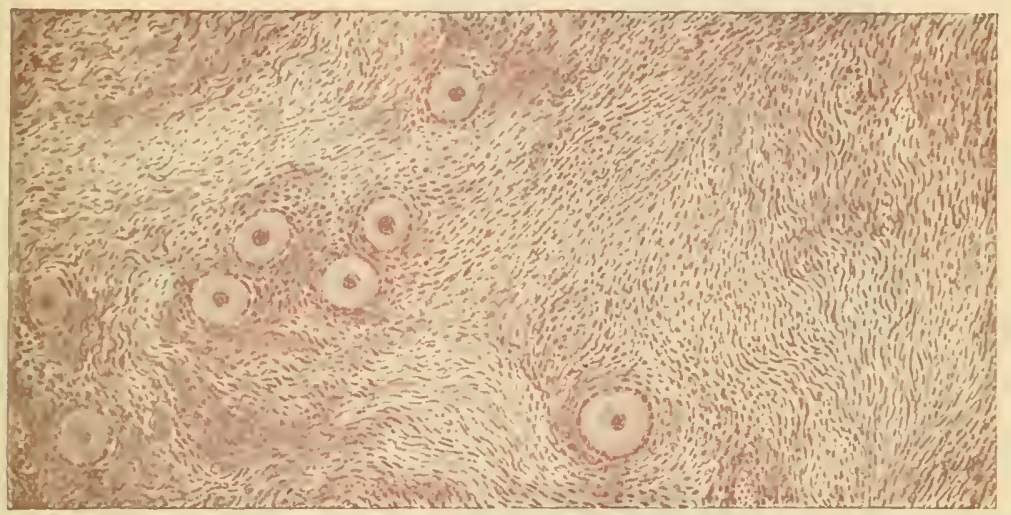

Fig. 421.- SEction OF PART OF HUMAN OVARY SHOWIN( SMALL GraAfiaN FOLLICLES IMBEDDED IX A FIBRO-CELLCLAR STROMA. (Sellheim.)

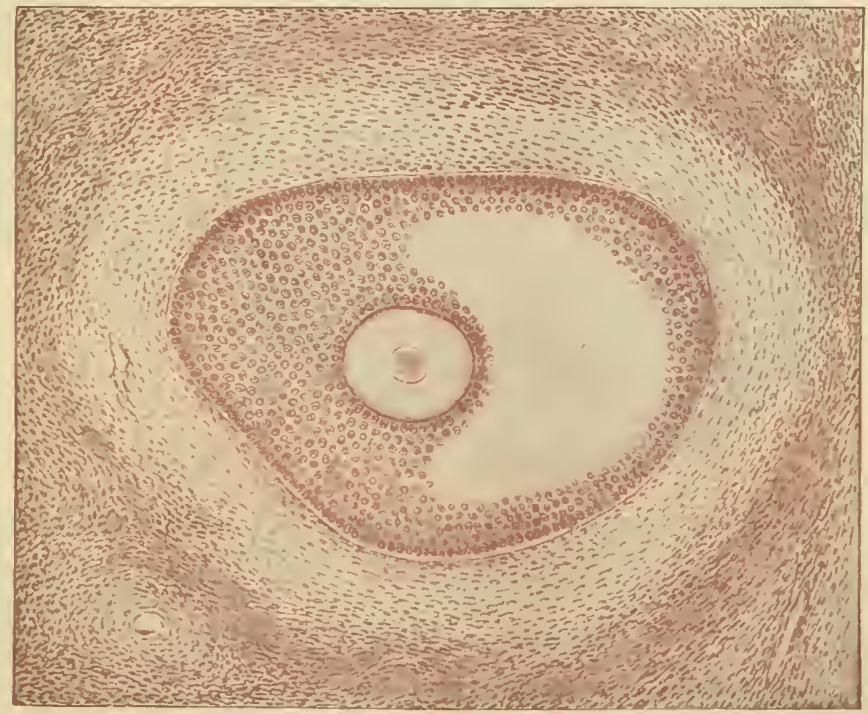

Fig. 422, - A MODERATELY LARGE GRAAFIAX FOLLICLE FROM THE HUMAN OVARY, SHOWIXG OVUM SCRROUNDED BY " DISCUS PROLIGERCS " AND WALL OF FOLLICLE LINED BY "MEMBRANA GRANLLOSA." BETWEEN THEM IS AN ACCUMULATION OF LIQUOR FOLLICULI. (Sellheim.) 
at the same time grows into the epithelium. The cords presently become broken $u$ py ingrowths of stroma into small isolated nests of

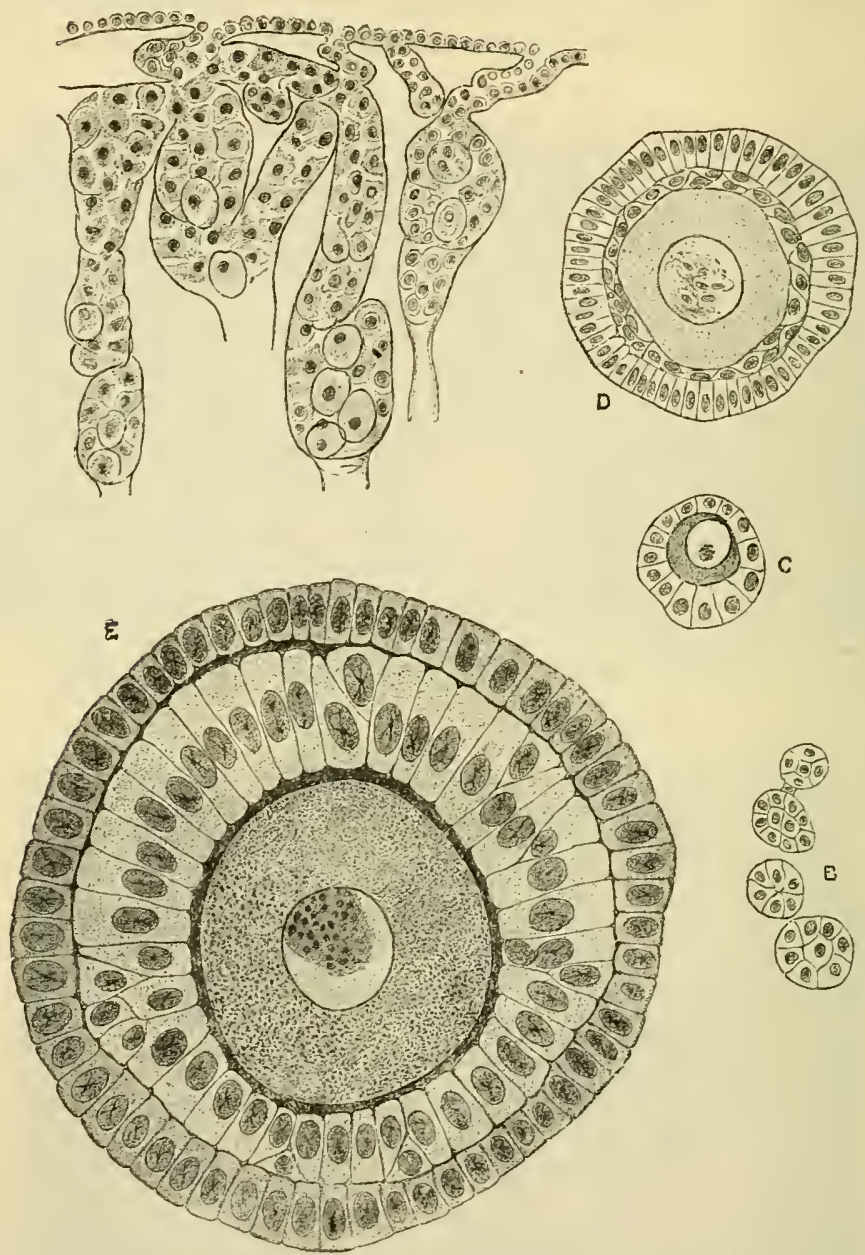

Fig. 423.-Figures SHOWING VARIOUS STAGES IN THE DEVELOPMENT OF THE GraAfian Follicles OF THE RABBIT.

A, frorn ovary of young ralıbit, showing "egg-tubes" of Pfluger growing in from germinal epithelium; some of the tubes contain primitive ova; B, primitive Graafian follicles formed from the breaking up of an egg-tube; c, a young Graafian follicle, witl a single layer of follicle-epithelium; D, a somewhat older follicle, witi the sccond layer forming within the first; $\mathrm{E}$, a more advanced folliele, showing two complete layers of columnar epithelium surrounding the ovum within the follicle.

epithelium-cells, each of which may represent a Graafian follicle. To form the ova, some of the cells become enlarged (primitive ova), and usually there is one such enlarged cell in each of the isolated 
nests. ${ }^{1}$ The remaining cells form the epithelium of the follicle (sce fig. $423, \mathrm{~B}, \mathrm{c})$. It is stated that the protoplasm of the ovum remains connected with the cells of the discus proligerus by fine processes

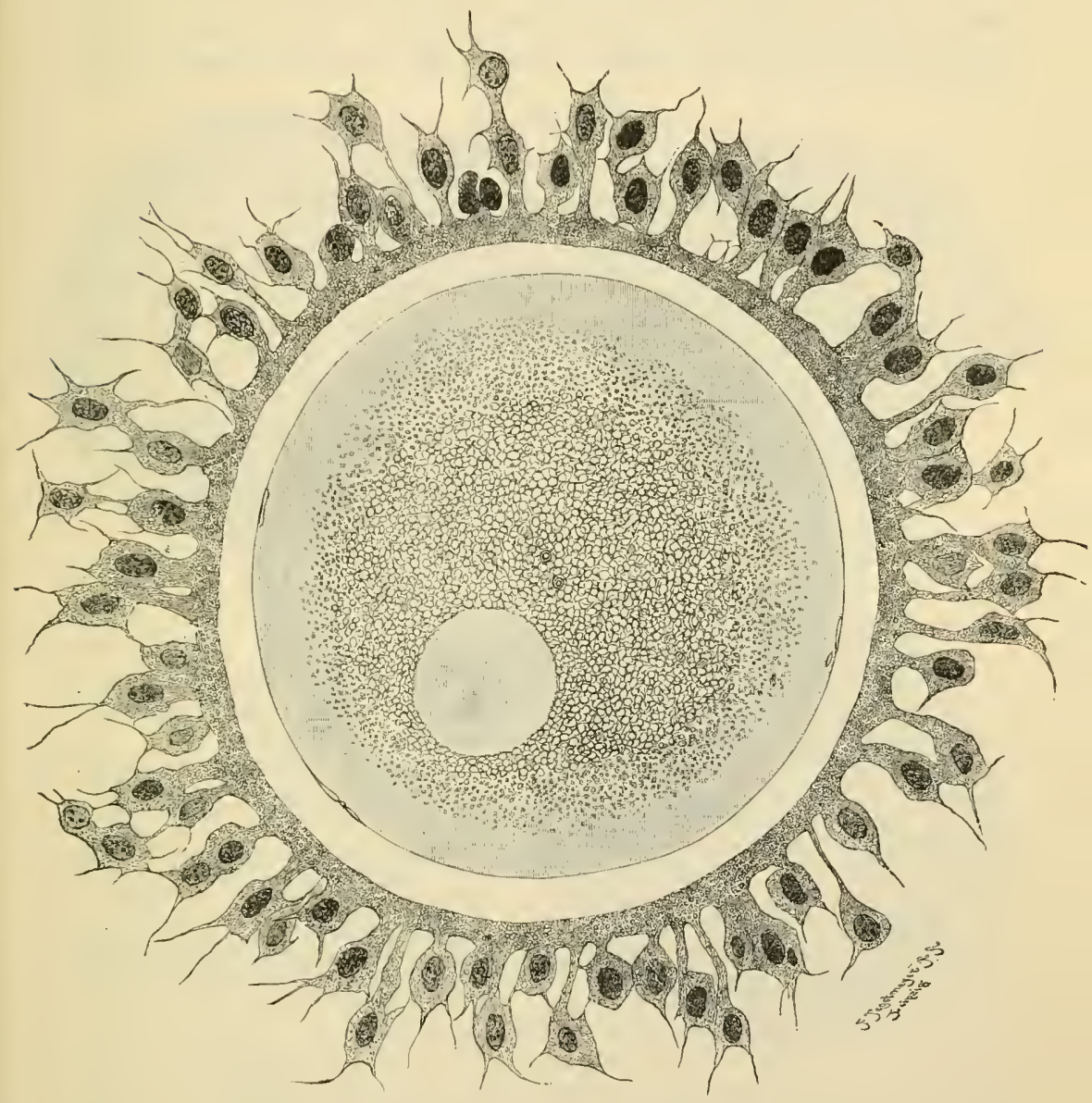

Fig. 424.-Human ovum; highly magnified. (Waldeyer.)

The zona pellucida is surrounded by cells of the discus proligerus, which are adherent to it.

which pass through pores in the zona pellucida, and on the other hand, the epithelium-cells of the follicle are themselves inter-connected by protoplasmic bridges, so that the whole forms a syncytium.

I The nuclei of the primitive ova pass through the pre-maiotic changes mentioned on p. 14. 
The stroma of the ovary contains, besides the spindle-shaped connective-tissue cells and plain mnscular fibres already mentioned, a number of epithelium-like interstitial cells. Some of these are derived from the germinal epithelium, and appear capable of developing into ova and follicle epithelium-cells (Lane-Claypon); others have originated from cells of corpora luten. These last are large yellow
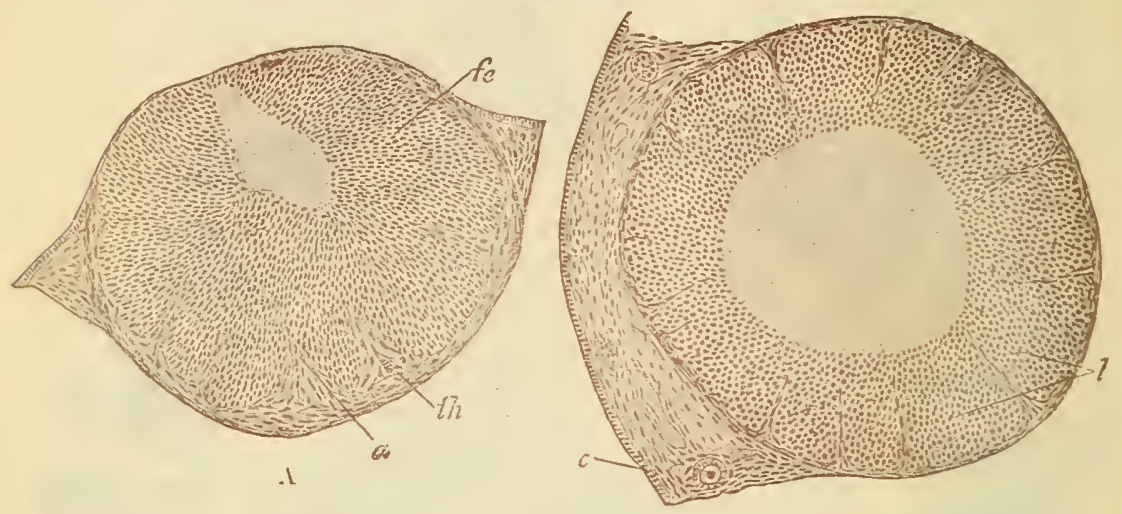

B

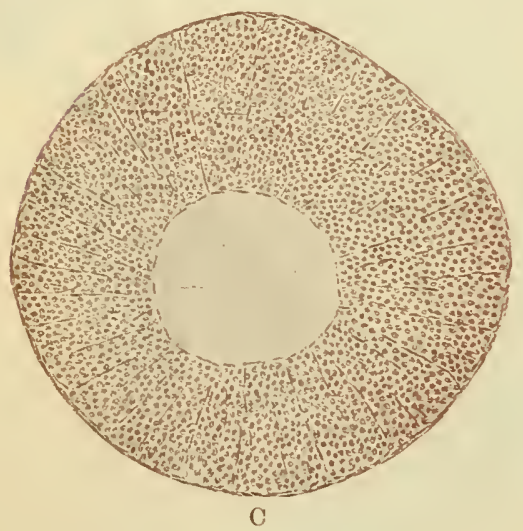

Fig. 425,-THREe STAGES IN THE FORMATION OF THE CORPUS LCTEUY IN THE MOUSE. (Sobotta.)

A. The follicular epithclium, fe, is hypertrophied, and vascular processes, $a$, of the theca, $t h$, or wall of the follicle are growing into it.

B. The epithelial mass is now subdirided into lobule-like masses, $l$, of luteal cells by the thecal ingrowths; $e$, epithelium of surface of ovary.

C: There are now very numerous thecal septit or trabecule, and the columns of luteal cells are much narrower. A central cavity is still seen.

nodules which are developer out of the Graafian follicles after the ova have been extruded (figs. 425,426 ). They consist of columns of large yellowish cells (luteal cells), with intervening trabecula of vascular fibrous tissue, which converge to a central strand of connective tissue occupying the axis of the nodule (fig. 426). The columns of cells are not unlike those of the cortex of the suprarenal capsule. The corpus luteum is derived from the wall-probably in the main from the epithelium - of the follicle, which becomes thickened and folded by multiplication and hypertrophy of its cells; between the folds 
connective tissue and blood-vessels grow in from the theca towards the centre of the follicle; in this way the columnar arrangement above mentioned is produced. After persisting for a time the corpus luteum gradually disappears, its tissue becoming merged in the surrounding stroma. Corpora lutea grow much larger and remain much longer persistent in the event of pregnancy supervening.

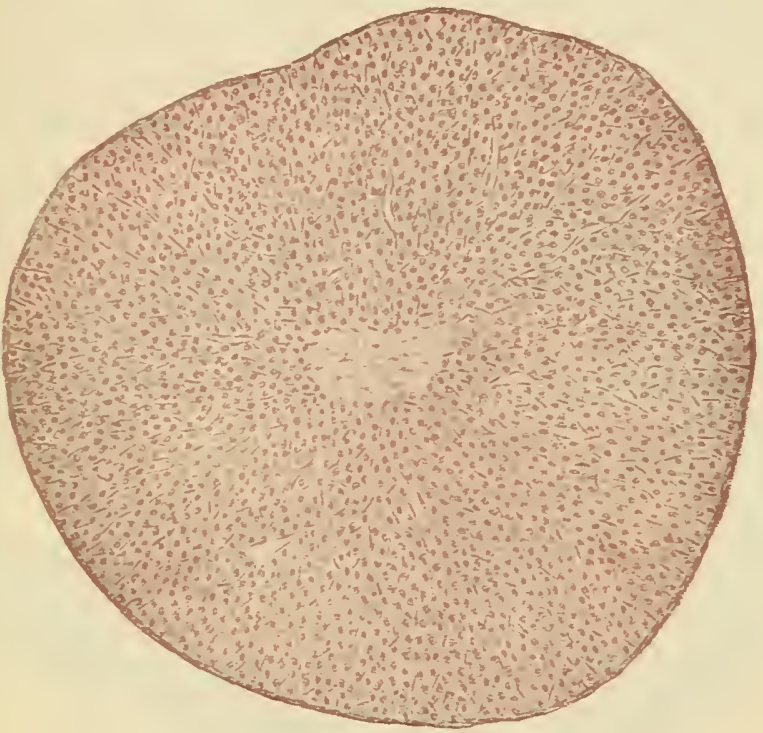

Fig. 426.-CORPCS LCTECy OF MOLSE. (Sobotta.)

This figure shows a more advaneed stage of derelopment, the luteal tissue being now vascularized and the central carity obliterated.

The use of the corpus luteum is not known certainly, but it has recently been suggested that it may vield an internal secretion, the effect of which is to produce the fixation of the fertilized orum in the uterine mucons membrane (Born). In confirmation of this, experiments seem to indicate that gestation does not supervene in animals whose corpora lutea have been destrored (Fraenkel and Cohn). or from which the ovaries have been remored during the first stages of pregnancy (Marshall and Jolly).

The blood-ressels of the orarv are rery large and numerous, and are especially distributed to the walls of the Graafian follicles, over which they form a close network.

\section{THE FALLOPIAN TLBES AND UTERLS.}

The Fallopian tubes are lined by a very vascular mucous membrane which is corered with ciliated epithelium, and has numerous longitudinal folds (fig. 427). Externally they are covered by a serous coat, within which is a thin longitudinal stratum of plain muscular 
fibres overlying circular fibres of the same tissue, but these layers are not distinctly marked off from one another.

The human uterus is composed of two parts, the body and cervix. The body of the uterus is formed of the following layers:

1. A serous layer, derived from the peritonem, which covers the greater part of the fundus.

2. A musculne layer, which is of considerable thickness and is formed of plain muscular fibres disposed in three, more or less blended, strata. Of these the outer has its fibres arranged partly longitudinally, partly circularly. The middle muscular layer, on the other hand, is thick;

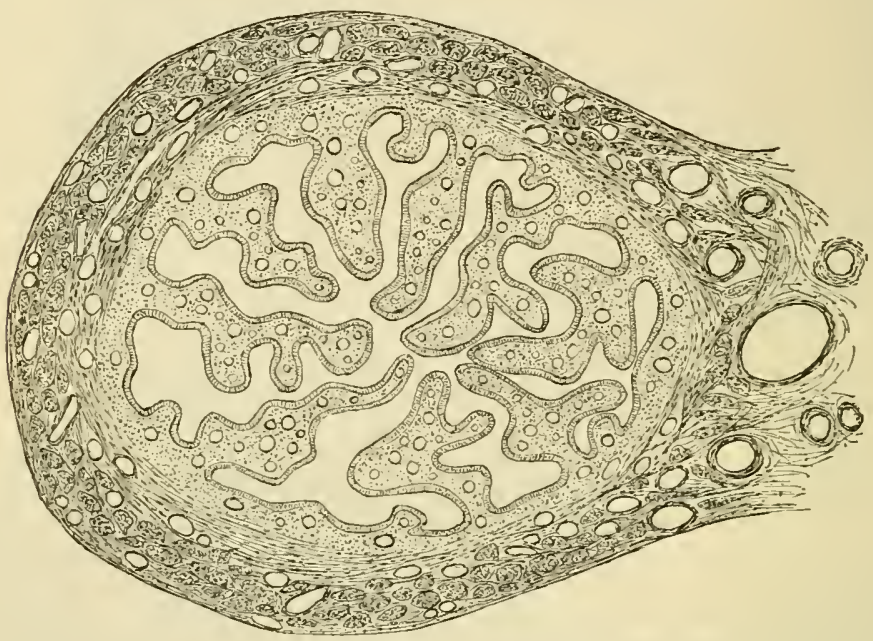

Fig. 42i.-SEction ACRoss THE FAllopiax tube. (Diagrammatic.)

its fibres run in different directions, and it contains the ramifications of the larger blood-vessels. The inner layer, again, is thinner and has both longitndinal and circular fibres, many of the latter being prolonged internally into the deeper part of the mucous membrane; the extremities of the uterine glands extend between and amongst its fibres.

3. A mucous membrane, which is very thick and is composed of soft connective tissue containing a large number of spindle-shaped cells. It is lined by ciliated epithelinm and contains long, simple, tubular glands, which take a curved or convoluted course in passing through the membrane (fig. 429). Their (ciliated) epithelium is continuous with that which covers the inner surface of the nucous membrane. In the cervix the mucous membrane is marked by longitudinal and oblique ridges, and the glands are shorter but more complex than those of the 


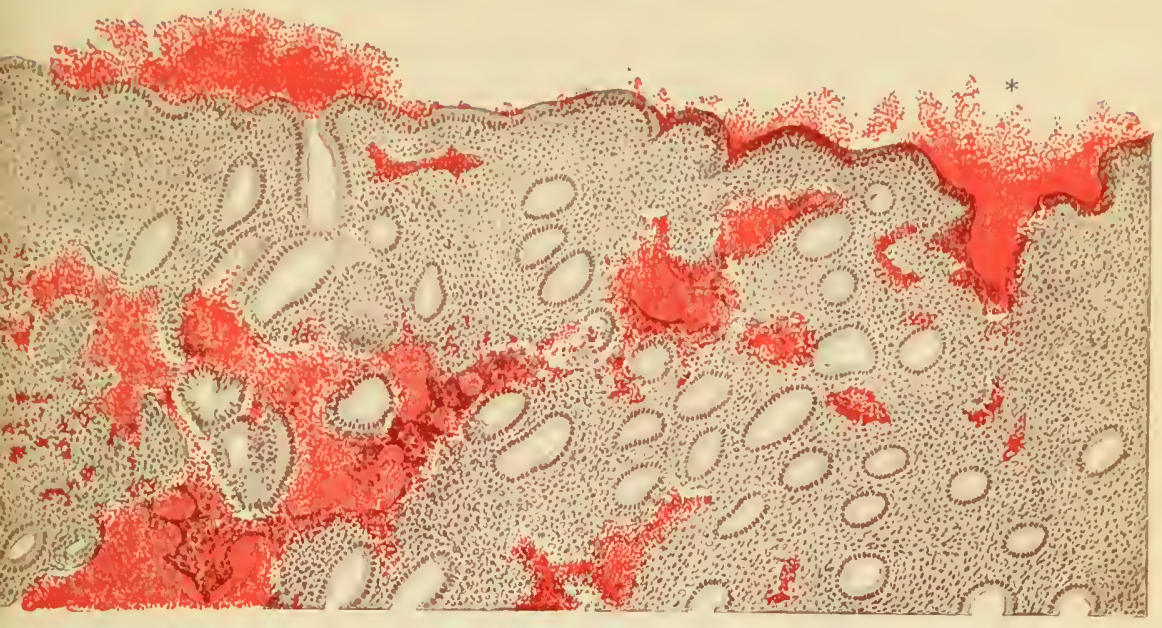

Fig. 428. - SEction OF IUCOUS MEMBRANE OF HUMAN UTERUS DURING MENSTRUATION, SHOWING MASSES OF BLOOD WHICH HAVE ESCAYED FROM RUPTURED CAPILLARIES INTO THE INTERGLANDULAR TISSUE, AND HAVE AT ONE PLACE (*) BROKEN THIOLgH THE StRFACE EPITHELIM. (Sellheim.)

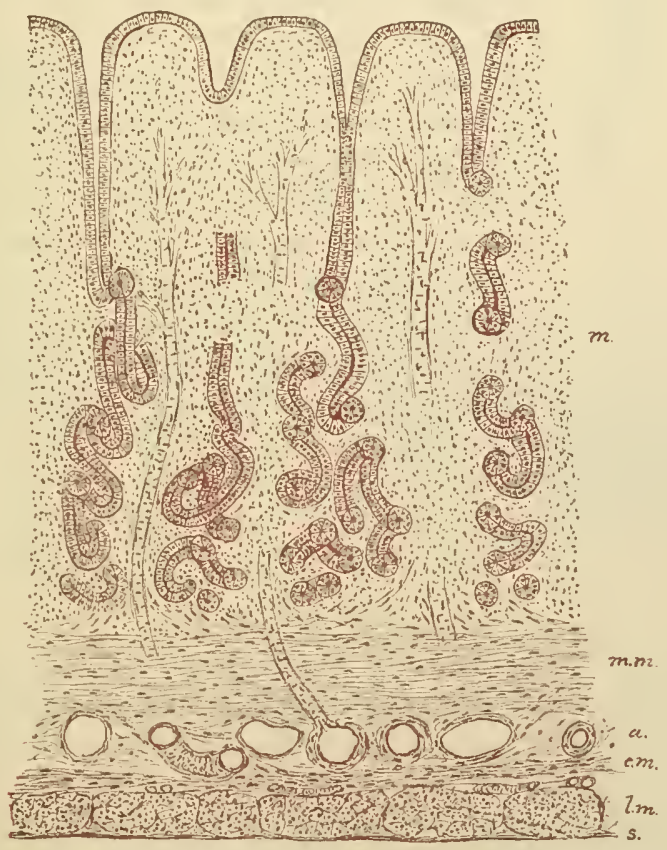

Fig. 429. - SECTION OF a CORNU OF THE RABBit's UterUS.

s, serous lay'er; l.m., longitudinal muscular fibres; c.m., circular muscular fibres of the muscular coat: $a$, areolar tissuc witb large blood-vessels; m.m., muscularis mucosæ; $m$, mucous membrane. 
body of the uterus, and are lined by columnar mucus-secretin

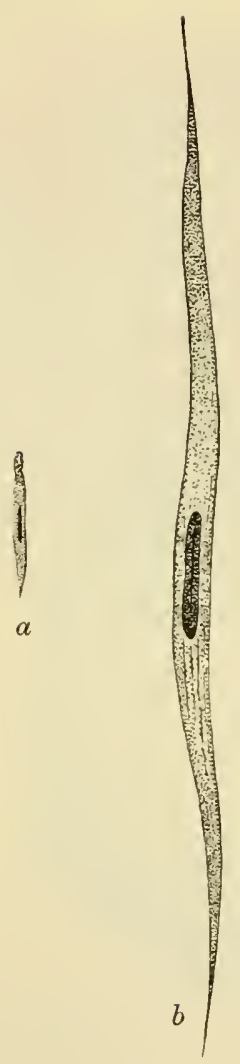

Fig. 430. - Muscular FIBRES (a) FROM NONPREGNANT, (b) FROM PREGNANT CTERUS, DRAWN TO THE SAME SCALE. (Sellheim.) cells. Near the os uteri the epithelium becomes non-ciliated columnar, and at the margin of the os uteri this passes into a stratified epithelium which overlies vascular papillæ of the corium. The mucous membrane is very vascular, and it also contains a large number of lymph-vessels.

In many animals the uterus is composed of two long tubes (cornua uteri): the arrangement of the muscular tissue in these is simpler than in the human uterus, which has been formed by the fusion of two such tubes. Fig. 429 exhibits the structure of a cornu of the uterus of the rabbit.

At each menstrual period the mucous membrane of the uterus undergoes a partial process of disintegration accompanied by an escape of blood from the capillaries of the membrane (fig. 428). This is succeeded by a rapid renewal of the disintegrated part. Should gestation supervene, the process of renewal results in the formation over certain parts of a greatly thickener mucous membrane, with long convoluted glands, which is then known as the decidua. The muscular layer also becomes enormously hypertrophied, this hypertrophy being produced by the enlargement of the individual muscle cells (fig. 430). 


\section{LESSONS XXXIX. AND ML.}

\section{STRUCTURE OF THE SPINAL CORD.}

1. SEctoxs of the spinal cord from the cervical, dorsal, and lumbar regions. If the human spinal cord cannot be obtained sufficieutly fresh, that of at dog, cat, or monkey may be used. It is to be hardenerl by suspending it immediately after removal from the body in a tall jar of formol (10 per cent. solution). After a few days it may be transferred to alcohol. Sections are to be made either by the paraffin or celloidin method: the former is preferable for small cords. The sections may be stained by Nissl's method, which brings to view the nerve-cells and also stains the axis-cylinders of the nervefibres. If it is desired to stain by the Weigert-Pal method, which colours the medullary sheaths of the nerve-fibres, the pieces of cord should be placed in 2 per cent. bichromate of potassium solution or Miller's fluid (either at once or after formol) and should be left for about a month, after which they are cut by a freezing microtome. (For the details of these methods see Appendix.) Carminate of ammonia or thionin may also be employed to stain the nerve-cells and axis-cylinders.

Notice the relative extent of the grey as compared with the white matter in the different regions of the cord.

Sketch a section from each region under a low power. Sketch also a small portion of the white substance, two or three nerve-cells, and the central canal with its lining epithelium and surrounding neuroglia under the high power.

Measure the diameter of some of the nerve-fibres in the anterior columns, in the lateral columns, and in the posterior columns.

2. Tracts in the spinal cord. The conducting tracts of the spinal cord may be studied in two ways, viz.: (1) by preparing sections of embryonic cords (from the 5 th to the 9 th mouth), the sections being stained by the Weigert-Pal process (Flechsig's method) ; (2) by preparing sections from the cord of an animal in which either a complete section or a hemi-section has been performed about 15 days before the animal is killed, and staining thin pieces of the cord from below and from above the section by placing them in a solution consisting of two parts of Müller's fluid and 1 part of 1 per cent. osinic acid (Marchi's method). The cord must first be partly hardened by placing it for a few days in Müller's fluid.

The spinal cord is composed of grey matter in the centre and of white matter externally. It is closely invested by a layer of connectivetissue containing numerous blood-vessels (pia mater), and less closely by two other membranes (fig. 431). One of these is an areolar membrane, resembling a serous membrane in general structure, but nonvascular and more delicate in texture (arachnoid). The other, which lines the vertebral canal, is a strong fibrous membrane known as the dura mater. At the middle of the anterior and posterior (ventral and 
dorsal) surfaces the pia mater dips into the substance of the cord in the anterior and posterior mediun fissures, so as to divide it almost completely into two lateral halves. These are, however, united by an isthmus or bridge, which is composed anteriorly of transversely crossing white fibres (uhite or anterior commissure), posteriorly of grey matter (grey commissure), in the middle of which is a minute canal lined by ciliated epithelium (central cumal).

Each lateral half of the spinal cord contains a crescent of grey matter, which is joined to the corresponding crescent of the opposite side by the grey commissure. Of the two horns of the crescent the posterior or dorsal is the narrower and comes near the surface of the

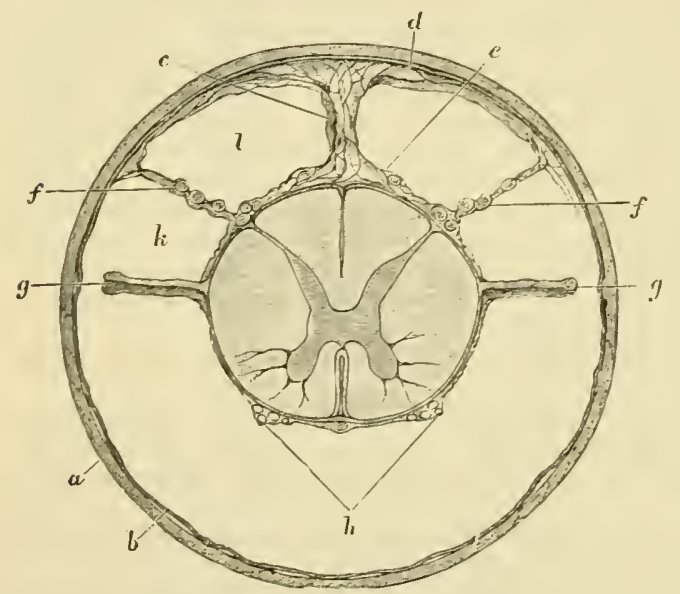

Fig. 431.-SECTION OF THE SPINAL CORD WITHIN ITS MEMBRANEs. (Key and Retzius.).

le, dura rnatcr; b, arachnoid; $c$, septum of arachnoid; $d, e$, trateculie of arachnoid; $g$, ligameutum denticulatum; $j$, bundles of posterior root; $h$, bundles of anterior root; $\hat{k}, l$, subarachnoid space.

cord; close to it the bundles of the posterior nerve-roots enter the cord. The bundles of the anterior nerve-roots emerge from the anterior horn.

According to Ingbert abont 1,300,000 nerve-fibres enter the cord by the posterior roots, and about one-third that number leave it by the anterior ronts.

The posterior root-fibres are derived fron the cells of the spinal ganglia, which lie outside the cord: the anterior root-fibres from cells within the grey matter, chiefly from cells in the anterior horn, but also from some cells in the middle and posterior parts of the grey natter and (especially in the thoracic region) from cells in the intermedio-lateral tract (lateral horn). The latter probably furnish the autonomic (sympathetic) fibres of the anterior roots, while the cells of the anterior horn furnish the fibres which are distributed to the voluntary muscles.

The rlite matter of each half of the cord is subdivided by the approach of the posterior born to the surface into two unequal columns-antero-lateral and posterior. A distinction is sometimes drawn between anterior and lateral portions of the antero-lateral 


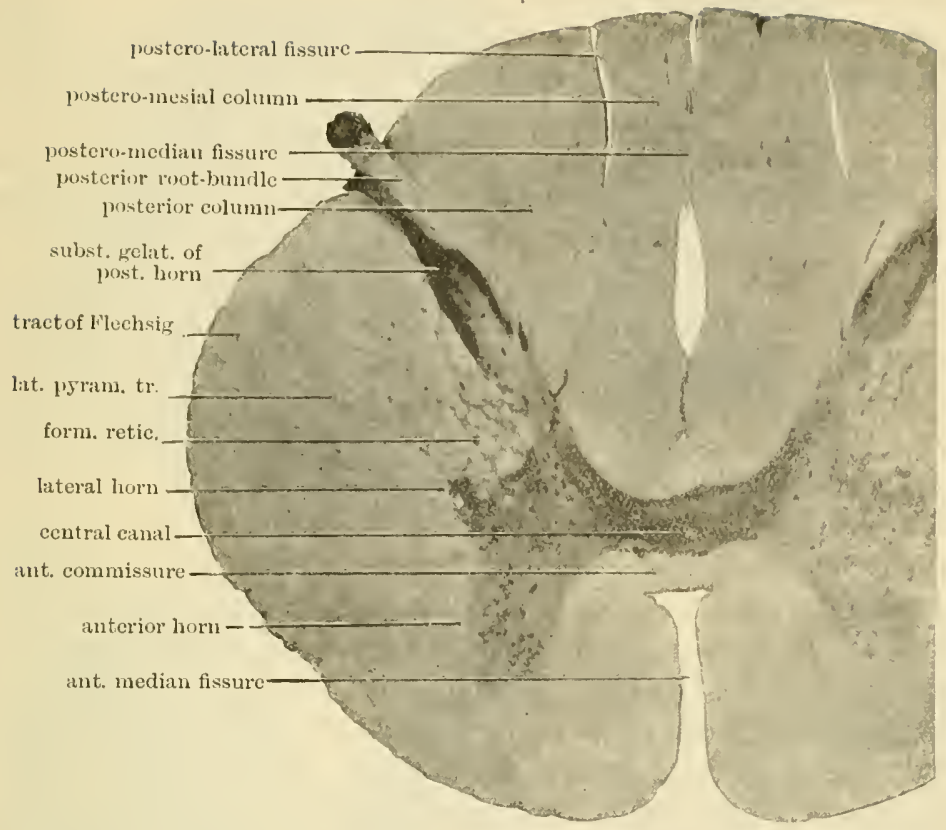

Fig. 432.- SECTION OF HUMAN SPINAL CORD FROM UPPER CERVICAL REgION. (Photograph.) Magnified ahout $S$ diameters.

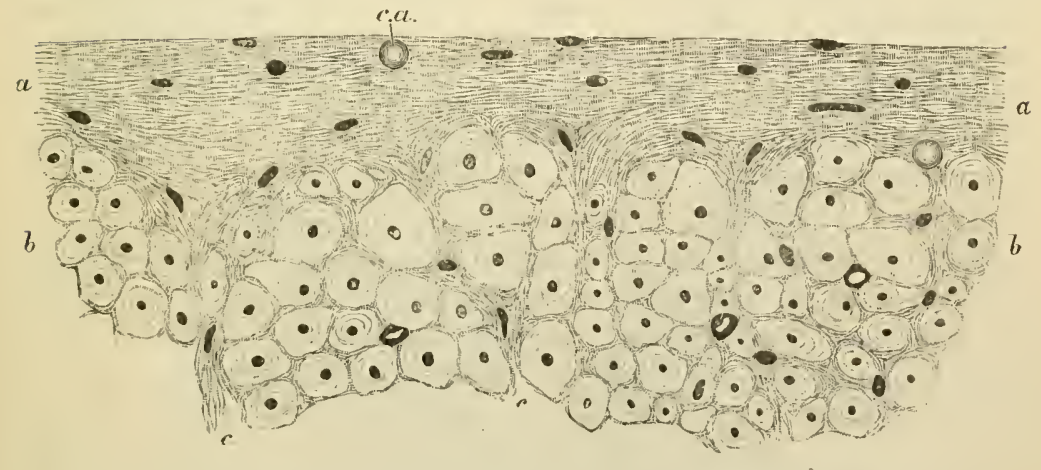

FIg. 433. - A SMALL PORTION OF A TRANSVERSE SECTION OF THE HCMAN SPINAL CORD IN THE REGION OF THE LATERAL COLUMN, TO SHOW THE SUPERFICIAL NEUROGLIA.

$a, a$, superficial neuroglia ; $b, b$, transverse section of part of the lateral column of the cord, in which the dark points are the axis-cylinders, and the clear areas the medullary substanee of the verve-fibres. The superficial neuroglia is seen to exhibit the appearance of is fine feltwork in which numerous nuclei and one or two corpora amuluce $c, \alpha .$, are crubedded, and to extend inwards $(c, c)$ among the nerve-fibres. 
column, although there is no line of demarcation between them. In the upper part of the cord the posterior column is subdivided by a septum of connective tissue into two-the postero-mesial column or funiculus gracilis, and the postero-lateral column or funiculus cuneatus.

The white matter is composed of longitudinally coursing medullated nerve-fibres, which in sections stained with carmine or thionin appear as clear circular areas with a stained dot, the axis-cylinder, near the middle (fig. 433); while in sections stained by the Weigert-Pal method they appear as black circles with a clear centre. The nerve-fibres vary in size in different parts; on the whole those which are nearest to the surface of the cord are larger than those nearest to the grey matter, but there is a bundle of very small fibres (at M, fig. 434) opposite the tip of the posterior horn.

The medullated tibres are supported by neuroglia, which is composed of fibrillated neuroglia-cells (fig. 192, p. 161). The neuroglia is accumulated in greater amount at the surface of the cord, underneath the pia mater (particularly in the human cord, near the entrance of the posterior roots (fig. 433)), and it extends into the grey matter, in which it is especially accumulated in the sulstantia gelatinosa at the apex (caput) of the posterior horn and around the central canal.

The grey mutter, besides neuroglia, contains an interlacement of nerve-fibres and the arborisations of the nerve-cells which are embedded in it.

Characters of the spinal cord in the several regions (figs. 434, 439). -In the cervical region the white matter, especially that of the lateral columns, oecurs in largest proportion. The grey matter in the cervical enlargement is also in considerable amount, and it encroaches, especially in the upper part of the region, in the form of a network (formatio reticularis) upon the arljacent part of the lateral white column (fig. 432). The anterior horns are thick and the posterior slender. The posteromesial column is distinctly marked off.

In the dorsul region the grey matter is small in amount, and both horns are slender. The whole cord is smaller in diameter than either in the cervical or lumbar region. The columns of nerve-cells known as Clarke's column and the intermedio lateral tract are well marked.

In the lumbar region the crescents of grey matter are very thick, and the white. substance, especially the lateral columns, relatively small in amount. The isthmus lies nearly in the centre of the cord, whereas in the cervical and dorsal regions it is nearer the anterior surface.

In the part of the spinal cord from which the sacrul and coccygeal nerve-roots take origin the grey matter largely preponderates, the 


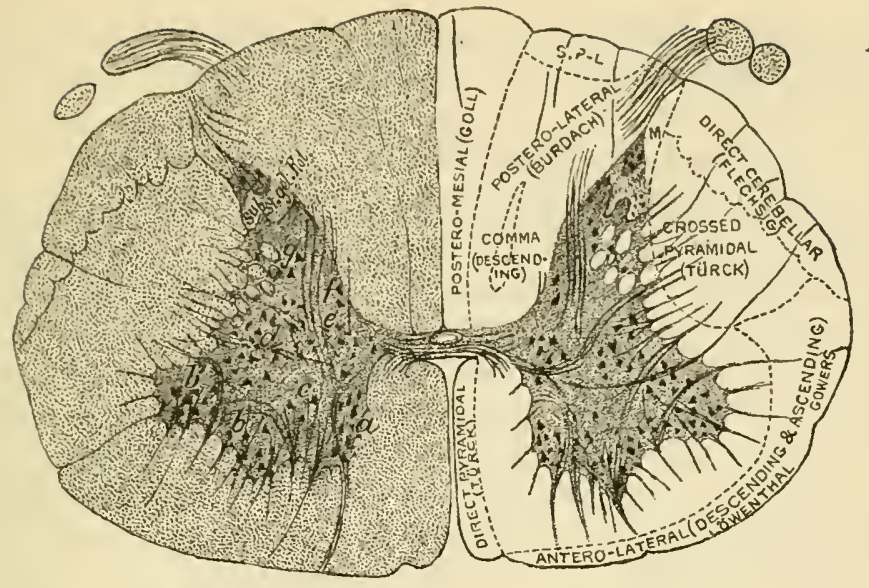

$\Lambda$

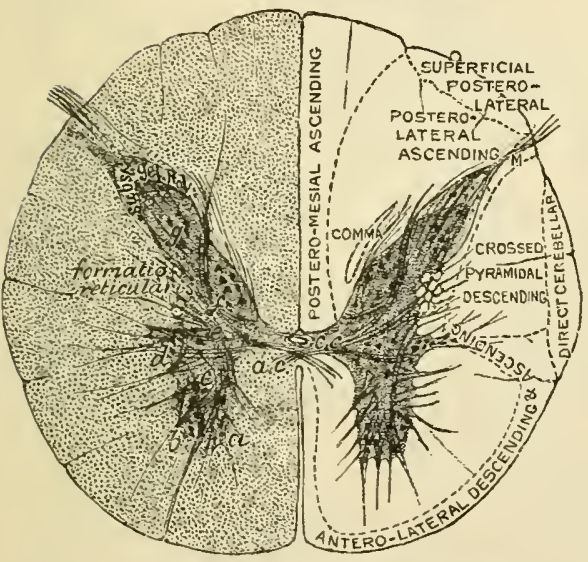

B

Fig. 434.-Sections of Hedan SPINAL CORD FROM THE LOWER CERVICAL (A), MID-DORSAI. (B), AND MID-LUMBAR (C) REGIONS, SHOWING THE PRINCIPAL GROUPS OF NERTE-CELLS, AND ON THE RIGHT SIDE OF FACH SECTION THE CONDUCTING TRACTS AS THEY OCCUR IN THE SEVERAL REGIONS.

$a, b, c$, groups of cells of the anterior horn; $d$, eells of the lateral horn: $e$, middle group of cells; $f$, cells of Clarke's column; $g$, cells of posterior horn; $c, c$, central canal ; a.c. anterior commissure; $\mathrm{M}$, marginal bundle of Lissauer ; $p-m$, septomarginal tract.

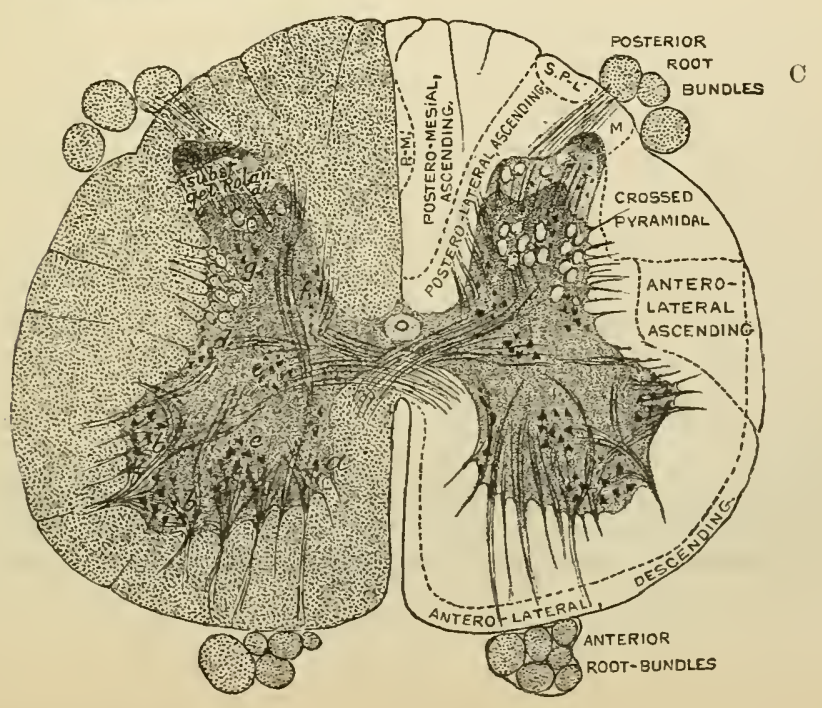


crescents form thick irregular masses, and the grey isthmus is also of considerable thickness.

\section{TRACTS OF NERVE-FIBRES IN THE WHITE COLUMNS.}

The course of the nerve-tracts in the spinal cord, and in other parts of the central nervous system, ean be made out by the method of Flechsig, which involves the stndy of seetions of the developing eord; for it is found that the formation of medullary substance occurs sooner in some traets than in others, so that it is easy to make out the distinction between them. Thus, the peripheral nerves and nerveroots beeome myelinated in the first half of the fifth month of foetal life. Of the tracts of the spinal cord, those of Burdach and Goll (see below) are the first to be myelinated, then the tracts of Flechsig and Gowers, all of these being sensory or eentripetally conducting, while the pyramidal tracts, which are motor or eentrifugally eonducting, do not receive their myelin sheath until after birth. ${ }^{\text {? }}$

Another methor (that of A. Waller) consists of investigating the course which is pursued by degeneration of the nerve-fibres in consequence of lesions produced accidentally or purposely. Those tracts in which degeneration of fibres occurs below the lesion are termerl "descending" tracts; those in which it oceurs above the lesion are termed "ascending."

The cells whence the fibres of any tract arise can be identified after a lesion of the tract by the chromatolysis or degeneration of Nissl which nerve-cells undergo after section of their axons (see pp. 154 to 159).

Tracts of the posterior coiumn.-1. Tract of Goll. - The fibres of the postero-mesial column belong to a tract which is known as the tract of Goll (fig. 435, 6). This consists of fibres derived from the posterior nerve-roots of the sacral, lumbar, and lower dorsal nerves, which, after having entered the postero-lateral colnmns, pass, as they ascend, towarcls the posterior median fissure and form a distinct tract, which is marked of from the rest of the posterior column in the cervical region by a slight furrow and a septum of pia mater (fig. 432). This tract ends amongst the cells of the nucleus gracilis of the medulla oblongatil.

2. Tract of Burdach.- The postero-laterul column (tract of Burdach) is also eomposed of fibres of the posterior nerve-roots, which all run for a certain distance in it before entering the grey matter of the eord or of the medulla oblongata. As each mass of posterior root-bundles

${ }^{1}$ Flechsig finds that the fibres of the posterior roots are myelinated in at least three stages, and that the postero-lateral tract shows a corresponding differentiation into three chief parts: the ventral, middle and dorsal root-zones. He suggests that this differentiation corresponds with functional differences of the fibres. 
enters the column close to the apex of the posterior horn it, so to speak, pushes the root-fibres which have already entered nearer to the median fissurc; hence those which are derived from the lowest nerve-roots are nearest that fissure (in the tract of Goll), while those which are derived from the highest remain near the posterior horn (in the tract of Burdach). Many of the fibres of both tracts pass into the grey matter either immediately on entering the eord or in their course upwards; the rest are continued into the medulla oblongata and those of the tract of Burlach end by arborising amongst the cells of the mucleus cuneutus.

3. Comma tract.-Besides the tracts of Burlach and Goll, which are wholly composed of long "ascending" fibres having their cells of oligin

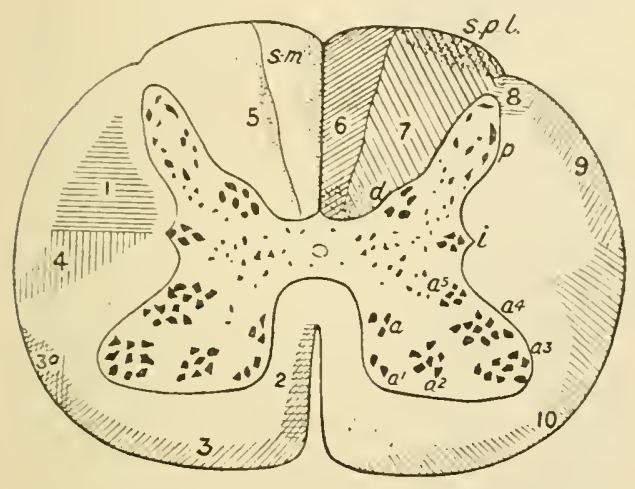

FIG. 435.-DIAGRAH sHOWING THE A.SCAIING (RIGHT SIDE) ANI) ILEXCENDING (LEFT SIDE) TRACTS IN THE SPINAL CORD.

1. Crossed 1yramidal; 2, direct prramidal; 3 , antero-lateral descending ; $3 n$, bundle of $\mathrm{H} \omega \mathrm{lweg}$; 4 , prepyramidal; 5 , comma; 6 , postero-mesial; 7 , postero-lateral; 8 , tritet of Lissauer; ? dorsal cerebellir ; 10 , antero-lateral aseend. ing or ventral cerebellar; $s-m$, septo-marginal ; s.p.l., superficial postero-lateral fibres (dorsal root zone of Flechsig); a to "5, groups of cells in the anterior horn; i, intermedio-lateral group or cellcolumn in the lateral part of the grey matter; $p$, cells of posterior horn ; $d$, dorsal nucleus of stilling or cell-column of Clarke. The fine dots indicate the situation of "endogenous" fibres (arising in grey matter of cord) having for. the most part a short course.

in the ganglia on the posterior roots, there are a few fibres which have a shorter "descending" course in the posterior column. These are believed by some authorities to arise from descending branches of the posterior root-fibres, by others to arise from cells in the grey matter of the cord. They form the so-called comme tract (fig. 435, 5).

Proprio-spinal or endogenous fibres of the posterior column.There are a few fibres (septo-marginal), chiefly accumulated near the median fissure (ovul bundle) and near the posterior surface (median triangle bundle), but also scattered in other parts of the column, which are derived from cells in the grey matter of the cord itself. These take a "descending" course in the posterior columm; while others which arise in the grey matter and have an "ascending" course are especially numerous in the ventral part of the colunin.

Descending tracts of the antero-lateral column.-1. Pyrumidal or cortico-spinal tract. - At the posterior part of the lateral column there is a tract of moderately large "descending" fibres (intermingled with 


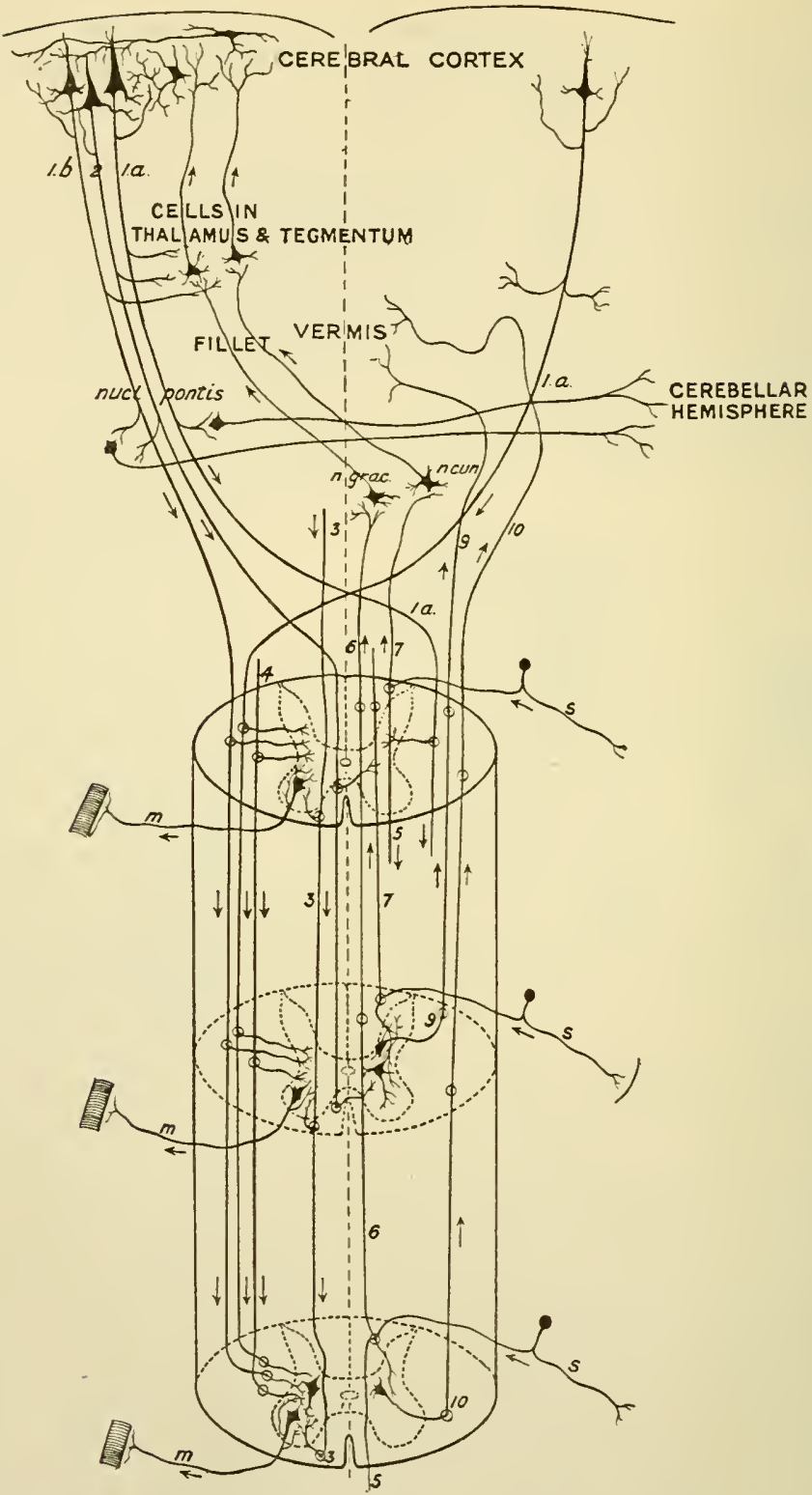

Fig. 436. -DIAGRAM SHOWING THE COURSE, ORIGIN, AND TERMINATION OF THE FIBRES OF THE PRINCIPAL TRACTS OF THE WHITE MATTER OF THE SPINAL CORD. (The numbers in this diagram refer to fibtes of the tracts shown with corresponding numbers in fig. 435.)

"Descending" tracts : $-1 a$, a fibre of the crussed pyramidal tract; $1 b$, an morossed fibre of the pyramidal tract passing to the lateral column of the same side; 2, a fibre of the direct pyramidal tract; 3 , a fibre of the antern-lateral descending tract; 4 , a fibre of the prepyramidal tract; " 5 , fibres of the comma trict. "Ascunding" tracts:-6. a fibre of the postero-mesial tract; $\gamma$, fibres of the postero lateral tract; 9 , one belonging to the dorsal cerehellar; 10 , a fibre of the ascending intero-lateral or ventral cerebellar tract. Also, $m$, motor nerves : 8 , sensory (afferent) nerves. 
smaller fibres) which are found to run in the lateral column of the spinal cord from the opposite side of the brain, after having for the most part crossed at the decussation of the pyramids of the medulla oblongata (crossed laterul pyrumidal tract, fig. 435, 1; fig. 436, 1a). Intermingled with the fibres of the erossed pyramidal tract in the lateral column are a few fibres of the pyramid which have not crossed in the medilla oblongata, and which are therefore derived from the cerebral cortex of the same side (uncrossed lateral pyrumidal fibres, fig. $436,1 b$ ). The large fibres which lie in the anterior colunns next to the anterior median fissure, which are especially numerons in the upper part of the human cord, also helong to a portion of the same tract which has not undergone decussation (direct pyramidul tract, figs. $435,436,2)$. The direct pyramidal tract is only found in man and the anthropoid apes; in some individnals it is absent, and it varies considerably in extent.

The pyramidal tracts are composed of "descending" fibres, which have their cells of origin in the cerebral cortex (ascending frontal and paracentral gyri) and end by arborisations in the grey matter at the base of the posterior cornua of the spinal cord. In some mammals (rat, mouse, guinea-pig, sheep, kangaroo, squirrel, etc.), the pyramidal tracts are situated in the posterior columns of the cord, in others, including the monkey, dog, cat, and rabbit, they run in the lateral colımns The pyramidal tracts are very small in the lower mammals, and are not found at all in vertebrates below mammals.

It has been calculated that there are about 80,000 fibres of the pyramidal tract in each half of the human cord. The pyranidal tracts are generally regarded as the paths along which volitional impulses are conveyed from the cerebral cortex to the spinal cord. But experiments have shown that they are not the only cortico-spinal paths nor even the most important in many animals, for the paralysis which results from their section is soon recovered from in most animals, whereas that resulting from section of the anterior column and adjacent part of the lateral column may be more marked and permanent. In man it appears to be the finer and more delicate movements which are permanently lost when the pyramidal tract is affected hy disease.

2. Tract of Loeventhal.-Besides the pyramidal tracts there are four other "lescending" tracts of filures in the antero-lateral column. (1) of these (the antro-luterul descending truct or tract of Lueventhal, figs. $435,436,3)$ lies on the side of the anterior median fissure, and extends along the margin of the cord in the "root" zone, even reaching the anterior part of the lateral column. These filhes are continued down, chiefly from the posterior longitudinal bundle (restibulo- 


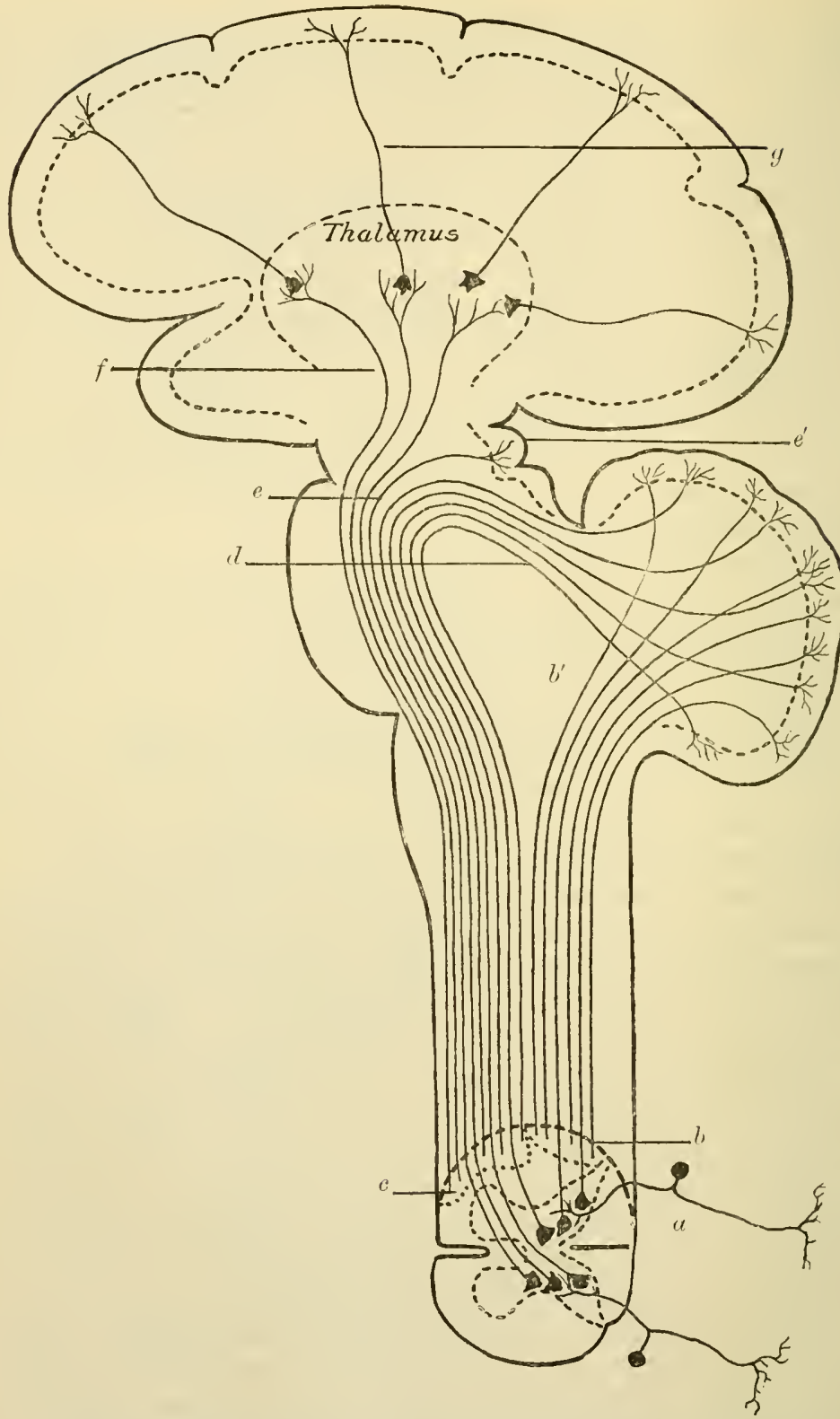

Fig. 437.-Diagram Showing the covrse of the tracts of Flechsig aND OF GOWERS IN THE SPINAL CORD ANI) THEIR CONTINUATIONS TO THE CEREBELLUM, CORPORA QUADRIGEMINA, THALANUS AND CORTEX CEREBRI.

$u$, posterior root-fibres; $b$, tract of Flechsig, passing at $b^{\prime}$, by the restiform body to the cerebcllar vermis ; $c$, tract of Gowers ; d, passage of most of its fibres along the superior periuncle to the cercbellum; $e$, fibres to the corpora quadrigemina, $e^{\prime} ; f$, others to the thalamus; $g$, fibres from tbalamus to cerebral cortex. 
spinul filres) of the medulla oblongatal and pons Varolii, partly from other sourees which will be afterwards referred to. They end by arborisations in the anterior horn. Similar arhorisations pass from the posterior longitudinal bundle to the melei of the motor cranial nerves. This tract is mainly unerossed.

3. Riubro-spinal tract.-Another "deseending" tract in the anterolateral column lies just in front of the erossed pyramiclal traet. This is the prepyramilal or vulvo-spinal tract (figs. 435, 436, 4); its fibres end by arborising in the grey matter of the middle of the creseent; the situation of its cells of origin is the red micleus of the tegmentum in the mid-brain. This tract is also known as Monakow's tract. Some of its fibres are staterl to be derived from cells in the retieular formation of the pons and medulla oblongata.

4. Tectu-spinal fibres.-Intermingled with the fibres of the rubrospinal tract (but far fewer in number in man) are fibres derived from the quadrigeminal bodies of the opposite side. These fibres form a part of the tecto-spinal tract. Another part of this tract passes into the anterior column of the cord in the tract of Loewenthal above mentioned.

5. Olivi-spinal tract.-Lastly a small triangular group' of "descending" fibres traceable from the neighbourhood of the olive in the medulla oblongata, and passing down the eervical eord in the anterior part of the lateral eolumn (fig. $435,3 \varkappa$ ), (the exact origin and destination of the fibres is unknown) is termed the bundle of Heluceg or oliro-spinal lract.

Ascending tracts of the antero-lateral column.-1. Tract of Flechsig.-This is a well-marked tract, whieh is however only distinct in the cervieal and dorsal regions, where it lies external to the erossed pyramidal traet. It eonsists of large fibres which are derived from the cells of Clarke's colımn (fig. $434, f$ ) and which pass up into the eerebellar vermis by way of the inferior peduncle of the same side (dorsul spino-cerebellar bundle or direct cerebellar truct of Flechsig, fig. 434; figs. $\left.435,436,9 ; 437, b, l^{\prime}\right)$.

2. Truct of Gouer.-This is situated more anteriorly, lying in front of the crossed pyramidal and direet cerebellar tracts in the lumbar region; while in the dorsal and cervieal regions it forms a narrow band of fibres curving round elose to the external surface of the cord, and extending even into the anterior column. It was termed the antero-lateral ascending tract by Gower's (figs. 435, 436, 10). Its fibres are intermingled with those of the antero-lateral deseending traet. Most of the fibres of the tract of Gowers are connected with the vermis of the cerebellum, eonstituting the ventral 
spino-cerebellar bundle, which passes to that organ over and parallel with the superior cerebellar peduncle (fig. 437). According to Van Gehuchten, confirmed by Collier and Buzzard, the tract of Gowers gives off a few fibres to enter the opposite cerebellar hemisphere by the middle peduncle.

Some of the fibres of the antero-lateral ascending tract (spino-tectal fibres) are continued up to the corpora quadrigemina. Others pass into the tegmentum of the crus cerebri, where they can be traced as far as the lower part of the thalamus (spino-thalamic fibres).

The cells from which the fibres of Gowers' tract take origin are not certainly known, but it is probable that they are cells situated in the middle and posterior parts of the grey crescent, partly on the same but chiefly on the opposite side of the cord. The latter is almost certainly the case with the cells from which the spino-thalamic fibres arise.

3. Tract of Lissauer.-Lastly, there is another small tract of fibres which nndergoes degeneration above the point of section. This is the murginal bunlle of Lissuuer (marked $\mathrm{x}$ in fig. 434). It is formed by fine fibres from the posterior roots.

Other portions of the antero-lateral columns near the grey matter which are differentiated by the method of Flechsig are probably short tracts uniting adjacent portions of the grey matter of the cord.

Proprio-spinal or endogenous fibres of the antero-lateral column.Sherrington has shown that in the dog the lateral column in the dorsal region of the cord contains a certain number of long fibres which take origin in the cervical, dorsal and upper lumbar segments and are traceable down to the lumbo-sacral enlargement. These must serve to convey excito-reflex impulses from the upper to the lower parts of the body. Probably similar fibres arise all along the cord from the cells of the lateral column and pass upwards as well as downwards.

A tract of endogenous fibres has been observed in man close to the anterior median fissure lying amongst the fibres of the direct pyramidal tract. This is known as the anterior sulco-marginal tract of Marie.

The antero-lateral column contains also many endogenous fibres, both ascending and descending, derived from cells in the grey matter of the cord, which have only a short course, serving to connect adjacent segments.

\section{GREY MATTER OF CORD.}

The nerve-cells which are scattered through the grey matter are in part disposed in definite groups. Thus there are several groups of large multipolar nerve-cells in the anterior horn in the cervical and 
1.

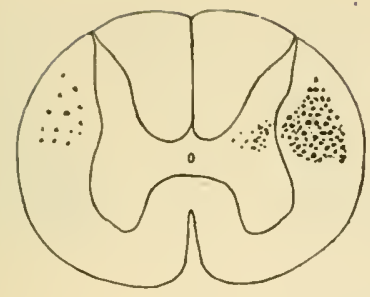

II.

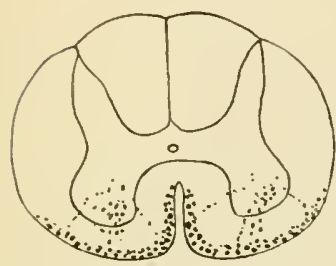

V.

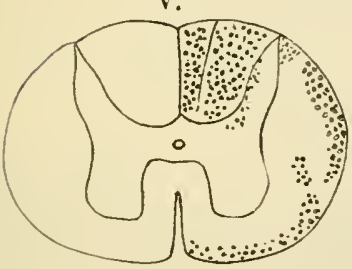

VI.

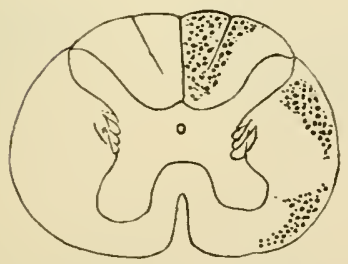

III.

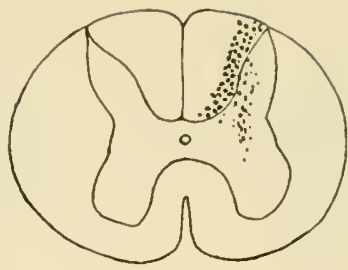

IV.

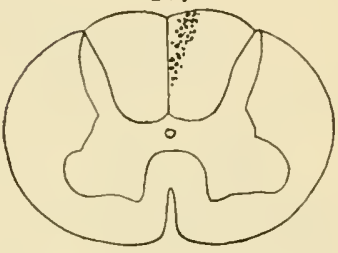

VII.
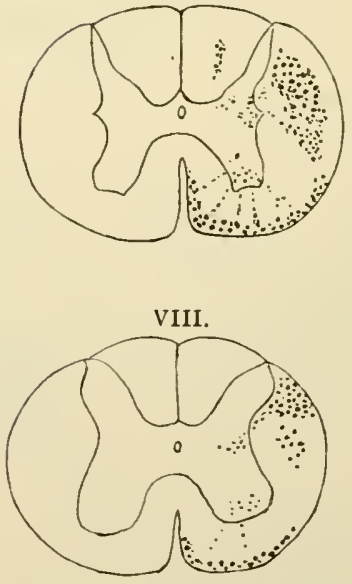

Fig. 43S. - DIAGRAM OF SECTIONS OF THE SPINAL CORD OF THE MONKEY SHOWING THE POSITION OF DEGENERATED TRACTS OF NERVE-FIERES AFTER SPECIFIC LESIONS OF THE CORD ITSELF, THE EFFERENT NERVE-ROOTS AND OF THE MOTOR REgION OF THE CEREBRAL CORTEX. (The degenerations are shown by the method of Marchi.) The left side of the cord is at the reader's left hand.

I. Degenerations resulting from extirpation of the motor area of the cortex of the left cerebral hemisphere.

II. Degenerations produced by section of the posterior longitudinal bundles in the upper part of the medulla oblongata.

III. and IV. Result of section of posterior roots of the first, second, and third lumbar nerves on the right side. Section III. is from the segment of cord between the last thoracic and first lumbar roots; section IV. from the same cord in the cervical region.

V. to VIII. Degenerations resulting from (right) semi-section of the cord in the upper thoracic region. V. is taken a short distance above the level of section ; VI., higher up the cord (cervical region); VII., a little below the level of section; VIII., lumbar region. 

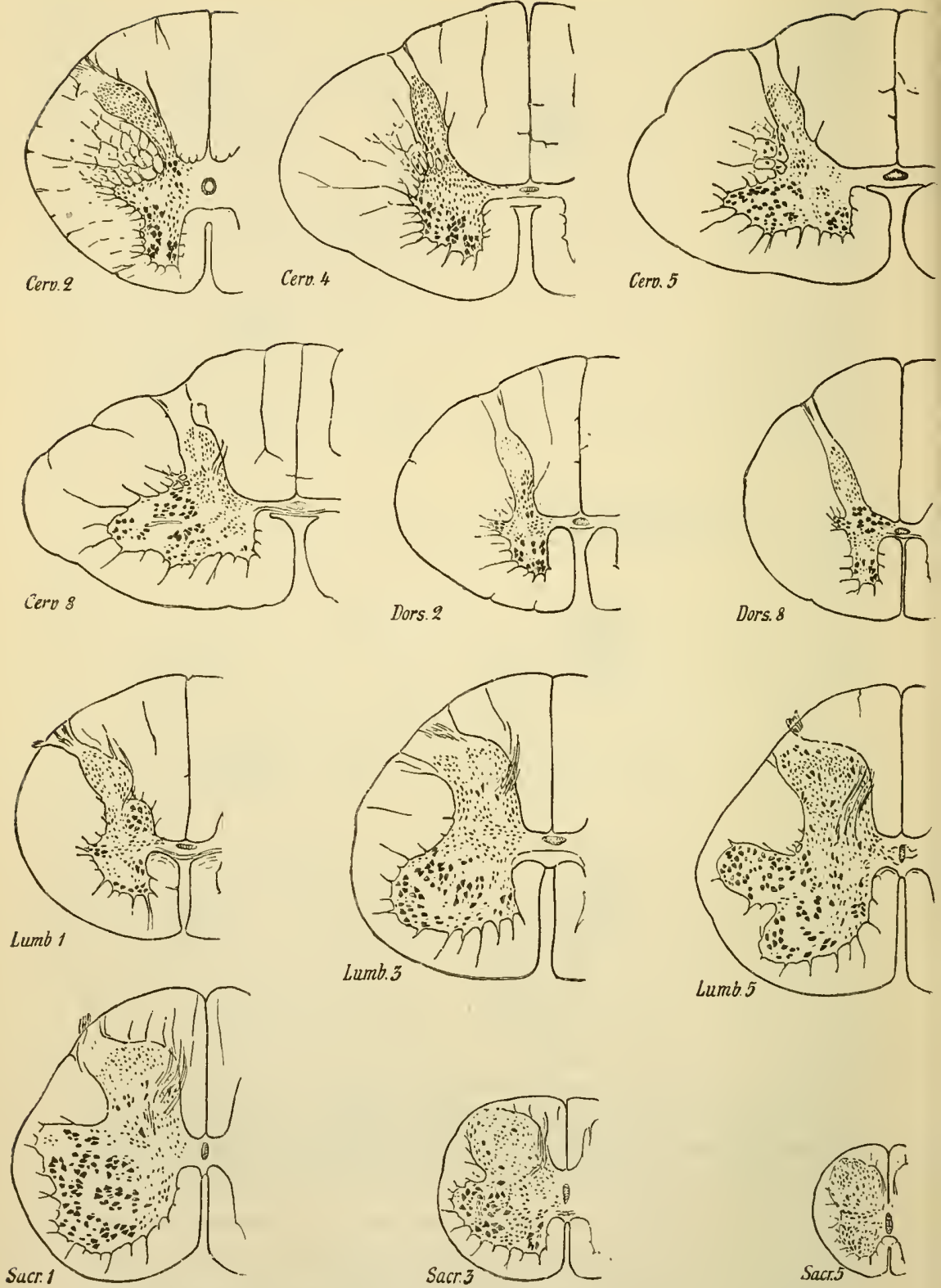

Fig. 439.-Diagram of Sections of human spinal cord at Different LEVELS. (Edinger.)

The names refer to the origin of the corresponding nerve roots. The relative shape and size of the cord and grey matter, and the relative amounts of grey and white matter, and the principal cell.groups are shown. 
lumbar enlargements (fig. 435), although in other regions of the cord the number of groups in this situation is reducer to two, a mesial and a lateral. 'The larger groups in the enlargements correspond with segments of the limb (Van Gehuchten); thus there appear to he groups associated with foot, leg, and thigh, and with hand, arm, and shoulder movements respectively. 'The groups from which the motor nerves to the shoulder and arm muscles arise appear in somewhat

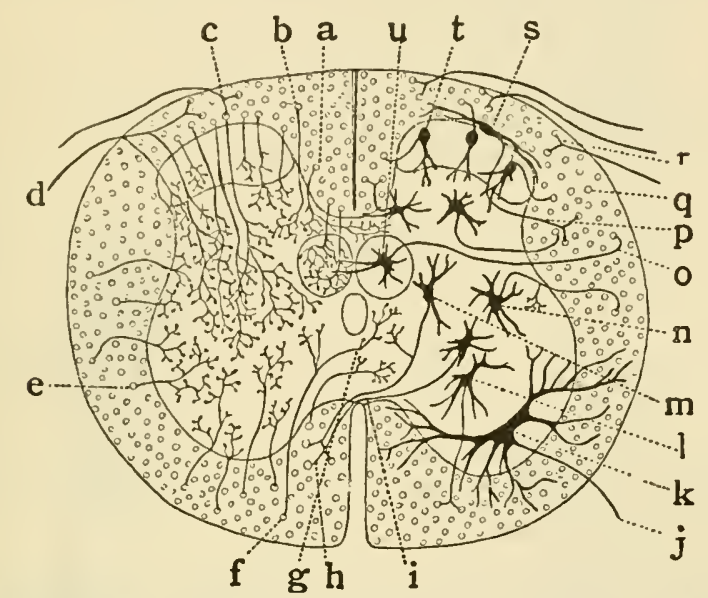

Fig. 440.-Disgral SHOWING THE PROBABLE RELATIONS OF SOME OF THE CELLS OF THE CORD TO THE WHITE COLUMNs. On the left side the collaterals from the fibres of the white columns are shown passing into the grey matter. (Cajal.)

$a, b$, fibres of posterior eolum sending collaterals into the grey matter; $c, d$, fibres of posterior root entering posterior column ; $e$, f, eollaterals passing from lateral and anterior columns into grey matter; $a, h, i$, fibres of white eommissure; $j$, anterior root-fibre springing from $k$, eell of anterior horn; $l, m$, $n$, other eells of grey creseent sending their axons into the white inatter: $a$, axon of cell of Clarke's column passing into the dorsal eerebellar tract: $p$, axon of cell of substantia gelatinosa; $q$, fibre of dorsal eerebellir tract; $r$, fibre of posterior root passing to tract of Lissauer; $s, t$, eells of substantia gelatinosa; $u$, cell of Clarke's eolumn.

higher segments of the cervical cord than those belonging to the hand muscles. The same holds good, mutatis mutandis, for the lumbar cord in relation to the leg and foot. Further, the larger groups show subdivisions which may be related to particular movements, i.e. to particular groups of muscles. In the case of the diaphragm there is a special cell-group or cell-column in the cervical cord (anterior horn) from which the fibres of the phrenic nerve arise, so that in this case a cell-group is set apart for a special muscle.

The axis-cylinder processes of the anterior horn cells mostly pass out into the corresponding anterior nerve-roots (fig. $436, m$; fig. $440, j$ ), but a few send their axons to the anterior column of the opposite side through the white commissure (fig. $440, m$ ) or to the anterior or lateral column of the same side $(l, n)$. It is noteworthy that in birds a few 
cells of the anterior horn send their axons into the posterior roots. A well-marked group of large rounded nerve-cells, best marked in the thoracic region, lies at the base of the posterior horn (nucleus of Stilling, Clarke's column, fig. $434, f$; fig. $435, d$; fig. $440, u)$. The cells of Clarke's column send their axis-cylinder processes into the dorsal cerebellar tract (Mott), and if this tract be cut experimentally, the

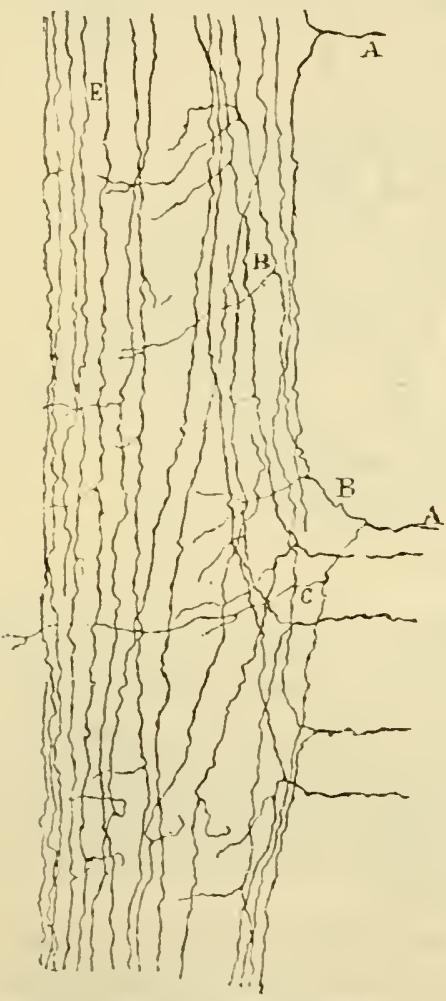

Fig 4t1.-Fron a LONGITUdinal SECTION OF SPINAL CORD, SHOWIXG THE ENTRANCE OF POSTERIOR ROOT-FIBRES. (Cajal.)

A, A, fibres entering the postero-lateral column, and bifureating into an ascending and descending division; $\mathrm{B}, \mathrm{C}$, collaterals passing from them into the grey matter; $\mathbf{E}$, other fibres of the posterior white columns also giring off collaterals.

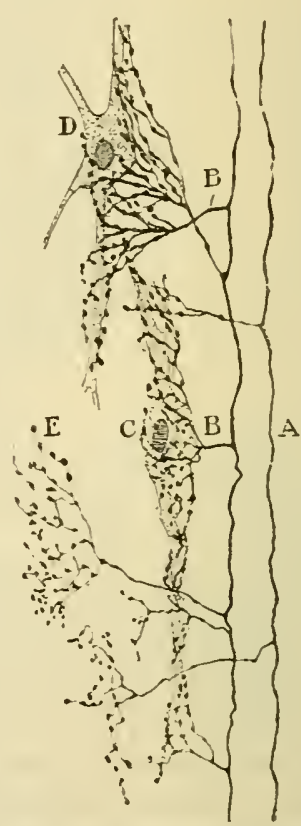

Fig. 442. - ARBORISATION OF COLLATERALS FROM THE POSTERIOR ROOTFIBRES AROCND CELLS IN THE POSTERIOR HORI OF GREY IATTER. (Cajal.)

A, fibres of posterior column derived from posterior root; B, collaterals; C, D, merrecells in grey matter surrounded by the arborisations of the collaterals; $\dot{E}$, an arborisation shown separately.

large cells of Clarke's column on the same side below the section undergo Nissl degeneration and eventually atrophy. There are, however, a few small cells with short axons in Clarke's column which do not undergo this change. 
Another group is seen on the onter side of the grey matter lying in a projection which is sometimes known as the lateral horn (lateral, cell-column, intermedio-luterul column, figs. $434, d ; 435, i)$. This is most distinct in the dorsal region (as far up as the second thoracie segment). The axons from its cells for the most part leave the cord along with the anterior roots, and probably furnish the outgoing viseeral and vasenlar filres. Another group (middle cell-column) lies in the middle of the crescent (fig. $434, e$ ). The cells of the posterior horn $(g)$ are very numerons but are not collected into definite groups. Those of the substantia gelatinosa of Rolando send their nerve-fibre processes partly into the lateral, partly into the adjacent posterior columns (fig. $440, s, t$ ).

The cells which send their axons into the adjacent parts of the white columns but not into any special tract are sometimes termed the "cells of the white columns."

Connection of nerve-roots with spinal cord.-The anterior roots leave the anterior horn in a number of bundles. Most of their fibres are directly continued from the nerve-cells in the anterior and lateral horns, and according to Golgi in part also from cells in the posterior horn. These cells, from which the anterior root-fibres arise, are surrounded by an interlacement of ramified nerve-endings, which are derived from various sources, especially the axons of cells of the posterior horn, from collaterals of the posterior root-fibres (see below), and from those of the fibres of the adjacent white columns.

The fibres of the posterior roots originate in the cells of the posterior root ganglia and pass into the postero-lateral column (see diagram, fig. 436), lut the smallest fibres enter the marginal bundle of Lissauer, and some pass directly into the posterior horn of grey matter. On entering the spinal cord the fibres bifureate (fig. 441), one branch passing upwards, the other downwards. Both from the main fibre and from its branches collateral fibres pass at frequent intervals into the grey matter, and end in arborisations of fibrils which envelop the nerve-cells both of the posterior and of the anterior horn (fig. 442 ) and in the dorsal region the cells of Clarke's column and those of the inter-

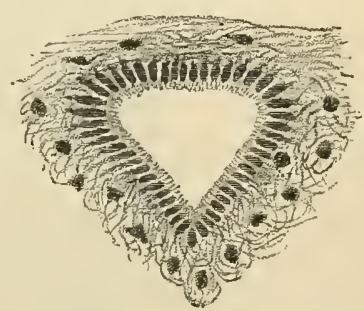

Fig. 443.-SEction OF the cenTRAL CANAL OF THE SPINAL CORD OF A CHILD, SHOWING ITS CILIATED EPITHELIUN AND THE SURROUNDING CENTRAL NEUROGLIA. (Moderately magnified.) medio-lateral tract. Many of the main fibres also ultimately end in a similar manner in the grey matter, some after a short course only, but 


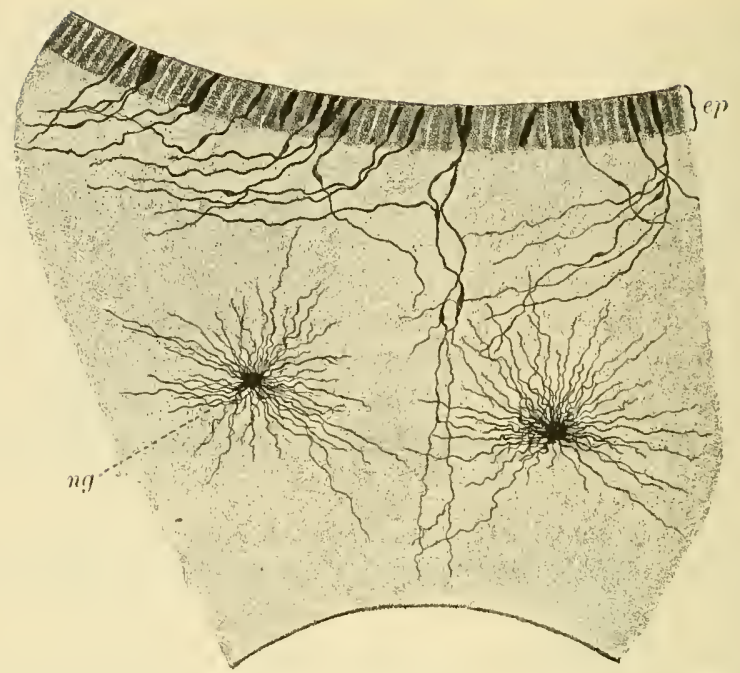

Fig. 444.-PART OF EPITHELIUM OF CENTRAL CANAL OF NEW-BORN CHILD, STAINED BY GOLGI's METHOD. (Sobotta.) $\times 120$.

$e p$, epithelium ; $n g$, neuroglia cells in adjacent grey matter.

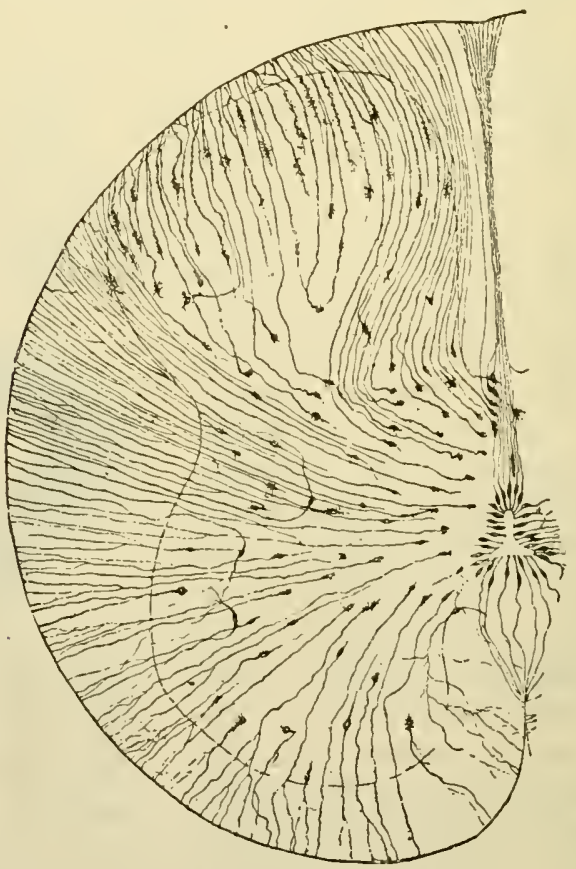

Fig. 445.- SECTION OF CORD OF EMBRYo, SHOWING SOME OF THE EPENDTMA CELLS DETACHED AND BECOMING CONVERTED INTO NEUROGLIA-CELLS. (Lénhossek.) 
others after a longer course. But a considerable number of fibres pass upwards in the postero-lateral and postero-mesial columns (in the latter espeeially those of the lower spinal nerves), until they arrive at the medulla oblongata. where they end in terminal arborisations around the cells of the nucleus graeilis and nucleus cuneatus.

The central canal of the spinal eord is lined by columnar eiliated epithelimm-cells (ependymu), which are surrounded by a quantity of neuroglia. The eells are best seen in the spinal eord of animals and in the child (figs. 443,444 ); in the human adult they have frequently become proliferated, and their eilia are no longer visible. In the early embryo their fixed extremities extend through the whole thickness of the cord to reach the pia mater. This condition is permanent in the eord of many of the lower vertebrata.

Blood-vessels of the spinal cord.-The blood-supply of the grey matter is derived mainly from a series of arterioles, which come off from the mesially-sitnated anterior spinal artery, pass into the anterior median fissure, and at the bottom of this divide each into two branches, one for the grey matter of each lateral half of the cord. In the grey matter is a very close capillary plexus which is supplied not alone by the vessels just mentioned, but also by small arterioles, which converge from the small arteries of the pia mater, passing through the white matter, and supplying this as they pass through it. These arterioles are branches of the abovementioned anterior spinal artery and of the posterior spinal arteries (which run on each side along the line of the posterior roots). The capillary plexus of the white matter is far less dense than that of the grey matter. It forms longitudinal meshes.

The veins of the spinal cord accompany the arteries. Two longitudinal venons vessels, accompanying corresponding anastomotic arterioles, are seen, one on either side of the central canal, in most transverse sections of the cord. 


\section{LESSON XLI. \\ THE IEDULLA OBLONGATA.}

Sectioxs of the medulla oblongata (made in the same way as with the spinal cord): $(a)$ at the lerel of the decussation of the pyramids. (b) just above the decussation, $(c)$ opposite the middle of the olivary body, and, $(d)$ either through the uppermost part of the olivary body, or just above it.

The brain consists of three great morphological divisions associated with the three primary cerebral vesicles of the embryo; they are termed respectively the hind-brain, mid-brain, and fore-brain.

The hind-brain is formed of the parts around the fourth ventricle, viz., the medulla oblongata or spinal bulb (myelencephalon), and above this the pons Varolii with the cerebellum (metencephalon); the region of the corpora quadrigemina forms the mid-brain (mesencephalon); the parts immediately above that region, and centring around the third rentricle, including the optic thalami, form the thalamencephalon; and the corpora striata and cerebral hemispheres constitute the telencephalon.

The structure of the medulla oblongata or spinal bulb can best be made out by the study of a series of sections taken from below upwards, and by tracing in these the changes which occur in the constituent parts of the spinal cord, taking note at the same time of any parts which may be superadded.

A section through the region of the decussation of the pyramids (fig. 446) has much the same form as a section through the upper part of the spinal cord, and most of the structures of the cord can be easily recognised. A considerable alteration of the grey matter is, however, produced by the passage of the large bundles of the crossed pyramidal tract from the lateral column of the spinal cord on each side through the root of the anterior horn and across the anterior median fissure to the opposite anterior column of the medulla oblongata, where, together with the fibres of the direct pyramidal tract, they constitute the prominent mass of white fibres which is seen on the front of the bulb, on each side of the middle line, and which is known as the pyramid. By this passage of fibres through the grey matter the tip of the anterior horn is cut off from 
the rest and becomes pushed as it were to the side; part of it appears as an isolated mass or masses of grey matter, one of which becomes known as the lateral nucleus. In sections just above the decussation of the pyramids a wavy mass of grey matter makes its

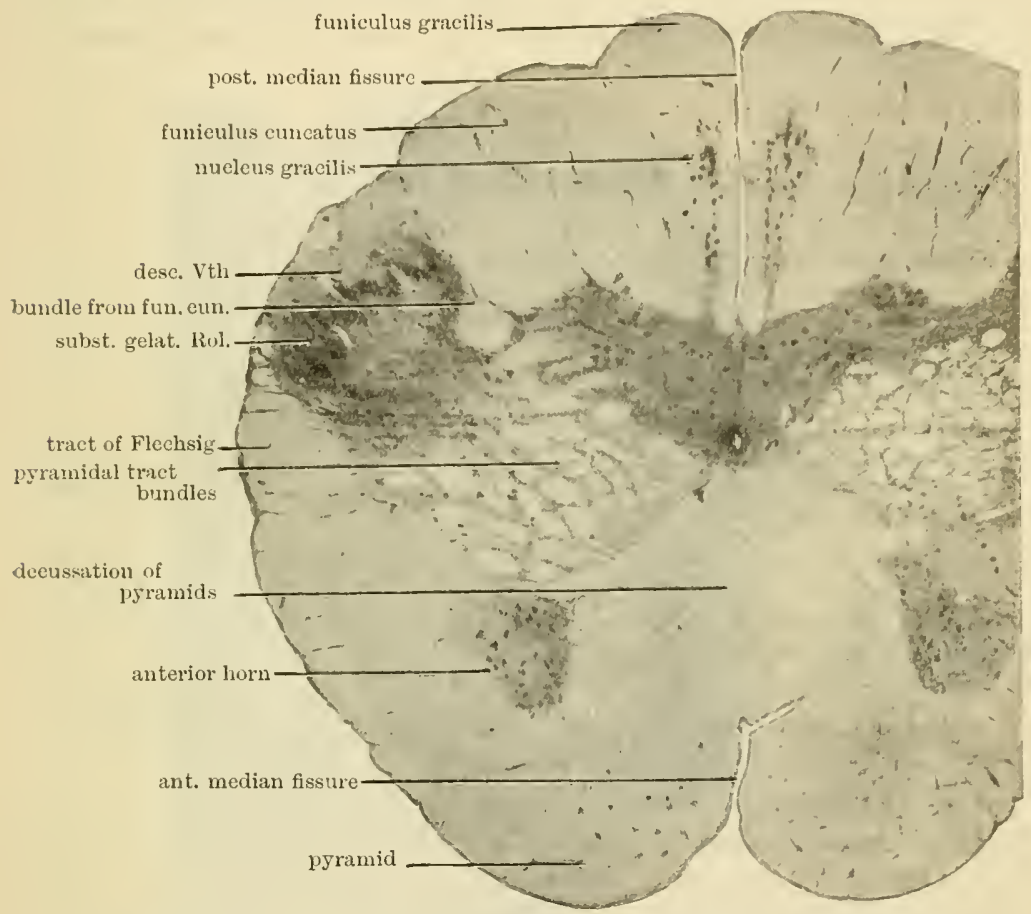

FIG. 446. - SECTION ACROSS THE LOWER PART OF THE MEDULLA OBLONGATA IN THE REGION OF THE DECUSSATION OF THE PYRAMIDS. (Magnified $6 \frac{1}{2}$ diameters.)

appearance on the lateral aspect of each pyramid, corresponding with a prominence on the surface which is known as the olive. The wavy or plicated grey matter is termed the olivary nucleus (figs. 447 to 449$)$.

The pyramids (anterior pyramids) of the medulla oblongata are formed of fibres which originate in the motor region of the cerebral cortex, and which can be traced from the axons of large cells in the grey matter of that cortex through the white matter of the hemisphere, through the middle third or more of the internal capsule and crusta, through the pyramid bundles of the pons Varolii and into these structures (pyramids) of the bulb. As we have just seen, they pass at the lower limit of the bulb chiefly to the opposite or erossed 
lateral column of the cord, but partly to the lateral column of the same side, and, in man and anthropoid apes, partly to the anterior column. They collectively constitute the pyramidal tract, which is smaller in the medulla oblongata than in the pons Varolii, since many of its fibres have left the main tract whilst within the pons and have passed across the middle line towards the grey matter on

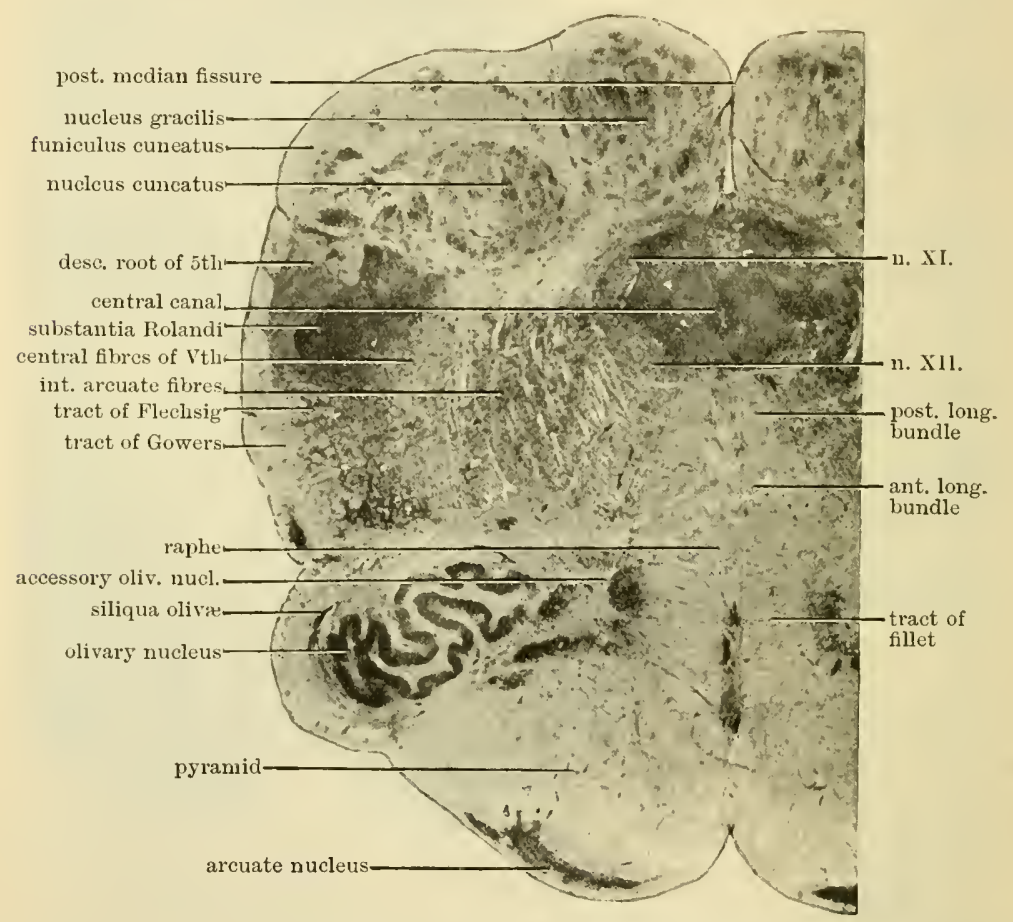

Fig. 447.- Section TAKEN IMMEDIATELY ABOVE THE DECUSSATION OF THE PYRAMIDS. (Magnified $6 \frac{1}{3}$ diameters.)

the dorsal aspect of the pons and medulla oblongata. Sometimes such a bundle of fibres, after passing towards the sensory nuclei in the lateral part of the medulla oblongata, does not end in them, but again comes ventral-wards and joins the main or central part of the tract near its decussation (bundle of Pick).

It is not a little remarkable that although the fibres of the pyramidal tract give off numerous collaterals to the grey matter of the cerebral cortex, the basal ganglia of the cerebrum, the substantia nigra of the mid-brain, the nuclei pontis of the pons Varolii, and the base of the posterior horn of the spinal cord, no collaterals are seen to leave them in their course through the medulla oblongata, except a very few to the olivary nuclei. Various observers have described collaterals and terminations of the pyramidal fibres 
as passing to the notor nuclei of the cranial nerves as well as to the anterior horns of the spinal cord, but statements to this effect must be reeeived with caution for although current in most text-books, they have not been substintiated by aceurate observations. It is certain that most if not all of the fibres of the pyamidal tract end not in the ventral but in the dorsal part of the wrey matter of the cord.

A change also oecurs in the posterior horn in eonsequence of the increased derelopment of the posterior column of white matter. This eauses the posterior horns to be pushed towards the side, the $V$ which they form with one another being thus opened out; at the same time the tip of the horm swells out and causes a prominence upon the surface of the medulla oblongata, which is known as the tubercle of Polando. Its grey matter forms the prolongation of the sensory nueleus of the fifth nerve. On its outer side and partly embracing it is a bundle of fibres seen in every section of the medulla oblongata, and traceable up to the pons Varolii. This is the inferior or descending root of the fifth nerve-formerly known as the "aseending" root. Its fibres extend down as far as the upper cervical region of the spinal cord. Grey matter also soon becomes formed within the upward prolongations of the gracile funiculus (postero-mesial column), and of the euneate funiculus (postero-lateral column) appearing at first as thin strands in the middle of the columns, but rapidly increasing in thickness so as eventually to oceupy almost the whole of them, and forming the nucleus gracilis and the nucleus cuneatus respectively.

It is in these nuclei that the fibres of Goll's and Burdach's tracts, which are continued up from the posterior columns of the spinal cord, find their ultimate ending in complicated arborisations amongst the cells of the nuelei. These nuclei do not, however, receive all the ascending branches of the posterior root fibres, for a considerable number of these have already disappeared by entering the grey matter of the eord, in which they also end by arborisation amongst its cells. The cells of the nucleus gracilis and nucleus cuneatus are small or of moderate size with long dendrons. Their axons pass as internal arcuate fibres through the reticular formation into the inter-olivary layer, cross the median raphe dorsal to the pyramids (fig. 447), and then turn upwards, constituting the tract of the fillet. This tract, which in its lowest part is thus formed by the nerve-fibres which belong to the second relay (or second neurones) of one of the sensory spinal paths, is reinforced in the higher regions of the medulla oblongata and in the pons by fibres derived from cells of the sensory nuclei of the cranial nerves. The majority of its fibres end in the lateral nucleus of the thalamus, but some pass to both the anterior and posterior eorpora quadrigemina. 
According to Van Gehuchten the fibres of the fillet which are derived from the nucleus cuneatus lie dorsally to those which are derived from the nucleus gracilis.

The continuation of the centrul canal of the spinal cord is still seen in the lower medulla oblongata (figs. $446,44 i$ ), but it comes nearer to the posterior surface and eventually opens out at the point of the calamus scriptorius of the 4 th ventricle (fig. 448). The grey matter which

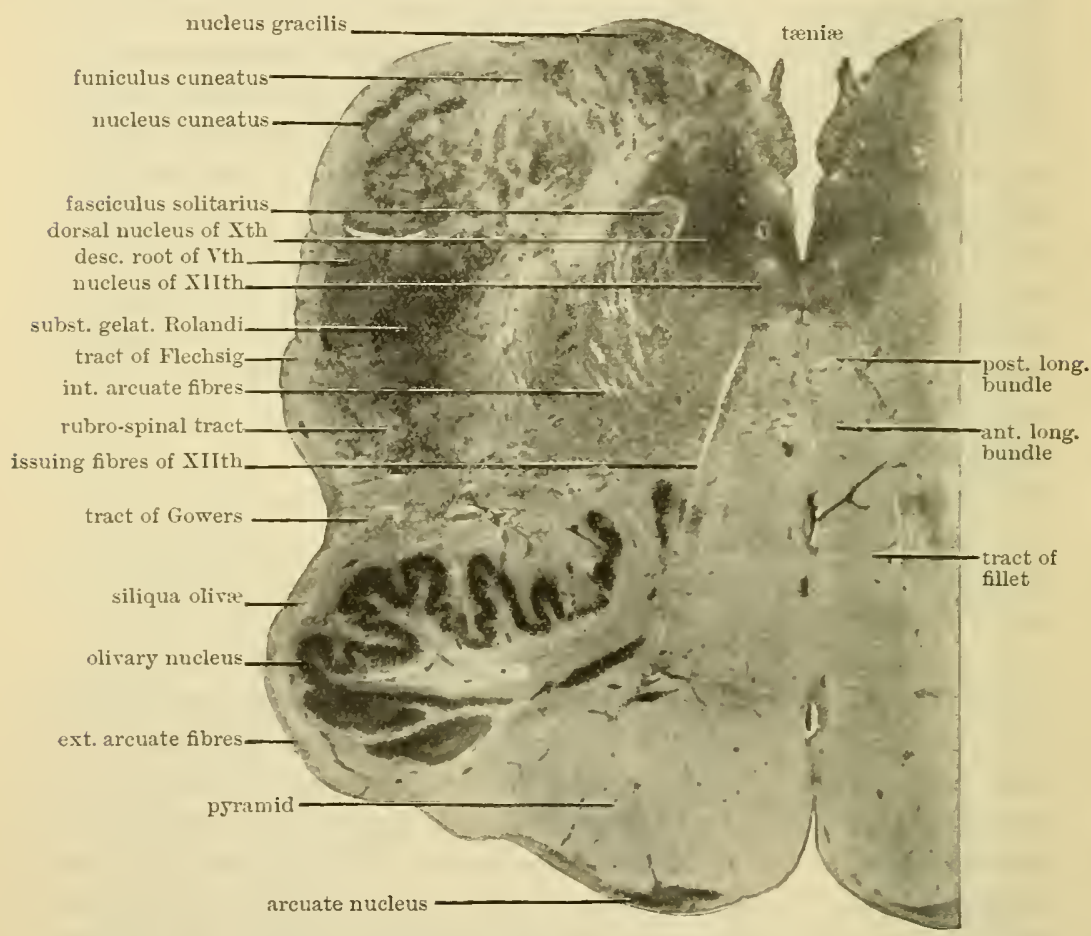

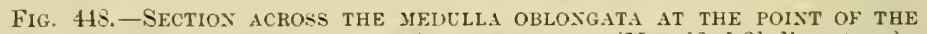
CALAMLS SCRIPTORIUS OF THE 4TH VENTRICLE. (Magnified $6 \frac{1}{2}$ diameters.)

surrounds it contains two well-marked groups of nerve-cells; the anterior (ventral) of these is the lower part of the nucleus of the hypoglossal or twelfth nerve, the posterior (dorsal), with smaller cells, that of the vago-accessory or tenth and eleventh. But most of the grey matter of the crescent becomes broken up, by the passage of bundles of nerve-fibres through it, into a reticular formation the production of which is already foreshadowed in the upper part of the spinal cord. Instead of the comparatively narrow isthnums which joins the two halves of the spinal cord, a broad raphe now makes its appearance; 
this is formed of olliquely and antero-posteriorly coursing fibres, together with some srey matter containing nerve-cells.

In the section at ulout the mildle of the olive (fig. 449 ), it will be seen that a marked change has been produced in the form of the merlulla oblongatin and the arrangement of its grey matter, by the opening out of the central canal into the fourth ventricle. This eauses the grey

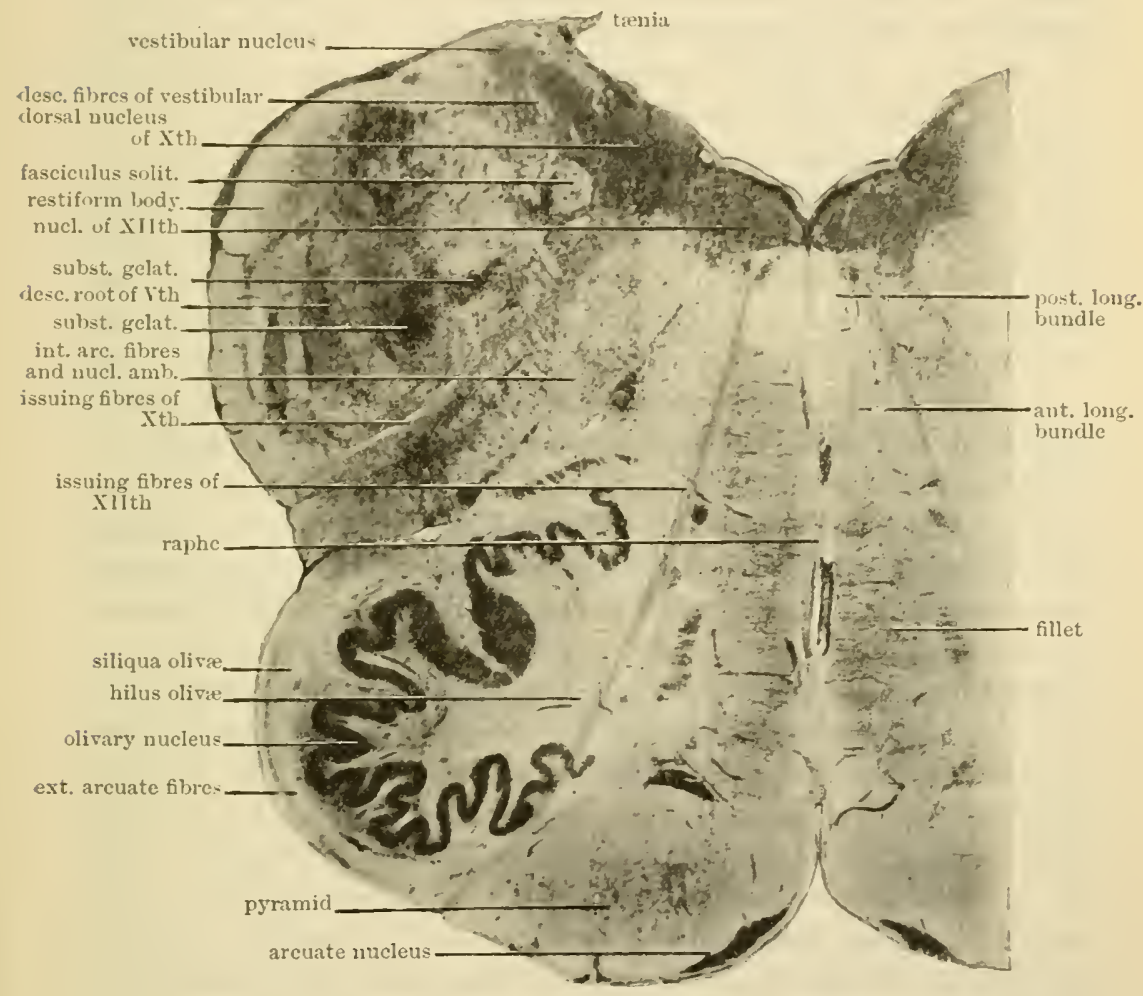

Fig. 449.-SECTION ACRoss THE MEDCLLA OBLONGATA, AT ABOLT THE MIDDLE OF THE OLIVART BODY. (Magnified $6 \frac{1}{2}$ diameters.)

matter which lower down surrounded the central canal to be now spread out at the floor of that ventricle, and the collections of nerve-cells from which the hypoglossal and vagus nerves respectively arise, now, therefore, lie in a corresponding situation near the ventricular floor. At this level the outer small-celled group which corresponds with the nucleus of the spinal accessory in the lower part of the bulb has become the dorsal nucleus of the vagus or tenth nerve, and yet higher up the dorsal nucleus of the ninth nerve or glosso- 
pharyngeal. The nerve-bundles of the roots of these nerves can be seen in some of the sections (fig. 449) coursing through the thickness of the bulb and emerging, those of the hrpoglossal just outside the pyramids, those of the ragus at the side of the medulla oblongata.

The posterior part of the section is chiefly occupied by the grey matter of the floor of the fourth rentricle, and by fibres which are passing obliquely upwards and outwards towards the cerebellum, forming its inferior crus (restiform body). The grey matter forming the nuclets of the funiculus gracilis and of the funiculus cuneatus has now almost disappeared, but in place of them and near the outer part of the floor of the fourth rentricle are seen some masses of grey matter with a number of bundles of nerve-fibres amongst them. The grey matter is the lower part of the principal nucleus of the vestibular nerve (see p. 387), and the white bundles are formed of descending branches of the fibres of that nerve. Below these structures is the descending root of the 5th, with its descending nucleus mesial to it.

The anterior part of the section is occupierl in front by the pyramid, and behind this by a reticular formation (reticularis allia): composed of longitudinally coursing bundles of fibres belonging mainly to the truct of the fillet and to the dorsal and rentral (posterior and anterior) longitudinal bundles, interlaced with internal arcuate fibres that are passing across the raphe from the nuclei of the contralateral posterior columns into the fillet, and from the opposite olive into the restiform body.

The middle portion of the section consists for the most part of a similar reticular formation, but with more grey matter and nerve-cells (reticularis grisea). This is a development of the formatio reticularis of the cervical cord, and the longitudinally coursing white bundles in it are probably association fibres, derived from cells in the upper part of the cord. On the other hand the nerre cells of this grey reticular formation in the medulla oblongata give origin to fibres which bifurcate and pass both upwards, probably serving as association fibres for the same area in the pons, and downwards towards the upper part of the cord. Some also are said to give origin to fibres, which either after traversing the raphe or passing directly to the same side as arched fibres, eventually enter the cerebellum through the inferior peduncle (Tan Gehuchten).

Ventro-laterally is the olive, within which is developed a peculiar wavy lamina of grey matter containing a large number of nerve-cells; this is the dentate nucleus of the olive. The lamina is incomplete at its mesial aspect (hilus olivo ), and here a large number of fibres issue, and, passing through the raphe, course as internal arcuate fibres to the opposite restiform body, and thus to the cerebellum. Some, however, 
turn sharply round and coirse helow the dentate nucleus, forming an investment and capsule to it (siliqua olive), and pass towards the restiform body of the same side: but the main connection of the olivary nucleus is with the cerehellar hemisphere of the opposite side. The olives receive numerous collaterals from the neighbouring white columns, including a few from the pyramids. Just dorsal, or clorso. lateral to the olive, is the continuation upwards of the rentral spino cerebellur bunlle (tract of Gowers) of the spinal cord; the continuation of the dorsal spino-cerebellar bundle (tract of Flechsig), just abore it, is now passing into the restiform body.

A tract of fibres which arise within the thalamus passes orer the lateral surface of the nucleus olive and ends within its grey matter (thalumo-olivury tract, central tegmental tract of Bechterew). The cells of the dentate nucleus have numerous dendrons; their axons all pass towards the hilus, where they emerge, and, for the most part, cross the raphe, pierce the opposite olivary nucleus and pass, as already mentioned, into the restiform body (oliro-cerebellur tract).

Nerves arising from the medulla oblongata.-The 12th, 11th, 10th, 9 th, and Sth nerres all take origin in the medulla oblongatil, and their fibres may be seen emerging on either side, those of the 12th ventrally between the pyramid and olive, and those of the other three nerves in succession at the side of the medulla oblongata hetween the olive and restiform body.

The XIIth or hypoglossal nerve arises from a well-marked nuclens of large cells, similar to those of the anterior horn of the cord. This nucleus is situated:-in the lower part of the bulb, rentro-lateral to the central canal (fig. 447); in the upper part, near to the floor of the th ventricle, close to the middle line (figs. 448, 449). None of the fibres cross to the opposite side; according to Van Gehuchten, this is true of all the cranial nerves, except a few fibres of the 3rd nerve and the whole of the th nerve. The hypoglossal nucleus extends throughout about the lower two-thirds of the bulb (fig. $450, n X I I$.). It receives many collaterals from adjacent sensory tracts in the reticular formation and from the descending sensory nuclei of the 5th, 9th, and 10 th nerres, as well as from the posterior longitudinal bundle. These form a plexus of fine fibrils within the nucleus which is highly characteristic. A similar plexus is seen in the oculo-motor nucleus.

Mesial to the hypoglossal nucleus, in the open part of the medulla oblongata, is the nuclens of the fasciculus teres, a column of moderate sized cells which extends towards the caudal end of the pons and appears to receive fibres from the cerebellum (Edinger).

The XIth nerve or spinal accessory begins to take origin from cells 
in the lateral part of the grey matter of the spinal eord as low down as the 5th cervical nerve. Its fibres from the cord (spinal fibres) are those to the (voluntary) sternomastoid and trapezius muscles. They pass from the cells of origin in the lateral horn (motor nucleus) at first dorsalwards and then take a sharp bend outwards through the lateral

$A$

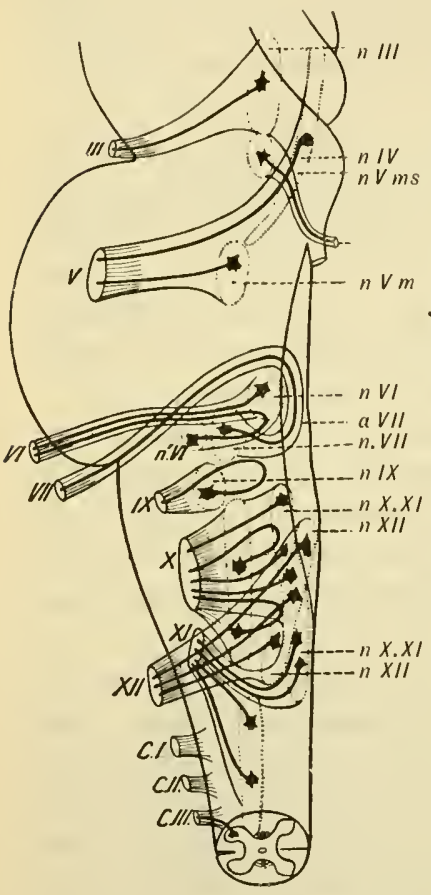

B

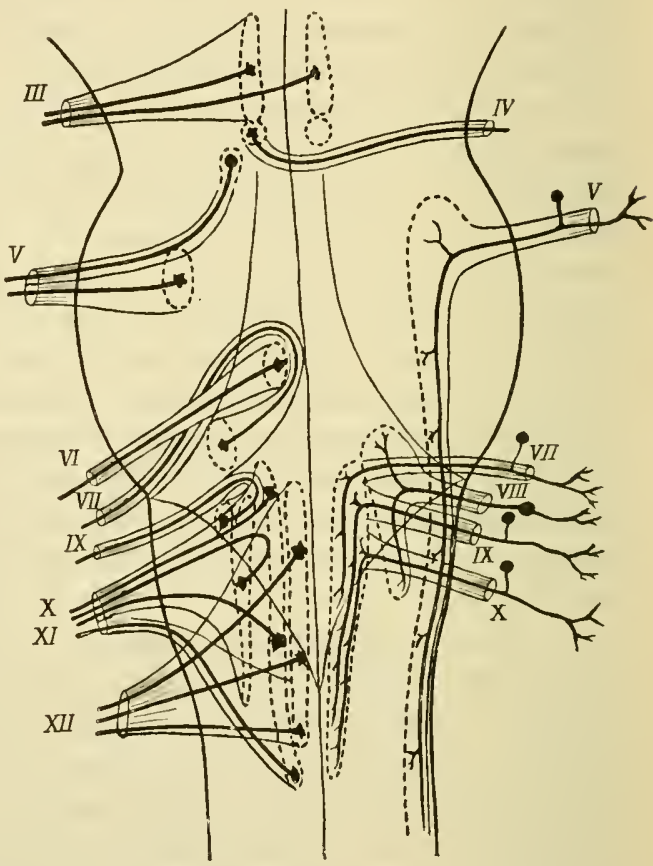

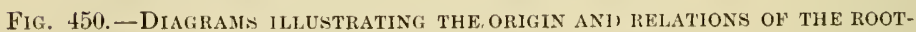
FIBRES OF THE CRANIAL NERVES.

A. Efferent fibres only : profile view.

$B$. Shows on the left the motor muclei and efferent fibres, except those of the 4 th nerve, and on the right side the afferent fibres: surface view.

column to emerge at the side of the cord and medulla oblongata. The bulbar fibres (which join the vagus) take origin in a nucleus of relatively small eells which lies dorso-laterally to the central canal of the medulla oblongata and lehind the hypoglossal nucleus. This nueleus is continuous above with the corresponding nueleus of the vagus, and with it forms the dorsal accessory-ragus nucleus (figs. 447 to 450). Below, it extends nearly as far as the first eervical nerve; its upper part (vagal part) is in the floor of the 4 th ventricle lateral to. 
the hypoglossal nuclens, and extends nearly as far as the lower horder of the pons. Of the whole nucleus about the lower two-thirds, i.e. as far as the lower end of the ealamus seriptorius gives origin to fibres of the accessory. These fibres, as alreacly stated, join the vagus, to which they supply the motor fibres of the thyro-arytenoid nuseles (Van Gehnchten). The 12 th and 11 th nerves are entirely efierent.

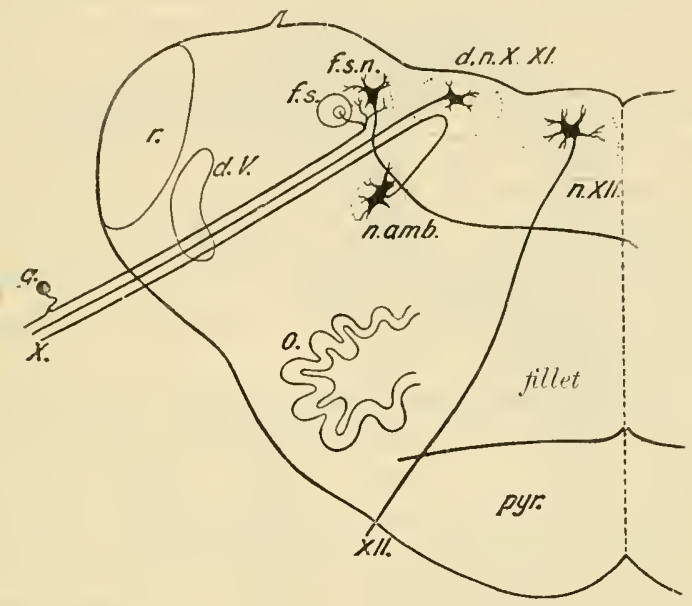

Fig. 451.-Plan of the origin of the XiIth and Xth nerves.

mm, pyramid ; n.XII., nucleus of hypoglossal : XII., hypoglossal nerve ; d.n.X. Y I., dorsal nucleus of vagus and accessory; $n_{*} u m b$, nucleus ambiguus; $f_{. s}$., fascieulus solitarius (descending root of vagus and glosso-pharyngeal); f.s.n., its nucleus; $X^{2}$, crossing nıtor fibre of vagus; $g$, cell in ganglion of vagus giving origin to a sensory fibre; d. $V$., descending root of fifth; $c . r$, corpus restiforme.

The Xth nerve or vagus (pneumogastric) contains both motor (efferent) and sensory (afferent) fibres. The efferent fibres arise (1) from the upper part of the dorsal aceessory-vagus nucleus just deseribed, (2) from a nucleus of grey matter containing large cells situated in the reticular formation (figs. $449,451, n . t m b$.). This nucleus begins near the lower limit of the bulb and extends nearly to the facial nuclens, which it resembles in general position: it is known as the nucleus ambiguns (ventral nuclens of the Xth nerve). The axons of its cells are directed at first backwards and inwards and then turn sharply round in the lateral direction to join the rest of the issuing fibres of the nerve, eoursing in the same manner as the spinal fibres of the accessory; indeed, this nucleus is continuous below with the column of cells from which those fibres take origin.

The sensory fibres take origin in the ganglion of the root and the ganglion of the trunk (jugular and plexiform ganglia) of the nerve, from 
unipolar cells like those of the spinal ganglia (fig. 451,g). They enter the medulla ollongata, and then bifurcate, one branch, a short (ascending) one, passing at once into the upper sensory or principal nucleus, the other, a long one, descending. The descending fibres (with similar fibres of the IXth and those of the pars intermedia of the VIIth) form the so-called fuscicnlus solitarius (figs. 448, 449, 451) (descending root of faciul, vagus, and glossophurymgeal), which is traceable to the lower limit of the medulla oblongata; they end in grey matter which lies along its mesial border' (descenling nucleus of facial, ragus, and glossopharyngeal). This nucleus approaches the middle line as it deseends, and in some animals terminates by joining its fellow of the opposite side over the central eanal to form the commissural nucleus of Cajal. The upper sensory nucleus (principal nucleus), in which the short branches from the sensory root end, lies in grey matter near the floor of the ventricle, and is continuous with that which accompanies the faseiculus solitarius.

The IXth or glossopharyngeal nerve also contains both efferent and afferent fibres. The former have their cells of origin in a special nucleus which occupies a position similar to that of the nucleus ambiguns, but is mesial to the anterjor end of that nuclens, and just below the nuclens of the facial (notor mucleus of glossoplaryngeal). The afferent fibres of the nerve arise in the upper or jugular and petrosal gangliu from unipolar cells like those of the spinal ganglia. Their central axons enter the medulla oblongata, and, like other sensory fibres, bifurcate into two branches, ascending and descending. Their course is like those of the vagus, the descending passing down in the faseiculus solitarius (extending to about one-third of its length, Bruce), and ending by arborising in the grey matter accompanying it (descending root and nucleus), while the ascending branches pass nearly horizontally backwards and inwards to a nucleus (mincipal nucleus) beneath the inferior fovea of the floor of the ventricle which is continuous with the upper end of the nucleus of the deseending root. The arrangement is almost exactly a counterpart of that of the vagus shown in the diagram given in fig. 451.

According to Edinger the sensory nuclei of these nerves receive fibres from the cerebelium, constituting a cerebello-bulbar tract, which is much better marked in lower vertebrata than in man and mammals.

The VIIIth nerve.-A section taken through the uppermost part of the olivary prominence will still show very much the same form and struetural arrangements as that just described. The nucleus of the hypoglossal (fig. $452, n . X I I$.) is still visible in the grey matter of the floor of the ventricle near the middle line, but the nerve which is now 
seen conneeted with the lateral part is the eighth or auditory (VIII.), the bundles of which, as they enter the bulb, embrace the inferior crus of the eerebellum (corpus restiforme, e.r.), which is now passing into that organ. The origin of the eighth nerve is thus subdivided into two principal parts, known respectively as the dorsul or cochlear and the ventral or vestibular divisions (fig. 452).

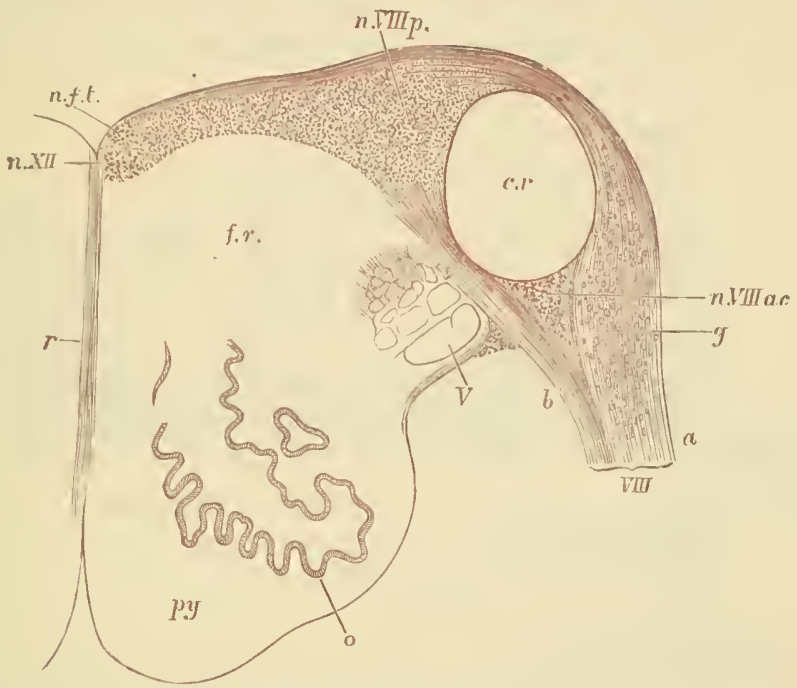

Fig. 452.-TRANSVERSE SECTION OF THE UPPER PART OF THE MEDULLA OBLONGATA. $\quad$ 4. (Schwalbe.)

py, nyramid; $o$, olivary nucleus; $V$, descending root of the fifth nerve; VIII., root of the anditory nerve, formed of two parts, $a$, cochlear, and $b$, vestibular, which inclose the restiform body, c.r.; n.VIIIp., principal nucleus of the vestibular division; n.VIIIac, , ventral or accessory nucleus of the cochlear division; $g$, lateral nucleus of the cochlear division; n.f.t., nucleus of the funiculus teres; $n . X I I .$, nucleus of the hypoglossal ; $r$, raphe ; $f . r$, reticular formation.

The real origin of the nerve fibres in these roots is in the ganglion of the cocllea and the ganglion of Scurpa respectively. These ganglia, which are sitnated at the periphery within and near the internal ear, are composed of bipolar cells, of which the peripheral axons end by ramifying amongst the cells of the auditory epithelium, and the central axons form the cochlear and the vestibular divisions of the auditory nerve and pass into the medulla oblongata in the manner here described.

The fibres of the dorsal or cochlear division (cochlear nerve) bifurcate as they enter the medulla oblongata. Each fibre divides into a thick and a thin branch. The thicker branches pass partly to a mass of ganglion cells which is wedged in between the two roots and the restiform body, and is known as the accessory auditory nucleus 
(figs. $452 ; 453$, n.tcc.), applying themselves with a peeuliar form of terminal arborisation to the cells of this nucleus, partly over the restiform body to terminate in a prominent mass of grey matter which overlies that body and also extends to the lateral part of the floor of the fourth ventricle at its widest part (lateral nucleus, tuberculum ucusticum). The cells of the tubercle have a peculiar spindle shape and are set vertically to the surface. They appear to begin in the root itself, lying amongst the fibres of the nerve. Here they are sometimes spoken of

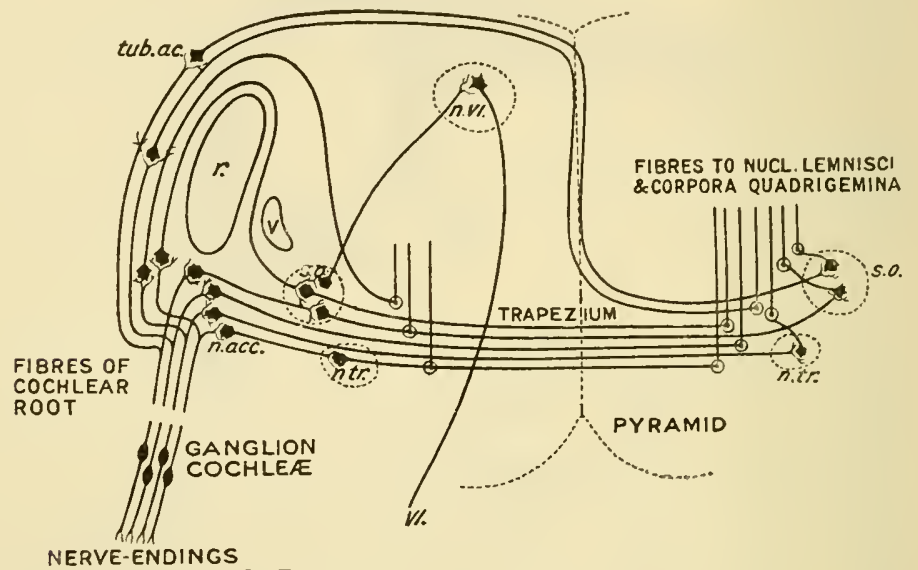

IN ORGAN OF CORTI

Fig. 453.-Plan OF THE COURSE AND CONNECTIONS OF THE FIBRES FORMING THE COCHLEAR ROUT OF THE AUDITORY NERVE.

$r_{.}$, restiform body; $V$. , descending root of the fif th nerve; $t u b . a c .$, tulerculum acustieum; n.acc., accessory nucleus; s.o., superior olive; n.tro, uucleus of trapezium; n.VI., nucleus of sixth nerve; $V I$., issuing root fibre of sixtl nerve.

as forming the "ganglion of the root." The thinner branehes of the bifurcated eochlear fibres pass downwards for a certain distance and break up into a plexus of fine fibrils.

These two nuclei, viz., the accessory nucleus and the acoustie tubercle, are the nuclei of ending of the eochlear fibres. From their nerve-cells new fibres arise which continue the auditory path centrally (see fig. 453). Those from the accessory nucleus enter the trapezium -which consists of transverse fibres running bebind the pyramid bundles of the pons Varolii-and pass in it partly to the superior olive and trapezoid nucleus of the same side of the pons, but mostly to the corresponding structures on the opposite side. Some end in those nuclei, but others merely traverse them, giving off numerous collaterals to them and to the superior olives and other nuelei close by (see p. 392), and then turn upwards in the lateral part of the tract of the fillet to pass ultimately towards the inferior corpora 
quadrigemina; in tending towards these structures at the side of the mid-brain they form the laterul fillet, or fillet of lieil, which is there conspicuous. Some of the fibres from the cells of the accessory uncleus do not pass directly to the trapezium, but first curve round the restiform body (Held); these form the most dorsally situated fibres of the trapezium. The fibres which arise in the acoustic tubercle pass for the most part over the floor of the fourth ventricle, where they are seen superficially as the medullary or acoustic strice, and, entering tho raphe, traverse it from behind forwards, and then join the others from the accessory nucleus in their course to the superior olive and lateral fillet of which they constitute the deeper layer. A few fibres are directed into the fillet of the same side as their cells of origin.

Edinger states that, at least in the dors, all the fibres of the trapezium end in its nucleus or in the superior olivary nucleus, the central acoustic path being wholly continued, so far as the trapezium fibres are concerned, by fresh nemrones, the cell-bodies of which lie in those nuclei, and the axons of which pass into the lateral fillet. On the other hand, from the cells in the tuberculum acusticum, the axons are said to be continued upwards in the opposite lateral fillet without the intervention of any corresponding nuclei. The lateral fillet passes above into the posterior colliculus of the mid-brain.

The accessory mucleus also receives fibres from the trapezium, which end by ramifying amongst its cells. These are perhaps derived from the accessory nucleus of the opposite side.

Both sets of fibres (from the accessory nucleus and tuberculum) give off collaterals near their origin, which terminate within these nuclei.

The ventral or vestibular division (vestibular nerve), which enters a little in front of (above) the cochlear division, passes between the restiform body and the descending root of the fifth (fig. 452 ), to enter a mass of grey matter containing for the most part cells of small size, which is termed the principal or dorsal nucleus of the vestibular division. Here each of its fibres divides with a $Y$-shaped division into an ascending and a descending branch (fig. 454). The descending branches are collected into smail bundles (descending vestibular root) which run downwards towards the lower part of the medulla oblongata, and gradually end by arborising around cells in the adjacent grey matter (descending vestibular nucleus), which is continued down from the principal nucleus. The ascending branches pass upwards on the inner side of the restiform body towards the nucleus tecti of the cerebellum. In their course they give off numerous collaterals which arborise round the large cells of two nuclei which occur in this part of the medulla 
oblongata and pons near the outer part of the floor of the fourth ventricle. These two nuclei are termed the nucleus of Deiters and the nucleus of Bechterew respectively (fig. 45t).

Van Gehuchten states that the nucleus of Bechterew alone receives fibres from the ascending branches and that all the other nuclei (dorsal, descending, and nucleus of Deiters) are furnished with fibres from the descending branches.

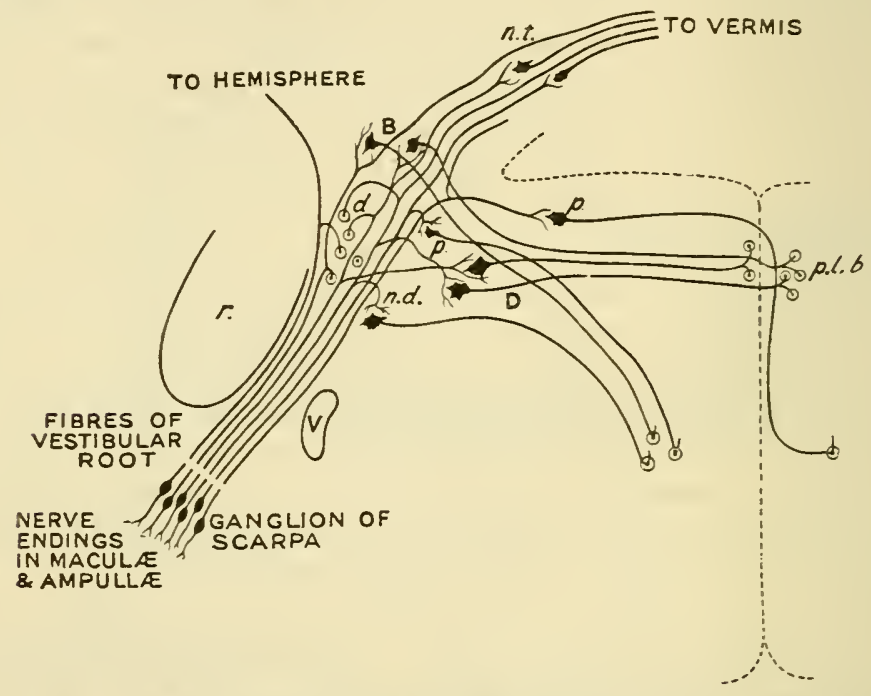

Fig. 45̆4.-PLAx OF THE COURSE AND CONNECTIONS OF THE FIBRES FORMING THE VESTIBULAR ROOT OF THE AUDITORY NERVE.

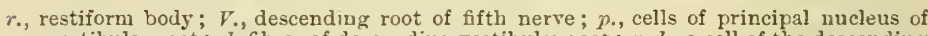
restibular root; $d$, fibres of descendiug vestibular root; n.d., a cell of the descending restibular nucleus; $D$., cells of nucleus of Deiters : $B$, cells of nucleus of Bechterew; n.t., cells of nucleus tecti (fastigii) of the cerebellum; p.l.. ., fibres of posterior longitudiual bundle. No attempt has been made in this diagram to represent the actual positions of the sereral nuclei. Thus a large part of Deiters' nucleus lies dorsal to and in the immediate vicinity of the restiform body.

The nucleus of Deiters is especially characterised by the large size of its cells and by the manner in which they are enreloped as by a basket-work by the ramifications of the collaterals in question. From these cells fibres arise which pass to the posterior longitudinal bundles of both sides: in these the fibres bifurcate (Cajal), one branch passing upwards to the oculomotor nuclens and giving off collaterals to the nucleus of the sixth nerve, and the other downwards, eventually reaching the anterior column of the spinal cord (antero-lateral descending tract) and terminating by arborisations amongst the cells of the anterior horn (see p. 365). By means of the collateral fibres which supply the sixth and oculomotor nuclei it is probable that the conjugate movements of the two eyes are brought about. Fibres have also been described as passing from Deiters' nucleus to the nucleus tecti of the 
cerehellum. Owing to its connections with the semicircular canals, the cerebellum, the oculomotor nuclei, and the nuclei in the anterior hor'n of the spinal cord, this nucleus has important functions in connection with co-ordination of head and eye movements and equilibration in general.

The fibres which originate in the nucleus of Bechterew pass into the reticular formation and become longitudinal, but their destination is not certainly known. Some are said to pass into the anterior column of the cord.

The reticular formation still occupies the greater part of each lateral half of the bulb between the grey matter at the floor of the fourth ventricle and the pyramids, and a small portion of the olivary nucleus may still be seen, as may also the descending root of the fifth nerve with its adjacent grey matter.

The restiform body is formed partly of the fibres of the cerebellar tract of Flechsig of the same side, which are derived below from the cells of Clarke's colımn, and pass above into the middle lobe of the cerelellum, partly of fibres from the opposite olivary nucleus, and partly of fibres from the olivary nucleus of the same side. The olivary fibres pass mainly to the cerebellar hemisphere. According to some authorities the restiform body contains fibres derived from the nucleus gracilis and nucleus cuneatus of the opposite side. It is said also to receive some fibres from a nucleus which lies just outside the main mass of grey matter of the funiculus cuneatus, and is known as the outer cuneate nucleus.

The floor of the fourth ventricle is covered by a layer of ciliated epithelium-cells, continuous below with those lining the central canal, and above, through the Sylvian aqueduct, with the epithelium of the third and lateral ventricles. The epithelium rests upon, and the prolonged extremities of its cells assist in forming, a layer of tissue known as the epemlyma of the ventricle. The fourth ventricle is roofed over by a layer of pia-mater, with projecting choroid plexuses, the under surface of which is covered by a thin epithelial layer continuous at each side with the ciliated epithelium of the floor. The roof becomes somewhat thickened as it is continued into the ependymal layer of the floor of the ventricle; this thickened part (trenia or ligula, figs. 448, $449, t)$, is often left attached when the thin epithelial roof is removed along with the pia-mater which covers it. 


\section{LESSONS XLII. AND XLIII.}

\section{THE PONS VAROLII, MESENCEPHALON, AND THALA MENCEPHALON.}

1. Sections through the lower, middle, and upper parts of the pons Varolii. 2. Sections across the region of the corpora quadrigemina, one at the level of the inferior, the other at the level of the superior, pair.

3. A section across the posterior part of the third ventricle passing through the optic thalami.

In all the above sections sketch under a low power the general arrangement of the grey and white matter, inserting the positions of the chief groups of nerve-cells.

[The tissue is hardened and the sections are prepared, stained, and mounted in the same way as the spinal cord and medulla oblongata.]

\section{THE PONS VAROLII.}

Sections through the lower part of the pons (figs. 455, 457, 459) show much the same arrangement of grey and white matter as that met with at the upper part of the medulla oblongata, but the general appearance of the sections is much modified by the presence of a large number of transversely coursing bundles of nerve-fibres, most if not all of which are passing to the hemispheres of the cerebellum (fibres of middle peduncle of cerebellum). ${ }^{1}$ Intermingled with these bundles is a considerable amount of grey matter (nuclei pontis) from the cells of which the fibres of the middle peduncle (of the opposite side) are derived. $^{2}$ Amongst the cells of the nuclei pontis many fibres and collaterals of the pyramidal tract end, and the cortico-pontine fibres also terminate here; thus forming a comnection between the cerebral hemisphere of the one side and the opposite cerebellar hemisphere (fig. 479). The continuation of the pyramids of the medulla oblongata (fig. $455, p y$ ) is embedded between these transverse bundles, but the pyramid bundles of the pons are much larger than the pyramids of the medulla oblongata, and, in addition to fibres of the pyramidal tract

${ }^{1}$ Some of the most anterior of these peduncular fibres often form a detached bundle which is known as the tenia pontis (fig. 461 ).

${ }^{2}$ Other of these fibres have becn described as arising in the cerebellar hemisphere and crossing the raphe; some becoming lost amongst the cells of the opposite nucleus pontis, and some passing to the reticular formation, there becoming longitudinal. But this double origin is denied by Van Gchnchten, apparently with good reason. 
proper (cortico-spinal system), derived from the motor area of the eortex, they are largely composed (especially the postero-lateral bundles) of fibres (cortico pontine system) connecting other regions of the cortex with this part of the hind-brain. The pyramid bundles are separated from the reticular formation by deeper transverse fibres, which belong to

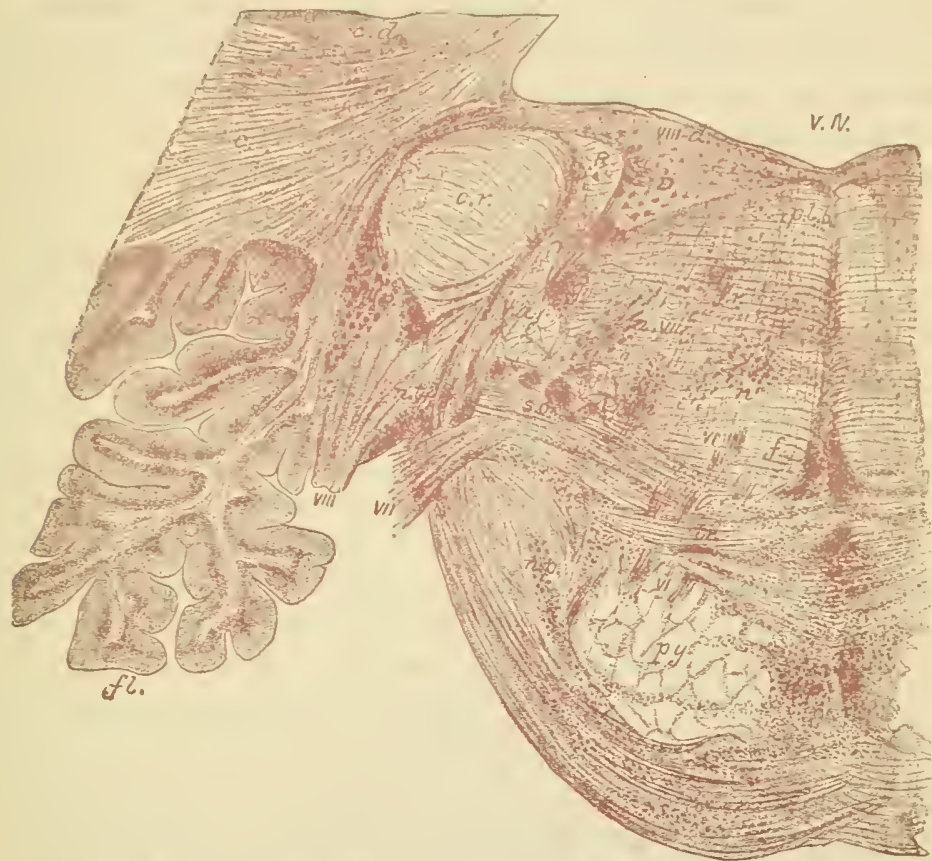

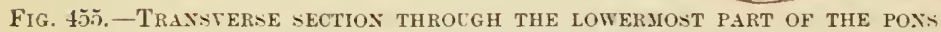
FAROLII. $\frac{4}{1}$. (From a photograph.)

$v . I V$., fourth ventricle; $c$, white matter of cerebellar hemisphere; c.d., corpus dentatum; $j$., flocculus; $c . r$., corpus restiforme; $R$, bundle of Roller, composed of the descending branches of the restibular nerve; $D$, nucleus of Deiters; VIII. issuing root of auditory nerve; VIII.d., principal or dursal nucleus of the restibular nerve; VIII. $\cdots$, nucleus of cochlear portion; $t r$., trapezium ; n.ti., its nucleus; $f$, fillet ; p.l.b., posterior longitudinal bundle; t.r., formatio reticularis; $n, n^{\prime}, n^{\prime \prime}$, various nuclei within it; V.a., descendiug root of fiftl nerve; s.g., substantia gelatinosa; s.o.. superior olire; VII., issuing root of facial nerve; $n_{2}$ VII., its nucleus; VI., root-bundles of sixth nerve; py, pyramid bundles; n.p., nuclei pontis.

a different system from those of the middle peduncle. They form what has already been referred to as the trape:ium (figs. 453,455 ); a collection of fibres which forms part of the central auditory path, and some of which appear to he commissural between the auditory nuclei of the two sides. The filbres of the trapezium traverse a collection of nerve-cells which lies mesial and rentral to the superior olivary nucleus, and is known as the nucleus of the trapezium (fig. $453, n . t r$.).

This nucleus is characterised by the peculiar chalice-like synapses which the entering axons of the larger acoustic fibres form with the cell.bodies 
(Held) (see fig. 171, p. 144). According to Cajal these large fibres are continued directly from the root-fibres of the cochlear nerve and are not derived from the cells of its accessory nucleus.

The olivary nucleus is no longer seen, but there are one or two small collections of grey matter, more conspicuous in some animals than in man, which lie in the ventral part of the reticular formation, and are known as the superior olivary nucleus (o.s.), the preolivary nucleus, and the semilunar nucleus (Cajal). All these, as well as the nucleus of the trapezium itself, are connected with the fibres of the trapezium which form the central auditory path, some of these fibres either ending in the nuclei in question or giving off to them numerous collaterals; whilst from the cells of the muclei axons pass into the trapezium or into the adjacent lateral part of the fillet (see p. 386). On the other hand, the superior olive is said to receive fibres from the posterior colliculi of the corpora quadrigemina. The nucleus of Deiters, which begins to appear in the upper part of the medulla oblongata, where it has been already studied (p. 388), extends into the pons Varolii, where it lies near the floor of the fourth ventricle, a little mesial to the restiform body ( $D$, fig. 455$)$. The nerve-filbres connected with its cells pass towards the middle line and enter the posterior longitudinal bundle. Here, as already stated, they divide, one branch passing upwards in the bundle and terminating by arborescence chiefly in the opposite oculomotor nucleus: the other branch extending downwards in the medulla oblongata and cord. In the spinal cord they are found in the antero-lateral descending tract; fibres from each nucleus of Deiters occur in both of these tracts (E. H. Fraser). They terminate by arborescence in the anterior horn of the spinal cord.

The nerves which enter or emerge from the grey matter of this region of the brain are part of the eighth, the seventh, the sixth, and somewhat higher up the fifth cranial nerves. Of these the eighth (already considered) and fifth are connected with groups of nerve-cells which occupy the grey matter opposite the external border of the floor of the ventricle; the sixth with a nucleus which is also placed in the grey matter of the floor of the ventricle but nearer the middle line, and the seventh with a special nucleus which lies in the formatio reticularis.

The VIIth or facial nerve and the nerve of Wrisberg (pars intermedia). - The motor fibres of the seventh nerve arise from the facial nucleus (in the formatio reticularis) which is homologous with the nucleus ambignus seen in sections of the medulla oblongata. It has been shown that the motor fibres to the stapedius arise from the mesial part of the nucleus and then in succession those of the external ear 
muscles, those of the mouth and face, and, finally, from a group of cells situated dorsally to the rest, the motor fibres supplied by the superior branch of the nerve (Marinesco, Van Gehuchten). From the nueleus of origin the fibres first pass obliquely backwards to the floor of the ventricle, then longitudinally upwards for a short distance (figs. $450, \mathrm{~A}$, 456 ), and finally bend obliquely forwards and downwards to emerge between the transverse fibres at the side of the pons. None of its fibres are derived from the mucleus of the sixth, as has sometimes been supposed. As it curves over this nucleus it gives off a lmulle of

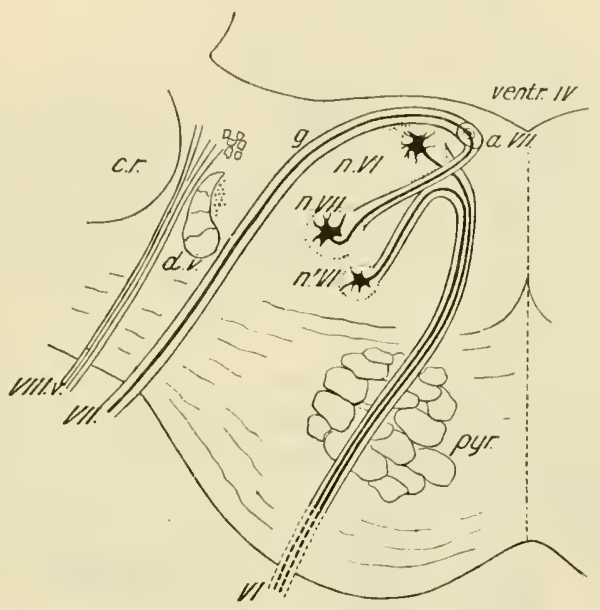

Fig. 456.-Plan (TRANSVERSE) OF THE ORIGIN OF THE SIXTH AND SEVENTH NERVES.

$V I .$, sixth nerve; VII., seventh nerve; $a . V I I$. , ascending part of root of seventh shown cut across near the floor of the fourth veutriele; $g$, genu of seventh; $n$.VI., ehief nucleus of the sixth nerve; $n . V I$, accessory nucleus of sixth; n.VII., nucleus of seventh; d.V., descending root of fifth; pyr, pyramid bundles; VIII.v., vestibular root of eighth nerve.

fine fibres which cross the raphe, but their destination is unknown. The nucleus of the facial receives collaterals from the adjacent sensory tracts in the formatio reticularis.

The facial is not a purely motor nerve, but has a ganglion upon it of the spinal type (geniculate ganglion) from which fibres arise (fig. 450, B) which pass centrally into the pars intermedia of Wrisberg, which enters the pons between the seventh and eighth nerves, and the fibres of which bifurcate into ascending and descending branches like other sensory nerves; the descending branches pass into the solitary bundle and end like those of the glossopharyngeal in the upper part of its accompanying grey matter. The peripheral axons of the cells of the geniculate ganglion pass into the large superficial petrosal and chorda tympanito which they probably furnish gustatory fibres. Other (efferent) fibres. 
pass into the pars intermedia and nltimately into the chorda tympani from certain large cells which occur in the dorsal part of the facial nucleus. These are probably the salivary and vasodilator fibres of the chorda.

The VIth nerve (abducens).- The fibres of the sixth nerve (figs. 450, 456), which are purely motor, pass out from the mesial aspect of the mucleus and turn forwards; traversing the pyramid bundles they

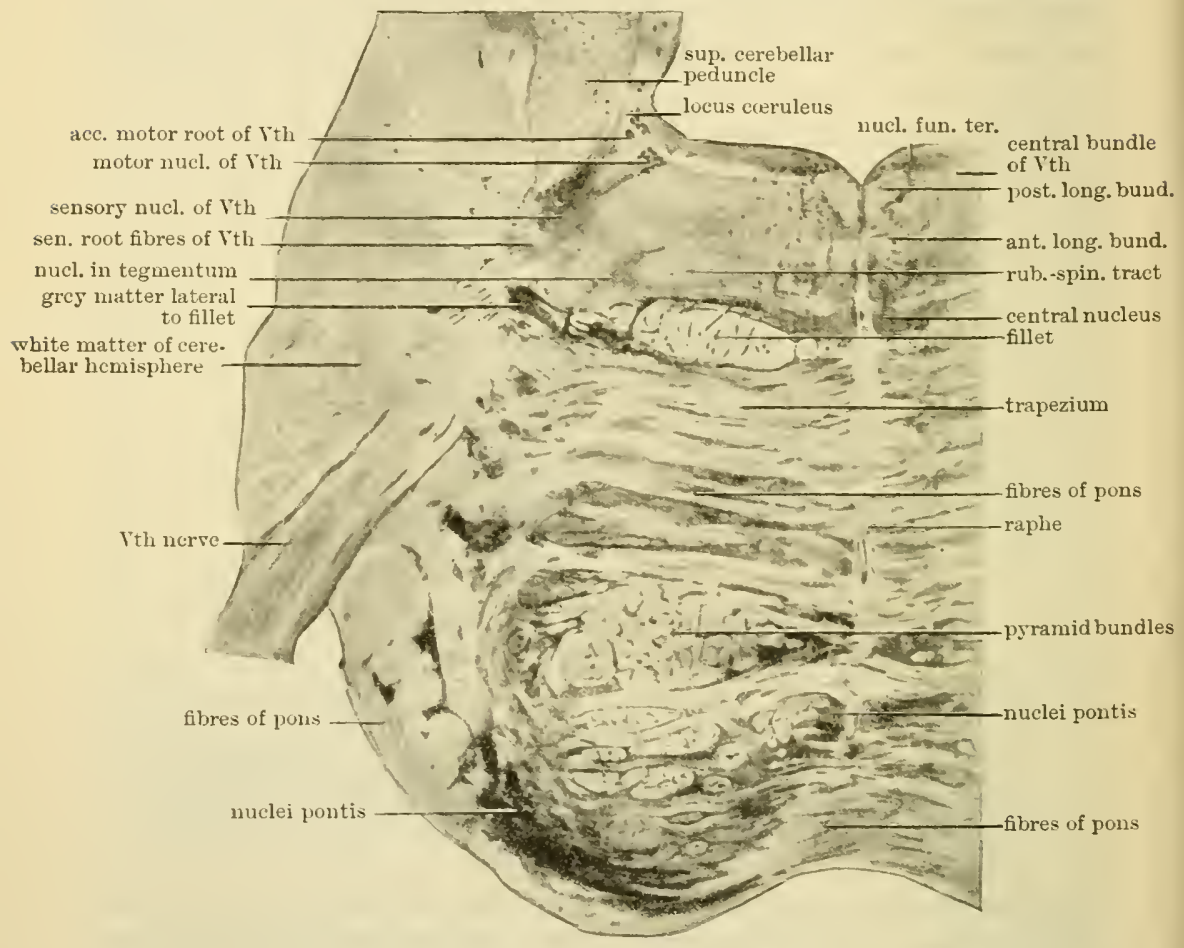

Fig. 457.-Sectiox across the MibdLe of the poxs varoliI. Magnified about 4 diameters.

emerge at the lower margin of the pons. A few fibres are derived from a small ventral nucleus lying near the nucleus of the facial; these run at first backwards and then turn forwards to join the others (Tan Gehuchten) (fig. $456, n^{\prime} V I$.).

The Vth or trigeminal nerve emerges at the side of the pons in two roots, a smaller motor and a larger sensory.

The motor root is derived partly from fibres which arise in the upper part of the pons and lower part of the mesencephalon from large spherical unipolar nerve-cells lying at the side of the grey matter bounding the Sylvian aqueduct (accessory or superior motor nucleus of 
fifth, fig. 450, $n V m s$; fig. 458, m'n.V.), partly from the motor nucleus proper (figs. $450, n V m ; 458, m n . V$.) which lies in the grey matter at the lateral edge of the fourth ventricle (fig. 457). As they pass the motor nucleus proper the fibres from the superior or accessory nucleus give off into it a large number of eollaterals which ranify between and around its cells.

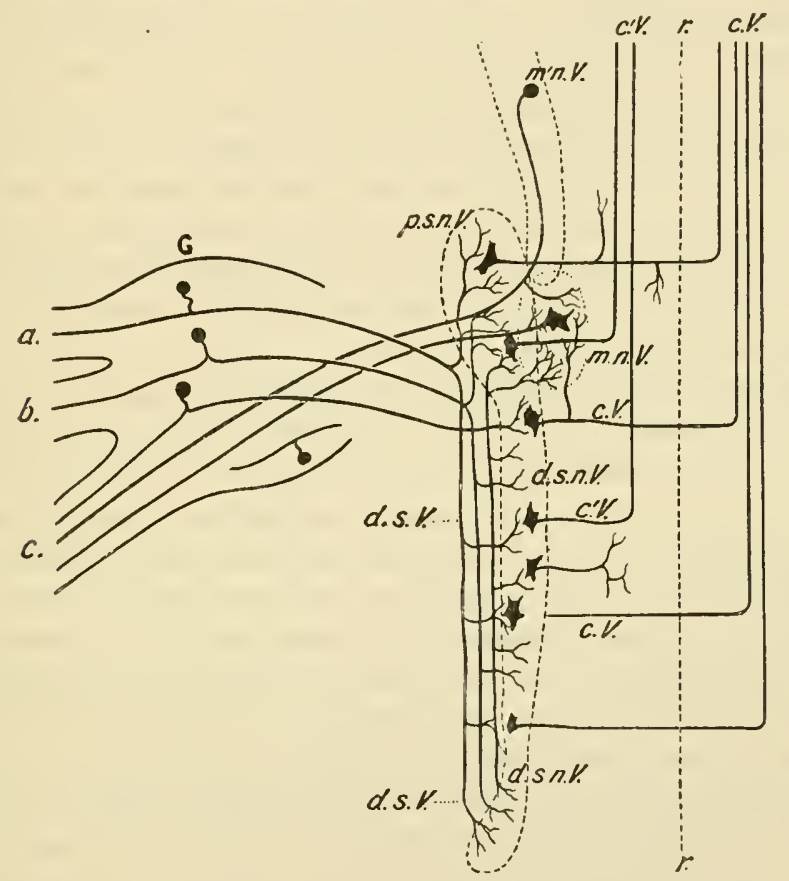

Fig. 458,-Plan OF THE ORIGIN OF THE FibRes OF THE FIFTH NeRVE.

G, Gasserian ganglion; $a, b, c$, three divisions of the nerve; $m^{\prime} \cdot n . V$., sulyerior motor mucleus; m.n.V., principal motor nucleus; p.s.n.V., principal sensory nucleus; d.s.n.V., descending sensory nucleus; $1 . s . V .$, descending root; $c V ., c^{\prime} V$. , central sensory tracts composed of fibres emanating from the sensory nuclei; $r$, plane of the raphe.

The fibres of the sensory root are derived from the cells of the Gasserian ganglion which are lomologous with the cells of the spinal ganglia. These fibres of the sensory root when traced into the pons are found to bifurcate, the ascending branehes ending in a mass of grey matter (principal sensory nucleus of the fifth, fig. 45s, p.s.n.V.) lying just lateral to the motor nucleus, while the descending branches trend downwards into the medulla oblongata where they form the descending or spinal root of the fifth (fig. 458 , d.s.V.); some even reach the upper part of the spinal cord. They lie immediately lateral to and in close connection with the substantia gelatinosa Rolandi 
which forms the inferior sensory uucleus (d.s.n.V.), and which is continued above into the principal nucleus. The substantia gelatinosa which forms the sensory nucleus of the fifth contains numerous nerve-cells, both small and large ; many of the small cells are grouped into nest-like clusters (islands of Calleja). The axons of the larger cells pass for the most part across the raphe to the formatio reticularis of the opposite side where they reinforce the ascending fibres of the intermediate fillet, but some ascend in the fillet of the same side, and others pass to a special ascending bundle of fibres on the opposite side of the raphe which lies nearer the floor of the fourth ventricle, and in the tegmentum of the mid-brain lies lateral to the posterior longitudinal bundle; hence it is continued upwards into the thalamus. Collaterals are given off from these ascending fibres to the adjoining grey matter, and especially to the nucleus of the facial nerve. Branches also pass downwards in the formatio reticularis.

Descending tracts in the pons and medulia oblongata.-Besides the fibres of the pyramills, which are much more numerous in the pons than in the medulla oblongata, and which send numerous collaterals into the grey matter of the nuclei pontis, there are several other descending tracts of fibres in the pons and medulla oblongata. One of these, which lies mesial to the fillet (see page 398) consists of fibres (cortico-bulbar) passing from the motor cortex towards the nuclei of the facial and hypoglossal. In the crusta of the mid-brain these fibres lie mesial to the ordinary pyramidal fibres, but they then leave the latter and pass into the ventral part of the tegmentum and are continued downwards in the formatio reticularis into the medulla oblongata. Another bundle, consisting of both ascending and descending fibres (restitulomotor), is very distinct, just ventral to the grey matter of the floor of the fourth ventricle, near the middle line; this is the dorsal or posterior longitudinal bundle; as already noticed (pp. 388, 392. See also p. 402) it connects Deiters' nucleus with the oculomotor nucleus, the nucleus of the sixth, and the anterior horn cells of the spinal cord ; it probably also receives fibres from the axons of the large cells of the formatio reticularis.

Other descending tracts in the pons which are not so distinctly marked in the normal condition, but which can be traced by the methods of Waller and Flechsig are:--1. Monatiow's bundle; 2. The anterior longitudinal bundle; 3. The ponto-spinal lateral tract; 4. The vestibulo-spinal tract; 5. The central tract of the tegmentum.

Monakow's bundle or the rubro-spinal tract has already been seen as the prepyramidal tract of the spinal cord (p. 365. See also p. 403). Its fibres arise from the cells of the red nucleus of the mid-brain of the opposite side, crossing the raphe in Forel's decussation (p. 403, foot- 
note). In the upper part of the pons it is dorsal to the mesial fillet, but lower down runs in the lateral part of the tegmentum, dorsal to the lateral fillet.

The anterior longitudinal bundle (terto-spinal tract) consists of fibres which arise in the opposite superior quadrigeminal body, these cross the raphe in Meynert's decussation (p. 403), and run down ventral to the posterior longitudinal bundle, giving off collaterals to the oeulomotor melei and the nuelei of the fourth and sixth nerves as they descend. Its fibres eventually mix with those of the posterior longitudinal bundle, and pass into the anterior eolumn of the cord, joining the antero-lateral descending tract (p. 363).

The ponto-spinal lateral tract is formed of fibres which arise from the large cells of the reticular formation, and run down within the lateral area of this formation in the pons and medulla oblongata to reach the part of the lateral column of the cord which lies between the grey matter and the tracts of Monakow and Gowers. It is, however, mixed here with many fibres of different origin. The destination of its fibres is similar to those of the posterior and anterior longitudinal bundles, viz. : the adjacent grey matter of the anterior horn.

The vestilulo-spinal tract is composed of fibres derived from the cells of the nuclei of Deiters and Bechterew, and is therefore similar in its origin to the fibres of the posterior longitudinal bundle. The destination is in part also similar, for the fibres pass below into the anterior root zone of the cord and end in the grey matter of the anterior horn, but in their course downwards they lie in the lateral part of the medulla oblongata mixed up with those of Monakow's tract and the ponto-spinal tract, as well as with the ascending fibres of Gowers' tract.

The central tract of the tegmentum (Bechterew) runs in the pons exactly in the middle of the reticular formation of the tegmentum, but in the medulla oblongata it lies more ventrally near the olivary nucleus, beyond which it has not been traced. The origin of its fibres is not certainly known, but appears to be the thalamus; their destination is the olivary body of the same side (see p. 381, thalamoolivary tract).

Ascending tracts in the pons and medulla oblongata.-In the ventral part of the reticular formation is a very well-marked tract of fibres, somewhat flattened (narrow in section) from above down in the pons; this is the tract of the fillet. Its fibres are partly derived from cells in the nuelei of the opposite fasciculus gracilis and fascieulus cuneatus of the medulla oblongata which have erossed the raphe as internal areuate fibres; partly from cells in the nuclei which are connected with the terminations of the sensory cranial nerves. 
In the mid-brain the fillet splits up into two distinct bundles of fibres termed respectively the lateral or lower and the intermediate or upper fillet. The fibres of the lower fillet are seen at the side of the mesencephalon (fillet of Reil), and are traceable partly to the grey matter of the inferior corpor'a quadrigemina (fig. 465), partly to the mesial geniculate body, in both of which they terminate; they are derived from the sensory nuclei of the medulla oblongata and pons (mainly from the acoustic nuclei). Those of the upper fillet go to the thalamus (fig. $469)$; they are chiefly the fibres from the cells of the opposite posterior columns of the medulla oblongata.

Besides the ascending fibres of the tract of the fillet, this bundle includes a certain number which degenerate below a section of the tract and are therefore descending (centrifugal) : their cells of origin appear to lie in the thalamus; the fibres themselves are situated mesial to the true fillet of which they were formerly considered to be a part (being termed "mesial" fillet): they form a thalumo-bulbar tract. Mesial to the tract just mentioned is a bundle, also consisting of descending fibres, belonging to the system of the pyramidal tract, and containing fibres which eventually come into relation with certain of the cranial motor nuclei (Hoche). This constitutes the cortico-bulbar tract (see page 396). In the crusta it lics clorso-lateral to the other pyramidal tract fibres.

Many of the fibres which continue the sensory path of the cranial nerves upwards lie in the formatio reticularis (tegmentum), somewhat dorsal to the tract of the fillet, forming a homologous but not clearly defined tract, which runs up through the pons and mid-brain to terminate in the subthalamic region and in the optic thalamus (central tract of the sensory cranial nerves). Another ascending tract is the special bundle of fibres from the sensory nucleus of the 5th to the thalamus previously referred to (p. 396).

At the upper part of the pons (fig. 459) the fourth ventricle narrows considerably towarls the Sylvian aqueduct, and above and on either side of it two considerable masses of longitudinal white fibres make their appearance. These are the superior peduncles of the cerebellum, and they tend, as they pass forwards, gradually to approach the middle line; across which immediately below and in the region of the posterior colliculi of the corpora qualrigemina they pass, decussating with one another, to enter the formatio reticnlaris of the opposite side.

The fibres of the superior cerebellar peduncles for the most part take origin in the cerebellum, emerging from its dentate nucleus, from the cells of which they are derived. They cross the raphe in the mid-brain and terminate in the red nucleus of the (opposite) tegmentum ; but some 
of them give off a branch within the perhucle before crossing, and these branches are described by Cajal as forming a descending cerelellur bundle which passes downwards towards the medulla oblongata and spinal cord on the inner side of the descending root of the fifth, and gives off

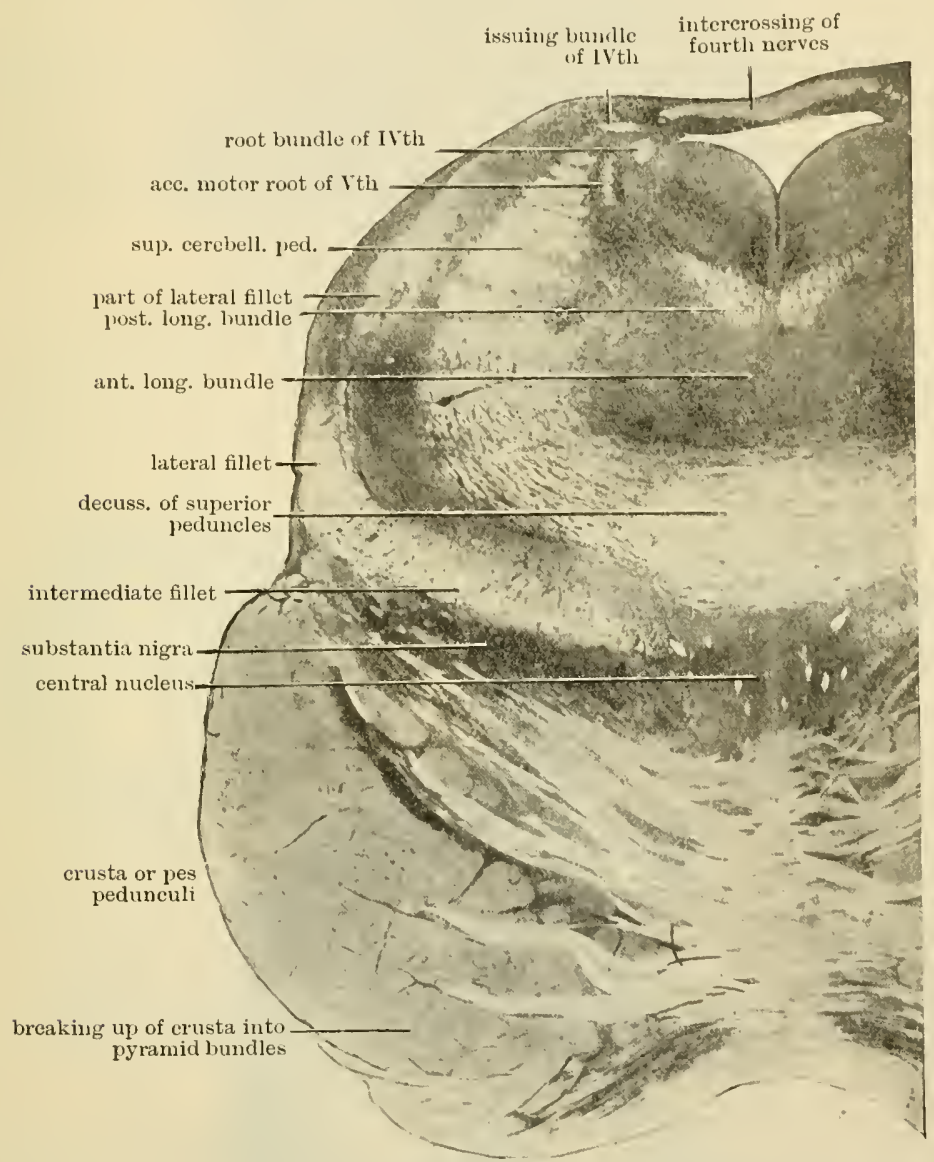

Fig. 459. - Transverse section throvgh the UPPER PART OH THE PONS.

collaterals to the motor nucleus of the fifth, to the facial nucleus, to the nucleus ambiguns, and to the anterior horn of the spinal cord (fig. 480). There is also in the superior peduncle a bundle of fibres which are derived from cells in the thalamus and which pass downwards in the peduncle.

The antero-lateral ascending tract of the spinal cord (p. 365) is con- 


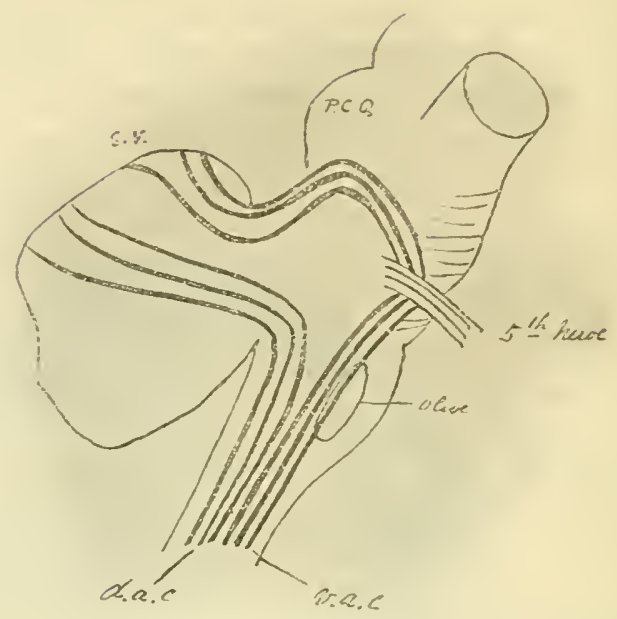

FIG. 460.-DIAGRAM TO SHOW THE MODE OF PASSAGE OF THE FIBRES OF THE DORSAL AND VENTRAL SPINO-CEREBELLAR TRACTS RESPECTIVELY INTO THE CEREBELlaR TERMIS. (F. W. Mott.)

p.c.q., posterior corpora quadrigemina; s.v., superior vermis of cerebellum; d.a.c., dorsal ascending cerebellar tract; $v$.a.c., ventral ascending cerebellar tract.

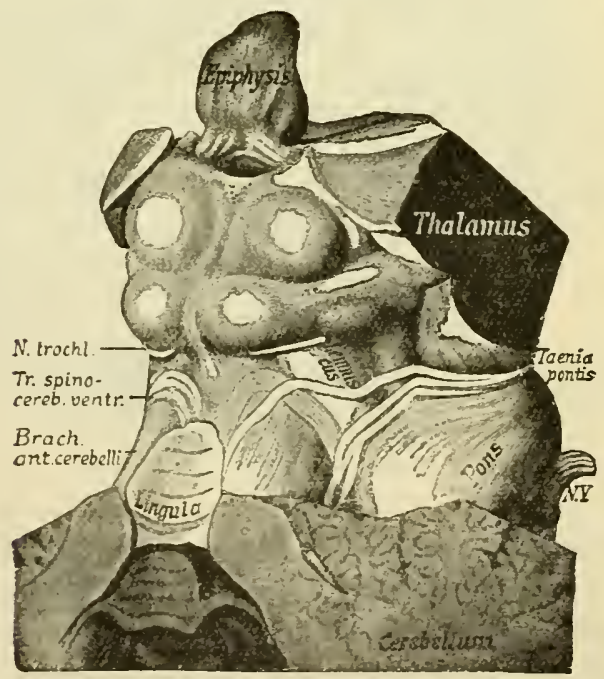

Fig. 461. - THE CORPORA QUADRIGEMINA AND NEIGHBOURING PARTS OF THE BRAIX. (Edinger from G. Retzius.)

Brark. ant. cerebclli, the supcrior cerebellar peduncles, between them the anterior medullary velum partly covered by the lingula; $T r$. spino-cereb. ventr., tract of Gowers curring round the peduncle; lemniscus, the lateral fillet; $N$. trochl., 4 th nerre; A. $V ., 5$ th nerve. 
tinued up in the lateral column of the medulla oblongata dorso-lateral to the olive and throngh the ventral part of the pons Varolii lateral to the pyramil bundles, but at about the level of the exit of the fifth nerve many of its fibres begin to pass obliquely towarls the dorsolateral part of the pons (fig. 460), where the superior cerebellar peduncle is emerging from the cerebellar hemisphere. The tract in question (anterior or ventral spino-cerebellar tract) now eurves over the lateral aspect of this peduncle (fig. $461, t r$. spino-cerel. ventr.), and then takes a sharp backward turn, passing over its dorsal aspect to enter the milddle lobe of the eerebellum in the superior medullary velum.

\section{THE MID-BRAIN OR MESENCEPIIALON.}

In seetions across the mesencephalon (figs. 463 to 466 ), the upward continuity of the parts which have already been described in the lower nerve-centres ean still in great measure be traced.

I

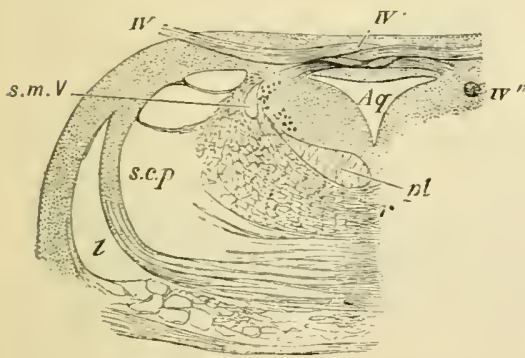

B

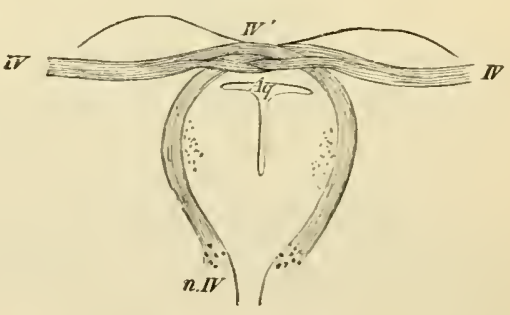

Fig. 462.- SECTION THROCGH THE ORIGIN OF THE FOURTH NERVE. (Schwalbe.)

A, transverse section at the place of emergence of the nerve-fibres. B, oblique sertion carried along the course of the bundlcs from the nucleus of origin to the place of emergence. Aq. Srlvian aqueduct, with its surrounding gres matter; $I V$, the nerrebundles ernerging; $I V^{\prime \prime}$, decussation of the nerves of the two sides ; $I V^{\prime \prime}$, a bundle passing by the side of the aqueduct to emerge a little lower down; $n . I Y$, nucleus of the fuurth ncrve; $l$, lateral fillet : s.c.p., superior cerebellar peduncle; s.m. $V$., supcrior motor root of the fifth uerre; $p l$, postcrior longitudiual bundle; $r$, raphe.

The Sylvian aqueduct (fig. $464, S y$ ), with its lining of eiliated epithelium, represents the central canal of the cord and the fourth rentricle of the medulla oblongata. In the grey matter which sur. rounds it (central grey matter) there is seen in all sections of the region a group (column) of large nerve-cells (oculomotor nucleus) lying ventrally on each side of the middle line, close to the reticular formation. From the lower part of this column the root-bundles of the fourth nerve arise at the lower part of the mesencephalon and pass obliquely backwards and downwards around the central grey matter. decussating with those of the opposite side to emerge just above the pons Varolii 
(figs. 459, 462). Higher up, in the region of the anterior colliculi, the bundles of the third nerve spring from a continuation of the same nucleus (fig. $465, n . I I I$.), and these pass forwards and downwards with a curved course through the reticular formation, to emerge at the mesial side of the crusta. According to Van Gehuchten some of the fibres of the 3rd nerve cross the middle line and emerge with the nerve of the opposite side.

Tegmentum.-The reticular formation of the pons is continued up into the mesencephalon and is here known as the tegmentum. It is com. posed as before of longitudinal and transverse or areuate bundles of fibres with much grey matter intermingled. The transverse fibres include the decussating fibres of the superior peduncles of the cerebellum (s.c.p.),

A

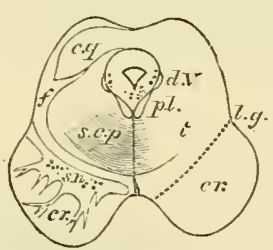

$\mathrm{B}$

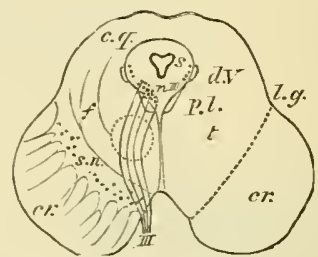

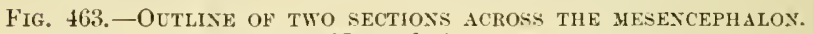
Natural size.

$A$, through the middle of the inferior corpora quadrigemina. B, through the region of the superior corpora quadrigemina. $c r$, crusta; s.n., substantia nigra; $t$, tegmentum ; $s$, Sylvian aqueduct, with its surrounding grey matter; c.q., grey matter of the corpora quadrigemina; $\ell . g$. , lateral groove; p.l., posterior longitudinal bnndle; d. I., superior root of the fifth nerve; s.c.p., superior cerebellar peduncle; $f$, lateral fillet; 11. ., third nerre; n.111., its nucleus. The dotted circle in B indicates the situation of the tegmental or red nueleus.

which are derived from cells in the dentate nucleus of the cerebellum, and on reaching the opposite side bifurcate. Their ascending branches become gradually lost amongst a number of nerve-cells which collectively constitute what is known as the red nucleus or nucleus of the tegmentum, whilst the descending branches turn downwards in the reticular formation (Cajal) (see p. 399). But some of the fibres of the superior peduncle go on past the red nucleus to the rentral part of the thalamus. The red nucleus also receives fibres in its lateral aspect which are derived from the lenticular nucleus of the corpus striatum, and some of which are said to come from the cerebral cortex; these fibres form a sort of capsule to the red nucleus before entering it.

Tracts in the tegmentum.-1. Vestibulo-motor tract; posterior longitudinal bundle.-This is well marked in the mid-brain, and gives off many collaterals and terminal filmes to the oculomotor nucleus which is immediately dorsal to it. The bundle largely consists of nerve fibres derived from the cells of Deiters' nucleus (see p. 388), which 
on reaching the sitnation of the bundle either on the same or on the opposite side, bifureate, one branch ascending, the other descending. But it receives fibres firom other sourees than Deiters' nueleus, e.g. from lirge eells of the sensory mucleus of the 5th, and from large cells in the retienlar formation of the medulla oblongata, pons, and midbrain. All these fibres, like those from Deiters' nucleus, bifureate on joining the bundle, one branch passing upwards, the other dowuwards. Some fibres of the bundle are of different origin from the rest, arising beyond the oculomotor nucleus. These are very fine; they are descending fibres, and are traceable from the cells of the nucleus of the posterior longitudinul bundle, which lies in front of the Sylvian arqueduct in the grey matter at the side of the third rentricle.

some of the fibres of the posterior longitudinal bundle are stated to be traceable as far up as the thalamus.

The bundle gives collaterals not only to the ocnlomotor nucleus but also to the nucleus of the sixth, and probably others to the nuclei of other cranial motor nerves. Its descending fibres are eventually continued down the spinal cord in the antero-lateral descending tract, and give off terminals and collaterals to the anterior horn.

2. Rubro-spinal tract; Monatiow's bundle.-The cells of the red nuclens send their axons downwards and forwards. They form Monakow's bundle or the rubro-spinal tract, which is continued below into the prepyrumidul tract of the spinal cord.

3. Tecto-spinal tract; anterior longitudinal bundle.-Other longitudinal fibres of the tegmentum are those of the fasciculus retroflexus of Meynert lying mesially to the red nucleus and passing obliquely downwards and inwards from the ganglion of the habenula to the interpeduncular ganglion of the opposite side, and the bundle of Mïnzer, which passes from the posterior tubercle downwards into the lateral part of the reticular formation of the pons. But the longest and most important is the anterior or ventral longitudinal bundle, which passes lateral to the red nucleus and partly through it. Although the red nucleus receives many collaterals from this bundle the fibres of the bundle are derived, according to Held and Cajal, from cells in the grey matter of the opposite anterior tuberele of the corpora quadrigemina; these cells send their axons sweeping round the central grey matter just central to the posterior longitudinal bundle to cross in the raphe, where they form the fountain-like decussation of Meynert (fig. 46t, $\left.d^{\prime}\right) .{ }^{1}$ The down-

${ }^{1}$ This is not to be confounded with the fountain-like decussation of Forel (tig. $464, d$ ), which lies nearer the ventral part of the tegmentum, and is partly formed by the intercrossing of Monakow's bundle and partly by v. Gudden's bundle coming from the corpora maminillaria to end in the tegmentum. 
ward continuation of the tecto-spinal tract has alrearly been studied (pp. 397 and 365), but it should be stated that the prolongation of its fibres into the anterior column of the spinal cord is denied by Van Gehuchten, who traces them only as far as the medulla oblongata.

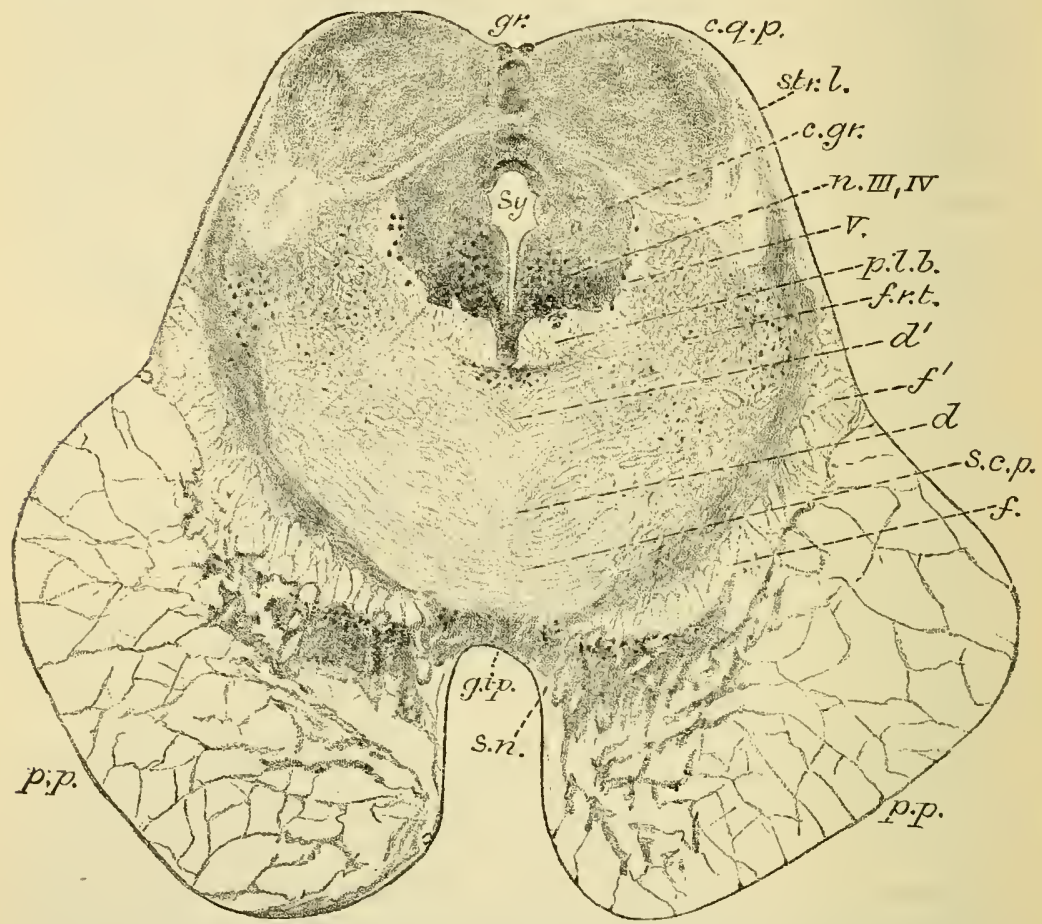

Fig. 46t.-SEction ACROSS THE MID-BRAIN THIOUgh THE INFERIOR PAIR OF CORPORA QUADRIGEMINA. Maguified about $3 \frac{1}{2}$ diameters. (From a photograph.)

Su., aqueduct of Sylvius; c.gi., eentral grey matter of the aqueduet; n.11I.1V., group of eells forming part of the conjuined nucleus of the third and fourth nerves; $c . q . p$., one of the posterior corpora quadrigeńina; $g r$, median groove separating it from that of the opposite side; str.l., stratum lenmisei (layer of the fillet), forming its superficial layer; $f$, upper fillet; $f^{\prime}$, lateral fillet; $V$., aceessory motor root of tifth nerve; $p, 2, b$, , nosterior longitudinal bundle: $r, t$. , formatio retieularis tegmenti ; $d, d^{\prime}$, decussating fibres of tegmenta (fountain-deeussations of Forel and Meynert); s.c. $p_{.}$, superior eerebellar peduneles, decussating; p.p., pes peduneuli (erusta); $s_{*} n$., substantia nigra; g. $i-p$. , interpeduncular ganglion.

4. Tract of the fillet.-The continuation upwards of the fillet is also apparent in this part of the brain. Some of its fibres are seen passing in an oblique manner to the side of the mesencephalon, to enter the grey matter of the prominences of the posterior corpora quadrigenina.

This part is the lateral fillet (see p. 398), which is formed chiefly by fibres derived from the accessory auditory, the inferior olivary, and the trapezoid nuclei of the opposite side, forming the central acoustic tract. 
Its fibres send numerous collaterals to the posterior tubercle (fig. 46.5 ) and a few to the anterior, and end by ramifying amongst the cells of the mesial geniculate body (Cajal). In its course it traverses the nucleus of the fillet, which consists of cells interpolated amongst its fibres (the greater number in the lower part near the superior olive), amongst which some of the fibres and many collaterals from them end. The axons of these cells trend inwards towards the raphe. The upper fillet is continued upwards in the ventral part of the tegmentum towards the thalamus (p. 409).

Crusta.-Lateral and ventral to the tegmentum is seen on either side the white mass known as the crustu or pes pedunculi (figs. $463, c r, 464$, $466, p \cdot p$.$) . This is formed by longitudinally coursing bundles of fibres$ lying on the rentral aspect of each half of the mesencephalon, and diverging above into the internal capsule of the cerebral hemisphere.

The fibres of the crusta are continued below into the so-called "pyramid bundles" of the pons - which contain, as we have seen, many more fibres than those of the pyramidal tract. This is also the case with the bundles of the crusta, in which the pyramidal tract proper-composed of fibres emanating from the ascending frontal and paracentral gyri-is confined to the middle three-fifths (which, however, includes many cortico-pontine fibres), whilst the mesial fifth is mainly occupied by fibres passing fron the lower frontal region to the pons, carrying impulses to the nuclei of the facial and hypoglossal; and the lateral fifth by fibres the origin and functions of which are not certainly known. But it is probable that these last are connected with the regions of the henisphere behind the Rolandic fissure, especially, perhaps, with the temporal and occipital regions; and are passing from the pyramidal cells of these parts to end in the nuclei of the pons.

Substantia nigra. - The crusta is separated from the tegmentum by a layer of grey matter containing a number of very deeply pigmented nerve-cells (substantiu nigra; figs. $464,466, s . n$.). The substantia nigra receives many collaterals from the adjacent pyramid bundles of the crusta. The crusta and tegmentum, together with the intervening substantia nigra, constitute the cerebral peduncle (pes or crus cerebri).

Interpeduncular ganglion.-Between the cerebral peduncles, just where they diverge from the mass of transverse fibres of the pons, is seen close to the ventral surface of the brain a small mass of grey matter containing a large number of small nerve-cells with large and irregular dendrons, and axons which are directed dorsally into the tegmentum. This is the interpedunculur ganglion (fig. $46 t$, g.i.p.). It receives on either side the ending of the fasciculus retroflexus of Meynert which comes from the ganglion of the habenula, a collection of nerve 
cells near the superior and mesial part of the thalamus, close to the commencement of the third ventricle (see fig. 472). 'These ganglia are both much better marked in many of the lower animals than in man.

Corpora quadrigemina.-The prominences (colliculi or tubercles) of the corpora quadrigemina are formed mainly of grey matter. Connected with each one is a bundle of white fibres forming the brachia of the geniculate bodies.

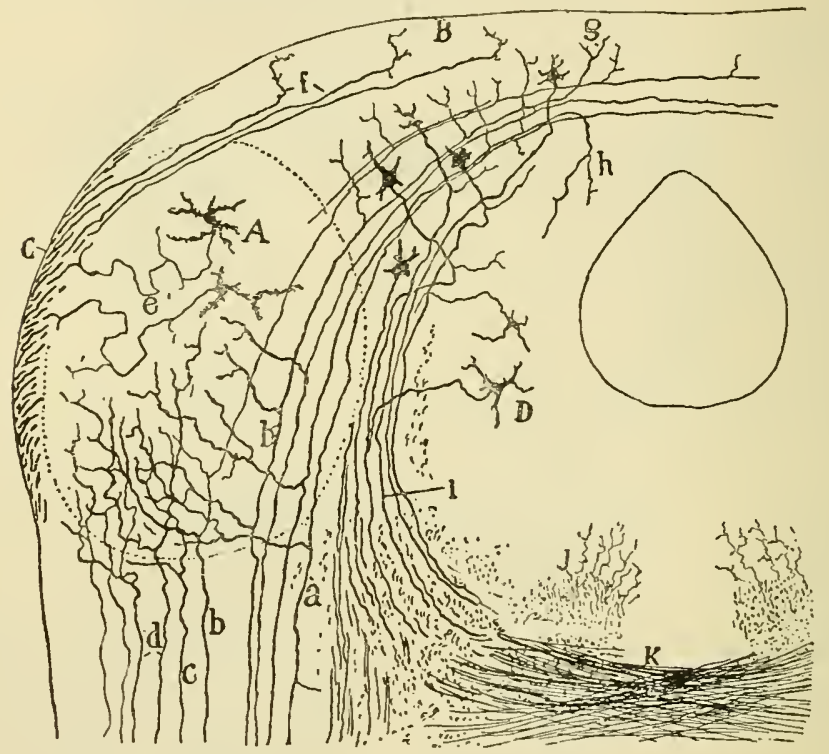

Fig. 465.-DIAgraM SHOWING THE GENeral STRUCttre OF THE POSTERIOR CORPORA QUAURIGEMINA. (Cajal.)

A, principal mass of grey matter; B, C, cortical layer; D, grey matter around Sylvian aqueduct; $\mathbf{K}$, decussation of superior peduncles of cerebcllum; $a, b, c, d$, fibres of central acoustic path from lateral fillet; $e$, axons from cells of princinal nucleus passing towards brachium; $f$, fibres from brachium passing into superficial layer; $q$, fibres from fillct passing into superficial Iayer; $h$, a fibre of fillet passing to central grey matter of aqueduct; $j$, collaterals from posterior longitudinal bundle passing to oculo-motor nuclcus; $l$, axons of cells in superomesial part of colliculus curving round grey matter of aqueduct and forming the deep white layer.

The posterior or inferior colliculi consist of a grey centre which is enclosed by superficial and deep white layers (figs. 464,465). The superficial white layer is derived mainly from the brachium. The fibres of the fillet divide as they approach the colliculus; one branch enters its grey matter while the other passes to the mesial geniculate body. In animals with a highly developed sense of hearing all these parts are proportionately developed. The deep white layer is derived from cells of the grey centre, but many of the cells of the latter send their axons towards the superficial layer. The destination of the fibres of 
the deep white layer is not certainly known; some pass over the central grey matter of the aqueluct to the opposite side.

In the anterior or superior colliculi four layers ean be distinguished, viz. : superficially, a thin white layer containing nerve-fibres and a few horizontally disposed nerve-cells (fig. $467, \mathrm{~A}$ ); next to this a grey cap

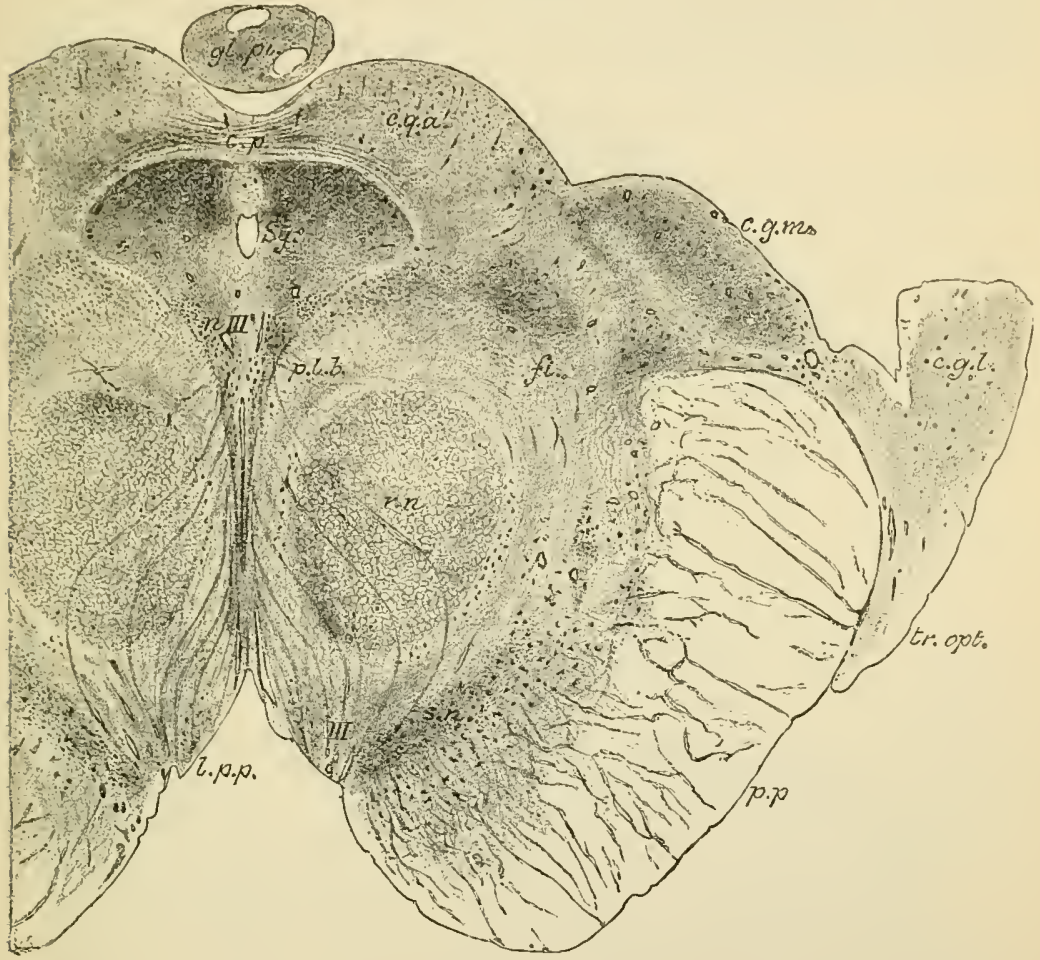

FIG. 466. - SECTION ACROSS THE MID-BRAIN THROUGH THE SUPERIOR CORPORA QUADRIGEMINA. Magnified about $3 \frac{1}{2}$ diameters. (From a photograph.)

c.p., posterior commissure of brain; gl.pi., pincal gland; c.q.ı., gres matter of one of superior corpora quadrigemina; c.g.m., mesial geniculate body; c.g.l., lateral geni. culate body; tr.opt., optic tract; p.p., crusta or pes pedunculi ; p.l.h,, posterior longitudinal bundle; $f$, upper fllet; $x, n$, red nucleus; 111. , issuing fibres of third nerve; $n . I I I .$, its nucleus ; l.p.p., locus perforatus posticus; sy, sylvian aqueduct.

(B) containing many and various nerve cells, amongst which the terminations of the optic nerve $(h, h)$ ramify; below this the optic nerve layer (C), which is formed of antero-posteriorly running fibres derived from the optic traet, and ending as just stated for the most part in the grey layer. This layer also contains some nerve-cells. Lastly there is a deep white layer, the so-called deep medulla, of transversely disposed fibres (D) derived partly from the fillet, but comprising many fibres which are derived from the cells of the collieulus itself, and a few which 
are continued up from the antero-lateral ascending tract of the spinal cord. This deep layer also contains a number of large dendritic cells amongst the fibres. The superior corpora quadrigemina receive through their brachia many of the fibres of the optic tract, which in mammals enter the grey matter at the middle of its thickness and traverse it from before back, so that in transverse sections of the mid. brain they appear cut across. In birds they form a superficial white

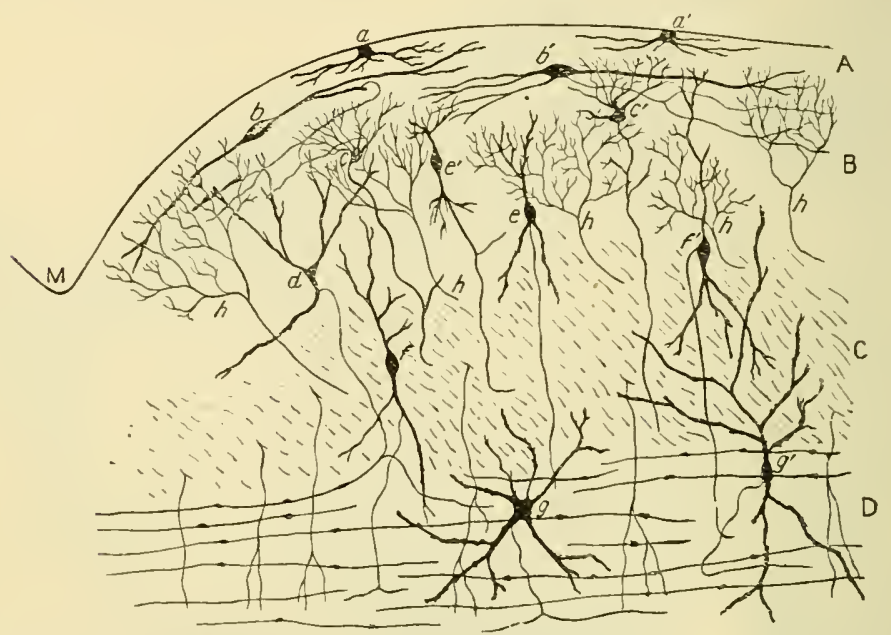

Fig. 467.-DIAgRAM SHOWING THE (HARACTERS OF THE CELLS IN THE GREY MATTER OF THE ANTERIOR CORPORA QUADRIGEMINA. (Cajal.)

$M$, portion of dorsal unedian groove; $A$, sujerficial white layer; $B$, grey cap; $C$, optic fibre layer (upper grey-white layer); $D$, layer of the fillet (lower grey-white layer).

$a, a^{\prime}$, marginal nerve eells: their axons are not represented; $b, b^{\prime}$, horizontal spindleshaped cells of Golgi's type II. ; $c, c^{\prime}$, small cells with much branched dendrons and an ixon extending to the optic fibre layer; $d, e \cdot \ell^{\prime}$, spindle and stellate cells of the grey cap, and $f, f^{\prime}$, cells of the stratmo opticum, sending their axuns into the stratum lemnisci; $g, g^{\prime}$, cells of the stratum Jemnisci; $h, h$, fibres of the optie nerve layer ending in the grey and superficial white layers.

stratum covering the grey matter, but this is not homologous with the superficial stratum of mammals, for the fibres in the latter are not derived directly from the optic tract. The optic fibres are derived from nerve-cells in the retina, and as they traverse the stratum opticum they pass obliquely into the grey matter (in a ventral direction in birds, in a dorsal direction in mammals) and end in arborisations amongst its cells. The cells of the grey matter are very various in form and size (fig. 467). Most of their axis-cylinder processes pass ventralwards. The destination of all is not certainly known, but many appear to join the anterior longitudinal bundle of the opposite side. Others run down on the same side towards the pons Varolii, intermingled with the ascending fibres of the fillet. A certain number of fibres which take origin in the cells of the anterior colliculi course 
over the central grey matter which surounds the Sylrian aquednet and sweep romd this towards the fillet-tract of the opposite side. These commisural fibres are continuous in front with those of the posterior commissure.

The nerve-fibres of the optic nerve and optic tract do not all enter the corpora fuadrigemina. Many, indeed the majority, pass into the lateral geniculate bodies and optic thalami to form arborisations there (fig. 4i1). On the other hand, axons from the cells of these structures pass to the cortex of the brain (occipital region).

As has just been stated, many arcuate fibres issue from the grey matter of the corpora quadrigemina and pass obliquely downwards into the ventral part of the mesencephalon encircling the eentral grey matter. These fibres intercross in the raphe, where they constitute the fountain-decissution of Meynert, and after crossing constitute the main mass of the anterior longitudinal bundles. These are continued into the anterior columns of the spinal cord; they give off collaterals to the motor nuelei of the eye-muscles, and probably to the motor nuclei generally. Other fibres which appear to belong to the same (tecto-spinal) system are traceable as a distinct tract into the lateral column of the cord (see p. 365).

In the cat, the anterior corpora quadrigemina receive a number of fibres from the pyramidal tract in the crusta of the same side, a few crossing over the aqueduct to the opposite corpora quadrigemina (Boyce, Sutherland Simpson). But in most animals the fibres which pass from the cortex cerel,ri to the corpora quadrigemina enter those bodies through their respective brachia.

No fibres are given off from the cells of the corpora quadrigemina to the cortex cerebri.

The optic nerves. - The only sensory nerves which are immediately connected with the micl-brain are the second or optic. Their origin is from the large nerve-cells of the ganglion of the retina (p. 455). The nerve leaves the globe of the eye at its posterior aspect, passes through the optic foranen to the base of the brain, and joins the nerve of the opposite side to form the optic chiasma (fig. 471). Of the fibres which enter the chiasma, those from the inner (or nasal) two-thirds of the retina cross to the optic tract of the opposite side, while the. remaining third, comprising the fibres from the temporal part of the retina, pass along the latelal border of the chiasma to the tract of the same side. In the optic tract they are continued to the parts of the brain where they have their terminal arborescences, viz., the external geniculate body and the adjoining posterior part of the thalamus (pulvinar) and the anterior corpora quadrigemina. A certain 
number of the fibres of the optic nerve bifurcate on reaching the chiasma, and the branches pass one into each optic tract (Cajal).

The fibres which pass to the anterior corpora quadrigemina are much finer than those to the corpora geniculata. It is probable that the former furnish the path for reflex movements of the pupil, etc., and the latter the path for visual impressions, since the lateral corpora geniculata and pulvinar thalami are directly connected with the visual cortex in the occipital lobe, while, as already stated, no such direct connection obtains between that cortex and the anterior corpora quadrigemina.

A small bundle of fibres (transverse pelunculter bundle) leaves the optic tract as it enters the mid-brain and passes round the cerebral peduncle to lose itself in the mesial part of the tegmentum near the fillet. Its destination appears to be a small nucleus situated near the red nucleus. Its fibres degenerate after enucleation of the opposite eyehall.

The optic tracts and chiasma also contain the fibres of $v$. Gudden's commissure, which connects the posterior corpora quadrigemina, but these fibres appear to have no relation to the visual function.

There are present in the optic nerve and tract a few fibres which originate in the nerve-centres-where is not known--and terminate in the retina.

Motor nerves. - The motor nerves arising from the mid-brain are the third and fourth. The position of their nuclei and their mode of exit have been already described (pp. 401, 402).

Posterior commissure.-Immediately in front of the corpera quadrigemina, visible in the roof of this part of the mid-brain, is the posterior commissure. This consists of fibres which arise in a nucleus at each side of the Sylvian aqueduct and which pass across the middle line dorsal to the central grey matter and then turn ventralwards and candalwards to pass down in the tegmentum lateral to the posterior longitudinal bundle, which is partly reinforced by the filbres in question. The posterior commissure extends into the region of the third ventricle.

\section{THE THALAMENCEPHALON.}

The optic thalamus (fig. $468, t h$.) which lies at the side of the third ventricle and forms part of the floor of the lateral ventricle, is covered externally by a layer of white fibres, most marked next to the internal capsule. Fibres from the latter pass into the thalamus and serve to connect it with the hemisphere.

The grey matter of the thalamus is partially subdivided by 
an oblique white lamina into a smaller, mesial, and a larger lateral nucleus; these contain a large number of small nerve-cells. Anteriorly another portion of grey matter (anterior nucleus) is divided off in a similar way; this contains comparatively large nerve-cells. These nuclei are themselves formed of several groups of cells having diflerent comnections, many of which still require elucidation.

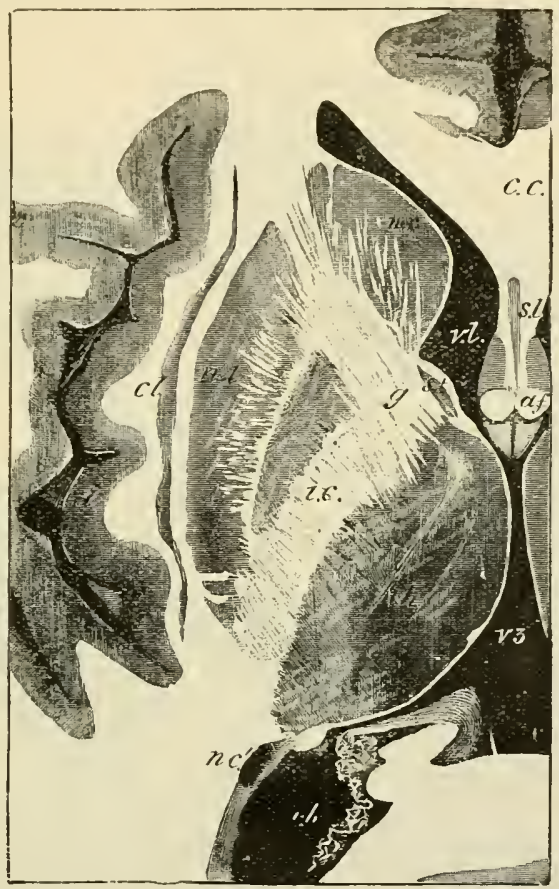

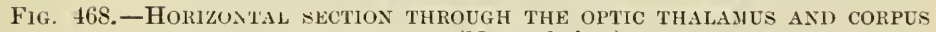
STRLATUM. (Natural size.)

乞.l., lateral ventricle, its anterior cornu; c.e., corpus callosum; s.l., septum lucidum; a.f., anterior pillars of the fornix; 23 , third rentricle; tho, thalamus opticus; st., stria medullaris; $n c ., n c^{\prime}$., nucleus caudatus, and $n \ell$., nucleus lenticularis of the corpus striatum ; i.c., internal capsule; $g$, its angle or genu : $n c^{\prime}$., tail of the nucleus caudatus appearing in the descending cornu of the lateral ventricle; $c l$, claustruin ; $I$, island of Reil.

The thalamus receives the terminal branehes of the fibres of the upper fillet, continued from the cells of the opposite nuclei of Goll and Burdach (spino-thalamic tract), of the central path of the fifth cranial nerve of the opposite side, and some fibres from the superior cerebellar peduncle of the opposite sicle; besides the fibres of the optic tract which pass to the external genieulate body and pulvinar thalami.

From the cells of the thalamus nerve-fibres pass in every direction into the white matter of the hemisphere, and eventually to the cortex (figs. 437, 469). From the outer part they tend especially into the 
occipital region, assisting to form the central visual tract which passes to the risual cortex. From the inner and deeper part they converge towards the subthalamic region and many are collected into the ansa lenticularis (see p. 415 ), by which they pass into the nucleus lenticularis, while others, as already stated, enter the corona radiata and thus reach the cortex of the hemisphere. These fibres from the thalamus to the cortex probably form the third and last link in the chain of sensory

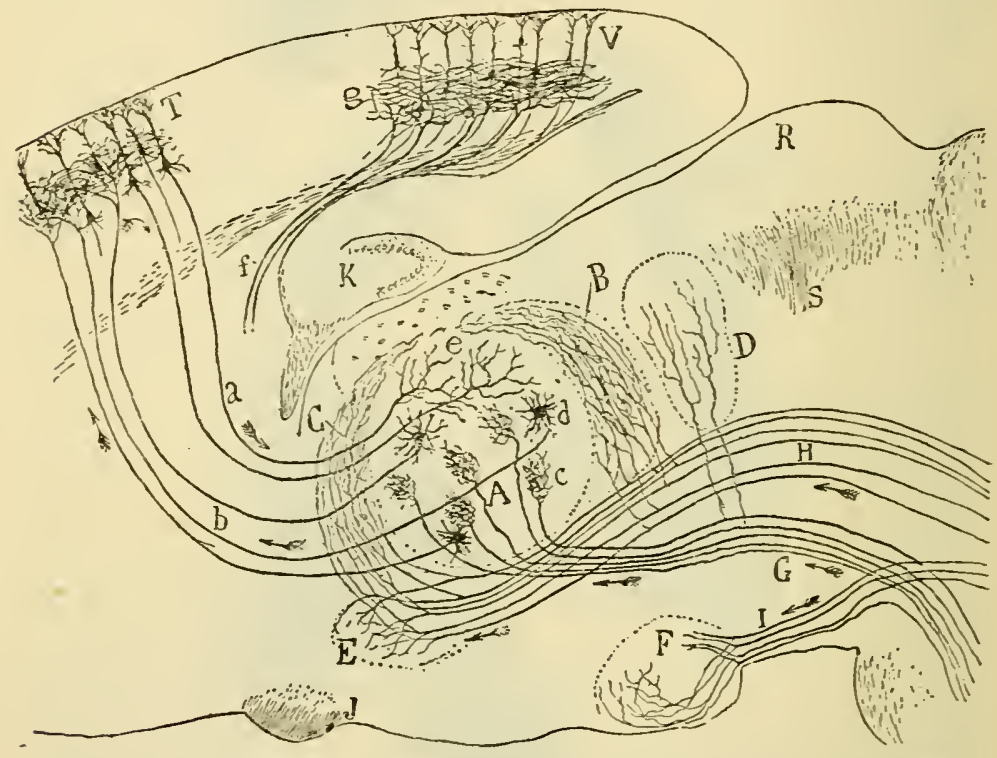

Fig. 469.-DIAGRAY OF THE CONNECTIONS OF THE THALAMTS WITH THE ASCENDING FIBRES OF THE 5̃TH NERVE, AYD OF THE CPPER FILLET ON THE ONE HAXD, AXD WITH THE CORTEX CEREBRI OX THE OTHER. (Cajal.)

A, B, C, D, E, rarious nuclei in thalamus; I, afferent fibres passing to mammillary body F; G, tract of upper fillet ending in A (at $c$ ), and giring collaterals to D (posterior nucleus); 11 , central tract from sensory nucleus of 5 th ; T, cortex cerel,ri ; V, visual cortex; $R$, anterior colliculus; $J$, optic chiisma; $s$, optic fibres ; $K$, hippocampus.

$a$, fibres from cortex to thalamus, ending at $e ; b$, fibres from cells in thalarnus $(d)$ to cortex; $j$, fibres from lateral geniculate body and thalamus to risual cortex, ending at $g$ in stria of Gennari.

neurones, the second being formed by the neurones of the fillet and the first by the neurones of the sensory roots. On the other hand, the thalamus receires fibres from the cortex and from the corpus striatum, which end amongst its cells.

Attached to the optic thalamus below and behind are the two geniculate bodies (fig. 470) which at first sight appear to be both connected with the optic tract, although only the outer one actually receives optic fibres. The inner or mesial geniculate body receives fibres from the central auditory tract through the lateral fillet. Of 
the geniculate horlies the outer or lateral has a lamellated structure consisting of alternating layers of grey and white matter, the white liners being composed partly of the entering optic fibres and partly of tilnes emerging from the grey matter and passing to the central optic path, while the grey sulstance contains very numerous nerve-cellsanongst

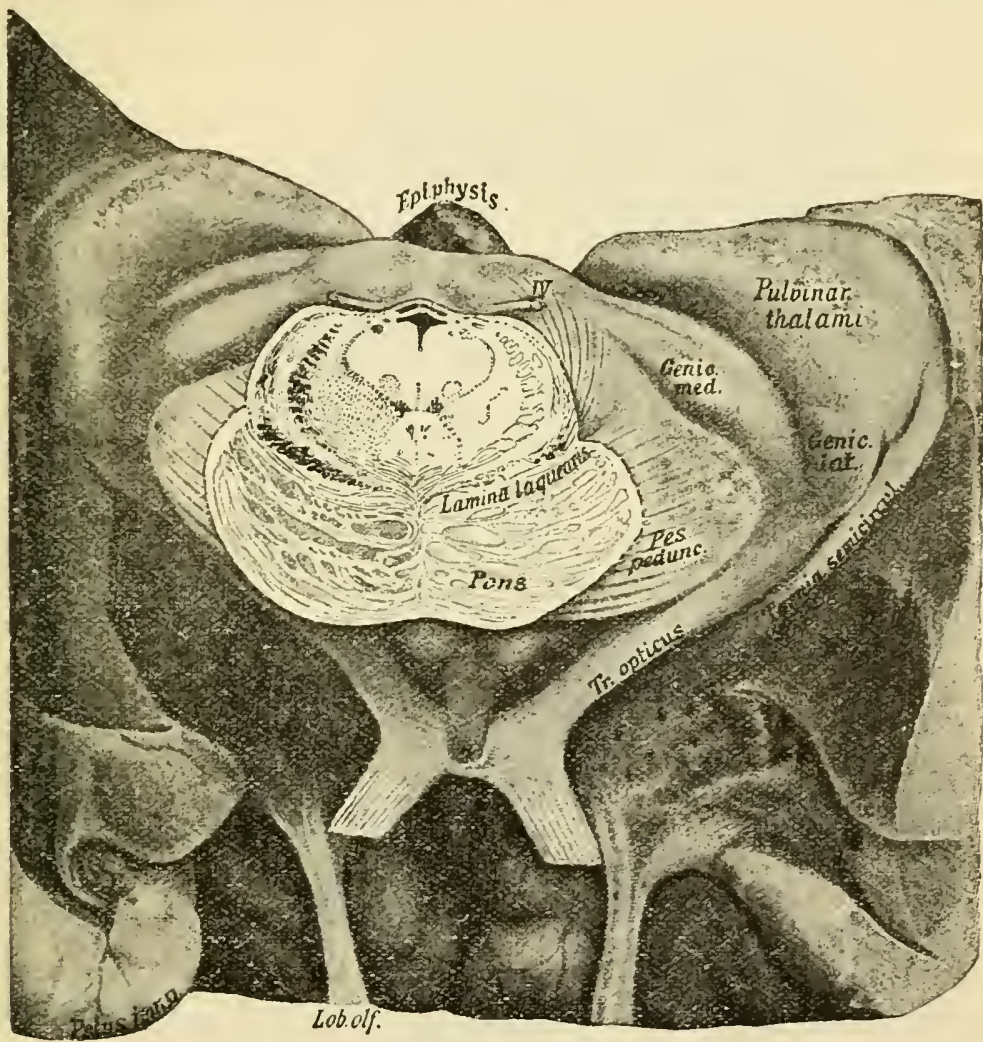

Flg, 470.-FIGURE SHOWING THE OLFACTORY TRACTS AND THEIR ROOTS: THE OPTIC CHIASUA ANI) OPTIC TRACTS: THE GENICULATE BODIEA ANI) THE PULVINAR THALAM. (Edinger.)

The pons is cut through at the anterior part, and the section shows the Sylvian aqueduct, the fillet (laminn laquearis), superior cerebellar peduncles, etc. (see fig. 459). The corpora mammillaria are partly concealed by the pous; between and in front of them is seen the infundibulum and pituitary body.

which the fibres of the optic tract end in complex arborisations. From these cells axons arise and join a bundle of fibres which enters the white matter of the hemisphere above and along with the internal capsule, and passes to the visual area of the cortex (central risual tract) Some of the fibres from the corpus geniculatum externum, as they enter the visual tract, send branches downwards towards the tegmentum. 
The ganglion of the habenula (fig. $47^{\circ}, g^{\prime}$ ) is a small collection of nerve-cells, which lies at the posterior part of the thalamus on each side, near the roof of the third ventricle. This ganglion receives on the one hand the fibres of the habenula or stria medullaris, and on the other hand gives off from its cells the fibres which form the fusciculus retroflexus (fig. 496), which pass downwards to the interpeduncular ganglion (p. 405). The two ganglia of the habenulæ are joined by a white commissure.

The corpora mammillaria (fig. 470) are seen at the base of the brain immediately below the posterior part of the third ventricle. Each is

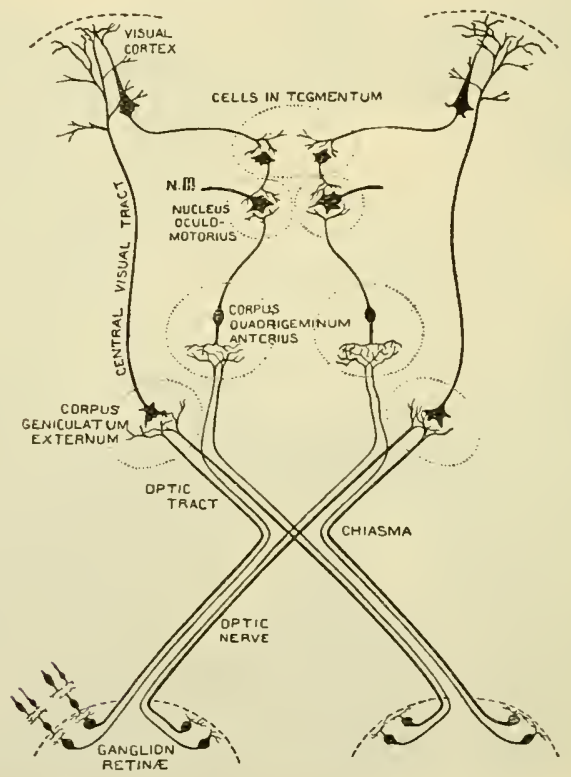

Fig. 471.-Diagram to show the probable coUrse AND ReLations of THE OPTIC FIBRES. ${ }^{1}$

composed of white matter externally and grey matter internally. It receives fibres from the anterior pillar of the fornix of the same side; these fibres arise from cells in the hippocampus and end in the mammillary body. According to Edinger some fibres from the olfactory tract pass directly to it. The axons of its cells bifurcate, one branch, the coarser, passing into the anterior and upper part of the thalamus in

${ }^{1}$ Only single fibres are shown emerging from the anterior quadrigeminal and external geniculate bodies, continuing the course of the two fibres from corresponding points in the retinae. This is merely to simplify the diagram and is not iutended to imply that the retinal impressions are fused in those sitnations. 
the bundle of Vieq d'Azyr, and the other into the tegmentum of the mid-brain in v. Gudden's bundle. The corpora mammillaria form part of the eentrial olfictory apparatus (fig. 496).

Subthalamic region. - The tegmentum of the crus cercbri is prolonged helow the thalamus optieus, and between it and the internal

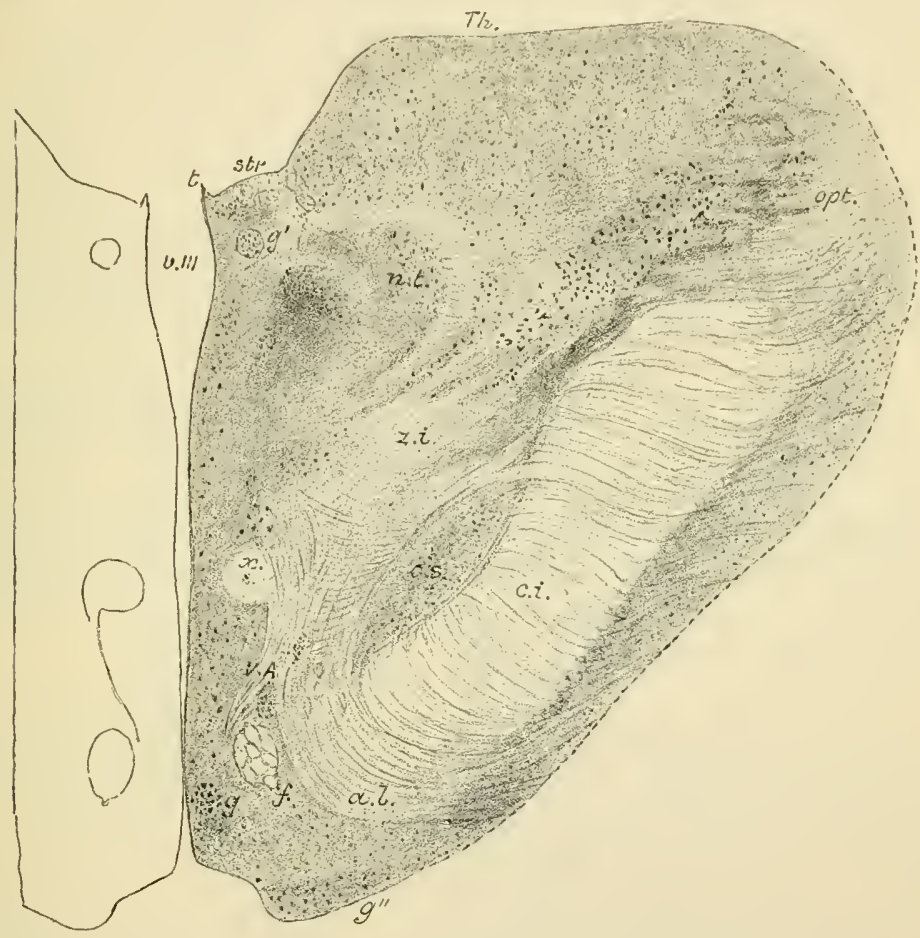

FIG. 472.-SECTION TAKEN OBLIQUELT THROUGH THE OPTIC THALAMUS AND INTERNAL CAPSULE SHOWING SOME OF THE STRANDS OF FIBRES OF THE SUBTHALAMUS. (Magnified 2! diameters.)

Th., thalamus ; viiii., third ventricle; $t$., tænia, or attachment of epithelial roof of ventricle; str., stria medulluris or habenula; $g^{\prime}$, ganglion of the habenula; n.t., mesial nucleus of thalamus; opt., optic fibres passing into pulvinar of thalamus ; $z i$, zonia incerta, from which fibies are seel emerging and sweeping as the ansit lenticularis, a.l., round the internal capsule, c.i., to pass towards the lenticular nucleus; c.s., corpus snbthalamicun ; $f_{0}$, anterior pillar of fornix passing backwards to corpus mammillare; V.A., bundle of Vicq d'Azyr, passing upwards and forwards from corpus rinammillare into thalamus ; $y$, group of nerve cells, probably belonging to the nucleus of the corpus mammillare; $x$, fasciculus retroflexus.

capsule, into a mass of grey substance, with longitudinally and obliquely erossing white bundles, which is known under the name of sulthalamus (fig. 472). Its deepest part contains a lens shaped mass of grey matter prolonged forwards from the substantia nigra, known as the corpus subthalamicum (Luys). A mass of fibres sweeps round this 
and round the internal capsule passing between the thalamus and the nuclens lenticularis, this is known as the anso lenticularis.

The pineal gland or epiphysis cerelri (fig. 461), which is developed in the roof of the third ventricle, but passes backward between the anterior corpora quadrigemina, is composed of a number of tubes and saccules lined and sometimes almost filled with epithelium, and containing deposits of earthy salts (brain sand). (Similar deposits may also oceur in other parts of the brain, especially in the pia-mater.) The follicles are separated from one another by vaseular connective tissne derived from the pia-mater, and along with the vessels are numerous nerve-fibres of sympathetic type (Cajal). No true nervecells can be seen, although there are a number of cells similar in general appearance to the "granules" of the cerebellum, but apparently without axons. In some animals (ox) striater muscular filbres have been met with.

In the chanieleon and some other reptiles, the pineal is better developed, and is connected by nerve-fibres with a rudimentary median eye of invertebrate type, placed upon the upper surface of the head.

The pituitary body or gland (hypoplysis cerebri) is connected with the third ventricle by the infundibulum. It consists of two lobes, a large anterior and a smaller posterior. The structure of the pituitary body has already been described (p. 224). 


\section{LESTONS XLIV. AND XLY.}

STRLCTERE OF THE CEREBELLUM ATU CERETRLY.

1. SEctoss of the cerehellum vertical to the surface, $(\alpha)$ across the rlirection of the laminie, (b) parallel with the lamina.

2. Sections across the whole of one hemisphere of the cerebrum of a monkey passing through the third ventricle.

3. Tertical sections of the cerebral cortex:-one across the ascending frontal and ascending parietal syri, another from the occipital lobe (calcarine region), another across the superior temporal gyrus and island of Peil, and one across the hippocampal gyrus and hippocanpus.

4. Transverse sections of the olfactory tract and bulb.

In all these preparations make sketches under a low power of the general arrangenent of the grey and white matter, and also of the nerve-cells in the grey matter. Sketch some of the details uniler a high power.

The preparations are made in the same way as those of the spinal cord. Other preparations shonld be made by the Golgi method to exhibit the relation of the cells to one another. Such preparations have been already partly studied (Lessons XVII. and XVIII).

\section{The Cerebelluy.}

The cerebellum is composed of a white centre, and of a grey cortex. Both extend into all the folds or laminæ, so that when the laminæe are cut across, an appearance is presented of a white arborescence covered superficially by grey matter. The white matter is in largest amount in the middle of each cerelsellar hemisphere. There is here present a peculiar wavy lamina of grey matter, similar to that in the olivary hody, and known as the nucleus dentutus (fig. $473, n . d$. .). This receives numerous nerve-fibres from the cells of Purkinje of the cortex, which end by arborising around its cells. The latter give oft axons which become the fibres of the superior cerebellar peduncles, and for the most part end in the opposite red nucleus, but some pass beyond this into the subthalamic region. The dentate nucleus also receives collaterals from fibres of the inferior peduncle (Cajal).

Other isolated grey nuclei lie in the white matter of the middle lobe over the roof of the th rentricle and constitute collectively the nuclei of Stilling. The most important of these appears to lie the nuclens tecti (s. fastigii) (fig. 473). This receives many of the ascending fibres of the vestibular nerve (p. 385) and collaterals from the spino-cerebellar tracts, and gives origin to a lundle of fibres which crosses to the opposite side 
and descends in the mesial part of the restiform body to the reticular formation of the medulla oblongata (Risicn Russell).

The grey matter of the cerelellum appears essentially of similar structure throughout the whole extent of the cortex. It consists of two layers. The inner one (that next to the white centre) is composed of a large number of very small nerve-cells interningled with a few larger ones and some neuroglia-cells (grunule luyer, fig. $474, d$ ). The outer one is thicker, and is formed chiefly of fine nerve-fibres (fig. $476, A$ )

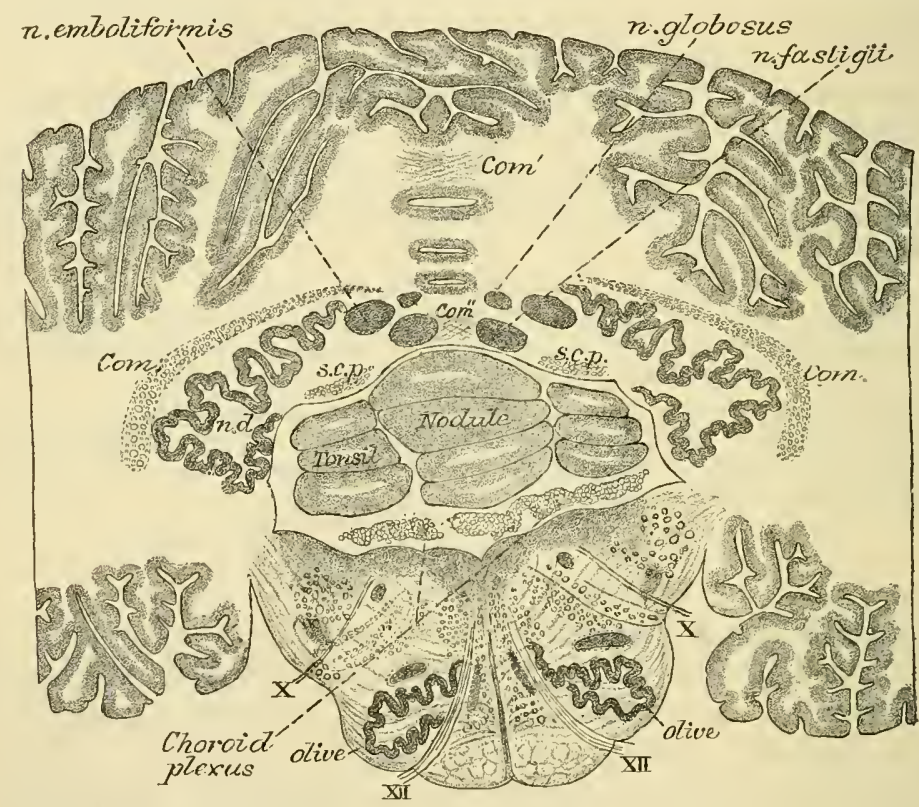

Fig. 473.-SECtion ACross the Cerebelluy aND MedUlla oblongata SHOWING THE POSITION OF THE NUCLEI IN THE WHITE CENTRE OF THE CEREBELLuM. (Stilling.)

n.d., nucleus dentatus cerebelli ; s.c.p., fibres of superior peduncle; com, com', $\mathrm{com}^{\prime \prime}$, commissural fibres; $X$, rootlet of vagus; $X I I$, rootlet of hypoglossal nerve.

with small nerve cells scattered through it (molecular layer, fig. $474, b$ ). Into its outer part processes of the pia-mater conveying blood-vessels pass vertically, and there are also in this part a number of long tapering neuroglia-cells, somewhat like the Müllerian fibres of the retina (fig. 479, $g l^{3}$. See also fig. 191, p. 161). Lying between the two layers of the grey matter is an incomplete stratum of large flask-shaped cells (fig. 474, c) (cells of Purlinje, fig. 475). Each of these gives off from its base a fine process (axon), which becomes the axiscylinder of one of the medullated fibres of the white centre, while from the opposite pole of the cell large ramified processes (dendrons) extend into the superficial layer of the grey matter. 
The dendrons of the eells of Purkinje spread out in planes transverse to the direction of the lamellae of the organ, so that they present a different appearance according to whether the section is taken across the lamella or along them (eompare figs. 476 and 477). These dendrons are invested at their attachment to the cell, and

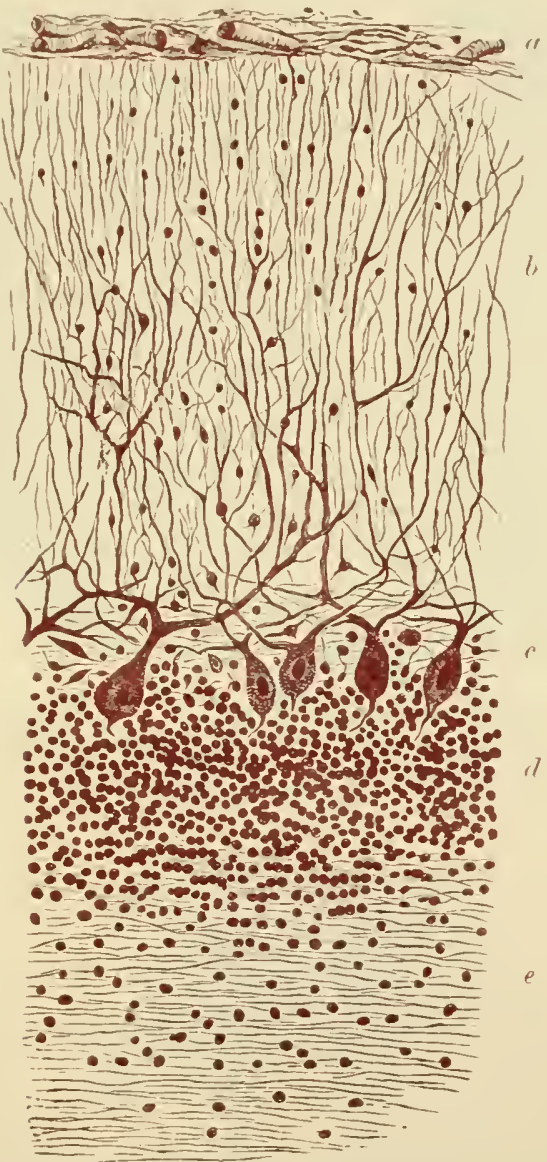

Fig. 474.-Section of Contex of cerebelium. (Sankey.)

$a$, pia.mater; $b$, external laye $r$; $c$, layer of corpuscles of Purkinje ; $d$, inner or granule lajer; $e$, medullarj centre.

for some extent along their branchings, by basket-works formed by the terminal arborisations of certain fibres (climbing or tendril fibres) of the medullary centre (fig. 479, cl.f.). The body of the cell of Purkinje is further invested by a felt-work of fibrils formed by the arborisation of axis-cylinder processes of nerve-cells (basket-cells) in the 
outer layer of the grey matter (figs. $478 ; 479, b$ ). Each cell has therefore a double investment of this nature, one covering the dendrons, the other the body of the cell and extending along the commencement of the axon.

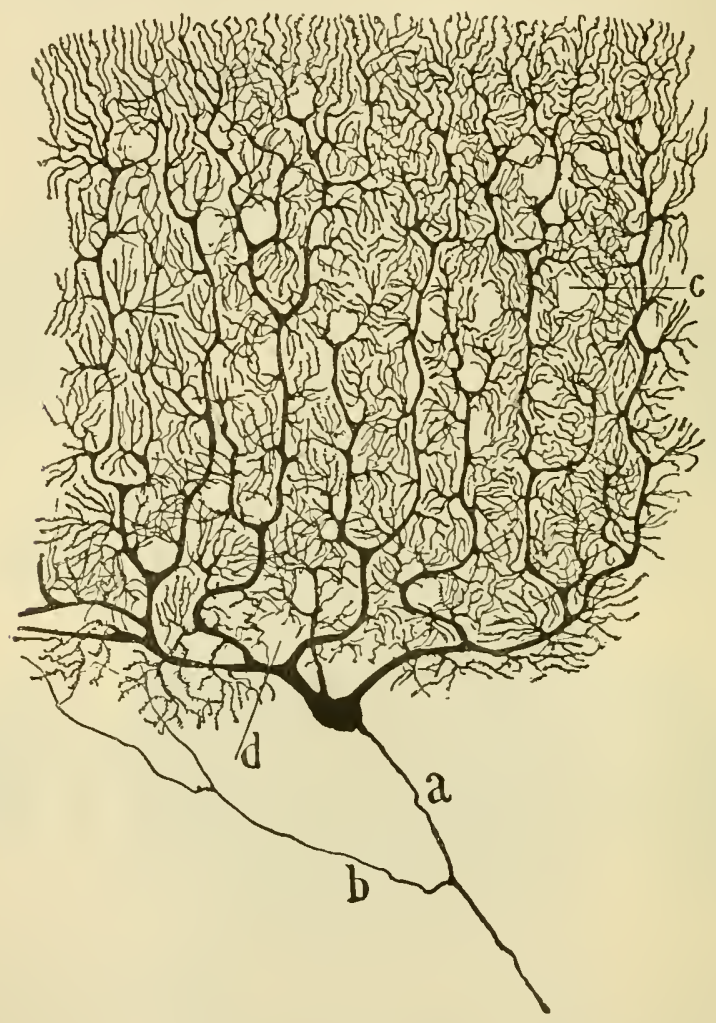

FIG. 475. - A CELL OF PCRKINJE OF 'THE CEREBLLLCM, SHOWN BY GOLGI'S METHOD. (Cajal.)

$u$, axon; $b$, collateral from axon; $c$, $d$, arborisation of dendrons.

The granules of the inner layer of grey matter are mostly small nerve-cells, each with a few dendrons penetrating amongst the other granules, and an axon which is directed between the cells of Purkinje into the outer layer. After penetrating a variable distance into this layer it bifurcates, and its two branches pass in opposite directions at right angles to the main stem, and parallel to the direction of the lamella (fig. 476). What ultimately becomes of the branches is not known. In sections cut across the lamella the cut ends of these fibres give a finely punctated appearance to the outer layer (fig. $4 \pi \tau$ ). 

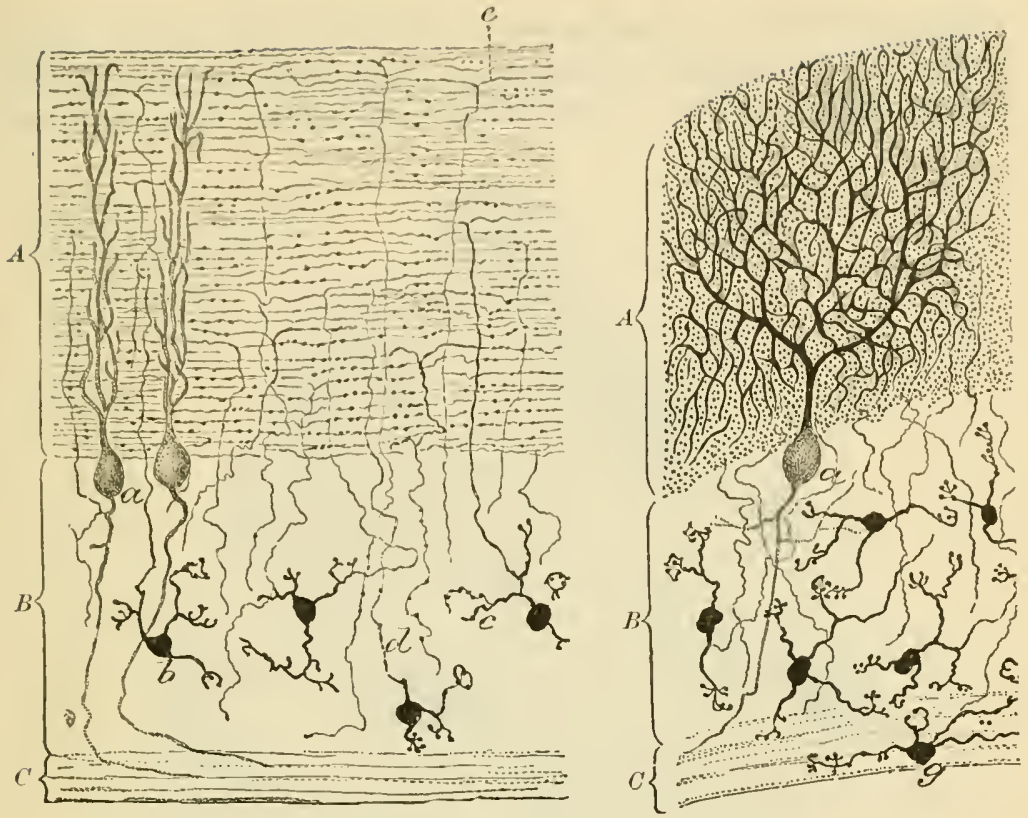

Figs. 476 AND 477.-SEctions of CORTEx CEREBELLI STAINED BY GOLGI's NETHOD. (Cajal.)

FIG. 4T6.-Section made in the direction of the lamina. FIG. 477.-Section taken across the lamina.

A onter or molecular layer; $B$, inner or granule layer; $C$, medullary centre,

$a$, corpuscles of Purkinje; $b$, small granules of jnuer layer; $c$, a protoplasmic process , corpuscles of Purkinje; $d$, nerve-fibre process of a granule passing into the molecular (dendron) of a granule; $d$, nerve-fibre process of a granule passing ig. $47 t$ these longi-

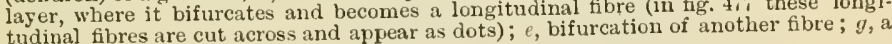
granule lying in the white rentre.

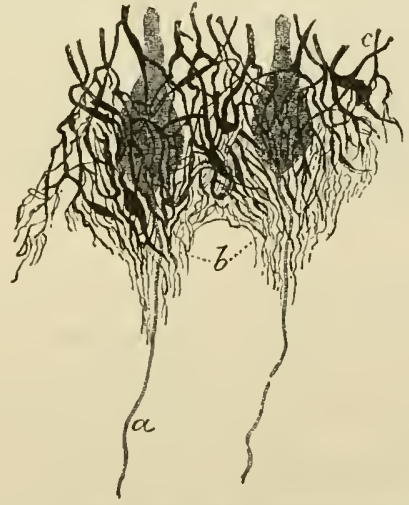

Fig. 478.-BASKET-WORK OF FIBRES AROUND TWO CELLS OF PURKINJE.

(Cajal.)

$a$ axis-cylinder or nerve-fibre process of one of the corpuscles of Purkinje; $b$, fibres prolonged over the beginning of the axis-cylinder process; $c$, branches of the nervefrolonged over the cells of the molecular layer, felted together around the bodies of the corpuscles of Purkinje. 
Some of the cells of the granule layer are far larger than the others, and send their much-branching axons amongst the smaller granules (cells of Golgi, fig. 479, G). Besides these, other large "granules" have

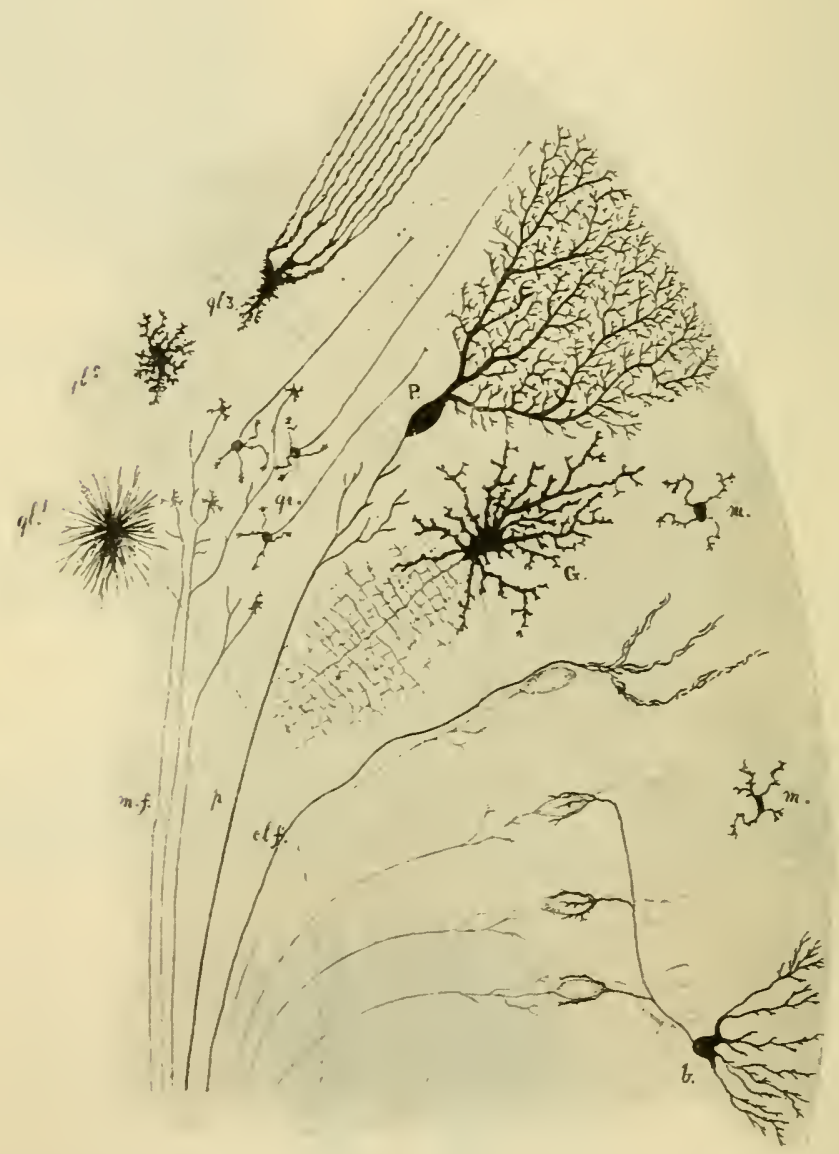

Fig. 479.-Diagrajatic SEctios of CEREBELLCy TO SHOW THE CHARACTERS AXD RELATIONS OF THE CELLS AND FIBRES MET WITH IX THE SEVERAL LAYERS AS EXHIBITEN BY THE CHROMATE OF SILver METHOD. (After Kölliker.)

$P$, a cell of Purkinje ; $G$, a cell of Golgi ; $b$, a basket-cell ; $m$, $m$, other cells of the molecular laver; $g r$, granules; $p$, a nerre-fibre of the white substance derived from a Purkinje cell; $m_{.} j_{.}$" moss"-fibres; $c l, f_{.}$, a climbing fibre; $g l^{2}, g l^{2}, g l^{3}$, types of neuroglia-cells.

been noticed by Cajal, occurring both in the granule layer and in the white centre, with long axons passing into the white matter of the cerebellum. These are, however, only rarely met with.

Ramifying amongst the cells of the granule layer are peculiar fibres derived from the white centre, and characterised by having pencils of 
fine short branches at intervals like tufts of moss (fig. $479, \mathrm{mf}$ ). These have been termed by Cajal the moss-fibres; they eul partly in the granule layer. partly in the molecular lisyer.

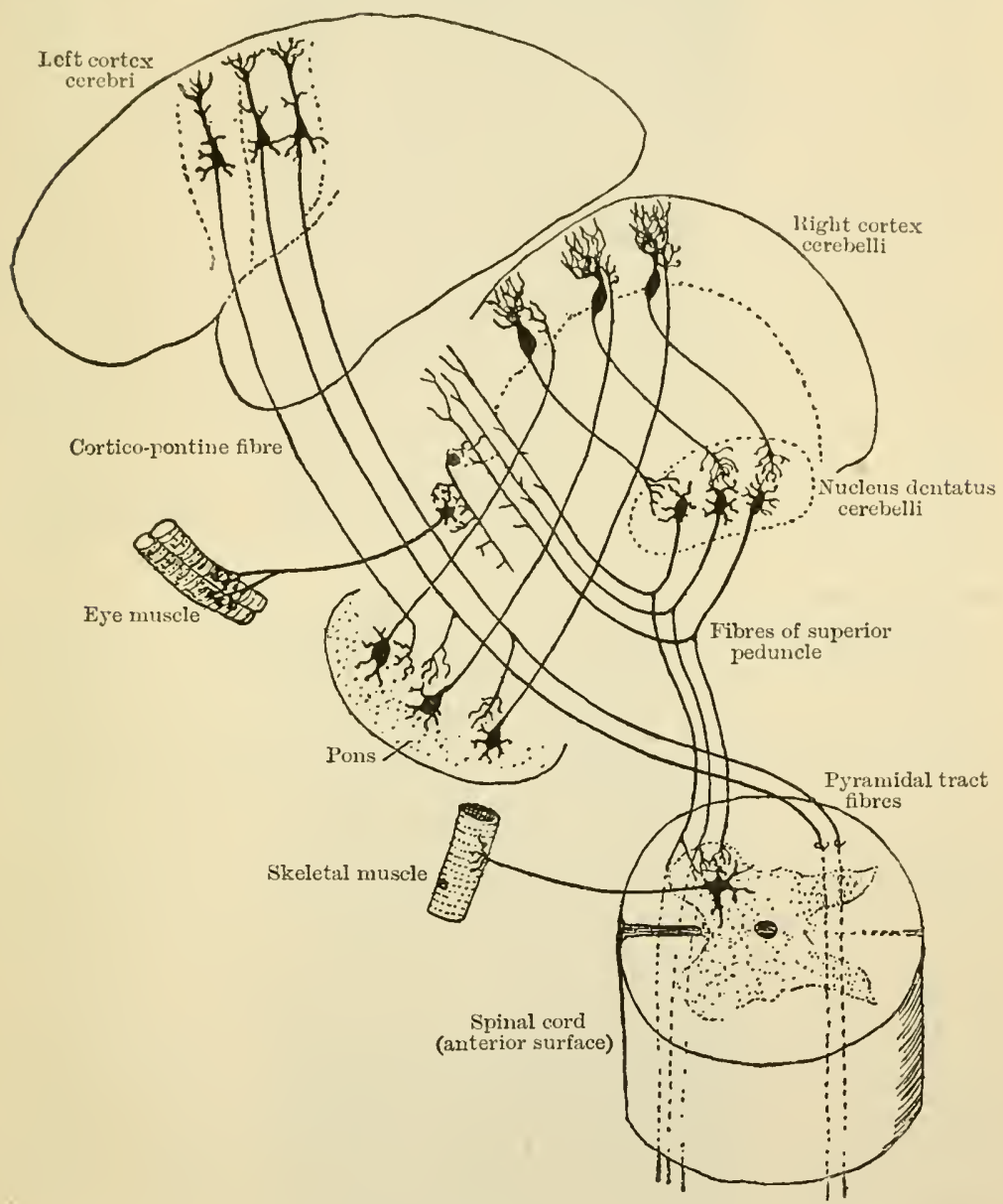

Fig. 480.-DiAgRAM OF THE CONNECTIONS OF THE CEREBELLUM THROUGH ITS PEDUNCles. (Cajal.)

The neuroglia of the cerebellum is peculiar in containing, besides the ordinary branched and unbranched neuroglia cells (fig. 479, $g l^{1}, g l^{2}$ ), cells which possess long parallel processes which extend through the molecular layer to be attached to the surface of the lamellæ $\left(g l^{3}\right)$. (See also fig. 191.) The cell-bodies of these lie at about the same level as those of Purkinje's cells. 
The peduncles of the cerebellum have been already studied in connection with the merlulla oblongata, pons, and mid-brain. The inferior peluncle (restiform body) is composed of ascending fibres derived from the dorsal spino-cerebellar tract, from both olivary nuclei-but chiefly from that of the opposite side; perhaps also from the nuclei of the gracile and cuneate funiculi, from cells and nuclei of the reticular formation of the medulla oblongata and from the sensory nuclei of the cranial nerves, especially of the vestibular nerve. The fibres of the spino-cerebellar tract occupy the outer part of the pedincle. Most of the fibres of the inferior peduncle pass to the vermis, crossing to the opposite side over the fourth ventricle, but before doing so they give off strong collaterals to the hemisphere of the same side. The inferior peduncle also contains a small bundle of fibres descending from the nucleus tecti of the opposite side to the medulla oblongata (Risien Russell) which bends round the superior peduncle to join the inferior peduncle, its fibres lying between those of the superior peduncle and Gowers' bundle. The inferior peduncle contains a very small nucleus of grey matter (Déjerine) which is almost completely concealed amongst the mass of white fibres.

The middle peduncle is formed of fibres from the cells of the nuclei pontis which are passing to the opposite hemisphere of the cerebellum.

The superior peduncle is formed of fibres which mostly take origin in the corpus dentatun cerebelli, but some are said to arise in the hemisphere and pass through this. The superior peduncles decussate in the mid-brain across the raphe, and their fibres then bifurcate into ascending and descending branches. The ascending branches pass forwards and end in the red nucleus, but some filres go past this into the ventral part of the thalamus. The descending branches are traceable into the dorsal part of the reticular formation of the pons. According to Cajal they are connected with the motor nuclei of the pons, medulla oblongata, and spinal cord (fig. 480). The superior peduncle, as it issues from the hemisphere, is joined by the bundle of Gowers, which runs over it, and passes backwards along its mesial border to the vermis.

\section{STRUCTURE OF THE CEREBRUM.}

The grey matter of the cerebral cortex is described as if-composed of a number of layers, but they are not sharply marked off from one another, and they vary in relative development in different regions of the cortex. The cells are for the most part of a pyramidal shape (fig. 481). The following layers are generally distinguishable, but in some parts of the cortex a larger number can be made out: 
1. A peripheral stratum (moleculur or plexiform layer, figs. 481, 48:-1) contitining seattered nerve-cells and many nemroclia-cells. In the most

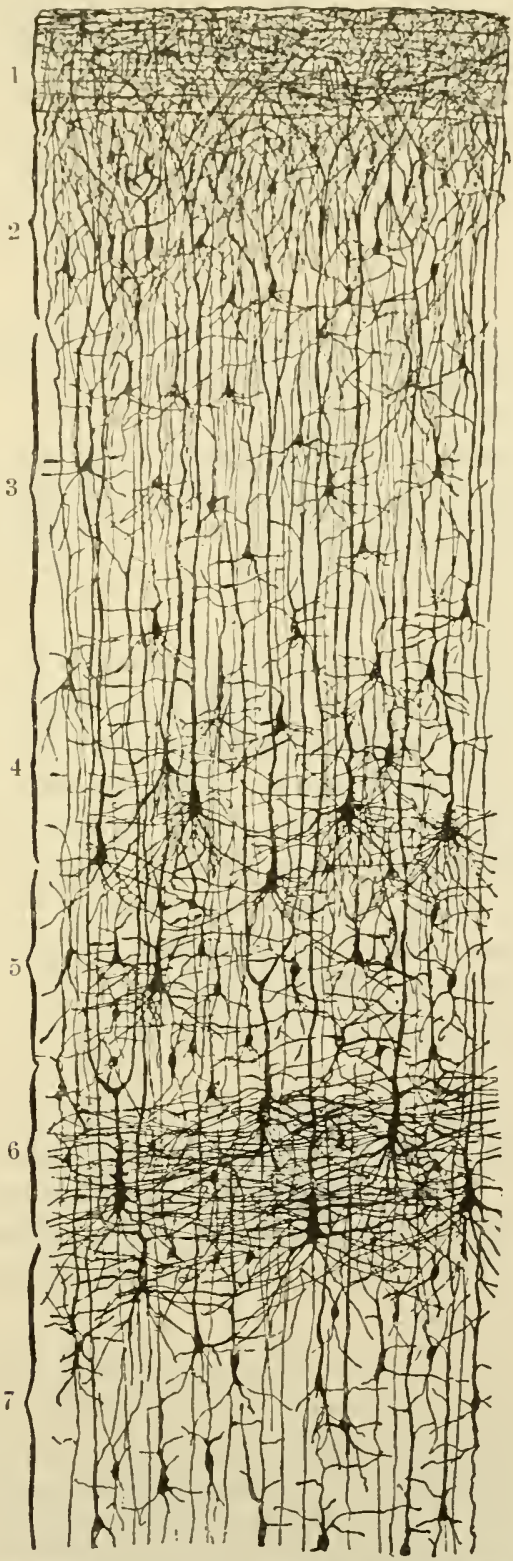

Fig. 481.-Ascexdixg parietal contolttion, golgi jethon. (Cajal.)

1, plexiform layer; 2 , small pyramids; 3 , medium pyramids; 4 , superficial large pyramids ; 5 , granules; 6 , deep large pyramids; $; 7$, deep medium pyramids. 
superficial part of this layer, immediately. under the pia-mater, is a thin stratum of medullated nerve-fibres, and besides these the layer contains a large number of fibres, many of which are ramified. They are largely derived from the rleeper nerve-cells of the cortex. Intermingled with these fibres are a certain number of ramified nerve-cells, which have several long horizontally disposed dendrons and a long axon, all of which terminate by arborisation within the superficial layer (horizontal cells of C'ujal) (fig. 48\%). Besides these, others of a somewhat similar character but with short axis-cylinder processes occur in this layer.

2. A layer of closely set small pyramidal nerve-cells, several deep (luyer of small pyramills, fig. 481, 2). This layer also contains other kinds of cells (fig. 491, F, F, G).

3. A layer of medium-sized pyramidal cells less closely set, with small granule-like cells amongst them (layer of medium-sized pyramids, fig. 481,3 ; fig. $491, \mathrm{~J}, \mathrm{H}, \mathrm{k})$.

4. A layer of larger pyramidal cells (superficial large pyramids, fig. 481,4$)$.

5. A layer of small irregnlar cells (small stellate cells, fig. 481, 5). The large pyramids may extend down into this layer.

6. A layer of still larger pyramids (deep large pyramids, fig. 481,6). In the motor region of the cortex, which in man is confiner to the ascending frontal gyrus and paracentral lobule, pyramidal cells of very large size (giant cells) oceur, and are disposed in small clusters or "nests" (Betz, Bevan Lewis). The fibres of the pyramidal tract arise from these giant cells. In some parts of the cortex this layer is absent or is blended with the next layer.

7. A layer of medium-sized pyramidal cells (deep medium pyramids, fig. 481,7$)$.

8. A layer of small scattered cells, many of a fusiform shape (polymorphous layer). This layer lies next to the white centre. In the island of Reil it is considerably developed, and is separated from the rest of the grey matter by a layer of white substance. It is here known as the claustrum, and on that account the layer is sometimes termed the claustral layer.

Some authorities describe the cortex as consisting only of three layers, viz. : the molecular layer, the layer of pyramids, and the layer of polymorplous cells; others of four, five, etc., up to nine. As a matter of fact, the complexity and the number of distinct layers vary in different regions. The pyramidal cells of the cortex are so termed from the shape of the cell-body, which usually gives off several dendrons from the base of the pyramid and one large dendron from its apex. This process extends to the plexiform layer, on approaching which it breaks up into nunerous ramifications which have a general vertical direction and extend almost to the outer surface. 


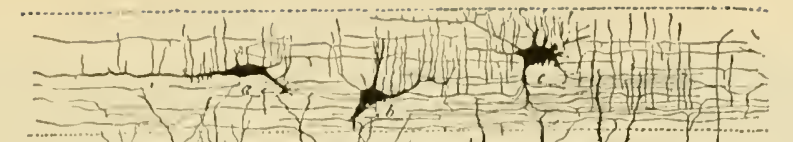

2

3

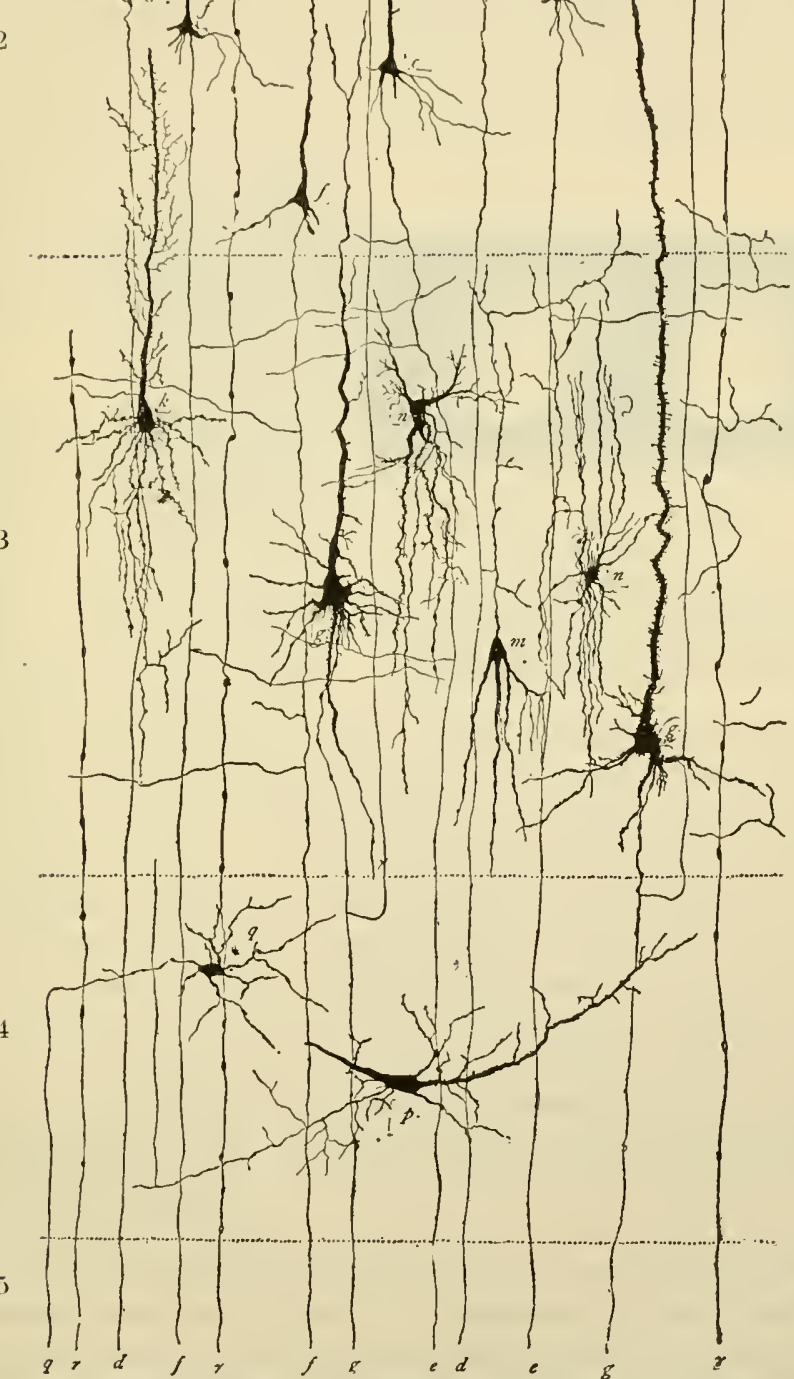

Fig. 482.-Diagram showing the relations of some of the cells in the CEREBRAL CORTEX. (Barker, after Starr, Strong and Leaming.)

1 , plexiform layer with cells of Cajal; 2 , small $(d, e)$ and middle sized $(f)$ pyramids; 3 , large pyramids $(g, g, k)$; also, $m$, cell with axon passing towards the surface, but soun ramifying; $n, n$, cell of Golgi's second type, with axon ramifying in the adjacent grey matter: one of these belongs to the kind termed by Cajal "double-brush" cells; 4 polymorphous cells, of which $p$ ends its axon towards the surface and $q$ its axon into the medullary centre, 5 , which contains also the axons of the pyramids ; $r, r$, afferent fibres, ending in the cortex. 
This apical dendron is beset, both in its undividert part and in its branches, by minute spinous projections (as seen in specimens prepared by the Golgi method). These projections are believerl by some authors to be retractile (amceboirl) and to be the means of effecting (or breaking) nervons conmection with afferent fibres; since they are in some preparations prominent, in others hardly visible; or the dendrons are entirely free from them, and have an even ontline or may be slightly monilifolm. All the pyramidal cells liave a single axon, which is usually directed towards the medullary centre, of which it forms one of the fibres ; but the axon sometimes curves back and passes outwards again, ending in arborisations in one of the other layers. Intermingled with the pyramids and polynorphons cells are two other kinds of cells, viz. : (1) cells with axis-cylinder process ramifying near the cell-body; these occur in all the layers (fig. $491)$, and (2) small cells sending

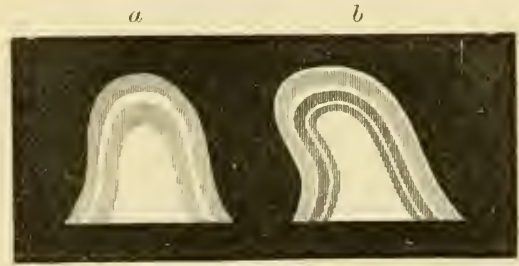

Fig. 483. - Sections OF CEREBRAL CONrolutioss. (After Baillarger.)

(Natural size.)

$a$, from the neighbourhood of the calcarine fissure with only one white line clearly visible (the line of Gennari); $b$, ordinary type, with the superficial white layer and outer and inner lines of Baillarger shown. their axoms towards the plexiform laver (Martinotti), these are found cliiefly in the deeper layers of the cortex.

From the white centre bundles of medullated nerve-fibres pass in rertical streaks through the deeper layers of the grey matter, to lose themselves amongst the pyramidal cells of the more superficial layers (figs. 487, 490). Many large fibres however are seen running not vertically but obliquely into the grey centre from the white matter. Most of the vertically clisposed fibres are the nerve-fibre processes of the pyramidal and polymorphous cells, and therefore take origin in the cortex; others, including the oblique fibres just mentioned, are passing into the cortex, probably from the thalamus, to end amongst the cells of the several layers in free arborisations (fig. 484).

Besides these vertical strands of fibres there are others which lie in planes parallel to the surface of the cortex, and which are derived partly from the fibres which enter the cortex from the white matter, partly from the collaterals which are given off from the axis-cylinder processes of the cortical cells themselves. The planes in which these fibres occur are (1) near the surface in the plexiform (molecular) layer: this superficial stratum of white fibres is best marked in the hippocampal region; (2) in the layer of medium-sized pyramids : here the fibres give the appearance of a whitish line in the section of the grey matter (outer line of Baillarger, fig. $483 \mathrm{~b}$ ). There is a particularly dense plexus of fibres in this situation in certain regions of the cortex, especially the oceipital lobe (in man in the convolutions bounding the calcarine fissure), producing a very distinct line, here known as the line of Gennuri (fig. $483, a$ ). This plexus of nerve-fibres is in intimate associa- 
tion withịcertain large and small stellate cells which are characteristic of the visual region. (3) In most regions of the hrain, in the plane of the laver of large pyramids, another white line is seen; this is known as the inner lime of buillarger. The planes in which these white lines are foumd are characterised especially in the occipital and temporal lobes, by the presence, amongst the pyramids, of great numbers of

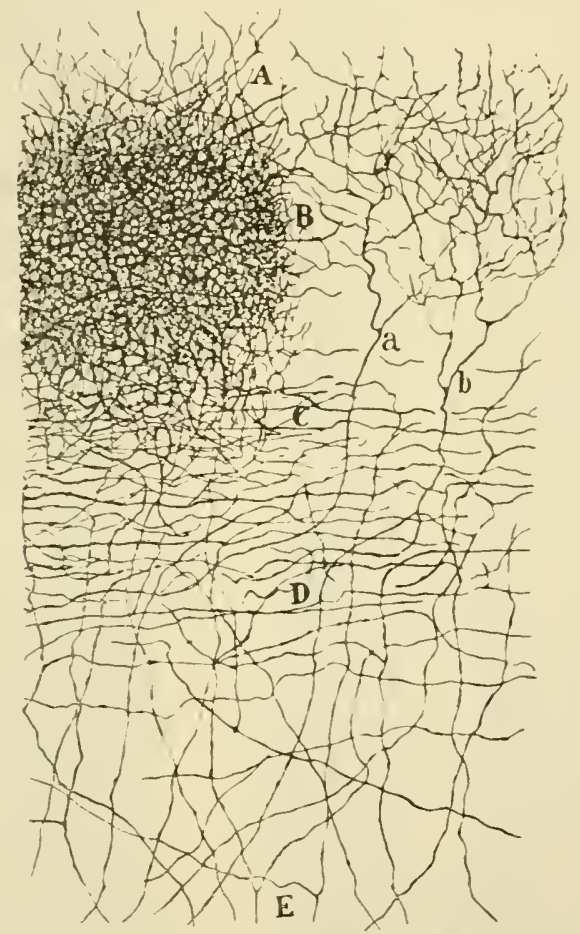

Flg. 484.--PReparatiox showisg soME OF THE AFFERENT FIBRES OF THE ASCEXING FRONTAL GTRES-HCMAN. (Cajal.)

$A$, part of second layer; $B$, layer of medium-sized pyramids with close terminal plexus; $C^{\prime}$ to $D$, intermediate plexus of horizontal fibres; $E$, deep plexus of large oblique afferent fibres ; $a, b$, afferent fibres arborising in the layer of middle pyramids, amongst which they form, along with fibres derived from cells in the cortex itself, the dense jlexus which is shown in the left half of the figure. The efferent fibres are not shown in this figure.

small nerve-cells, amongst which the white fibres of the layers ramify and probably terminate.

The axis-eylinder processes of the pyramidal cells pass into the white centre. Here some of them are continned into the corpus callosum, and through this to the cortex of the opposite hemisphere (commissural fibres); others form as:aciation-filres which eventually pass again into the grey matter of other parts of the same hemisphere; 


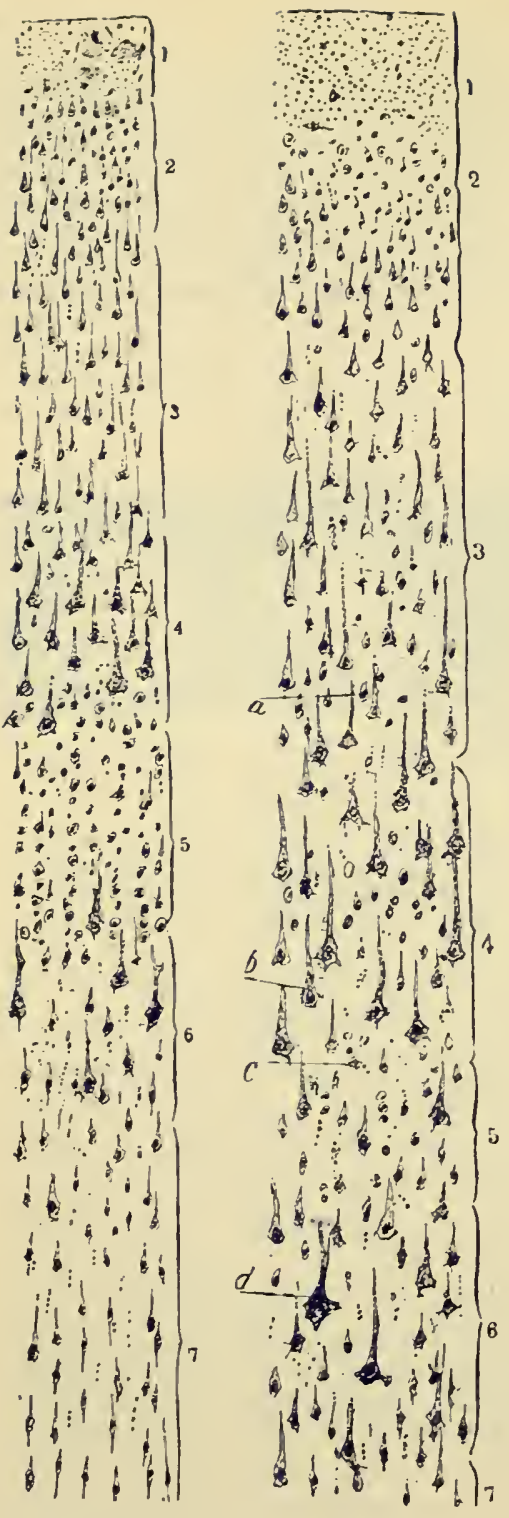

FIG. 486.

FIG, 485 ,

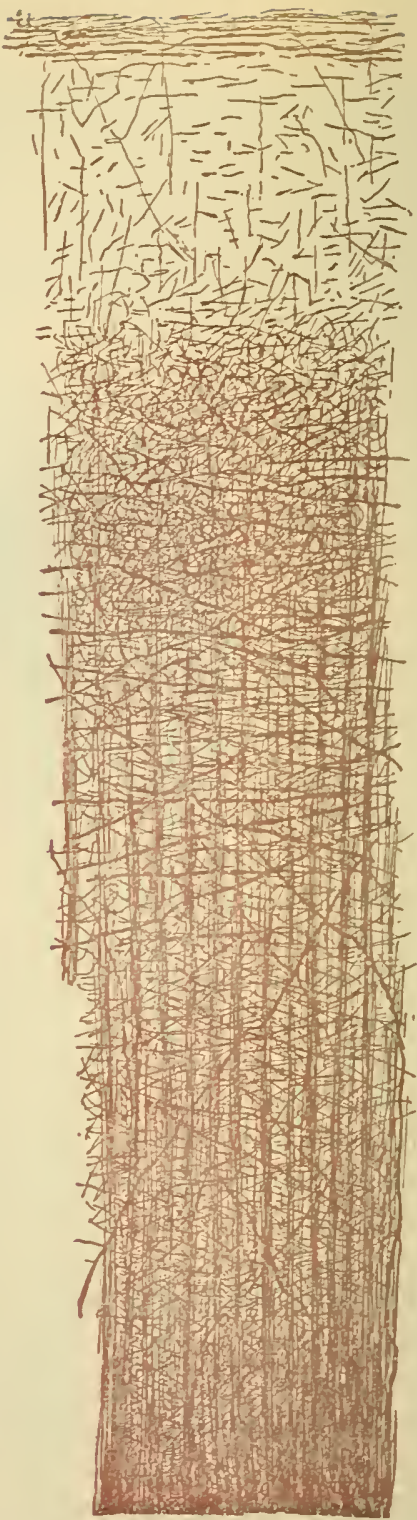

FIG. 457.

ASCEYDING PARIETAL GYRLS OF MAN, STAINED BY Nissl's MethoD. (Cajal.)

1, plexiform layer; 2, small pyramids; 3, mediurn pyramids; 4, superficial large pyramids; 5 , small stellate cells (granules); 6 , deep large and medium pyramids ; 7 , fusiform cells.

Fig, 486.-SECTION OF ASCENDINg FRONTAL GYRLS (MOTOR CORTEx), STAINED BY Nisslis HeTHOU. (Cajal.)

1 to 6 as before; $a, c$, small cells amongst the pyramids; $b$, a large pyramid; $d$, a giant cell of Betz.

Fig. 48\%,-SECTION OF ONE OF THE HOTOR CONTOLCTIONS (MAN), STAINED BT WIEIGRT'S METHOD. (Cajal.) 


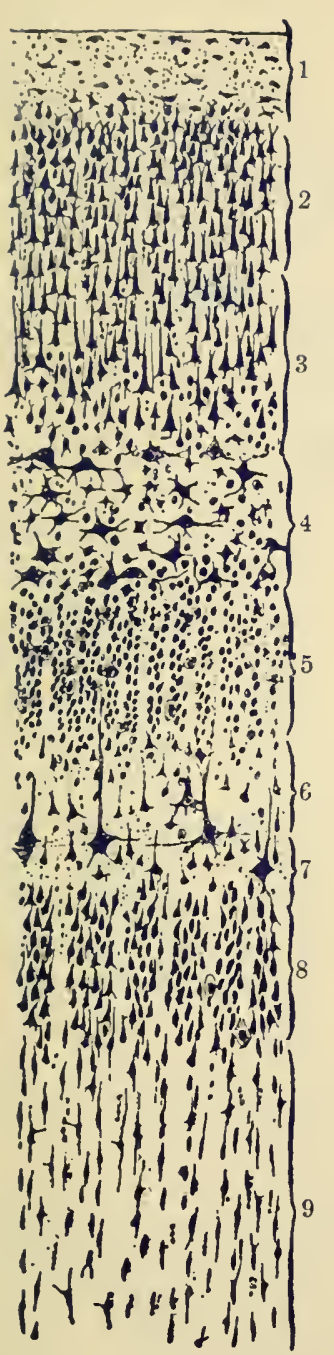

FIG. 488.

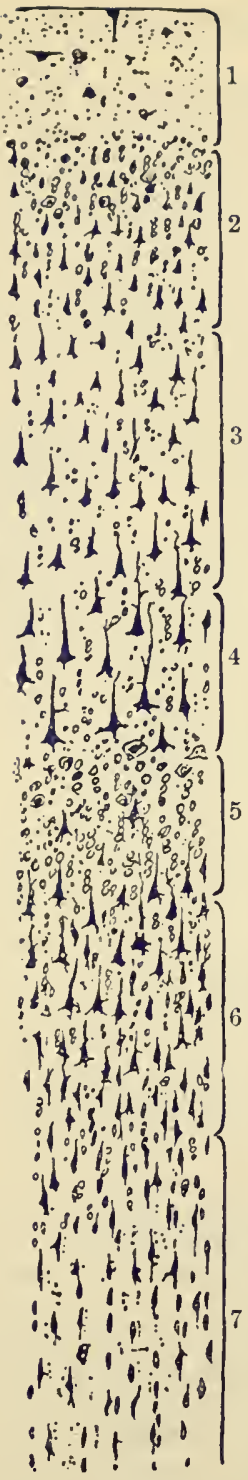

FIG. 489.

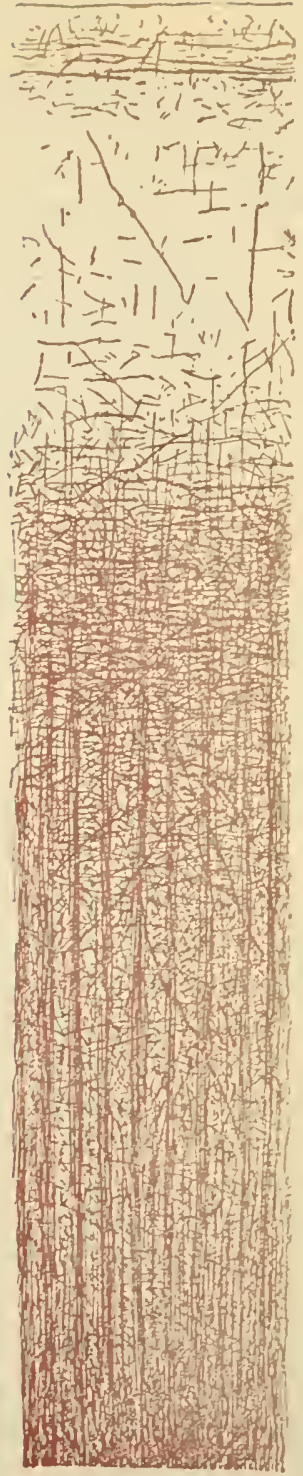

FIG. 490.

Fig. 488. - Calcakine (VIstal) Cortex of MaN. (Cajal.) Nissl's method.

1, plexiform layer; 2, small pyramids; 3 , medium pyramids; 4, large stellate cells (characteristic of this part of the cortex); 5 , small stellate cells; 6 , a deep plexiform layer, containing some small pyramids; $\pi$, large pyramids; 8 , layer of small and melium pyramids with bent ascending axons; !, fusiform cells.

Fig. 489. - SECTION OF FiRst TEMPORAL GYRCS (ACOLSTIC CORTEX OF MAN), STAINED BI Nissl's Method, (Cajal.)

1, plexiform layer; 2, layer of small pyramids ; 3 , superficial medium pyramids; 4, large pyramids ; 5 , small stellate cells (granules); 6 , deep medium pyramids ; 7 , fusiform cells.

FiG. 490.-SECTION OF THE FIRST TEMPORAL GYRL' (MAN), STAINED BY WEIGERT'S METHOD. (Cajal.) 
whilst others again, especially those of the largest pyramidal eells, extend downwards through the corona radiata and internal capsule. These include the projection-fibres of the pyramidal tract and of the cortico-pontine tract. As the projection fibres pass through the grey and white matter of the hemisphere they give off collateral fibres to the arjacent grey matter, to the corpus callosum, and to the corpus striatum and optic thalamus, and some probably end in these masses of grey matter. Aecording to Cajal, in the brain of man as compared with the lower mammals, there is a marked preponderance of cells of Golgi's type II. (with short axis-eylinder ramifying near the cell body). Such cells are most numerous in the layer of stellate cells and in the layer of snall pyramids.

Special features of certain parts of the cortex.-There is, as already staterl, a great amount of variation met with in the relative extent of development of the above layers. This is exemplified in the aecompanying drawings by Cajal (figs. 485 to 488 ) of eertain convolutions in the human brain. From these it will be seen that smaller-sized cells prevail in some regions of the cortex (occipital, temporal); larger and fewer eells in others (frontal, parietal, limbic). Nests or gronps of very large "giant" cells are characteristie of the "motor" region (ascending frontal gyrus and paracentral lobule in man and anthropoid apes); these cells give origin to the fibres of the pyramidal tract, and undergo Nissl degeneration when these fibres are severed. The oecipital region (in man, the neighbourhood of the ealcarine fissure) is especially characterised by the great numbers of small stellate cells and hy the presence in the layer superficial to them of a stratum of very large stellate cells with long spreading dendrons (fig. 488, 4): amongst these stellate cells (small and large) the optic fibres from the lateral geniculate bodies ramify. A preponderanee of small stellate cells is also seen, but to a less extent, in sections of the temporal lobe: to a still less extent in the prefrontal and parietal regions. The first temporal gyrus is eharacterised by the presence in nearly all the layers, but especially the deepest, of special large cells with widely-spreading dendrons and an axon passing towards the white substance but giving off many collaterals in the grey matter. There are also very many cells of Golgi's type II. with axis cylinder ramifying in a most complex manner near the cell-body, mainly in a plane vertical to the surface. The cortex of the insula has special cells similar to those in the first temporal gyrus, and is further characterised by the peenliar spindle-shape of many of the large pyramids.

The size and number of the medullated fibres vary in different 
regions. In some they are large and mumerous (motor part of ascending frontal, calcarine area, hippocampal area), in others fine and much less conspicuous (gyrus fornicatus, temporal area, parietal area, prefrontal area, insula and lobus pyriformis), whilst in intermediate condition

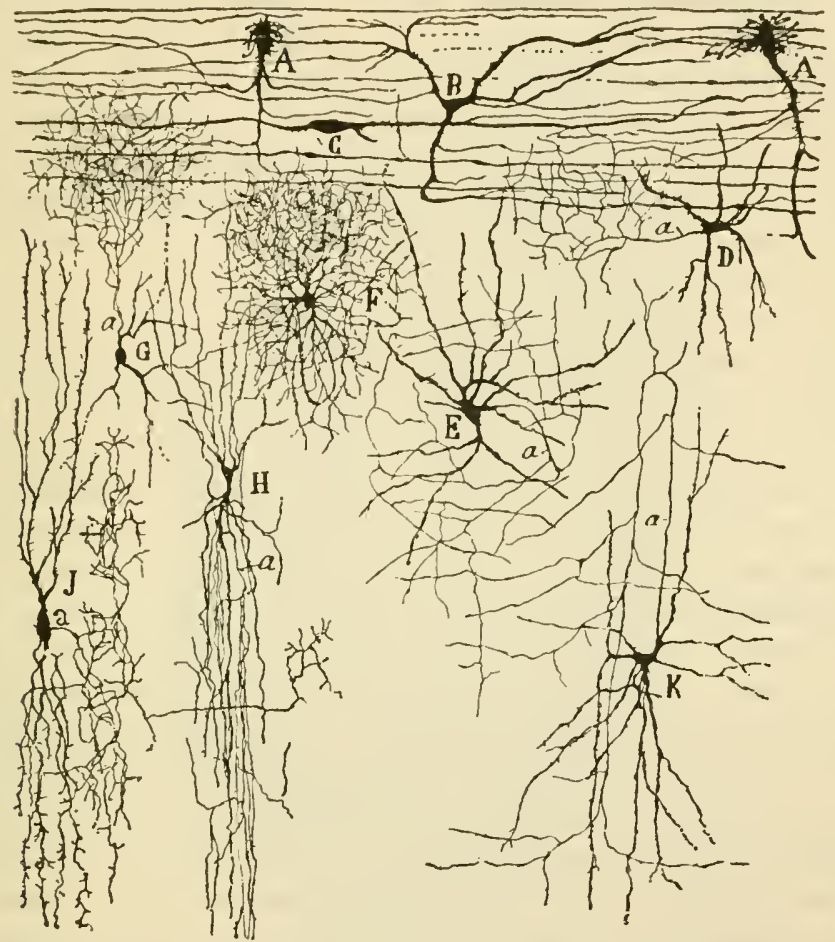

Fig. 491.-Superficial layers of motor cortex of Child, Golgt Methol, (Cajal.)

A, B, C, cells of Cajal in plexiform layer; D to K, cells of type ii. of Golgi (with axous ramifying near cell-body); H, J, "double-brush" types of cell.

presents itself in the occipital area (except the calcarine region), the transverse temporal gyri and superior temporal gyrus, the part of the frontal immediately in front of the motor region and the ascending frontal. These differences have been employed by Campbell in attempting to differentiate the functions of the various cerebral regions by a comparison of their structure.

\section{THE RHINENCEPHALON.}

The rhinencephalon (olfactory region of the telencephalon), on account of the peculiarities of its structure, its importance in most animals, and the fact that it has been the part of the telencephalon to 
appear first in phylogenetic development (archipallium of Elliott-Smith) merits a special description, although in man and primates generally, and in some other (microsmatic) mammals, it is reduced to a comparatively rudimentary condition. On the other hand, in the so-called osmatic (macrosmatic) mammals there is a large hollow olfactory bulb forming the anterior termination of a thick olfactory lobe which broadens out behind, where it is continuous with the hippocampal gyrus and hippocampus. The whole forms a pyriform mass, which is separated from the rest of the cortex (neopallium) by a well-marked fissure-the limbic fissure - and has special connections through the anterior commissure and fornix with other parts of the brain on the same and on the opposite side.

In man the rhinencephalon consists anteriorly of the small olfactory bulb from which the thin olfactory tract extends backwards to the grey matter at the base of the brain and to the hippocampal region. Posteriorly the cortex of the rhinencephalon is doubled in so as to form a projection, the hippocumpus mujor, into the descending cornu of the lateral ventricle: its edge here thins off and is continned merely as an epithelial covering to the choroid plexus of the pia-mater, which is invaginated into the ventricle. At this thin edge the white matter comes to the surface as the fimbria (which is continuous with the fornix); lying along this is the small and half-concealed dentate gyru.s, which is formed by the sharp bending of the grey matter, and which is traceable round into the hippocampus major (from this it is separated by the hippocampal fissure), while this again is directly continuous externally with the gyrus hippocampi. The olfactory lobe (tract) is connected directly with the hippocampal region by its lateral root, whilst a mesial root passes into the anterior commissure and connects it with the rhinencephalon of the opposite side. The structure and connections of all these parts as they occur in man may be briefly alluded to.

In the region of the hippocampus major (figs. 492, 493), the cortex is simpler in structure than elsewhere, and in the hippocampus major itself, which is an infolded part of the cortex, the pyramids are reduced to a single layer of large cells lying in the deeper portion and sending their apical dendrons as long fibres into the plexiform layer. The plexiform layer and the superficial white stratum which overlies it are both very strongly marked, the plexiform layer having a distinctly reticular aspect, due partly to neuroglia cells, partly to the arborescence of the dendrons of the pyramids: the plexiform layer is here termed stratum laciniosum; internal to it near the dentate gyrus is a layer of closely packed small cells termed stratum granulosum. The pyramidal cells lie close to the white layer known as the alveus. This is the part 
of the hippocimpus seen within the ventricle, and represents the white matter of the hemisphere. The alveus is prolonged externally into the fimbria, in which its fibres become longitudinal in direetion and are continned into part of the fornix.

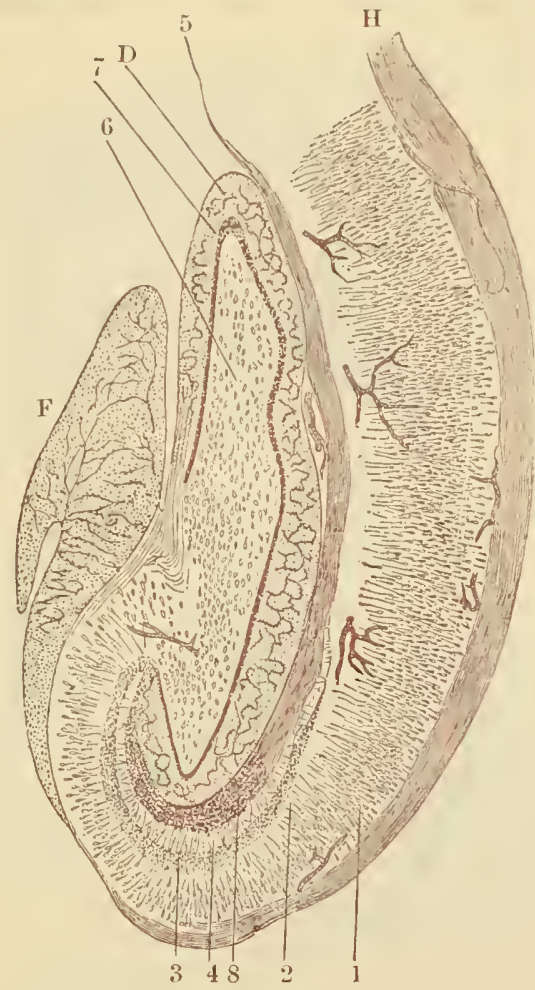

Fig. 492.- SEction across the hippocampus major, dentate fissure, DENTATE FASCIA ANI FIMBRIA. (W. Krause.)

D, fascia dentata, or dentate convolution; F, fimbria, composed of longitudinal fibres here cut across; $H$, medullary centre of the hippocampal gyrus prolonged around the hiplocimpus, as the so-called alveus, into the fimbria; 1 , layer of large pyra. midal cells; 2 , their processes (stratum radiatum); 3 , stratum granulosum; 4 plexiform laser (stratum lacíniosum); 5 , superficial white layer; 6 , nerve-cells of fascia dentata; 7 , stratum granulosum of fascia dentata; 8 , plexiform layer of the fascia dentata.

In the dentate gyrus ( fascic dentata, figs. $492,493, \mathrm{D}$ ) the pyramidal cells (6) are arranged in an irregularly radiating manner, occupying the centre of the convolution, and surrounded by a ring of closely packed small cells (stratum granulosum, fig. 492, 7 ). External to these is a thick plexiform layer, ocenpied by interlacing fibres (stratum laciniosum).

The anterior part of the hippocampal gyrus, which is known as the lobus pyriformis, and receives the lateral root of the olfactory 
tract, is characterised by the presence in the plexiform layer of peculiar nests of nerve-cells. The cells in these nests are of two types, viz., large polymorphous cells and small pyramidal cells, each being confined to its own nest. This part of the cortex is regarded by Cajal as the true olfactory region. In some animals the anterior

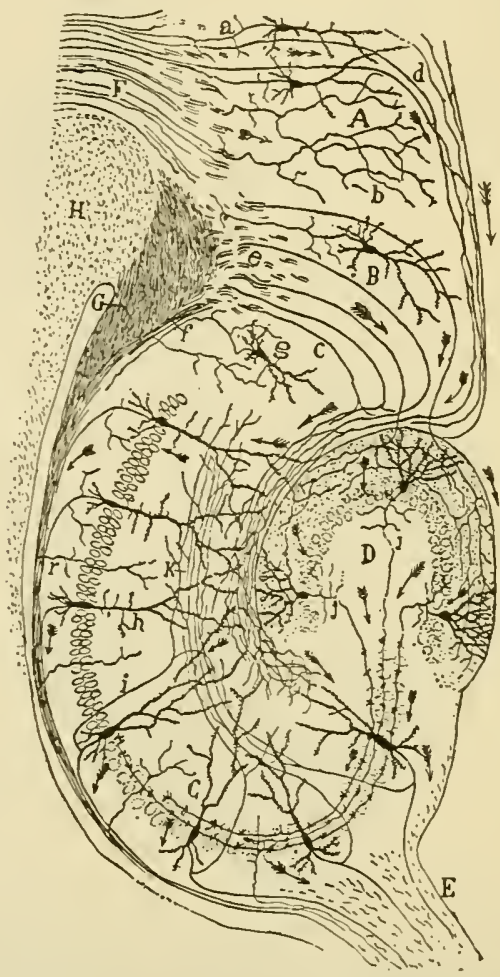

Fig. 493.-Hippocampal Regiox, Golgi Methoi, (Cajal.)

A, B, hippocampal grrus; C, hippocampus major; D, dentate gyrus; E, fimbria ; F, white matter of hippocampal gyrus; G, lateral ventricle; H, fibres of corpus callosum.

$a$, efferent fibres of hippocampal grrus ; $l$, afferent fibres of hippocampal grrus ; $c$, afferent fibres of hippocampus and dentate gyrus; $d$, others perforating grey matter of hippocampal gyrus; $e$, others cut obliquels (from sphenoidal part of brain); $f$, fibres of alveus: $g, h$, cells of hippocampus major sending their axons in to the alveus and towards the fimbria; $i, k$, collaterals from these axons passing to the molecular layer; $r$, afferent fibres of alreus. The arrows indicate the probablc course of the nerve impulses.

perforated space forms a distinct prominence of the cortex (tuberculum olfactorium) and this is also characterised by cell-nests (islets of Calleja). They also occur in the cortex of the hippocampal fissure.

The olfactory tract is an outgrowth of the brain which was originally hollow, and remains so in many animals; but in man the 
cavity has become obliterated, and the centre is occupied by neuroglia, containing no nervecells. Outside the central neuroglia lies the white or medullary substance, consisting of bundles of longitudinal white fibres. Most externally is a thin superficial layer of neuroglia.

The olfactory bulb (fig. 494 ) has a more complicated strueture. Dorsally there is a flattened ling of longitudinal white bundles

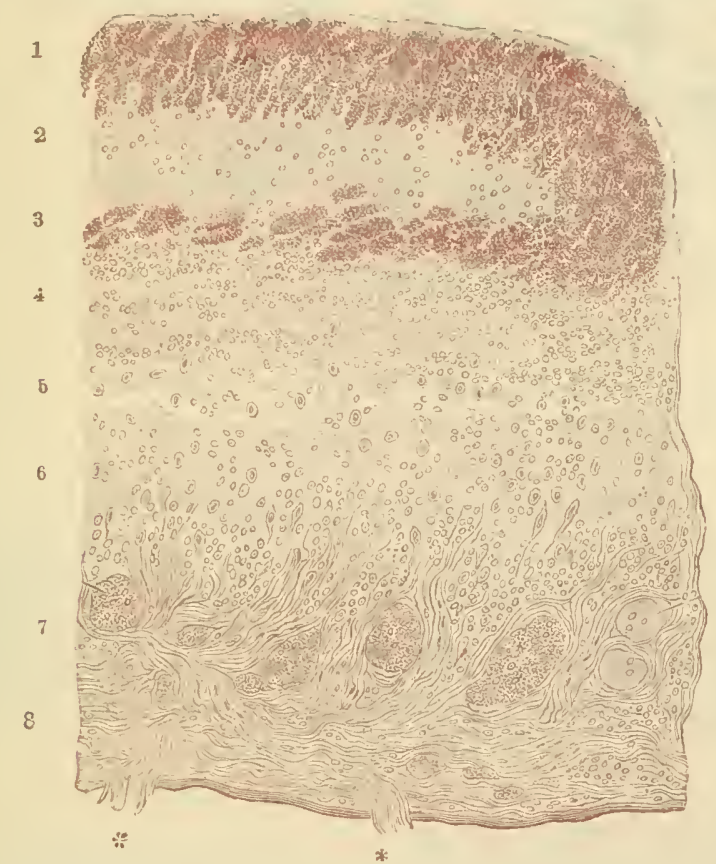

Fig. 494,-Section across a part of the olfactory BUlb. (Henle.)

1,3 , bundles of very fine transversely eut nerve-fibres, forming the flattened medullary ring, inclosing the central neuroglia, 2 : this ring is the anterior continuation of the olfactory tract; 5 , white layer with ummerous small cells (granules); 6 , mitral-cell layer; 7 , layer of olfactors glomeruli; $S$, layer of olfactory nerve-fibres, bundles of which are seen at * passing through the cribriform plate of the ethmoid bone.

inclosing neuroglia $(1,2,3)$, as in the olfactory tract, but below this ring several layers are recognised as follows:

1. A white or medullary layer (fig. 494, 4, 5), characterised by the presence of a large number of small cells ("granules") with reticulating bundles of medullated nerve-fibres running longitudinally between them.

2. A layer of large nerve-cells (6), with smaller ones ("granules") intermingled, the whole embedded in an interlacement of fibrils which are mostly derived from the cell-dendrons. From the shape of most 


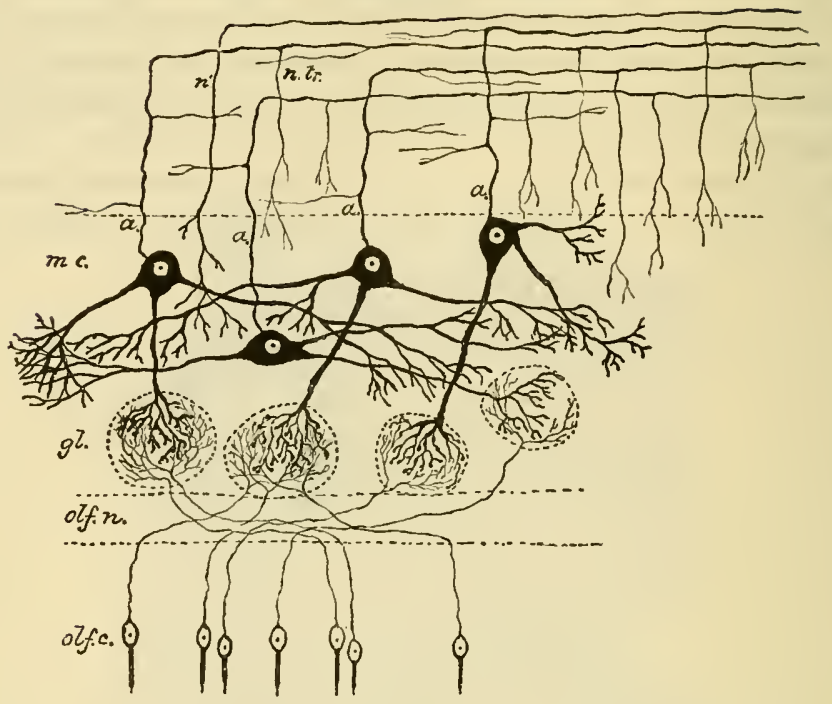

Fig. 495.-Diagram to SHOW THE RELATIONS OF CELLS AND Fibres IN THE OLFACTORY BULB.

olf.c., olfactory cells of M. Schultze in the olfactory mucous membrane, sending their basal processes as non-medullated nerve-fibres into the deepest layer of the olfactory bulb (olf.n.); gl, olfactory glomeruli containing the terminal arborisations of the olfactory fibres and of processes from the mitral cells; mc., mitral cells, sending processes down to the olfactory glomeruli, others laterally to end in free ramifications in the nerve-cell layer, and their axis-cylinder processes, $a, a$, upwards, to turn sharply backwards and become fibres of the olfactory tract $\left(n, t r^{\circ}\right.$ ). Numerous collaterals are seen coming off from these fibres; $n^{\prime}$, a nerve-fibre of the olfactory tract ending in a free ramification in the olfactory bulb.

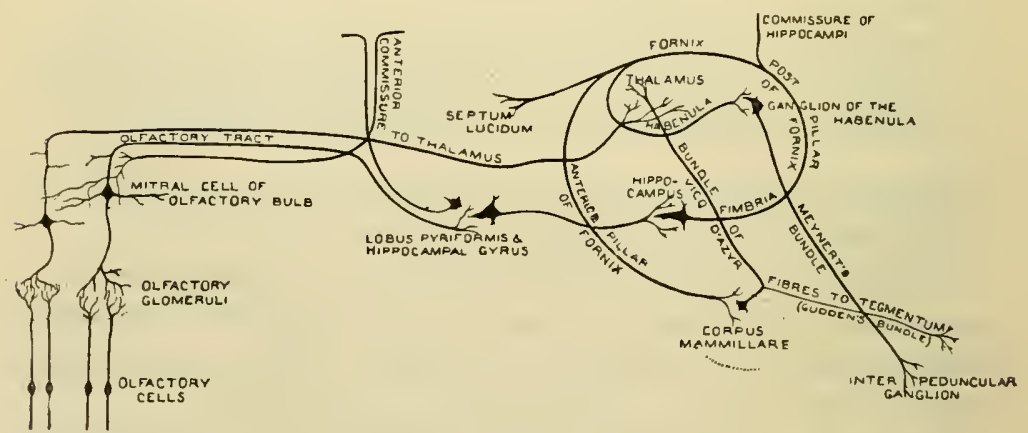

FIG. 496.-DIAGRAM OF THE OLFACTORY PATH IN THE BRAIN. To simplify the diagram the various divarications of the olfactory path have been represented by branchings of individual fibres, although in some cases the divarication is brought about by the turning aside of bundles of entire fibres. 
of the large cells of this layer (fig. 495, m.c.) it has been termed the "mitral" layer. These cells send their axons upwards into the next layer, and they eventually become fibres of the olfactory tract and pass along this to the base of the brain, giving off numerous collaterals into the bullb as they run backwards.

3. The layer of olfuctory glomeruli (fig. 494, 7 ; fig. 495, gl.). 'This consists of rounded nest-like interlacements of fibrils which are derived on the one hand from the terminal arborisations of the non-medullated olfactory fibres which form the subjacent layer, and on the other hand from arborisations of dendrons of the large "mitral" cells of the layer above. There are also a few small nerve-cells immediately external to and extending within the glomeruli (periglomerular cells). These belong to Golgi's type II., and appear to conneet neighbouring glomeruli.

4. The layer of olfactory nerve-fitres (fig. 494, 8; fig. 495, olf.n.). These are all non-medullated, and are continued from the olfactory fibres of the olfactory mueons membrane of the nasal fossæ. In this mucous membrane they take origin from the bipolar olfactory cells which are characteristic of the membrane (see Lesson XLV. fig. 528 ), and they end in arborisations within the olfactory glomeruli, where they come in contact with the arborisations of the mitral cells. The relations of the olfactory cells and fibres to the mitral cells, and the continuation of the axis-cylinders of the latter upwards and backwards in the olfactory tract, are shown in the accompanying diagrams (figs. 495, 496). Besides these centripetal nerve-fibres there are a certain number of centrifugal fibres which end by ramifying in the olfactory bulb amongst the mitral cells.

As is seen in fig. 496 , many of the fibres of the olfactory tract pass to the hippocampal region of the brain, terminating by arborescence in the grey matter (molecular layer) of the base of the olfactory lobe in the region of the anterior perforated space, as well as in that of the uncus and the hippocampal gyrus. Fibres are also given off from the olfactory tract to the anterior commissure which proceed to the opposite tract and bulb. Besides these the anterior commissure contains many fibres which are passing from the hippocampal region of one side to the corresponding region on the opposite side of the brain. From the pyramid-cells of the base of the olfactory lobe and hippocampal gyrus fibres pass to the grey matter of the hippocampus, and from the pyramid-cells of the hippocampus others proceed by way of the fimbria and fornix to the hippocampus of the other side, to the subcallosal gyrus and septum lucidum, to the ganglion of the habenula, and finally by the anterior pillar of the fornix to the corpora mammillaria. 


\section{CORPUS STRIATUN.}

Besides the grey matter of the cerebral cortex the cerebral hemispheres conceal in their deeper parts certain other masses of grey substance (fig. 497). The principal of these are the corpus striatum (nucleus caudatus, n.c., and nucleus lenticularis, n.l.) and optic thalamus $(t h$.$) . Between them run the bundles of white fibres which are$ passing downwards to the crus cerebri, forming a white lamina termed the internal capsule. Above the level of these nuclei the internal capsule expands into the medullary centre of the hemisphere. Below the optic thalami are the prominent ganglia known as corpora albicantia or mammillaria. Of these the optic thalami and corpora mammillaria have already been described.

The nucleus caudatus of the corpus striatum is composed of a reddishgrey substance containing cells some with long, others with short axiscylinders; some of the former being very large. It receives fibres from the part of the internal capsule which separates it from the nucleus lenticularis, and next to the lateral ventricle it is covered by a thin layer of neuroglia, and over this by the epithelium of the cavity (ependyma).

The nucleus lenticularis, which corresponds in position internally with the island of Reil externally, is divided by two white laminæ into three zones. It is separated from the nucleus caudatus and optic thalamus by the internal capsule (fig. $497, i . c$.), which consists of the bundles of medullary fibres which are passing between the white centre of the hemisphere and the crus cerebri ; it receives on its inner side many white fibres from the capsule, and these impart to it a radially striated aspect. Many of the nerve-cells of the nucleus lenticularis contain yellow pigment. The fibres of the ansa lenticularis appear to arise from some of them, but the exact course and destination of these fibres is not known.

The internal capsule (fig. 497), which is continued below into the crusta (pes) of the crus cerebri, consists mainly of projection-fibres, which are derived from the cortex cerebri, and are passing down to the thalamus, mid-brain, pons, medulla oblongata, and spinal cord. A horizontal section across the internal capsule shows it to be bounded laterally by the lenticular nucleus, mesially by the caudate nucleus, the stria medullaris, and the optic thalamus. Its section shows a sharp bend-the genu. The fibres from the motor region of the cortex (pyramidal tract) pass down in the part of the capsule extending from the genu as far as the posterior limit of the lenticular nucleus. In this area the fibres for the head and eyes are massed 
chiefly in the anterior part: those of the lower limb in the posterior part, and those of the face, arm, and trunk occupy intermediate positions from before backward, in the order named (Beevor and Horsley), but without being strictly confined to definite zones.

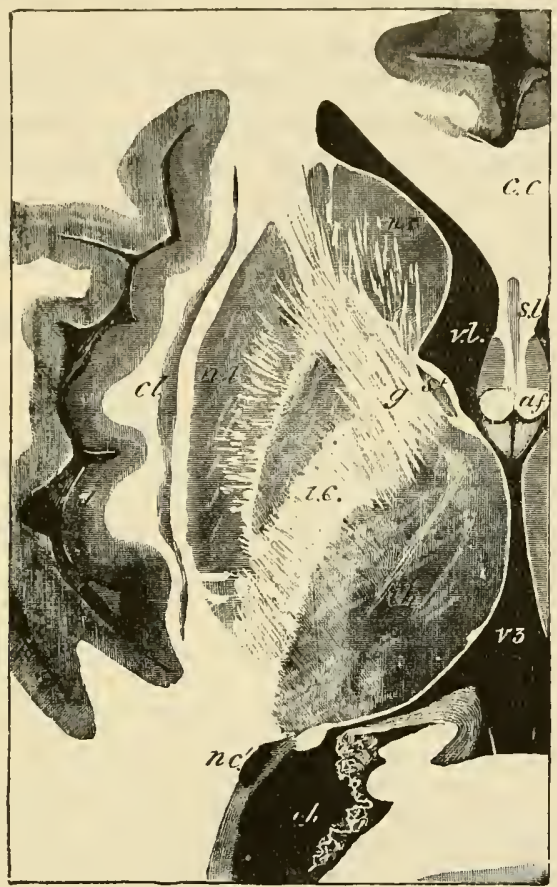

Fig. 497.-Horizontal section throvgh the optic thalames anin corpus STRIATUM. (Natural size.)

$v . l$, lateral ventricle, its anterior cornu; c.c., corpus callosum; s.l., septum lucidum; a.f., anterior pillars of the fornix; $v 3$, third ventricle; th., thalamus opticus; st., stria medullaris; $n c ., n c^{\prime}$., nucleus caudatus, and $n l$., nucleus lenticularis of the corpus striatum ; $i_{0}$. ., internal capsule ; $g$, its angle or genu ; $n c^{\prime}$., tail of the nucleus caudatus appearing in the descending cornu of the lateral ventricle; $c l$., claustrum ; $I$, island of Reil.

The fibres from the cortex to the thalamus lie mainly in the anterior. limb of the capsule, while the afferent fibres from the thalamus to the cortex oceur in the posterior part of the posterior limb, but extend forwards so as to mingle with the descending fibres just referred to as belonging to the pyramidal tract.

The membranes of the brain are similar in general structure to those of the spinal cord. The dura mater is, however, more closely adherent to the inner surface of the bony enclosure than is the case in the vertebral canal. The arachnoid is in many places close to the dura mater, and separated by a wide subarachnoid space (which is bridged 
across by finely reticulating bands of areolar tissue) from the pia mater. In the vicinity of the longitudinal sinus, small rounded elevations (arachnoidal villi, Pacchionian glands) project into the dura mater, and even become embedded in the skull itself. The pia mater is closely adherent to the surface of the brain, and dips into all the sulci, but without forming actual folds ('Tuke). In it the blood-vessels ramify before passing into the substance of the brain, and they are accompanied, as they thus enter the cerebral substance, by prolongations of the pia mater, which do not, however, closely invest them, but leave a clear space around each vessel, presumably for the passage of lymph (perivascular space). The capillary network is much closer in the grey than in the white matter. 


\section{LESSONS XLVI., NLVII, AND XLVIII.}

\section{STRUCTCRE OF THE EYELIDS AND OF THE PARTS OF THE EYEBALL.}

1. SEctioss of the eyelid vertical to its surfaces and transverse to its long axis.

Notice the long sacculated Meibomian glands lying in dense connective tissue close to the conjunctival surface, their ducts opening at the margin of the lid. External to these the small fibres of the orbicularis palpebrarum are cut across; a few of the fibres of the muscle lie on the conjunctival side of the duct. A short distance from the Meibomian gland may be observed a tolerably large sebaceous gland; ontside this again are the eyelashes. In the skin covering the onter surface of the evelid a few small hairs may be seen. At the attached part of the evelid are some bundles of iuroluntary muscular fibres cut longitudinally in the section, and in the upper eyelid the fibrous attachment of the elevator muscle may be observed attached to the dense connective tissue.

Make a general sketch under a low power.

2. Sections through the posterior part of an eyeball. These sections will show the relative thickness of the several coats and the layers of which each coat is formed. Sections which pass through the point of entrance of the optic nerve will also exhibit the manner in which the nerve-fibres pierce the several coats to reach the inner surface of the retina. The modifications which are found in the neighbourhood of the yellow spot may be made out in sections through that region; but they must be taken from the liuman ere, or from that of the monkey.

3. Sections of the anterior half of an eveball. These sections should pass through the middle of the cornea. The leus may be left in situ, but this renders the preparation of the sections and the mounting of them difficult on account of the extreme hardness which is imparted to the lens-tissue by alcohol. ${ }^{1}$

In these sections make a general sketch under a low power, showing the relations of the several parts one with another; and study carefully, and sketch in detail, the layers of the cornea, the junction of the cornea and sclerotic, the ciliary muscle, the muscular tissue of the iris, the mode of suspension of the lens, and the pars ciliaris retinx.

4. Mount in glycerine thin tangential sections of a cornea stained with chloride of gold by Cohnheim's method; if from the frog, the cornea cau be torn with fine forceps into thin lamelle, which are mounted whole. Sketch three or four of the connective-tissue cells (corneal corpuscles). The arrangement and distribution of the nerve-fibres and their termination amongst the epithelium-cells as shown in chloride of gold preparations have been already studied (Lesson XIX., p. 176). kind.

The celloidin method of embedding is well adapted for preparations of this 
5. Mount in dammar sections of a cornea which has been stained with nitrate of silver. Notice the branched cell-spaces corresponding with the connective-tissue cells of the last preparation.

[This preparation is best made by rubbing the surface of the cornea of a recently killed animal with lunar caustic, after scraping off the epithelium with a scalpel. After ten minutes (by which time the nitrate of silver will have penetrated the thickness of the cornea) the eye is washed with distilled water, and exposed to the light. When brown, tangential sections may be made, for which purpose the stained cornea may be hardenel in spirit.]

6. Remove the sclerotic from the anterior part of an eye which has been preserved in Miller's fluid, and tear off thin shreds from the surface of the choroid, including amongst them portions of the ciliary muscle. Stain the shreds with hrematoxylin and mount them in glycerine. Sketch the branched pigment-cells, the elastic network, the mode of attachment of the fibres of the ciliary muscle, etc.

7. Injected preparation of choroid and iris. Mount portions of the choroir coat and iris from an eye (preferably of an albino animal), the blood-vessels of which have been filled with coloured injection. Make sketches showing the arrangement of the capillaries and veins.

8. Teased preparation of buman retina. Break up with needles in a drop of glycerine a minute fragment of retina which has been placed in 1 per cent. osmic acid solution for some hours, and has subsequently been kept in dilute glycerine. Complete the separation of the retinal elements by tapping the cover-glass. Draw carefully under a high power some of the isolated elements-e.g. the rods and cones with their attached fibres and nuclei, the inner granules, the ganglion-cells, the fibres of Miiller, hexagonal pigmentcells, etc. In some of the fragments the arrangement of the elements in the retinal layers may be made out even hetter than in actual sections. ${ }^{1}$

Measure the length and diameter of some of the cones, the length of the cone-fibres, and the diameter of some of the onter and inner muclei.

9. Teased preparation of frog's retina. To be prepared in the same way as 8. Notice the rery large rods, their outer segments breaking up into disks, and the relatively small cones. Also the pigment extending between the rods, the distance varying according as the eye has been kept in the dark or in the liglit. A fresh frog-retina should also be teased in salt solution.

10. Sections of retina of ox or $\mathrm{dog}$, which have been prepared by Golgi's method. A curled-up piece of fresh retina is placed in osmium-bichromate mixture and is subsequently treated with nitrate of silver solution. ${ }^{2}$

11. Teased preparation of lens. Separate in water the fibres of a crystalline lens which has been macerated for some days in bichromate of potassium or dilute formol solution. Sketch some of the fibres, together and separate.

The eyelids (fig. 498) are covered externally by the skin, and internally or posteriorly by a mucous membrane, the conjunctiva, which is reflected from over the globe of the eye. They are composed in the main of connective tissue, which is dense and fibrous under the conjunctiva, where it forms what is known as the tarsus.

1 The distribution of the nerve-fibres and cell-processes within the retina can only be made out satisfactorily by the employment of Golgi's silver chromate method (see $\S 10)$.

${ }^{2}$ See Appendix. Cajal's reduced silver method may also be employed. 
Embedded in the tarsus is a row of long sebaceous glands (the Meibomian ylunds, $f$ ), the duets of which open at the edge of the eyelid. The rest of the thickness of the eyelid is composed of a somewhat loose connective tissue, and contains the bundles of the orlicularis

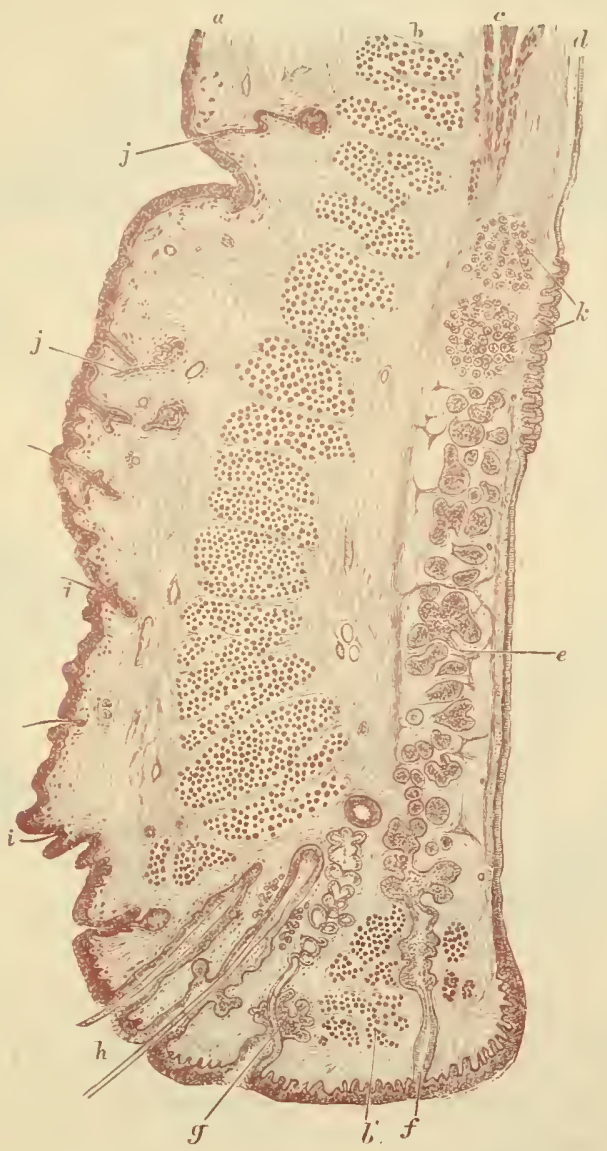

Fig. 498. - Vertical Sectiox throlgh the upper eyelid. (Waldeyer.)

$a$, skin; $b$, orbicularis; $b^{\prime}$, cilliary bundle; $c$, involuntary muscle of eyelid; $d$, conjunctiva ; $e$, tarsus with Mleibomian gland; $\vec{j}$, duct of the gland; $g$, sebaceous gland near eyelashes; $h$, eyelashes; $i$, small hairs in outer skin $; j$, sweat-glands; $k$, posterior tarsil glands.

muscle $(b)$. In the upper eyelid the levator palpebre is inserted into the tarsus by a fibrous expansion, and some bundles of involuntary muscle are also present near the attachment of the eyelid. The skin has the usual strncture; it contains small sweat-glands, and the follicles of small hairs, and, in addition, at the edge of the eyelid, the 
large hair-follicles from which the eyelashes grow. The epithelium of the conjunctiva palpebræ is columnar, passing at the edge of the lid into the stratified epithelium of the skin ; it also becomes stratified in the part which is reflected over the globe of the eye. The nerves of the conjunctiva terminate for the most part in end-bulbs, which in man are spheroidal, and formed chiefly of a small mass of polyhedral cells; but in the calf and most animals they are elliptical.

The lacrymal gland may be briefly mentioned in connection with the eyelic. It is a compound racemose gland, yielding a watery secretion. Its alveoli are lined by columnar cells, which are normally
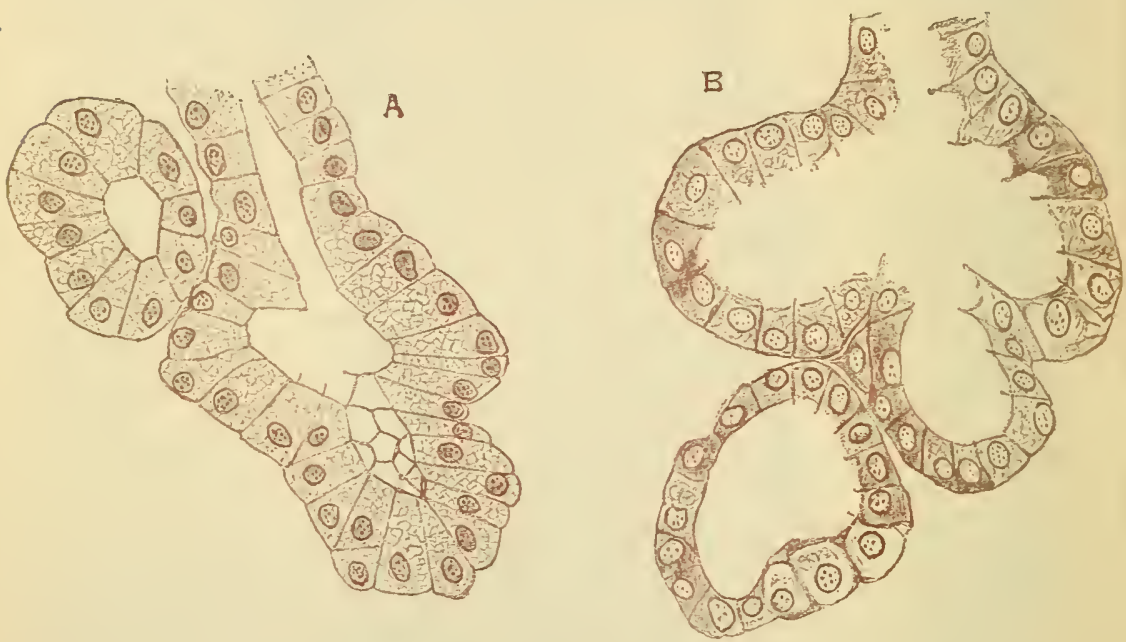

Fig. 499.-SEction OF LACRTMAL GLAND OF DOG. A, RESTING; B, AHTER COPIOUS SECRETION PRODECEL BY PILOCARPINE.

filled with granules, but, after profuse secretion, these disappear, and the cells become much shorter and smaller (fig. 499, A, B). Its ducts, of which there are several, open at the upper fold of the conjunctiva, near its outer extremity.

The globe of the eye (fig. 500) is inclosed by three coats, the corneasclerotic, choroid (with the iris), and retina. It is filled by the vitleous and aqueous bumours and the crystalline lens which lies. between them.

The sclerotic coat is composed of dense fibrons tissue, the bundles of which are intimately interlaced. It is thickest at the back of the eyeball. It is covered externally with a lymphatic endothelium, while internally it is lined by a layer of connective tissue containing pigmentcells, which give it a brown appearance (lamina fusca). At the entrance- 
of the optie nerve the sclerotic is prolonged into the sheath of that nerve, the bundles of which, piercing the coat, give a sieve-like aspect to the part (lamina cribrose, fig. 512, L.).

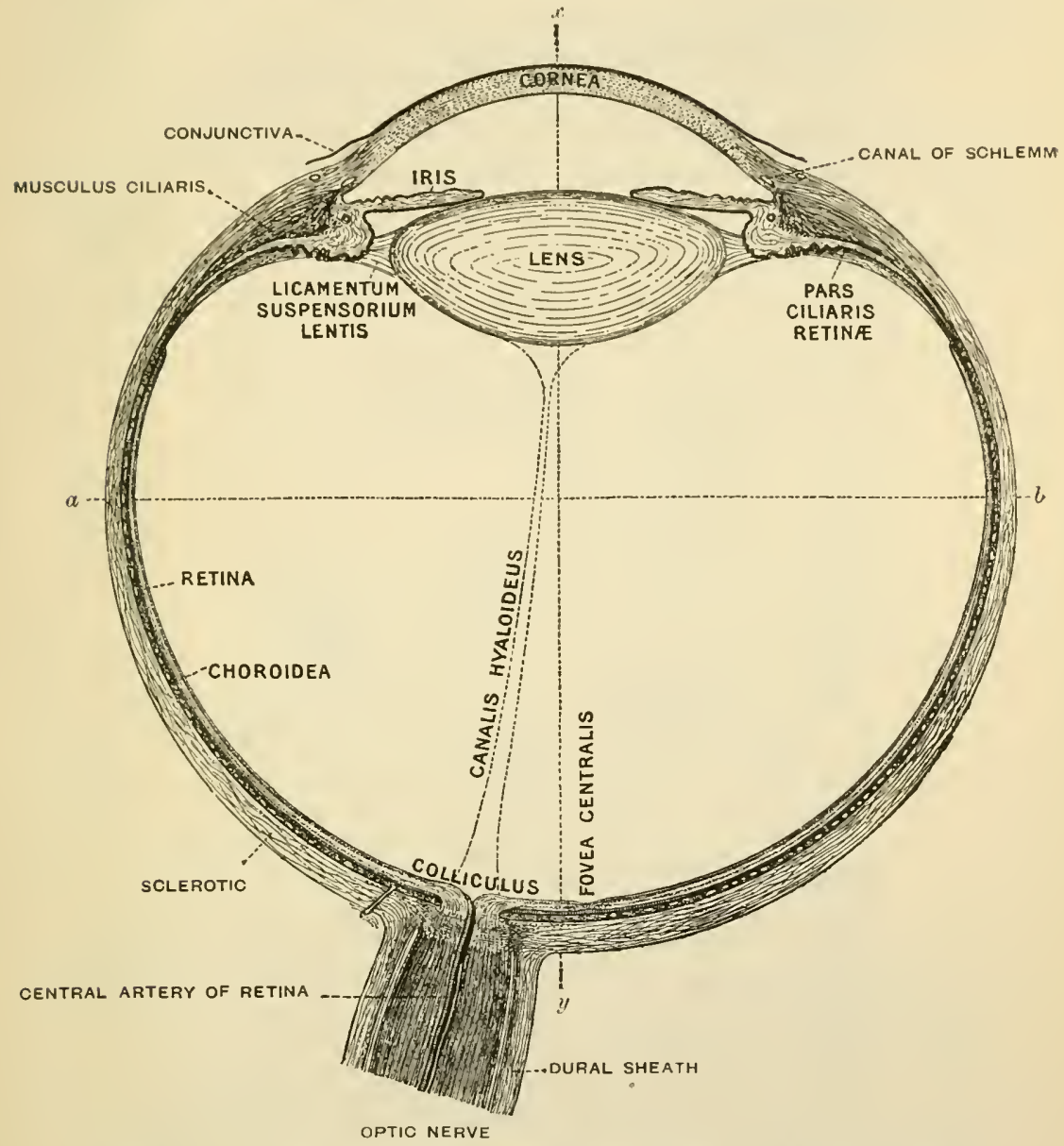

Fig. 500.-Diagram of a SECTION THROUGH THE (RIGHT) HUMAN EYE PASSING HORIZONTALLY NEARLY THROUGH THE MIDDLE. (Magnified about 4 diameters.)

$a, b$, equator ; $x, y$, optic axis.

The cornea (fig. 501) consists of the following layers (enumerated from before back):

1. A stratified epithelium continuous with the epitheliun of the conjunctiva (1).

2. A thin lamina of homogeneous eonnective tissue (membrane of Bowman), upon which the deepest cells of the epithelium rest (2). 
3. A thick layer of fibrous connective tissue which forms the proper substance of the cornea (3). This is continuous laterally with the tissue

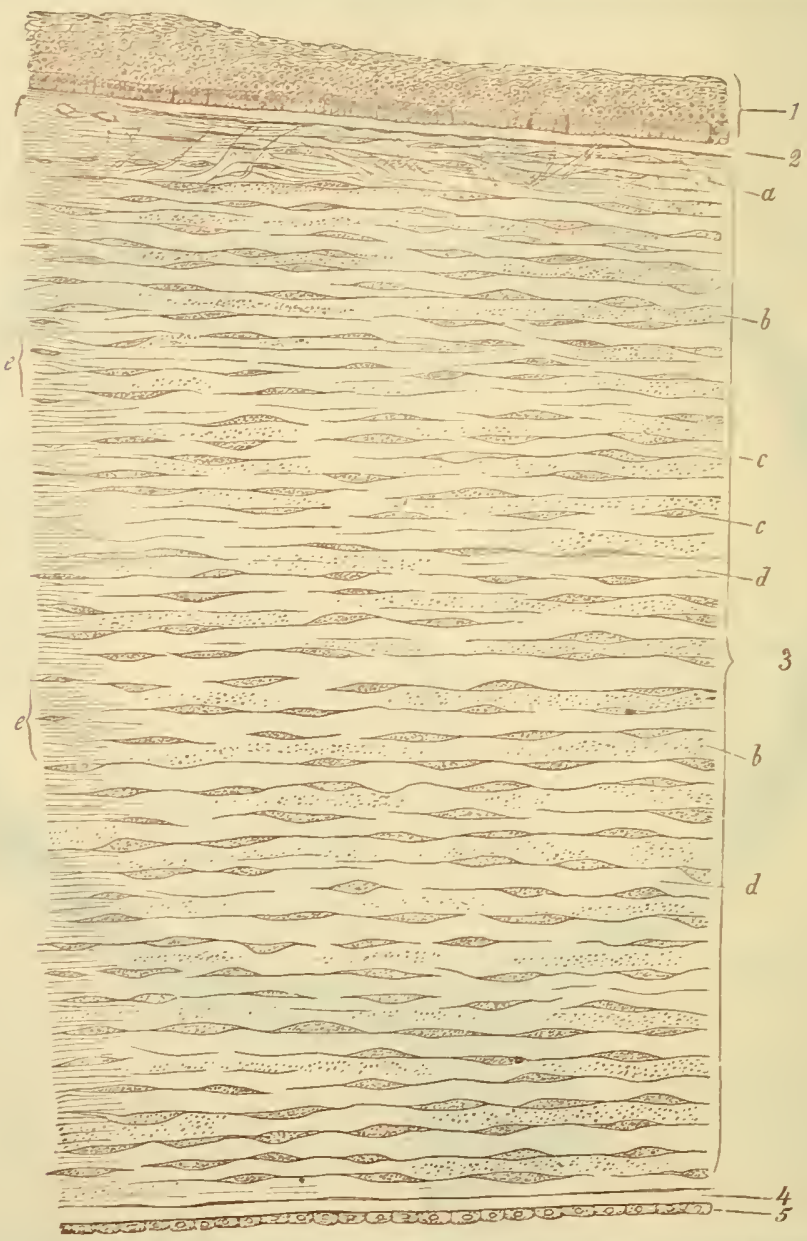

Fig. 501.- Tertical SECTION OF HUMAX CORNEA FROM IEAR THE MARGIN. (Waldejer.) (.Magnified.)

1, epithelium; 2, anterior homogeneous lamina ; 3, substantia propria corneæ ; 4, posterior homogeneous (elastic) lamina; 5 , epithelium of the anterior chamber; $a$, oblique fibres in the anterior laver of the substantia propria; $b$, lamellæ, with their fibres cut across, producing a dotted appearance ; $c$, corneal corpuscles appearing fusiform in section; $d$, lamellæ with the fibres cut longitudinally; $e$, transition to the sclerotic, with more distinct fibrillation, and surmounted by a thicker epithelium ; $f$, small blood-ressels cut across near the margin of the cornea.

of the sclerotic. It is composed of bundles of white fibres arranged in regular laminæ, the direction of the fibres crossing one another at right angles in the alternate laminæ. Between the laminæ lie flattened 
comnective-tissue corpuscles (fig. 50\%), which are branched and united by their processes into a continuous network; there is of course a corresponding network of cell-spaces. In rertical sections the cells appear narrow and spindle-shaped (fig. 501, c). In the superficial lamine there are a few bundles of fibres which run obliquely towards the surface $(a)$.

4. A homogreneous clastic layer (membrane of Descemet, fig. 501, t). This completely corers the back of the cornea, but near the angle which the cornea forms with the iris it breaks up into separate fibres (ligamentum pectinatum) which are partly continued into the iris as the pillars of the iris.

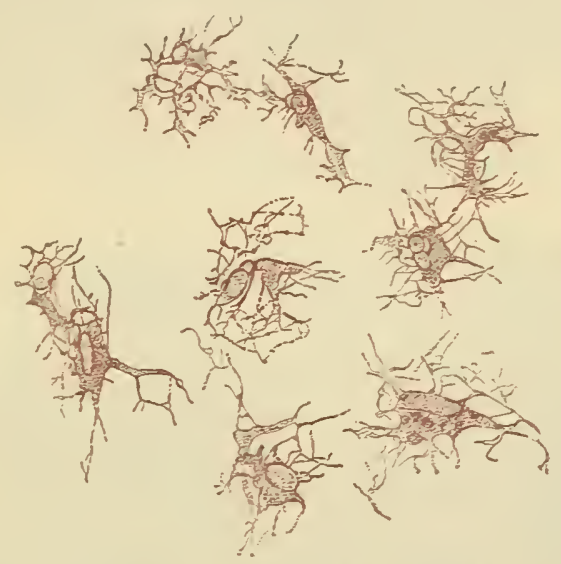

Fig. 502.-CORPCSCles of THE CORXEA, isolaten. (Waldeyer.)

5. A layer of parement-epithelium (epithelium of Descemet's membrane) covering the posterior surface of the elastic lamina, and lining the front of the anterior chamber of the eye (fig. 501,5). At the sides it is continued orer the ligamentum pectinatum into a similar epithelium, covering the anterior surface of the iris. The cells of the epithelium of Descemet's membrane are separated from one another by intercellular spaces, bridged across by bundles of fibrils which pass through the cells (fig. 503). Each cell has a peculiar basket-like reticulum close to the nucleus: perhaps a modified centrosome.

The nerves of the cornea pass in from the periphery, losing their medullary sheath as they enter the corneal substance. They form a primary plexus in the substantia propria, a secondary or sub epithelial plexus immediately under the epithelium which covers the anterior surface, and a terminal plexus of fine fibrils which pass from the subepithelial plexus in pencil-like tufts and become lost 
between the epithelium-cells (Fig. 504). There are no blood-vessels or lymphatics in the cornea, although they come close up to its margin.

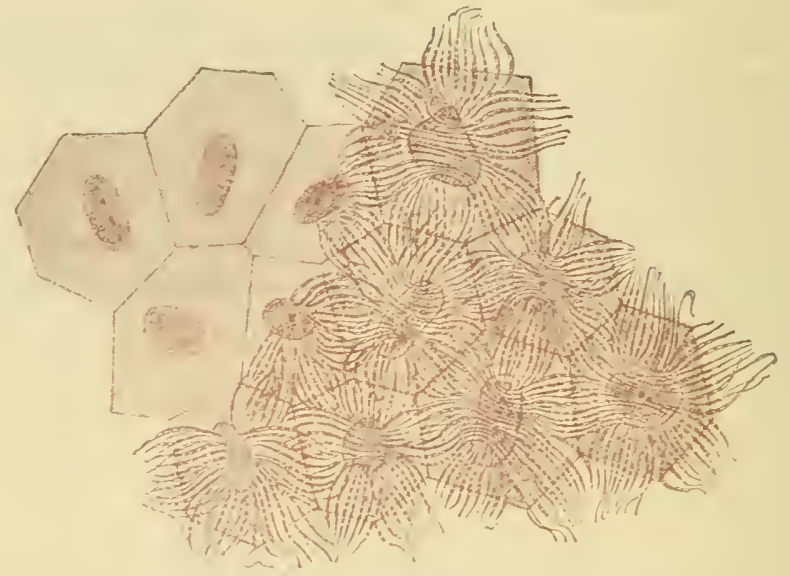

Fif. 503.-Epithelicy-CELLs of DEsceset's yesbraxe. (After Sinirnow and Nuël.)

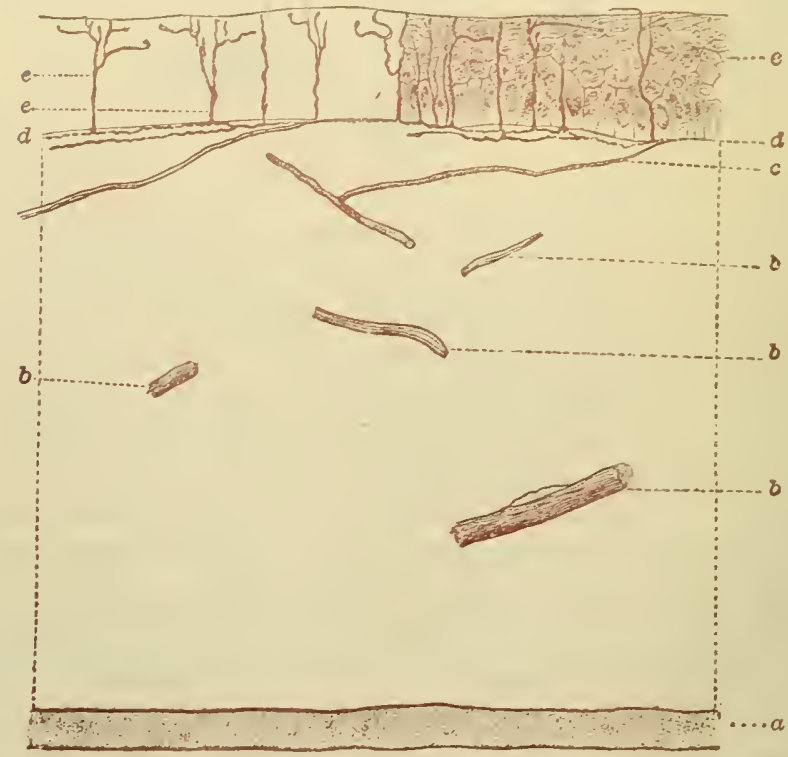

Fig. 504.-Vertical Section throcgh THE corsea. (Barker, after Cohnheim.)

The corneal corpuscles and the cells of Descemet's membrane are not represcnted; the anterior epithelium has been drawn in only in part. $a$, Descemet's membrane; $b$, parts of nerve plexus in substantia propria ; $c$, branches going to the epithelium; $d$, fibres of the subepithelial layez; $e$, vertical fibrils with horizontal outrunners. 
The choroid or vascular coat of the cye is of a black colonr in many animals, but in the human eye it is diuk brown. It is composed of connective tissue, the eells of which are large and filled with pigment (figs. 505, 506). It contains in its inner layer a close

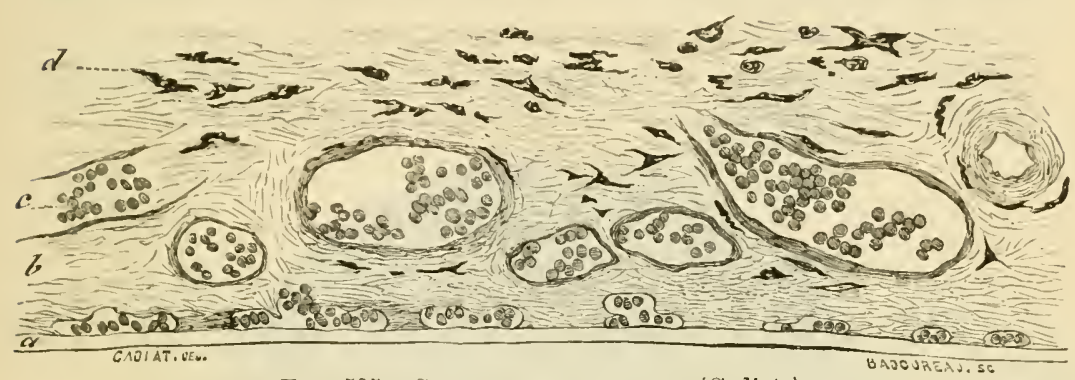

Fig. 505.,-SECtion of chorom, (Cadiat.)

$a$, mcmbrane of Bruch: the chorio-capillaris is just above it; $b$, vascular layer; $c$, vessels with blood-corpuscles; $d$, lamina suprachoroidea.

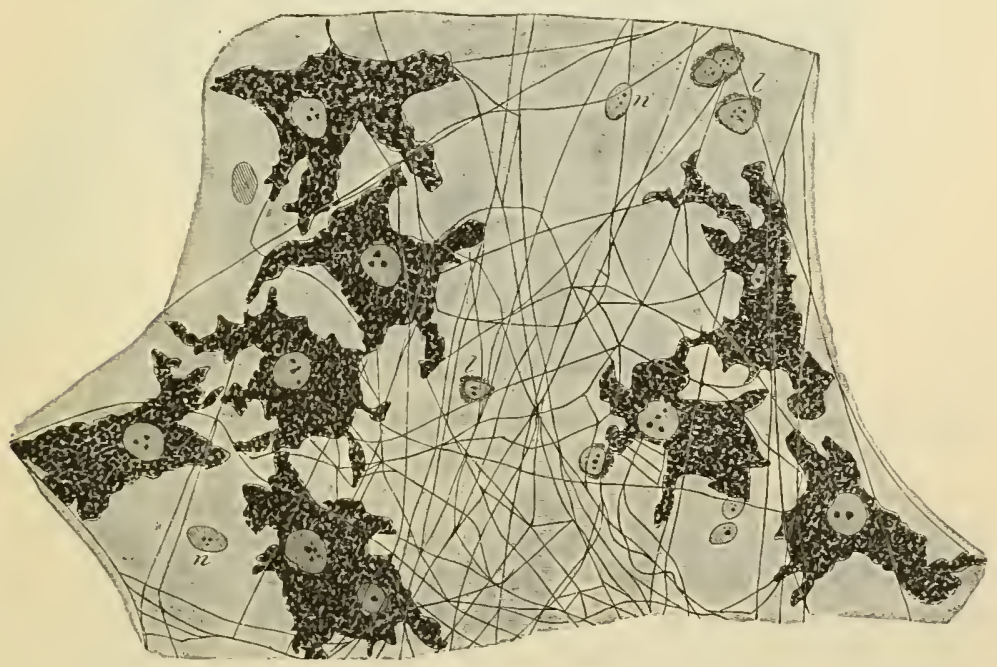

Fig. 506.-A smale portion OF the Lamina acprachoromea. (Highly magnified.)

The pigment-cells and elastic fibres are well shown; $n$, nuclei of endothelial cells (the outlines of the cells are not indicated); $l$, lymph-cells.

network of blood-vessels, and in its anterior part the involuntary muscular fibres of the ciliary muscle, which pass backwards from their origin at the junction of the cornea and sclerotic, to be inserted into the choroid. The choroid is separable into the following layers (enumerated from withont in):

1. The lamina suprachoroidea (fig. 505, $d$ ). This is a loose membrane 
composed of delicate connective tissue pervaded by a network of fine elastic fibres, and containing many large branched pigment-cells and lymph-corpuscles (fig. 506). It is covered superficially by a lymphatic endothelium, and is separated from the lamina fusca of the sclerotic by a cleft-like lymph-space which is bridged across here and there by the passage of vessels and nerves, and by bands of connective tissue.

2. The vascular layer of the choroid (fig. 505, b), which resembles the suprachoroidea in structure, but contains the blood-vessels of the

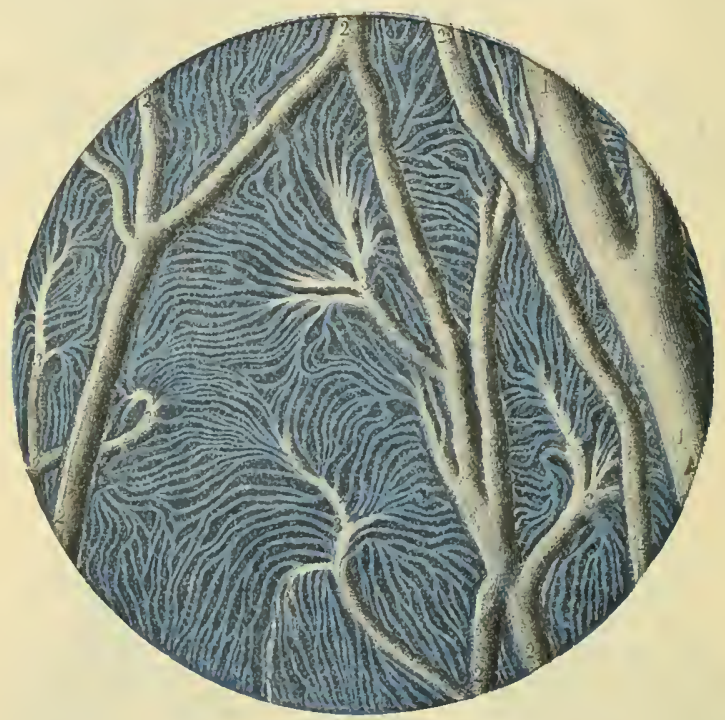

Fig. 507.-INJected BLOOI-vessels of THE Choroid coAt. (Sappey.)

1 , one of the larger veins; 2 , small anastomosing vessels; 3 , branches dividing into the smallest vessels.

coat. In its outer part are the larger vessels (arteries and veins), the veins having a peculiar vorticose arrangement; in its inner part (chorio-capillaris) are the capillaries, which form an extremely close network with elongated meshes, the capillaries radiating from the extremities of the small arteries and veins in a highly characteristic manner (fig. 507). In the ciliary processes the vessels have for the most part a longitudinal direction, but there are numerous convoluted transversely disposed capillaries uniting the longitudinal vessels (fig. $510, d$ ).

3. Lining the inner surface of the choroid is a thin transparent membrane known as the membrane of Bruch (fig. 505, a).

The ciliary muscle consists of involuntary muscular bundles which arise at the corneo-sclerotic junction, and pass meridionally backwards 
extend from the attachment of the iris nearly to the pupil, lying close to the posterior surface and constituting the dilatutor muscle (fig. 509, b).

The back of the iris is covered by a thick layer of pigmented epithelium (uvea) continuous with the epithelium of the pars ciliaris retinæ.

The muscular tissue of the iris is stated to be developed from the epithelium at the back of the iris (Nussbaum, Szili).

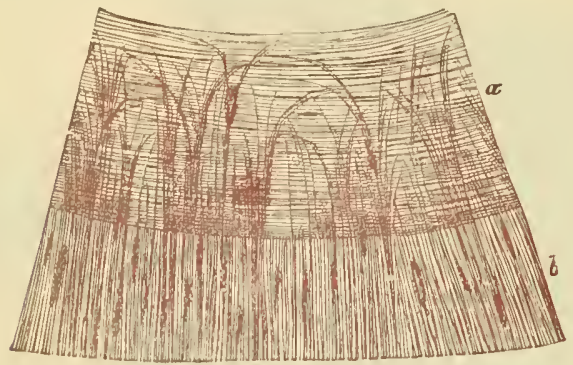

FIG. 509.

Fig. 509.-SEgMeNT OF THE IRIS, SEen FROM THE POS. TERIOR SURFACE AFTER REMOVAL OF THE UVEAL PIG MENT, (Iwanoff.)

$a$, sphincter muscle; $b$, dilatator musele of the pupil.

Fig. 510- - Vessels OF THE CHOROID, CILIARY PROCESSES AND IRIS OF A CHILD. (Arnold.) (10 diameters.)

$a$, capillary network of the posterior part of the choroid, ending at $b$, the ora serrata ; $c$, arteries of the coronn ciliaris, supplying the ciliary processes, $d$, and passing into the iris, $e f$, the capillary network close to the papillary margin of the iris.

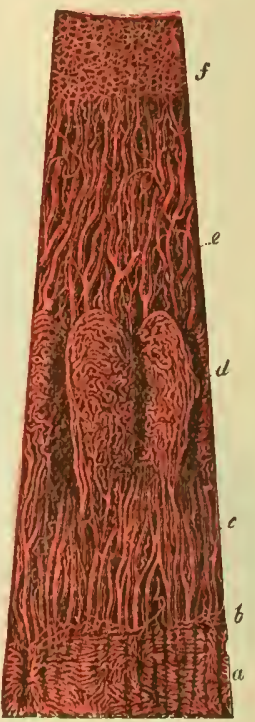

F1G. 510.

The blood-vessels of the iris (fig. 510,e) converge towards the pupil. Near the pupil the small arteries form an anastomotic circle, from which capillaries arise and pass still nearer the pupil, around which they form a close capillary network.

A large number of nerve-fibres are distributed to the choroid and iris, probably going chiefly to the muscular tissue of those parts (ciliary muscle and sphincter and dilatator pupillæ).

The retina consists of the eight layers shown in the accompanying figure (fig. 511), numbered as they occur from within ont.

The inner surface of the retina, which is smooth, rests upon the hyaloid membrane of the vitreous humour. It is formed of the united bases of the fibres of Müller, which will be afterwards described.

The layer of nerve-fures is formed by the expansion of the optic nerve after it has passed through the coats of the eye (fig. 512). At its 
entrance the nerve forms a slight eminence (colliculus nerri optici). The nerve-fibres lose their medullary sheath on reaching the retina. Most are commected with (derived from) the cells of the ganglionic or optic nerve-cell layer (fig. 513), but some (centrifugal) fibres pass through the ganglionic and moleenlar layers to form a terminal arborisation in

()uter or choroidal surfice.

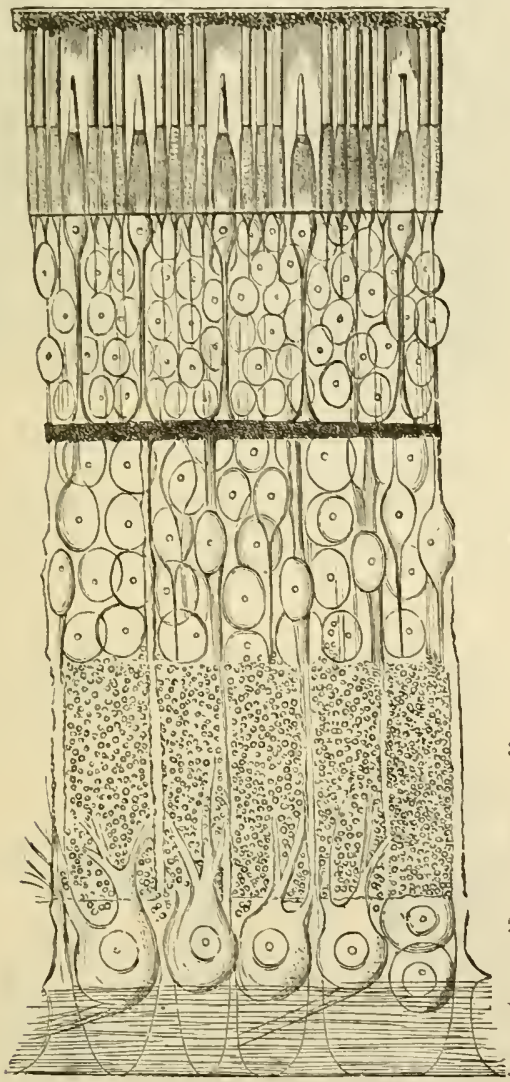

S. Layer of pigment-cells.

7. Layer of rods and cones.

. Membrana limitans externa.

6. Outer nuclear layer.

5 Outer synapse or molecular layer.

4. Inner nuclear or bipolar layer.

3. Inuer synapse or molecular layer.

2. Layer of optic nerve-cells.

1. Layer of optic nerve-fibres.

lnuer surface.

Fig. 511. -Diagramiatic sectios of the humax retiNa, (M. Schultze.)

the inner nuelear layer (fig. 514 and fig. $513, j$ ). The layer of nervefibres becomes gradually thinner in the anterior part of the retina.

The layer of optic nerre-cells, or ganglionic layer, is composed of nerve cells somewhat like the cells of Purkinje of the ecrebellum but varying in size, although those of large size are prevalent in most parts of the retina. In the yellow spot, on the other hand, smaller nerve-cells are met with, and they may here lie several deep. These nerve-cells have 


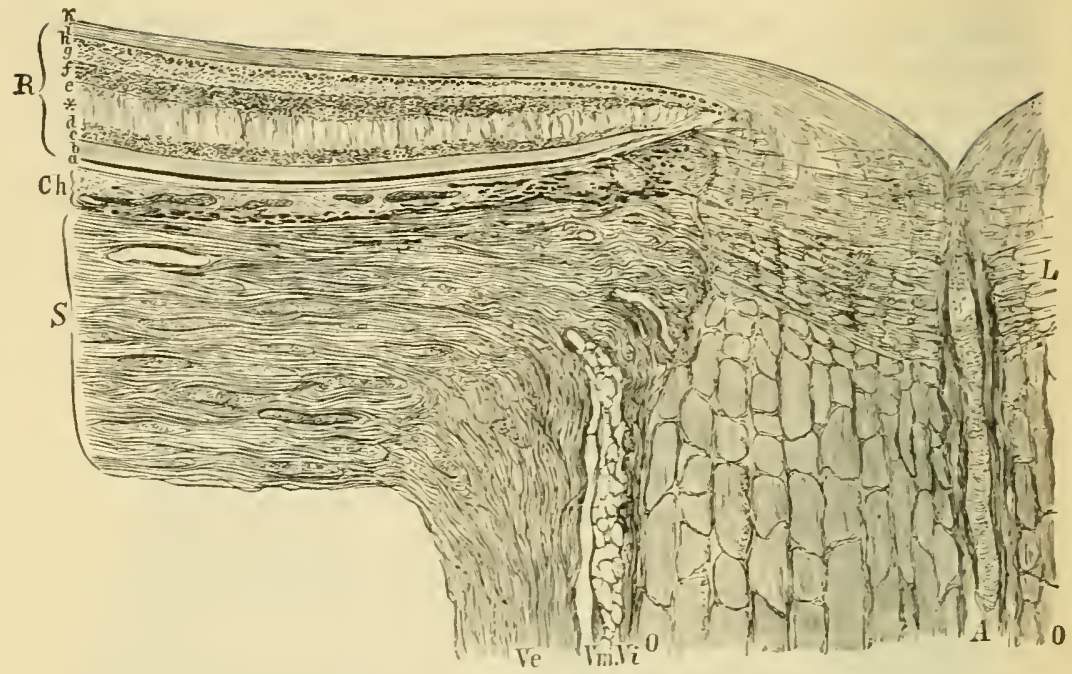

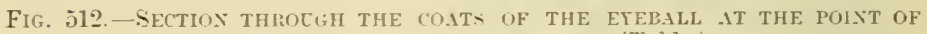
EXTRAICE OF THE OPTIC NERTE. (Tolil.)

$\Gamma \epsilon$, dural sheath; $\Gamma_{m}$, arachnoidal sheath, and $I^{\prime}$, pia-matral sheath of the optic nerre, with lsmphatic spaces between them; $O, O$, funiculi of the nerre $: L$, lamina cribrosa: $A$, central arters; $s$, sclerotic ; $C \%$, choroid; $R$, retina. The small letters refer to the rarious parts of the retina, $l$ being the lager of rods and cones, and $i$ tbat of nervefibres.

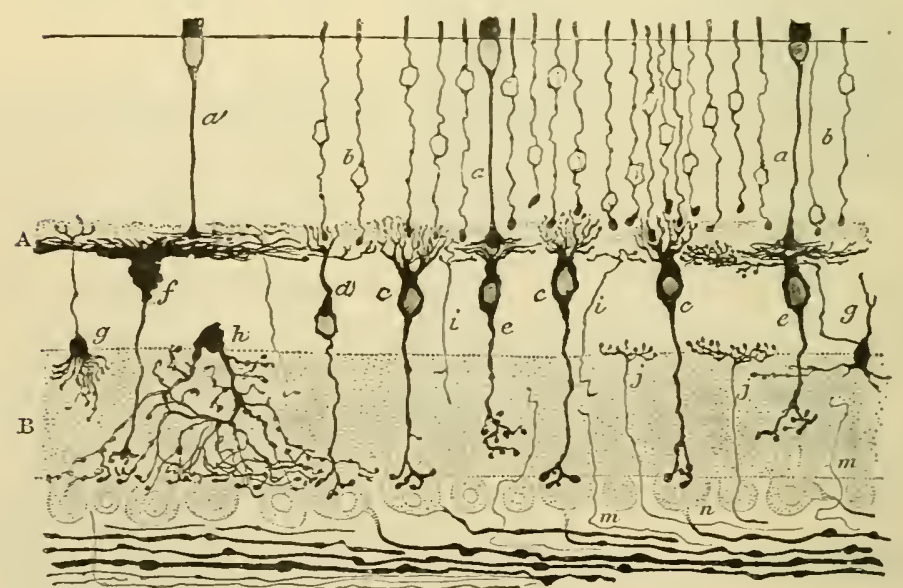

Fig. 513.-SECTION OF DOG's RETINג, GOLGI yethod. (Cajal.)

$a$, cone-fibre; $b$, rod-fibre and nucleus : $c, d$, bipolar cells (inner gramules) with vertica] ramifications of their outer processes or dendrons: in the centre of the ramification lie the enlarged ends of rod-fibres; $\epsilon$, other bipolars with flattened ramifications abutting against ramificd ends of cone-tibres; $f$, large bipolar with fattened ramification; $\%$, iuner granule-cell sending an axon towards the rod and cone-fibres; $h$, amacrine cell with diffusc arborisation of its processes in inner molecular layer; $i, j, i$, nerre-fibrils passing re:-pectively to outer molecular, inner nuclear, and inner molecular layers; $n$, ganglionic cells, with axons passing into netre-fibre layer. 
a fine axis-cylinder proeess prolonged into a fibre of the layer just noticed, and a thick branching process, the ramifications of which terminate in the next layer in flattened arborisations at different levels (fig. 515, A, B, C).

The inner synapse layer or inner moleculur layer is comparatively thick, and has an appearance very like parts of the grey matter of the nerve-

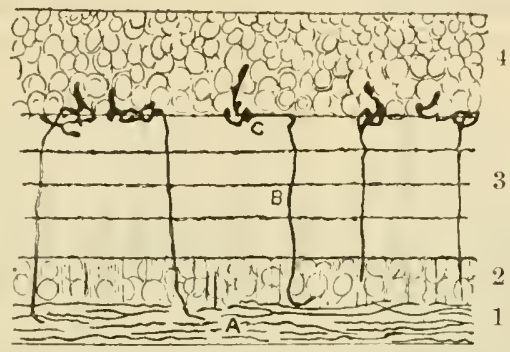

FIG. 514.-SECTION THROCGH THE INNER LAYERS OF THE IRETINA OF A BIRI), PREPARET BY GOLGI'S METHOI). (Cajal.)

A, nerve-fibres of optic nerve layer; B, some of these fibres passing through the inner molecular layer to end in an arborisation at the junction of the inner molecular and inner nuclear layers. The layers in this and in the two succeeding cuts are numbered in correspondence with the layers in fig. 511.

centres. A few nuclei are seattered through it, and it is occupied by the processes of the nerve-cells and of the inner granules (bipolars and amacrine cells) which form synapses in it; it is also traversed by the centrifugal fibres from the optic nerve layer, as well as by the fibres of Müller.

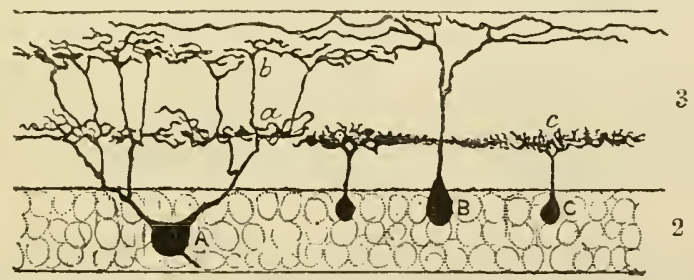

Fig. 515. - SECTION ACROSS THE MOLECULAR AND GANGLIONIC LAYERS OF BIRT'S RETINA, PREPARED BY GOLGI's METHOD. (Cajal.)

Three or four ganglionic cells, A, B, C, and the terminal arborisations of their dendrons, $a, b, c$, in the molecular layer, are shown.

The inner granule layer (also termed inner nuclear layer) is mainly composed of bipolar nerve-cells containing large nuclei. A process (the axon) of each of these cells (fig. 513) extends inwards into the inner molecular layer where it spreads out into a terminal arbori. sation. These arborisations oceur at different levels in the layer, forming synapses with the optic nerve-cells. Another process (dendron) is directed outwards, and arborises in the outer molecular 
layer, where it forms synapses with the terminations of the rod-and cone-fibres. It has been shown by Ramón y Cajal that there are two kinds of bipolars, one kind (rod-bipolars, fig. 513, c.d) being connected externally with the rods of the retina, and passing inwards to ramify over the bodies of the nerve-cells, whereas those of the other kind (cone-bipolars, $e$ ) are connected with the cone-fibres, and ramify in the middle of the inner molecular layer. The ontwardly directed processes of these cone-bipolars are, in sone animals, but not in mammals,

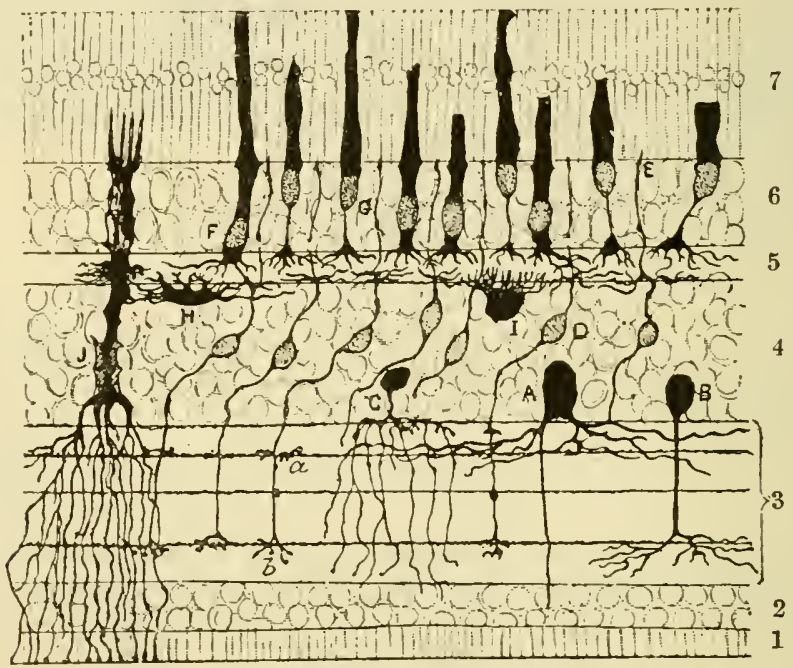

Fig. 516.- SECtion OF BIRD's RETINA, PREPARED BY GOLG's METHOD. (Cajal.)

A, large nerve-cell of inner nuclear layer ; B, C, amacrine cells ; D, small bipolar nervecells with one process, ramifying in the immer molccular layer and the other one ramifying in the outer molecular layer, and extending (E) as far as the rods and cones as a fibre of Landolt; F, G, rod-and cone-nuclei respectively; H, 1, cells with dendrons ramif fing in outer molecular layer; J, fibre of Milller.

continued on as far as the external limiting membrane, where each ends in a free extremity (fibre of Landolt, fig. 516, E). Besides these bipolar nerve-cells, there are other larger inner granules (spongioblasts of some authors) which are different in character, having ramified processes which extend into the inner molecular layer (figs. 513, $h$; 516, A, B, C), in which the bodies of these cells are often partly embedded. The cells in question have been regarded as of the nature of neuroglia-cells, but according to Cajal they are probably all nervecells. He has termed them amacrine-cells, from the fact that they are destitute of a long process; but some have been noticed to give off, besides the branching processes or dendrons, which ramify in the molecular layer, an axis-cylinder process which may extend into the 
nerve-fibre layer. There are also some eells in the outer part of the granule layer which send their processes entirely into the onter molecular layer (fig. 516, 11). These are the horizontul-cells of Ramón y Cajal (termed spongioblasts of outer moleeular layer by some authors). The fibres of Miiller have nueleated enlargements (fig. 516, J) in the inner nuclear layer.

The outer molecular layer is thin, and is composed mainly of the arborisations of the inner granules, of the rod and cone-fibres, and of the horizontal cells (figs. 513, 516), which all form synapses in this layer.

The outer muclear layer and the layer of rods and cones are composed of elements which are continuous through the two layers, and they should properly, therefore, be described as one. It has been termed the sensory epithelium of the retina (fig. 517, 6 and 7). The elements of which this nerveepithelium consists are elongated nerve-cells of two kinds. The most numerous, which may be termed the rod-elements, consist of peculiar rod-like structures (retinal rods) set closely side by side, each of which is prolonged internally into a fine varicose fibre (rod-fibre) which swells out at one part of its course into a nucleated enlargement, and ultimately ends (in mammals) in a minute knob within the outer molecular layer, where it is em-

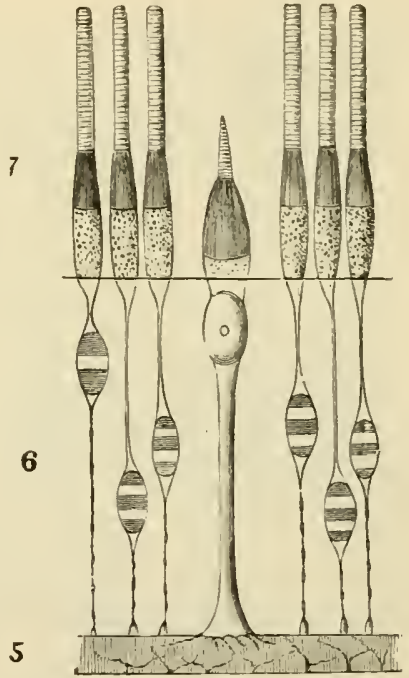

Fig. 517.-Diagramatic RepreSENTATION OF THE ROD AND CONE ELEMENTS OF THE RETINA. (After Sichwalbe.)

The designation of the numbers is the same as in fig. 5 !l. bedded in the ramifications of the dendrons of the rod-bipolars. The rod consists of two segments, an outer cylindrical and transversely striated segment, which during life has a purplish-red colour if the eye has not been recently exposed to light, and an inner slightly bulged segment which in part of its length is longitudinally striated. The nucleus of the rod-element in some animals, but according to Flemming not in man, has a transversely shaded aspect in the fresh condition (fig. 517). The cone-elements are formed of a conical tapering external part, the retinal cone, which is directly prolonged into a nucleated enlargement, from the farther side of which the cone-fibre, considerably thicker (in mammals) than the rod-fibre, passes inwards, to terminate by an expanded arborisation in the outer mole- 
cular layer; here it comes into relation with a similar arborisation of dendrons of a cone-bipolar. The cone, like the rod, is formed of two segments, the outer of which, much the smaller, is transversely striated; the inner, bulged segment being longitudinally striated.
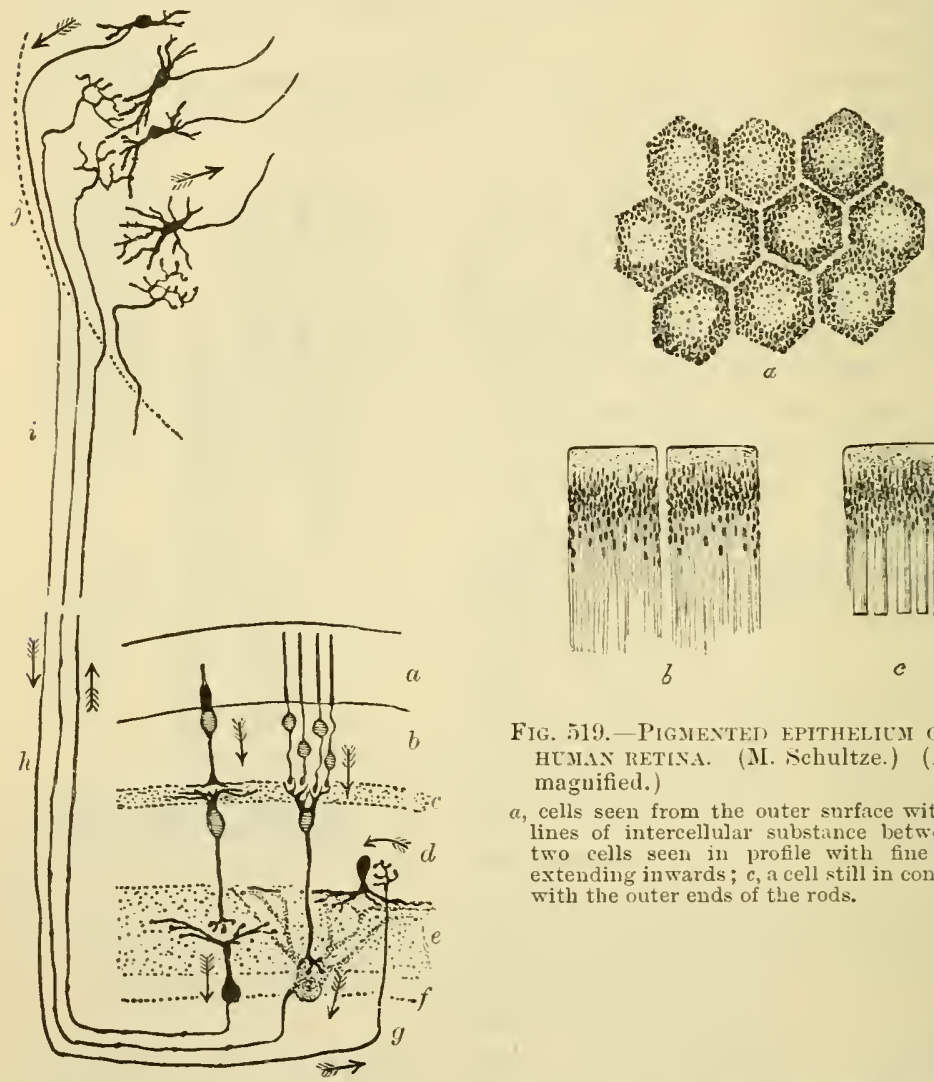

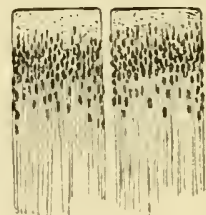

b

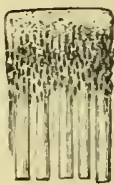

c

Fig. 519. - PIgyexten EPITHELICI OF THE HCM.1. RETIxA. (M. F̈chultze.) (Highly magnified.)

$a$, cells seen from the outer surface with clear lines of intercellular substance betwecn; $b$, two cells seen in profile with fine offsets extending inwards; $c$, a cell still in connection with the outer emds of the rods.

Fig. 518.-DIAGRAM OF THE CONNECTIONS OF THE RETINAL ELEMENTS WITH ONE ANOTHER ANT WITH THE CENTRAL XERTOLS SYSTEM. (Cajal.)

$a$ to $g$, layers of retina; $a$, rods and cones; $b$, outer nuclear laser; $c$, outer molecular layer; $d$, inner nuclear laser; $c$, inner molecular laser; $i$, nerre-cells giving origin to fibres of optic nerve; $q, k, i$, a centrifugally conducting fibre, with a terninal arborescence in the retina; $j$, grey matter of corpus geniculatum or corpus quadrigeminum.

The inner encls of the rod- and cone-fibres, as already stated, form synapses with the peripheral arborisations of the bipolars, and through the latter elements and their synapses in the inner molecular layer a connection is brought about with the nerve-cells and nerve-fibres of the innermost layers. The connection of the retinal elements with one another and through the optic fibres with the central nervous 
system (auterior corpora quadrigemina and lateral geniculate bodies) is shown diagrammatically in fig. 518.

In birls, reptiles, and amphibia, a small oil-ghlobule, often bioghtly coloured red, yellow, or green, is found in the inner segment of each cone. Other variations of strueture are met with in different arimals.

The cones are most numerous at the back of the retina; they are fewer in number, and the rols are proportionally more numerous towards the anteriol part.

$\Lambda$

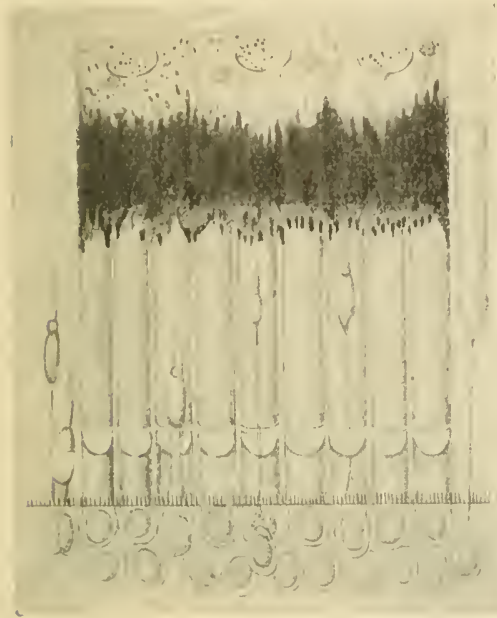

1)

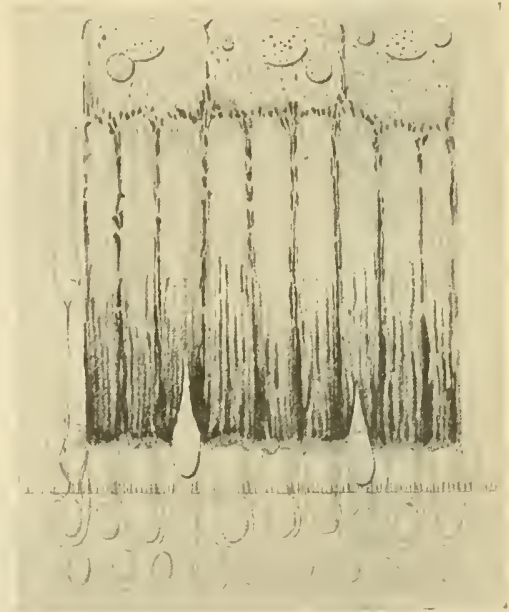

FrG. 530. - A. PART OF A SECTION OF THE RETINA FROM THE EYE OF A FROG WHICH HAI BEEN KEPT IN THE DARK FOR SOME HOURS BEFORE DEATH. (v. Genderen-Stort.)

The pigment is collected towards the outer cnds of the rods, which were red, except the onter detached rod, which was green. The cones, which in the frog are much smaller than the rods, are mostly elongated.

B. A SIMLAR SECTION FRON A FROG WHICH HAD BEEN EXPOSED TO LIGHT.

The pigment is extended between the rods, and is accumulated near their bases. The rods were colourless. All the cones are contracted.

The pigmentary layer forms the most external part of the retina. It consists of hexagonal epithelium-cells (fig. 519), which are smooth externally where they rest against the choroid, but are prolonged internally into fine filaments which extend between the rods. The pigment-granules, many of which are in the form of minute crystals, lie in the inner part of the cell, and after prolonged exposure to light they are found extending along the cell-processes between the rods (Kühne), their function being probably comneeted with the restoration of the purple colouring matter which has been bleached by the light. This extension of the pigment is accompanied by a shortening of the cones (Engelmann) (fig. 520). 
Fibres of Muiller.--The fibres of Muiller (fig. 516, J, and fig. 521) are long stiff cells which pass through several of the retinal layers. Commencing at the inner surface of the retina by expanded bases which unite with one another to form the so called internal limiting membrane (fig. 522), they pass through all the layers in succession, until they reach the outer gramnle layer. Here they branch and

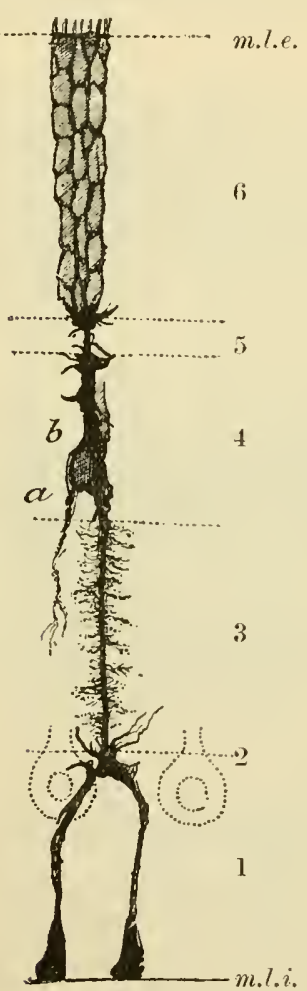

FIG. 521.

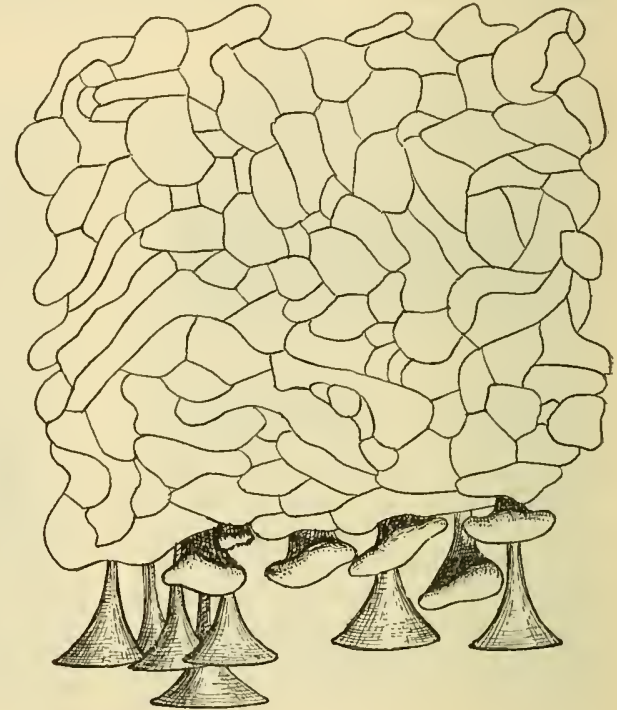

FIG. 522 .

Fig. 521. - A FIBRE OF MÜLLER FROM THE DOG'S RETINA, GOLGI MIETHOI). (Cajal.)

1, nerve-fibre layer; 2, nerve-cell layer ; 3 , imner moleeular layer ; 4 , inner gramule lay er ; 5 , outer molecular layer ; 6 , outer granule layer; $b$, nueleus of the fibre; $a$, a nrocess extending into inner molecular layer; m.l.i., membrana limitans interna; m.l.t., membrana limitans externa.

Fig. 522.-INTERNAL LIMITING MEMBRANE OF RETINA TREATED WITH SILVER NITRATE, SHOWING THE OUTLINES OF THE BASES OF THE FIBRES OF MÜLLER. (G. Retzius.)

expand into a sort of honeycomb tissue which serves to support the fibres and nuclei of the rod-and cone-elements. At the bases of the rods and cones, this sustentacular tissue ceases, being here bounded by a distinct margin which has been called the external limiting membrane (fig. 521, m.l.e.), but delicate sheaths pass from it around the bases of the rods and cones. Each Müllerian fibre, as it passes through the inner granule layer, has a nucleated enlargement $(b)$, indicating the cell-nature of the fibre. The fibres of Muiller represent ependyma 
cells or perhaps long nenroghia-eells such as are found in some parts of the nerve-centres, e.g. the cerebellum (see fig. $479, g^{3}$ ).

'There are two parts of the retina which eall for special description.

The macula lutea (yellow spot), with its central fovea, is the part of the retina which is immediatcly concerned in direct vision. It is characterised firstly by its greater thiekness (exeept at the middle of the fovea), secondly by the large number of its ganglion-cells, which are rounded or conical, and thirdly by the large number of cones

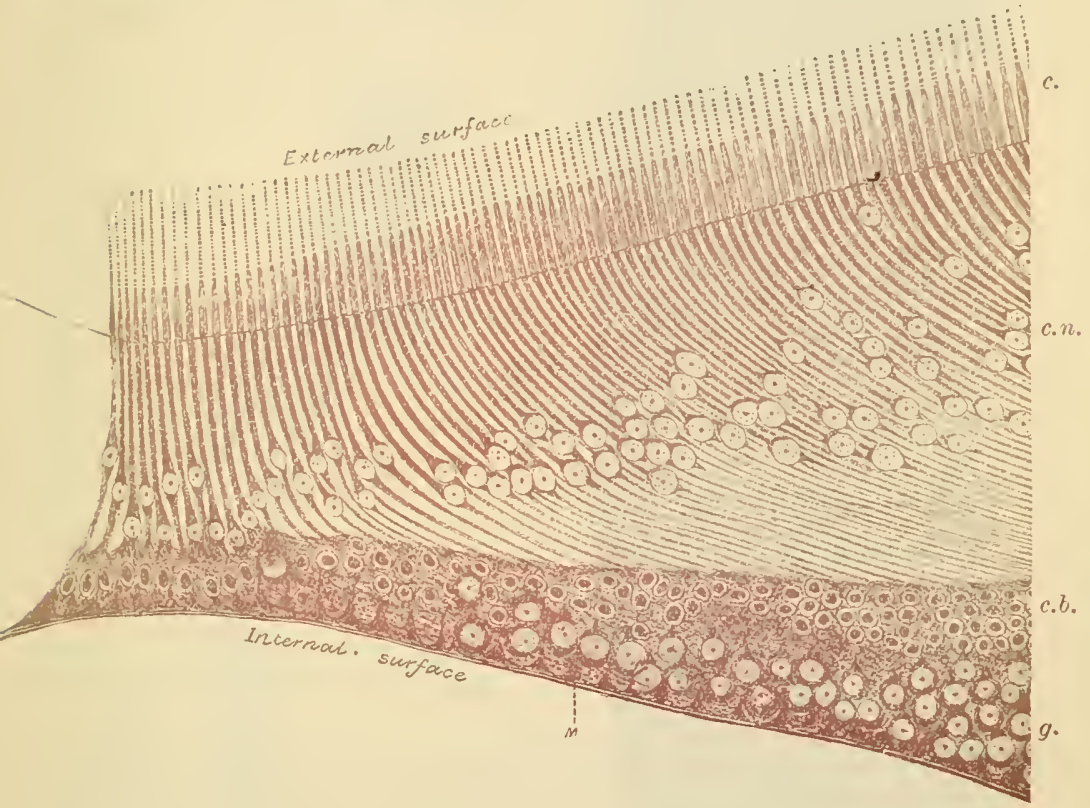

FIG. 523. - SECTION THROCGH THE CENTRAL PART OF THE FOVEA CENTRALIS. 3.0. (From a preparation by C. H. Golding-Bird.)

$M$, bases of Mullcrian fibres; $c . b$. , nuclei of inner granules (bipolars); $c . n$. , cone-fibre nuclei ; $c$, cones.

it contains as eompared with the rods. In the eentral fovea itself (fig. 523) there are no rods, and the cones are very long and slender, measuring not more than $2 \mu$ in diameter; all the other layer's become gradually thinned down almost to complete disappearance, so that the middle of the central fovea is the thinnest part of the retina. Since there are few rods, the onter granule layer loses in great measure its appearance of being composed of closely packed nuclei, and the cone-fibres are very distinct, forming the so-ealled fibrous layer. The direction of these fibres is for the most part very oblique in this part of the retina. 


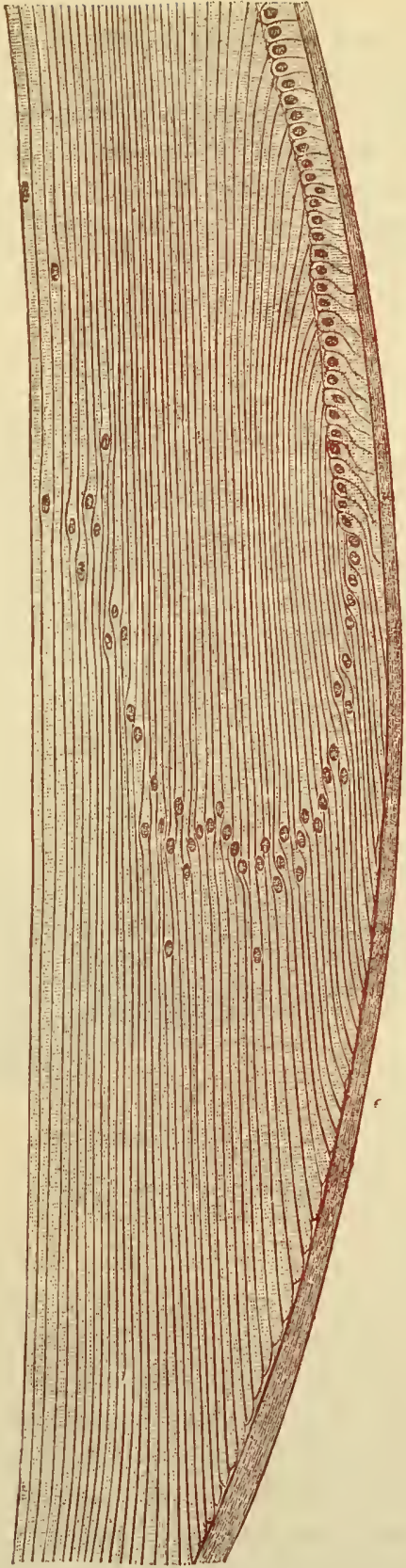

Fig. 525.-SECTION THROUGH THE MARGIN OF THE RABBIT'S LENS, SHOWING THE TRANSITION OF THE EPITHELICI OF THE CAPSULE INTO THE LENSFIBRES. (Babuchin.)

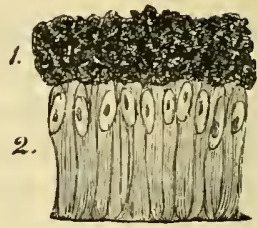

Fig. 524. - A SUALL PORTION OF THE CILIARY PART OF THE RETINA. (Kölliker.) 350 diameters.

1, pigment-cells ; 2, columnar-cells.

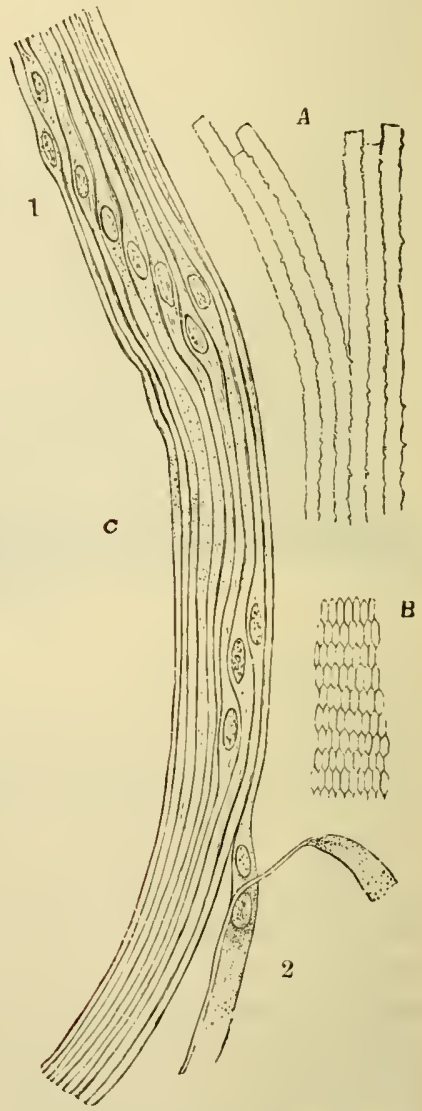

Fig. 526.-Fibres of the CRTstalline LENs. (350 diameters.)

A, longitudinal vicw of the fibres of the lens from the $o x$, showing the serrated edges. $B$, transverse section of the fibres of the lens from the human eye. C, longitudinal view of a few of the fibres from the equatorial region of the human lens. Most of the fibres in $\mathrm{C}$ are seen edgewise, and, towards I, present the swellings and nuclei of the 'nuclear zone'; at 2 , the flattened sides of two tibres are seen. A and B from Kölliker; C from Henle.) 
The pigmentary layer is thickened over the fovea, and there is also a thickening in the choroid coat here, due to a large accumulation of capillary vessels.

The pars ciliaris retinæ, which commences at the ora serrata, where the retina proper abruptly ends, is composed of two epithelial layer's (fig. 524), and has 110 nervous structures. Of the two layers, the external is a thick stratum of pigmented epithelium formed of rounded cells and continuous with the pigmentary layer of the retina on the one hand, and with the uvea of the iris on the other; the inner is a layer of columnar cells, each containing an oval nucleus. They probably represent the Müllerian fibres of the retina.

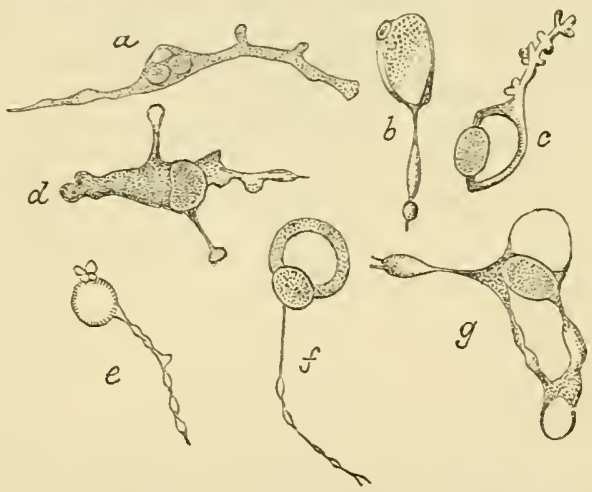

Fig. 527.-Cells of vitreocs. (Schwalbe.)

$a, d$, without vacuoles ; $b, c, \epsilon, J, g$, with racuoles.

The retina contains but few blood-vessels. The central artery enters and the vein leaves it in the middle of the optic nerve. The larger vessels ramify in the nerve-fibre layer, and there are capillary networks in this layer and in the inner nuclear layer. There are perivascular (ly $\mathrm{mph}$ ) spaces around the veins and capillaries. The sensory epithelium receives no blood-vessels, but is nourished from the ressels of the choroid.

The lens.- The lens is a laminated fibrous body inclosed by a transparent elastic capsule to which, around the circumference, the fibres of the suspensory ligament are attached (fig. 508). Immediately within the capsule, in front and at the sides, there is a layer of cubical epithelium termed the epithelium of the capsule, but at the margin of the lens the cells become longer and pass by a gradual transition into the lens-fibres (fig. 525). The fibres which compose the lens are long and riband-shaped, with finely serrated edges (fig. 526, A); in transverse section they appear prismatic (B). Many of the superficial fibres are 
nucleated (c), the lens-fibres having originally been developed by the elongation of epithelium-cells.

The vitreous humour.-This is composed of soft gelatinous tissue, apparently structureless when examined in the fresh condition, but containing fibres and a few scattered cells, the processes of which are often long and varicose, and the cell-bodies distended by large vacuoles (fig. 527). The hyaloid membrane, which invests the vitreous humour, is homogeneous and structureless except in the region of the ciliary processes, where it is fibrous in structure, forming the zonule of Zinn and spreading out into the suspensory ligament of the lens (fig. 508). This part of the hyaloid membrane is connected with a circular fibrous portion of the vitreous humour which serves to give additional firmness to the attachment of the fibres of the suspensory ligament of the lens (Anderson Stuart). 


\section{LESSON TLIX.}

\section{STRUCTURE OF THE OLFACTORY MUCOUS MEMBRANE AVD UF THE EXTERALL AND VIDDLE EAR.}

1. Vertical sections of the nasal mucous membrane. The sections may be carried either across the upper turbinate bone, after decalcification or across the upper part of the nasal septum. Make a sketch nnder the low power. Notice the difference in the character of the epithelium in the olfactory and respiratory parts of the membrane.

2. Teased preparation of the epithelinm of the olfactory mucous membrane. A piece of the membrane is placed quite fresh in osmic acid ( 1 per cent.) for a few hours, and is then macerated for two days or more in water. The epithelium is broken up in dilnte glycerine; the cells easily separate from one another on tapping the cover-glass. Notice the two kinds of cells. Sketch some of the cells under a high power. ${ }^{1}$

3. Sections of the external ear (these have been already studied for the cartilage, Lesson XII.).

4. Sections across the cartilaginous part of the Enstachian tube. Sketch mider the low power.

5. Preparation of the membrana tympani. A piece of the membrane, stained with magenta and gentian violet (see Lesson IX., 52 ), is mounted flat in xylol balsam or damnar.

Determine the composition of the membrane-i.e. the several layers composing it-by focussing carefully with the high power.

\section{THE OLFACTORY MUCOUS MEMBRANE.}

The olfactory region of the nasal fossæ includes the upper and middle turbinate processes and the upper third of the septum. It is covered by a soft vascular mucous membrane of a yellow colour in man.

The epithelium of the olfactory mucous membrane (figs. 528, 529) is very thick and is composed of long cells, set closely side by side and bounded superficially by a cuticular lamina, through which the free ends of the cells project. The cells are of two kinds: 1. Long narrow spindle-shaped or bipolar nerve-cells consisting of a larger part or body $(b)$, containing the nucleus, and of two processes or poles, one (c) straight and cylindrical and extending to the free surface, the other (d) very delicate and varicose, looking not unlike a nerve-fibril and

${ }^{1}$ The connection of the olfactory cells with the olfactory nerve-fibres is displayed in embryos, the method of Golgi being employed. 
extending down towards the corium. The position of the nuclear enlargement varies, and with it the relative length of the two processes. The distal or free process terminates in a small clear projection, which passes beyond the cuticular membrane; in amphibia, reptiles, and birds, and perhaps also in mammals, it bears fine stiff hairlike fila. ments. The proximal or varicose process becomes lost amongst the plexus of olfactory nerve-fibres at the base of the epithelium; it is connected with one of these fibres, and ultimately passes through the
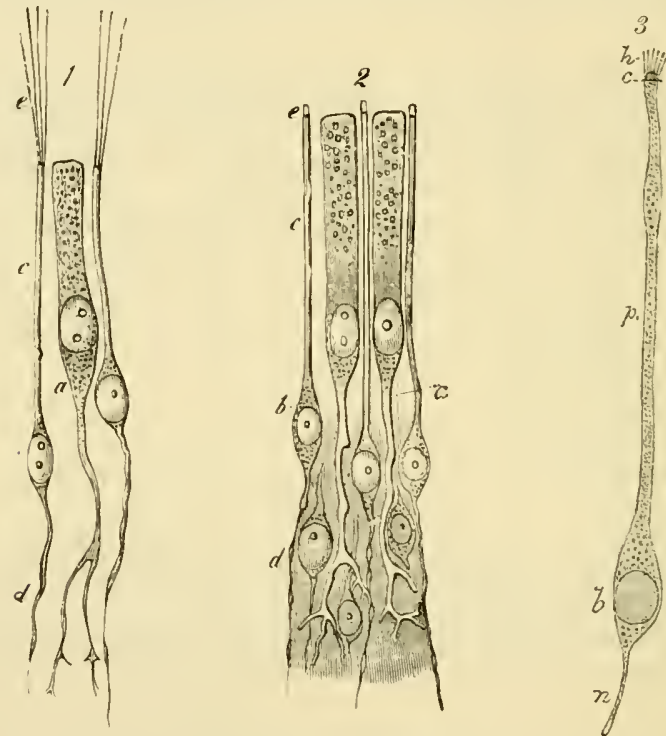

Fig. 528.-CElls ANI) TERMiNAL NERVE-Fibres OF THE OLFACTORY REgioN. (Highly magnified.)

1 , from the frog; 2 and 3 , from man. In 1 and $2:-a$, epithelial cell, extending deeply into a ramified process; $b$, olfactory cells; $c$, their peripheral rods; $e$, the extremi ties of these, scen in 1 to be prolonged into fine hairs; $d$, their central filaments. In $s:-h$. hairlets; $c$, free border of cell; $p$, peripheral process; $b$, body of cell; $n$, nerve-fibre. 1 and 2 from $M$. Schultze; 3 from $v$. Brumn.

cribriform plate of the ethmoid to end in an arborisation within one of the olfactory glomeruli (see diagram, fig. 495, p. 438). These cells have been termed the olfuctory cells. 2. Long columnar epithelium cells (a), with comparatively broad cylindrical nucleated cell-bodies placed next to the free surface, and long, forked, and branching tail-like processes extending down to the corium. These are regarded not as sensory epithelium-cells, but merely as serving to support the proper olfactory cells. They are the columnar or sustentacular cells. 3. Tapering cells are present, at least in some animals, in the deeper part of the epithelium. They rest by their bases upon the corium, and project between the other cells, which they assist to support. 
The corium of the olfactory nucous membrane is also very thiek (fig. 529). It contains numerous blood-vessels, bundles of the olfactory nerve-fibres (whioh are non-medullated), and a large number of serous glands known as Bowman's glands (b), which open upon the surface by duets which pass between the epithelium-cells.

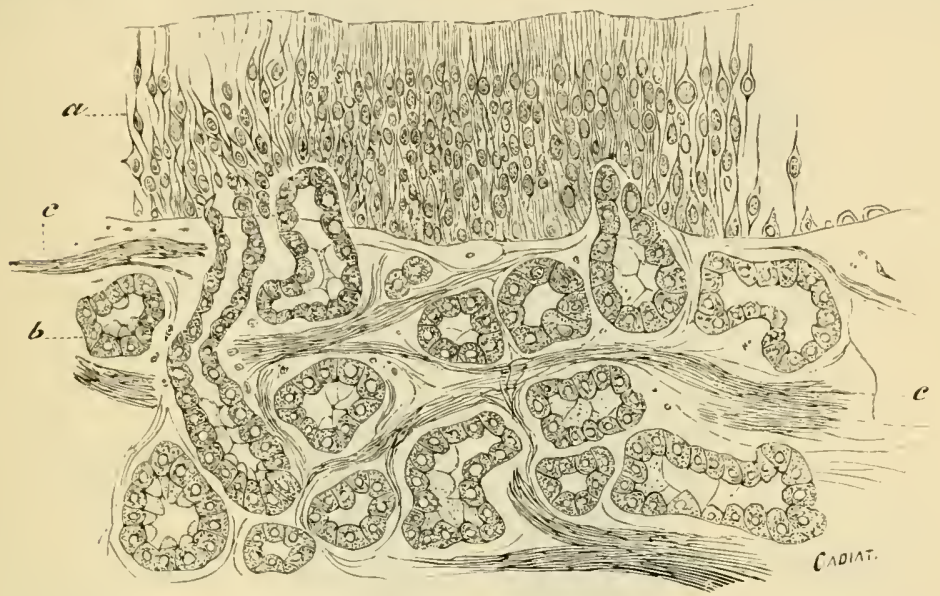

Fig. 529.-Section of Olfactory mucous membrane. (Cadiat.)

", epithelium ; $b$, glands of Bowman ; $c$, nerve-bundles.

THE EXTERNAL AND MIDDLE EAR.

The external ear proper (pinna) is composed of elastic fibro-eartilage, invested by a thin closely adherent skin. The skin 'is covered by small hairs, and connected with these are the usual sebaceous follicles. In the lobule there is a considerable amount of adipose tissue; and voluntary muscular fibres are in places attached to the eartilage of the pinna, and are seen in sections.

The external auditory meatus is a canal formed partly of cartilage continuous with that of the pinna, partly of bone. It is lined by a prolongation of the skin and is elosed by the membrana tympani, over which the skin is prolonged as a very thin layer. Near the orifice the skin has hairs and sebaceous glands, and the meatus is also provided throughout the cartilaginous part with small convoluted tubular glands of a brownish-yellow colour, which yield a waxy secretion (ceruminous glands). They appear to represent modified sweat-glands. They are represented in fig. 530 .

The tympanum is lined by a mueous membrane which is continuous through the Eustachian tube with the mucous membrane of the pharynx; it is also prolonged into the mastoid cells. The epithelium 
is columnar and ciliated in some parts, but in others-e.g. roof, promontory, ossicles, and membrana tympani-it is a pavementepithelium.

The membrana tympani is a thin membrane formed of fibrous bundles which radiate from a central depression (umbo). Within the radial fibres are a few annular bundles. Covering the fibrous

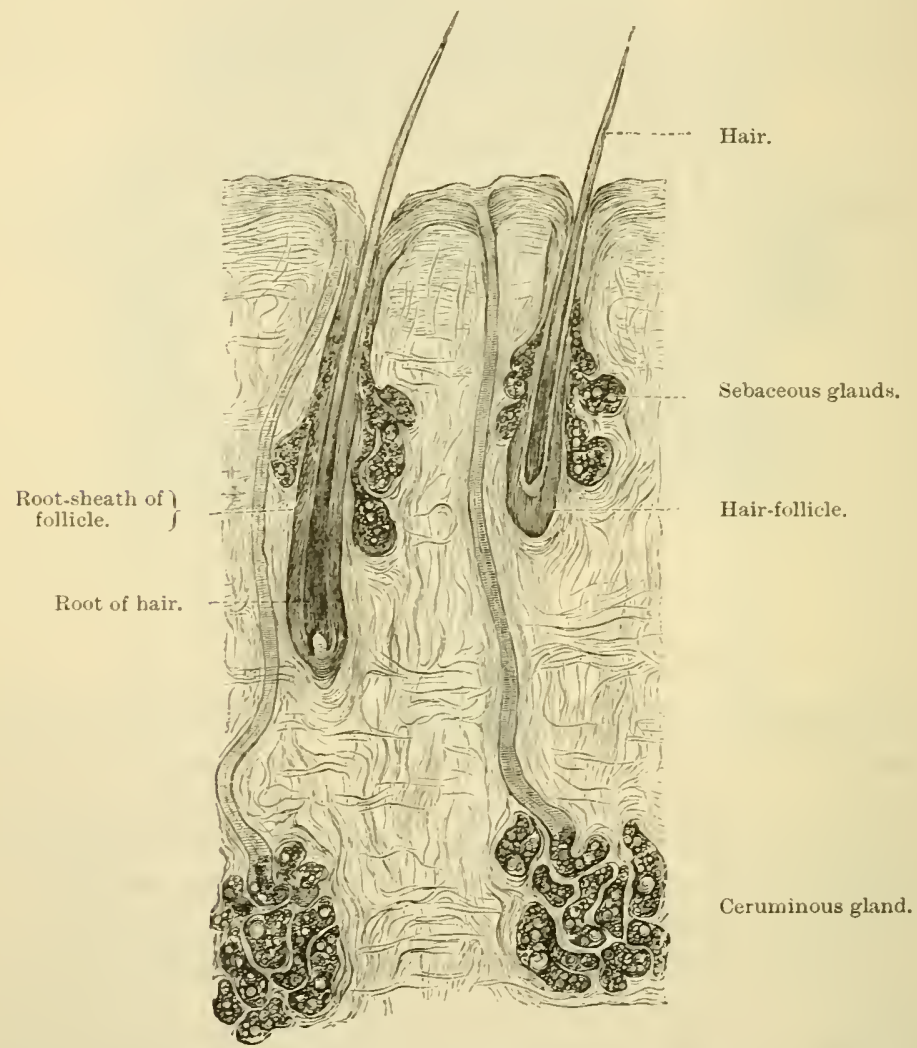

Fig. 530.-CERcyinot's glaNds aNd hairs of the EXtersal Ear. (Grüber.)

membrane externally is a thin layer continuous with the skin of the meatus; covering it internally is another thin layer, derived from the mucous membrane of the tympanic cavity. Blood-vessels and lymphatics are distributed to the membrane chiefly in the cutaneons and mucous layer's.

The Eustachian tube is the canal leading from the tympanum to the pharynx. It is formed of bone near the tympanum, but below, 
near the pharynx, it is bounded partly ly a bent piece of cartilage (fig. 5.31, 1, 2), partly hy fibrous tissue. The latter contains numerous

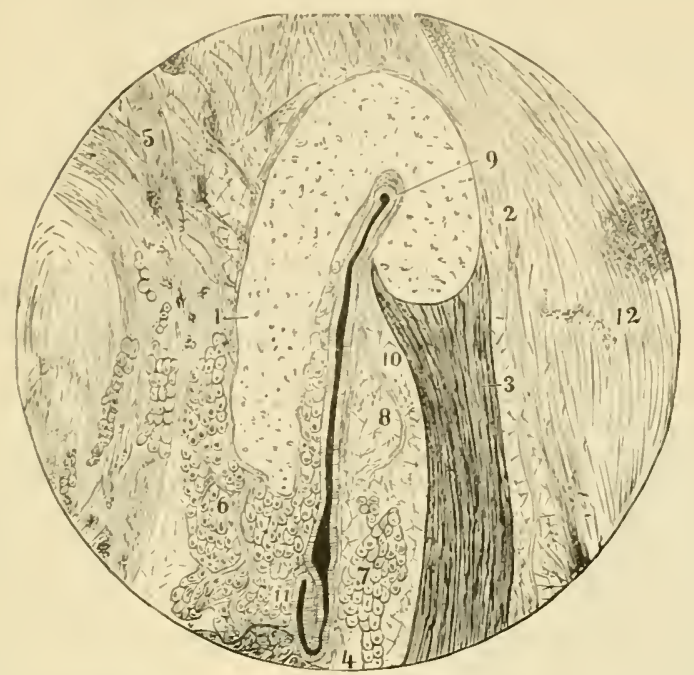

FIG. 531. -SECTION ACROSS THE CARTILAGINOC'S PART OF THE ECSTACHIAN TLBE. (Pü̈linger.)

1, 2, bent cartilaginous plate; 3 musc dilatator tube; to the left of 4 , part of the attachment of the levator palati muscle; 5 , tissue uniting the tube to the base of the skull; 6 and 7 , mucous glands; 8,10 , fat; 9 to 11 , lumen of the tube; 12 , connective tissue on the lateral aspect of the tube.

mucous glands $(6,7)$, which open into the tube, and on the outer side a band of muscular tissue (3) which joins the tensor palati. The epithelium is ciliated. 


\section{LESSON L.}

\section{THE INTERNAL EAR.}

1. Sectioss across one of the membranous semicircular canals of a fish (skate).

2. Longitudinal sections throngh the ampulla of a semicircular canal (skate).

1 and 2 may be hardened in chromic and osmic acid (see below under 5) and emberlded in celloidin.

The semicircular canals and their ampulle may also be seen cut across in sections of the petrosal of the guinea-pig or other mammal.

3. Golgi preparations of the macula of the ntricle from the skate.

4. Teased preparations of the auditory epithelium of an ampulla or of the macula of the utricle, from the skate.

5. Vertical sections through the middle of the cochlea of a mammal (guinea-pig).

The cochlea is put quite fresh into $0: 2$ per cent. chromic acid containing one-fifth its volume of 1 per cent. osmic acid, or into Flemming's solution, or 10 per cent. formol. The decalcification can be effecter by the use of the phloroglucin-nitric acid fluid, or by sulphurous acid. ${ }^{1}$ When decalcified, the preparation is well washed, and then transferred to alcohols of gradually increasing strength.

In preparing sections of the above three preparations it is advisable, in order that the epithelium should be kept in position, to embed in celloidin. If the paraffin method of embedding be user, the sections are fixed to the slide by an allhesive process. The organ should preferably be stained in bulk.

6. Teased preparations of the epithelium of the organ of Corti from the guinea-pig.

Both 4 and 6 are made from osmic preparations.

Make sketches from all these preparations under the high power.?

The labyrinth, which is the essential part of the auditory organ, consists of a complex membranous tube lined by epithelium and filled with endolymph, contained within a bony tube-the osseous labyrinth - of corresponding complexity of shape (figs. 532, 533). The membranous labyrinth does not wholly fill the bony cavity; the rest of the space is occupied by perilymph. The membranous labyrinth (fig. 532) is composed of the utricle $(u)$, and the three semicircular canals (each

1 See Appendix.

"For details of the methods of obtaining the various parts of the labyrinth for microscopical examination, the student is referred to the author's Course of Practical Histology. 
with an enlargement or ammella which opens into it), the saccule (s), and the cunul of the cochlea (c.c.).

The branches of the auditory nerve pass to certain parts only of the membranous labyrinth, viz. the macula of the utricle and sacenle, the crista of the ampullie, and along the whole length of the canal of the eochlea (the shaded parts in fig. 532).

It these places the lining epithelium is specially modified to form a sensory or nerve-epithelium; elsewhere it is a simple pavementepithelium.

The membranous semicircular canals and the utricle and saccule are composed of fibrous tissue, which is adherent along one side to the

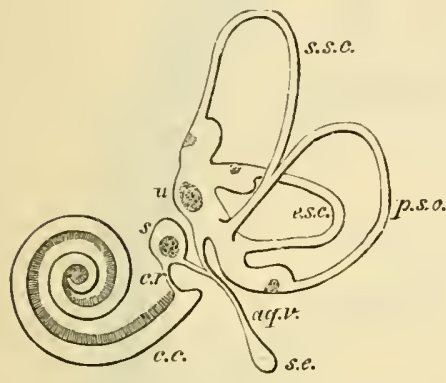

FIG. 532. PLAN OF THE RIGHT MEM BRANOUS LABYRINTH VIEWED FROM THE MESIAL ASPECT, $\frac{2 \frac{1}{2}}{1}$.

$u$, utricle, with its macula and s.s.c., p.s.c., and e.s.c., the three semicireular canals with their ampullæ; s, saccule; $a q . v$. , aquaductus vestibuli; s.e., saccus endolymphaticus; c.r., canalis reuniens; c.c., canal of the cochlea.

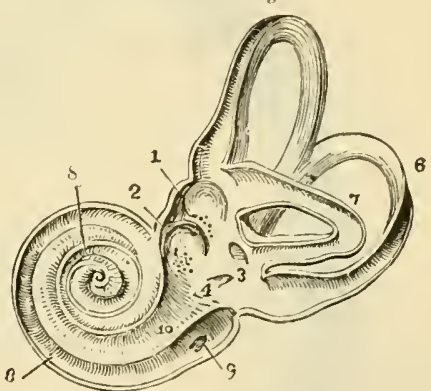

FIG. 533. - VIEW OF THE INTERIOR OF THE LEFT OSSEOUS LABYRINTH

The bony wall of the labyrinth is removed superiorly and externally. 1, fovea hemielliptica; 2 , fovea hemisphrrica ; 3 , common opening of the superior and posterior semicircular canals; 4, opening of the aqueduet of the vestibule; 5 , the superior, 6 , the posterior, and, 7 , the external semicircular canals; 8 , spiral tube of the cochlea ; 9 , scala tympani; 10 , scala vestibuli.

endosteum of the bony canal ; from the opposite side bands of fibrous tissue pass across the perilymph (fig. 534). Within the fibrous membrane is a thick elear tunica propria, which, in the semicireular eanals, may form papilliform elevations in the interior of the tube (fig. 535).

The places of entrance of the nerve-fibres are marked in each ampulla by a transverse, inwardly projecting ridge (crist $\iota$ ), in the saceule and utricle by a thickening of the tuniea propria (macula). The epithelium at these places is formed of columnar cells (fig. 536), which are surmounted by long, stiff, tapering hairs (auditory hairs, fig. $536, h)$. Around these hair-cells the axis-cylinders of the nervefibres ramify (fig. 538); they are therefore-like the gustatory cells of the taste-buds-sensory epithelium cells. Between them are a number 
of thin and somewhat rigid nucleated cells (fibre-cells of Retzins), which rest upon the basement-membrane, and are connected at their free extremity with a euticular membrane, through which the anditory hairs project.

The auditory hairs do not jut freely into the endolymph, but into a soft mucus-like substance, of a dome-like form in the ampullice (cupula

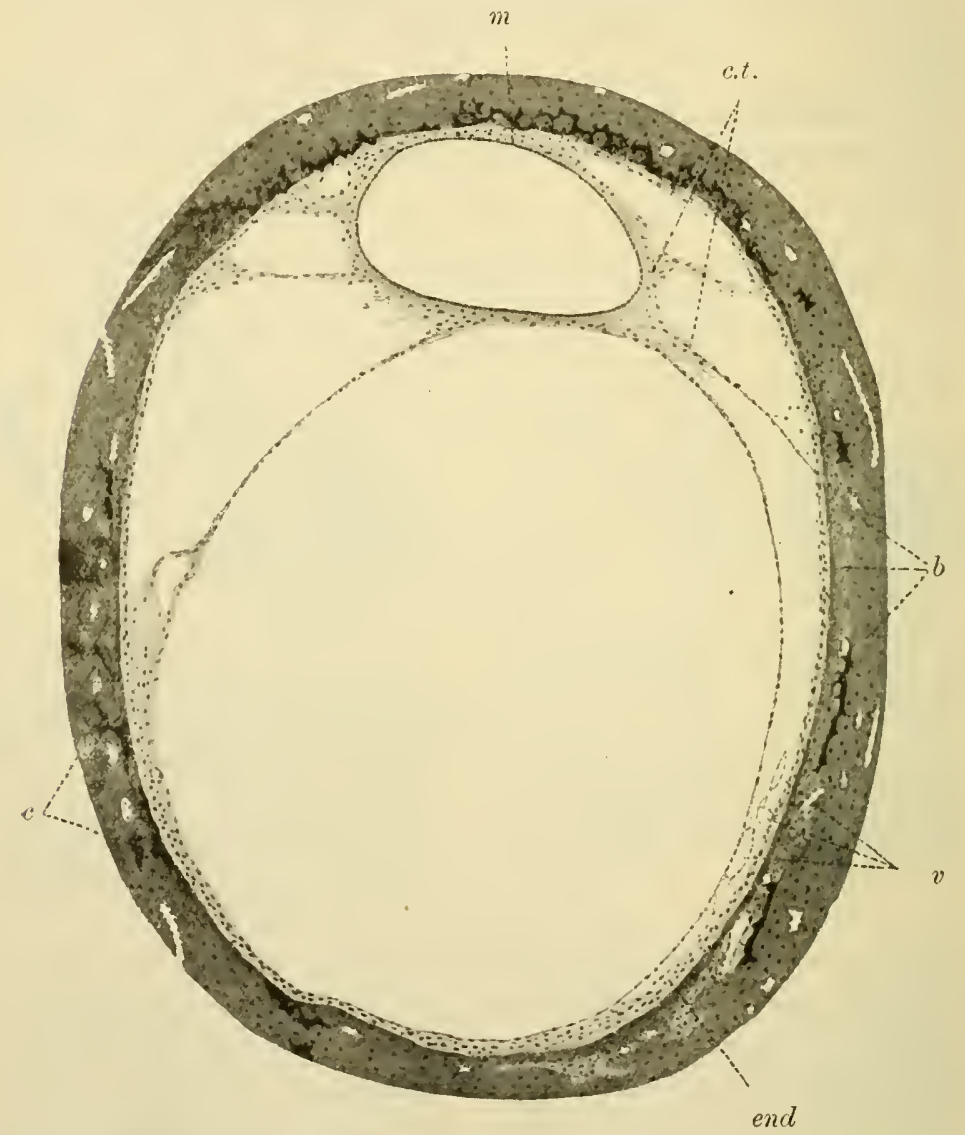

Fig. 534.-SECtION OF A SEMICIRCULAR CANAL, NEW-BORN CHILI. (Sobotta.) $\times 55$.

c.t., connective tissuc strands, between membranous canal and endosteum of bony canal; $i$, membranous canal; $h$, wall of bony canal; $c$, remains of fetal cartilage; end, endosteum ; $v$, blood.ressels.

terminalis, fig. 536), and which in the saccule and utricle has a mass of calcareous particles (otoliths) embedded in it.

The cochlea consists of a bony tube coiled spirally around an axis 


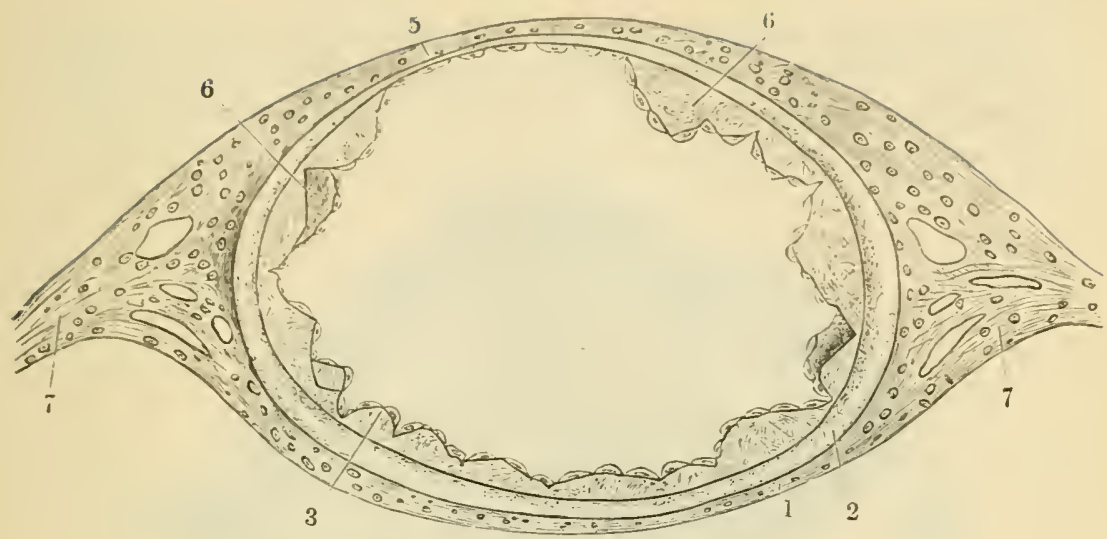

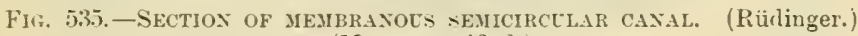

(More magnified.)

1 , outer fibrous layer; 2 , tunica propria; 3,6 , papilliform projections with epithelial covering; $\overline{5}$, fixed side of the canal, with rery thin tunica propria without papillit; 7 , fibrous bauds passing to periosteum.

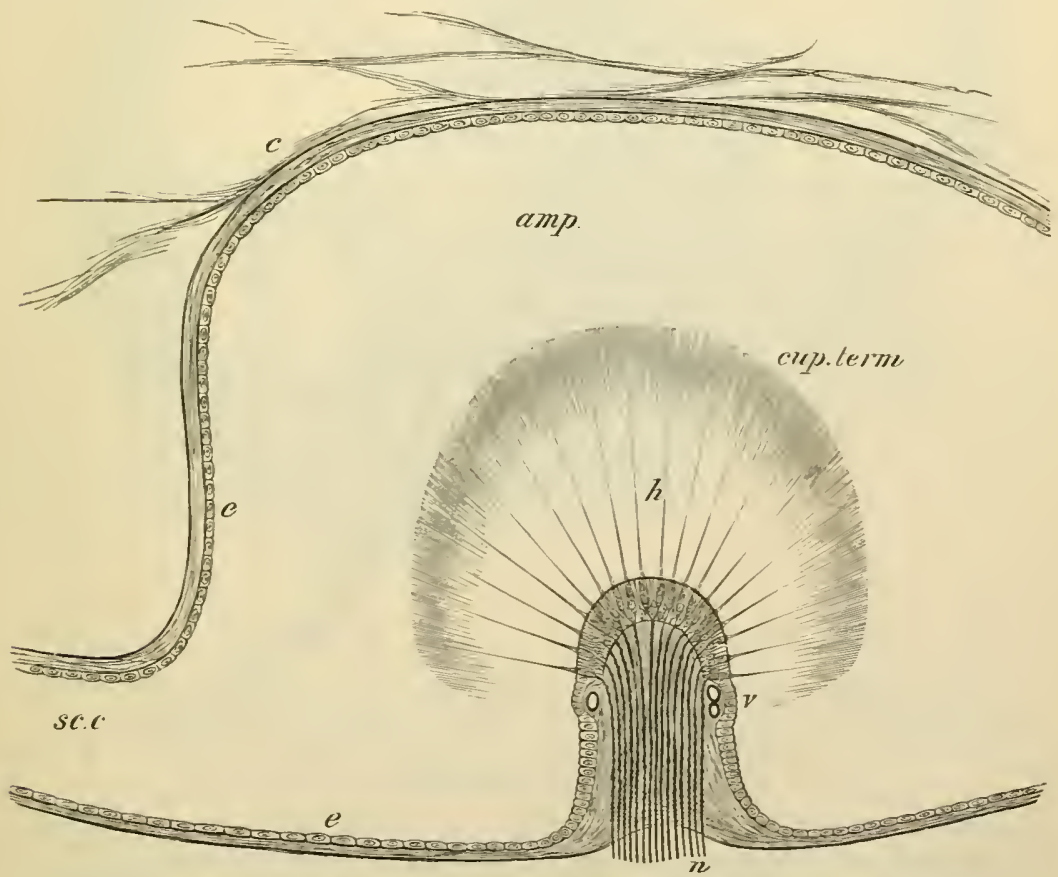

Fig. 536. -LONGITUDINAL SECTION OF AN AMPCLLA THROtgh THE CRISTA ACESTICA (DIAGRAMMATIC).

ump., cavity of the ampulla; sc.c., semicircular canal opening out of it ; $c$, connective tissue attached to the wall of the membranous ampulla and traversing the perilympb; $e, e$, flattened epithelium of ampulla; $h$, auditory hairs projecting from the columuar cells of the auditory epithelium into the cupula, cup.term; $\gamma$, blood-vessels ; $n$, nervefibres entering the base of the crista and passing into the columnar cells. 
which is known as the columella (fig. 539, 540). The tube is divided longitudinally by a partition which is formed partly by a projecting lamina of bone (spiral lamina), partly by a flat membrane (basilar

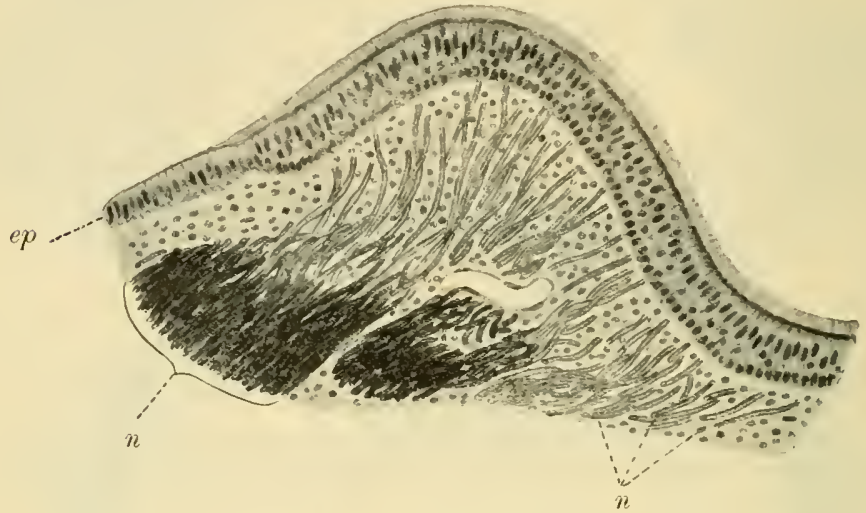

Fig. 537.--Section of Hacela Accstica, cat. (Sobotta.) $\times 120$. $\epsilon p$, epithelium; $n, n$, fibres of vestibular nerve.

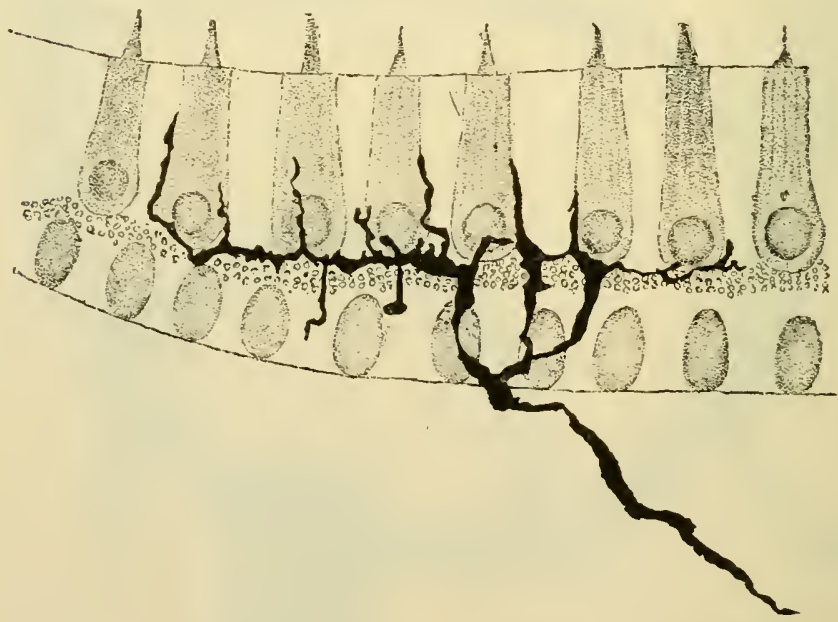

Fig. 538. - Nerve termiNations in MaCUla. Golgi Method. (Barker, from Lénhossek.)

membrane), into two parts or scalce; the upper (supposing the cochlea resting base downwards) being termed the scala restibuli, the lower scala tympani; the latter is closed near its larger end by the membrane of the fenestra rotunda. The scalæ are lined by endosteum, and are filled with perilymph, continuous with that of the rest of the osseous 
labyrinth at the commencement of the scala vestibuli ; they communicate at the apex by an opening, the helicotrema.

The scala vestibuli does not oceupy the whole of that part of the bony tube of the cochlea which is above the partition. Its onter and

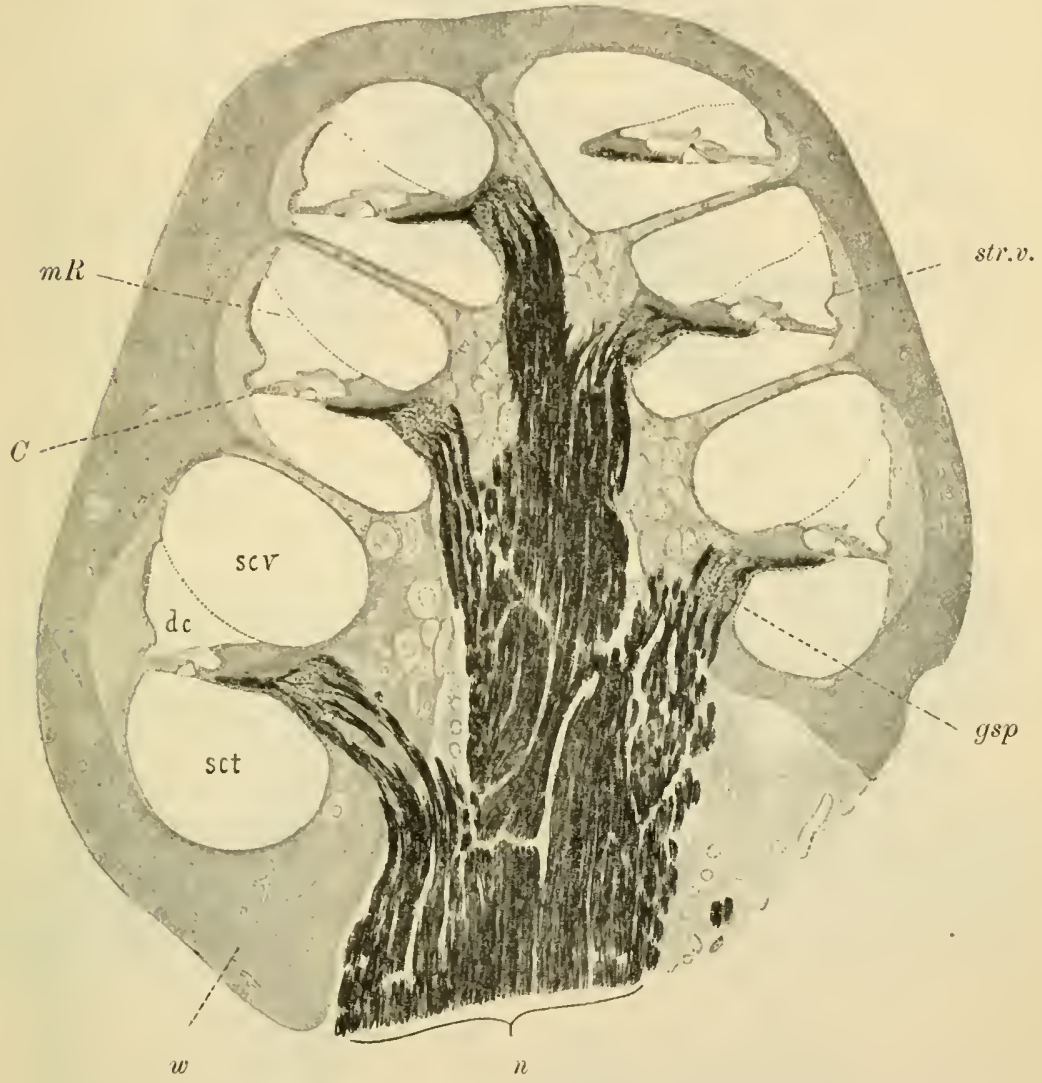

Fig, 539.-Section throdgh the COChlea of the CAT. (Sobotta.) $\times 25$.

$d c$, duct of cochlea; scv, scala vestibuli ; sct, scala tympani ; $v$, bony wall of cochlea ; $C$, organ of Corti on membrana basilaris ; $m R$, membrane of Reissner; $n$, nerve fibres of cochlear nerve; gsp, ganglion spirale; str.v., stria vascularis.

lower third is cut off by a delicate connective-tissue membrane (membrane of Reissner, fig. $5+1, R$ ), which springs from near the end of the spiral lamina, and passes upwards and outwards to the outer wall, thus separating a eanal (d.c.) triangular in section, which is lined by epithelium, and represents the membranous labyrinth of the cochlea (duct or canal of the cochlea). 


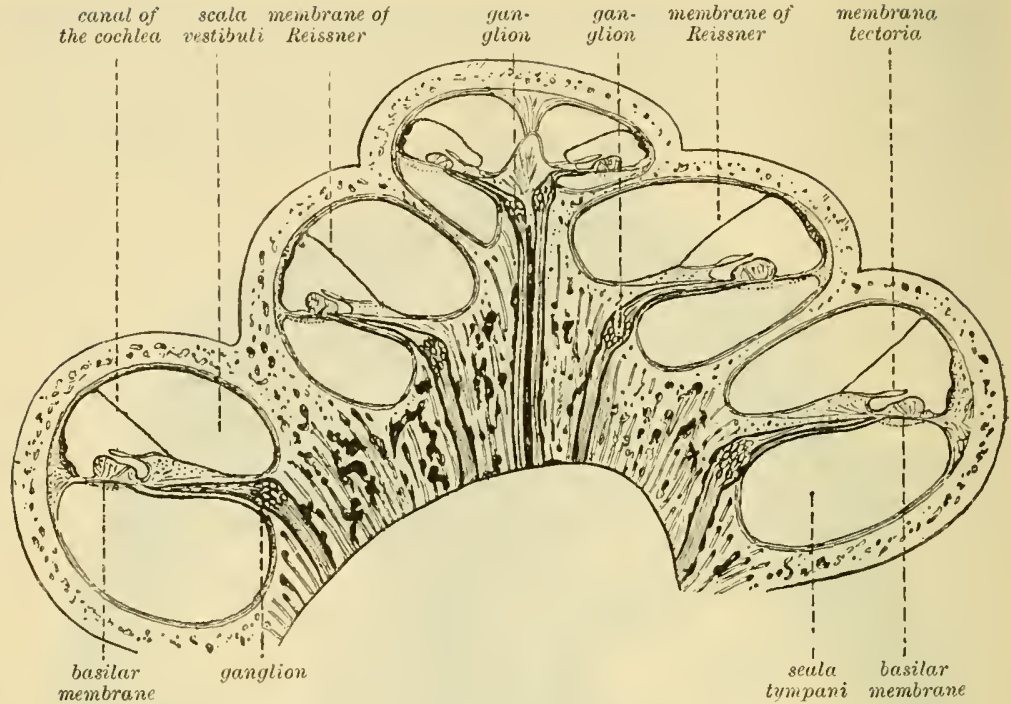

Fig. 540. - Vertical SECTION THROUgh THE MIDILE OF THE HUMAN COCHLEA.

(Diagrammatic.)

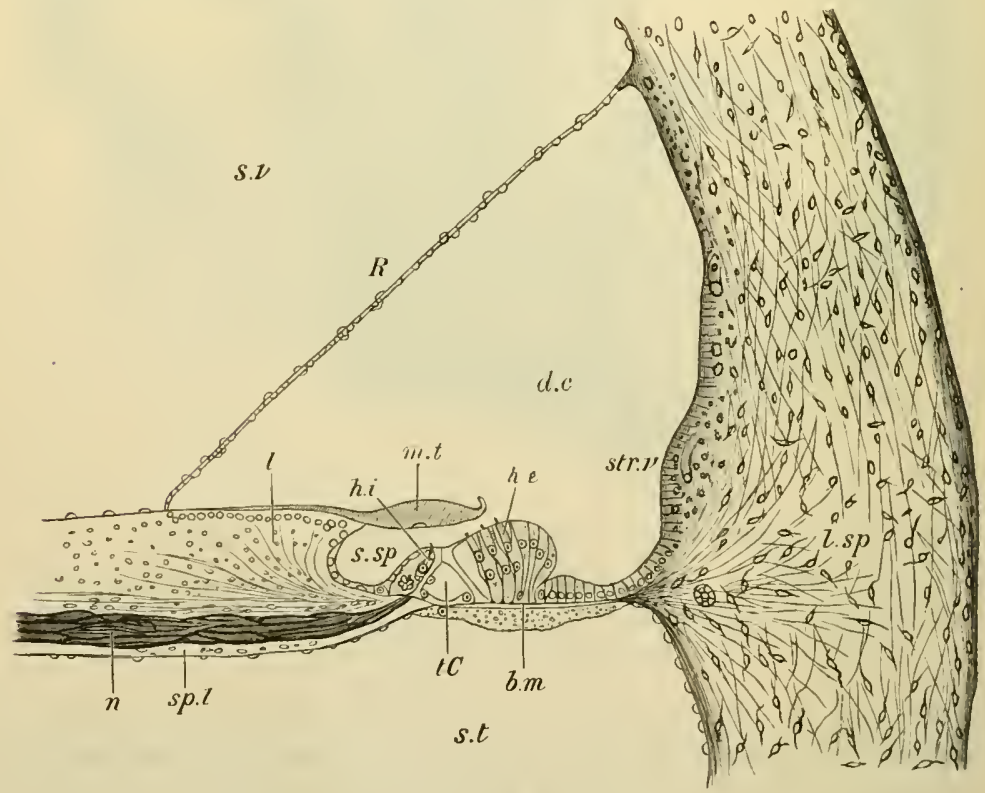

Fig. 541. - Vertical SECTION OF THE FIRST TURN OF THE HUMAN COCHLEA.

(G. Retzius.)

$s . v$, scala vestibuli ; s.t, seala tympani ; l.c, canal or duct of the cochlea; $s p . l$, spiral lamina ; $n$, nerve-fibres; $l . s p$, spiral ligamcnt; $s t r . v$, stria vascularis; $s . s p$, spiral sulcus ; $R$, section of Reissner's membrane : $l$, limbus laminae spiralis ; m.t, membrana tectoria ; $t C$, tunnel of Corti ; $b . m$, basilar membrane; $h_{.} i$, h.e, internal and external hair-cells. 
The organ of Corti consists of the following structures:

1. The rods of Corti, two series (inner and outer) of stiff, striated structures, of a peculiar shape, the inner somewhat like a human ulna, the outer like a swan's head and neck (fig. 542). They rest by one extremity (the foot) on the basilar membrane a short distance apart, and are inclined towards one another, their larger ends (heads) being jointed together ; the series of rods thus enclose a sort of tunnel, the floor of which is formed by a part of the basilar membrane (fig. 544). Close to their feet may usually be seen the remains of the cells from which they have been formed. The inner rods are narrower and

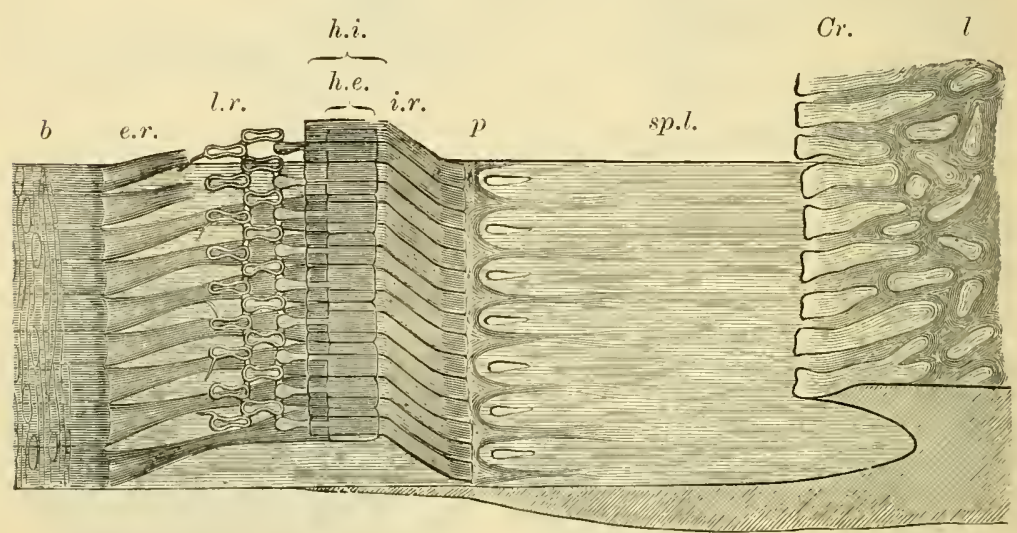

Fig, 544.- Semi-diagramatic VIEW OF PART OF THE BASILAR MEMBRANE AND TUNNEL OF CORTI OF THE RABBIT, FROM ABOVE AND THE SIDE. (Much magnifierl.)

$l$, limbus; $C r$, extremity or erest of limbus with tooth-like projections; $b$, basilar mem. brane; sp.l., spiral lamina with, $p$, perforations for transmission of nerve.fibres; $i . n$, fifteen of the inmer rods of Corti; h.i., their flattened heads seen from above; e.r., nime outer rods of Corti ; h.e., their heads. with the phalangeal processes extending outward from them and forming, with the two rows of phalanges, the lamina reticularis, $l . r$.

rather more numerous than the outer. The head of each outer rod has a process which extends ontwards and is known as the phalangeal process. This forms part of-

2. A reticular lamina (fig. 544, l.r.), which is a cuticular structure extending like a wire-net over the outer epithelium-cells of the organ of Corti, and is composed of two or three series of stiff fiddle-shaped rings (phalanges) cemented together in such a manner as to leave square or oblong apertures through which the hair-cells (see below) project.

3. The outer hair-cells placed external to the rods of Corti. These are epithelium-cells of columnar shape, arranged in three or four series 
(fig. 5+3). The free extremity of the cell is surmounted by a bundle of short anditory hairs, and projects through one of the apertures in the reticular lamina; the fixed extremity is prolonged into a stiff enticular process, which is attached to the basilar membrane. Between them are other supporting cells which are tapered in the same manner, but rest by their larger end upon the basilar membrane, and are prolonged above into a cuticular process which is attached to the reticular lamina (cells of Deiters, figs. 543,545$)$.

4. The inner huir-rells (fig. 543), placed internal to the rods of Corti. They form a single series of eolumnar cells surmounted hy auditory hairs, lying in elose apposition to the inner rods.

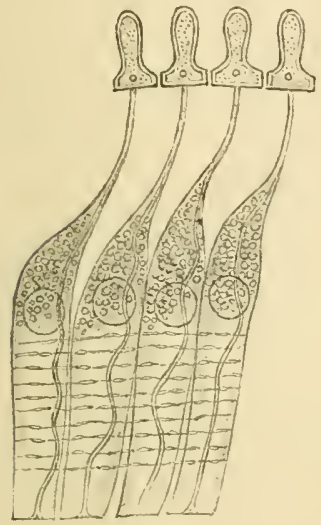

Fig. its.

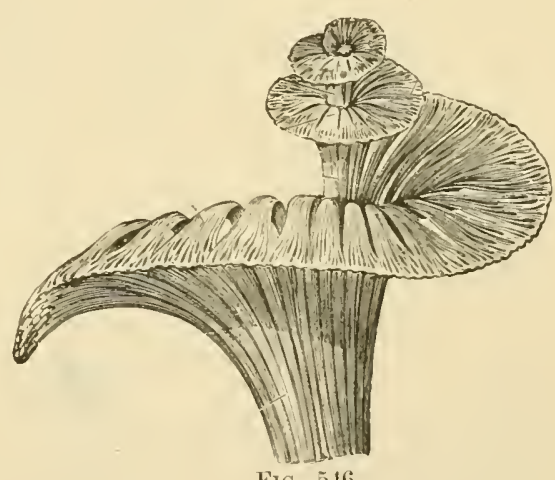

Fig. 546 .

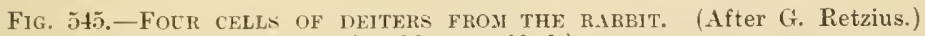
(Highly magnified.)

The varicose lines are nerve-fibrils. The phalangeal processes are attached above to a portion of the lamina reticularis.

Fig. J46.-CiExeral VIEW OF THE MODE OF IUISTRIBUTION OF THE COCHLEAR XERVE, ALL THE OTHER PARTS HAVING BEEX RENOTEN. (ArHold.)

The remaining epithelinm-cells have no important eharacteristics. They are long and columnar next to the outer hair-cells, but soon diminish in size, becoming cubical, and in this form they are continued over the outer wall of the cochlear eanal. Here they cover a very vascular membrane (stria vasculuris, fig. 541, str.x.), which is frequently pigmented; its eapillary blood-vessels penetrate between the epithelium-cells. Internal to the inner hair-cells the epithelium also soon becomes cubical; it is prolonged in this form over the limbus of the spiral lamina. The epithelium of Reissner's membrane is of the parement variety. 
The membrana tectoria (figs. 541,543 ) is a soft, fibrillated structure, which is attached along the upper surface of the limbus, and lies like a pad over the organ of Corti. It thins out towards the distal margin, here becoming somewhat reticular, and, according to Retzius,

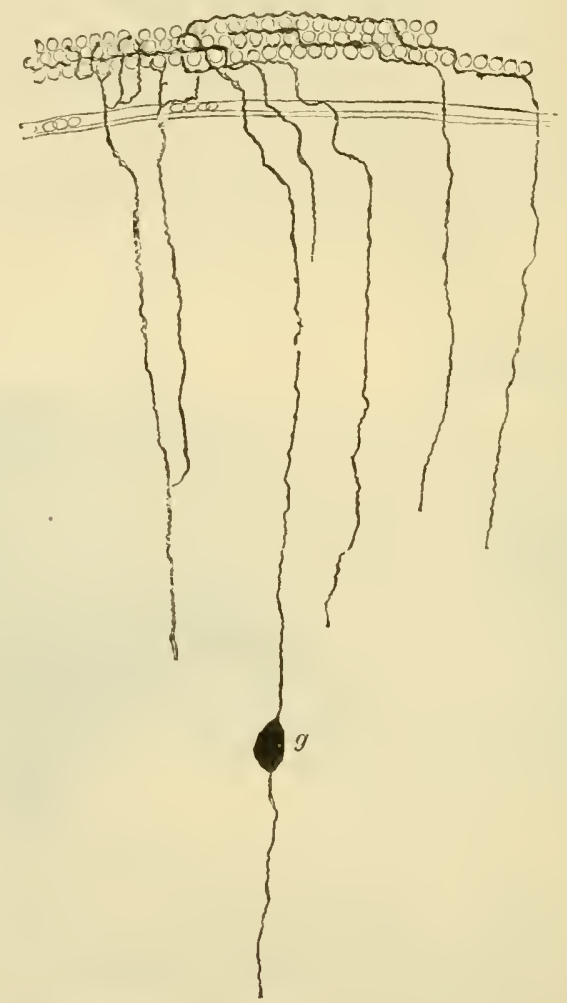

FIG. 547.-ExDIxg OF SOME OF THE FIBRES OF THE COCHLEAR NERVE AMONGST THE HAIR-CELLS. (G. Retzius.)

This preparation is made by Golgi's method, and is viewed from abore. $g$, a cell belonging to the spiral ganglion.

it is attached to the lamina reticularis. In sections it usually appears raised a short distance above the auditory hairs, but it is probable that it always rests upon them during life.

The fibres of the cochlear branch of the auditory nerve enter the base of the columella, and run in canals through its substance (figs. $539,5 t 0$ ), being gradually deflected outwards as they pass upwards into the spiral lamina, at the base of which they swell out into a ganglionic cord (spiral ganglion). The fibres take origin from the cells of this ganglion. 
After traversing the spiral lamina they cmerge in bundles, and the fibres then, having lost their mednllary sheath, pass into the epithelium of the imner hair-cell region. Here some of them eourse at right angles and are direetly applied to the inner hair-cells, whilst other's cross the tumnel of Corti, to become applied in like manner to the onter hair-eells and the cells of Deiter's (figs. 543, 545). 'They apparently lie between and in close contact with these cells, but there does not appear to be any direet continuity between the nerve-fibrils and the cell-substance. 


\section{A P P E N D I X.}

Mounting solutions :- 1. Normal satine solution.- A 0.6 to 0.9 per cent. solution of common salt is nsed in place of serum for mounting fresh tissues for immediate examination. Tle lower percentage is used for frog's tissues, the higher for mammals'. Preparations mounted in salt solutiou cannot be preserved permanently.

2. Glycerine, dilnted with an equal quantity of water. The corer-glass may be fixed by gold size.

3. Canuda balsam, from which the volatile oils have been driven off by heat, dissolved in xylol.

4. Dammar iurnish, made by dissolving dammar resin in xylol. 'The solution is filtered through paper wetted with chloroform. This is used for the same purposes as xylol lualsam and has the adrantage of remaining colourless, whereas Canala balsam becomes ytllow after long keeping.

5. Acetate of potassium, a nearly saturated solution. This is the best medium for osmic preparations and for iodine-stained liver, to show glycogen within the cells. The cover-glass may be fixed by soluble glass or by gold size.

General methods of preserving and hardening tissues and organs. ${ }^{1-}$ The following fluids may be used:-Alcohol ( 75 per cent. to absolute); acetone: Carnor's fluid (absolute alcohol 60 c.c., chloroform 30 c.c., glacial acetic acid 10 c.c.); formol (diluterl witl from 9 to 99 parts of water); corrosive sublimate (saturated solution in water or spirit); chromic acid solution ( 1 in 200 to 1 in 500, to which glacial acetic acid may advantageously. be added in the proportion of 2 parts acetic acid to 1000 chromic solution); picric acid solution (saturated, either alone or containing 2 parts of uitric or sulphuric acid to 1000); Manu's fluid (a mixture of equal parts of saturated aqueous solutions of mercuric chloride and picric acid) ; osmic acid solution (1 per cent.) ; bichromate of potassium solution (3 per cent.), to which for more rapid hardening glacial acetic acid may be added to the extent of 5 per cent. or less; Miiller's fluid (bichromate of potash $2 \frac{1}{2}$ parts, sulphate of soda 1 part, water 100 parts): Zenker's fluid (which is Miiller's fluid containing 5 parts per cent. of mercuric chloride, to which $;$ c.c. of acetic acid is addect at the time of using); and mixtures of Miiller's fluid and osmic acid 1 per. cent. in varying proportions.

IDetails of the methorls of preparing fixing and staining solutions as well as a discussion of the theory of their action will be found in Mann's Physiological Histology, Oxford, 1902. 
It is best, if possible, to inject the flud used for harlening into the bloodressels after washing them ont with warm normal saline; if this is not p ssible, very small pieces of tissue should be taken, and always a considerable amount of the hardening tluid.

The fluid of most moiversal application is formol. This is a 10 per cent. solution of formaldehyele. Mixed in the proportion of 10 parts formol to 9) water, it penctrates readily and har lens quickly. The tissue may remain in formol a few days and should then be transferrenl to alcohol. For rapirl fixation a rery small piece of the tissue is placed in 10 per cent. formol and wimed to a temperature of about $40^{\circ}$ or $50^{\circ}$; it will be sutfieiently hamlened in half an hom, and may then be transferred first to weak anl then gradually to absolute alcohol, so that it is rearly for the preparation of seetions in about an hour.

Pure acetone is also of utility for ripid fixation and hardening. Small pieces of the tissue are dropper into a large amount of acetone, which not only fixes and harlens but also lehydiates, so that the tissme can be transferred in an hour or so (lirect to molten praffin for emberlding. But much better results are got by placing in 10 per cent. formol for thirty minutes hefore transferring to acetone.

Eor preserving the structure of eells aml nuclei, one of the best fixing fluis is that recommented by Flemming. This consists of 15 vols. of 1 per went. chromic acid, $t$ vols. of 2 per cent. osmic acicl, and l vol. glacial acetic acil. It must be freshly prepared. It is sometimes diluted with from two to five times its bulk of water before use. One or two days is sufficient for fixation and hardening. The tissue should be washed for several hours in rmming water after removal from the mixture, and then placed in lilute alcohol. Carmoy's tluid is in many cases excellent for cell-structure and mitotic changes, and very rapid in its action.

Tissnes to be hardened in alenhol are usually placed at once in absolute alcohol, but for some tissues it is best to begin with 50 per cent. alcohol, and pass the pieces through successive grades of 75 per cent., 95 per cent., inti) absolute alcohol, leaving them a few hours in each. They are ready for cutting as soon as they are dehydrated, but as a rule they may be left a long time in alcohol without deterioration. Organs which contain much fihrons tissue, such as the skin and teuclons, should not go into stronger alcohol than about 80 or 95 per cent. ; otherwise they become too hari to cut. Alcohol is generally used after the other fixing reargents, partly to complete the harlening, partly on account of its dehydrating property, since previous to embedding in paraffin all trace of water must be eliminaterl from the tissue. If mereuric chloricle be used for hardening, tincture of iodine must be added to the alcohols subseruently user (exeept the final alcolıol), to get rid of the excess of sublimate. Mercuric ehlorile in alcohol (*ituratel solution) is one of the most rapirl fixing and hardening leagents, and may be used if sections are desired within a very short time. It can also be used in place of alcohol and ether mixture for fixing blood films (Lesson II. $\$ 5)$, in which case it my be saturated with eosin, aml used for fixing aur staining at the same time. An immersion of is minutes is sufficient. 
Many tissues can be instantly hardened by being plunged for a minute into boiling water and then placed in alcohol: this is not, however, a good method for glandular organs.

For tissues that are to be hardened in chromic acis an immersion of from seven to fourteen days is generally necessary ; they may then, after washing for some hours or days in tap-water, be placed in alcohol for preservation and to complete the process of hardening. The alcohol should be changerl once or twice.

Organs placed in bichromate of potassium or Miiller's fluid are ready for section in a fortnight or three weeks; they may, however, be left for a much longer time in those fluids withont reterioration.

With picric acid the hardening process is generally complete in two or three days; the organs may then be transferred to alcohol, which ought to be frequently changed.

The hardening of the brain and spinal cord in Hiiller's fluid takes from three weeks to as many months. It can be hastened by warmtl, and.lyy the aldition of atcetic acid, or by placing snall pieces in Marchi's solution (see below), after they have been a week or ten days in Miiller's fluid.

Tissues containing calcareons matter, e.g. bone and tooth, may be rapilly decalcified in a solution made by dissolving, with the aid of heat, 1 grm. phloroglucin in 10 c.c. nitric acid, and filling up to 100 c.c. with water, to which more nitric acid may be added if desirerl. Another rapid decalcifying fluid is commercial sulphurous acid solution. If it is desired to preserve the soft parts within the bone, it should first be placed for a few honrs in 10 per cent. formol. For decalcifying more slowly a 1 to 5 per cent. solution of nitric acid in water or alcohol, a saturated solution of picric acid containing a superabundance of crystals, or a 1 per cent. solution of chromic acid are employed.

Embedding of hardened tissues, and preparation of sections. Sections are most advantageously made with some form of microtome. It is generally needful to support the hardened tissue whilst it is being cut, and with this object it is embedded in some substance which is applied to it in the fluid condition and becomes solid on standing. The embedding substance can either simply inclose the tissue, or the tissue may be soaked in it; the latter methor is the one commonly employed.

The embedding substance chiefly used is paraffin of about $50^{\circ}$ C. melting point.

Embedding in paruffin.-Before being soaked in melted paraftin, the piece of tissue may be stained in bulk; it is then dehydrated by a series of alcohols (50 per cent., 75 per cent., 95 per cent.), finishing up with absolnte alcoliol; after which it is soaked in cedar-wood oil, xylol, or ehloroform. It is now transferred to molten paraftin, which should not be too hot, and is soaked in this for one or several honrs, according to thickness. Very delicate objects are sometimes passed through a solution of paraftin in chloroform. When thoronghly impregnated with the paraffin the object is placed in a mould or glass which has been smeared with glycerine, and is covered with molten paraffin which is 
allowed to cool quickly. A square block of the paratlin containing the tissue is then fixed in the lesired position on the microtone, thin sections are cut inrl fixed to a slide (see below), the paraffin dissolved out by turpentine or xylol, and the sections mounted in Canada balsam or ditumar.

If it be desired to cut a riband of successive sections, and the paratin used prove too hard for them to stick to one another at the edges, a paraftin of lower melting point $\left(40^{\circ} \mathrm{C}\right.$.) is smeared over the opposite sicles of the block; the sections then adhere together as they are cut.

rreparation of frozen sections.- The bichromate solutions and formol are the best fluids to use for preserving tissues which are to be frozen in place of being embedied. The tissue requires to be soaked in gum-water before being placed upon the freezing microtome. A thin syrup of either gum arabic or dextrin may be nsed.

Embedding in celloidin-The piece to be embedded is delyydrated by alcohol, and is then placed over night in a solution of celloidin in alcohol and ether similar to ordinary collodion, and afterwards in collodion of double strength. After twenty-four hours more it is removed from the celloidin (collodion) and placed upon a wood or metal holder. When the celloidin is set by evaporation of its ether the holder is plunged in alcohol ( 85 per cent.), and after a few hours sections may be cut with a knife wetted with spirit of the same strength. The sections are placed in 95 per cent. alcohol; then passed throngh cedar-wood oil or bergamot oil iuto xylol balsam. They nust not go into clove-oil, nor into absolute alcohol. The advantage of the method is that the celloidin, which is quite transparent, need not be got rid of in mounting the sections, and serves to keep the parts of a section together; it is thus very useful for friable tissues or for large sections. The tissue may either be stained in bulk before embedding. or the sections nay be stained.

Microtomes. - A section-cutting a]praratus or microtome is essential for histological work. Useful instruments for students are the Cathcart microtome for freezing and the tripor microtome for objects which have been embedded in paraftin.

The tripod michotome is a simple and efficient little instrument, and has the advantage of being inexpensive. It consists of a metal frame (fig. 548) in which the razor is fixed, provided with a micrometer screw by which the height of the razor-erlge is adjusted. The paraftin block eontaining the tissue is fixed by the aid of heat on a flat piece of glass over which the tripod slides. The razor-edge is lowered after each successive section.

In the Cathcart freezing microtome (fig. 549) the tissue, after being soaked in gum-water, is placed on a metal plate and frozen by playing an etherspray on the under surface of the plate. The plate is moved upwards ly a finely-cut screw, and the knife or plane used to cut the seetions is guided over the plate by passing over glass slips. In the Williams microtome the freezing agent is ice and salt mixture. In using any freezing microtome, especially for the nervous system, it is important not to freeze the tissue too hard, or the section will roll up. 
Somewhat more expensive and complicated, but also more efficient, instruments are the rocking microtome of the Cambridge Scientific Instrument Company and the microtomes resigned by C. S. Minot and by Delépine. The

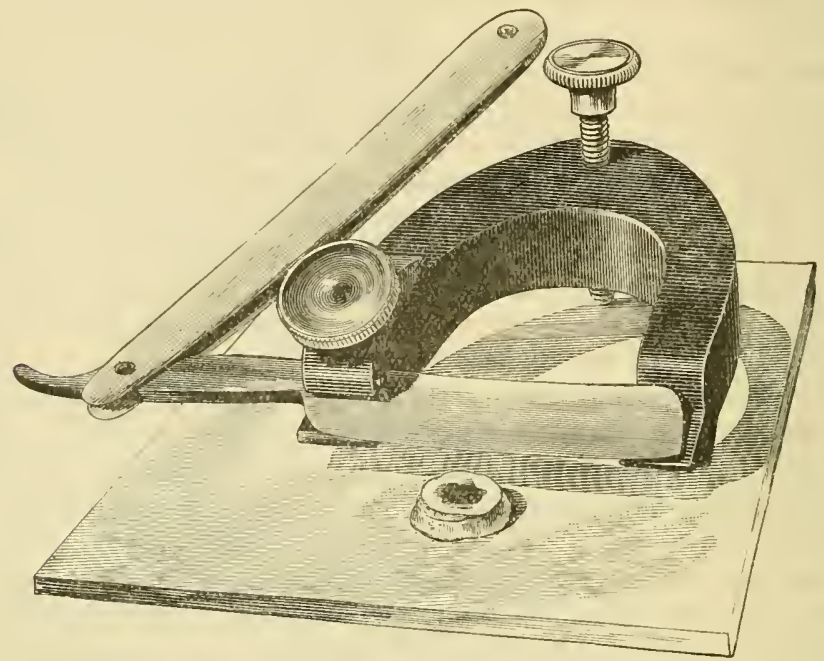

Fig. 548,-TRIPON MICRoTOME. (Birch's pattern.)

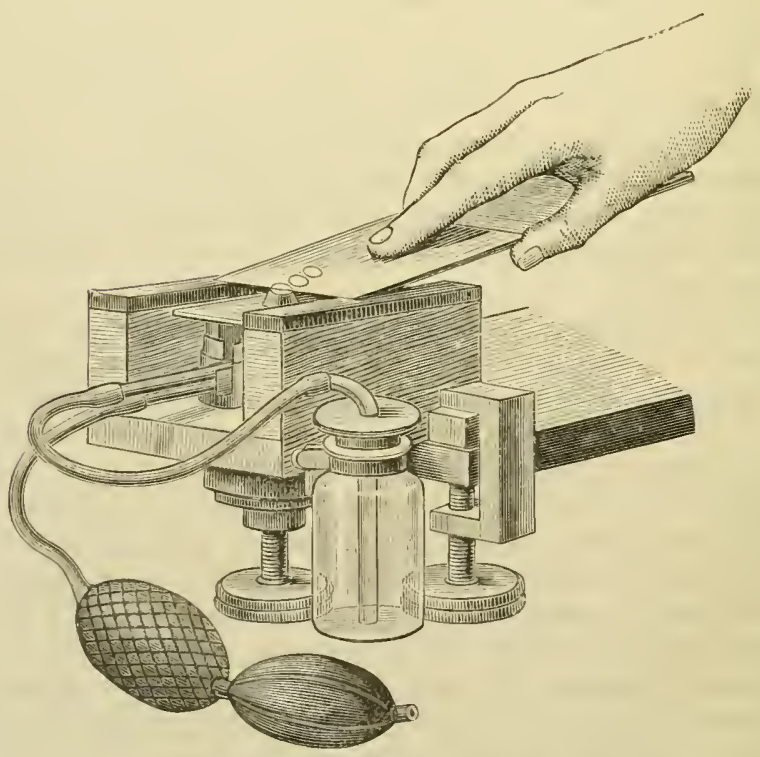

Fig. 549,-CathCaRt Freezing Microtome. 
antion of all of these is antomatic. Hor example, with the rocker microtome (sery to-and-for movement of the handle, 11 , not only cuts a section of the tissue of definite thickness, hut also moves the paraflin block forwards in readiness for the next section. And hy employing a rectangular block of

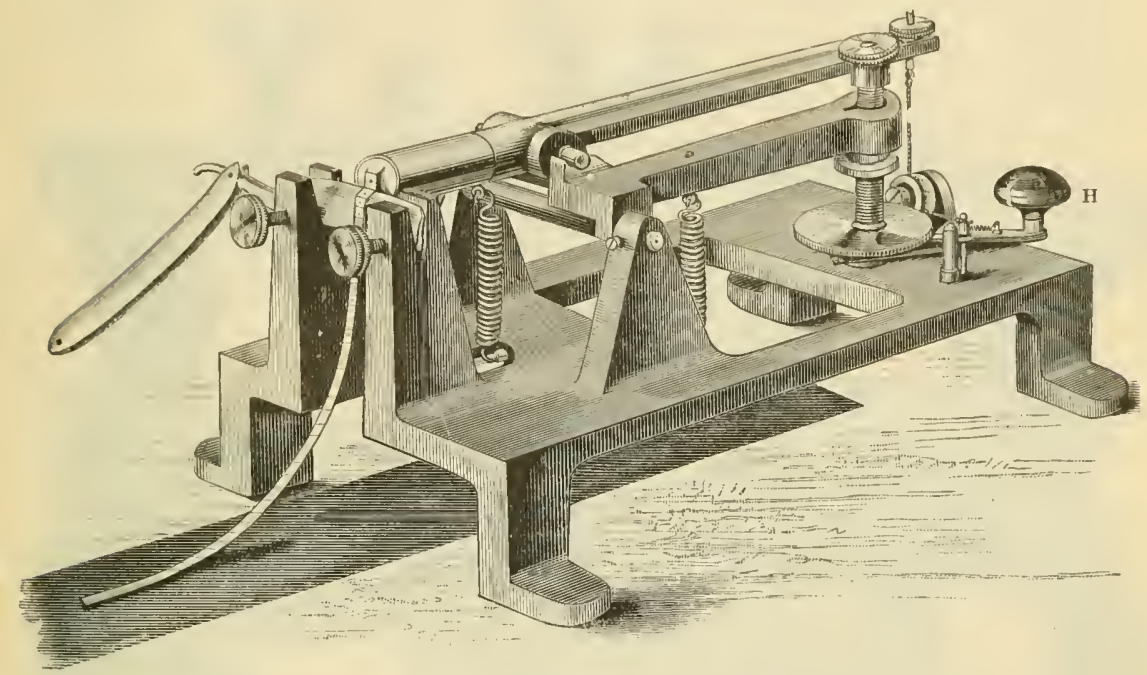

FIG. 550.-ROCKING MIR⿴囗十) E.

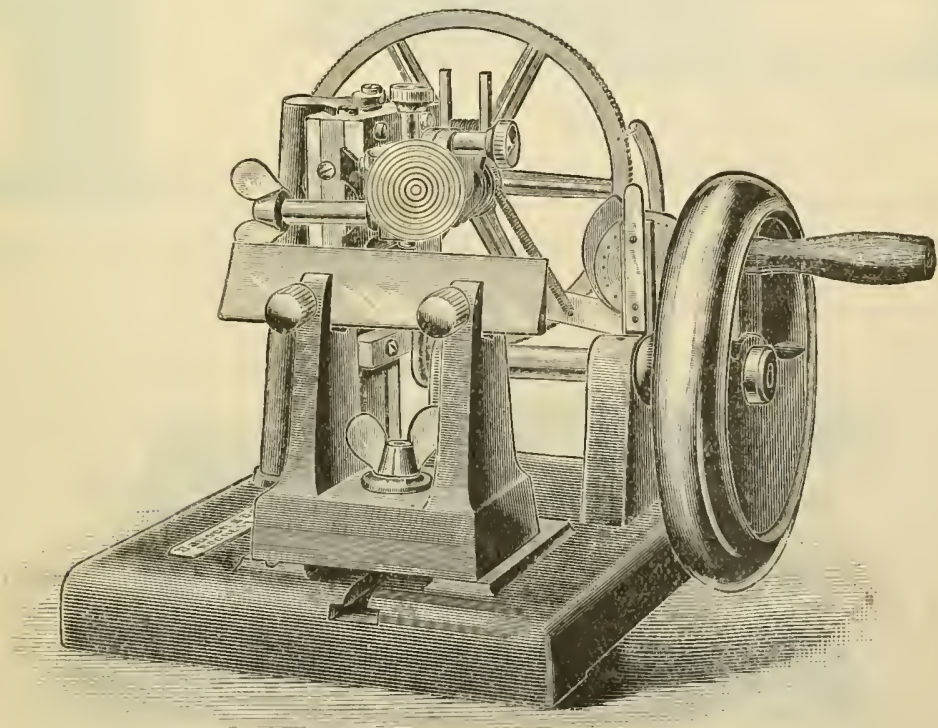

Fig. 551.-Minot's AUTOMATIC ROTARY MiOROTOME. 
parathin of the proper consistency, a long selies of sections of the same object, of equal thickness, can be ohtained and made to adhere together in a riband (as shown in fig. 550). The sections can be kept in series upon

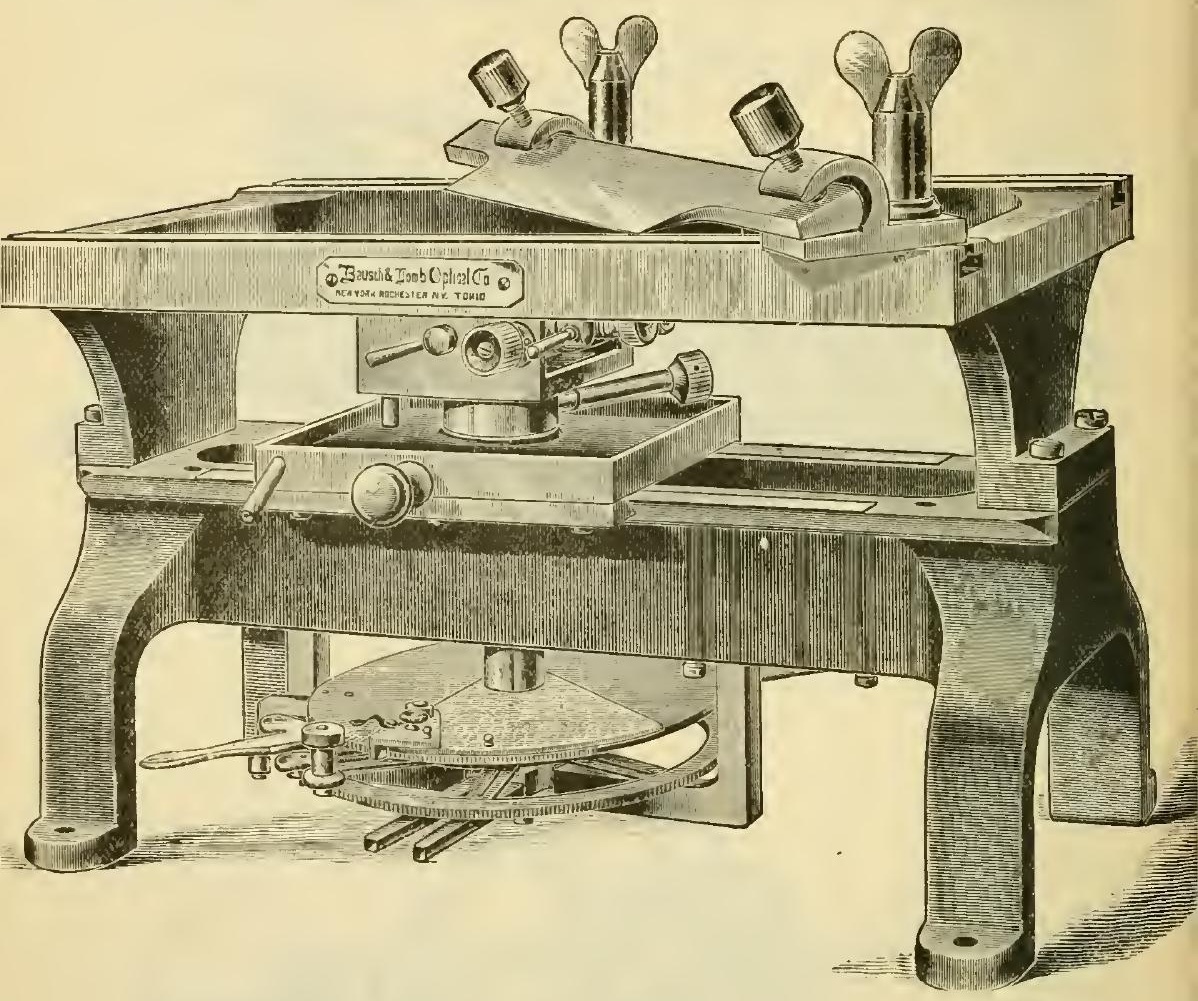

Flg. 552.-MInot's PRECisiox mickotome. This is especially adapted for large sections.

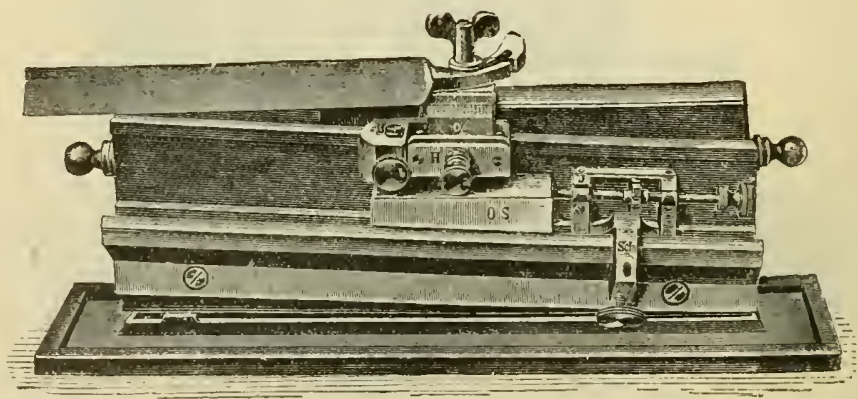

FIG. 553.--INCLINEI) PLANE MICROTOME. 
the slide by the employment of some adhesive methorl of momuting the riband.

For celloidin-embedded preparations it is necessily to cut the sections with a knife kept wetted with spirit. For this purpose a sliding microtome, in which the knife or razol is moved horizontally over the tissue, with the edge olniquely inclined to the direction of movement, is the most useful. The best instrument for this purpose, especially for large sections of brain, is one in which tho celloidin-soaked object is immersed in spirit during the actuil process of making the sections. It is all-important for. every kind of microtone that the knife should be in perfect order.

Methods of mounting in xylol balsam or dammar.-Individual paraftiucut sections or ribanels of sections, such as are cut with the rocking and other mierotomes, are fixed to a slicle or eover-glass-preliminary to heing treated with stains and other fluids-in the following way :-The slide (or cover-glass), after hiving been carefully (-leaned, is smeared rery thinly" with fresh white of eggr: this can be done with the finger or with a clean rag, ant the slides may be put aside to dry, protected from dust. It is convenient to prepare a large number of slides at a time in this way, and to keep them at hand in a suitable receptacle. When required for use a litile water is poured on to the slicle and the riband of sections is placed on the water, which is then warmerl on a hot plate or over a small flame until the paraftin becomes Hattened out, without actually melting. The water is then drained off, the slicle put in a warm place for the remainder' of the water to evaporate (this will take from half an hour to an hour aceording to the size of the section and the temperature at which it is kept), and then heater sufficiently to melt the paraffin. It is next immersed in xylol to remove the paraffin, after which the sections may, if alrearly stained, be mounted at once in xylol halsam or clammar ; if not stained, treat, after xylol, first with absolute and then with gradually lower grades of alcohol, then water; and then stain and tinally pass throngh water, alcohol (in grades), clove-oil, and xylol, into xylol balsam or dammar. For many sections some of the grailes of alcohol ean be omitted, but it is always best to place in 50 per cent. between water aud absolute alcohol.

A simpler method, but one which, in most cases, answers the purpose perfectly well, is to place the riband or the inclividual sections cut from paraffin on the surface of water in a basin, just sufficiently warm to flatten ont the parafin, but not to melt it, then pass a perfectly clean slide under the surface of the water and float the sections on to it; remove, drain off the water, and put the slide and sections aside for one or nore hours until all the water has evaporated. The sections are fomd to have adhered firmly to the slide (they may, if clesired, be yet more firmly fixed by diawing a brush moistened with solution of celloidin in oil of cloves over them). The paraftin can now he removed by washing the slide with xylol or immersing it in xylol. If not previmusly stained they can then be passed through alcohols and stained and momuted as just described. It is convenient to keep the several solutions which are required in cylindrical tubes or groored glass receptacles in a regular row upon the working table, 
and transfer the slide from one to the other in succession. Thus such a series would be (1) xylol; (2) absolute alcolool; (3) 75 per cent. alcohol; (4) 50 per cent. alcohol ; (5) distilled water; (6) staining solution ; (7) tap water ; (8) distiller water; (9) 50 per cent. alcohol; (10) 75 per cent. alcohol ; (11) absolute alcohol; (12) clove oil or xylol. The changes can also be effected by pouring the solutions over the sections and draining off, but this is less satisfactory.

The following table shows the methorls which may be adopted for the treatment of paraftin-cut sections or ribands of sections:

1. Place on a slicle or cover-glass in a drop of tap-water : the glass may previonsly have been smeared with egg-white: warm gently.

2. Drain off water and allow to dry completely.

3. Warm until paraffin is just melted.

4. Dissolve parafina away with xylol.

If tissue is alrearly stainer in bulk. | If tissue is not already stained.

Mount in xylol balsam or dammar. $\quad 5$. Absolute alcohol.

6. Descending grades of alcohol.

For sections cut by the freezing or celloillin methorls, if the tissue has alrearly been stained in bulk, the sections need only be put throngh the ascending grades of alcohol and bergamot oil, and then mounted in dammar. If the tissue has not already been stained, begin at No. 7.

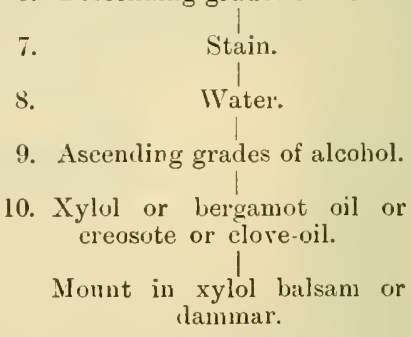

Staining of sections. - The tluids most commonly employerl for the staining of sections are:-(1) Solntions of hematoxylin and alum; (2) solutions of carmine with or withont alun ; (3) certain aniline dyes. The time of immersion in the staining fluid varies accorling to the strength of the fluid and the mode by which the tissue has been hardened. The necessity of staining sections may be avoided if the tissue is stainerl in $1, n k$ before emberlling. For this purpose a piece of tissue is left to stain for twenty-four hours or more in a moderately diluted hematoxylin solution or in carmalum or borax carmine, and is then embedied and cut in to sections by the paraftin or freezing methods. If the latter be employed the sections are thoroughly washed with tap-water, dehyllated by alcohol, and passed through clove-oil or xylol into xylol balsam or dammar. For some purposes (e.\%. the study of ossifying cartilage) an alcololic solution of magenta is useful for stainiug in bulk; from this the tissue goes direct into a small quantity of oil of cloves, and after being soaked with this it is passed into molten paratin. Sections may also be staised whilst still infiltrated with parntin by floating them on to the surface of the staining solution, which 
maly le gently warmed (lout not enough to melt the paraftiu). They senerally require far longer exposure to the stain. The sulsequent treatment is quite simple, for they need only be transfered to warm water, floated on to a slide and allowed to dly. The paraflin is then merterl, dissolved away with xylol, and the sections are nounterl in dammar.

The following are some of the principal staining solutions and methods of staining for special purposes:

1. Delefield's homutoxylin.-To 150 culic centimetres of a saturated solution of potash almm in water add 4 cubic centimetres of a satmated solution of hematoxylin in alcohol. Let the mixture stand eight clays, then decant, and add 25 cnbic centimetres of olycerine, and 25 cubic centimetres of methylic alcohol. The solution must stand a few days before it is ready for use.

To stain sections add a few trops of this solution to a watch-glassful of distilled water. If overstained the excess of colour can he removerl by alcohol containing 1 per cent. nitric or hydrochloric acid. With loug keeping this solution becomes ren instead of blue; a trace of ammonia will restore the blue colour.

2. Ehrlich's hematorylin.-Dissolve -2 grammes hrenatoxylin (or, better, hamatein) in 100 cubic centimetres alcohol; adı 100 cubic centimetres water, 100 cubic centimetres glycerine, and 10 cubic centimetres glacial acetic acid: adil potash alum to saturation. This solution will keep almost indefinitely: it is valuable for staining in bulk, as it does not easily overstain. For staining sections it is best to dilute the solntion either with clistilled water or with 30 per cent. alcohol. After the sections have been stained they must be thoroughly washed with tap-water. This develops the blue colour of the liematoxylin.

3. Kultschitzky's hemutr.'ylin.--Dissolve 1 gramme hrmatoxylin in a little alcohol, and add to it 100 cubic centimetres of a 2 per cent. solution of acetic acid. This solution is raluable for staining sections of the nerrous system (see Weigrert-Pal process).

4. Humainm.-Hrmatoxylin-ahm solutions acquire their colouring properties only as the hamatoxylin on keeping becomes converted into hæmateïn. The latter substance may, therefore, as recommended by Mayer, be used advantageonsly in place of hrematoxylin if the stain is required immediately. The following mode of preparing the solution may be adopted:-Dissolve 50 grammes of ammonia alum in 1 litre of water, and 1 gramme of hemateïn in 100 c.c. of rectified spirit. Add the hæmatein solution gradually to the alum. The mixture is ready for staining at once, either as it is or diluted with distilled water. A small piece of thymol or a little carbolic acid should be added to prevent the growth of moulds.

5. R. Heidenhain's method.-After harlening in alcohol, or in saturated solution of picric acid and then in alcohol, place the tissue from twelve to fourteen hours in a 1 per cent. watery solution of hrmatoxylin, and then from twelve to twenty-four hours more in a $\frac{1}{2}$ per cent. solntion of yellow chromate of potash, which may be changed more than once. Then wash in water, place in alcohol, pass through xylol, and embed in paraftin. 
(5. H. Heidenhain's method.-Harden in sublinate, followed by alcolnol; fix sections to slide by water method; treat with iodised alcohol, transfer to $2 \cdot 5$ per cent. iron-alum (solution of sulphate (or tartrate) of iron and anmonia) and leave a quarter of an hour or longer; rinse with distilled water; place in 1 to 0.5 per cent. pure hrematoxylin in water containing 10 per cent. alcohol for a few minutes; wash with water ; differentiate in the iron and ammonia solution until nearly decolorised; wash for fifteen minutes in tap-water; dehydrate and mount in the usual way. This method is especially adapted for exhibiting the centrosomes of cells. It is also useful for retiform tissue and glands.

Both the process of mordanting with iron-alum and the subsequent staining with hematoxylin may be considerably prolonged with advantage for some tissmes.

7. Carmalum (Mayer).-Useful either for sections or bulk-staining. If the sections are subsequently passed through alcohol containing picric acid in solution a double stain is produced.

Carminic acid,

Ammonia alum,

Distilled water,
1 gramme.

10 grammes.

200 c.c.

Boil together, allow to cool and filter. Add thymol or a little carbolic acid to prevent the growth of moulds.

8. Carminate of ammoniu.-Prepared by dissolving carmine in ammonia, and allowing the excess of ammonia to escape by slow evaporation. The salt should be allowed to dry and be dissolved in water as required.

9. Picric acid.-A saturated solution of picric acid in spirit may be used as a second stain after lrematoxylin or carmine. Any excess of picric acid is dissolved ont by rinsing with strong spirit. This form of double stain is valuable for exhibiting keratinised tissues and muscle-fibres.

10. Picro-carminate of ammonia, a double stain. a. Ranvier's picrocarmine.-To a saturated solution of picric acil add a strong solution of carmine in anmonia, until a precipitate begins to form. Evaporate on the water bath (or, better, allow it to evaporate spontaneously) to one half its bulk; add a little carbolic acid to prevent the growth of moulds; filter from the serliment.

B. Bourne's picro-camine.-" Add is c.c. of ammonia to 2 grammes carmine in a bottle capable of containing abont 250 c.c. Stopper, shake, and put aside till next day. Add slowly, shaking the while, 200 c.c. of a saturated solution of picric acio in clistilled water. Put aside till next day. Add slowiy, constantly stirring, 11 c.c. of 5 per cent. acetic acid. Put aside till next day. Filter; to the filtrate add four drops of ammonia, put back in the stoppered bottle" (Langley).

11. Borar'-rarmine.-Dissolve 4 grammes borax and 3 grammes carmine in 100 cubic centimetres of warm water. After three days add 100 cubic centimetres of 70 per cent. alcohol, let stand two days and filter. This solution improves on keeping. It is useful for staining in bulk.

After staining with borax-carmine, the tissue shonld be placed in 70 per 
(ent. aleohol containing 5) drops of hydrochloric acid to 100 cubic eentimetres.

12. Anitine dyes. - These are used either in aqueous solution (which may contain 0.01 per cent. of (austic potash) or in water shaken up with aniline oil, and it is usual to orerstain a tissue with them, and subsequently to decolorise with absolute alcolol containing $\frac{1}{5}$ its bulk of aniline oil (from which the sections ean pass directly into xylol) or with acid-alcohol (1 to 10 fer 1000 hrohochloric acid) followed by absolute alcohol and this by xylol. Those most employed are the "basic" dyes-methyl-blue, methyleneblue, gentian-violet, toluidin-blue, thionin, saftianin, and vesuvin; and the "acid" dyes-eosin, erythrosin, acid magenta or acid fuchsin, and orange G. A clouble stain is obtined by combining eosin with methylene blue or toluidin blue, the sections being first stained for ten mimtes in 1 per cent. aylueous eosin and then, after rinsing with water, for twenty minutes in 1 per cent. of the blue solution, after which they are decoloriser by absolute alcohol or alssolnte alcohol and aniline oil. The decolorisation is arrested by xylol. Other gond double stains are the eosin-methyl blue mixture devised by G. Mann ${ }^{1}$ and . Tenner's stain, which is made by dissolving in pure methyl alcohol the precipitate which is produced when eosin solution is alded to methylene blue solution. Jenner's stain is valuable for blood filus. For the same purpose Ehrlich's triple stain is also used. This is formed by mixing together aqueous solution of orange G., acidfuchsin, and methyl-green in certain proportions."

13. Eosin.-A 1 per cent. solution in water may be used. The sections are first stained deeply with hematoxylin and rinsed with water. They are then stained with the eosin solution, passerl through 75 per cent. alcohol, and then through strong spirit-which is allowed to dissolve ont some but not all of the eosin stain-into elove-oil : they are finally mounted in xylol balsam or dammar.

Eosin stains hamoglobin of an orange red colour: so that the blood corpuscles are well shown by it when fixing fluids have been employed which do not remove the hremoglobin from them (such as mercuric chloride, bichromate of potassium, and formol.

14. Mur's method of double-staining with eosin and methylene blue.-For staining hemoglobin and oxyphil grannles in cells the method devised by Richard Muir will be fonnd valuable. It consists in staining the sections of formol-hardened tissue (which are fixed on a.slide) with satmated solution of alcohol-soluble eosin crystals dissolvel in rectified spirit. This solution is poured over the sections, and evaporated over a flane until the alcohol is diven off, leaving only a watery solution. Rinse with water, place in saturated solution of potash alum for three minntes, and wash again. Decolorise with alcohol rendered very faintly alkuline with ammonia. Wash. Stain with saturated water-solution of methylene blue; wash with water; deliydrate and mount in usual way.

15. Acid fuchsin.-A 1 per cent. solution in 50 per cent. alcolol (to which

${ }^{1}$ See Methods of Physiolorical Histology, p. 216.

${ }^{2} \mathrm{It}$ is best to purchase this solution ready-made. 
1 drop of 1 per cent. alcohol-solution of gentian-violet nay be arder per cubic centimetre), is an excellent stain for connective tissue (see p. 67). It ma also advantageously be used for developing bone and tooth and for lymph-glands. The piece of tissue is left for several days in a 1 per' cent. solution in 9.5 per cent. alcohol and is then placed direct in a small quantity of clore-oil for a few hours, after which it is transferred to molten paraffin.

16. Uirein. - Dissolve 1 granme orcein in 100 c.c. absolute alcohol containing 1 c.e. hydrochloric acid. Place the sections in some of this solution in a watch-glass and warm slightly, allowing the fluid to nearly evaporate to dryness. Dehydrate in alcohol, which removes the excess of stain: pass through xylol into dammar. Orcein stains especially the elastic fibres.

17. Flemming's methor for koryohinetic nuclei.-This is especially valuable for staining cell-nuclei in mitosis. The tissue having been appropriately fixed, small shreds or thin sections are placed for two days in saturated alcoholic solution of saffranin, mixed with an equal amount of anilinewater. They are then washed with distilled water and decoloriser in aniline-alcohol or in alcohol containing 1 per 1000 hydrochloric acid until the colour is mashed out from everything except the nuclei. Ther are then again rinsed in water and placed in saturated aqueous solution of gentian-riolet for two hours, washerl again in distilled water, decolorised with aniline-alcohol until only the nuclei are left stained, then transferred to bergamot oil or xylol, and from this are mounted in xylol balsam or dammar. Gentian-violet and several other aniline colon's may be employerl in place of saffranin from the first. Delafield's biematoxylin (followed by acid), or Ehrlich's hematoxylin also stain the mitotic figures well.

18. Staining with nitiute of silier (Fecklinghansen). - Wash the fresh tissue with distilled water : immerse in $\frac{1}{2}$ to 1 per cent. nitrate of silver solntion for from one to five minutes; rinse with distilled water and expose to bright smlight either in water, 70 per cent. alcohol, or glycerine. The tissue, which is generally a thin memhrane, may either be mounted in glycerine, or it nay be spread ont flat in water on a slide, the water drained off, the tissue allowed to dry completely, and thes dammar added. This method is used to exhibit endothelium, and generally to stain intercellular substance. It depends upon the fact that the chlorides of the tissues are almost exclusively confined to the intercellular substance.

The following methods are especially nseful in investigations relating to the nerrous system :

19. Marches solution.-This is a mixtme of Miiller's fluid (2 parts) with 1 per cent. osmic acid ( 1 part). It is of ralue for staining nerve-fibres in the earhiel stages of degeneration, before sclerosis sets in (especially a few days after the estahlishment of a lesion). All the degenerated medullated fibres are stainel black, whilst the rest of the section remains almost mnstained. It is best to put thin pieces of the brain or cord to be investigated singly into a large quantity of the solution (after previously hardening for ten dars in Miillel's fluid), and to leare them in it for a week or more : but if necessary sections can be stained; in this case the process is more 
complicated. ${ }^{1}$ In either case they are lixed on a slide and mounted by the usual process in xylol balsaur or dammar.

20. Weigert-Pal methorl.-This methorl is chiefly used for the central nervous system. By it all mednllated nerve-fibres are stained dark, while the grey matter and any selerosed tracts of white matter are left uncolıured. The following modifieation of the original method can be recommended: Pieces whieh have been hardened in Miiller's fluid and afterwards kept a short time in alcohol (without washing in water) are embedded in celloidin, and sections are cut as thin as possible. Or sections may be made by the freezing method direct from Miiller's fluid, if the tissue is first soaked in gum-water for a few hours. In either case they are placed in water, and from this are transferred to Marchi's fluid (see above, \$ 19), in which they are left for a few hours. They are then again washer in water and transferred to Kulschitzky's hamatoxylin (see above, $\$ 3$ ). In this they are left overnight, by which time they will be completely black. After again washing in water they are ready to be bleacher. This is accomplished by Pal's method as follows: Place the overstained sections, first in $\frac{1}{4}$ per cent. solution of potassium permanganate for five minutes (or for a longer time in a weaker solntion); riuse with water and transfer to Pal's solntion (sulphite of soda 1 gramme, oxalic acid 1 gramme, distilled water 200 cubic centimetres), in which the actual bleaching takes place. ${ }^{2}$ They are usually sufficiently differentiated in a few minutes: if not, they cin be left longer in the solution without detriment. If after half an hour they are not differentiated enough, they must be put again (after washing) into the permanganate for some minutes, and then again into Pal's solution. After differentiation they are passed through water, alcohol (with or without eosin), and oil of bergamot (or xylol), to be monnted in xylol balsam or dammar. The advantages which this modification has over the original method are (1) even the finest medullated fibres are brought to view with great surety; (2) the staining of the fibres is jet black, and offers a strong contrast to the colourless grey matter; (3) the sections are easily seen and lifted out of the acid hæmatoxylin, which has very little colour; (4) it is difficult to overbleach the sections; (5) the stain is remarkably permanent.

As a modification of the above, Bolton recommends to harden with formol, place the sections for a few minutes in 1 per cent. osmic acid, stain for two hours in Kulschitzky's hæmatoxylin at $40^{\circ} \mathrm{C}$, and then proceed with the bleaching process.

21. Staining with chloride of gold.- $\alpha$. Cohnheim's method.-Place the fresh tissue for from thirty to sixty minutes in a $\frac{1}{2}$ per cent. solution of chloride of gold ; then wash and transfer to a large quantity of water faintly acidu-. lated with acetic acid. Keep for two or three days in the light in a warm place. This answers very well for the cornea. If it be principally desired to stain the nerve-fibrils within the epithelium, the comea may be transferred after twenty-four hours (the outlines of the larger nerves should be

1 See Hamilton, Brain, 1897, p. 180.

${ }^{2}$ Diluted sulphurous acid solution may be employed instead of Pal's solution. 
just apparent to the naked eye) to a mixture of glycerine (1 part) and water (2 parts), and left in this for twenty-four hours more (Klein).

$\beta$. Löcit's method.-Place small pieces of the fresh tissue in a mixture of 1 part of formic acid to 2 to 4 parts of water for one-half to one minute ; then in 1 per cent. chloride of gold solution for ten to fifteen minutes; then back again into the formic acid mixture for twenty-four hours, and into pure formic acid for twenty-four hours more. After removal from the gold, and whilst in the acid, the tissue must be kept in the dark. This method is especially good for motor nerre eudings in skeletal muscle.

$\gamma$. Ranvier's method.-Immerse in lemon-jnice for fire to ten minutes, then wash with water and place in 1 per cent. gold-chloride solution for twenty minutes. Then treat either as in Cohnheim's or as in Löwit's method.

22. Golgi"s chromate of silier methods.-These are chiefly emplored for investigating the relations of cells and fibres in the central nervous srstem. Two methods are mostly used, as follows :

a. Tery small pieces of the tissue which has been hardened for some weeks in 3 per cent. bichromate of potassium or Müller's fluid are placed for half an hour in the dark in 0.75 per cent. nitrate of silver solution, and are then transferred for tweuty-four hours or more to a fresh quantity of the same solution (to which a trace of formic acid may be added). They may then be placed in 96 per cent. alcohol (half an hour), and sections, which need not be thin, are cut either from celloidin with a microtome or with the free hand after embedling (lut not soaking) with paraffin. The sections are mounted in xylol balsam, which is allowed to dry on the slide: they must not be covered with a cover-glass, but the balsam must remain exposed to the air.

$\beta$. Instead of being slowly hardened in bichromate, the tissue is placed at once in very small pieces in a mixture of bichromate and osmic ( 3 parts of 3 per cent. bichromate of potash or of Miuller's thid to 1 of osmic acid). In this it remains from one to eight days, a piece being transferred each day to 0.75 per cent. silver nitrate. The subsequent procedure is the same as described under a. For some organs it is found advantageous to repeat the process, replacing them for a day or two in the osmic-bichromate mixture after silver nitrate and then putting them back into silver nitrate (Cajal's double method). This method is not only more rapid than that in which bichromate of potassium alone is used, but is more sure in its results.

23. Ehrlich's methylene-llue method.--This method is one of great value for exhibiting nerve-terminations, and in some cases the relations of nervecells and fibres in the central nervous system. For its application the tissue must be living: it is therefore best applied by injecting a solution of methylene-blue (1 part to 100 of warm saline solution) into a vein in an anæsthetised mammal, until the whole blood is of a bluish colour; or the injection may be made through the ressels of the part to be investigated, immediately after killing an auimal. But fairly good results can also be obtained by immersing small pieces of freshly-excised living tissue in a less concentrated solution $\left(0^{\circ} 1\right.$ per cent.), or, in the case of the central 
nervous system, by dusting the methylene-blue powder over a freshly-cut surface, allowing some time for it to penetrate, and then treating it with picratc of ammonia and Bethe's solution. In either case the tissue should be freely exposed to air; the blue colour then appears in the nervecells and axis-cylinders, even to their finest ramifications. It does not however remain, but after a time fades from them while other tissues become coloured. To fix the stain the tissue is taken at the moment that the nerve-fibres are most distinctly seen and is placed for an hour or two in saturated solution of picrate of ammonia, after which the preparation can be mounted in glycerine containing picrate of ammonia. But to allow of sections being made from it for mounting in balsam or daminar, it must, subsequently to the treatment with picrate of ammonia, be placed for some hours in Bethe's fluid, viz. :

Molybulate of ammonia,

Chromic acid 2 per cent. solution,

Distilled water, -

Hydrochloric acid, l gramme.

ii) c.c.

10 c.c.

1 drop.

This renders the colour insoluble in alcohol.

24. Sihler's method of staining nerve-endings in muscle and blood-vessels.Macerate the tissue for eighteen hours in the following solution :

Ordinary acetic acid,

Glycerine,

1 per cent. chloral hydrate solution,
1 part.

1 part.

(i) parts.

From this transfer to glycerine for from one to two hours; then unravel somewhat with needles and place for from three to ten days in the following :

Ehrlich's hæmatoxylin,

1 part.

Glycerine.

1 per cent. chloral hydrate solution,

1 part:

6 parts.

It may then be kept for any desired time in glycerine, which should be changed several times.

Preparations are made by careful dissociation with needles. If overstained they may be differentiated by acetic acid until the dark-blue colour is changed to violet. The muscle spindles and the end-plates are well shown by this method.

25. Nissl's method of staining the chromatic granules in nerve-cells. - This is a method of overstaining with methylene blue and subsequent differentiation with alcohol (see $\$ 12$ ). Nissl recommended 90 per cent. alcohol as the hardening agent, but both formol and corrosive sublimate followed by alcohol may be employed also. Toluidin-blue (Mann) may be used in place of methylene-blue. The sections may first be stained with 1 per cent. aqueous solution of eosin, aud then, after rinsing in water, with 1 per cent. methylene-blue solution: they are best differentiated in aniline-alcohol. The effect of heating the solutions to about $70^{\circ} \mathrm{C}$. is to accelerate and accentuate the staining, which will then take only a few minutes, 
A Nissl stain may also be obtained by placing thin pieces of the fixed and hardened nervous tissue in 1 per cent. solution of thionin for several days; after which the tissue is dehydrated and embedded in paraffin.

26. Cujal's reduced silver method for exhibiting neurofibrits within nerve-cells and -fibres.-A small piece of the tissue (brain, spinal cord, ganglion, etc.), not more than $4 \mathrm{~mm}$. thick, and preferably from a young animal, is placed in 50 c.c. of rectified spirit to which 5 drops of anmonia are added. After twenty-four hours in this, rinse with distilled water and place in a large quantity of 1 per cent. solution of silver nitrate, which is maintained at a temperature of about $30^{\circ} \mathrm{C}$. After being five or six days in this solution, the piece is removed, mixed for a few seconds in distilled water, and transferrer for twenty-four hours to the following solution:

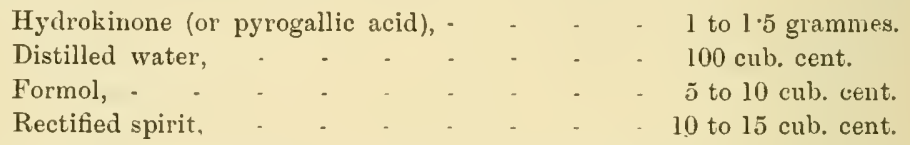

The addition of alcohol to the above is not indispensable, but favours penetration. The piece is then washed in water for some minutes, transferred to alcohol, embedded in celloidin, and sections are prepared and mounted in the ordinary way. 


\section{INDEX.}

$\mathrm{AC} H$

Acukonatic spindle, 7,31 .

Achromatic substance, 8 .

Adenoid tissue, 76 .

Adipose tissue, 73 .

Actrenals. See suprarenal capsules.

Air-bubbles, 27.

Ameloblasts, 271 .

Amolsa, 3.

Angioblasts, 196.

Ansa lenticularis, 415 .

Aorta, structure of, 1s?.

Appendix, 484. (See also vermiform.)

Archoplasu, 8.

Areolar tissue, 68 .

- - cells of, 70 .

- - fibres of, 68 .

Arrector pili, 243.

Arteries, nerves of, 196.

- structure of, 184 .

- variation in structure of, 189.

- and veins, smaller, structure of, 192.

Articular cartilage, 87.

- corpuscles, 169.

Attraction sphere, 7 .

Auerbach, plexus of, 296 .

Autonomic nerves, 132 .

Axon, 138, 143.

BACTERIA, 27.

Baillarger, lines of, 428 .

Basilar membrane, 479 .

Basement membranes, 77.

Bechterew, nucleus of. See nucleus.

Bellini, ducts of, 324 .

Bile-clucts, 313.

Bladder, 329.

Blastoderm, 22 .

Blood-corpuscles, action of reagents upon, 41,44 .

- of amphibia, 45 .

- coloured, 31, 32, 41 .

- colourless, 32 .

- - amœboid phenomena of, 48.

- - granules of, 33.

- migration from blood-vessels, 51,72

- - varieties of, 33 .

- development of, 36, 40.

- enumeration of, 30.

- structure of, 31 .
CLL

Blood-crystals, 43.

Blood-film, 28.

Blood-platelets, $35,47$.

Blood-vessels, development of, 36,196 .

- structure of, 184, 192.

bone, 96.

- development of, 101.

- lacuna and canaliculi of, 98 .

- lamellæ of, 98.

- marrow of, 38.

Bowman, glands of. See glands.

- membrane of, $4+7$.

Bronchi, 25.5.

Bronchial tubes, 257 .

Brain. See cerebrum, cerebellum, medulla oblongata, mesencephalon, pons Varolii.

- divisions of, 374 .

- membrines of, 441 .

Brumer, glands of. See glands.

Burdach, iract of. See tracts.

Bundle. See tracts.

Calleja, islands of, 396.

Capillaries, 193.

- circulation in, 194.

Carotid gland, 222.

Cartilage, 86.

- articular, 87.

- costal, 87,92

- development of, 90 .

- embryonic, 90.

- hyaline, 87.

- ossification of, 101.

- parenchymatous, 90.

- transitional, 88.

- varieties of, 86 .

Cartilage-cells, 87 .

- capsules of, 88 .

Cajal's method of staining neurofibrils, 499 .

Celloidin for embedding, 487.

Cell-plate, 16.

Cells, division of, 10.

-_ - amitotic, 10.

- - reduction, 14 .

- embryonic, 1 .

- membrane of, 8 .

-n nucleus of, 8.

- structure of, 2 . 
CEM

Cement. See crusta petrosa.

Central fovea of retina, 463.

- tendon of diaphragm, 191.

Centriole, 7 .

Centrosome, 7.

Cerebellum, 417 .

- peduncles of, $398,402,424$.

- - superior, $398,411,424$.

- - inferior. See restiform body.

- middle, 390, 424.

Cerebrum, 424.

- basal ganglia of, 440 .

- cortex of, 424 .

- - structure of different parts, 4.32 .

- peduncle of, 405.

Chondrin-balls, 90.

Choroid coat of eye, 451.

Chromatic substance, 8 .

Chromatolysis, 140.

$[224$.

Chromaffin or chromophil cells, 221,

Chromosomes, 9, 12.

Cilia, 64 .

- action of, 65 .

- - theories regarding, 66 .

Ciliary muscle, 452.

Clarke, column of, 370 .

Claustrum, 426.

Coccygeal gland. See glands.

Cochlea, 474 .

Cohnheim, areas of, 112.

- method of staining nerve-enrlings, 497.

Collaterals, 145 .

Colostrum-corpuscles, 248.

Comma tract. See tracts.

Commissures of cerebrum, anterior, 439.

- - posterior, 410.

- of spinal cord, 356 .

Conjunctiva, 444.

Connective tissue, cells of, 70 .

- - development of, 82 .

- - fibres of, 68 .

- - jelly-like, 77.

- tissues, 68.

Cornea, 447.

- nerve endings in, 176, 449.

Corpora albicantia (mammillaria), 414 .

- geniculata, 412.

- quadrigemina, 406.

Corpus luteum, 350 .

- striatum, 440.

- subthalamicum, 415.

Corti, nrgan of, 479 .

Cotton tibres, 27.

Cowper, glands of. See glands.

Crusta, 405.

- petrosa, 269.

Cutis vera, 230 .

Cy tomitome, 7 .

Cytoplasm, 2.
FIB

Deiters, cells of, 481 .

- nuclens of. See nucleus.

Dendrons, 138.

Dentine, 263.

-- formation of, 272 .

Descemet, membrane of, 449 .

Deutoplasm, 5.

Dilatator pupillæ, 454.

Dobie, line of, 113.

Doyère, eminence of, 182.

Dinst, 27.

$\mathrm{E}_{\mathrm{AR}}, 469$.

Ebner, glands of. See glands.

Ehrlich's methylene-blne method, 495.

Elastic tissue, 79 .

Elëiden, 2:28.

Emberding, methods of, 486.

Enamel, 263.

- formation of, 271.

- organ, 272.

Find-bulbs, 168.

Endocardium, 252.

Endomysium, 115.

Endoneurium, 135.

Endoplasm, 5.

Endothelinm. 5.5.

End-plates, 180.

Ependyma, 373, 38!

Epicardium, 2.5.

Epidermis, 2:6.

Epididymis, 334.

Epineurinm, 134.

Epiphysis cerebri. See pineal gland.

Epithelium, 52.

- ciliated, 55, 64 .

- classification of, 53.

- columnar, 55, 61.

- glandular, 56.

- nerve endings in, 174 .

- pavement, 55.

- stratified, 54.

- transitional, 55.

Epitrichial layer, 229.

Erectile tissue, 330.

Erythroblasts, 36.

Erythrocytes. See blood-corpuscles, coloured.

Eustachian tube, 470 .

Exoplasm, 5.

Eye, 443.

Eyelids, 444.

Eye-piece, 24.

Fallopian tubes, 351.

Fat. See adipose tissue.

- absorption of, 304.

— in cartilage cells, 90, 92 .

Fenestrated membrane, 187.

Fibres. See connective tissue, muscle, nerve, etc.

Fibrin, 35. 
FIIB

Fibro-cartilage, elastic, 93.

- white, 93 .

Fihrous tissue, so.

Fillet. see tract of tillet.

Fimbria, 434.

Flechsig, method of, 360 .

- tract of. See tracts.

Flemming, germ-centre of, $205,209,2016$.

- stainable bodies of, $: 205,216$.

- method of staining nnclei, 4 SO.

Forel, decussation of, 1133 (footnote).

Freezing methoul for preparation of sections, $48 \%$.

GalL-BL.1บurk, 314.

(ianglia, 138.

- cells of, 14\%.

- development of, $16: 2$.

Ganglion of cochlea, 355.

- - of glossopharyngeal, 384.

- - Scarpa, 3S.5.

- - of vagus, 383 .

- Ciasserian, 395.

- geniculate, 393 .

- of habenula, 405,414 .

- interpeduncular, 40.5 .

Gas-chamber, 60.

Genital corpuscles, 169.

Gennari, line of, 4:8.

Germ-centre, 205, 209, 216 .

Germ-nuclei, Is.

Gianuzzi, crescents of, 253 .

Fland or glands.

- agminated, 209, 300 .

- anal, $30 \mathrm{~s}$.

- of Bowman, 469.

- of Brunner, 294, :311.

- carotid, 2.2.2.

- ceruminous, 245,469 .

- classification of, 56 .

- coccygeal, 222.2.

- of Cowper, 331 .

- ductless, 59 .

-. of Ebner, 276.

- gastric, $2 \mathrm{SS}$.

- hremal, 207.

- internally secretĭıg, 59 .

- lacrymal, 446.

- of Lieberkỉhn, 279 .

- of Littré, 331.

- lymph, 203.

- mammary, 246.

- Meibomian, 445.

- Pacchionian, 442.

- pineal, 415 .

-. pituitary, 204

- racemose, .58.

- saccular, js.

- salivary, 281.

- sebaceous, $2 \pm 3$.

- secreting, 56 .
HFN

Fland or glanrls, secreting, varieties of, 58 ,

serous, 276 .

- solitary, :209, :-9.9!)

- sweat, 244.

- thymus, 210 .

- tubular, 58 .

(ilisson, capsule of, 311 .

(ilomeruli of kiclney, $3: 0$.

- olfactory, 439.

Glycogen in colourless blood-cor. puscles, 47 .

- in liver cells, 313.

(ioblet-cells, (ii).

Gold-methods of staining nerve endings, $497,49 \mathrm{~s}$.

Golgi, organs of, 174 .

- cells of, 415 .

- methods of preparing the nervons system, 498.

- reticulum of, $141,1+2$.

- types of nerre-cells, 148.

Goll, tract of. Sce tracts.

Gowers, tract of. Siee tracts.

Graafian follicles, 345.

Grandry, corpuscles of, 169.

Grantes of protoplasm, 4.

- of colourless blood-corpuscles, 33.

Ground-substance of comective tissue, 2,68 .

Gudden, atrophy of, 15 s.

- bundle of. See tracts.

- commissure of, 410.

Gullet. See wsophagns.

iustatory cells, 278 .

- pore, $27 \mathrm{~s}$.

H.æuAL glands. See glands.

Hæmatoidin, 44.

Hæmin, 44.

Hæmoglobin, 43.

Hæmolysis, 42.

Hair-cells of internal ear, $473,480,481$.

Hair-follicle, structure of, 235 .

Hairs, 27, 234.

- development of, 241 .

- muscles of, 243 .

Hassal, concentric corpuscles of, 211.

Haversian canals, 98.

- systems, 99.

Haycraft, views of, on muscle structire, 113.

Heart, 250.

- muscle of, 123.

- nerves of, 253.

- valves of, 253 .

Helweg, bundle of. Sice tracts.

Henle, feuestrated membrane of, 187 .

- looped tribules of, 324.

- sheath of, 136.

Hensen, line of, 113. 
Hepatic lobules, 310.

-- cells, 312 .

Herbst, corpuscles of, 173 .

Hippocantpus major, 434.

His, bundle of, $25 \%$.

Histogenesis, 20 .

Histology, meaning of term, 1 .

Hyaloplasn, $t$.

Hypophysis cerebri. SeE pituitary body.

\section{IDIOZOME, 342.}

Internal capsule, $\$+0$.

Intestine, large, 318.

- small, 296.

$1 \mathrm{ris}, 4.53$.

\section{JELLY of Wharton, \$.5.}

KARYOKISEsIs, 10.

Kerato-hyaline, 2.29 .

Kidney, 320.

- blood-vessels of, 3207.

Iirause, membrane of. 113. 116.

LABYRIsth of ear, 472 . of kidney, 325 .

Lacteals, :304.

Langerhans, islets of, 316 .

- centro-acinar cells of, 31.

Lanugo, 242.

Larvix, 256.

Lens, 465 .

Leucocytes. (Wet blood-corpuscles, colourless).

Lieberkiihn, crypts of, 297.

Linen fibres, 27 .

Lissauer, bundle of. See tracts.

Littré, glands of. See glands.

Liver, 310.

— blood-ressels of, 198, 311 .

- cells of, 257 .

- ducts of, 313 .

- lobules of, 310 .

- lyuphaties of, 31 .

Loewenthal, tract of. See tracts.

Lung, 256 .

- alveoli of, 261.

- blood-vessels of, 261 .

- ly mph-vessels of, 262 .

Lymph-glands or lymphatic glands, 203.

- - hrmal, 206.

Lymph-vessels or lymphatics, 195.

- connection with cells of connective tissue, $73,201$.

-ndevelopment of, 201.

- nerves of, $2(x)$.

L.mph-corpuscles. See blood-corpuscles, colourless.

Lymphocytes, 34 .
Lynıphoid tissue, 76, 209.

- - development of, 209 .

M.Accla lutea of retina, 463 .

Malpighi. rete mucostm of, 227 .

- pyramids of, 3201.

Malpighian corpuscles of kidney, 320 .

- of spleen, $209,214$.

Mammary glands, 246.

Narchi's method of staining degenerated nerre-fibres, 496.

Marrow, 35.

Measuring objects, $2 \tilde{2}$.

Nedulla oblongata, 374 .

Megakaryocytes, 40, 218.

Meissner, plexus of, 297.

Nembrana tectoria, $4 \$ 2$.

- tympari, 469 .

Mesencephalon, 401.

Nesothelium, $\check{\text { J̃. }}$.

Methouls of embedding, 456 .

- of measuring microscopic objects, 25 ,

- of mounting sections, $\$ 91$.

- of preparing sections, $\mathbf{4} 6$.

- of preserving and hardening, 484 .

- of staining, 492 .

IIeynert, bundle of. See tracts.

- decussation of, $4(13,414)$.

Micrometer, 25.

Alicroscope, 24 .

Ulicroserpic work, requisites for, 24 .

Nicrotomes, $45 \%$.

Migration of colourless bloorl-corpuscles, $51,195$.

Mitochondria, 5 .

Mitosis, 10.

Nloist chamber, 61 .

Ionakow, bundle of. See tracts.

Mould, 2-7.

Mounting solutions, 484 .

Il ucus-secreting cells, 63 .

Iitler, fibres of, 462 .

- helicine arteries of, 331).

- muscle of, 453 .

Iuscle, accessory disks of, 117 .

- blood-ressels and lymphatics of, 121 .

- cardiac, 123.

- changes in contraction, 116, 119.

- corpuscles, 113.

- development of, 122.

- emding of, in tendon, 120 .

- involuntary or plaiu, 126.

- - development of, 127.

- - of arteries, 1s $\%$.

- nerves of, 121, 17\%, 180.

- nuclei of, 113.

- of heart, 12:3.

- of insects, 115, 116.

- in polarized light, 118. 


\section{MIUS}

Mnsele, principal disk of, 117.

- reel, 115.

- spimlles, 12.2, 17\%.

- structure of, compared with protoplasm, 11 !.

- voluntary or cross-striaterl, III.

Myeloplaxes, 40.

Myocardimm, 2.50.

NAILS, 2:32.

- development of, 234 .

Nerve-cells, 138.

- development of, 161 .

- processes of, 139, 143.

- reticulum of, 141 .

- trophospongium of, 143 .

- types of, $14 \mathrm{~s}$.

Nerve-fibres, axis eylinder of, 132.

- degeneration of, 154.

- ievelopment of, 161.

- medullated, 129.

- merilulary segments of, 131.

- motor, terminations of, 180.

- non-medullated, 133.

- regeneration of, 157 .

- sensory, modes of termination of, $166,177$.

- sheaths of, 130 .

- varieties of, 128.

Nerve-trunks, structure of, 134 .

Nervi nerrorum, 136.

Neuroblasts, 161.

Neurofibrils, 1:32, 140, 17\%.

Neuroglia, 159.

Neurokeratin, 131,

Neırolemma, 130.

Neurone, 138.

- theory, 148.

Neuro-synapse, 148.

Nissl, gramules of, in nerve-cells, 138.

Nissl's degeneration of nerve-cells, 140,155 .

- method of staining nerve-cells, 499 .

Nucleolus, 8 .

Nuclens of cell.

Nucleus or nuclei.

- of abducens, 394 .

- of accessory, $378,381$.

- of Bechterew, 3s9. 397 .

- caudatus, 440.

- of cochlear nerve, 385.

- cuneatus, 377.

= of Deiters. 388, 392, 397, 402.

- dentatus cerebelli, 417 .

- of facial, 392.

- of glossopharyngeal, $374,344$.

- gracilis, 377.

- of hypoglossal, 378, 381 .

- lenticularis, 440.

- oculoinotor, 401.

- of olive, 380 .

\section{PI'}

Nuclens or nuclei. of pous, 390.

- of posterior lungitudinal bumdle, 403 .

prcolivary, 392.

- red, of tegumentum, 40:2. semilunar, 392.

- of Stilling, 417 .

- superior olivary, 392.

tecti (s. fastigii), 417 .

- of thalamns, 411 .

- of trapezinm, 391.

- of trigeminal, $39 t$.

- of vagus, $379,383$.

of vestibular nerve, 387 .

Objective, 24.

Ocular, 24.

Odontoblasts, 268.

(Esouhagus, 280.

Olfactory bulb, 436 .

- cells, 439, 465.

- nucous membiane, 467.

- path, 439 .

- tract, 436.

Olive, 375 .

- superior, 392.

Omentuin, 191.

Onychogenic substance, 232.

Opsonins, 50.

Optic chiasma, 409.

- nerves, 409.

- thalamus, 410.

- tract, 409.

Ossification in cartilage, 112.

- in membrane, 108.

Osteoblasts, $100,103$.

Osteoclasts, 105.

Osteogenic filures, 108.

Ovary, 344 .

Ovum, 22, 343 .

- division of, 17 .

Pacinian corpuscles, 169.

Pancreas, 316.

Papillæ of tongue, 275. of skin, 230 .

Paranucleus, 5, 318.

Paraplasm, 5.

Parathyroids, 222.

Penis, 330.

Pericardium, 252 .

Perineurinm, 134.

Periosteum, 100.

Peyer, patches of, 2019, 300.

Phagocytes, 33, 50, 218.

Pharynx, 280.

Pick, bundle of, 376 .

Pigment-cells, 72.

Pineal gland, 415 .

Pituitary body, 2:4. 
PIE

Pleura, 262.

Polar borlies, 17.

Pons Varolii, 390.

Portal canal, 311.

Posterior longitudinal bundle. Ser tracts.

- commissure. See commissures.

Prickle-cells, 54.

Promclei, 18.

Proprio-spinal fibres of cord, 361, 366.

Prostate, 331.

Protoplasm, :2.

Purkinje, cells of, 418 .

- fibres of, 125, 252.

Pyramids of medulla oblongata, 375.

RaNYIER, constrictions of, 130 .

Recklinghansen, method of staining with silver nitrate, 496 .

Reil, fillet of, 398 .

- islanel of, 426 .

Reissner, membrane of, 477 .

Remak, fibres of, 133.

Restiform body, 380, 389, 4:2.

Reticular ol retiform tissue, 75 .

Retina, 454.

- macula lutea of, 463 .

- pars ciliaris of, 465.

Rhinencephalou, 433.

Rolando, tubercle of, 377 .

Rollett's method of staining muscle, 110.

Rouleanx (of blood-corpuscles), cunsation of, 43.

Ruffini, organs of, 173.

SACCULE, 473.

Salivary corpuscles, 52 .

- glands, 281 .

Sarcolemma, 111.

Sarcomeres, 116.

Sarcoplasm, 112.

Sarcostyles, 112.

Sarcous elements, 116.

Schwann, sheath of, 130.

Sclerotic coat of eye, $\mathbf{4 4 6}$.

Sebaceons glands. Sre glands.

Sections, preparation of, 486 .

Semicircular canals, 473.

Seminiferous tubules, 337 .

Serous nembranes, 201.

Sertoli, eells of, 341 .

Sharpey, fibres of, 99, 100.

Sihler's method of staining nerveendings, 499.

Silver-methods, 496, 499.

Sinusoids, 185, 197.

Skin, 2:6.

Spermatogenesis, 341 .

Sper'matozoa, 338.
TRA

Sphincter ani, internal, 308.

Sphincter pupillie, 453.

Spinal bulb. See medulla oblongata.

Spinal cord, 355.

- - bloorl-vessels of, 373.

- central canal of, $356,373,378$.

- characters in different parts, 358.

- ..- connection of nerve roots with, 371.

- - grey matter of, 366 .

- - membranes of, $3 \overline{5} 5$.

- - nerve-cells of, 366 .

- - tracts in, 360 .

Spinal ganglia, 149 .

Spleen, 213.

Spongioblasts, 161 .

Spongioplasm, 4.

Staining of sections, 493.

Stanley-Kent, bundle of, 252 .

Starch granules, 25 .

Stilling, nucleus of, in cord, 370 .

Stomach, 287.

— blood-vessels of, 294 .

- glands of, $28 s$.

- lymphatics of, 294.

Stomata, 201.

Stroma (of blood corpuscle), 43.

Substantia nigra, 405.

Subthalamus, 415.

Suprarenal capsules, 218.

Sweat-glands, 244 .

Sylvian aqueduct, 401 .

Sympathetic ganglia, 150 .

- nerves, 133.

Synapse, 148.

Syncytium, 2, 125, 194.

Synovial membranes, 90.

Tactile corpuscles, 167.

- disks, $169,177$.

Taste-buds, 277 .

Teeth, structure of, 263 .

- formation of, 269 .

- pulp of, 268 .

Tegmentum, 402.

Tendon, 82.

- nerve-endings in, 174.

Testicle, 332.

Thalamencephalon, 410.

Thalamus, 410 .

Thrombocytes, 35.

Thymus gland, 210.

Thyroid body, 221.

Tissues, enumeration of, 1.

- formation from blastodemic layers, 22.

Tongue, 275.

Tonsils, 207.

Tooth. See teeth.

Trachea, 254. 
Tlid

'Tract or tracts or bumlles.

- anterior longitudinal. See tectospinial tract.

- anterolateral ascending. See tract of Gowers.

- - descending. See tract of Loew. enthal.

- bulbo thalamic. See truct of fillet.

— of Burdach, $360,37 \%$.

- central, of cranial nerves, 398.

- central, of tegmentum, 381,397 .

- cerebello-bulbar, 384.

- comma, 361 .

— of cord, 360 .

- cortico-bulhar, 396, 395.

- cortico-spinal. See pyramidal tract.

- crossed pyramidal. See pyramidal trict.

- descending cerebellar, 399.

- direct pyramidal. See pyramidal tract.

— of Goll, 360,37 .

- myelination of, 360 .

- of fillet, 377, 387, 397, 404, 4I1.

- of Flechsig, 365, 381 .

— of (rowers, $365,3>1,399$.

- of Ciulden, 403 (footnote), 414.

— of Helweg, 365.

- of Lissauer, 366,371 .

- of Loewential, 363.

- of Marie, 366.

- of Meymert, 40.5.

- of Monakow, 365, 396, 403.

- of Münzer, 403.

— of Pick, 376.

- olfactory, 436 .

- olivo-spinal. See tract of Helweg.

- optic, 409.

- ponto-spinal, 397 .

- posterior longitudinal, 363, 3ss, $392,396,402$.

- prepyramidal. See tract of Monakow.

- pyramidal, 361, 376, 390, 396, 405, 409.

- of Risien-Russell, 41S.

- rubro-spinal. See tract of Monakow.

\section{Y WA}

Tract or tracts or bumdles.

- spino-cerebellar, $365,37 \%$.

- spino-tectal, 366.

- spino-thalamic, 366.

- tecto-spinal, $36.5,397,403$.

- thalamo-bulbar, 395.

- thalamo-olivary, 397 .

- transverse peduncular, 410.

- ventral longitudinal. See tecto. spinal tract.

- vestibulo-motor. See posterior longitudinal tract.

- vestibulo-spinal, 363, 397.

- of Vieq d'Azyr, 414.

Trapezium, 39I.

Trophospongium, 4, 143.

Tympanum, 469.

URETER, $32 S$.

Urethra, 231.

Urinary bladder, 329.

Uriniferous tubules, course of, 322 .

Uterus, 352.

Utricle, 473 .

VAS deferens, 335.

Vasa vasorum, 196.

Vasoformative cells, 36, 196.

Veins, structure of, 189.

- valves of, 190 .

- variations in, 190.

Vermiform appendix, 308 .

Vesicula seminales, 336 .

Villi, arachnoidal, $44^{\circ}$.

— of intestine, 302 .

- of synovial membrane, 91.

Vitreous humour, 466.

Volkmann, canals of, 99 .

Wallerian degeneration, 154, 360.

Warming apparatus, $4 \mathrm{~S}$.

Weigert-Pal method for staining sections of the nerions system, 496 .

Woollen fibres, 27.

YEAST, 27. 



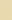




\section{COLUMBIA UNIVERSITY LIBRARIES}

This book is due on the date indicated below, or at the expiration of a definite period after the date of borrowing, as provided by the rules of the Library or by special arrangement with the Librarian in charge.

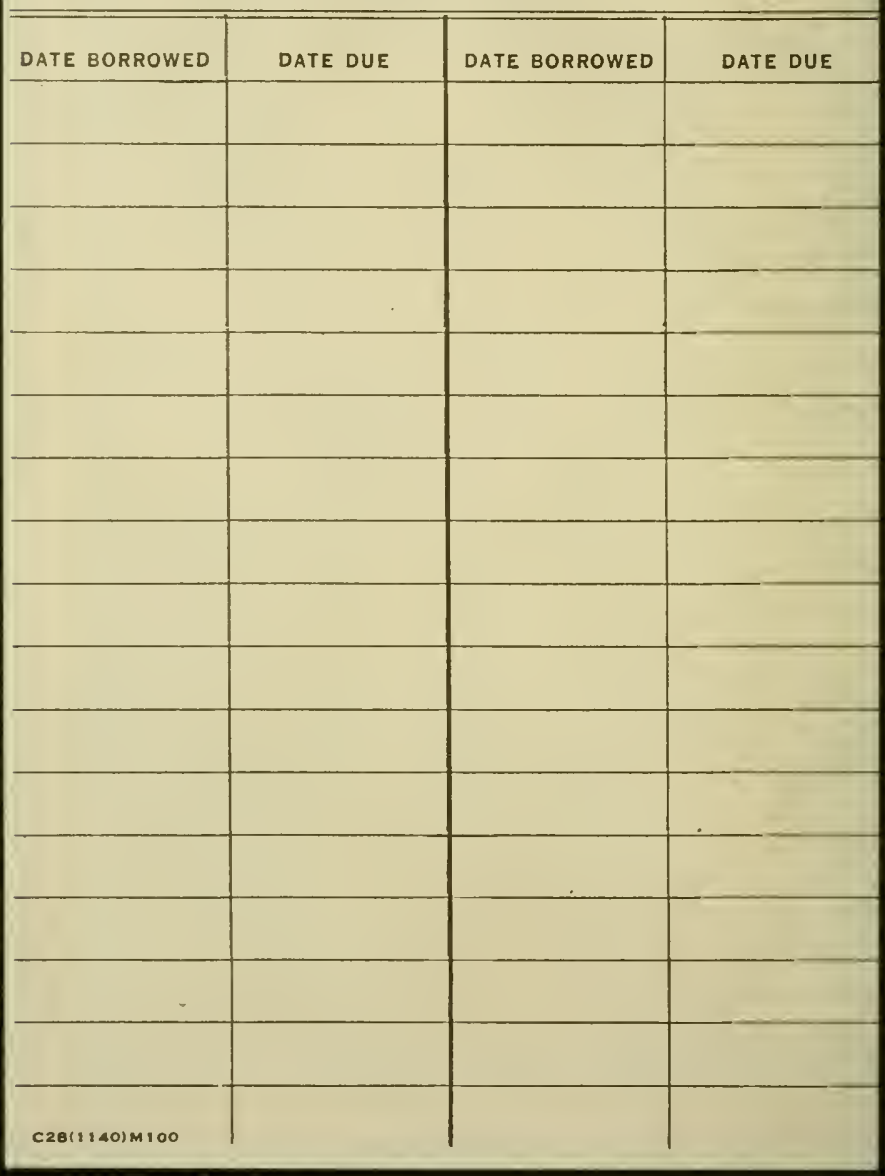




\section{Q1455I}

Sharpey-Schafer

Schl2

1907

The

essentials

of histan 
